\title{
Zur Rezeption des Spielfilms der Weimarer Republik in Südafrika 1928 - 1933
}

Eine kinohistorische Untersuchung

\author{
DISSERTATION \\ zur Erlangung des sozialwissenschaftlichen Doktorgrades \\ der Sozialwissenschaftlichen Fakultät \\ der Georg-August-Universität Göttingen
}

vorgelegt von

DIPLOM-KULTURWISS. MICHAEL ECKARDT, M.PHIL. aus Schmalkalden in Thüringen

Göttingen 2007 
1. Gutachter:

Prof. Dr. Helmut Korte

2. Gutachter :

Prof. Dr. Wolfgang Mühl-Benninghaus

Tag der mündlichen Prüfung : 6. Juli 2007 


\section{Inhaltsverzeichnis}

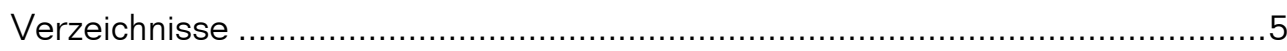

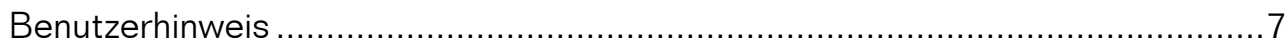

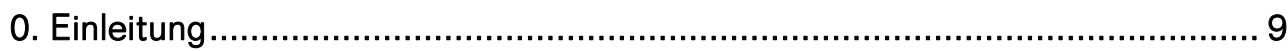

1. Kino und Film in Theorie und Geschichte: ein Überblick ............................. 23

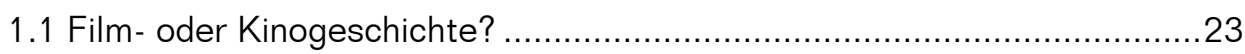

1.2 Filmgeschichte als Analyse der Rezeptions- und Wirkungsgeschichte .....27

1.3 Perzeption - Rezeption - Medienrezeption ...................................... 30

2. Kino und Gesellschaft in Südafrika in den 1920er und 1930er Jahren .......... 41

2.1 Zum Stand der südafrikanischen Kinogeschichtsschreibung ...................42

2.2 Südafrika in der Zwischenkriegszeit ..............................................48

2.3 Die wirtschaftlichen Verhältnisse in den „Roaring Twenties“ ...................52

2.4 Die südafrikanische Filmindustrie in den 1920er und 1930er Jahren .......58

2.5 Annahmen über das südafrikanische Kinopublikum .................................69

3. Presselandschaft und Filmkritik in Südafrika .......................................... 77

3.1 Die südafrikanische Presse und ihre Sonderstellung in Afrika ...................77

3.2 Sprachliche Polarität am Zeitungsmarkt: Englisch vs. Afrikaans ..............79

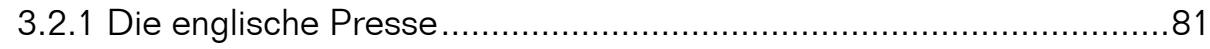

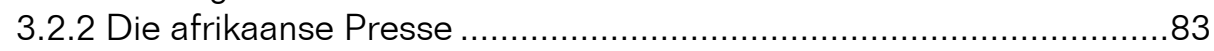

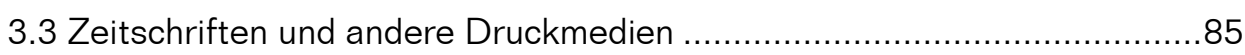

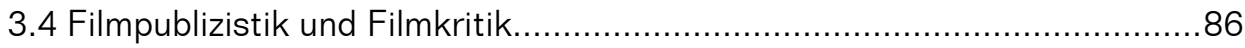

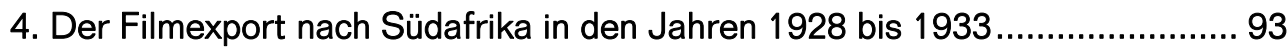

5. Deutsche Spielfilme als Teil der Programmgeschichte ............................. 111

5.1 Deutsche Spielfilme im südafrikanischen Kino .......................................111

5.1.1 Deutsche Spielfilme in den Kinos von Kinemas............................115

5.1.2 Deutsche Spielfilme in den Kinos der Schlesinger-Organisation.....117

5.1.3 Deutsche Spielfilme in unabhängigen Spielstätten .......................120

5.2 Schlussfolgerungen aus der Programmgeschichte ..............................122

5.2.1 Programmkontext, Erfolgsfilme, Kategorisierungen ......................122

5.2.2 Ein Filmkanon und seine Systhematisierung ................................ 134 


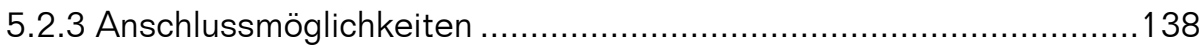

6. Ausgewählte Rezeptionsanalysen: Dokumente, Meinungen, Vergleiche..... 141

6.1 Rezeptionsdokumente zu Filmen unabhängiger Veranstalter .................141

6.1.1 Ausnahmefilm I: MÄDCHEN IN UNIFORM ..............................150

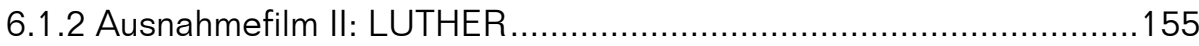

6.2 Rezeptionsdokumente zu Genre 1-Filmen: Kriminal- und Abenteuerfilme .159

6.2.1 Exemplarische Dokumentenanalyse von FAUST ..........................160

6.2.2 Untersuchung weiterer "Ml>10-Filme“ .........................................168

6.2.3 Untersuchung der „MI <10-Filme“ unter den Genre 1-Filmen........184

6.3 Exkurs: Filmzensur in Südafrika.......................................................190

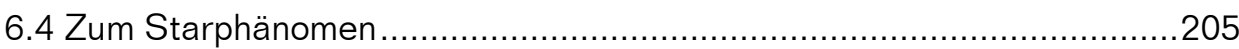

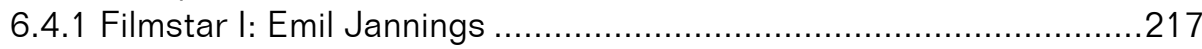

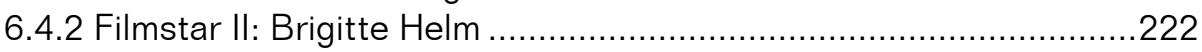

6.5 Rezeptionsdokumente zu Genre 2-Filmen: Liebes- und Sittenfilme .......225

6.5.1 Auswahlanalyse von DER BLAUE ENGEL ...............................226

6.5.2 Exemplarische Dokumentenanalyse von ASPHALT .....................274

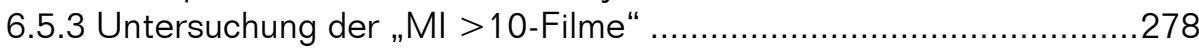

6.6 Rezeptionsdokumente zu Genre 3-Filmen: Walzer- und Operettenfilme 283 6.6.1 Exemplarische Dokumentenanalyse von DER KONGRESS TANZT285 6.6.2 Untersuchung weiterer Genre 3-Filme ..........................................291

6.7 Rezeptionsdokumente zu Genre 4-Filmen: Science Fiction- und Kriegsfilme ....................................................................................296

6.7.1 Exemplarische Dokumentenanalyse von METROPOLIS ................297

6.7.2 Untersuchung weiterer Genre 4-Filme .........................................314

7. Ergebnisse - Schlussfolgerungen - Ausblick ........................................... 321

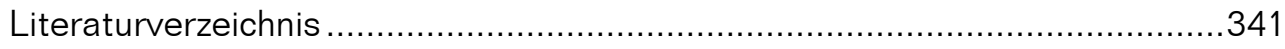

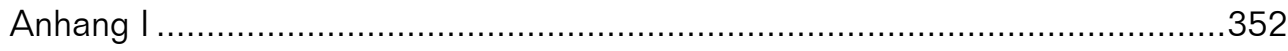

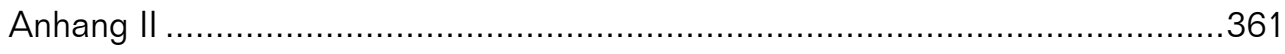

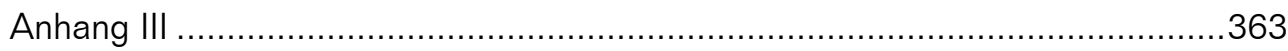

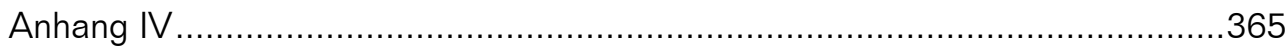

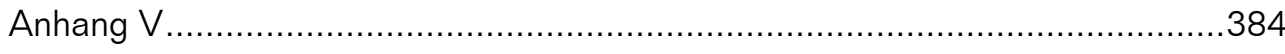




\section{Verzeichnisse}

Tabellen

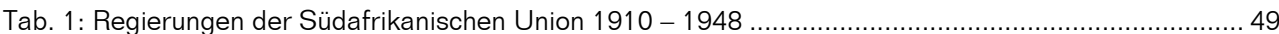

Tab. 2: Prozentuale Verteilung der Land- und Stadtbevölkerung Südafrikas 1890 - 1931 ....................... 51

Tab. 3: Veränderungen des Nationaleinkommens in drei ausgewählten Zeiträumen ..................................5 54

Tab. 4: Anzahl der industriell beschäftigten Südafrikaner europäischer Herkunft $1916-1949$.................55

Tab. 5: Die politische Ökonomie der südafrikanischen Filmindustrie im Zeitraum 1895 - $1956 \ldots \ldots \ldots \ldots \ldots \ldots . . . .60$

Tab. 6: Die kinohistorische Entwicklung Südafrikas 1895 -1940 nach Gutsche ......................................61

Tab. 7: Periodisierung und Vergleich der Marktformen des Kinosektors in Südafrika und den USA .......... 69

Tab. 8: Anzahl der registrierten Zeitungen in Südafrika 1928 - 1933................................................. 78

Tab. 9: Sprachliche Gliederung Südafrikas und der südafrikanischen Presse 1926 ....................................79

Tab. 10: Publizistische Eigenschaften ausgewählter Kapstädter Tageszeitungen ..................................... 88

Tab. 11: Die südafrikanische Zeitungsgruppen in den 1920er und 1930er Jahren ................................... 91

Tab. 12: Gesamte Filmausfuhr des Deutschen Reiches 1928 - 1933 (in Mio RM).................................. 95

Tab. 13: Gesamteinfuhr Südafrikas 1928 - 1933 (in Mio SA £) …….............................................. 99

Tab. 14: Südafrika: Einfuhr von Filmen bzw. Filmprojektoren 1928 - 1933 (in 1000 SA £) ..................... 100

Tab. 15: Einfuhr von Filmprojektoren 1928 - 1933 (in 1000 SA £) ..................................................... 102

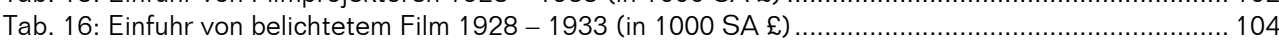

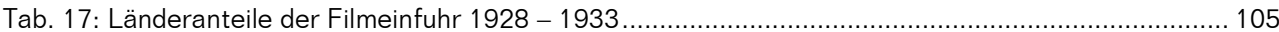

Tab. 18: Deutsche Spielfilme im Programm der Kinokette Kinemas 1928 - 1931 (chronologisch) .......... 115

Tab. 19: Deutsche Spielfilme im Programm von African Theatres 1927 - 1932 …............................... 118

Tab. 20: Deutsche Spielfilme im Programm unabhängiger Lichtspielhäuser 1928 - 1933 ....................... 121

Tab. 21: Gesamtanzahl der „K-Filme“ in den Premierenkinos in Kapstadt $1928-1930$........................ 123

Tab. 22: Kategorisierungsvarianten nach Korte (1998) und Albrecht (1969) ....................................... 131

Tab. 23: Liste der „S-Filme“ nebst Qualitätseinstufung und Standardreferenzen ................................. 135

Tab. 24: Filme in unabhängigen Spielstätten (ausnahmebereinigt) ...................................................... 141

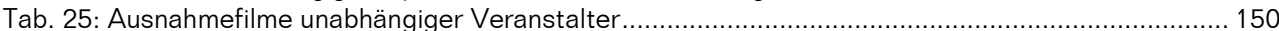

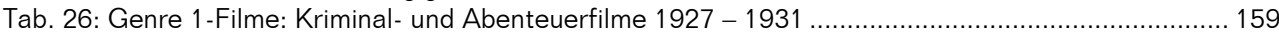

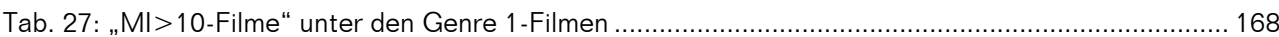

Tab. 28: „Ml<10-Filme“ unter den Genre 1-Filmen ....................................... 184

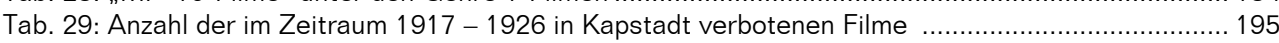

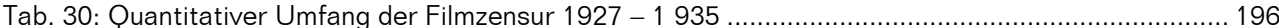

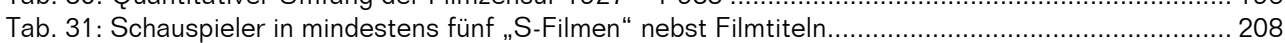

Tab. 32: Genre 2-Filme: Liebes- und Sittenfilme 1928 -1931 …............................................. 225

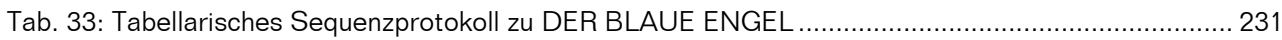

Tab. 34: Anlehnung des BLAUEN ENGELS an die klassische Dramenstruktur .................................. 236

Tab. 35: Überlange Einstellungen zur Verdeutlichung des Autoritäsverlustes........................................... 238

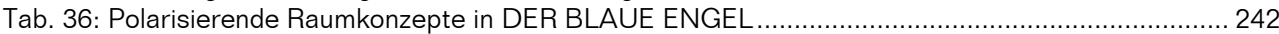

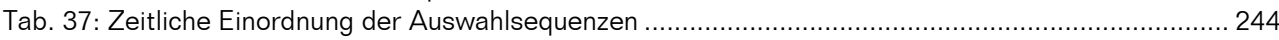

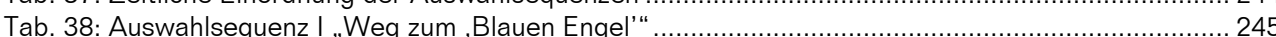

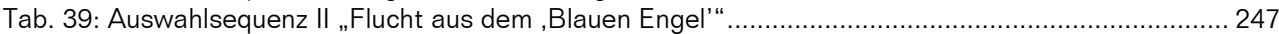

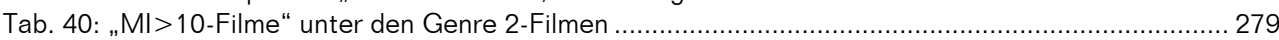

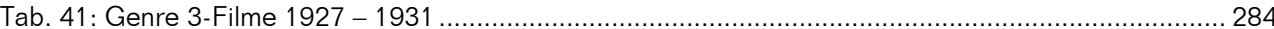

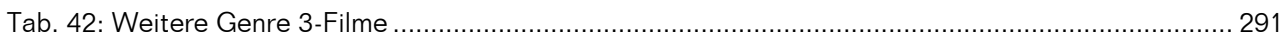

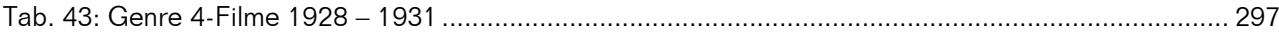

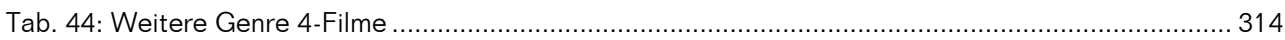

Tab. 45: Anzahl der im Zeitraum 1928 - 1930 in den Premierenkinos Kapstadts gezeigten Spielfilme ... 352

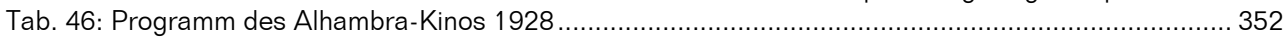

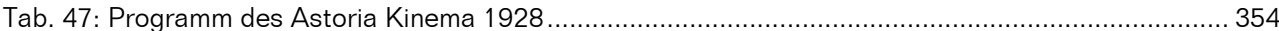

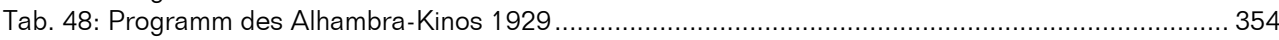

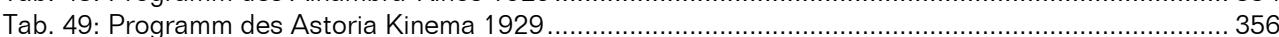

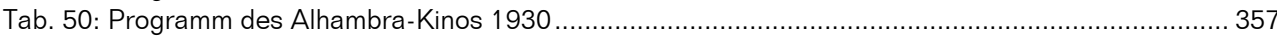

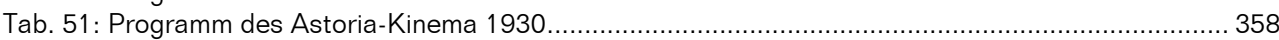

Tab. 52: Filme mit einer überdurchschnittlichen Spielzeit in Kapstadt 1928 - 1930_............................. 359

Tab. 53: Gesamtqualifikation der „S-Filme“ Südafrika nach Paimann's Filmlisten .................................. 366

Tab. 54: Stammdaten und Kurzbeschreibung aus Paimann's Filmlisten, sowie ergänzende Angaben..... 367

Tab. 55: Einstellungsfolge E 89 - E 98 (18.20-20.27) „Raths Weg in den ,Blauen Engel' “...................... 384

Tab. 56: Einstellungsfolge E 490 bis E 508 (97.45 - 102.14) „Raths Flucht aus dem ,Blauen Engel'“..... 385 


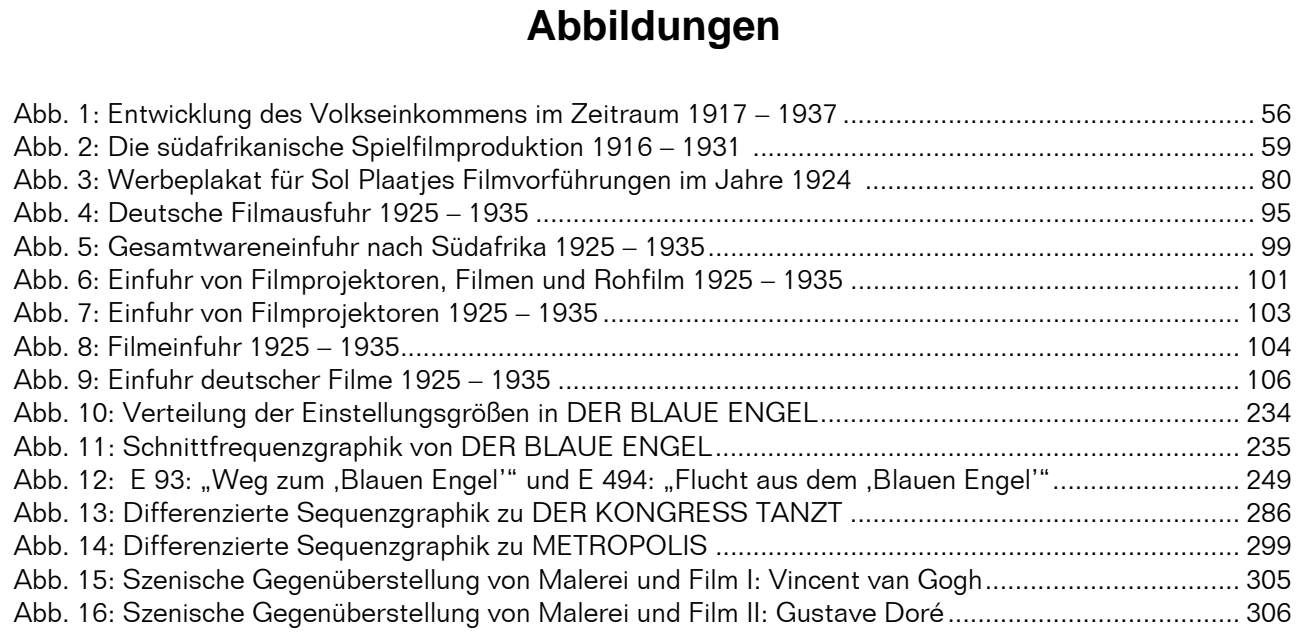

\section{Abkürzungen}

In der Regel werden die im Text verwendeten Abkürzungen mit der ersten Nennung erläutert. Zum gezielten Nachschlagen sind die häufigsten Abkürzungen hier aufgelistet.

$\begin{array}{ll}\text { A } & \text { African Theatres Ltd. } \\ \text { Bpk. } & \text { Beperk (GmbH) } \\ \text { CA } & \text { Cape Argus } \\ \text { CT } & \text { Cape Times } \\ \text { D } & \text { Deutschland } \\ \text { DA } & \text { Die Afrikaner } \\ \text { DB } & \text { Die Burger } \\ \text { DDA } & \text { Der Deutsch-Afrikaner } \\ \text { DFA } & \text { Diamond Fields Advertiser } \\ \text { EPH } & \text { Eastern Province Herold } \\ \text { Erf } & \text { Erfolgs(-film) } \\ \text { FK } & \text { Filmkurier } \\ \text { HR } & \text { Hans Rompel (Rompel 1942a/b) } \\ \text { HUI } & \text { Die Huisgenoot } \\ \text { K } & \text { Kinemas Ltd. } \\ \text { LBB } & \text { Lichtbildbühne } \\ \text { Ltd. } & \text { Limited (GmbH) } \\ \text { ME } & \text { Michael Eckardt (Verfasserkürzel) } \\ \text { MI } & \text { Materialindikator } \\ \text { NA } & \text { Natal Advertiser } \\ \text { NM } & \text { Natal Mercury }\end{array}$

$\begin{array}{ll}\text { NW } & \text { Natal Witness } \\ \text { OFS } & \text { Oranje-Freistaat } \\ \text { PFL } & \text { Paimann's Filmlisten } \\ \text { RDM } & \text { Rand Daily Mail } \\ \text { RM } & \text { Reichsmark } \\ \text { S } & \text { Stammuntersuchung/Sample } \\ \text { SA } & \text { Südafrikanisches Pfund } \\ \text { SCL } & \text { Stage, Cinema and Listener } \\ \text { ST } & \text { Sunday Times } \\ \text { t } & \text { täglich } \\ \text { T } & \text { Tonfilm } \\ \text { TF } & \text { The Friend } \\ \text { TG } & \text { Thelma Gutsche (Gutsche 1972) } \\ \text { TS } & \text { The Star } \\ \text { U } & \text { unabhängiger Filmvertrieb bzw. Kino } \\ \text { UA } & \text { Uraufführung } \\ \text { UFA } & \text { Universium Film Aktiengesellschaft } \\ \text { UK } & \text { Großbritannien } \\ \text { VNK } & \text { Valenzklasse } \\ \text { VB } & \text { Die Volksblad } \\ \text { w } & \text { wöchentlich }\end{array}$




\section{Benutzerhinweis}

Zur besseren Abgrenzung der für diese Studie zentralen Filme („S-Filme“) wurden deren Titel in Großbuchstaben wiedergebenen. Alle anderen Filmund Buchtitel, sowie wörtliche Zitate sind durch Anführungszeichen, Hervorhebungen oder Ironisierungen durch halbe Anführungszeichen markiert. Nach der ersten Nennung der Filme erfolgt in der Regel die Angabe des Produktionsjahres und des Regisseurs. Zitierte Periodika sind generell in Kursivschrift gehalten. Für die „S-Filme“ sind alle relevanten Daten nebst Inhaltsangaben in Anhang IV wiedergegeben. Durch die Nutzung ausländischer Quellen im Anhang (Paimann's Filmlisten, Wien) haben einige selten verwendete Austriazismen Einzug in diese Arbeit gehalten, die sich teilweise auch im Text wiederfinden. Bei diesbezüglichen Verständnis- und Formulierungsunklarheiten sind die entsprechenden Standardnachschlagewerke zu konsultieren. 


\section{Einleitung}

"Jede Gegenwart schreibt sich die Filmgeschichte, die sie haben will; Filmgeschichtsschreibung ist nichts Objektives" (Engell 1992: 43f.). Trotz dieser apodiktischen Feststellung ist Filmgeschichte objektivierbar, sie braucht sich nicht an einen wie auch immer gearteten cineastischen Essayismus zu klammern. Filmgeschichte bezieht sich in jedem Falle auf einen konkreten Gegenstand, auf den ,Film' als Objekt, und auf die soziale Praxis ,Kino' als lebensweltlichen Kontext des Films: beide Phänomene kann man wissenschaftlich, d.h. intersubjektiv nachvollziehbar und Wahrheitskriterien beachtend, untersuchen.

Eine allgemein ,objektivierte' Filmgeschichtsschreibung hätte zunächst die Minimalforderung zu erfüllen, den Film als solchen und seine internationale Entwicklung darzustellen. Wie sich am zeit- und technikhistorischen Entstehungskontext um 1895 belegen lässt, könnte man den Film mit gutem Gewissen als eine deutsche Erfindung betrachten. Genauso berechtigt wäre es aber auch, ihn als eine französische, englische, italienische, amerikanische, russische oder polnische anzusehen (Haucke 2005). Die Vielzahl der technischen Anfänge des Films in den verschiedenen Ländern macht deutlich, wie sehr um 1895 der Film „in der Luft lag“ und dass die „Erfindung“ des Films zu diesem Zeitpunkt keineswegs überraschend, sondern vorhersagbar war (Engell 1995: 102). Auch die Entstehung des Films war an einen spezifischen historisch-gesellschaftlichen Kontext gebunden, es gab demnach bestimmte gesellschaftliche Entwicklungen, welche der Arbeit an einer derartigen Erfindung förderlich waren (Mikos 1993: 155). Innerhalb der offiziellen Filmgeschichtsschreibung gilt allerdings nicht etwa die Erfindung der Kamera zu Aufnahme bewegter Bilder oder die erste Herstellung bewegter Bilder als Geburtsstunde des Films, es wird vielmehr die erste öffentliche Vorführung eines Films als solche angesehen (ebd. 156).

Mit dem Aufeinandertreffen des Films als Kommunikationsmittel und dem die Vorführung verfolgenden Publikum entstand jenes soziologische Ereignis, welches später als ,Kino' bezeichnet werden wird. Damit rücken sowohl die Rezeption, als auch die Aneignung von Filmen sowie deren Wirkung in den Blickpunkt und werden zu zentralen Aspekten der Filmgeschichte (Mikos 1993: 156).

Seine optimalen Ausbreitungsbedingungen fand das Kino jedoch fast ausschließlich in den damals am weitesten entwickelten Industriestaaten, also in Frankreich, England, den USA und Deutschland. Deshalb scheiterten auch die meisten Anfänge des Kinos außerhalb dieser Länder (Engell 1992: 46). 
Fast unbemerkt ,nationalisiert' sich mit dieser Feststellung die allgemeine Filmgeschichtsschreibung. Im Mittelpunkt der Betrachtung steht fortan die Filmindustrie und mit ihr die Produktionsperspektive, aus der sich das Herkunftslandprinzip ableiten lässt. Dabei wird übersehen, dass die Filmindustrie als ein Komplex anzusehen ist, der aus den drei Teilbereichen Filmproduktion, -vertrieb und -vorführung besteht (Rotha/Griffith 1967: 20). Ohne Zweifel hatte wiederum die Filmindustrie der entwickelten Industriestaaten den Vorteil, beispielsweise mit dem als Kamera und Projektor verwendbaren "Cinematographe Lumière", sich mit ihrem Angebot auch selbst die Nachfrage schaffen zu können, da das Publikumsinteresse lediglich durch die entsprechende Auslastung der ohnehin vorhandenen Technik bedient werden musste.

Die qualitative wie auch quantitative Bevorzugung des Herkunftslandprinzips verhinderte bisher nur zu oft, dass auch in den nicht filmproduzierenden Ländern die Teilbereiche Vertrieb und Vorführung von der Filmgeschichtsschreibung in den Blick genommen werden konnten. Dieser auf die Hauptproduktionsländer verengte Betrachtungshorizont lässt den Film aus europäischer und US-amerikanischer Produktion auch filmhistorisch als dominant erscheinen. An den Rand gedrängt wird nicht nur die Rezeptionsperspektive, sondern auch der Film jenseits der maßgeblichen internationalen Zentren der Filmindustrie. Durch die genannten Fixierungen entstanden Leerstellen innerhalb von Werken der Filmgeschichte, die trotz ansehnlichen Umfangs resigniert feststellen mussten, dass

„über den wichtigen japanischen Film (...) hier nichts gesagt (wurde), nichts über den indischen Film, obwohl Indien heute als größtes filmproduzierendes Land allein ein Drittel aller Filme herstellt, fast dreimal so viele wie Hollywood, und obwohl es das größte Massenpublikum in der Geschichte des Films hat; nichts über die Filmproduktion in Hongkong und in Ägypten, nichts über die Türkei, nichts über Schwarzafrika (...)" (Engell 1992: 308).

Bisher hat die Filmhistoriographie den Kontinent Afrika besonders stiefmütterlich und allenfalls als ein Randgebiet der Fachgeschichte behandelt. So kommen manche Standardwerke zur internationalen Filmgeschichte ganz ohne die Berücksichtigung Afrikas aus (z.B. Jeanne/Ford 1947, v. Zglinicki 1956, Gregor/Patalas 1989, Toeplitz 1992, Faulstich 2005, Monaco 2006). Andere begnügen sich mit knappen Zusammenfassungen über ,das' schwarzafrikanische Kino (Kurowski/Römhild 1975: 12-14) und suggerieren eine Homogenität, die kaum zu rechtfertigen ist. Glücklich können sich die 
Länder schätzen, denen ein paar Zeilen zur nationalen Filmproduktion gewidmet sind (Bawden 1976), wobei die Tendenz zur vereinheitlichenden Trennung Afrikas in "Black African Cinema" bzw. "Sub-Saharan Africa" (Thompson/Bordwell 1994: 791-794) und das arabisch geprägte Kino Nordafrikas nicht zu übersehen ist (Armes 2005).

Als ursächlich für diese Marginalisierung ist zweifellos die weitgehend koloniale Vergangenheit Afrikas anzusehen. Diese hat es erfolgreich verhindert, dass sich frühzeitig eine von den ehemaligen ,Mutterländern' unabhängige Filmproduktion mit spezifischen Inhalten, nationalen Filmstars, eigener Filmsprache etc. etablieren und entsprechende Zeugnisse hinterlassen konnte. Afrikanische Filmgeschichte beginnt für viele Autoren erst mit dem Ende der Kolonialzeit bzw. der staatlichen Unabhängigkeit zu Beginn der 1960er Jahre (Thompson/Bordwell 1994: 625ff.). Die Auffassung, dass die afrikanischen Kinos fast ausschließlich mit billigen Filmen der US-Filmindustrie von einem Anbietermonopol aus französischen und amerikanischen Gesellschaften versorgt wurden, wird dabei als unhinterfragbare Selbstverständlichkeit angesehen (Kurowski/Römhild 1975: 13). Die Orientierung der Filmgeschichtsschreibung am Herkunftslandprinzip lässt jedoch außer acht (Ukadike 1998: 569ff.), dass sich trotz des Fehlens einer eigenen Filmproduktion nationale Kinokulturen auf der Rezeptionsseite entwickeln konnten. Diese entstanden als Antwort auf die Markterschließung und -beherrschung durch den internationalen Film US-amerikanischer oder europäischer Herkunft und erzeugten oftmals spezifische Aneignungsweisen im regionalen Kontext (Ambler 2001).

Die Geschichte des Kinos in Afrika vor dem Ende der Kolonialära stellt jedoch keinen weißen Fleck auf der Filmweltkarte dar, wie es die genannten Ausführungen vielleicht vermuten lassen (z.B. Smyth 1989). Die ausgezeichnete, aber leider viel zu wenig beachtete Filmgeschichte des Schweden Rune Waldekranz (Waldekranz/Arpe 1956) folgt zwar ebenfalls dem Herkunftslandprinzip, identifiziert jedoch trennscharf die Filmnationen Ägypten, Marokko, Südafrika (ebd. 369, 382, 387) und vermittelt durch die Angabe von Jahresproduktion, Anzahl der Lichtspielhäuser etc. einen ersten Überblick zur Situation des Film- und Kinosektors auf dem schwarzen Kontinent (ebd. 421).

In anderen Fällen begnügte sich die Filmgeschichtsschreibung zuweilen mit dem bloßen Feststellen der Existenz dieser Art von Film- oder Kinokulturen, um jene sogleich als Anhängsel der Filmindustrie des europäischen ,Mutterlandes' zu vereinnahmen und in der jeweiligen nationalen Filmgeschichte aufgehen zu lassen (z.B. Benali 1998 oder Burns 2002). Als Gegen- 
reaktion darauf kann die afrikazentrierte Filmhistoriographie angesehen werden, welche streng zwischen der europäisch dominierten kolonialen und der afrikanisch-nationalistisch geprägten post-kolonialen Filmgeschichte unterscheidet (z.B. Diawara 1992, Ukadike 1994, Thackway 2003, Shaka 2004). Durch diese Fixierung auf die nationale Herkunft der Filmproduktion wird allerdings verhindert, die Kolonialepoche gleichberechtigt in die Filmgeschichtsschreibung mit einzubeziehen. Die in Südafrika entstandenen filmhistorischen Arbeiten von Hans Rompel (1942a,b), Thelma Gutsche (1972) und Keyan Tomaselli (1983), auf die später noch detailliert eingegangen wird, müssen als Ausnahmen angesehen werden. Deren wegweisende Überlegungen wurden durch die auch den Wissenschaftsbereich treffende Isolierung Südafrikas in der Apartheidsära national wie auch international kaum rezipiert. Generell muss jedoch angemerkt werden, dass Arbeiten zur frühen Film- und Kinogeschichte nicht zu den bevorzugten Themenfeldern medienwissenschaftlicher Forschung in Südafrika gehören (Eckardt 2006).

Glücklicherweise hat die internationale Filmgeschichtsschreibung mit Beginn der 1980er Jahre einen Paradigmenwechsel vollzogen und nimmt seitdem nicht nur ausschließlich die Geschichte der Filmproduktion(en) in ihren Blick, sondern beschäftigt sich zunehmend mit Fragen der Filmaufführung und dem kulturellen bzw. sozialen Kontext in welchem diese Vorführungen stattfanden. Dieser Wechsel hat neue Aufmerksamkeiten für Regionen wie Asien, den Nahen Osten, Süd- und Mittelamerika sowie Afrika erzeugt (z.B. Ramirez/Rolot 1985, Van de Perre 1990, Bergmann 1993, Shafik 1996, Mathys 2003, Carels 2004), in denen es zwar keine einheimische Spielfilmproduktion gab, in denen aber der Kinobesuch als massenkulturelle Praxis von Bedeutung war (Abel 2005: XXIX).

Die Ausbildung der unterschiedlichen Film- und Kinokulturen in Afrika fußte auf lokalen und regionalen Besonderheiten, die gemeinsam mit dem kulturellen Hegemonialstreben der Kolonialmächte einen speziellen Rezeptionskontext für den Film entstehen ließ (z.B. Convents 1982, Convents 2005). Bei der afrikazentrierten Zugangsweise zur Filmgeschichte ist nicht zu übersehen, dass Südafrika aus ideologischen Gründen übergangen wird, da es sich nicht in das gängige Schema von Kolonialisierung und Dekolonialisierung einordnen lässt, sondern vielmehr eine gänzlich eigenständige Entwicklung vollzogen hat. An dieser Stelle bremst die vorrangig ideologische und wissenschaftsfremde Ausrichtung der afrikazentrierten bzw. post-kolonialen Filmgeschichtsschreibung den Erkenntnisfortschritt, da sie aus politischen Gründen Forschungsfelder (wie z.B. Südafrika) vom Diskurs ausgeschlossen 
und sich damit um einen elementaren Bestandteil der Frühgeschichte des afrikanischen Kinos gebracht hat.

Als Beispiel für die Unzulänglichkeiten dieser Art Filmgeschichtsschreibung sei hier der betont autoritativ daherkommende Beitrag „Schwarzafrikanische Kinematografien" der "Oxford History of World Cinema" genannt (Novell-Smith 1998). Die eigentliche afrikanische Filmhistoriographie beginnt dort selbstverständlich erst zu Anfang der 1960er Jahre und lässt sich trennscharf in frankophones und anglophones Afrika gliedern. Ergänzt wird diese Darstellung durch einen vollkommen ahistorischen Absatz zu Südafrika, welcher der tatsächlichen Entwicklung hohnspricht:

„Mit dem Zusammenbruch der Apartheid in Südafrika und angesichts der reichen finanziellen und technischen Ressourcen der Republik (die so lange nur von den weißen kontrolliert wurden) kann man auf einen großen Schritt vorwärts des anglophonen afrikanischen Films hoffen" (Magombe 1998: 632). ${ }^{1}$

Für die Protagonisten dieser Schule existieren nur drei Arten von ,afrikanischem' Kino: 1. das radikale, welches weniger mit Unterhaltung, dafür mehr mit sozio-politischen bzw. kulturellen Diskursen und deren Praxis beschäftigt ist; 2. das imitative oder eskapistische, welches sich Holly- oder Bollywood zum Vorbild nimmt oder 3. das dominante ausländische, dass als Feindbild skizziert wird, welches nur Stereotypen über Afrika reproduzieren würde (Niang 2003: 89). Da der frühe südafrikanische Film sich all dieser Elemente bediente und das erste ,afrikanische Kino' als solches hervorbrachte, müsste eine ,afrikanische' Filmhistoriographie eigentlich wie selbstverständlich auch die Überlieferung dieser Region und Zeitspanne mit einschließen. Durch das Nichtanerkennen Südafrikas als filmgeschichtlichen Sonderfall übergeht die post-koloniale Schule jedoch dieses Faktum und kultiviert ihre Stereotypen vom südafrikanischen Film als von „European Expatriates“ für „European settler populations" und "white masters" verfertigte Kunstprodukte (Niang 2003: 90).

Mit dieser unnötigen ideologischen Einengung nimmt es die afrikazentrierte, post-koloniale Filmgeschichtsschreibung in Kauf, sich wissenschaftlich zu diskreditieren, und sogar hinter den gesicherten Forschungsstand der 1950er Jahre zurückzufallen. Wie nachteilig sich das Ignorieren der Filmgeschichts-

\footnotetext{
${ }^{1}$ An anderer Stelle heißt es ähnlich irreführend „The situation in southern Africa began to change with the liberation of Zimbabwe and South Africa, two countries with relativly advanced filmmaking technical infrastructures, which seemed to poised to join the ranks of major African cinema producers" (Niang 2003: 89).
} 
schreibung in Bezug auf Afrika auswirken kann, wird aus einem Vergleich der Einschätzung von Magombe und den differenzierten Ausführungen von Waldekranz u.a. ersichtlich:

„Südafrika produziert seine Filme auf afrikaansch. Die Pioniergesellschaft ,African Film Productions' hat schon um 1920 herum in Johannesburg gedreht. Aber erst unter der Ägide der ,Union Film' entstand der erste, im eigentlichen Sinne afrikaansche Spielfilm - der auch auf Englisch herauskam -, nämlich Francis Coleys und A.L. Bennets ,Sarie Marais' (1948), die Geschichte eines Burenmädchens zur Zeit des Burenkrieges. Es ist jedoch bezeichnend, dass die einzigen Filme, die ein unverfälschtes Bild von dem Leben der Neger im südafrikanischen Slum geben, englischer Herkunft sind. Sowohl Zoltan Kordas großartiger ,Denn sie sollen getröstet werden' (Cry the Beloved Country, 1951) nach Alan Paton als auch Donald Swansons ,Zaubergarten' (The Magic Garden, 1951) haben in authentischen Milieus wesentliche Züge aus dem Alltag der Neger in den schmutzigen Vorstädten der Weißen eingefangen. Im Gegensatz zu den reaktionären Erlassen der Malan-Regierung zeigen Kordas und Swansons Filme menschliche Wärme und verständnisvolles Einleben" (Waldekranz/Arpe 1956: 387).

Selbst mit den aus heutiger Sicht etwas irritierenden exotischen Einsprengseln versteht es der noch ohne post-koloniale ,blinde Flecken' daherkommende Eintrag in George Sadouls "Geschichte der Filmkunst" (1957) bestens, die verbürgte Filmgeschichte Afrikas zu umreissen und historisch angemessen darzustellen:

„Afrika ist ein Kontinent ohne Filmateliers, abgesehen von Ägypten und gelegentlich Französisch-Nordafrika und der Südafrikanischen Union. In diesem Dominion drehte der Regisseur Leslie Lulecoque mit einer kleinen britischen Gruppe 1919/20 ,Die Rose von Rhodesien' und ,König Salomons Diamanten' nach Rider Haggard, sowie einige Filme, in denen die Zuluhäuptlinge Kentani und Yumi mitwirkten. Die Südafrikanische Union, die fast 500 Kinos zählt, produzierte 1946 einige Filme auf Afrikaans" (Sadoul 1957: 325).

Eine den tatsächlichen Gegebenheiten angemessene Filmgeschichtsschreibung sollte daher vom Konzept einer strickt auf das Produktionsland fixierten Historiographie abrücken, da in den afrikanischen Kolonien im Vergleich zu Europa oder den USA durch die fehlende Industrialisierung oft keine nennenswerte Spielfilmproduktion stattfand. Im Kontext disziplinübergreifender Diskurse zur Globalisierung und ihrer ökonomischen und kulturellen Bedingungen, Folgen und Artikulationsformen, zeichnet sich seit einigen Jahren 
ohnehin ein Paradigmenwechsel der internationalen Filmgeschichtsschreibung ab. Anstatt nationale Filmlandschaften als in sich geschlossene Entitäten zu begreifen, nimmt man zunehmend transnationale/-kulturelle Einflüsse und internationale Verflechtungen in den Blick (Jahn-Sudmann 2007).

Da die eigentliche Filmproduktion neben Vertrieb und Vorführung nur einen von drei gleich relevanten Teilen der Filmindustrie ausmacht, kann die Filmhistoriographie durchaus davon gewinnen, sich in Ländern ohne umfängliche Filmproduktion der Geschichte von Filmvertrieb und -vorführung anzunehmen, mit anderen Worten verstärkt den Zuschauer, also die Rezipientenseite in den Mittelpunkt des Interesses rücken.

Um in der gegebenen filmhistorischen Situation die vorhandenen Quellen - die im wesentlichen aus Rezeptionsdokumenten bestehen - sinnvoll nutzen zu können, muss eine aussagefähige Filmhistoriographie auf einer rezeptionsorientierten Analyse aufbauen. Dabei steht außer Frage, Filme aus früheren Epochen nicht anders als mit unseren Augen sehen zu können, d.h. im Lichte der gesamten Entwicklung, wie sie seither stattgefunden hat. Gerade dieser Umstand macht rezeptionshistorische Forschungen interessant, die nicht nur anhand von Kritiken, überlieferten Reaktionen usw. versuchen, die Sichtweise eines zeitgenössischen Publikums zu rekonstruieren, sondern die den Film selbst rezeptionsanalytisch als Projektionsfläche vergangener und gegenwärtiger möglicher Lektüren auffassen (Engell 1995: 95).

Aufgabe dieser rezeptionsorientierten Filmgeschichtsschreibung wäre es dann, die lokalen oder regionalen Aneignungsweisen in Bezug auf die gezeigten internationalen Filme nachvollziehbar zu machen. Die angestrebte, auf einer Kontextanalyse basierende historische Filmanalyse, muss dabei die vorhandenen Rezeptionsdokumente befragen, daraus Bausteine einer Programmgeschichte gewinnen und die nachweisbaren Tendenzen der Rezeption, also die zeitgenössische Wirkung, ordnen und synthetisieren (Korte 1998: 43). Mittels der Produktanalyse ausgewählter Filme könnte dazu festgestellt werden, ob die dargestellte Filmrealität im regionalen Kontext eine andere zeitgenössische Rezeption zur Folge hatte, und auf welche Faktoren dies zurückzuführen ist. Das Ziel ist dabei:

„Ausgehend von den Erkenntnissen der Produkt- und Kontextanalyse (,dominante Botschaft') unter Einbeziehung der erreichbaren Rezensionen und Informationen über Vermarktung, Zielpublikum etc. mit dem Konstrukt eines ,kompetenten Betrachters' den Rezeptionsprozeß ,simulierend' erfahrbar zu machen" (Korte 2001: 23). 
Südafrika stellt in der geschichtlichen Entwicklung Afrikas, und so auch innerhalb der afrikanischen Filmgeschichte, einen absoluten Ausnahmefall dar. Als einziges Land wurde es seit 1652 dauerhaft europäisch besiedelt, auch konnte die kontinentaleuropäische Diaspora dort ihre eigenen kulturellen Formen (Sprache usw.) entwickeln. Vor diesem Hintergrund wird deutlich, dass die Filmgeschichte in Südafrika aufgrund ihrer engen Verbindung zu europäischen und internationalen Entwicklungen einen anderen Weg als im übrigen Afrika genommen hat. Der Afrika zugewiesene filmgeschichtliche Exotenstatus (Vints 1981), der Filmdokumente aus eigener Produktion jenseits ethnographischer Reisebilder nur schwer vorstellbar macht, wird leider viel zu oft auch auf Südafrika übertragen. Dabei wird häufig übersehen, dass in Südafrika ein zentrales Ereignis der frühen Filmgeschichte stattfand. Der in den Jahren 1899 bis 1902 erbittert geführte Burenkrieg zwischen Großbritannien und den südafrikanischen Burenrepubliken (Oranje-Freistaat und Transvaal) war weltweit der erste filmisch dokumentierte Krieg überhaupt. Der damit einhergehende Popularisierungsschub für das neue Medium Film übernahm zum Teil auch die gesellschaftliche Funktion der Identitätsstabilisierung für die jeweilige Kriegspartei. Dabei kam dem britischen Aggressor zugute, mit dem Film eine entsprechende Aufbruchsideologie für das neu zu schaffende Sozialsystem „Britisch Südafrika“ produzieren und transportieren zu können, dass seine Selbstdefinition nicht auf Bestand und Vergangenheit (wie z.B. die der Buren), sondern auf Expansion, Wandel und Zukunft gründen konnte (Engell 1995: 139).

Führt man sich vor Augen, dass Bildnachrichten aus aller Welt, bald unter dem Namen „Film-Gazetten“ oder „Wochenschauen“ bekannt, die ersten kontinuierlich und am häufigsten aktualisierten Bestandteile des Kinoprogramms waren, wird klar, welche Verbreitung Filmdokumente des Burenkrieges erfahren haben. Die Kunde vom fernen Krieg drang mittels der gefilmten Bilder sogar bis in die deutsche Provinz. So weiß z.B. die Filmhistoriographie Weimars zu berichten, dass der lokale Kinopionier Theodor Scherff in den Anfangsjahren seiner Unternehmung kaum finanzielle Erfolge verbuchen konnte, sich dies jedoch durch den Burenkrieg als filmhistorisches Ereignis änderte:

„Der Umschwung trat erst im Jahre 1899 ein, als der Burenkrieg ausbrach und Scherff die Konjunktur insofern auszunutzen verstand, als er sich Burenfilme verschaffte und einen Lichtbildervortrag über Südafrika und den Kriegsschauplatz vorführte. Bekanntlich waren die Sympathien des deutschen Volkes auf Seiten der Buren. So war es kein Wunder, dass die Vorstellungen Tag für Tag ausverkauft waren" (Doernfeldt 1926: 8f.). 
Die Tatsache, dass der Burenkrieg gefilmt wurde, trieb sowohl die Produktion, als auch die Aufführung solcher Filme voran und leistete für deren Verbreitung einen enormen Vorschub (Gutsche 1972: 42ff.). Die lokalen, meist noch mobilen Veranstalter bedienten das öffentliche Interesse am Kampfgeschehen und legten den Grundstein für Südafrikas einmalige filmund kinotechnische Infrastruktur. Das Beispiel der internationalen Rezeption des Burenkrieges als ersten gefilmten Krieg der Weltgeschichte macht deutlich, welche filmgeschichtliche Ausnahmestellung Südafrika innerhalb Afrikas zukommt.

Für den ausgewählten Untersuchungszeitraum, 1928 bis 1933, mag dies eher unerheblich erscheinen, allerdings illustriert es die Dimension des Filmgeschäfts, welche bei entsprechender Nachfrage von Beginn an weltumspannend und transnational war. Der zu untersuchende Zeitraum von 1928 bis 1933 stellt in der Filmgeschichte beider Länder eine besondere Periode dar. Die deutsche Filmindustrie befand sich durch spektakuläre finanzielle Fehlkalkulationen (z.B. METROPOLIS 1926/27), sowie den absehbaren Wegfall des internationalen Marktes durch den aufkommenden Tonfilm in einer Krise und suchte händeringend nach neuen Absatzgebieten. Der südafrikanische Markt hingegen befand sich zu diesem Zeitpunkt in einer von Prosperität getragenen Umbruchphase (Lichtbildbühne, Abk. LBB 11.1.29: 16).

Das Jahr 1928 war für die südafrikanische Kinobranche ein Jahr positiver Veränderungen. Viele neue Spielstätten mit großer Kapazität wurden errichtet bzw. geplant, federführend war die Kinokette African Theatres Ltd. Insgesamt existierten in ganz Südafrika ca. 400 Spielstätten für Kinofilme. Daran anschließend ist zu untersuchen, welche wirtschaftliche Situation vor 1928 gegeben war, worin die Gründe für den angezeigten Aufschwung lagen, welche Konkurrenten die prosperierende Kinokette African Theatres hatte und wie lange die positive Entwicklung andauerte. Es kann angenommen werden, dass es im Jahre 1928 zu Veränderungen innerhalb der südafrikanischen Kinobranche kam, welche filmhistorisch von Bedeutung waren und die vorgenommene Eingrenzung des Untersuchungszeitraumes unterstützen.

Der Filmmarkt in Südafrika war weitgehend von US-amerikanischen Produktionen dominiert, wenngleich deren Position im Vergleich zu vorherigen Perioden auf einen Anteil von ca. 75 Prozent sank. Der verringerte Anteil von US-Produktionen war auf den Markteintritt anderer Anbieter zurückzuführen, was zu einem erhöhten Angebot britischer und deutscher Filme in Südafrika führte. An dieser Stelle kann nach den Gründen der schwindenden US- 
Dominanz gefragt werden, wie sich jene im zeitlichen Verlauf darstellte, sich die Marktanteile veränderten und welchen Umfang der deutsche Filmexport nach Südafrika hatte.

Aus diesen Fragmenten lässt sich in Bezug auf den deutschen Film vereinfachend die leitende Fragestellung dieser Untersuchung herleiten. Was hat dazu geführt, dass gerade in diesem Zeitraum ganz bestimmte deutsche Filme nach Südafrika exportiert wurden, wann war diese Phase beendet und was waren die Gründe dafür?

Südafrika verfügte bereits seit etwa 1910 über eine eigene Filmproduktion, die im Wesentlichen von der African Film Productions Ltd. getragen wurde. Durch den Ersten Weltkrieg von den traditionellen Filmmärkten abgeschnitten, wurden im Zeitraum von 1916 bis 1922 ca. 43 eigene Produktionen zur Befriedigung der einheimischen Nachfrage gedreht (Tomaselli 1996: 61). Mit der wirtschaftlichen Normalisierung nach Ende des Krieges kam das Aus für die südafrikanischen Produktionen, da sie nicht mit der internationalen Konkurrenz mithalten konnten. Erst 1928 wurde der weitere Ausbau des heimischen Studiokomplexes angestrebt. Die bis dahin produzierten Spielfilme, wie z.B. „The Buried City" (1921, N.N.) oder „The Blue Lagoon“ (1923, W. Bowden), erhielten recht positive Pressestimmen. Das Vorhandensein einer einheimischen Filmproduktion und deren geplante Ausweitung stellen abermals die Entwicklungsbedingungen der südafrikanischen Kinobranche des Jahres 1928 in den Vordergrund. Positive Kritiken in den Printmedien lassen nach dem Status der Presse und nach der Rolle der Filmkritik fragen.

Bis 1928 gab es in Südafrika eine strenge Filmzensur die von den einzelnen Provinzen ausgeübt wurde. Die Filmzensur stellt für jeden Filmimporteur eine bedeutende Markteintrittsbarriere dar. Ist die Zensur dezentral organisiert, birgt jedes Zensurverfahren fast unkalkulierbare Risiken. In dieser Hinsicht wäre zu untersuchen, ob die Zensurgesetze möglicherweise voneinander abwichen, welche Inhalte zensiert wurden und ob die beanstandete Zensurpraxis im ausgewählten Untersuchungszeitraum tatsächlich keinen Änderungen unterworfen war.

Südafrika durchlebte also mit dem Aufkommen des Films 1895 und der nachfolgenden Verankerung des Kinos in der Alltagskultur nahezu im Gleichschritt mit Europa oder den USA alle film- und kinohistorischen Entwicklungsstufen. Dies wirft u.a. folgende Fragen auf:

- Welche Struktur hatte der südafrikanische Kinomarkt im Untersuchungszeitraum und welche Faktoren führten dazu, dass deutsche Spielfilme nach Südafrika exportiert wurden? 
- Welche Interessen verbanden die deutschen und die südafrikanischen Partner?

- Welchen Umfang hatte der Filmexport, welche Filmtitel wurden ausgeführt und wie kam diese Auswahl zustande?

- Wie reagierte das Publikum bzw. die Presse auf die Filme und wie sind diese Reaktionen zu erklären?

- Welche Rolle spielten die Filme in der Programmgeschichte des südafrikanischen Kinos?

- Warum kam der deutsche Filmexport nach Südafrika um 1931 zum erliegen?

- Erfüllten sich für beide Seiten die mit dem deutschen Film verbundenen Hoffnungen?

Darüber hinaus sollte eine kino- und filmhistorische Untersuchung folgende Bereiche thematisieren:

- Filmangebot (Importeure), Filmnachfrage (Publikum, z.B. Gelegenheitspublikum vs. Gewohnheitspublikum), die herrschenden Marktbedingungen (z.B. Konkurrenz der Kinoketten, Übergänge von Monopol zu Oligopol und zurück, Verhältnis von internationalen zu einheimischen Produktionen etc.),

- Zugangsbeschränkungen (z.B. durch Politik, Zensurgesetze, Zölle etc.), Medienkonkurrenz (z.B. Filmkritik in den Printmedien, Situation der Theaterbranche etc.), sowie den kulturellen Status von Film und Kino innerhalb eines historisch sicher eingrenzbaren Untersuchungszeitraumes.

In Bezug auf die Rezeption des Spielfilms der Weimarer Republik in Südafrika müsste zudem geklärt werden, welche Einstellungen das Publikum gegenüber kontinentaleuropäischen Produktionen allgemein und den deutschen im Besonderen hegte. Im Standardwerk zur südafrikanischen Filmgeschichtsschreibung, auf welches später im Literaturbericht noch ausführlicher eingegangen werden wird, findet sich die Bemerkung, dass von den im Jahre 1928 in Südafrika gezeigten kontinentaleuropäischen Filmen die deutschen UFAProduktionen am Erfolgreichsten waren (Gutsche 1972: 218). Eine Erläuterung dieser Feststellung bleibt jedoch paradoxerweise aus.

Aus der deutschen Berichterstattung über die Burenkriegsfilme ist hingegen bekannt, dass es infolge der damaligen antibritischen Stimmung ein starkes gesellschaftliches Engagement für die Buren und eine fast hysterische Begeisterung für deren Repräsentanten gegeben hat (Kronauer 2000: 73). Daraus kann man schlussfolgern, dass zumindest auf Seiten der Afrikaaner kaum Resentiments gegenüber deutschen Filmen zu erwarten waren. 
Die angestrebte rezeptions- und wirkungsgeschichtliche Studie muss sich daher vor allem auf die ursprünglichen Rezeptionsdokumente stützen, daraus Annahmen über das Publikum gewinnen, um auf dem Wege einer indiziengestützen Argumentation einen Beitrag zur Strukturgeschichte von Kino und Film in Südafrika leisten zu können. Durch die schwierige Materiallage ist es zudem erforderlich, sich auf die dichte Rekonstruktion einzelner Knotenpunkte zu beschränken.

Zu diesem Zweck soll zunächst die Menge der gezeigten deutsche Filme erfasst werden, dazu gehört ebenso die Feststellung der Filmtitel und der filmischen Grunddaten. Mit Hilfe dieser Angaben soll eine Evaluierung vorgenommen werden, durch welche sich die Filme thematisch gruppieren lassen, um daraus Rückschlüsse auf bevorzugte Genres, gängige Themen, beliebte Schauspieler etc. ziehen zu können. Eingedenk der vorhandenen Tendenzen innerhalb der Filmkritik, sollen durch eine Analyse der Filmbesprechungen die Einstellungen des Publikums gegenüber einzelnen Filmen und gegenüber dem deutschen Film im Allgemeinen nachgezeichnet werden können. Mittels eines Vergleiches der lokalen, deutschen bzw. internationalen Medienrezeption sollen die im südafrikanischen Kontext vorgefundenen subjektiven und kontextbedingten Wirkungsfaktoren festgestellt werden.

Die wissenschaftliche Synthese soll auf diesem Wege zu einer Beschreibung der angestrebten und der tatsächlichen Wirkung der Filme führen, welche die zeitgenössischen Rezeptionsangebote und das vorhandene Rezeptionsspektrum mit einschließt. In Einzelfällen soll bei ausreichender Materialbasis auch eine Differenzierung der kollektiven Rezeption, bezogen auf die jeweils relevanten Publika, unternommen werden (Korte 1998: 43). Damit wird jedoch auch in Kauf genommen, dass durch eine praktische Umsetzung der rezeptionshistorischen Postulate der analytische Aufwand explosionsartig anwächst und bei den derzeit gegebenen Möglichkeiten der Materialrecherche nur eine geringe Aussicht auf Erfolg verspricht (Korte 1989: 136). In der Studie soll nicht zuletzt aus diesem Grunde versucht werden, die methodisch möglichen Fragestellungen im Einklang mit der tatsächlich befragbaren Dokumentenbasis zu entwickeln, um zu wissenschaftlich tragfähigen Ergebnissen zu kommen.

Diese in der Filmhistoriographie nahezu unbearbeitete Thematik macht es zunächst notwendig, den zeit- und filmgeschichtlichen Kontext Südafrikas eingehender darzustellen, um auch die leitende Fragestellung verständlicher zu machen. Anschließend soll die ökonomische Dimension der Filmeinfuhr nach Südafrika dargestellt werden. Um die aufgefundenen Rezeptionsdokumente entsprechend diskutieren zu können, schließt sich eine Übersicht zum 
südafrikanischen Pressewesen und zum Status der Filmkritik an. Darauf folgt die auf den Rechercheergebnissen basierende Rekonstruktion der partiellen Programmgeschichte des deutschen Spielfilms in Südafrika, welche einer Synthetisierung in Bezug auf die möglichen Kriterien des Zustandekommens dieser Auswahl unterzogen wird. Zusätzlich soll ein Exkurs zur südafrikanischen Zensurgesetzgebung den Einfluss der staatlichen Regulationsbemühungen auf die Filmrezeption sichtbar machen. Abschließend wird geklärt werden, welche Bedingungen Erfolg und Scheitern des Spielfilms der Weimarer Republik in Südafrika beeinflussten, und welche Schlussfolgerungen daraus für die deutsche, südafrikanische und internationale Filmgeschichte zu ziehen sind. 


\section{Kino und Film in Theorie und Geschichte: ein Überblick}

Bevor die eigentliche Überblicksdarstellung zu Kino und Film in Südafrika erfolgen kann, scheint es angebracht, den gewählten filmhistorischen Zugang zu erläutern. Dazu werden die unabdingbaren theoretischen Prämissen kurz genannt und das verwendete Theoriedesign erklärt.

\subsection{Film- oder Kinogeschichte?}

Durch neue Quellenfunde zum Ende der 1970er bzw. Anfang der 1980er Jahre befand sich die herkömmliche, vor allem erzählende, Filmgeschichtsschreibung in einer klassischen Dilemmasituation: Mit dem neu zugänglichen Material wurde vielen Filmhistorikern bewusst, dass es auf allen Ebenen mehr zu sagen gab, als bisher bekannt war, und dass manches von dem, was die traditionelle Filmgeschichtsschreibung als undiskutierbare Wahrheit dargestellt hatte, falsch war und korrigiert werden musste (Brill 1997: 10). Die Ergebnisse der bahnbrechenden Studien von Barry Salt (1983), Robert Allen und Douglas Gomery (1985) oder Steve Neale (1985) und deren Auswirkungen auf die künftige Filmgeschichtsschreibung wurden vielfach unter dem Schlagwort „New Film History“ zusammengefasst (z.B. Elsaesser 1986).

„Based on this data, a quiet revolution in film historiography is now under way. Scholars are turning from macrohistory to microhistory, from surveys to monographs, reformulating basic approaches in a nonnarrative, nonlinear fashion. The new work focuses on the structure and conduct of the industry as a whole (production, distribution, and exhibition); it examines corporate behaviour, industrial relations, and the place of film in international trade, as well as the films and filmmakers themselves. It takes into account the interaction of social, aesthetic, economic, and technological forces" (Gomery in Nagel 1988: 18).

Ziel dieser Art ,Schule' war es, aufzuzeigen, wie eine neue Filmgeschichtsschreibung auf der Ebene der Theorie funktioniert. Nicht mehr Abenteuergeschichten von Meistern und Meisterwerken erklärten die Filmgeschichte, sondern Theorien, die erstens anerkannten, dass eine komplexe Struktur von Faktoren Ursache einzelner Ereignisse war, zweitens über eine gesicherte empirische Basis verfügten und drittens die Basis ihrer Schlussfolgerungen transparent machten durch möglichst genaue Verweise auf die Primärquel- 
len, was in der Vergangenheit kaum stattgefunden hatte (Brill 1997: 13). Anscheinend hatte die herkömmliche Filmgeschichtsschreibung weniger Wert auf Recherche, sondern vielmehr auf's Geschichtenerzählen gelegt (Brill 1997: 20). Es wurde immer offensichtlicher, dass die traditionelle Filmgeschichtsschreibung nicht nur schlecht darin war, vernünftige Theorien zu entwickeln, die etwas erklärten, sondern sie war bereits auf der empirischen Ebene eine Ansammlung von Legenden, Halbwahrheiten und Selbstdarstellungen. Nicht zuletzt aus diesem Grund hielt man es für erforderlich, Filmgeschichte neu schreiben zu müssen, ein Plädoyer für empirische Grundlagenforschung zu halten und Neurecherchen auf dieser Ebene anzumahnen (Brill 1997: 21).

$\mathrm{Zu}$ Recht wurde festgestellt, dass das bloße Anschauen eines Filmes als Forschungsmethode völlig ungeeignet sei:

„It is true that for one narrow form of historical inquiry prints of films are the only valid data. However, for broader (and more interesting) questions, we think, nonfilmic materials prove invaluable. For certain investigations, film viewing is really an inappropriate research method" (Allen/Gomery 1985: 38).

Die ersehnte akademische Legitimation des Faches Filmgeschichte brachte es mit sich, dass nach immer exakteren wissenschaftlichen oder empirischen Standards gestrebt wurde. Gleichsam entstand der Wunsch, stärker zwischen der Interpretation als künstlerischer Wertschätzung (wie z.B. in der Literaturwissenschaft) und einer formalen, oft sprachwissenschaftlich orientierten Textanalyse zu unterscheiden (ebd.). Dies hatte zur Folge, dass

„Old film history, conceived as a history of films following each other in orderly progression or of film-makers passing on the torch of innovation, found itself opposed by a new theory of history, but also a new theory of films. Their tactical alliance brought about New Film History, which should really be called New History of the Cinema" (Elsaesser 1986: 247).

Die Abhängigkeit jeder künstlerischen Entwicklung des Films wird auch von der Filmtechnik bestimmt. Diese wiederum von wirtschaftlichen Faktoren, die nur in einem bestimmten gesellschaftlichen Umfeld möglich waren. Die Geschichte des Films kann nie isoliert von Systemen wie der Unterhaltungsindustrie, den Massenkommunikationsmitteln, dem Wirtschaftssystem oder dem Wandel der verschiedenen Kunstgattungen etc. betrachtet werden (Mühl-Benninghaus 1987). Diesen Wechselseitigkeiten musste auch die Filmhistoriographie Rechnung tragen: 
„To do film history today, one has to become an economic historian, a legal expert, a sociologist, an architectural historian, know about censorship and fiscal policy, read trade papers and fan magazines, even study Lloyds Lists of ships sunk during World War One to calculate how much of the film footage exported to Europe actually reached its destination" (ebd.: 248).

Da diese Komplexität mit dem Begriff ,Filmgeschichte', als Zusammenspiel zwischen der Geschichte des Mediums Film und der Geschichte des Films als Produkt (Hickethier 1997: 9), nur unzureichend erfasst scheint, müsste eigentlich in dieser Studie stets von ,Kinogeschichte' die Rede sein. Die angloamerikanische Filmgeschichtsschreibung ist längst dazu übergegangen, die Bezeichnungen synonym zu gebrauchen, da der Film als technisches Produkt in die genannten gesellschaftlichen Entwicklungen eingebunden war und dessen Geschichte nicht losgelöst vom Kontext dieser Entwicklungen betrachtet werden kann. Nicht ohne Grund wird die erste öffentliche Vorführung eines Filmes, die demnach innerhalb eines sozialen Kommunikationsraumes, wie z.B. eines Kaffeehauses oder später in einem speziellen „KinoTheater" stattfand, als Beginn der Filmhistoriographie angesehen (Mikos 1993: 156).

Die vorgeblich problematische Unterscheidung zwischen Film- und Kinogeschichte existiert eigentlich nur noch im deutschsprachigen Raum, da hier Kinogeschichte oft als Lokalgeschichte begriffen wird. Streng genommen verbirgt sich auch hierhinter nur ein Teil der Sozialgeschichte des Films, eine Art Chronologie der Kinogeschichte mit den Gegensätzen Stadt vs. Land auf der horizontalen oder dem Gegensatz zwischen unabhängigen Kinos und Kinoketten auf der vertikalen Ebene (Paech 1989: 44). Die zwei Betrachtungsebenen gelten auch für die Typologie der Kinobauten, wonach veränderte kulturelle Ansprüche auf der Horizontalen Gaststättenkinos, Ladenkinos, Kinotheater, Lichtspielhäuser, Filmpaläste, Filmtheater, Kino-Center etc. entstehen ließen und auf der Vertikalen zwischen Erstaufführungstheatern, Nachspielkinos etc. unterschieden wurde (ebd.). Es leuchtet ein, dass im Filmprogramm eines Kinos die Filmgeschichte auf der Konsumtionsseite konkret wird, jedoch darf die Aussage bezweifelt werden, dass sich Filmgeschichte und Kinogeschichte erst beim Filmprogramm berühren (ebd.: 46).

Film- und Kinogeschichte fallen keineswegs auseinander, beide sind vielmehr nur als eine Einheit denkbar, wenngleich es sich bei der Geschichte des Kinos eher um die Untersuchung außerfilmischer Praktiken handelt, die Produktion, Herstellung und die Konsumierung von Filmen umfassen (Sorlin 
1996: 28). Ohne das Kino, also ohne eine Aufführung vor Publikum, bliebe jeder Film nur ein sehr langer, dünner Plastestreifen, ohne einen zeigbaren Film bliebe jedes Kino nur ein beliebiger Zuschauerraum. Als einfacher Gegenstand existiert ein Film selbstverständlich in seiner blechernen Schutzhülle, auch wenn ihn niemand betrachtet. Die für seine Analyse interessanten Eigenschaften resultieren jedoch aus der Interaktion zwischen den formalen Strukturen des Werks und den mentalen Verarbeitungsprozessen des Zuschauers, mit denen er auf diese Strukturen antwortet (Thompson 1995: 44).

Das hier vertretene Verständnis von Film- bzw. Kinogeschichte versteht stets dann, wenn von Filmgeschichte gesprochen wird, auch immer Kinogeschichte und umgekehrt. Die Filmgeschichte eines bestimmten Zeitraumes an einem bestimmten Ort manifestiert sich immer in der Programmgeschichte der jeweiligen Kinos. Ohne die Einheit der zwei filmhistorischen Komponenten, also der tatsächlich gezeigten Filme des Kinoprogramms, ist keine quellensichere Filmgeschichtsschreibung möglich. Zudem kann die filmhistorische Problematik der häufig unbewussten Kanonbildung mit der Konzentration auf die Programmgeschichte des Kinos wirksam umgangen werden. In den meisten Fällen neigen die mit speziellem Vorwissen und Intentionen ausgestatteten Autoren dazu, von der heutigen Einschätzung unvermittelt auf eine entsprechende historische Wirkung der Filme zu schließen (Korte 1989: 135). Die Programmgeschichte selbst gibt jedoch noch keinerlei Wertungen vor, sie kann vielmehr als die unabdingbare Basis der Kinogeschichtsschreibung angesehen werden.

Der Einfluss von Wirtschafts- und Technikgeschichte, aber auch der Programmgeschichte auf die Filmhistoriographie hat zu einer gewissen Verschiebung weg von der Text-, hin zur Kontextdominanz geführt (Elsaesser 1986: 251). Dabei besteht für die Disziplin Filmgeschichte die Gefahr, dass sie zu einer Art intellektuellen Spielerei verkommt, deren einzige Herausforderung nur noch in einer im Vergleich zu den relativ einfach strukturierten Ausgangsdaten immer komplexer werdenden Methodisierung besteht (ebd.). Unter Filmgeschichte als Kinogeschichte muss man das Ergebnis eines komplexen Prozesses von technischen, ästhetischen, politischen, wirtschaftlichen etc. Entwicklungen verstehen. Die Bedeutung des Films für das zeitgenössische Publikum kann dabei am ehesten an konkreten Beispielen aufgezeigt und erfahrbar gemacht werden (Faulstich 1997: 156). Dies erfordert wiederum, Filmgeschichte als Rezeptions- und Wirkungsgeschichte zu begreifen, was im Folgenden verdeutlicht werden soll. 


\subsection{Filmgeschichte als Analyse der Rezeptions- und Wirkungs- geschichte}

Für den hier vertretenen rezeptionshistorischen Ansatz der Filmgeschichtsschreibung ist es notwendig, jenen als eine übergreifende Methodenverschränkung zu verstehen. Dies sollte am besten mit einer filmhistorischen Abgrenzung zur Geschichte von Regisseuren und deren Werken, der Kinound Filmindustrie, der Stil- oder Gattungsgeschichte etc. einhergehen (Faulstich 1997: 156). Filmgeschichte als Rezeptions- und Wirkungsgeschichte vollzieht aber auch stets eine Synthetisierung der genannten Einzelaspekte der Filmgeschichte und konstruiert sich als ein Mosaik aus Ereignisketten, Zusammenhängen, Bedeutungen etc. (ebd.: 155), dass als Kinogeschichte neben der Produktgeschichte auch den historischen Kontext berücksichtigen muss (ebd.: 153).

Dies umschreibt zusammenfassend Lothar Mikos (1993) in „Filmgeschichte als Rezeptions- und Wirkungsanalyse", worauf sich in den folgenden Ausführungen bezogen wird.

Wie bereits erwähnt, wird in der offiziellen Filmgeschichtsschreibung nicht die Erfindung der Kamera zur Aufnahme bewegter Bilder oder die erste öffentliche Herstellung bewegter Bilder als Geburt des Films angesehen, sondern die erste öffentliche Vorführung eines Films. Da der Film sein Potential offenbar erst in der Vorführung vor Publikum entfaltet, kann man den Film als ein Mittel der Kommunikation betrachten. Somit stellt die Aufführung von Filmen zweifellos ein gesellschaftliches Ereignis dar (Mikos 1993: 156). Das chronologische Faktensammeln der traditionellen Filmgeschichtsschreibung wird dabei von einer historischen Bezugnahme abgelöst, welche die Fakten in Beziehung zu den gesamtgesellschaftlichen Entwicklungen setzt, um daraus eine gewisse Erklärungskraft abzuleiten (ebd.). Dazu ist es notwendig, die folgenden fünf Aspekte in eine rezeptions- und wirkungsgeschichtliche Analyse zu integrieren (ebd. 157):

- ökonomische (z.B. Filmeinfuhr, Konkurrenz),

- technologische (z.B. Kinotechik, Stumm- und Tonfilm),

- ästhetische (z.B. Genre, Stil),

- psychologische (z.B. Perzeption, Identifikation, Sehgewohnheiten),

- soziologische (z.B. Rezeptions- und Aneignungsweisen, Kinoraum, soziale Aspekte des Kinobesuchs). 
Dabei kommt den Rezeptions- und Aneignungsweisen eine besondere Bedeutung zu, da

„(...) Filme, wie alle anderen Kulturprodukte auch, (...) ihren Sinn erst in der Aneignung durch das Publikum, mithin die verschiedenen Publika (entfalten). (...) Sinn macht ein Film erst, wenn er von Zuschauern in deren eigene Lebenspraxis übernommen wird. Das heisst auch, dass der Sinn, der sich über einen Film mitteilt, ein vom Publikum an den Film herangetragener sein kann, der mit der im Film erzählten Geschichte nur marginal etwas zu tun hat" (ebd.: 158).

Verstanden als Moment des gesellschaftlichen Kommunikationsprozesses, kann Film demnach nicht losgelöst vom kulturellen Kontext und den lebensweltlichen Bezügen des Publikums gesehen werden (ebd.: 160). Da sich der Sinn eines Filmes erst im Verlauf seiner Aneignung durch ein Publikum entfaltet, muss Filmanalyse als Kultur- und Lebensweltanalyse immer auch die Analyse der Dialektik von Filmen und ihrer Rezeption als Aneignung durch handelnde Subjekte sein (ebd.: 161). Erst als Moment von Kultur und Lebenswelt wird dieses Sinnpotential zur Wirkung und ist damit immer zugleich auch Wirkungsgeschichte (ebd.). Filmgeschichtsschreibung als Rezeptionsund Wirkungsgeschichte muss daher immer die Bedeutungen berücksichtigen, die im zeitgenössischen Publikum und in der Gesellschaft umgehen (ebd.), was eine kontextuelle Einbindung von Filmen, Genres, Stilen, Werken von Regisseuren und ihrer Rezeption und Aneignung mit einschließt (ebd.: 159). In dieser Hinsicht bildet der Film auch jene ,dialektische Symbiose' aus, welche für literarische Texte und deren Aneignung charakteristisch ist:

„Das Werk und die in inm dargestellte Welt gehen in die reale Welt ein und bereichern sie, und die reale Welt geht in das Werk und in die in ihm dargestellte Welt ein, und zwar im Schaffensprozess wie auch im Prozess seines späteren Lebens, in dem sich das Werk in der schöpferischen Wahrnehmung durch die Hörer und Leser ständig erneuert" (Bachtin 1989: 205).

Die Rezeptions- und Wirkungsgeschichte von Filmen sagt weiters etwas über ihre theoretische und (laien-) philosophische, manchmal anekdotenreiche Legitimation durch Autoren, Regisseure oder Produzenten, über die Beeinflussung der öffentlichen Meinung durch die etablierte Filmkritik, sowie über ihre Rezeption und Aneignung durch das ,normale' Publikum wie auch durch die Cineasten. Sie sagt aber auch etwas über die sich historisch verändern- 
den Wahrnehmungsmuster, Sehgewohnheiten und die sozialen Bedingungen von Rezeption und Aneignung (Mikos 1993: 162f).

Als ein Beispiel des wechselseitigen Einflusses von der Wirkung der Publikumsrezeption auf die Filmproduktion kann die Ausbildung von verschiedenen Filmgenres angesehen werden. Der Gattungsbegriff ,Genre' bezeichnet dabei Typen von Werken, die wichtige Haupteigenschaften teilen und ganz bestimmten filmischen und kulturellen Konventionen folgen (Beicken 2004: 131). Durch ihren gemeinsamen narrativen Kontext machen die Genres intersubjektiv gültige Erfahrungszusammenhänge in symbolischer Form allgemeinverständlich kommunizierbar (Mikos 1993: 163). Unabdingbar für das Entstehen von Genres ist das ökonomische Potential einer gut funktionierenden Filmindustrie, die Muster erfolgreicher, d.h. populärer Filme massenhaft zu kopieren und zu variieren. Die Standardisierung typischer Züge im Visuellen, in Handlung, Figuren, Ausstattung, Erzählkonvention, Musik und Starbesetzung erleichterte Vorhersagen möglicher Zuschauerreaktionen und damit eine weitgehende Risikominderung bei den finanziellen Investitionen (Beicken 2004: 133). Aus diesem Grund entstanden Filmgenres vorwiegend in der arbeitsteilig organisierten und kapitalintensiven Filmindustrie Hollywoods, aber kaum in den nicht sehr entwickelten europäischen Filmindustrien (Mikos 1993: 163). Dort kam es hingegen zur Ausbildung bestimmter Stilrichtungen, die einerseits einem spezifischen gesellschaftlichen und kulturellen Kontext in einem bestimmten historischen Zeitabschnitt verbunden waren, die andererseits aber ihre Existenz häufig der Zuschreibung durch Filmkritiker und Journalisten verdankten (ebd.: 164).

Ganz gleich ob man den Film als Teil der Populärkultur oder der Hochkultur („Film als Kunst“, Arnheim 1931) ansieht, wird kein Werk der populären Kultur oder der Hochkultur ohne die Erfahrung anderer Werke oder ,Texte' der Pop- bzw. Hochkultur erlebt und angeeignet (Mikos 1993: 166). Das spezifische Sinnpotential des Films entfaltet sich allerdings erst in der Aneignung durch das Publikum, das ihm im Rahmen lebensweltlicher Zusammenhänge Bedeutungen zuweist, die von der Zugehörigkeit verschiedener Publika zu verschiedenen Interpretationsgemeinschaften abhängt (ebd.: 167). Diesen Interpretationsgemeinschaften obliegt auch die vergleichende, als Intertextualität umschriebene, Auswahl an Sekundärtexten, die als lebensweltliche Verweisungszusammenhänge dem Primärtext ,Film' seine spezifische Bedeutung geben (ebd. 166).

Eine Binnendifferenzierung von ,Intertextualität' nimmt John Fiske mit seiner Unterscheidung in horizontale und vertikale Intertextualität vor (ebd.: 165ff., Fiske 1987: 108ff.). Auf der vertikalen Ebene kann man alle sekundä- 
ren Texte wie Kritiken, Programmankündigungen etc. (m.a.W. die Medienrezeption) fassen, die Kontextwissen zum Film liefern und von tertiären Texten wie Leserbriefen sowie Gespräche der Zuschauer über Filme und Fernsehsendungen unterscheiden (ebd.). Die Aneignung der Filme durch das Publikum spiegelt sich in den tertiären Texten, die das Ergebnis von Zuschaueraktivitäten sind. Auf der horizontalen Ebene zeigen Filme als primäre Texte einen referentiellen Charakter hinsichtlich des Genres, der Charaktere, der Schauspieler und des Regisseurs als Teil eines Starsystems, aber auch des Inhalts und verweisen damit auch auf ausserfilmische populäre Texte (ebd.). Diese Texte beeinflussen neben der eigentlichen Rezeption während der Dauer des Filmerlebnisses auch die Aneignung der Filme, also ihre spätere Verarbeitung durch andere Medien (ebd.: 170). Genrekonventionen beispielsweise schränken diese Beeinflussung gewissermaßen im Ausschlussverfahren ein, da sie keine Interpretationen nahelegen, die sich außerhalb ihrerselbst bewegen (ebd.: 171).

Nach der Klärung des hier vertretenen Verständnisses eines rezeptionsund wirkungshistorischen Ansatzes der Filmgeschichtsschreibung soll abschließend der Begriff der Filmrezeption als Rezeptionsprozess und die Analyse der Medienrezeption als Untersuchungsmethode dargestellt werden.

\subsection{Perzeption - Rezeption - Medienrezeption}

Um Filmgeschichte als Rezeptions- und Wirkungsanalyse betreiben zu können, muss an dieser Stelle die Begriffskette Perzeption-RezeptionMedienrezeption einer genaueren Betrachtung unterzogen werden. Dies dient vor allem der angestrebten begrifflichen Differenzierung, da in der deutschsprachigen oder anglo-amerikanischen Fachliteratur diese Begriffe nicht immer einheitlich verwendet bzw. auch falsch übersetzt werden.

In einer ersten Annäherung an den Problemkreis kann man sich die Rezeption eines Filmes durch das Kinopublikum als einen dreistufigen Prozess vorstellen, der sich aus den Bestandteilen Kinowahrnehmung, Filmerleben und Filmrezeption zusammensetzt (Hickethier 1980: 75). Im Gegensatz zum passiven Rezipienten des linear gedachten kommunikationstheoretischen Reiz-Reaktions-Schemas ist von einem weitgehend aktiven Zuschauer auszugehen, der damit wesentlich zur letztendlichen Wirkung eines Werkes beiträgt:

„Der Zuschauer sucht im Werk aktiv nach Hinweisen (,cues') und reagiert darauf mit den Wahrnehmungsfähigkeiten, die er durch seinen Umgang 
mit anderen Kunstwerken und mit dem Alltagsleben erworben hat. Der Betrachter wird perzeptiv, emotional und kognitiv gefordert, wobei diese drei Ebenen unauflösbar miteinander verbunden sind" (Thompson 1995: 30).

Trotz der Abhängigkeit des Mediums Film von den ,automatischen' Fähigkeiten des Gehirns und der Sinne im Zuge der sinnhaften Filmaneignung erscheinen die perzeptiven Prozesse aus filmwissenschaftlicher Perspektive oft als selbstverständlich. Sie werden mehr oder weniger ohne Interesse als gegeben hingenommen, um sich analytisch auf die vorbewussten und bewussten Aktivitäten zu konzentrieren (ebd.: 45). Der Zuschauer lässt sich jedoch als eine hypothetische Entität fassen, die auf der Basis von ,automatischen' perzeptiven Prozessen und seiner Erfahrung aktiv mit den sogenannten ,cues' in einem Film umgeht. Durch die Einwirkung historischer Kontexte werden die Rezeptionsvorgänge wiederum intersubjektiv, man kann die Filme analysieren, ohne ständig auf Subjektivität zu rekurrieren (ebd.: 48).

Um im Hinblick auf das später zu untersuchende Material einschätzen zu können, welche Prozesse dem Zustandekommen der Rezeptionsdokumente vorangegangen sein müssen, soll an dieser Stelle etwas ausführlicher auf die Begriffe Perzeption, Rezeption und Medienrezeption eingegangen werden.

Stark vereinfachend könnte man einen dreistufigen Prozess skizzieren und von primärer, sekundärer und tertiärer Rezeption sprechen. Die erste Rezeptionstufe oder die elementare Rezeption stellt demnach die Kinowahrnehmung oder Filmperzeption dar, in der vor allem die physiologischpsychologische Wahrnehmung des Zuschauers stattfindet. Man könnte auch von einer Filmwahrnehmung jenseits der hermeneutischen Vermittlung sprechen. Dabei werden die disparaten Bewegungs- und Lichtreize auf der Leinwand (z.B. 24 monochrome Bilder pro Sekunde) durch Auge und Gehirn in einen sinnhaft wahrnehmbaren Zusammenhang transformiert. Oft genug wird der Zuschauer bereits auf dieser elementaren Stufe den Versuchen der Filmproduzenten ausgesetzt, die intuitiv gewonnenen Vorstellungen von menschlichen Perzeptionsgewohnheiten in technische Herstellungskonventionen umzusetzen. Dabei wird (nicht selten unzutreffend) unterstellt, dass die der kognitiven Ebene vorausliegenden basalen Strukturen bei den Produzenten narrartiver Strukturen die gleichen sind wie bei den Rezipienten (Kaczmarek 1996: 104):

„Auf einer ersten Ebene wird der Film nur auf der Grundlage dessen interpretiert und damit auch erlebt, was gesehen und gehört wird, ohne daß dabei soziale und ästhetische Erfahrungen, den Filminhalt tangierendes 
Wissen (...) für Interpretationen und Wertungen herangezogen werden" (Bisky/Wiedemann 1985: 66).

Das Drei-Ebenen-Modell sollte jedoch nicht derart missverstanden werden, dass die beschriebenen Prozesse streng chronologisch und vollkommen isoliert voneinander ablaufen. Vielmehr ist von interdependenten Wechselwirkungen auszugehen, die alle drei Ebenen umfassen und die Verstehensprozesse zeitlich nebeneinander ablaufen. Für bestimmte Rezipientengruppen verbinden sich bereits in der Perzeptionsphase Reizkonfiguration mit normierten Unterprogrammen komplexen psychischen Verhaltens, wozu Wahrnehmungsmuster, Denkweisen, Emotionen, Vorstellungen und Wertungen gehören, die abgerufen werden, wenn beispielweise bestimmte Stereotypen erscheinen (Wuss 1999: 60). Auf der perzeptiven Ebene werden semantisch instabile Reizkonfigurationen als Stimulusangebote der filmischen Komposition eher unbewusst wahrgenommen (Wuss 1992: 27). Dennoch führt das Orientierungsverhalten gegenüber jenen Informationsdarbiertungen, auf welche die Aufmerksamkeit des Zuschauers gelenkt wird, zu einer psychischen Aktivierung des Rezipienten, da er sich um Sinnererschließungen bemüht (ebd.).

Allgemein kann der Rezeptionsprozess als schemageleitete Informationsverarbeitung verstanden werden (Wuss 1992: 25), wobei ein Film grundsätzlich als ein geschichtetes Zeichensystem zu verstehen ist und die Annahme eines direkten referentiellen Bezugs auf die Wirklichkeit nicht zwingend vorausgesetzt wird (Kaczmarek 1996: 101). Orientierung bieten dem Rezipienten dabei drei Grundformen filmischer Strukturen, die in perzeptionsgeleitete, konzeptgeleitete, stereotypengeleite Strukturen („PKS-Modell“) unterschieden werden können (Wuss 1992: 26). Jene drei Typen treten jeweils in Wechselbeziehung zueinander und formieren zusammen den Sinngehalt eines Films. Filmische Stereotypenstrukturen sind beispielsweise daran zu erkennen, dass ihre evidente Formgestalt längst zeichenhaft geworden ist und in vielen Filmen eines kulturellen Repertoires kommunikativ genutzt werden (ebd.: 28). Von Film zu Film gibt es freilich Unterschiede hinsichtlich Ausprägung, Verteilung und Korrelation der Strukturanteile zu beobachten, was sich u.a. in variierenden Dominanzverhältnissen äußert (ebd.).

Als zweite Stufe kann das Filmerleben (=Publikumsrezeption) angesehen werden, m.a.W. welche Interpretationen der einzelne Zuschauer für sich selbst vornimmt, oder mehrere Zuschauer als Interpretationsgemeinschaften oder Teilpublika vornehmen. Die Verarbeitung von Filmen im Bewusstsein 
des Zuschauers stellt dabei ein den Film überhaupt erst konstituierendes Merkmal dar (Hickethier 1980: 75).

„Eine zweite Ebene unterscheidet sich von der eben beschriebenen dadurch, daß hier der Film als Mittler verschiedener politischer, moralischer, kultureller ,Botschaften' (...) interpretiert wird, daß die Rezeption ,konventionell oder systemhaft' wird. Auf dieser Ebene wird das im Film Gesehene und Gehörte in einen größeren Zusammenhang gestellt, indem die Rezipienten ihre Erfahrungen, Kenntnisse und Wertorientierungen in ihre Filmerlebnisse einbringen" (Bisky/Wiedemann 1985: 67).

Ruft man sich ins Gedächtnis, was zu den kognitiven Prozessen der Filmperzeption ausgeführt wurde und welche Filmstrukturen die Annahme der schemageleiteten Informationsverarbeitung nachsichzieht, wird klar, dass die modellierte Abgrenzung der drei Ebenen keiner statischen Struktur entspricht, sondern dynamische Wechselbeziehungen zwischen den Filmstrukturen und den Wahrnehmungsleistungen der Rezipienten impliziert. Genauso wie ein Film dessen Wahrnehmung und Verarbeitung in eine bestimmte Richtung weist (Thompson 1995: 49), beeinflusst das menschliche Wahrnehmungsvermögen die dafür verwendbaren Strukturen. Die Filmkomposition erscheint somit als Rezeptionsvorgabe, welche die Informationsaufnahme steuert und dabei immer auf ein Vorwissen beim Rezipienten Bezug nimmt (Wuss 1999: 11). Eine isolierte Betrachtung der Rezeptionsebenen erscheint auch deshalb als unangemessen, weil der Zuschauer als Subjekt viel enger in den kulturellen und sozialen Systemen von Signifikation verstrickt und auch durch sie definiert ist (Lowry 1992: 116).

Als dritte Stufe des Rezeptionsprozesses soll an dieser Stelle die Rezeption des Filmerlebnisses durch die Medien verstanden werden, gewissermaBen eine Rezeption zweiter Ordnung, die auf den beiden vorherigen Rezeptionsstufen fußt. Medienrezeption meint daher jede Form einer bereits dokumentierten Rezeption der Publikumsrezeption, also auch die Rezeption durch andere Individuen oder Interpretationsgemeinschaften wie z.B. Filmkritiker oder Journalisten, die im Nachgang des Filmerlebnisses in die Aneignung durch den Zuschauer mit eingeht. Die Medienrezeption wird dabei durch die Einbeziehung verschiedenster intertextueller Bezüge aktualisiert, wodurch Rezeptionsdokumente (also sekundäre oder tertiäre Texte) entstehen, deren Darstellungen über das unmittelbare Filmerleben hinausgehen.

„Eine dritte Ebene sehen wir schließlich dann erreicht, wenn der jeweilige Film als Produkt einer bestimmten politischen, moralischen, kulturellen oder auch philosophischen Traditionslinie, Richtung oder Strömung inter- 
pretiert wird; wenn er in ein übergreifendes Konzept eingeordnet werden kann. Hier müssen den Rezipienten sehr umfangreiche, weit über die unmittelbare Filmbedeutung hinausgehende Erfahrungen, Kenntnisse und Wertorientierungen zur Verfügung stehen und mit dem Film in Verbindung gebracht werden. Sie sind dann beispielsweise in der Lage, von ihren unmittelbaren Filmerlebnissen soweit zu abstrahieren, daß sie die Botschaft eines Films als Modell eines bestimmten gesellschaftlichen Sachverhaltes, einer sozio-kulturellen Traditionslinie oder einer philosophischen Strömung erkennen und interpretieren können" (ebd.: 68f.).

Da die zwei ersten Stufen des Rezeptionsprozesses nur selten wissenschaftlich verwertbares Material hinterlassen, bleibt der Filmgeschichte oft nichts anderes übrig, als die Dokumente der Medienrezeption daraufhin zu untersuchen, welche Diskssionen in der dokumentierten Öffentlichkeit über die gezeigten Filme geführt wurden. Auch kann davon ausgegangen werden, dass die Rezipienten so gut wie nie die Chance haben, direkt nach den während des Kinobesuchs entstandenen Einstellungen gefragt zu werden und diese Aussagen - mit der Ausnahme wissenschaftlicher Laborsituationen - in filmhistorisch verwertbare Dokumente eingehen zu lassen. Im Sinne der kinohistorischen Ausrichtung dieser Studie kann eine Auswertung der Medienrezeption im Einzelfall mit einer exemplarischen Filmanalyse gekoppelt werden. In einer solchen Zusammenführung ließe sich dann ergänzend zur Textanalyse feststellen, ob die in den Medien vertretenen Auffassungen auf filminhärente Strukturen zurückgehen oder lediglich dem Kontextwissen der Interpretanten entstammen.

Die Voraussetzungen beim Rezipienten für die gewünschte Reflexionstiefe der dritten Ebene sind vor allem umfangreiche Kenntnisse und stabile Wertmaßstäbe (ebd.: 69), die bei der Mehrzahl der Zuschauer nicht in jedem Falle vorliegen. So ist Kinowahrnehmung z.B. bei Erwachsenen in stärkerem Maße in einen Gesamtbereich kultureller Verhaltensweisen integriert, schichtenspezifisch unterschiedlich ausgeprägt und häufig von kulturellen Wahrnehmungsstandards überformt und ritualisiert (Hickethier 1980: 81). Die professionellen Erfordernisse des Medienbetriebes lassen immerhin den Schluss zu, dass die genannten Voraussetzungen eher bei den berufsmäßig mit Film betrauten Journalisten und Kritikern zu finden sind. Dies bedeutet allerdings nicht, dass Dokumente der Medienrezeption in jedem Falle über die ersten beiden Rezeptionsstufen hinauskommen müssten, oft genug ist das Gegenteil der Fall. Für die subjektive, wie auch die mediale Rezeption gilt daher:

„Auf welcher Ebene ein Film rezipiert wird, hängt ab von der Art und Weise (Qualität) der filmischen Rezeptionsangebote, dem erreichten Stand 
der Persönlichkeitsentwicklung und den aus einer konkreten Situation erwachsenden spezifischen Anforderungen" (Bisky/Wiedemann 1985: 71).

Der Rezeptionsprozess als solcher verfügt unabhängig davon, ob dieser später medial aufbereitet wird oder undokumentierter Teil der subjektiven Filmaneignung bleibt, über folgende Merkmale (ebd.: 77f.):

1) Zuschauer vergleichen das Gesehene ständig mit ihren eigenen Erfahrungen und kommentieren es aus ihrer Sicht;

2) Zuschauer interpretieren das Filmgeschehen teilweise im Sinne ihrer Erwartungen und ihrer Realitätssicht;

3) Zuschauer wehren sich gegen Botschaften, die ihrer politischen Haltung oder ihrem ideologischen Selbstverständnis widersprechen;

4) Zuschauer reagieren auf Filme in unterschiedlichem Maße, abhängig vom Grad ihrer Betroffenheit, ihrer sozialen Position sowie ihren lebensgeschichtlichen Erfahrungen (im Rahmen der Betroffenheit können Zuschauer kurzfristig Positionen übernehmen, die ihren Wertvorstellungen eigentlich widersprechen);

5) Zuschauer ,übersehen' Szenen und Sequenzen, die ihren Erwartungen, Interessen und Einstellungen widersprechen;

6) Zuschauer nehmen die Reaktionen der übrigen Kinobesucher wahr und verarbeiten sie unterschiedlich (von offener Ablehnung der anderen Reaktionen bis hin zu Solidarität, wo über Blickkontakte oder Berührungen Einverständnis hergestellt wird);

7) Zuschauer nehmen Teile eines Filmes primär als Abfolge von Ereignissen und Handlungen wahr, gewissermaßen auf einer ersten Sinnstufe, ohne sie gleich im Sinne ihrer Wertvorstellungen oder ihrer sozialen Position zu interpretieren.

In der Medienrezeption lässt sich zusätzlich zu den Merkmalen des Rezeptionsprozesses auch nach Strukturaussagen zur historischen Entwicklung der Medienwahrnehmung suchen, welche die Veränderungen im Medienangebot, die soziale Einbettung der Medienbenutzung und die Akkumulation medialer Erfahrung wiedergeben. Filmwahrnehmung geht jedoch nicht völlig in einer historisch bestimmbaren Mediensozialisation auf, bestimmte Phänomene filmischen Verstehens sind anthropologisch bedingt (Hickethier 1980: 80). Durch die Mediensozialisation entstanden sind z.B. der heute weitgehend passive europäische Zuschauer im Gegensatz zum meist viel aktiveren afrikanischen Zuschauer (Burns 2000).

Neuere Forschungsansätze jenseits des einfachen Reiz-ReaktionsSchemas gehen davon aus, dass die Reaktionen des Publikums als eine Frage der Erziehung und des Bewusstseins gegenüber bestimmten Normen 
und nicht als eine Frage der passiven Akzeptanz von Normen, die ihm von den Filmemachern aufgezwungen werden, zu begreifen sind (Thompson 1995: 51). Dass die Zuschauer dabei nicht als ein homogenes Massenpublikum anzusehen sind und diese einzeln oder in Gruppen, je nach Erziehungsund Bewusstseinsgrad bzw. Normakzeptanz, zu unterschiedlichen Auffassungen über das Gesehene kommen können, soll mit Hilfe des in den Cultural Studies u.a. als Antwort auf die Unzulänglichkeiten des Uses-and Gratifications-Approach entwickelten Modells des „Encoding/Decoding“ (Hall 1995) kurz beschrieben werden.

Trotz der zeitnahen Entstehungsgeschichte der beiden Erklärungsansätze (Hall um 1980, Bisky/Wiedemann 1985) soll das Encoding/Decoding-Modell als eine Weiterentwicklung des linearen Stufenmodells aufgefasst werden, da es einen zirkulären Erklärungsansatz bietet und das vielfach übersimplifizierte Reiz-Reaktions-Modell sinnvoll ersetzt. Dieser Ansatz lässt sich vielmehr als eine zweckmäßige Erweiterung des Stufenschemas begreifen, der die Merkmale des Rezeptionsprozesses und die zugehörigen kognitiven Voraussetzungen kombiniert, um unter Berücksichtigung des soziokulturellen Kontextes gewisse Wirkungsannahmen zu konstruieren. ${ }^{2}$

Beim Encoding/Decoding-Modell wird davon ausgegangen, dass Prozesse des Kodierens/Dekodierens den Kommunikationsprozess determinieren und dadurch Nachrichten nicht in einer statischen, sondern diskursiven Form übermittelt werden (Hall 1995: 94). Dabei wird der Aufbau eines aus Nachrichten bestehenden Programms strukturell vom angewandten Wissen aus den Produktionsroutinen, von historisch bestimmten technischen Fertigkeiten, professionellen Ideologien, von institutionellem Wissen, Definitionen und Annahmen, von den Einschätzungen des Publikums etc. gerahmt (ebd.: 95). Die so kodierten Nachrichten nehmen die Form eines sinntragenden Diskurses an, die erst durch diese dekodierten Bedeutungen eine Wirkung haben, was äußerst komplexe, die Wahrnehmung und das Verhalten betreffende, kognitive, emotionale oder ideologische Konsequenzen nachsichziehen kann (ebd.: 96). Aufgrund der unterschiedlichen Produktions- und Konsumptionskontexte auf der Sender- bzw. Empfängerseite können im Augenblick der Transformation in und aus der diskursiven Form Asymmetrien entstehen, welche die Passgenauigkeit der Kodes und damit auch die sinntragenden

\footnotetext{
2 Trotz der bei Hall und Bisky/Wiedemann ähnlichen wissenschaftstheoretischen Postulate, der marxistisch geprägten „Analyse der politische Ökonomie“ bzw. dem „dialektischen Materialismus“, unterlagen die Ausführungen von Bisky/Wiedemann politische bedingten Sachzwängen, die einen gedanklichen Anschluss an Stuart Hall erschwerten. So galt z.B. das einfache Sender-Empfänger-Modell als ein metawissenschaftliches Dogma, da es analog zum offiziellen Verständnis von Partei („Richtungsgeber“) und Volk modelliert werden konnte (Haney 2007: 69).
} 
Diskurse beeinflussen (ebd.: 98). Im Falle des Films kommt noch hinzu, dass visulle Kodes kulturspezifisch sind, d.h. eventuelle Missverständnisse viel eher auf historisch tradierte Auffassungen zurückzuführen sind (z.B. Bilderverbot im Islam) als auf situative sozio-ökonomische Einflüsse. Auf der Dekodierungsseite nimmt die Wirkungsweise der Kodes häufig den Status einer naturalisierten Perzeption an, wenngleich diese Wahrnehmungsbedingungen das Ergebnis komplexer und nahezu unbewusster Operationen - den Dekodierungen eben - sind (ebd.: 100). So verstanden gelten auch Filmbilder als Zeichen, deren Dekodierung sich durch situationsbedingte Ideologien verändern und transformieren kann:

„Kodes stellen die Mittel dar, vermöge deren Macht und Ideologie in bestimmten Diskursen zum Tragen gebracht werden. Sie führen die Zeichen auf die ,Landkarten der Bedeutungen' zurück, in die jede Kultur eingeordnet wird; und solchen ,Landkarten der sozialen Wirklichkeit' ist die gesamte Bandbreite sozialer Bedeutungen, Praktiken und Bräuche, von Herrschaft und Interesse, eingeschrieben'“ (ebd.: 102).

Die Kodes einer Nachricht sind am stärksten auf der Ebene der Denotation (,Hauptbedeutung') fixiert, auf der Ebene der Konnotation (,Mitbedeutung') jedoch sind Nachrichten relativ offen für Umwandlungsprozesse, welche den polysemen (mehrdeutigen) Charakter vieler Zeichen wirksam werden lassen (ebd.: 103). Polysemie bedeutet jedoch nicht, dass die konnotativen Kodes in jedem Falle gleichrangig sind, da „jede Gesellschaft bzw. Kultur [...] mit variierenden Graden der Geschlossenheit dazu [neigt], ihre jeweiligen Klassifizierungen der gesellschaftlichen, kulturellen und politischen Welt durchzusetzen", um eine dominante kulturelle Ordnung zu bilden (ebd.). Diese keineswegs homogene Ordnung lässt sich in unterschiedliche diskursive Gebiete aufteilen, die hierarchisch nach dominierenden oder bevorzugten Bedeutungen organisiert sind (ebd.). ,Dominant' bezeichnet dabei das Muster ,bevorzugter Lesarten', denen die institutionelle, politische und ideologische Ordnung eingeschrieben sind und sie selbst schon institutionalisiert wurden (ebd.). Daraus lässt sich ableiten, dass Polysemie sowohl auf der Produktions-, als auch der Rezeptionsseite vorhanden sein kann, da die variierenden Grade der kulturellen Geschlossenheit verschiedene Deutungsmöglichkeiten der bevorzugten Lesarten zulassen. Dadurch wiederum entstehen auf beiden Seiten variierende Arten der Kombination von Kodierungs- und Dekodierungsvorgängen (ebd.: 106), die je nach sozio-ökonomischem oder kulturellem Kontext unterschiedliche Produktions- bzw. Rezeptionsweisen hervorbringen können. 
Mit dieser Auffassung soll in Bezug auf das zu untersuchende Material allerdings nicht ein „unendliches Spiel der Lesarten“ gerechtfertigt werden, dass ein breites Spektrum verschiedenster Hintergründe für ein und denselben Film heranzieht. „Da zu jedem spezifischen historischen Moment bloß eine endliche Anzahl von Lektüre-Konventionen existiert, erlauben sie zwar eine Reihe verschiedener "Lesarten', aber eben nicht unendlich viele" (Thompson 1995: 43). Vor dem Hintergrund der hier angestrebten Untersuchung zur Rezeption deutscher Spielfilme in Südafrika sollte in den Rezeptionsdokumenten dem ausgehandelten Kode als dominantem Kode unter lokalen Bedingungen nachgegangen werden (Hall 1995: 108). Im südafrikanischen Kontext bedeutet dies vor allem herauszufinden, ob innerhalb der zwei dominanten Bevölkerungsgruppen (englischsprachige vs. afrikaanse Südafrikaner) unterschiedliche Lesarten in Bezug auf den deutschen Spielfilm im Allgemeinen oder auf Einzelfilme existierten und wie das Zustandekommen dieser Lesarten erklärt werden kann.

Ganz allgemein liegt das Hauptinteresse der an den Cultural Studies orientierten Filmgeschichtsschreibung immer mehr bei den konkreten Produktions-, Aufführungs- und Rezeptionsprozessen, in deren Kontext mögliche Bedeutungen von Filmen und Kinobesuchen verhandelt werden. Untersucht wird z.B. die Art und Weise, wie etwa Fans, Subkulturen oder ethnische Minderheiten Filme für sich aktivieren, oder wie politische Großwetterlagen, technologische Innovationen oder ökonomische Imperative einen höchst variablen Horizont für die Verbreitung und Aneignung gewisser Filme und ihrer Bedeutung abstecken (Koepnick 2002: 199). Dabei darf jedoch nicht übersehen werden, dass gewisse Ströhmungen innerhalb der Cultural Studies (z.B. die US-amerikanische) dazu tendieren, Politik per se als Kultur zu definieren und so in bestimmten Fällen einer undifferenzierten Politisierung jeglicher Kulturanalyse das Wort zu reden (ebd.):

„Politisch relevante Bedeutungen liegen nicht einfach in der symbolischen Sprache gewisser Filme oder Filmzyklen verborgen, sondern entstehen als Resultat pluraler Aneignungsstrategien, deren oft unvorhersagbare, historisch spezifische und lokal verankerte Dynamik den Intentionen der Filmemacher durchaus widersprechen kann. Bedeutungen sind Produkt dessen, was zwischen Film und Zuschauer unter bestimmten Rezeptionsbedingungen verhandelt wird. Der Weg vom Film zum Publikum ist dabei weder als Einbahnstrasse noch als eingleisig zu denken. Zugleich sind bestimmten Filmen und Filmgenres immer wieder Spuren des Versuchs eingeschrieben, die Aufmerksamkeit der Zuschauer zu lenken, gewissen Bedeutungsmöglichkeiten auf Kosten anderer zu privilegieren und unerwünschte Aneignungspraktiken von vornherein zu blockieren" (ebd.: 206). 
Dabei fällt der formalen Textanalyse im Rahmen einer sich an die Cultural Studies anlehnenden Filmhistoriographie die Rolle zu, Erklärungen dafür zu geben, was vor dem Hintergrund institutioneller Dispositive als mögliche Rezeptionshaltung antizipiert oder ausgeschlossen werden sollte. Obwohl oft von Teilen der Cultural Studies argwöhnisch beäugt, eröffnen gerade genaue Textanalysen Einsichten in jene Strategien, die den kreativen Akt des Zuschauens entweder zu reglementieren oder zu intensivieren suchen (ebd.: 206). Das damit gewiss auch eine problematische Textdominanz einhergehen kann, soll vor dem Hintergrund der verschiedenen Dimensionen einer systematischen Filmanalyse nicht verschwiegen werden.

Neben den allgemeinen Merkmalen des Rezeptionsprozesses und der historischen Medienentwicklung unterliegen die veröffentlichten Rezeptionsdokumente von Kritikern und Journalisten den kommerziellen Verwertungsinteressen der jeweiligen Publikationsorgane und der Unterhaltungsindustrie. Diese üben mal mehr, mal weniger direkten oder indirekten Einfluss auf die Berichterstattung über das Filmerleben aus. Oft genug beeinflusst die journalistische Filmkritik durch nicht-objektivierte Einschätzungen ganz wesentlich die spätere Filmrezeption des vor dem Kinobesuch Orientierung suchenden Zuschauers. Dabei ist das filmhistorische Gedächtnis der Filmkritk so divers und unzuverlässig, dass nach vielen Kritiken von äußerst mittelmäßigen Filmen der nächstbeste, nur wenig bessere Film als Ausnahme und um so viel besser beurteilt wird, dass mit dem Vorwissen um die historisch unbestrittenen Filmklassiker eine gesunde Skepsis in Bezug auf das Urteilsvermögen der journalistischen Filmkritik angebracht erscheint (Pardoe 1945/46: 120).

Ein Desiderat der Filmgeschichtsschreibung als Analyse der Rezeptionsund Wirkungsgeschichte ist daher die Rekonstruktion einer Zuschauergeschichte, die sich nicht nur als Reflex der Kinoindustrie verstehen soll, sondern nach dem den Verwertungsinteressen widerständigen Momenten fahnden könnte (Hickethier 1980: 78). Einen nicht zu unterschätzenden Einfluss auf die Medienrezeption geben auch der politische Standort und die Interessenverflechtung der einzelnen Medien in Bezug auf die Aussagen der Filmberichterstattung vor (Korte 1998: 135). Diese Problematik wird nachfolgend in Kapitel 3 behandelt.

Nach der notwendigen Erläuterung der zu beachtenden theoretischen Prämissen der Filmhistoriographie kann jetzt der Überblick zur Situation von Film und Kino in Südafrika in den 1920er und 1930er Jahren erfolgen. 


\section{Kino und Gesellschaft in Südafrika in den 1920er und 1930er Jahren}

Wie bereits dargelegt, resultierte das Interesse an einer Untersuchung der Rezeption des Spielfilms der Weimarer Republik in Südafrika u.a. aus einer von der Filmgeschichtsschreibung bisher unbeachtet gebliebenen Bemerkung nebst Fußnote, wonach es sich bei den erfolgreichsten kontinentaleuropäischen Filmproduktionen Ende der 1920er Jahre um die deutschen UFA-Filme gehandelt habe (Gutsche 1972: 218). Um diese Bemerkung innerhalb der südafrikanischen Kinogeschichte richtig einordnen zu können, soll ein Überblick zur Situation von Film und Gesellschaft im damaligen Südafrika gegeben werden. Dabei wird im Rahmen eines Literaturberichtes auch kurz auf die politische Situation, die Auswahl des Untersuchungszeitraumes und der aktuelle Stand der südafrikanischen Filmgeschichtsschreibung eingegangen.

Um im weiteren Verlauf der Studie keine terminologische Verwirrung aufkommen zu lassen, soll an dieser Stelle kurz geklärt werden, mit welchen Bezeichnungen die einzelnen Bevölkerungsgruppen Südafrikas gemeint sind. Die schwierige Geschichte Südafrikas vor dem Hintergrund der jahrhundertelangen ethnischen Diskriminierungen hat dazu geführt, dass im Lauf der Geschichte verschiedene Volksgruppen mit wechselnden Bezeichnungen bedacht wurden, die aus heutiger Sicht problematisch geworden sind und nur mehr auf Unverständnis stoßen. Da das Hauptaugenmerk dieser Untersuchung auf dem europäischen Bevölkerungsteil Südafrikas liegt, wird künftig von Südafrikanern europäischer Herkunft die Rede sein, also jene, die historisch als ,Weiße' bezeichnet wurden (Holloway 1936). Diese wiederum lassen sich in die zwei maßgeblichen Gruppen der englischsprachigen und afrikaanssprachigen Südafrikaner untergliedern. Die ebenfalls historisch gewordene Bezeichnung ,Buren' für die afrikaanssprachigen Südafrikaner wird nach Möglichkeit durch ,Afrikaaner' ersetzt. Um vor allem für den deutschsprachigen Leserkreis die Verwechslungsgefahr mit den herkömmlich als ,Afrikaner' bezeichneten indigenen Völkern Schwarzafrikas zu vermeiden, ist hier von ,Afrikaanern' mit doppel-a die Rede, eine Bezeichnung, die sich von deren Sprache, das dem Niederländischen sehr ähnliche Afrikaans, ableitet. Alle übrigen Bevölkerungsgruppen sollen daher als Südafrikaner nichteuropäischer Herkunft bezeichnet werden, um die vormaligen Umschreibungen als ,Kaffer', ,Bantu', ,Blacks', ,Bastards', ,Hottentots', ,Coloureds', ,Asians', ,Cape-Malay' etc. zu neutralisieren. Das nur den Südafrikanern europäischer Herkunft gewährte Zuordnen in englisch- oder afrikaanssprachig soll an dieser Stelle keine Wertung beinhalten, sondern stellt eine ver- 
einfachende Konvention dar. Es ist eine Selbstverständlichkeit, dass viele Südafrikaner nicht-europäischer Herkunft Afrikaans, Englisch oder beide Sprachen beherrschen. Dem mit den südafrikanischen Verhältnissen weniger betrauten Leser mag diese Regelung umständlich erscheinen. Sie ist jedoch bei diesen scheinbar alltagssprachlichen Bezeichnungen ebenso notwendig wie bei fachwissenschaftlicher Textarbeit, um nicht durch „aktualisierende Übersetzungen gleich in die Fallstricke variabler Bedeutungen von Worten in wechselnden Kontexten zu geraten“ (Stolleis 2005: 37).

\subsection{Zum Stand der südafrikanischen Kinogeschichtsschreibung}

In Vorgriff auf den in Abschnitt 2.4. und 2.5. ,zwischen den Zeilen' verarbeiteten Stand der südafrikanischen Film- und Kinoforschung soll hier eine kurze Kontextualisierung der entstandenen Ergebnisse und deren Autoren erfolgen. Dabei könnte es bei einem Blick auf die Literaturverweise verwundern, dass sich strenggenommen nur auf drei Autoren gestützt wird. Die südafrikanische Filmgeschichtsschreibung für den Zeitraum bis zum Zweiten Weltkrieg besteht im Wesentlichen aus ganzen drei Büchern: Thelma Gutsches „The History and Social Significance of Motion Pictures in South Africa 18951940“ (1972), Hans Rompels zweibändiges Werk „Die bioskoop in diens van die volk" (1942a und 1942b) und Keyan Tomasellis "Ideology and Cultural Production in South African Cinema" (1983). Auch bei einer Betrachtung der anderen meist unveröffentlicht gebliebenen akademischen Qualifikationsschriften fällt auf (Eckardt 2005c, Eckardt 2006), dass besonders die Dominanz von Gutsches Werk zu dem schwerwiegenden strukturellen Mangel geführt hat, dass alle filmgeschichtlichen Daten für den Zeitraum vor dem Zweiten Weltkrieg ausschließlich aus ihrem Standardwerk entnommen und keine neuen Untersuchungen angestrengt wurden. Dies spricht weniger gegen das Werk und ihre Autorin, aber eben auch nicht gerade für ihre zahlreichen Nachahmer.

Thelma Gutsches im Jahre 1972 veröffentlichtes Standardwerk ist ihre bereits 1946 an der Universität Kapstadt für das Fachgebiet Sozialgeschichte eingereichte Dissertation, die erst nach 26 Jahren und fast ohne Überarbeitung veröffentlicht wurde. Ihre kulturhistorische Studie für den Zeitraum 1895 bis 1940 ist durch die wenigen Gelegenheiten, sich mit originär südafrikanischen Filmproduktionen zu beschäftigen, eine hervorragende kinohistorische, deskriptiv-hermeneutische Abhandlung. Ihr Rückgriff auf von Zeitzeugen zur Verfügung gestelltes Material und das weitgehende Fehlen systema- 
tisch gesammelter Quellen zur südafrikanischen Filmgeschichte bringt es allerdings mit sich, dass sich Aussagen zum Überlieferungszusammenhang der Quellen vielfach nicht mehr rekonstruieren lassen. Dies schränkt die Bedeutung ihres Werkes jedoch nur unwesentlich ein, es sollte jedoch bei Studien zum gleichen Untersuchungszeitraum etwas kritischer mit ihren Daten umgegangen werden. Um ihren filmhistorischen Einschätzungen folgen zu können, sind auch einige wenige biographische Details erwähnenswert.

Thelma Gutsche (1915-1984) entstammte einer deutsch-südafrikanischen Familie die auf den ersten deutschen Baptistenprediger in Südafrika, Carl Hugo Gutsche (1843-1926), zurückgeht. Nach einem Philosophiestudium in Kapstadt (B.A. 1933, M.A. 1934) promovierte sie 1946 mit der Arbeit „The History and Social Significance of the Cinema in South Africa" bei Prof. F.C.L. Bosman, u.a. langjähriger Vorsitzender des Amateurfilmklubs in Kapstadt. Tätig als Filmkritikerin für verschiedene Medien, erwarb sie sich eine Filmkennerschaft, die sie 1939 für eine Position im State Bureau of Information qualifizierte. In den Jahren 1947 bis 1959 fungierte sie als Leiterin des Educational and Information Service von African Consolidated Films Ltd., welcher Teil des Medienverbundes der Schlesinger-Organisation war. ${ }^{3}$ In den Jahren 1955 bis 1958 war sie Vorsitzende des südafrikanischen National Council of Women. Von 1960 bis zu ihrem Tode war sie als freiberufliche Historikerin tätig, nahm mehrere Vorstands- und Beraterposten ein und publizierte zu den verschiedensten Themen (Eckardt 2004).

Durch die Sprachkenntnisse infolge ihres Familienhintergrundes konnte Thelma Gutsche auch deutschsprachige Publikationen (z.B. Niessen 1934) für ihre Forschungen heranziehen (Gutsche 1972: 393f.). In diesen Zusammenhang überrascht es allerdings, dass ihr in Bezug auf die gezeigten deutschen Spielfilme mehrere Falschzuschreibungen unterlaufen. Sie nennt beispielsweise acht Filmtitel, die als deutsche bzw. UFA-Produktionen bezeichnet wurden (ebd.: 217f. und 228ff.). ${ }^{4}$ Dabei vereinnahmt sie den fränzösischen Film „Koenigsmark“ (1923, Léonce Perret) als deutschen Film, lässt die Tatsache der deutsch-britischen Koproduktion bei ATLANTIK (1929, E.A. Dupont) unberücksichtigt, ebenso die deutsch-indisch-britische Zusammenarbeit bei „Shiraz-Grabmahl einer großen Liebe“ (1928, Franz Osten). Der Bekanntheit und dem Starruhm von Emil Jannings scheint es geschuldet zu

\footnotetext{
${ }^{3}$ Mehr zur Bedeutung der Schlesinger-Organisation in Abschnitt 2.3.

4 METROPOLIS, THE SPY, THE WONDERFUL LIE (Gutsche 1972: 217), „Koenigsmark”, THE STUDENT OF PRAGUE, "The Way of All Flesh”, THE LOVES OF JENNY NEY, „The Last Command” (Gutsche 1972: 218).
} 
sein, dass Gutsche seine in Hollywood produzierten Filme "The Way of All Flesh“ (dt. Der Weg allen Fleisches; 1927, Victor Fleming ) und „The Last Command" (dt. Sein letzter Befehl; 1928, J. v. Sternberg) den deutschen Produktionen zuschlägt. Dem Mangel dieser Falschzuschreibungen in einem kinohistorischen Standardwerk steht der Glücksfall gegenüber, mit den genannten Filmtiteln die ersten Anhaltspunkte zur Existenz von deutschen Spielfilmen in der Programmgeschichte des südafrikanischen Kinos geliefert zu haben. Die genannten Ausführungen machen deutlich, dass die südafrikanische Filmhistoriographie über die Zeit bis 1940 kaum an Gutsche vorbeikommt, jedoch das unkritische Übernehmen ihrer Darstellungen dem Anspruch einer faktenorientierten Filmgeschichtsschreibung nicht immer gerecht wird.

Bedenkt man die Anstellung Thelma Gutsches beim langjährigen Film- und Kinomonopolisten African Consolidated Films, verwundert es nicht sonderlich, dass dessen marktbeherrschende Stellung recht unkritisch beschrieben wurde. Beim Rückgriff auf vorwiegend englischsprachige Quellen blendete sie die vielfach konträren Meinungen der afrikaansen Veröffentlichungen aus. Der Vorteil ihrer Darstellung besteht jedoch u.a. darin, dass sie moderne Konzepte der Filmgeschichtsschreibung als Rezeptions- und Wirkungsgeschichte gewissermaßen vorwegnahm und das Ziel hatte, eine gewisse Ordnung in den ,Kulturraum Kino' zu bringen und dessen chaotische Formen in rational-zusammenhängende Strukturen zu überführen (Masilela 2000: 53). In Abkehr vom produktionsfixierten Herkunftslandprinzip verstand sie, dass

„... South African cinema is not constituted by the totality of films made by South Africans on aspects of South Africanness, but rather, in the early decades of its inspection, by the impinging of foreign films on the imagination of South Africans as well as the cultural and social institutions that made this possible. In other words, Gutsche approaches the making of South African cinema as a historian of social and cultural institutions, rather than a film historian of artistic processes or from concern with aesthetics of form" (Masilela 2000: 50).

Ein weiterer Vorteil ihres Werkes besteht in dem Streben nach einer fast allumfassenden Geschichte des Kinos in Südafrika bis 1940. Diese Konzeption macht ebenfalls deutlich, dass keine ernstzunehmende Studie zur südafrikanischen Kinogeschichte auf die Nutzung von Gutsches Monumentalwerk verzichten kann.

Als einzig ebenbürtiger afrikaanssprachiger Filmhistoriker und Zeitgenosse von Thelma Gutsche kann Hans Rompel angesehen werden. Hans Rompel 
(1902-1981) begann 1927 nach seinem Medizinstudium (Psychatrie) eine Tätigkeit als Pressephotograph und Filmrezensent für die einflussreiche Kapstädter Tageszeitung Die Burger (Rompel 1965). Neben seinen Kritiken schrieb er seit 1927 auch zahlreiche Aufsätze über Film und Kino in den weit verbreiteten Zeitschriften Die Huisgenoot und Die Brandwag. Aus diesen Überlegungen entstand zunächst eine mehrteilige Artikelserie zur Geschichte des Films (Rompel 1938), die er 1942 um seine Zukunftsvorstellung einer afrikaansen Filmproduktion erweiterte und als zweibändiges Taschenbuch namens „Die bioskoop in diens van die volk“ (übersetzt: Der Film im Dienste des Volkes) ${ }^{5}$ veröffentlichte (Rompel 1942a und 1942b). In seinen zeitgenössischen Filmschriften versuchte er seine Beobachtungen und Schlussfolgerungen theoretisch zu reflektieren und dies wiederum praktisch zu verwerten. Auf seine Initiative gründete eine der einflussreichsten Afrikaanerkulturorganisationen, der Reddingsdaadbond (RDB), eine Amateurfilmorganisation mit dem Auftrag, aktiv im Sinne des Afrikaanernationalismus tätig zu werden und die Grundlagen für eine spätere afrikaanse Filmproduktion zu schaffen. Diese Idee erwuchs vor allem aus dem als volksgefährdend oder volksfeindlich angesehenen Einflusses des Hollywoodtonfilms, der nur auf Englisch daherkam, Werte propagierte, die in konservativen Afrikaanerkreisen beargwöhnt wurden und durch seine Dominanz einen Imperialismus materialisierte, dem man sich durch das Hollywoodmonopol im südafrikanischen Kino hilflos ausgeliefert sah (Rompel 1942a: 114ff.). Die Amateurfilmabteilung RARO (Reddingsdaadbond-Amateur-Rolprent-Organisasie) produzierte unter Rompels Leitung in den 1930er und 1940er Jahren einige Filme (z.B. 1938 'n Nasie hou koers). Ohne einen konkurrenzfähigen Vertrieb konnte der Schlesinger-Organisation dadurch keine wirksame Konkurrenz erwachsen, so dass diese Initiativen infolge mangelhafter Finanzierung eingestellt werden mussten.

In seinen trotz einiger positiver Ansätze (z.B. Wheeler 1986) bisher noch nicht vollständig erfassten Schriften, stellte Rompel den Film als eine Art ,unerkannte Kulturmacht' dar, die es politisch und ökonomisch zu nutzen gelte (Rompel 1945 und 1948). Seine Filmgeschichte orientierte sich an ästhetischen Parametern und betonte schon früh den Nationalcharakter der Tonfilmproduktionen aus den USA oder Europa im Gegensatz zum (sprach-) grenzenlos rezipierbaren Stummfilm. Als theoretische Grundlage zog er u.a. Hans Buchers kritisch-konservative Studie „Im Banne des Films“ (1927)

5 Wenn nicht anders gekennzeichnet, sind alle im Text enthaltenen Übersetzungen durch den Autor [ME] verfertigt. 
heran (Rompel 1930: 8). In seinen Analysen benutzte er vielfach deutsche Produktionen als Beispiele dafür, wie dem Hollywoodmonopol stilistisch und ökonomisch erfolgreich begegnet werden könnte (Rompel 1937). Aus seiner Sicht bestand der filmische Hauptgegensatz zwischen den unrealistischen US-Produktionen und dem Realismus der europäischen Filme. Für eine künftige afrikaanse Filmproduktion schwebte ihm eine Kombination aus dem ästhetischen Realismus der deutschen Spielfilme und der Montagetechnik des sowjetischen Revolutionsfilms vor (Eckardt/Tomaselli 2007). Beeindruckt vom Wiedererstarken der deutschen Filmindustrie nach der nationalsozialistischen Gleichschaltung Mitte der 1930er Jahre, empfahl er deren Strukturen einer noch aufzubauenden afrikaansen Filmindustrie als wünschenswertes Vorbild und Abgrenzung zu Hollywood (Rompel 1942b: 23-34). Nach 1948 widmete sich Rompel voll und ganz seinem Beruf als Psychiater und Übersetzer medizinischer Fachliteratur, als Verfasser filmbezogener Publikationen trat er nicht wieder in Erscheinung.

Trotz der Zeitgenossenschaft können Hans Rompel ob seiner stark politischen Agenda und Thelma Gutsche aufgrund ihres Anstellungsverhältnisses im Staatsdienst und bei der Schlesinger-Organisation als filmhistorische Antipoden gelten. So verwundert es auch nicht, dass Gutsche Rompel nur nebenbei als Gründer von RARO und Produktionsleiter von „'n Nasie hou koers“ erwähnt (Gutsche 1972: 263 und 344). Die (Wieder-) ,Entdeckung' Hans Rompels als Filmtheoretiker ist in der Fachwelt interessiert aufgenommen worden, eine genauere Untersuchung seines Schaffens stellt ein filmhistorisches Desiderat dar (Engelen 2006: 107).

Mit "Ideology and Cultural Production in South African Cinema" (1983) von Keyan Tomaselli (*1948) liegt eine ähnlich umfassende Studie wie jene von Thelma Gutsche vor. Der Schwerpunkt liegt dabei eher auf der südafrikanischen Filmproduktion im Zeitraum von 1910 bis 1980, schließt aber eine Betrachtung der Vertriebs- und Vorführungsstrukturen mit ein. Methodisch stark von den marxistischen Theorien der späten 1970er und frühen 1980er Jahre (Strukturalismus etc.) geprägt, übte Tomaselli eine Kritik an der politischen Ökonomie der südafrikanischen Filmindustrie und belegte deren ideologischen Einfluss auf die thematische Ausrichtung der Spielfilme. Für die Entwicklung der südafrikanischen Filmindustrie bis zum Ende des Zweiten Weltkrieges vollzog er u.a. eine Marktformenanalyse, mit der in Anlehnung an Gutsche z.B. Annahmen über die Finanzierungsstruktur der Filmindustrie getroffen wurden. Als einer der wenigen südafrikanischen Filmforscher verwendete Tomaselli neben Gutsches Standardreferenz auch die Arbeiten von Hans Rompel. Der größte Nachteil von Tomasellis 1983 an der University of 
the Witwatersrand (Johannesburg) eingereichten Dissertationsschrift ist darin zu sehen, dass sie wegen ihres damals brisanten Inhaltes nicht veröffentlicht werden konnte. Die Präzision und Fülle der enthaltenen Gedanken hat allerdings dazu geführt, dass es in Tomasellis späteren Veröffentlichungen zur Filmgeschichte kaum mehr Fakten gab, die nicht schon in seiner Disseration erwähnt wurden (u.a. Tomaselli 1983, 1989 bzw. 2006).

Keyan Tomaselli kann als der einflussreichste aktive Filmwissenschaftler in Südafrika angesehen werden. Mit einer Arbeit zur Filmsemiotik graduierte er 1980 in Johannesburg (Tomaselli 1980b), daneben war er als Kameramann tätig und produzierte einige ethnographische Dokumentarfilme. Nach seiner Promotion wechselte er in den Wissenschaftsbereich und etablierte an der University of Natal in Durban das erste Graduiertenprogramm für Cultural and Media Studies in Südafrika. Als Lehrstuhlinhaber und Programmdirektor konnte er eine film- und medienwissenschaftliche Schulenbildung vorantreiben, die theoretisch die Methoden der anglo-amerikanischen Cultural Studies lehrte und diese durch die von ihm herausgegebene Zeitschrift Critical Arts popularisierte. Durch die internationale Ausrichtung des damaligen Centre for Cultural and Media Studies konnte im Jahre 2000 in Durban die Grundidee der hier vorliegenden Abhandlung entwickelt werden.

Neben den drei genannten Hauptwerken zur Filmgeschichte existieren nur wenige zeitlich vergleichbar ausgerichtete Arbeiten. Diese wiederum beschäftigen sich hauptsächlich mit den frühen südafrikanischen Filmproduktionen (z.B. Le Roux 1942, Strebel 1976/77 und 1979 oder Hees 2003). Die in Überblickswerken zur Mediengeschichte Südafrikas enthaltenen Abschnitte zu Film und Kino (z.B. Louw/Botha 1993 oder Wigston 2001) sind sehr oberflächlich und teilweise fehlerhaft (dazu Abschnitt 2.4.). Eine Auflistung aller Filmproduktionen von 1910 bis 1980 (inkl. kurzer Inhaltsbeschreibungen) bieten Le Roux/Fourie (1982), die allerdings in Widerspruch zu den Daten von Tomaselli (1989) und Moses (2006) stehen.

Aus dieser Mangelsituation entstand die Notwendigkeit umfangreicher Vorarbeiten für die hier vorliegende Studie. Die Ergebnisse dieser Recherchen (v.a. Eckardt 2000 und 2005) gehen in die vorliegende Untersuchung teilweise mit ein. Im Sinne einer „Mikrogeschichtsschreibung“ wurden einzelne lokal bzw. chronologisch begrenzte Elemente ,unter die Lupe genommen' und der Frage nachgegangen, welche Kombination von Faktoren und Mechanismen diese Phänome hervorgebracht hat. Durch die kontextuelle Herangehensweise sollte deutlich werden, auf welche Weise und aus welchem Grund die Phänomene entstanden sind, in welchem Verhältnis sie zu anderen Erscheinungen standen und welchen Einfluss es auf diese gehabt hat (Kusters 
1996: 49f.). Diese analytischen Vorarbeiten hatten das zusätzliche Ziel, eine ausreichende empirische Datenbasis zu schaffen, das Übernehmen von Fehleinschätzungen aus den überzitierten Standardwerken zu vermeiden, und das ,Vetorecht der Quellen' wirksam werden zu lassen.

\subsection{Südafrika in der Zwischenkriegszeit}

In Südafrika waren auch die 1920er und 1930er Jahre noch von den Bemühungen geprägt, die für das Land verheerenden Folgen des Burenkrieges der Jahre 1899-1902 zu überwinden. Die Teilnahme Südafrikas im Ersten Weltkrieg auf Seiten der Entente hatte sich überwiegend positiv ausgewirkt. Errungen hatte man die Verwaltungshoheit über die deutsche Kolonie Südwestafrika und am Niederringen der Schutztruppe in Deutsch-Ostafrika waren südafrikanische Soldaten maßgeblich beteiligt. Dem gegenüber stand die Zahl von ca. 19.000 getöteten oder verwundeten Soldaten.

Schwerwiegender waren die Ergebnisse des Unabhängigkeitskrieges der Südafrikanischen Republik (Transvaal) und Oranje-Freistaat gegen die britische Kolonialmacht in den Jahren 1899-1902 (Weber 1999). Die Ursache des Krieges lag im agressiven Expansionismus des britischen Kolonialreiches, welches die um 1886 entdeckten Gold- und Diamantenvorkommen in Südafrika (,The Mineral Revolution', Worden 2000: $41 \mathrm{ff}$.) zu kontrollieren suchte. Im Friedensvertrag von Vereeniging mussten die unterlegenen Burenrepubliken schließlich 1902 die britische Oberhoheit anerkennen.

Die Südafrikaner hatten zwar ,nur' etwa 5.000 Soldaten verloren, allerdings starben ca. 28.000 südafrikanische Frauen und Kinder - davon 22.000 im Alter von unter 16 Jahren - in britischen Konzentrationslagern oder an den Folgen der Kämpfe (Giliomee 2003: 264). Es wurde geschätzt, dass die Buren 10 Prozent ihrer Gesamtbevölkerung oder eine ganze Generation verloren hatten. Die wirtschaftliche Grundlage der Buren, die Landwirtschaft, war durch die ,verbrannte Erde'-Taktik der Briten vollkommen zerstört. Zum ersten Mal wurde ein kolonialer Krieg, nach britischem Verständnis eine „Expedition disziplinierter Soldaten gegen Wilde und halbzivilisierte Rassen“, gegen eine europäisch-autochtone Nation in Afrika geführt, dessen Methoden in Europa längst als moralisch verwerflich und rechtlich unzulässig erachtet wurden (Eckert 2007: 8). Mit der Wendung zum totalen Krieg, der Einbeziehung der Zivilbevölkerung, einer Mobilisierung aller Ressourcen und der zentralen Rolle der Guerillataktik nahm dieser Krieg den Charakter der Vernichtungskriege des 20. Jahrhunderts vorweg (ebd.). Der Friedensschluss 
wiederum folgte paradoxerweise der von den britischen Imperialisten zur Höchtsform entwickelten Logik des „divide and conquer" (dt. „teile und herrsche"). Auf die Hilfe der Buren zur Kontrolle des Landes angewiesen, gewährte Großbritannien eine Entschädigung von 16 Millionen Pfund zur Überwindung der Kriegsschäden (Giliomee 2003: 265).

Die immateriellen Folgen des Krieges waren u.a. ein bis heute schier unüberbrückbares Misstrauen auf Seiten der Afrikaaner gegenüber dem ehemaligen Kriegsgegner, sowie eine auseinanderdriftende Entwicklung der beiden maßgeblichen südafrikanischen Volksgruppen in sozio-ökonomischer Sicht. Die Ergebnisse des Burenkriegs überschatteten noch bis zum Ende des Zweiten Weltkrieges die südafrikanische Politik. Dies verwundert nicht, bedenkt man die Tatsache, dass sich die politischen Führer der Afrikaaner und spätere Premierminister Louis Botha (1862-1919), Berry Hertzog (18661942) und Jan Smuts (1870-1950) ausschließlich aus ehemaligen südafrikanischen Generälen rekrutierten.

Tab. 1: Regierungen der Südafrikanischen Union $1910-1948^{6}$

\begin{tabular}{|l|l|l|l|l|}
\hline Zeitraum & \multicolumn{1}{|c|}{ Regierung/Partei } & \multicolumn{1}{|c|}{ Politik } & \multicolumn{1}{|c|}{ Premierminister } & \multicolumn{1}{|c|}{ Hauptopposition } \\
\hline $1910-1924$ & $\begin{array}{l}\text { 'Unionist Government' - } \\
\text { South African Party (SAP) }\end{array}$ & $\begin{array}{l}\text { ausgleichend/pro- } \\
\text { britisch }\end{array}$ & $\begin{array}{l}\text { Botha (†1919) } \\
\text { Smuts }\end{array}$ & $\begin{array}{l}\text { National Party } \\
\text { (NP), (Hertzog) }\end{array}$ \\
\hline $1924-1934$ & $\begin{array}{l}\text { 'Pact Government'- NP \& } \\
\text { Labour Party }\end{array}$ & $\begin{array}{l}\text { zunehmend } \\
\text { national }\end{array}$ & Hertzog (NP) & SAP (Smuts) \\
\hline $1934-1939$ & $\begin{array}{l}\text { 'Fusion Government' - } \\
\text { United Party } \\
\text { (SAP+NP=UP) }\end{array}$ & ausgleichend & $\begin{array}{l}\text { Hertzog } \\
\text { (Smuts, Vize) }\end{array}$ & $\begin{array}{l}\text { Nerrenigde } \\
\text { (HNP) (Malan) }\end{array}$ \\
\hline $1939-1948$ & 'War Cabinett' - UP & pro-britisch & Smuts & HNP (Malan) \\
\hline $1948-$ & $\begin{array}{l}\text { 'Nationalist Government' - } \\
\text { NP }\end{array}$ & stark national & Malan & SAP (Smuts) \\
\hline
\end{tabular}

1910 schlossen sich die ehemalige Südafrikanische Republik (Transvaal), die Oranjefluss-Kolonie und die britischen Kolonien Kapprovinz und Natal zur Südafrikanischen Union zusammen. Das Streben, eine Politik im Sinne des britischen Weltreiches und der südafrikanischen Eigeninteressen zu folgen, unternahmen in den 1920er und 1930er Jahren vier Regierungen mit unterschiedlichen Orientierungen (Tabelle 1). Je nach parteipolitischer Ausrichtung war das Regierungshandeln den Prämissen „Empire first" oder „South Africa first" unterworfen (Giliomee 2003: 399). Innerhalb des Britischen Weltreiches war Südafrika seit der Balfour-Declaration 1926 wie die anderen Dominions „(...) autonomous communities within the British Empire (...) though united by a common allegiance to the crown" (Tompson 2001: 160).

${ }^{6}$ Davenport 1977: $410 f$. 
Mit dem Abkommen von Westminster 1931 wurde dieser Status erweitert und die Südafrikanische Union war nicht länger den legislativen Einflüssen des Vereinigten Königreichs unterworfen und in seiner Außenpolitik vollkommen eigenständig.

Der gesamte Zeitraum von 1910 bis 1948 wird gemeinhin als ,Consolidation Era' (Ross 1999: 84ff.) oder ,Segregation Era' (Thompson 2001: 154ff.) bezeichnet, eingebettet in die systemische Periode des britischen Imperialismus und der politisch-ökonomischen Vorherrschaft des englischen Establishments (Terreblanche 2003: 239ff.). Diese drei Charakterisierungen umreißen grob die wichtigsten historischen Landmarken der genannten Periode: 1. den Wiederaufbau eines funktionierenden Staatswesens und die Aussöhnung der Kriegsgegner; 2. die Schaffung der Grundlagen für eine Politik der Rassentrennung und 3. die Dominanz des britischen Finanzkapitals und dessen Einfluss auf die Politik der südafrikanischen Regierungen.

Mit der ,Mineral-Revolution' (z.B. Entdeckung großer Gold- und Diamentenvorkommen 1886) erlebte die südafrikanische Gesellschaft einen tiefgreifenden Strukturwandel, der sich vor allem für die Mehrheit der ländlich geprägten afrikaansen Bevölkerung, die durch die Kriegsfolgen ohnehin schon benachteiligt war, katastrophal auswirkte und zu deren weitgehender Proletarisierung führte (Worden 2000: 57). Man darf dabei nicht vergessen, dass die sozio-ökonomischen Institutionen des südafrikanischen Hinterlandes vor 1886 etwa denen Europas um 1700 glichen und den Anpassungsprozess der afrikaansen Bevölkerung zusätzlich erschwerten:

„The new economic activities, which then set in, came without preparation, were virtually wholly unconnected with existing forms, and the initiators of this new order were people from the most advanced countries of Europe and America. (...) Mining and capitalism, modern communications and international trade were in spirit and language foreign to the older population with its simple and archaic farming traditions: there were practically two separate and parallel currents. (...) Here in South Africa the pioneer work was accomplished chiefly by one section of the population, which had virtually been out of touch with Europe for generations, while the sudden economic change was almost entirely the work of immigrants straight from Europe" (Grosskopf 1932: 55).

Die in Massen in die Städte strömenden ungelernten afrikaansen Tagelöhner sahen sich dazu noch in der vollkommen ungewohnten Konkurenz zu Immigranten aus Übersee, sowie den indigenen schwarzafrikanischen Arbeitern. Das ethnisch begründete Lohngefälle machte es den Minenkonzernen einfach, statt teurer ,weißer', billige ,schwarze' Arbeitskräfte einzustellen. Den 
Kulminationspunkt des Widerstandes gegen die Auswirkungen der sich vollziehenden Proletarisierung bildete die ,Rand-Revolte' der Minenarbeiter um Johannesburg im Jahre 1922. Dieser Aufstand endete mit 200 Toten, verursacht durch den massiven Einsatz von Regierungssoldaten und dem Bombardement einiger Johannesburger Arbeiterviertel durch die südafrikanische Luftwaffe (Worden 2000: 60).

Die massive Veränderung der Bevölkerungsstruktur wird aus nachstehender Tabelle ersichtlich.

Tab. 2: Prozentuale Verteilung der Land- und Stadtbevölkerung Südafrikas 1890 - $1931^{7}$

\begin{tabular}{|l|c|c|c|c|c|c|}
\hline & $1890 / 91$ & 1904 & 1911 & 1921 & 1926 & 1931 \\
\hline $\begin{array}{l}\text { Europäische } \\
\text { Bevölkerung }\end{array}$ & -- & 1.116 .806 & 1.276 .242 & 1.519 .488 & 1.677 .322 & 1.828 .175 \\
\hline $\begin{array}{l}\text { Ländliche } \\
\text { Bevölkerung }\end{array}$ & $64,98 \%$ & $47,09 \%$ & $48,30 \%$ & $44,22 \%$ & $41,83 \%$ & $38,73 \%$ \\
\hline $\begin{array}{l}\text { Städtische } \\
\text { Bevölkerung }\end{array}$ & $35,02 \%$ & $52,91 \%$ & $51,70 \%$ & $55,78 \%$ & $58,17 \%$ & $61,27 \%$ \\
\hline
\end{tabular}

Die Industrialisierung und die Politik zu Gunsten der Bergbaukonzerne mündete in einen Verstädterungsprozess, der innerhalb von nur zwei Generationen die Umkehrung der Bevölkerungsstruktur nach sich zog. Innerhalb der afrikaansen Bevölkerung entstanden sowohl als Folge des nicht vollzogenen wirtschaftlichen, als auch mentalen Wertewandels im Zuge der Industrialisierung die „Arm Blankes/Poor-Whites“ (,Verarmte Weiße'), ein neues extrem bedürftiges ,Lumpenproletariat', dessen Stärke auf ca. 20 Prozent geschätzt wurde (Grosskopf 1932: vii und Worden 2000: 67).

Aus den genannten Umständen lässt sich wiederum schließen, dass sich in den Städten die Anzahl potentieller Kinozuschauer erhöhte, auf deren gesteigerte Nachfrage an Filmen mit neuen Vorführungsstätten und einem erweiterten Angebot reagiert werden musste. Um diese Nachfrage erzeugen zu können, mussten die Neubürger der Städte über entsprechende Einkommen verfügen, die nicht zur Existenzerhaltung, sondern zur Freizeitgestaltung ausgegeben werden konnten. Die mit dem Verstädterungsprozess verbundenen ökonomischen Härten abzumildern und das Problem der „Poor-Whites“ zu beheben, war das erklärte Ziel der 1924 neu gewählten Regierung unter Premierminister Hertzog. In diesem Zusammenhang spielte vor allem die

\footnotetext{
${ }^{7}$ Vgl. Grosskopf 1932: 57 und Official Yearbook 1939: 1034.

8 Die genannten Zahlen wurden durch die Volkszählungen der entsprechenden Jahre ermittelt. Die südafrikanische Bevölkerung europäischer Abstammung machte etwa 20 \% der Gesamtbevölkerung aus (Official Yearbook 19/1939: 1038).
} 
veränderte Wirtschaftspolitik eine entscheidende Rolle, auf die hier kurz eingegangen werden soll.

\subsection{Die wirtschaftlichen Verhältnisse in den „Roaring Twenties“}

Mit dem Übergang von der SAP-Alleinregierung zum ,Pact-Government' unter Premierminister Hertzog wurde auch das Arbeitskräftemonopol der vor allem die Bergbaukonzerne unterstützenden Politik gebrochen. Von nun an genossen verstärkt die einheimische Industrie und die kommerzielle Landwirtschaft das Wohlwollen der Regierung, mit anderen Worten dem nationalen wurde eine Vorrangstellung vor dem internationalen Kapital eingeräumt (ebd.: 65). Dabei kam der neuen Regierung zugute, dass die europäischen Arbeiter beider Bevölkerungsgruppen nach der starken Hand des Staates riefen, nachdem die Bergbaukonzerne ihren Sieg über die Streikenden des Jahres 1922 im Folgejahr dazu nutzten, die Rechte der Arbeiter noch weiter zu beschneiden und ihre radikale Lohnpolitik beibehielten (Davenport 1977: 196).

Das Regierungsprogramm des Jahres 1924 beinhaltete daher drei Schwerpunkte: 1. Arbeitsplätze für die ,Verarmten Weißen' schaffen, 2. eine Sicherung der Arbeitsplätze der ,weißen' Facharbeiter und 3. die Verbesserungen der Verhältnisse für die ,Weißen' auf dem Lande (Bilger 1976: 422). Einen wesentlichen Beitrag zur Erfüllung dieser Ziele war auch die Kampagne für die Zweisprachigkeit (Englisch und Afrikaans) im Öffentlichen Dienst. Mit der 1925 erfolgten Anerkennung von Afrikaans als zweiter offizieller Amtssprache eröffnete Innenminister Malan für ,seine Leute' unzählige neue und bedeutsame Beschäftigungsmöglichkeiten (Davenport 1977: 200). Der angestrebte soziale und wirtschaftliche Wandel in der Zwischenkriegszeit sollte also maßgeblich durch staatliche Interventionen herbeigeführt werden. Dazu wurde die südafrikanische Wirtschaft vollkommen protektionistisch durch eine Reihe von strikt an der Marktlage orientierten Budget- und Tarifgesetzen reorganisiert, um der Industrie wieder auf die Beine zu helfen. So wurde z.B. der Montanriese ISCOR (Iron and Steel Corporation) trotz Kritik der Opposition erfolgreich in ein öffentliches Unternehmen umgewandelt (ebd.: 199f.).

Die Landwirtschaft wurde dahingehend unterstützt, dass ihre Exportbemühungen nun staatlich gefördert wurden und landwirtschaftliche Kreditgenossenschaften unter Aufsicht der Land-Bank auch an jene Bauern Darlehen vergeben konnten, die sonst keine Sicherheiten für herkömmliche Anleihen 
aufwiesen. Ebenso wurden Ansiedlungsprojekte für Arbeitskolonien von sozial Bedürftigen auf dem Land kapitalschwacher Bauern gefördert (Davenport 1977: 199f.). Auch die Politik gegenüber den Arbeitern von Seiten der mitregierenden Labour-Party führte endlich zu Wachstum und dem lang ersehnten Arbeitsfrieden jenseits der Streiks. Dazu wurde der Kündigungsschutz für Mieter trotz Wohnraummangel gestärkt, Gesetze zur Anerkennung von Berufskrankheiten verbessert, sowie die Regelungen zur Länge der Arbeitszeit und zur Kinderarbeit internationalen Standards angepasst (ebd.).

Die genannten Regelungen gingen jedoch einher mit einem Bündel von diskriminierenden Gesetzen zur Ausgrenzung aller Südafrikaner nichteuropäischer Herkunft (Übersicht in Bilger 1976: 692-701). So sicherten z.B. der Wage Act des Jahres 1925 ungelernten ,weißen' Arbeitern ein besseres Einkommen gegenüber jenen nichteuropäischer Herkunft, während der Colour Bar Act des Jahres 1926 bestimmte Berufe nur für ausgebildete bzw. angelernte Südafrikaner europäischer Hernkunft reservierte (Davenport 1977: 199f.). Dies führte beispielsweise dazu, dass im Zeitraum von 1924 bis 1933 die Anzahl der bei den südafrikanischen Eisenbahnen und Häfen angestellten Schwarzafrikaner von 37.564 auf 22.008 fiel, ebenso die Anzahl der dort beschäftigten Farbigen (Mischlinge) von 5.628 auf 4.663. Im Gegenzug stieg die Anzahl der beschäftigten Südafrikaner europäischer Abstammung von 4.760 auf 17.683 (ebd.: 361).

„The industrial policy of General Hertzog's Government aimed to do three things in particular: to protect South African industry against outside competition and thus conserve foreign exchange, to protect poor whites against black and Coloured competition in the unskilled field, and to protect skilled white workers from undercutting by black competition in the higher trades. The Government's attempt to nurse the industrial sector took the form of high tariffs against imported goods which threatened to compete with local manufacturers (...). Tariff concessions were also offerd to firms whose labour policies were 'satisfactory' - that is, if they were trying to place white workers in employment, if necessary by putting them into jobs previously done by black or Coloured" (ebd.: 361).

Es wurden aber auch Stimmen eines die Rassentrennung befürwortenden Liberalismus laut, welcher die Notwendigkeit des Schutzes der traditionellen afrikanischen Kultur gegenüber den Attacken der entstehenden Industriegesellschaft forderte (Worden 2000: 88).

Die geschilderten staatlichen Maßnahmen führten dazu, dass die wirtschaftliche Entwicklung Südafrikas in der Zwischenkriegszeit im Vergleich mit der weltwirtschaftlichen Situation einen anderen Verlauf nahm. Die wirt- 
schaftshistorische Standardeinteilung dieses Zeitraumes in (a) Phase der Inflation und Wechselkursschwankungen 1919-1925; (b) Phase des Wachstums und der US-Großkredite in den späteren 1920ern; (c) Phase der Weltwirtschaftskrise von 1930 bis 1933 und (d) Phase der teilweisen Erholung von 1933 bis 1939 (Henderson 1955 in Fedderke 2006: 18) trifft somit nur teilweise auf Südafrika zu. Stattdessen lassen sich im Zeitraum von 1911 bis 1939 drei wesentliche Wachstumsperioden identifizieren: Periode I: 1911/12 - 1919/20; Periode II: 1922/23 - 1928/29 und Periode III: 1932/33 1938/39 (Frankel/Herzfeld 1944: 117). Die stattgefundene Entwicklung verdeutlicht folgende Tabelle:

Tab. 3: Veränderungen des Nationaleinkommens in drei ausgewählten Zeiträumen ${ }^{9}$

\begin{tabular}{|l|c|c|c|c|c|c|}
\hline & \multicolumn{2}{|c|}{ Periode I (1911-1920) } & \multicolumn{2}{c|}{ Periode II (1922-1929) } & \multicolumn{2}{c|}{ Periode III (1932-1939) } \\
\hline & $1911 / 12$ & $1919 / 20$ & $1922 / 23$ & $1928 / 29$ & $1932 / 33$ & $1938 / 39$ \\
\hline $\begin{array}{l}\text { Volkseinkommen zu } \\
\text { Marktpreisen in Mio SA £ }\end{array}$ & 130,9 & 248,3 & 208,7 & 270,7 & 234,7 & 394,8 \\
\hline $\begin{array}{l}\text {,Reales' Volkseinkommen } \\
\text { in Mio SA £ }\end{array}$ & 159,1 & 207,3 & 212,0 & 281,4 & 279,5 & 434,7 \\
\hline $\begin{array}{l}\text { Durchschnittliches Pro } \\
\text { Kopf-Einkommen in SA £ }\end{array}$ & 48,4 & 55,7 & 53,2 & 61,4 & 56,2 & 77,3 \\
\hline
\end{tabular}

Aus Tabelle 3 ist auch ersichtlich, dass zwischen den identifizierten längeren Wachstumsphasen kürzere Phasen der wirtschaftlichen Rezession in den Jahren 1920 bis 1922 und 1929 bis 1932 lagen. Für den für diese Untersuchung maßgeblichen Zeitraum Ende der 1920er Jahre lässt sich bei der Betrachtung des Volkseinkommens feststellen, dass die wirtschaftspolitischen Bemühungen der Regierung zu einem höheren durchschnittlichen ProKopf-Einkommen geführt haben. Führt man diese Feststellung mit der in Tabelle 2 dargestellten Verstädterung Südafrikas zusammen, liegt die Vermutung nahe, dass die neuen Stadtbewohner tatsächlich über steigende Einkommen verfügten und diese neben den Aufwendungen zur Existenzsicherung z.B. auch zur Freizeitgestaltung ausgeben konnten.

Diese Zahlen allein sind jedoch nur bedingt aussagefähig, da dass Volkseinkommen auch durch Produktivitätsfortschritte bei sinkender Beschäftigung hätte steigen können, oder einer zahlenmäßig kleinen Inländergruppe größere Einkommen aus dem Ausland zugeflossen sein könnten. Um belegen zu können, dass der Mehrzahl der Südafrikaner europäischer Abstammung in der ausgewählten Untersuchungsperiode steigende Einkommen zur Verfügung standen, müsste die Anzahl der tatsächlich Beschäftigten

${ }^{9}$ Den Angaben sind die Preise des Jahres 1929 zugrundegelegt (Frankel/Herzfeld 1944: 117). 
herangezogen werden. Diese Angaben wurden jedoch bis 1945 statistisch nicht bzw. nur lückenhaft erfasst. Für den Zeitraum 1914 bis 1945 wurden lediglich für den Bergbau, die private Industrie (v.a. Elektrizitäts- und Gaswerke, Baugewerbe) und das Eisenbahn- und Hafenwesen Beschäftigungsstatistiken geführt. Die in den Volkszählungen erhobenen Daten für die Landwirtschaft wurden nicht immer für den gleichen Monat des Jahres ermittelt, was sinnvolle Vergleiche erschwert. Erhebungen für alle Wirtschaftsbereiche wurden nur in den Volkszählungen 1921, 1936 und 1946 durchgeführt, Daten der schwarzafrikanischen Bevölkerung nur 1946 (Fedderke 2006: 28). Um trotz der fehlenden Angaben eine Aussage treffen zu können, sollen die für Industriearbeiter vorliegenden Zahlen als Orientierungshilfe dienen.

Tab. 4: Anzahl der industriell beschäftigten Südafrikaner europäischer Herkunft $1916-1949^{10}$

\begin{tabular}{|c|c|c|c|c|c|c|}
\hline Jahre & $1916 / 17$ & $1924 / 25$ & $1929 / 30$ & $1932 / 33$ & $1938 / 39$ & $1948 / 49$ \\
\hline Anzahl & 46.000 & 71.000 & 91.000 & 87.000 & 145.000 & 228.000 \\
\hline
\end{tabular}

Aus den Zahlen in Tabelle 4 geht hervor, dass in der maßgeblichen Periode in den 1920er Jahren die Tendenz einer steigenden Beschäftigung in einer das Volkseinkommen beeinflussenden Höhe bestanden hat. Es kann daher angenommen werden, dass eine Vielzahl der durch den Verstädterungsprozess entstandenen Lohnarbeiter in der privaten Industrie und im Bergbau beschäftigt wurden. Gleiches dürfte für den öffentlichen Sektor gegolten haben, der mit der durchgesetzten Zweisprachigkeit und dem Verdrängen der nichteuropäischen Arbeiter zahlreiche neue Beschäftigungsmöglichkeiten bot. Die Gründe für die wirtschaftliche Entwicklung Südafrikas im Zeitraum von 1914 bis 1932 stellen sich zusammenfassend wie folgt dar:

"In common with many others, the South African economy floundered between 1914 and 1932 with a spell of prosperity between 1922 and 1928. War-time inflation, postwar dislocation, the return to the gold standard and the great depression all had adverse impacts. Nonetheless, the gold mining industry navigated its way through difficult times and manufacturing developed throughout the period, aided by natural geographic protection as well as protective tariffs. Manufacturing sectors grew in different ways: many as the result of increased capital and labour inputs, but some as a result of technological progress. South Africa's experience differed from those of its European suppliers of capital and trading partners after 1933, partly because of its status as a supplier of gold and partly because

\footnotetext{
${ }^{10}$ Feinstein 2005: 122. Aus welchen Quellen bzw. Zusammenrechungen Feinstein seine Angaben herleitet, geht aus seiner Darstellung leider nicht hervor.
} 
its political stability did not deteriorate in the way that European stability did" (Fedderke 2006: 67).

In Abbildung 1 wird noch einmal deutlich, welcher gesammtwirtschaftliche Verlauf sich anhand der Entwicklung des Volkseinkommens ablesen lässt.. ${ }^{11}$

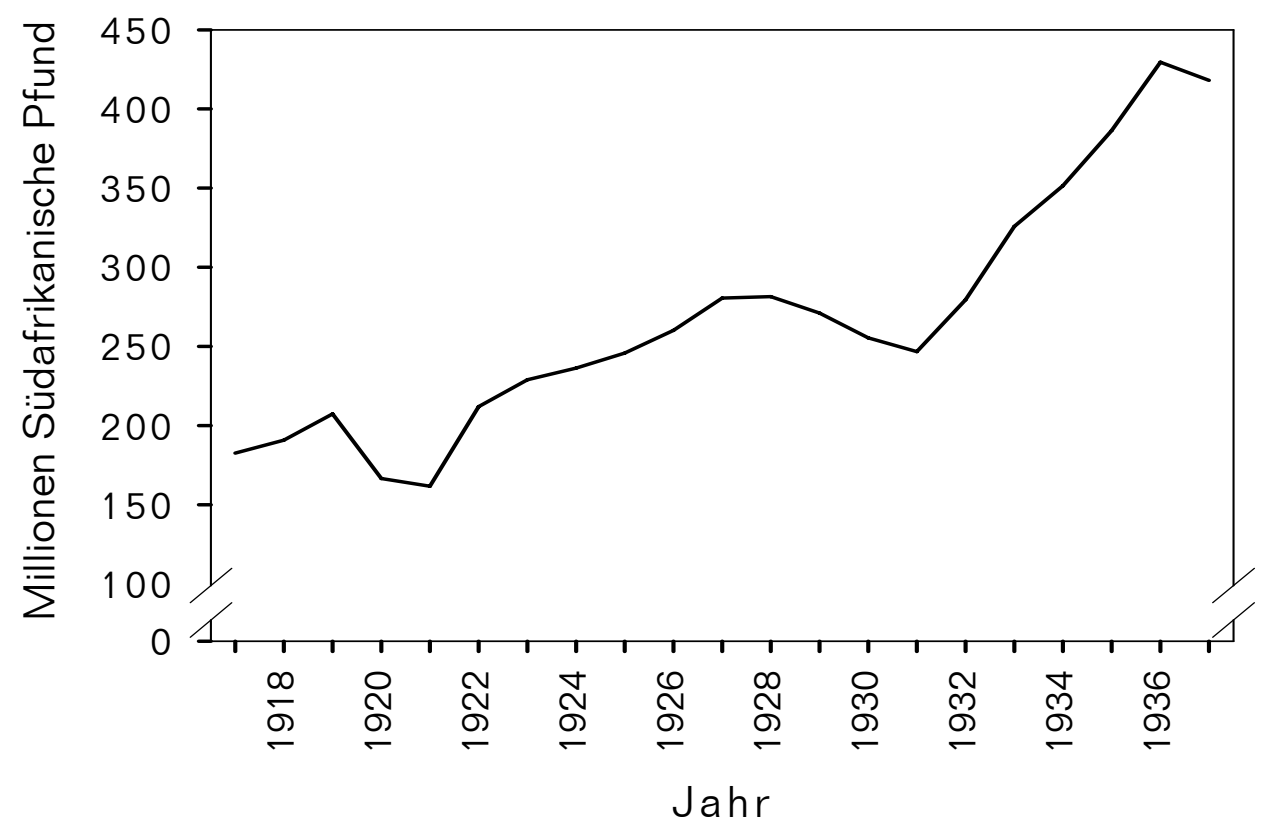

Abb. 1: Entwicklung des Volkseinkommens im Zeitraum $1917-1937^{12}$

Angesichts der spezifischen südafrikanischen Verhältnisse muss auch bei der Entwicklung des Volkseinkommens erwähnt werden, dass die gestiegenen Einkommen in erster Linie der europäischstämmigen Bevölkerung zugute kamen. Obwohl deren Anteil im Untersuchungszeitraum nur bei ca. 20 Prozent lag, flossen dieser Bevölkerungsgruppe ca. 70 Prozent des Volkseinkommens zu (Terreblanche 2002: 392f.).

In wirtschaftshistorischer Globalperspektive stellt der Zeitraum vom Beginn der ,Mineral-Revolution' um 1866 bis ca. 1922 die Vorphase (,Pre-take-

\footnotetext{
11 „National income may be described as payments to the economic factors of production, namely labour and capital. Labour's share consists of cash salaries and wages, including payments in kind and the employer's contributions to pension/provident and medical funds. Capital's share, also described as property income, includes the net profit of business enterprise, net rent of all fixed property and interest on capital" (Bureau of Census and Statistics 1960: S-7).

12 Vgl. Frankel/Herzfeld 1944: 134, Anhang D. Die Angaben fußen auf den am Verbraucherpreisindex ausgerichteten Basispreisen des Jahres 1929. Die Entwicklung des Bruttoinlandsproduktes mit dem Höhepunkt 1928 und dem Tiefpunkt 1932 zeigt vergleichbare Phasen des wirtschaftlichen Auf- bzw. Abschwungs (Bilger 1976: 743). Ein ganz ähnliches Bild zeichnet sich auch auf Grundlage des Pro-KopfVolkseinkommens in Basispreisen des Rechnungszeitraumes 1958/59 (Bureau of Census and Statistics 1960: S-3 und S-6).
} 
off') zur ersten Industriealisierung dar (O'Dowd 1978: 33). In dieser Vorphase wurden die infrastrukturiellen Grundlagen für die Industrialisierung geschaffen, was auch in Südafrika durch Phasen relativer politischer Instabilität (z.B. 1. Burenkrieg 1880, Großer Burenkrieg 1899-1902) und potentielle Revolutionen (z.B. Generalstreiks der Bergleute 1914 und 1922) einherging. Das Ende dieser Vorphase fiel in Südafrika in die 1920er Jahre, in der die Regierungen ihre Macht rücksichtslos aber effektiv in den Dienst der Industrialisierung stellten (ebd.: 34). Mit den durch staatliche Maßnahmen erfolgreich begegneten sozialen Härten (z.B. der Landflucht, Entstehung eines ,Lumpenproletariats', Entlohnung unter Existenzniveau etc.) gelang später der almähliche Übergang zur zweiten Phase der Industrialisierung. Die 1920er Jahre können als eine Art Übergangsphase angesehen werden, in der eine stetig größer werdende Anzahl von Beschäftigten einen ökonomischen Status erreichte, der diese Gruppe nicht mehr nur zu einem Resservoir billiger Arbeitskräfte degradierte, sondern als Nachfrager von Gütern und Dienstleistungen interessant machte (ebd.: 32).

Zusammenfassend und unter Vorwegnahme des begründet ausgewählten Untersuchungszeitraums (1928-1933) bedeutet dies, dass der Verstädterungsprozess, zusammen mit dem Wirtschaftswachstum und dem steigenden Volkseinkommen, dazu geführt hat, dass ein immer größer werdendes, homogenes Massenpublikum eine erhöhte Nachfrage nach Unterhaltung jeglicher Art auslösen konnte und so auch die bestehenden Filmvorführungsstätten öfter aufgesucht wurden.

Hinter dieser Nachfrage stand ebenso ein im Vergleich zur bisherigen ruralen Gesellschaft vollkommen neuer Konsumzyklus. Während sich die bisherigen Nachfrageentscheidungen auf den Zeitpunkt nach der Ernte (einmaliger Kapitalzufluss) konzentrierten, entstand mit den in Bergbau und Industrie gezahlten Wochenlöhnen (wiederkehrender Kapitalzufluss) ein konstant periodischer Konsumptionszeitraum, in dem sich Angebot und Nachfrage finden konnten. Derartige Prozesse waren selbstverständlich nicht nur auf Südafrika beschränkt, sie erfolgten aber in der dortigen Einwanderergesellschaft (wie auch in den USA, Kanada oder Australien) schneller und radikaler.

Diesem allgemeinen Verstärkungs- und Verdrängungsprozess waren auch die verschiedenen Unterhaltungsformen unterworfen. Während in Europa aufgrund der gewachsenen Theater-, Tanz- und Musiktraditionen mit dem Aufkommen neuer Unterhaltungsformen wie Varieté, Revue, Film etc. zunächst ein gegenseitiger Stimulationsprozess einsetzte, der dann zu Anpassungs- bzw. schleichenden Ablösungsprozessen führte, fand in der südafrika- 
nischen Einwanderergesellschaft das Gegenteil statt. Die meist vor wirtschaftlicher Not fliehenden und überwiegend jungen Einwanderer hatten selbst in ihren Ursprungsländern nicht genügend Zeit, eine traditionsbildende Kulturisation zu durchlaufen (Kruger 1996: 28). Ohne eine ausgeprägte ethnische Verwurzelung und dem Mangel an Bildung, empfanden die Neuankömmlinge die kulturgeschichtlich tradierten, meist performativen Medien (Theater usw.) als nicht ihrem eher einfach strukturierten Unterhaltungsbedürfnis entsprechend, was durch die Sprachenvielfalt noch verstärkt wurde. Im Kampf um die Aufmerksamkeit der Konsumenten konnte somit das die geringsten Anforderungen stellende, allen gleichermaßen zugängliche Medium die Konkurrenz ohne viele Zwischenschritte ablösen.

Der Stummfilm erfüllte diese Eigenschaften par excellence, zumal dessen Erfolg in den USA die Marktrisiken kalkulierbar erscheinen ließ und von einem strukturidentischen Anbietermarkt ausgegangen werden konnte. Die südafrikanische Unterhaltungsindustrie war ihrerseits durch die positive Entwicklung in der Lage, hohe Überschüsse zu erzielen, was zu einer stärkeren Konkurrenz innerhalb des Kinosektors führte und weitere Investitionen in die notwendige Infrastruktur nach sich zog. Dies macht eine genauere Betrachtung der im Wesentlichen aus dem Filmvertrieb bestehenden südafrikanischen Filmindustrie erforderlich, die im folgenden Abschnitt im Mittelpunkt des Interesses steht.

\subsection{Die südafrikanische Filmindustrie in den 1920er und 1930er Jahren}

Auch bei Betrachtungen zur Entwicklung der südafrikanischen Filmindustrie werden allgemein drei große Perioden unterschieden: vor der Apartheid (>1948), die Apartheidsära selbst (1948-1992) und der Zeitraum bis in die Gegenwart (Tomaselli/Shepperson 2000: 141ff.). Das entscheidende Merkmal dieser Gliederung ist die ab 1948 von der Regierung praktizierte Filmpolitik, die vor allem jene Produktionen unterstützte, welche der Ideologie der Rassentrennung dienlich waren (Tomaselli 1980a). Für den Zeitraum vor 1948 - und besonders für die 1920er und 1930er Jahre - bedeutet dies, dass bis auf Ausnahmen keine systematische Unterstützung der Filmindustrie durch staatliche Stellen erfolgte.

Mit "The Kimberley Diamond Robbery“ (N.N.) begann 1910 die Ära des südafrikanischen Spielfilms (Gutsche 1972: 125), welche sich seit 1916, verstärkt durch das Ausbleiben internationaler Spielfilme als Folge des Ersten Weltkriegs, entwickelte. Im gleichen Jahr konnte bereits mit 14 Produkti- 
onen aufgewartet werden (Le Roux/Fourie 1982: 205f.). Von 1913 bis 1984 wurde mit dem „African Mirror" sogar eine eigene Wochenschau produziert. Nach Kriegsende ging die einheimische Produktion kontinuierlich zurück, bis im Jahre 1926 keine Spielfilme mehr hergestellt wurden, eine Situation die bis 1931 anhielt (Tomaselli 1989: 262). Die südafrikanische Filmindustrie verfügte also weniger über einen umfangreichen Produktionssektor, dafür aber über eine ausgedehnte Vertriebs- und Vorführinfrastruktur. Trotz einiger herausragender Produktionen, wie z.B. „De Voortrekkers/Winning a continent" (1916, Harold Shaw) oder „Symbol of Sacrifice“ (1918, I.W. Schlesinger), soll an dieser Stelle nicht weiter auf die südafrikanische Filmproduktion eingegangen werden, da sie nur einen sehr geringen Teil vom Umfang der insgesamt zur Vorführung gelangten Filme (s. Kapitel 4: Filmexport) ausmachten. Dieser Umstand wird aus Abbildung 2 ersichtlich.

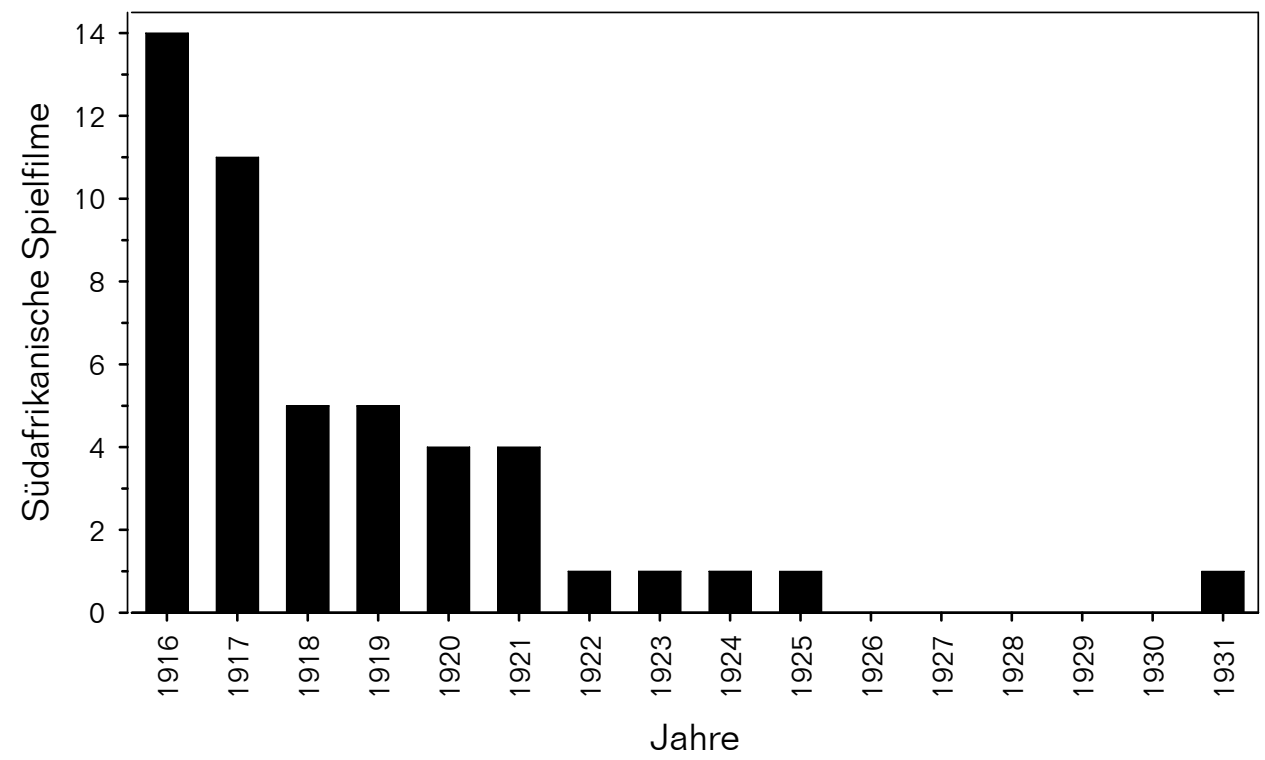

Abb. 2: Die südafrikanische Spielfilmproduktion $1916-1931^{13}$

Die wesentliche Filmvertriebs- und Vorführinfrastruktur lag seit 1913 in den Händen des African Theatre Trusts, einer von vielen Unternehmungen des US-amerikanisch-südafrikanischen Finanzmagnaten Isidor William Schlesinger (1871-1949) (Tomaselli 1983: 45). Dieser konnte seine fast unangefochtene Stellung in den folgenden Jahren noch weiter ausbauen und vereinte

\footnotetext{
${ }^{13} \mathrm{Vgl}$. Le Roux/Fourie 1982: 205ff. Mit besonderem Dank an Trevor Moses vom South African National Film, Video and Sound Archiv (SANFVSA) für die Bereitstellung der geprüften Angaben aus seinem Manuskript „Riding The High Wind“ zur südafrikanischen Filmproduktion im Zeitraum von 1910 bis 2006 (Moses 2006).
} 
unter dem Dach des African Film Trust alle bedeutenden Filmimporteure und Vorführungsstätten (Gutsche 1972: 119). Noch vor Ende des 1. Weltkrieges war die weitgehende Monopolisierung des südafrikanischen Kinowesens durch das Unternehmenskonglomerat der Schlesinger-Organisation erreicht. Die Schlesinger-Ära erstreckte sich in bewegter Zeit (1913-1956) fast über ein halbes Jahrhundert (Cartright 1960). Um die Verhältnisse der 1920er und 1930er Jahre besser einschätzen zu können, sollen in Anlehnung an Tomasellis Analyse der politischen Ökonomie der südafrikanischen Filmindustrie (1983) kurz die verschiedenen Phasen der Entwicklung im Zeitraum 1895-1956 genannt werden. Tomaselli unterscheidet in Anlehnung an Eric Mandel (1978) sieben historische Entwicklungsphasen, denen er vier Entwicklungszyklen der erweiterten Kapitalreproduktion zuordnet (Tomaselli 1983: 40ff.):

Tab. 5: Die politische Ökonomie der südafrikanischen Filmindustrie im Zeitraum 1895 - $1956^{14}$

\begin{tabular}{|c|l|l|}
\hline Zeitraum & \multicolumn{1}{|c|}{$\begin{array}{c}\text { Politisch-ökonomische Grundlagen } \\
\text { (Eigentumsstruktur) }\end{array}$} & $\begin{array}{l}\text { Zyklen der erweiterten Kapitalre- } \\
\text { produktion in der Filmindustrie }\end{array}$ \\
\hline $1895-1913$ & $\begin{array}{l}\text { Vorformen bzw. -bedingungen der Kapitalzentralisie- } \\
\text { rung }\end{array}$ & $\begin{array}{l}\text { I: Fragmentierung und finanzielle } \\
\text { Instabilität }\end{array}$ \\
\hline $1913-1926$ & Konzentration des Kapitals & II: Kinoketten \\
\hline $1926-1930$ & Schutz des nationalen Kapitals & \multirow{2}{*}{ III: Der Tonfilm } \\
\hline $1930-1931$ & Eindringen von internationalem Kapital & \\
\hline $1932-1938$ & $\begin{array}{l}\text { Koexistenz von nationalem und internationalem } \\
\text { Kapital }\end{array}$ & IV: Technische Innovationen \\
\hline $1938-1950$ & Hinzuwahl von nationalem Kapital & \\
\cline { 1 - 2 } $1950-1956$ & Phase der Stabilisierung &
\end{tabular}

Aus Tabelle 5 lässt sich für den gewählten Untersuchungszeitraum ablesen, dass in jenem der Schutz des einheimischen Kapitals im Vordergrund stand, bis kurz darauf das Eindringen von internationalem Kapital erfolgte. In diese ökonomischen Phasen fallen der zweite und der dritte Zyklus der erweiterten Reproduktion, die für den Kinosektor von der Entstehung und Konkurrenz der Kinoketten, sowie später durch das Aufkommen des Tonfilms markiert werden.

Die Grundlage von Tomasellis der Filmindustrie angepassten Analyse der Eigentumsstruktur bildet dabei weniger eine statistisch-empirische Auswertung der tatsächlichen Marktsituation, sondern eine terminologische Vereinfachung in Anlehung an Thelma Gutsches (1972) deskriptiv-hermeneutische Analyse der südafrikanischen Kinogeschichte. Ihre strikt chronologische

${ }^{14} \mathrm{Vgl}$. Tomaselli 1983: 38ff. 
Unterteilung in kinogeschichtliche Phasen ergibt zusammenfassend folgende Stufengliederung:

Tab. 6: Die kinohistorische Entwicklung Südafrikas 1895 -1940 nach Gutsche

\begin{tabular}{|c|l|}
\hline Zeitraum & Kinohistorische Entwicklungsstufe \\
\hline $1895-1899$ & Bewegte Bilder als Kuriosum \\
\hline $1899-1909$ & Der Burenkrieg und die Wanderkinos \\
\hline $1910-1913$ & Die ersten permanenten Kinos \\
\hline $1913-1919$ & $\begin{array}{l}\text { Der Zusammenbruch und die Neuorganisation der Unterhaltungs- und Filmindustrie } \\
\text { durch I.W. Schlesinger (African Film Trust Ltd. etc. =,Schlesinger-Organisation') }\end{array}$ \\
\hline $1919-1927$ & $\begin{array}{l}\text { Der Ausklang der Stummfilmära und das Entstehen einer nationalen Unterhaltungsin- } \\
\text { dustrie als Monopol (,Schlesinger-Organisation') }\end{array}$ \\
\hline $1927-1931$ & $\begin{array}{l}\text { Der Bruch des Monopols durch Kinemas, der Tonfilm und die Übernahme von Kinemas } \\
\text { durch die Schlesinger-Organisation }\end{array}$ \\
\hline $1931-1937$ & Das neue Schlesinger-Monopol, MGM und der Film als Massenmedium \\
\hline $1937-1940$ & Neue Konkurrenz aus den USA: 20th Century Fox und United Artists vs. Schlesinger \\
\hline
\end{tabular}

Mit dem Kauf des ersten Theaters im Jahre 1913 war die südafrikanische Unterhaltungs- bzw. Filmindustrie untrennbar mit dem Namen Schlesinger verbunden. Die zum damaligen Zeitpunkt weitgehend bankrotte Theaterlandschaft wurde durch Anteilsaufkäufe und Beteiligungen Schlesingers zu einer Art Theaterkooperation, die er unter der Führung seiner African Theatres Trust Ltd. zentralisierte (Cartright 1960: 194). ${ }^{15}$ Neben anderen Firmen kontrollierte er spätestens ab 1921 über die African Theatres Ltd. die Aufführung von Filmen, über die African Films Ltd. deren Vertrieb bzw. die Filmherstellung (Wochenschau und Spielfilme) und mittels African Caterers Ltd. die Zuschauerversorgung in seinen Kinotheatern (ebd.). Für eine positive Einführung des Kinoprogramms sorgte das einzige südafrikanische Programm- und Fachblatt für die Unterhaltungsindustrie Stage, Cinema and Listener (1915-1928), welches ebenfalls vom African Theatres Trust/African Theatres Ltd. kontrolliert wurde. Die wenigen unabhängig gebliebenen Vorführungsstätten und Filmvertriebe stellten für den Monopolisten Schlesinger keine ernsthafte Gefahr mehr dar. Der bis dahin bestehende erbitterte Konkurrenzkampf wurde durch eine gemeinsame Ausbeutung des Marktes abgelöst:

„Within a few weeks, the entire organisation of the variety and bioscope industry had been placed on a new basis. Coöperative exploitation of films

\footnotetext{
${ }^{15}$ In der Sekundärliteratur hat sich die Bezeichnung ,Schlesinger-Organisation' für das von I.W. Schlesinger kontrollierte Unternehmens- und Beteilungskonglomerat durchgesetzt (z.B. Dickson 1977: 23). Trotz des Mangels, dass es sich hierbei nicht um eine historisch überlieferte Bezeichnung handelt, soll diese synonym mit den jeweiligen Schlesingerschen Einzelunternehmungen genannt werden, um seinen Einfluss in angemessener Weise darzustellen.
} 
replaced the internecine competition of independent organisations and both exhibition and distribution were controlled by solidly-founded administrations operating on an assured market. A new era in South African entertainment had started" (Gutsche 1972: 119).

Im Gegensatz zum US-amerikanischen oder europäischen Markt, in dem die Filmunternehmen durch das Eigentum an einzelnen Kinos oder Kinoketten ihre Vertriebs- und Vorführungsstrukturen selbst besaßen, beherrschte in Südafrika die Schlesinger-Organisation mit ihrem Vertriebs- und Vorführungsmonopol den gesamten Filmmarkt. Jeder Filmanbieter musste demnach entweder auf Schlesingers Kinokonglomerat zurückgreifen oder eine komplett neue Infrastruktur errichten, was bis 1927 jedoch keinem Konkurrenten gelang. Durch weitreichende Verträge mit den wichtigsten Hollywoodstudios hatte der US-Amerikaner Schlesinger den südafrikanischen Markt direkt an das Hollywood-Studiosystem angekoppelt, was zu einer fast vollständigen Amerikanisierung des Kinoprogramms führte (Fawcett 1928: 34). Die in den USA für Filme vorherrschende Distributionsstruktur, die alle Kinotheater einer Kette in unterschiedliche Kategorien (z.B. Premierenhäuser, Nachspielkinos etc.) einteilte, wurde direkt auf Südafrika übertragen und bestimmte maßgeblich das Kinoprogramm jedes Geschäftsjahres:

"South Africa is even more thoroughly Americanised. Practically all the theatres are owned by African Theatres, Ltd., of which Mr. I.W. Schlesinger, an American by birth, is the principal. The picture-theatres throughout the country are divided into three groups, the ' $A$ ' circuit, the ' $\mathrm{B}$ ' circuit, and the ' $\mathrm{C}$ ' circuit. The whole of the programme for the year is determined for each circuit in New York at the beginning of the film-year (September), and no programme can be altered. The films are chosen from the outputs of the principal producing companies. It is practically impossible for any South African independent to book a picture from America. If a British firm, for example, was willing to supply pictures to a new picture-theatre not in the African Theatres Syndicate, the theatre would be able to obtain no pictures for the rest of its programme from any of the leading American firms, for they agree with African Theatres not to supply anyone else with films" (ebd.: 58).

Durch die Oktroyierung dieses Systems erfolgte die unmittelbare Eingliederung des südafrikanischen Marktes in die Distributionssphäre Hollywoods. Zunächst hatte der Erste Weltkrieg dafür gesorgt, dass die europäische Filmproduktion verkümmerte bzw. ihre angestammten Auslandsmärkte nicht mehr erreichen konnte. In den USA dagegen waren durch Fusionen die neuen unabhängigen Filmfirmen rasch imstande, ihre Position auf dem Binnenmarkt 
zu konsolidieren und ebenso den Weltmarkt zu versorgen (Monaco 2000: 239). Bis 1920 hatten die von der Motion Pictures Patents Company (,Trust Company') unabhängigen Firmen (z.B. die Studios Universal, Famous Players Lasky etc.) ein informelles Oligopol gebildt, das mit ähnlich aggressiven Marktstrategien wie die Trust-Company aufwartete. Jede der großen Firmen war vertikal integriert, d.h. auf allen Ebenen der „Film-Kette“ aktiv: bei Produktion, Distribution und Präsentation (ebd.). Neben den sich selbst ausgeschalteten europäischen Konkurrenten waren eine Ursache der USamerikanischen Herrschaft über den internationalen Filmmarkt die industriellen Aspekte des amerikanischen Produktionssystems (Monaco 2000: 242). Gemäß den US-amerikanischen Studiostrukturen und deren ,Produktionsphilosophie', nach der Filme standardisiert und als Massenerzeugnis vorrangig für den einheimischen Markt produziert wurden (Thompson 1985: 1), musste eine möglichst breite und konstante Amortisationsbasis angestrebt werden, um die immensen Fixkosten (z.B. Stargehälter etc.) entsprechend verteilen zu können. Außer der Herstellung von technischer Ausrüstung und Rohfilm kontrollierten die führenden Studios jeden Schritt des Filmprozesses von der Produktion über die Distribution bis zu den Theatern. Das Blockbuchungssystem und die engen Verbindungen zwischen den meisten Studios und großen Theaterketten bedeutete, dass fast jeder Film, den ein Studio produzierte, auch gezeigt wurde. (Monaco 2000: 246)

Dies führte u.a. zu einer thematischen ,Vermassung', die bewusst einen gewissen Schematismus in Kauf nahm (z.B. Genres) und nur wenig Rücksicht auf potentielle Auslandsmärkte nehmen musste. Eventuelle Flops konnten durch die schiere Masse erfolgreicher Filme kompensiert werden, kein Studio riskierte kostspielige filmische Einzelkunstwerke, deren Misserfolg sie in existenzielle Nöte gebracht hätte. Zur Absicherung des Oligopols hatte sich ab ca. 1921 eine kleine Gruppe von Firmen unter Führung von FamousPlayers Lasky, die inzwischen 50 Prozent des US-Marktes kontrollierten, zur Produktion von abendfüllenden Spielfilmen (,feature lenght films') mit einer Reihe von Filmsstars entschieden (Allen/Gomery 1985: 146). Damit wurde eine dreistufige Marktdurchdringungsstrategie ins Werk gesetzt, die durch Produktdiversifikation (lange vs. kurze Filme), der Kontrolle des nationalen und internationalen Filmvertriebs, sowie durch die Beherrschung der Aufführungsstruktur mittels des Eigentums einer bestimmten Anzahl von Premierenkinos (,first-run theatres') realisiert wurde (ebd.: 146f.). Eine der wirksamsten Diversifizierungsstrategien war die Etablierung des Starsystems, die jeden Film zu einem einzigartigen Produkt machte mit dessen ganz spezifischen Eigenschaften (Genres, spezielle Stories für spezielle Stars etc.) 
geworben werden konnte (ebd.). Die Studios wiederum banden die Stars über Langzeitverträge an sich, so das jene nicht durch höhere Gagen geködert bei der Konkurrenz unterschreiben konnten (ebd.: 148). Umso populärer ein Star war, desto größer war die Einnahmensicherheit bei den Studios, die zusätzlich durch ausgefeilte Werbemaßnahmen erhalten bleiben sollte (ebd.).

Darüber hinaus wurde in Sachen Filmvertrieb eine Kosteneffizienz durch Arbeitsteilung erreicht, die maßgeblich durch eine Spezialisierung in Werbung, Verkaufsförderung und Kundendienst zustande kam (ebd.).

„The large concerns could use these savings to acquire more popular stars. After twelve producers und numerous regional distributors united to form Famous Players'-Lasky in 1916, few competitors could match Famous Players' cost efficiency. Such cost savings also helped to block the emergence of serious competition. It was only logical for the film companies to extend their sales territory to include the entire world. The cost of film was already in hand; the revenues from world-wide rental far exceeded the publicity and advertising costs and the amortization of a set of offices" (ebd.).

Als letzte Stufe der Marktdurchdringungsstrategie hatte sich die Erkenntnis durchgesetzt, dass es gar nicht notwendig war, alle Vorführungsstätten selbst zu besitzen, sondern vielmehr die Einrichtung einer beschränkten Anzahl von Premierenhäusern, Exklusivgebieten (,first-run status') bzw. die Festlegung einer bestimmten Zeitspanne zwischen Erst- und Zweitaufführung eines Films (das sog. ,run-zone-clearance'-System) die optimale Preisdiversifikation zur maximalen Gewinnabschöpfung darstellte (Allen/Gomery 1985: 140). In Zusammenarbeit mit internationalen Vertragspartnern wurde versucht, dieses System weltweit auf alle relevanten Kinomärkte auszudehnen.

Die seit 1913 durch die Schlesinger-Organisation geschaffene Monopolstellung am Kinomarkt sorgte für eine nahezu vollständige Besetzung der südafrikanischen Distributionssphäre durch den US-amerikanischen Film (Fawcett 1928: 46). Dessen Dominanz zwang dem Publikum eine Art „kulturelle Programmierung" durch Massenprodukte auf, die über kurz oder lang ob des zu erwartenden Gewönungseffekts in eine Suche nach Alternativangeboten münden würde.

Die Marktmacht des Monopolisten Schlesinger gestattete es ebenso, die von ihm vertriebenen Filme im sogenannten ,Block-booking'-Verfahren auch an jene Vorführungsstätten zu veräußern, die mit ihm nur assoziert oder formell noch unabhängig waren. Bei diesem Verfahren handelte es sich um 
eine Geschäftspraxis, die den Kinobetreiber dazu zwang, zum Erhalt erfolgversprechender populärer Filme (z.B. mit bestimmten Stars) ein ganzes Paket mit wenigen erstklassigen und vielen (unter-) durchschnittlichen Filmen von den entsprechenden Vertrieben zu akzeptieren, ohne Einfluss auf die tatsächliche Zusammenstellung der Filmtitel zu haben (z.B. Blumenthal 1985). Diese Praxis von Seiten der Filmvertriebe kann auch als systematische Unterbewertung der erfolgreichen bzw. als systematische Überbewertung der mittelmäßigen Filme charakterisiert werden (Kenney/Klein 1983: 523). Das ,Block-booking' realisiert somit den Transfer des Angebotsmonopols von populären Filmen mit beliebten Darstellern zu mittelmäßigen Filmen mit unbekannten Schauspielern (ebd.).

Das Monopol der Schlesinger-Organisation wurde erst mit Aufkommen eines neuen und ernsthaften Konkurrenten im Jahre 1927 herausgefordert, als die Kinemas Ltd., gegründet mit britischem und südafrikanischem Kapital, antrat, das faktische Angebotsmonopol zu brechen (Gutsche 1972: 199ff.). Kinemas kam dabei der technische Fortschritt zugute, da sich das Unternehmen die Alleinvertriebsrechte für die nach Lee de Forrests ,Phonofilm'Patent produzierten Tonfilme gesichert hatte (Kilcoin 1929b 297). Zusammen mit einer Auswahl von in Südafrika noch nicht gezeigten britischen und USamerikanischen Produktionen begann Kinemas sein Programm zunächst in Stadthallen oder Gebäuden von ähnlich großer Kapazität vorzuführen. Die noch mangelhafte Qualität der frühen ,Phonofilme' wurde unter diesen Bedingungen besonders deutlich. Kinemas begann schon bald, eigene Lichtspielhäuser zu errichten und eine mit African Theatres Ltd. konkurrenzfähige Kinokette aufzubauen. Die Schlesinger-Organisation und Kinemas bildeten wenn man von den wenigen noch unabhängigen Kinotheatern absieht - ein angebotsseitiges Duopol, bei dem nur zwei Anbieter den Markt beherrschten. Diese Marktsituation brachte es mit sich, dass jede Ankündigung zukünftiger Entwicklungen des einen Konkurrenten durch eine direkte Gegenreaktion des anderen beantwortet wurde:

„Kinemas continued their policy of expansion apperantly without limit and both organizations now entered a phase of competitive development which was to provide South Africa with some of the best cinema entertainment ever presented" (Gutsche 1972: 201).

Diese Situation wäre allerdings ohne den bis 1927 erzielten Monopolgewinn Schlesingers, also den durch die Marktmacht des Monopolisten erzielten Überschuss der Erlöse über die Gesamtkosten, undenkbar gewesen. In diesem Sinne war das vormalige Monopol für die Zuschauer nicht von Nach- 
teil, da nur ein Monopolanbieter jene Großinvestitionen (wie z.B. in neue luxuriöse Lichtspielhäuser) tätigen konnte, die für ein rasches Marktwachstum notwendig waren, „da sie die Schaffung großer Anlagewerte mit einem hohen Kapitalbedarf aufgrund ihrer Größe und der damit verbundenen finanziellen Ausstattung erst ermöglichen" (Gablers Wirtschaftslexikon, 4. Band 1988: 469f.).

Am Beispiel Kapstadts lässt sich verfolgen, dass mit der Eröffnung des Metropolitan Kinema 1929 in der Innenstadt direkt auf das Zuschauerpotential der beiden African Theatres Häuser Alhambra und Royal abgezielt wurde. Ebenso verhielt es sich auch mit den neuen Kinemas-Lichtspielhäusern in den Vorstädten Wynberg und Muizenberg (Eckardt 2005a: 35). Die gleiche Strategie verfolgte auch Schlesinger, der die Eröffnung von immer neuen Spielstätten ankündigte und diese auch errichtet wurden (Kilcoin 1929a: 101). Um jenseits der baulichen ,Materialschlachten' mit African Theatres Ltd. konkurrieren zu können, verlegte sich Kinemas auf eine qualitative Strategie und ließ im Oktober 1928 verkünden, verstärkt britische Produktionen aufzuführen und

„Ten days later, Kinemas announced their purchase of the entire 1928 output of UFA, the best-known and most popular make of German films which became a vogue in South Africa (one of these films, THE SPY was already being shown in the Union with great success)" (Gutsche 1972: 205).

Die quantitativen Auswirkungen dieser neuen Marktsituation werden im Kapitel zum Filmexport nach Südafrika in dieser Studie noch näher erläutert werden. Das Tonfilmmonopol von Kinemas wurde schon bald aktiv von African Theatres Ltd. angegriffen, in dem es den nach dem „Panatrop“-System (Kombination aus Film und Schallplatte) nachvertonten Film „The Jazz Singer" (1927, A. Crosland) aufführte (ebd.: 205). Kinemas erster etwas längerer Tonfilm, obgleich eigentlich immer noch eher ein experimenteller Kurzfilm (ca. 25 min.), war „Mr Smith wakes up“ (1929, J. Harrison), welcher am 6. Juli 1929 im Astoria Kinema in Johannesburg gezeigt wurde (Gutsche 1972: 208). Mit „Syncopation“ (1929, B. Glennon, 1929) folgte der erste Tonspielfilm von Kinemas, gekontert von African Theatres' „The Singing Fool“ (1928, L. Bacon) (ebd.: 209).

Wie die Ausführungen zu den gezeigten Tonfilmen belegen, manifestierte sich auch in Südafrika ab 1928 die filmhistorische Epochenschwelle des Übergangs vom Stumm- zum Tonfilm. Die Gründe für die Durchsetzung des Tonfilms waren trotz anfänglichem Zögerns auch in Südafrika die folgenden: 
1. Die Gewinnerwartungen von Film- und Kinobranche, 2. die gesteigerten Absatzerwartungen der Elektroindustrie (Umrüstung usw.) und 3. die Komplettierungserwartung des Publikums (Bild \& Ton) und eine aufgeschlossene Öffentlichkeit (Prümm 1989: 95). Dabei trat anfangs beim Publikum noch das Problem auf, dass Körper und Stimme in der frühen Tonfilmwahrnehmung nur schwer zusammengebracht werden konnten. Dafür war vor allem die noch fehlende Habitualisierung des Publikums ursächlich, welche die mechanisch reproduzierte Stimme und den auf der Leinwand projektierten Körper noch nicht in jener kompakten Einheit zu sehen vermochte, wie sie dann schnell selbstverständlich wurde (ebd.: 98).

Die Verdrängung des Stumm- zugunsten des Tonfilms setzte 1929 ein und war bereits um 1933 vollständig abgeschlossen. In den großen Städten, wie z.B. Kapstadt, war die Tonfilmumstellung auch in den zweitklassigen Lichtspielhäusern bereits 1930 vollzogen (Eckardt 2005a: 33). Die völlige Umstellung zu diesem frühen Zeitpunkt verdeutlicht abermals den Gleichschritt der südafrikanischen Filmindustrie mit der internationalen Entwicklung, in Deutschland war dieser Prozess beispielsweise erst 1935 abgeschlossen (Prümm 1989: 95). Auf die wirtschaftliche Dimension dieser Entwicklung wird in den Ausführungen zum Filmimport detailliert eingegangen.

Auf die rechtlich komplizierte Durchsetzung des Tonfilms im Streit zwischen den konkurrierenden Patenten europäischer und US-amerikanischer Herkunft soll an dieser Stelle nicht weiter eingegangen werden (dazu Strohm 1934 und Jossé 1984). Nach Beilegung der Streitigkeiten 1930 im „Pariser Tonfilmfrieden" wurde Südafrika keinem der Exklusivgebiete zugeschlagen, sondern es galt als "freies Gebiet", in welchem die Systeme beider Gruppen miteinander konkurrieren konnten (Mühl-Benninghaus 1999: 171). Vor diesem Hintergrund wird auch die Schwierigkeit deutlich, die Bruchstelle des Übergangs vom Stumm- zum Tonfilm für eine faktenorientierte und nicht nur technikgeschichtlich fixierte Mediengeschichtsschreibung zu nutzen. So stehen z.B. die unter Verwendung der Detailanalysen von Tomaselli und Gutsche präsentierten Periodisierungen in dieser Studie anscheinend im Gegensatz zu den oft zitierten technikgeschichtlichen Einteilungen innerhalb der südafrikanischen Filmgeschichtsschreibung.

Für Wigston umfasst die Stummfilmära die Jahre 1910 bis 1926, die Ankunft des Tonfilms periodisiert er für den Zeitraum 1926 bis 1939 (2001: 75f.). Ähnlich agieren Louw/Botha mit ihrer Unterscheidung in 1920 bis 1929 als Stummfilmperiode und 1930 bis 1939 als den Beginn der Tonfilmepoche (1993: 161f.). Dabei übersieht Wigston, dass trotz der in Europa vereinzelt produzierten Tonfilme bis 1928 kein einziger in den südafrikanischen Kinos 
gezeigt wurde. Erst 1928 folgten die von Kinemas importierten De ForrestPhonofilme. Auch war bis 1930 die erforderliche flächendeckende technische Infrastruktur zur Tonfilmwiedergabe noch nicht vorhanden, so dass die vorgenommene Periodisierung vielleicht den technologischen Möglichkeiten entsprach, nicht aber den tatsächlichen Gegebenheiten Südafrikas.

Auch Louw/Botha periodisieren in einer eher spekulativen Weise und negieren das Bestehen einer Übergangsphase in den Jahren 1928 bis 1930, in der noch keinesfalls klar war, dass sich der Tonfilm wirklich durchsetzen und nicht nach kurzer Zeit als eine Modeerscheinung oder technische Spielerei abgetan würde. Während Kinemas von Beginn an auf den Tonfilm gesetzt hatten, verhielt sich die Schlesinger-Organisation noch abwartend. Endgültig vollzogen wurde der Wechsel vom Stumm- zum Tonfilm mit der Entscheidung, die von Schlesingers African Films Ltd. produzierte Wochenschau "African Mirror" als Tonfilm herzustellen (NA 2.5.1930: 10), ein Schritt der ohne das Vorhandensein einer ausreichenden Tonfilminfrastruktur nicht wirtschaftlich gewesen wäre. Zudem produzierte African Films Ltd. ein Jahr später den ersten afrikaansen Tonfilm „Moedertjie“ (1931, J. Albrecht), eine Investition, die nur dann eine wirklich erfolgreiche Einspielung der Herstellungskosten versprach, wenn die flächendeckende Vorführung vor einem afrikaansen Publikum gesichert war.

Der erbitterte Konkurrenzkampf zwischen Kinemas und der SchlesingerOrganisation, 1931 noch zusätzlich verschärft durch die Ankündigung eines Engagements von Metro-Goldwyn-Meyer, wurde mit Blick auf die sich abzeichnende weltwirtschaftliche Krise eingestellt und die Fusion der beiden Unternehmen am 2. Dezember 1932 verkündet (Gutsche 1972: 214). Die Gründe dafür lagen auf der Hand:

"The parallel development of the two organisations was in fact commercially impracticable. The fact that either organisation would go to great length to thwart the other was known overseas and exploited to the advantage of the production and distribution firms. Bidding against each other, African Films and Kinemas would raise the price of outstanding films to a point where payable returns were practically impossible. Secondly, competition in erecting cinemas was exhausting the ressources of both organisations. Thirdly, competition had resulted in the opening of cinemas by both interests in dorps whose population could barley support one. Fourthly, under circumstances of economic stress, the importation of six distinct cinema programmes by both organisations for their competitve circuits was an unneccessary extravagance, three being sufficient for the total requirements. Fifthly, the financial situation had become increasingly precarious and there was no immediate sign of amelioration" (ebd.). 
Als "African Consolidated Theatres" und „African Consolidated Films" verantworteten diese als Holding geführten Unternehmen innerhalb der Schlesinger-Organisation von nun an die Aufführung bzw. den Vertrieb der Filme für die in der Vorstellung der Öffentlichkeit noch immer unabhängig voneinander agierenden Kinoketten (ebd.: 214f.). Zusammenfassend lässt sich die wirtschaftliche Entwicklung des südafrikanischen Kinosektors bis in die 1930er Jahre wie in der nachstehenden Tabelle darstellen:

Tab. 7: Periodisierung und Vergleich der Marktformen des Kinosektors in Südafrika und den USA

\begin{tabular}{|c|c|c|c|c|}
\hline Zeitraum & Marktform SA & Zeitraum & Marktform USA & Filmhistorischer Abschnitt \\
\hline \multirow[t]{2}{*}{$1895-1913$} & \multirow{2}{*}{$\begin{array}{l}\text { Polypol (viele kleinere } \\
\text { Anbieter) }\end{array}$} & $1896-1908$ & Polypol & \multirow[t]{3}{*}{ Stummfilmära } \\
\hline & & \multirow[t]{3}{*}{$1909-1929$} & \multirow[t]{3}{*}{ Oligopol } & \\
\hline $1913-1927$ & Monopol (Schlesinger) & & & \\
\hline $1928-1931$ & $\begin{array}{l}\text { Duopol (Schlesinger } \\
\text { vs. Kinemas) }\end{array}$ & & & $\begin{array}{c}\text { Dualismus von Stumm- und } \\
\text { Tonfilm }\end{array}$ \\
\hline $1931-1937$ & Monopol (Schlesinger) & 1930-1946 & Monopol & Tonfilmdominanz \\
\hline
\end{tabular}

Wenn in den obenstehenden Ausführungen eine stark gesamtwirtschaftliche Perspektive in Bezug auf die Periodisierung eingenommen wurde, so geschah dies bereits im Hinblick auf Überlegungen zur Struktur des Publikums im ausgewählten Untersuchungszeitraum. Dazu liegen leider nur sehr allgemeine Aussagen vor, empirische Studien existieren überhaupt nicht. Um dennoch begründete Annahmen über das Publikum treffen zu können, sollte anhand der durch die wirtschaftliche Struktur der Filmwirtschaft vorgegebenen Rahmenbedingungen ein Muster für die Einschätzung der Zuschauerstruktur geschaffen werden. Dazu wird im Folgenden unter besonderer Berücksichtigung von Dieter Prokops „Soziologie des Films“ (1982) und der darin enthaltenen Marktformenanalyse versucht, abgesicherte Einschätzungen über das südafrikanische Kinopublikum vornehmen zu können.

\subsection{Annahmen über das südafrikanische Kinopublikum}

Für das südafrikanische Publikum entsprach der damalige Kinobesuch noch ganz dem klassischen Ritual aus Verdunkelung, Vorhangöffnung, Wochenschau, Vorfilm, Wiederbeleuchtung zum Eiscremeverkauf, erneuter Verdunkelung, Vorschau und Hauptfilm. All das schuf eine positive Erwartungshaltung, ein Herbeisehnen der schönen Stunden der Zerstreuung und Unterhaltung (Beicken 2004: 8). 
Wie bereits am Beginn dieses Kapitels angedeutet, beziehen sich die Ausführungen zum Kinopublikum ausschließlich auf die Südafrikaner europäischer Abstammung, da meist nur sie über die notwendigen Mittel zum Kinobesuch verfügten und nicht durch offen oder verdeckt diskriminierende Regelungen davon ausgeschlossen werden konnten. Die Zensurproblematik selbst wird in einem gesonderten Abschnitt behandelt.

Das langjährige Hollywoodmonopol brachte es jedoch mit sich, dass auf die Bedürfnisse der südafrikanischen Zuschauer keine besondere Rücksicht genommen werden musste. Zur Vorführung gelangten konsequent für einen Massenmarkt produzierte Filme, denen die Vorstellung eines homogenen Publikums zugrunde lag. Im Falle des Fehlens einer echten Konkurrenz zu Hollywood wird dies als Konsequenz des Verkäufermarktes angesehen, der immer dann entsteht, wenn das Angebot langsamer wächst als die Nachfrage, was auf Südafrika bis zur Weltwirtschaftskrise zweifellos zutraf (Tomaselli 1980a: 106). Allenfalls eine Unterscheidung in "A-Movies“ und „BMovies" und deren Publika wurde erkannt, wobei die „B-Movies" eher Zerstreuung als Anregung für den Zuschauer bieten sollten (ebd.). Die auch nach der Durchsetzung des Tonfilms gleichbleibende Nachfrage nach Hollywoodfilmen gab dieser Annahme auch scheinbar recht. Allerdings beklagte sich ein Teil des ,Massenpublikums' über die Handlung vieler Hollywoodfilme, die vielfach unbegreiflich war und höchstens das US-amerikanische Publikum ansprach (Gutsche 1972: 223). Über diese beiden Bemerkungen hinausgehende Einschätzungen des frühen südafrikanischen Kinopublikums existieren leider nicht, nur Weniges lässt sich ,zwischen den Zeilen' aus den filmgeschichtlichen Standardwerken herauslesen. Umso wichtiger erscheint das vergleichende Analysieren der entsprechenden Marktformen, aus denen am Beispiel Hollywoods und in Übertragung auf Südafrika nach der möglichen Struktur des dortigen Publikums gefragt werden soll.

Ein fundamentaler Unterschied zwischen den beiden Filmindustrien bestand allerdings darin, dass in Südafrika die Filmindustrie im wesentlichen nur aus Filmvertrieb und -vorführung aufgebaut war, während in den USA die weltgrößten Filmproduktionen residierten. Beim Betrachten der Struktur der US-amerikanischen Filmwirtschaft unterscheidet Prokop (1982) chronologisch folgende Phasen und Marktformen im Zeitraum von 1886 bis 1946:

- 1896-1908: Polypol, Unterschichtenpublikum

- 1909-1929: Oligopol, Übergang zum Mittelschichtenpublikum

- 1930-1946: Monopol, Dominanz der unteren Mittelschicht 
Zunächst fällt auf, dass sich diese Periodisierung von jener in Südafrika nur unwesentlich unterscheidet, jedoch die dazugehörigen Marktformen voneinander abweichen (Tabelle 7). Auf die Frühphase bis ca. 1913 soll hier nicht weiter eingegangen werden, sie war in beiden Ländern sehr ähnlich (z.B. viele kleine Anbieter, Wanderkinos, Jahrmarktpublikum, Themenvielfalt etc.). Auf den ersten Blick scheinen in Südafrika die zweite und die dritte Phase miteinander vertauscht, wobei das in Südafrika vorherrschende Duopol zwischen Kinemas und der Schlesinger-Organisation eine Sonderform des Oligopols darstellte. Durch die Amerikanisierung des südafrikanischen Kinoprogramms unter Monopolbedingungen kann davon ausgegangen werden, dass das Angebot auf dem südafrikanischen Markt mit dem der USA fast identisch war. Somit wurden die Präferenzen des US-amerikanischen Publikums zu Zeiten des Oligopols auch auf den monopolistisch geprägten südafrikanischen Markt importiert. Im Programm müsste sich also jene Prestigefilmpolitik Hollywoods mit seinen phantastischen Filmen, ,göttlichen Stars' und ungewöhnlichen Millieus wiedergespiegelt haben; realistische oder gar sozialkritische Filme entsprachen dagegen nicht diesen standardisierten marktgängigen Rezepten (Prokop 1982: 71).

Da das südafrikanische Publikum unter der Schlesinger-Dominanz ohnehin keinen Einfluss auf die angebotenen Filme hatte, scheinen Vergleiche mit der US-amerikanischen Publikumsstruktur sowohl unter Polypol-, als auch Monopolbedingungen angebracht. In beiden Fällen musste sich sowohl die Filmproduktion (USA), als auch der Vertrieb (SA), auf eine möglichst breite Amortisationsbasis ausrichten, die auf einer vergleichbaren Präferenzstruktur innerhalb des gesamten Absatzgebietes beruhte (ebd.: 101). Das Vorliegen der dazu notwendigen ,universalen Strukturen' (bspw. Freizeit, Kaufkraft, Kinoinfrastruktur etc.) kann trotz des Rückstandes Südafrikas in Bezug auf die Industriealisierung als gegeben angesehen werden.

Zu Zeiten des Polypols in den USA bzw. des Duopols in Südafrika veränderte sich die Publikumsstruktur weg vom Unterschichten-, hin zum Mittelschichtenpublikum. Dafür ursächlich waren die Bemühungen der Kinokonzerne, diese ökonomisch potentere Zielgruppe durch eine gezielte Produktdifferenzierung anzusprechen, um damit höhere Eintrittspreise erzielen zu können. Dies wurde auf beiden Märkten durch eleganter ausgestattete Kinobauten bewerkstelligt, da für die Zusammensetzung des Publikums weniger die Qualität des Dargebotenen, sondern vielmehr die Ausstattung des Kinotheaters oder die Höhe des Eintrittsgeldes von Bedeutung war (ebd.: 65). In Südafrika, wie auch in den USA, schlug sich diese Strategie ab etwa 1927 in der Errichtung der sogenannten ,Atmospheric Theatres' nieder (Gutsche 
1972: 221 bzw. Herzog 1980). Die neuen Lichtspielhäuser verfügten über ein palastartiges Ambiente im römischen, maurischen oder Tudor-Stil, selbst die sanitären Einrichtungen wandelten sich von den schäbigen „Bioscopescloakrooms" der Unterschichten zu luxuriösen „Cinema-cosmetic-rooms“ für die Mittelschicht (Gutsche 1972: 221). Das Publikum dieser Kinos wurde mit Filmen bedient, die vor allem das Leben der ,feinen Leute' mit phantastischen Häusern, Kleidern, Automobilen und ebenso phantastischer Lebensführung zeigten (Prokop 1982: 65). Zur Architektur passend wurden in Südafrika ,Glamourfilme' vorgeführt, deren Hauptdarsteller vor allem ,Sheiks', ,Vamps' und 'Sirens' waren, über deren Privatleben die Klatschpresse ausführlich berichten konnte (Gutsche 1972: 217). In der Endphase des Duopols rückten die phantastischen Charaktere Hollywoods in die zweite Reihe und machten Platz für Filme und Darsteller mit mehr, sex-appeal'. Halbnackte Bade- oder Chormädchen standen im Mittelpunkt, exemplarisch verkörpert durch den US-amerikanischen Filmstar Clara Bow (ebd.: 219).

Ein nicht zu unterschätzender Teil des Publikums wandte sich Ende der 1920er Jahre von den ,sex-appeal' Filmen ab und erzeugte eine Nachfrage nach anderen Filmthemen. Diese Situation konnte der neue Mitkonkurrent Kinemas nutzen und lenkte diese Zielgruppe mit gehobeneren britischen und kontinentaleuropäischen Produktionen in seine Kinos (ebd.: 220). Auch damit verstärkte sich die Tendenz von den eher phantastischen zu den mehr realistischen Filmthemen, die der schleichende Übergang vom Oligopol zum Monopol innerhalb der US-amerikanischen Filmindustrie mit sich brachte (Prokop 1982: 114). Ohne das Ausweichen auf die Nicht-Hollywoodfilme von Kinemas hätte sich mit der unterstellten Änderung der Publikumspräferenzen ein Rückgang der Anzahl der Kinobesucher eingestellt. In der Situation des monopolistischen Verkäufermarktes in Südafrika bis 1928 hätte dies jedoch nicht zu einer Veränderung des Filmangebots führen müssen, erst die Konkurrenzsituation ließ eine bemerkbare Artikulation der Publikumspräferenzen zu. Ohne diese Möglichkeit wäre die veränderte thematische Ausrichtung der Filme nur als eine Spiegelung der Filmpolitik Hollywoods am südafrikanischen Markt wahrnehmbar gewesen. Dabei hätte das Schlesinger-Monopol dazu eingeladen, die Prestigefilmpolitik so lange fortzusetzen, bis sich die durch die geänderten amerikanischen Publikumspräferenzen eingestellten Verluste wenigstens in Südafrika amortisiert hätten.

Wie bereits dargelegt wurde, konnte sich in Südafrika in den 1920er Jahren durch die erfolgreiche Wirtschaftspolitik tatsächlich eine ökonomisch potente Mittelschicht bilden, welcher durch die neuen Arbeitszeitregelungen mehr Freizeit zur Verfügung stand. Am Indikator des Volkseinkommens 
gemessen, verfügte jene Schicht auch durchschnittlich über ein höheres Einkommen, das zum Konsum von Unterhaltung genutzt werden konnte. Der Freizeit, sowie der Institutionalisierung des Filmkonsums als Freizeitverhalten kam in dieser Zeit eine sogenannte ,Ventilsitten-Funktion' zu. Derartige ,Ventilsitten' geben dem Gesellschaftsmitglied innerhalb eines sozial definierten Rahmens eine gewisse Freiheit, die normalerweise geltenden Normen und Verhaltensweisen zu übertreten (Parsons 1951: 306). Eine vergleichbare 'Ventilsitte' als funktionaler Eskapismus stellt heutzutage noch der Besuch eines Fußballspiels (Gruppenerlebnis, Agression auf und neben dem Spielfeld etc.) oder die Betätigung als Extremsportler dar (Flow-Erlebnis in Einzelkämpfersituationen). Oft werden in den ,Ventilsitten' gewisse Aufstiegs- und Konsumideale von den aufstrebenden, aber ökonomisch stillgestellten Bevölkerungsschichten überhöht artikuliert, die im gewöhnlichen Alltag tabuisiert wären. ${ }^{16}$

Um als solche Ideale fungieren zu können, müssen sich die in den Freizeitangeboten enthaltenen Themen zur Identifizierung eignen, was auch eine subjektive Projektionsfähigkeit durch den Einzelnen beinhaltet. Die Definition der Kinosituation als ,Ventilsitte' schließt von den Publikumspräferenzen her die Präferenz für sozialkritische und auch ästhetisch experimentierende Filme eigentlich aus. Zuschauer, die auf die Ventilsituation eingestellt sind, können - bewusst oder unbewusst - die Verweigerung des Ausnahmecharakters dieser Situation durch realistischere oder sozialkritische Filme damit sanktionieren, dass jene Filme als nicht projektionsfähig angesehen werden, da sie es nicht zulassen, den Zuschauern die Projektion ihrer Wünsche zu gestatten (Prokop 1983: 115). Dieser institutionelle Rahmen schränkt die Filmgestaltung einerseits in der Entwicklung zum ,phantastischen' Film (fehlende Identifikationsfähigkeit), andererseits jedoch auch in der Entwicklung zum ,realistischen' Film (eingeschränkte positive Projektionsfähigkeit) ein (ebd.: 128f.).

Desweiteren wurde eine einkommensabhängige Präferenzstruktur nachgewiesen, wonach Angehörige mittlerer Einkommensschichten sowie mittlerer und höherer Schulbildung häufiger ins Kino gingen als die höherer und niedrigerer Einkommensschichten (ebd.: 125ff.). ${ }^{17}$ Angaben zur tatsächlichen Häufigkeit des Kinobesuchs in Südafrika existieren bis in die 1940er Jahre überhaupt nicht. Der Filmkritiker Hans Rompel schätzte 1945 lediglich, dass

\footnotetext{
16 ,Ökonomisch stillgestellt' soll an dieser Stelle als die relative Unmöglichkeit eines weiteren sozioökonomischen Ab- bzw. Aufstieges verstanden werden.

17 Konkrete Angaben dazu liegen für Südafrika erst mit dem für die Jahre 1946/47 aufgestellten „First Census of Distribution and Service Establisments 1946-1947. Preliminary Report, No. 51, Cinemas” vor.
} 
in Johannesburg pro Woche etwa 100.000 Menschen ins Kino gingen (Rompel 1945: 53). Allgemein galt jedoch:

„Die hinsichtlich der Realisierungschancen von Aufstiegs- und Konsumidealen relativ deprivierte (benachteiligte, Anm. ME), besonders, freizeitorientierte' untere Mittelschicht tendierte in den industriellen Gesellschaften [...] zu besonders häufigem Kinobesuch" (Prokop 1983: 129f.)

An dieser Stelle soll noch nicht auf die konkreten Publikumspräferenzen eingegangen werden, da lediglich Daten für die USA (1942) vorhanden sind (Mandel 1950). Für Südafrika können etwaige Vergleiche erst nach einer Betrachtung der Programmgeschichte vorgenommen werden, welche um eine Analyse der in den Filmkritiken geäußerten Meinungen ergänzt wird. ${ }^{18}$

Die vergleichende Betrachtung der Marktformen und der Publikumsstrukturen hat gezeigt, dass die Verhältnisse der Filmindustrie im Produktionsland trotz unterschiedlicher Marktform die Publikumsstruktur im Distributionsland mitprägten. Ende der 1920er und Anfang der 1930er Jahre kann der südafrikanische Durchschnittszuschauer daher als ein relativ gebildeter Angehöriger der ,weißen' unteren Mittelschicht rekonstruiert werden, der infolge der gesunkenen Wochenarbeitszeit über mehr Freizeit verfügte, die er ob seines verbesserten ökonomischen Status' durch Konsum von Unterhaltung gestalten konnte. Seine ,gelenkten Präferenzen' waren bis 1928 durch das Hollywoodmonopol amerikanisiert. Diese Annahme wird durch die Tatsache belegt, dass sich z.B. in einem Kino der Schlesinger-Organisation in Kapstadt unter den 57 gezeigten Filmen des Jahres 1928 nur ganze fünf NichtHollywood-Produktionen befanden (Eckardt 2005: 102ff.). Erst mit dem Aufkommen von Konkurrenzanbieter Kinemas erhielt der Zuschauer die Chance, seine Präferenzen durch die Wahl von Alternativangeboten artikulieren zu können. Diese veränderte Marktsituation schuf auch für andere Filmproduzenten Anreize, das Gewinnpotential des südafrikanischen Marktes zu bedenken. Der Konkurrenzkampf und die sich wandelnden Publikumspräferenzen machten es ebenso für die beiden südafrikanischen Marktführer erforderlich, sich nach neuen Filmanbietern umzusehen. So gelangten verstärkt die bis dato vernachlässigten britischen oder kontinentaleuropäischen Produktionen in die Kinos am Kap.

Die anhaltende Popularität des Films sorgte dafür, dass sich zu Anfang der 1930er Jahre der Kinobesuch in Südafrika soweit habitualisiert hatte,

\footnotetext{
${ }^{18}$ Vorwegzunehmen wäre lediglich, dass die ,romantische Liebe' das dominante Thema der auf eine breite Amortisation angewiesenen Unterhaltungsindustrie war und als die Basis generalisierter Rezeptivität schlechthin fungierte (Prokop 1982: 122).
} 
dass unabhängig vom gezeigten Programm die Lichtspielhäuser aufgesucht wurden (Gutsche 1972: 237). Diese Tendenz änderte sich auch durch das Aufkommen des Tonfilms und dessen vollständige Durchsetzung ab 1930 nicht. Allerdings wandelte sich mit dem Übergang vom Stumm- zum Tonfilm dessen Status vom Zerstreuungs- zum Unterhaltungs- und Informationsmedium. Die Komplettierungserfahrung durch die Tondimension ging einher mit dem Verschwinden der oft phantastischen Charaktere der Stummfilmära. Der Realitätseindruck sprechender Darsteller in wirklichkeitsnahen Situationen ließ das Kino zu einem maßgeblichen Teil der gesellschaftlichen Wirklichkeit werden:

"The silent cinema, broadly speaking, had had the social significance of distraction only. The sound film widened that significance to embrace almost every aspect of social life. Where there had been distraction only, there was now entertainment, information, culture, political propaganda (largely in newsreels), demonstrations and moral suasion. Sound gave the cinema a consciousness of purpose which had always proved abortive on the silent screen. If it annulled the figures of fantasy of the silent screen, it gave added emphasis to the figures of reality that emerged in the talkie film. With sound, the cinema became a social force, not merely a feature of the social situation" (ebd.: 227)

Mit dem Einfluss der im Kinoprogramm widergespiegelten Publikumsstruktur des Produktionslandes auf die Distributionsländer wird deutlich, welchen Einschränkungen die Überlegung unterliegt, wonach Filme als Spiegel der bestehenden Gesellschaft fungieren würden (Kracauer 1963: 279). Dies mag vielleicht auf Länder mit einer umfangreichen eigenen Spielfilmproduktion zutreffen. In Ländern, deren Filmindustrie im wesentlichen nur aus Filmvertrieb und -vorführung bestand, mussten andere Identifikationsstrategien wirksam werden. Dem dazu erforderlichen Rechercheaufwand ist es möglicherweise geschuldet, warum sich die produktionszentrierte Filmgeschichtsschreibung nach dem Herkunftslandprinzip im Falle Afrikas so dominant profilieren konnte.

Um die Möglichkeiten einer rezeptionshistorischen Studie zu erkunden und deren Möglichkeiten am empirischen Material ermessen zu können, schließen sich dem Einführungskapitel eine Darstellung zur südafrikanischen Presse und zum Filmimport im ausgesuchten Untersuchungszeitraum an. Danach erfolgt eine programmgeschichtliche Erfassung der tatsächlich gezeigten deutschen Filme, deren Rezeptionsdokumente dann eingehend analysiert werden. 


\section{Presselandschaft und Filmkritik in Südafrika}

\subsection{Die südafrikanische Presse und ihre Sonderstellung in Afrika}

Um die Struktur der südafrikanischen Presse zu überblicken und deren Konsequenzen für die Filmkritik ermessen zu können, soll hier zunächst ein Überblick des südafrikanischen Pressewesens erfolgen.

Innerhalb Afrikas nahm die vielfältige, überaus vitale und weitgehend unabhängige südafrikanische Presse schon immer eine Ausnahmestellung ein. Bereits im Jahre 1800 erschien in Kapstadt die erste Zeitung Afrikas überhaupt, bereits kurz danach folgten die ersten zweisprachigen, auf Englisch bzw. Niederländisch herausgegebenen Blätter (Botha 1935: 32f.). ${ }^{19}$ Politische Beeinflussungsversuche von Seiten des Governeurs resultierten zuweilen in angedrohten bzw. vollstreckten Publikationsverboten (Gunter 1930; Barton 1979: 189). Durch ihren permanenten Widerstand erwirkten die Zeitungsherausgeber jedoch beim britischen Kolonialamt ein Pressegesetz nach britischem Vorbild, welches am 30. April 1828 in Kraft trat und die Freiheit der Presse im Rahmen der Landesgesetze garantierte (Ainslee 1966: 40).

Die stark heterogene Zusammensetzung der südafrikanischen Bevölkerung und deren unterschiedlicher Alphabetisierungsgrad ließen eine Presselandschaft entstehen, die qualitativ-technisch problemlos mit ihren europäischen Vorbildern britischer oder niederländischer Provinienz mithalten konnte, jedoch exklusiv den Interessen der südafrikanischen Bevölkerung europäischer Herkunft diente. Die historisch bedingte Zusammensetzung der europäischstämmigen Bevölkerung aus niederländisch-afrikaanssprachigen Siedlern und englischsprachigen Kolonisten oder Händlern bestimmte von Beginn an die Entwicklung des Pressewesens. Die sprachlichen und politischen Gegensätze der zwei dominanten Bevölkerungsgruppen spiegelten sich pressegeschichtlich insofern wieder, als dass bereits seit Mitte des 19. Jahrhunderts eine den Wirtschaftsinteressen verpflichtete Presse in englischer Sprache aufblühte, der eine ums Überleben kämpfende und die Sprache als kulturell-politisches Abgrenzungsinstrument benutzende afrikaanse Presse gegenüberstand (du Plessis 1944 bzw. Kitchen 1956: 42).

Mit der 1884 erfolgten Gründung der ersten dauerhaften Zeitung in einer Bantusprache (Imvo Zabantsundu) entstand die dritte große Gruppe südafri-

19 1800: The Cape Town Gazette and African Advertiser; 1824: South African Commercial Advertiser bzw. South African Journal/Het Nederduitsch Zuid Afrikaansche Tijdskrift; vgl. Botha 1935: 32f. bzw. Nienaber 1951. 
kanischer Zeitungen, die zusammenfassend als die nicht-europäische bzw. alternative oder Bantu-Presse bezeichnet wird (Barton 1979: 196 und Ambrosch 1970: 47f.). Einige der im 19. Jahrhundert gegründeten und zur zweiten Generation südafrikanischer Zeitungen gehörenden englischen Blätter können seit dem auf eine nahezu ungebrochene Tradition blicken und erscheinen bis zum heutigen Tage (z.B. Cape Times, Argus, The Star). Im Zuge einer Gesamtbetrachtung der Presse der Kolonialmächte und als Teil der englischen Kolonialpresse wurde der Presse der Südafrikanischen Union aus den genannten Gründen von je her eine Sonderstellung zugebilligt (d'Ester 1937: 301, Prakke 1962: 154 und Hachten 1971). Im ausgesuchten Untersuchungszeitraum stellte sich die südafrikanische Zeitungslandschaft quantitativ wie in Tabelle 8 dar.

Tab. 8: Anzahl der registrierten Zeitungen in Südafrika $1928-1933^{20}$

\begin{tabular}{|c|c|c|c|c|c|}
\hline Jahr & Kap-Provinz & Natal & Transvaal & OFS $^{21}$ & Total \\
\hline 1928 & 157 & 36 & 141 & 34 & 368 \\
\hline 1929 & 164 & 36 & 152 & 36 & 388 \\
\hline 1930 & 168 & 48 & 159 & 41 & 416 \\
\hline 1931 & 141 & 34 & 142 & 41 & 358 \\
\hline 1932 & 143 & 38 & 138 & 31 & 350 \\
\hline 1933 & 140 & 33 & 131 & 32 & 336 \\
\hline
\end{tabular}

Aus Tabelle 8 wird ersichtlich, dass es in den Jahren 1928 bis 1933 trotz leicht abnehmender Tendenz und geringen regionalen Unterschieden kaum nenneswerte Schwankungen in der Anzahl der publizierten Zeitungen gegeben hat. In Provinzen mit einem relativ geringen aber stabilen Anteil der europäischen Bevölkerung wie Natal (überwiegend englischsprachig) und dem Oranje-Freistaat (überwiegend afrikaanssprachig) kam es zu weniger Neugründungen oder Schließungen als dies in Provinzen mit einer höheren Bevölkerungsfluktuation wie dem Kap und Transvaal (zweisprachig; Englisch dominierte in den Städten, Afrikaans auf dem Lande) der Fall war.

Hinter den obenstehenden Zahlen verbirgt sich eine Vielzahl von Zeitungen, die in Hinsicht auf Sprache, Periodizität, Verbreitungsgebiet, Auflage, politische Orientierung usw. kaum unterschiedlicher sein könnten. Allen ist hingegen gemeinsam, dass ihre publizistische Reichweite nur schätzungsweise feststellbar ist. Ursächlich dafür ist ein gegenseitiges Übereinkommen, nach dem die Auflagenhöhe der einzelnen Zeitungen geheimgehalten wurde, um das desaströse Hochtreiben der Auflagen zu vermeiden und damit einem

\footnotetext{
${ }^{20}$ Vgl. Official Yearbook 17(1934/35), 202.

${ }^{21}$ Abk. für Oranje-Freistaat.
} 
unlauteren Wettbewerb im Annoncengeschäft entgegenzuwirken (Zapp 1938: 8). Neben Zeitungen in den Amtssprachen Englisch und Afrikaans bzw. zweisprachigen Blättern (s. Tabelle 9) existierten auch solche in den Sprachen der schwarzafrikanischen oder indischstämmigen Bevölkerung, ${ }^{22}$ ebenso einige in deutscher (Friebel 1935 und Schmidt-Pretoria 1955: 199ff.) ${ }^{23}$ oder jiddischer Sprache (Pohl 1943 und Poliva 1967). Viele der registrierten Zeitungen waren Regional- oder Lokalzeitungen von geringem Umfang, niedriger Periodizität und kleiner Auflage (de Villiers 1976 und de Jager 1980). Man konnte allerdings davon ausgehen, dass es in Südafrika kaum eine Gegend gab, in der nicht zumindest eine der ländlichen Kleinstadtzeitungen (,platteland-koerante') erhältlich war (Breyne 1925: 4). ${ }^{24}$ Allerdings gab und gibt es bis heute keine in ganz Südafrika verbreitete überregionale Tageszeitung. ${ }^{25}$

Tab. 9: Sprachliche Gliederung Südafrikas und der südafrikanischen Presse $1926{ }^{26}$

\begin{tabular}{|c|c|c|c|}
\hline $\begin{array}{c}\text { Sprachliche Gliederung der europäischen Bevölke- } \\
\text { rung Südafrikas }\end{array}$ & \multicolumn{2}{|l|}{ Sprachliche Gliederung der südafrikanischen Presse } \\
\hline Sprache & Anteil & Sprache & Anteil \\
\hline Afrikaans & $57,5 \%$ & Afrikaans & $20 \%$ \\
\hline Englisch & $33,7 \%$ & Englisch & $68 \%$ \\
\hline & & Englisch/Afrikaans & $5 \%$ \\
\hline Deutsch & $2,5 \%$ & Deutsch & $1 \%$ \\
\hline Jüdisch & $4,3 \%$ & Andere & $1 \%$ \\
\hline Andere & $2,0 \%$ & Nichteuropäische Sprachen & $5 \%$ \\
\hline
\end{tabular}

\subsection{Sprachliche Polarität am Zeitungsmarkt: Englisch vs. Afri- kaans}

Wenn sich im Fortgang dieser Untersuchung vor allem auf die englische und afrikaanse Presse konzentriert wird, so erfolgt dies aus der pragmatischen Überlegung, dass sich der Hauptanteil des südafrikanischen Kinopublikums aus genau diesen beiden Sprach- bzw. Bevölkerungsgruppen zusammensetzte und die Zeitungen jener Gruppen am ehesten auf das Informationsbedürf-

\footnotetext{
${ }^{22}$ So wurde z.B. die Zeitung Indian Opinion 1906 in Durban von Mahatma Gandhi gegründet und von dessen Sohn Manilal bzw. Manilas Witwe weitergeführt (Barton 1979: 196).

${ }^{23}$ Z.B. Der Deutsch-Afrikaner (1921-39) und Deutsche Afrika Post (1929-43).

${ }^{24}$ Eine Titelliste mit einigen z.T. noch heute existierenden ,Platteland-koerante' findet sich im Anhang von Varley 1952: 34-36; eine Charakterisierung der ,Plattelandse Pers' findet sich in Du Plessis 1943: 156 175 (Kapitel VII).

${ }^{25}$ Der jüngste erfolglose Versuch fand 2003-2004 mit der Tageszeitung This Day statt (von Lucius 2004).

${ }^{26} \mathrm{Vgl}$. Böhmer 1937: 75.
} 
nis ihrer filminteressierten Leserschaft eingegangen sein dürften. Für die Presse der schwarzafrikanischen Bevölkerungsmehrheit hingegen bestand nur wenig Anlass zu einer intensiveren Filmberichterstattung, da deren Leserschaft nur ausnahmsweise Zugang zu Filmvorführungen erhielt, nur wenige ausschließlich ihnen vorbehaltene Lichtspielhäuser existierten (Haasbroek 2001) und die geringe Seitenzahl der Zeitungen einer detaillierten Filmberichterstattung entgegenstand. Eine Stichprobenuntersuchung in einigen der zweisprachig (eine Bantusprache und Englisch) erschienenen Zeitungen für die nicht-europäische Bevölkerung auf Kinowerbung bestätigte diese Vermutung.

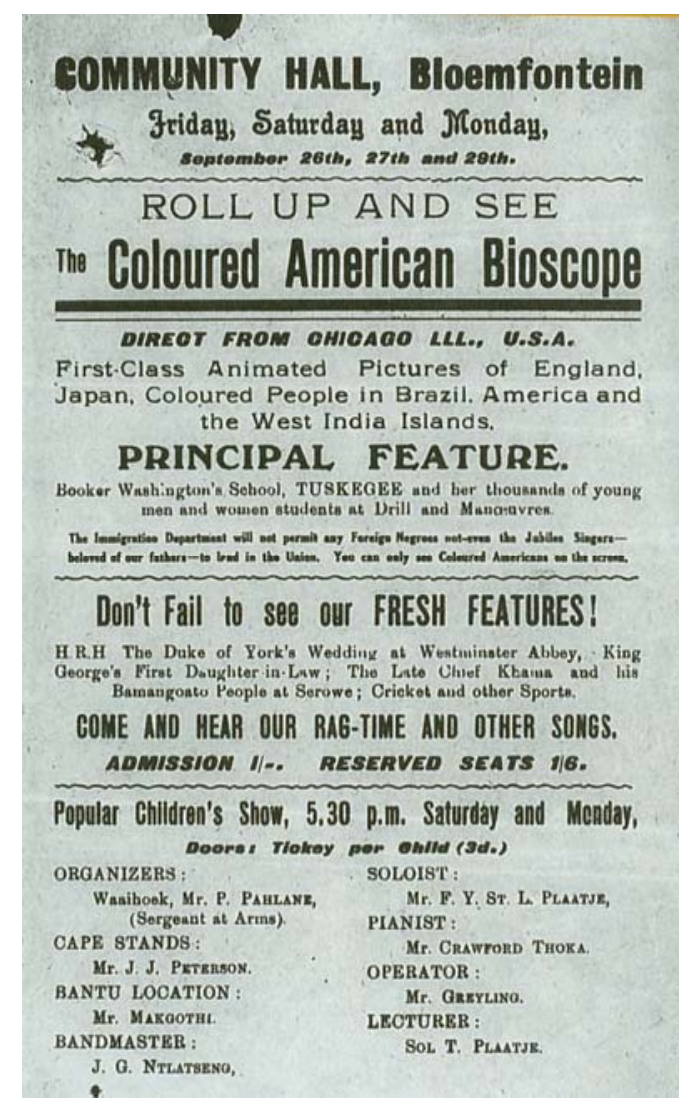

Abb. 3: Werbeplakat für Sol Plaatjes Filmvorführungen im Jahre $1924{ }^{27}$

Aus Abbildung 3 (unten rechts) geht zwar eindeutig hervor, dass es in der Person des tswanasprachigen bzw. polyglotten Journalisten, Schriftstellers, Filmaufklärers und Politikers Sol Plaatje (1877-1932) auch eine bedeutende Ausnahme gab (Willan 1996 und Midgley 2000). Durch seine Europa- bzw.

${ }^{27}$ Vgl. Willan 1996: 332. 
USA-Aufenthalte konnte er sich kompetent zu Filmen äußern, ${ }^{28}$ zudem wurde ihm der Zugang zur europäischen Presse Südafrikas nicht verwehrt. ${ }^{29}$ Allerdings entstand dadurch aufgrund der genannten Einschränkungen noch keine dauerhaft geführte Filmberichterstattung in den nicht-europäischen Blättern. ${ }^{30}$ Ohne Zweifel können die Bemühungen Sol Plaatjes im Zuge der US-amerikanisch inspirierten „New Negro“-Bewegung als Anfang der alternativen Filmkultur innerhalb der nicht-europäischen Bevölkerung und deren Presse angesehen werden (Masilela 2003). Diese Versuche standen jedoch qualitativ als auch quantitativ in keinem Verhältnis zur europäisch dominierten Kinokultur. ${ }^{31}$

Wie bereits angedeutet, lässt sich die südafrikanische Presse der 1920er und 1930er Jahre im Wesentlichen in die englische und afrikaanse Presse einteilen, wobei für beide Gruppen eine weitere Binnendifferenzierung notwendig ist. Innerhalb der englischen Presse existierten neben kleineren unabhängigen Blättern zwei miteinander konkurrierende Gruppen. Bei diesen handelt es sich zum einen um die Argus-Gruppe „Argus Printing \& Publishing Co. Ltd" mit ihren Kooperationspartnern und die Gruppe der südafrikanischen Morgenzeitungen "The South African Morning Newspapers, Ltd." und die mit ihnen assoziierten Zeitungen. Bei beiden Gruppen handelt es sich weniger um Zusammenschlüsse in Bezug auf homogene Eigentumsverhältnisse, sondern mehr um vielschichtig verflochtene Beteiligungsbeziehungen formal unabhängiger Zeitungen ohne zentrale Koordination. Ebenso können beide Gruppen als regierungsunabhängig angesehen werden, jedoch standen die Interessen von Handel und Wirtschaft im Rahmen des britischen Empire eindeutig im Vordergund der Berichterstattung (Beuckes 1946).

\subsubsection{Die englische Presse}

Zur Gruppe der südafrikanischen Morgenzeitungen zählten die großen regionalen Tageszeitungen Cape Times (Kapstadt), Natal Mercury (Durban), Rand Daily Mail (Johannesburg), Daily Dispatch (East London), Eastern

\footnotetext{
${ }^{28}$ So z.B. vernichtend über D.W. Griffith' „The Birth of a Nation“, vgl. Plaatje, S.T. (1931): An inflammatory bioscope film; Umteteli wa Bantu 18.7.1931 oder Plaatje, S.T. (1931): Counteracting negrophilism in SA: race hatred and a film; Diamond Fields Advertiser 10.7.1931.

${ }^{29}$ Vgl. z.B. Plaatje, Sol T. (1929): The Man who rose from the Dead. Strange Origins of Bantu Names and Place Names; Cape Argus 26.10.1929: 12.

${ }_{30} \mathrm{Zu}$ ausführlichen Darstellungen der schwarzafrikanischen Presse in Südafrika vgl. St. Leger 1975, Johnson 1991, Switzer 1996.

31 Wie Masilela (1996) und Maingard (2003) nachgewiesen haben, entstand die eigentliche nichteuropäisch/afrikanische Filmkultur in Südafrika zu einem wesentlich späteren Zeitpunkt. Auf eine gesonderte Betrachtung kann daher in dieser Studie verzichtet werden.
} 
Province Herold (Port Elizabeth), Evening Post (Port Elizabeth) und als auflagenstärkstes Blatt Südafrikas die Sonntagszeitung Sunday Times (Johannesburg). Die Berichterstattung der genannten Zeitungen profitierte zudem von einer gemeinsamen Nutzung des Nachrichtenmaterials, kultureller Beiträge, Berichten von Auslandskorrespondenten und der Produktionskapazitäten (Ainslee 1966: 45).

Die mächtige Argus-Gruppe vereinte die Tageszeitungen Cape Argus (Kapstadt), The Star (Johannesburg), Natal Advertiser (Durban), Pretoria News (Pretoria), The Friend (Bloemfontein), Natal Witness (Pietermaritzburg) und den Diamond Fields Advertiser (Kimberley). Ebenso wie bei der Gruppe der südafrikanischen Morgenzeitungen praktizierte die Argus-Gruppe eine inhaltliche und technische Zusammenarbeit. Teilweise erhielten die zur Argus-Gruppe gehörenden Zeitungen Nachrichtenmaterial, Korrespondentenberichte und einen Teil der Leitartikel von der Arguspresse fertig geliefert, welche dann redaktionell unverändert abgedruckt wurden (Zapp 1938: 33). Minenkonzerne und Banken aus dem Finanzzentrum Johannesburg hielten zudem Anteile beider Zeitungsgruppen (Ainsley 1966: 74f.), was sich oft in wohlwollenden Kommentaren zur Politik der Bergbaukammer (,Chamber of Mines') niederschlug (Sacks 1937: 23).

Die Versorgung der englischsprachigen Presse Südafrikas mit internationalen Nachrichten und Korrespondentenberichten lag in der Hand der Nachrichtenagentur Reuters Südafrika (Reuters South African Press Agency Ltd.). Beide Zeitungsgruppen verfügten neben Reuters London über Anteile an Reuters Südafrika. Bis auf eine einzige afrikaanse Tageszeitung, Die Vaderland (Pretoria), versorgte die Nachrichtenagentur alle südafrikanischen Zeitungen mit Nachrichten aus Europa und lokalen Nachrichten aus der Union. Der Dienst von Reuters Südafrika verfügte über ein fast absolutes Monopol und duldete kein zweites Nachrichtenbüro in seiner Einflusssphäre (Zapp 1938: 70). Nicht zuletzt durch diese Konstellation ähnelte die englische Presse Südafrikas inhaltlich stark ihren britischen Vorbildern, was (wie später noch gezeigt werden wird) auch einen gewissen Einfluss auf die Filmkritik ausübte.

In Bezug auf die Filmberichterstattung konnten zwischen den beiden Gruppen keine gravierenden Unterschiede festgestellt werden. Generell ist zu bemerken, dass die größeren, umfangreicheren Zeitungen filmbezogenen Themen in der Berichterstattung mehr Platz einräumten. Mehrere konkurrierende Zeitungen in einer Stadt belebten in der Regel auch die Filmpublizistik, was z.B. in der Provinz Natal und dort besonders in Durban/Pietermaritzburg (Natal Advertiser vs. Natal Mercury vs. Natal Witness) mit einer allumfas- 
senden und regelmäßigen Berichterstattung einherging (Eckardt 2000); gleiches trifft für Kapstadt (Cape Times vs. Cape Argus) und Johannesburg (Rand Daily Mail vs. The Star vs. Sunday Times) zu. In kleineren Tageszeitungen (z.B. Daily Dispatch oder Diamond Fields Advertiser) war die Filmpublizistik oft kaum vom Agenturjournalismus zu unterscheiden, gelegentlich wurden Kommentare aus den führenden Blättern der südafrikanischen Macht- und Wirtschaftszentren (Kapstadt, Johannesburg, Durban) einfach übernommen.

\subsubsection{Die afrikaanse Presse}

Ganz im Gegensatz zu den genannten Zeitungsgruppen stand die afrikaanse Presse. Durch ihren Ursprung aus und ihrem Wirken für die afrikaanse Sprachgemeinschaft versorgte sie ihre Leser vorrangig mit innenpolitischen Nachrichten und stand infolge des Burenkrieges (1899-1902) der britischen Kolonialpolitik ablehnend gegenüber. Während des Sprachstreites (,taalstryd') Anfang der 1920er Jahre spielten die afrikaansen Zeitungen eine entscheidende Rolle für die Anerkennung und Durchsetzung von Afrikaans als gleichberechtigte Amtssprache (Steyn 1986). In ihrer politischen Ausrichtung klar als Parteiorgane erkennbar, vertrat die afrikaanse Presse unumwunden die Interessen der Nationalen Partei (NP) (Beuckes 1946). Auch personell zeigte sich bei der afrikaansen Presse die enge Verbundenheit mit der Politik; erster Chefredakteur von Die Burger (Kapstadt) war z.B. der spätere NP-Premierminister D.F. Malan, andere Blätter hatten NP-Minister in ihren Herausgebergremien.

Innerhalb der afrikaansen Presse lassen sich die bedeutenderen Zeitungen in drei Gruppen untergliedern: Die unabhängigen Zeitungen (z.B. Die Volkstem [Pretoria], Die Afrikaner [Pietermaritzburg]), die Afrikaanse Pers Bpk. (Afrikaanse Presse) mit ihrer einzigen Zeitung Die Vaderland (Johannesburg) und die bedeutendste afrikaanse Zeitungsgruppe Nasionale Pers Bpk. (Nationale Presse) mit Die Burger, ihrer assozierten Wochenzeitschrift Die Huisgenoot (beide Kapstadt), sowie Die Volksblad (Bloemfontein). Während Die Volkstem für Auslandsnachrichten direkt mit der Argus-Gruppe kooperierte, bezogen die Zeitungen der Nationalen Presse Nachrichten von Reuters Südafrika und tauschten miteinander Inhalte aus. Einzig Die Vaderland hatte eine Reuters-unabhängige Nachrichtenversorgung und verfügte über ein Abonnement der deutschen Presseagentur Trans-Ocean (Zapp 1937: 64, ferner Klee 1991). 
Neben der differierenden politischen Ausrichtung der englischen bzw. afrikaansen Zeitungen unterschieden sich jene auch deutlich in Umfang und Aufmachung. Die kommerziell erfolgreichen englischen Blätter waren druckund gestaltungstechnisch auf dem neuesten Stand und publizierten neben den umfangreichen Tagesausgaben auch seitenstarke Wochenendeditionen. Ihre afrikaansen Gegenspieler erschienen zum Teil nur zwei mal pro Woche. Auf nur einen Bogen Zeitungspapier mit wenigen Seiten druckte man mit veralteten Drucktypen Texte nebst einem Minimum an Abbildungen. Die ständigen finanziellen Schwierigkeiten versuchte man mit Spendenkampagnen zu kompensieren (Breyne 1925: 4). Bei manchen Zeitungen half jedoch auch dies nicht und so verlor die afrikaanse Gemeinschaft in der englisch dominierten Provinz Natal 1932 ihr einziges Blatt, als Die Afrikaner eingestellt werden musste (Picton 1969: 72).

Der Vertrieb aller Presseerzeugnisse lag in den Händen der Central News Agency (CNA), welcher eine Monopolstellung zukam. Aufgrund der Eigentümer- und Interessenstruktur der CNA (u.a. Argus-Gruppe und Gruppe der Morgenzeitungen) konnte die englischsprachige Presse für ihren Vertrieb Vorzugskonditionen erwirken, während die afrikaanse Presse strukturell benachteiligt wurde (Potter 1975: 51).

Auch innerhalb der in drei Gruppen untergliederten afrikaansen Presse lassen sich keine strukturellen Unterschiede in Bezug auf die Filmberichterstattung feststellen. Auch für diese galt, je umfangreicher das Blatt, desto ausführlicher der Filmteil. Dadurch erklärt sich auch generell die quantitative Dominanz der englischsprachigen Blätter, der die afrikaanse Presse durch ihre beschränkten finanziellen Möglichkeiten nicht viel entgegensetzen konnte. Qualitativ stellt die Kapstädter Zeitung Die Burger eine Ausnahme dar. Durch die direkte Konkurrenz zu den großen englischsprachigen Zeitungen hatte sich dort eine anspruchsvollere Filmpublizistik etabliert, die nicht zuletzt durch die Persönlichkeit ihres ersten Pressefotographen und ausgewiesenen Filmkenners Hans Rompel getragen wurde (Pretorius 1947, Rompel 1965 und Eckardt 2005: 19ff). Mangels vergleichbarer Persönlichkeiten blieb diese Entwicklung trotz ähnlicher regionaler Zeitungskonkurrenz in Städten wie Bloemfontein (Die Volksblad vs. The Friend) oder Pietermaritzburg (Die Afrikaner vs. Natal Witness) aus. 


\subsection{Zeitschriften und andere Druckmedien}

Als einzige anspruchsvolle südafrikanische Zeitschrift kann die afrikaanse Wochenzeitschrift Die Huisgenoot angesehen werden (Joubert 1983). Als ,Universität des Volkes' war die Zeitschrift äußerst populär und verfügte durch ihre landesweite Verbreitung unter den vielköpfigen Afrikaanerfamilien einen weit über die aktuelle Auflage hinausgehenden Leserkreis (du Plessis 1967). Die mit der Tageszeitung The Friend (Bloemfontein) assoziierte und eigentlich auf Motorsport festgelegte englische Zeitschrift The Outspan veröffentlichte vereinzelt allgemein-populäre Filmbetrachtungen (z.B. Arliss 1928, Anderson 1930, Prechner 1933 oder Collins 1933).

In Südafrika existierte mit Stage, Cinema and Listener (1915-28) ${ }^{32}$ nur ein einziges Blatt für die gesamte Unterhaltungsbranche. Herausgegeben von der Schlesinger-Organisation, bis 1928 uneingeschränkter Marktführer im Unterhaltungssektor, verstand es sich als verlängerter Arm des Filmvertriebs und informierte sowohl die Kinobetreiber als auch die Zuschauer über Neuerscheinungen und Filmklatsch. Leider stellte diese Zeitschrift ihr Erscheinen mit Beginn des ausgewählten Untersuchungszeitraums ein. Im Gegensatz zu Europa existierte keine Vielzahl an branchenspezifischen Fachblättern wie das britische Bioscope oder die deutsche Lichtbildbühne in denen ausführlich über Film und Kino berichtet wurde. ${ }^{33}$ Diese Aufgabe musste in eingeschränkter Form von den südafrikanischen Tageszeitungen übernommen werden.

Eine gewisse Ausnahmestellung nahmen die beiden großen konfessionellen Wochenblätter ein. De Kerkbode (Kapstadt) vertrat die Interessen der unter den Afrikaanern dominierenden Niederdeutschen Reformierten Kirche (,Nederduitse Gereformeerde Kerk -NG Kerk'), das englischsprachige Pendant The Southern Cross wurde vom katholischen Bischof in Kapstadt herausgegeben. Lediglich bei der Aufführung von Filmen mit religiösem Inhalt (z.B. „From Manger to Cross“, 1913, R: S. Olcott oder LUTHER 1929, R: H. Kyser) äußerten sich beide Blätter zu aktuellen Filmen, ansonsten spielten sie in Bezug auf die Filmberichterstattung keine Rolle. ${ }^{34}$ Das Gleiche galt für die deutschsprachige Presse (z.B. Der Deutsch-Afrikaner, Pretoria), die nur sporadisch über jene Filme berichtete, die in den deutschen Klubs südafrika-

\footnotetext{
${ }^{32}$ Alternativer Titel: South African Pictorial, Stage and Cinema.

${ }^{33}$ Gerade in Bezug auf den politisch-zeithistorischen Kontext ist vielfach festgestellt worden, dass man „Niemals wieder, weder zuvor noch danach, (...) in Deutschland einen Film so farbenreich beurteilt (hat) wie in der Presse der Weimarer Republik" (Haacke 1970: 300).

${ }^{34} \mathrm{Vgl}$. The Martin Luther Film; The Southern Cross 6.11.29: 3-4; Die Roomse Kerk; De Kerkbode 20.11.29: 869-870.
} 
nischer Großstädte gezeigt wurden. ${ }^{35}$ Als eigenständige Filmpublizistik jenseits der Lokalnachrichten kann man diese Beiträge allerdings nicht ansehen.

Selbst wenn es innerhalb der beiden Sprachgruppen Zeitungen mit unterschiedlichen politischen Präferenzen gab, so lässt sich doch die englische Presse Südafrikas als grundsätzlich den pro-britischen Parteien (South African Party, Dominion Party) und dem Empire zugeneigt, die afrikaanse Presse als überwiegend national (Nationale Partei) eingestellt charakterisieren. Dementsprechend fiel auch die Unterstützung der Zeitungen in Bezug auf die jeweilige Innen- oder Außenpolitik aus (Kriel 1930).

\subsection{Filmpublizistik und Filmkritik}

Das Fehlen einschlägiger Fach- und Branchenblätter, die enge Verbindung zur britischen Presse und die eingeschränkten Möglichkeiten der afrikaansen Blätter bremsten die Entwicklung einer eigenständigen südafrikanischen Filmpublizistik. Nur gelegentlich gelang es z.B. den Kolumnisten der Branchenzeitschrift Stage, Cinema and Listener im ersten Jahrzehnt des 20. Jahrhunderts dem Medium Film angemessen zu berichten. Mit dem Niedergang der südafrikanischen Filmproduktion zu Anfang der 1920er Jahre war es damit allerdings schnell vorüber (Tomaselli 1980a: I). Es ist daher kein Zufall, dass Thelma Gutsches umfangreiche Grundlagenstudie zur südafrikanischen Kino- und Filmgeschichte das Thema Filmkritik auf nur knapp anderthalb Seiten unter ,Sonstiges' (,Miscellaneous') zusammenfasst (Gutsche 1972: 383f.). Nach Gutsche bestand die zeitgenössische Filmkritik zum großen Teil aus flüchtigen und unkritischen Filmbesprechungen, deren kommerzielle Liaison mit der Kinowerbung nicht zu übersehen war. Am ehesten erfuhren Filme in den Kinos unabhängiger Betreiber eine ausgewogene Bewertung. Um gleichzeitig die Nachfrage der Leserschaft nach möglichst unparteiischen Filmrezensionen mit dem Verlangen der Werbeinserenten nach positiv publikumswirksamen Besprechungen in Einklang zu bringen, entwickelten die südafrikanischen Journalisten eine sogenannte ,HintertürMethode' (,back-door method'). Die wahre Qualität eines Films erschloss sich aus diesen Filmbesprechungen nur dem eingeweihten Leser. So wurden in den Rezensionen die Filme generell als ,sehenswert' bezeichnet. Im Miteinander von als ,ausgezeichnet' oder ,sensationell' bezeichneten Filmen stand der werbewirksame Euphemismus, sehenswert' jedoch als Synonym

${ }^{35}$ Vgl. bspw. Deutsche Filme in Johannesburg; Der Deutsch-Afrikaner (Abk. DDA) 10.10.29: 4; Der Lutherfilm in Pretoria und Johannesburg; DDA 17.10.29: 3. 
für ,mittelmäßig'. Gemessen am internationalen Maßstab war diese Art der Filmkritik durchaus nicht unüblich, da

„...die Wirkung auf den Verfasser, seine eigentliche Einschätzung gar nicht als Klartext vorhanden, sondern aufgrund wirtschaftlicher oder politischer Interessen und Rücksichtnahmen hinter Umschreibungen verborgen (ist), die auf der manifesten Ebene sogar gegenteilig formuliert sein können" (Korte 1998: 142).

Weitere Ausführungen zur ,Hintertür-Methode' finden sich bei Gutsche nicht, so dass keine Aussage darüber möglich ist, ob diese Methode bei allen Zeitungen üblich war oder ein Unterschied zwischen der englischen und der afrikaansen Presse bestand.

Die Forderung nach weniger kritischen Rezensionen durch die Inserateabteilungen der Zeitungen hatte zur Folge, dass das Schreiben von Filmkritiken im redaktionellen Alltag dem gerade verfügbaren Mitarbeiter zufiel. Die damit betrauten Sport- oder Gerichtsreporter hielten es oft nicht einmal für nötig, die Filmvorführungen überhaupt zu besuchen. So kam es vor, dass die Besprechung in der Morgenzeitung Rand Daily Mail einen Film als ,leichte Komödie' auswies und Derselbe Film in der Abendzeitung The Star als ,nachdenklichmachend' charakterisiert wurde (Gutsche 1940: 17). Kritische Besprechungen oder Leserbriefe wurden nur selten publiziert, lediglich die Einführung des Tonfilms entfachte eine Diskussion über die Zukunft von Film und Kino. So veranstaltete die Cape Times beispielsweise 1928 einen Essaywettbewerb zur Zukunft des Films, der die Anzahl filmbezogener Zuschriften und Leserbriefveröffentlichungen ansteigen ließ. Die diesen Wettbewerb flankierenden Artikel, sowie die quantitativ und qualitativ höchst unterschiedlichen Einsendungen erschweren allerdings einen Vergleich mit der alltäglichen Filmberichterstattung.

Darüber hinaus waren in den 1920er und 1930er Jahren Filmbesprechungen noch eine weitgehend anonyme journalistische Praxis, Filmkritiken wurden in der Regel nicht durch den Verfasser autorisiert. Die einzigen Filmkritiker die Thelma Gutsche erwähnt sind C.H. Parsons („Baton“) vom Natal Advertiser, R.A. Nelson von The Star und Olga Racster („Treble Violl“) von der Sunday Times (Gutsche 1972: 383f.). Der einflussreichste Filmkritiker der afrikaansen Presse, Hans Rompel von Die Burger, blieb hingegen unerwähnt. Aus den dargelegten Umständen lässt sich auch erschließen, welchen Einfluss die Werbeabteilungen der Filmvertriebe auf einen großen Teil der damaligen Filmpublizistik hatten. Die Zeitungen und deren Rezensenten waren stets der Gefahr ausgesetzt, durch missliebige Filmbesprechungen 
ihrerseits einen Entzug von Inseraten zu riskieren oder von den Interessenverbänden der Filmwirtschaft in ihrer Glaubwürdigkeit als Kritiker diskreditiert zu werden (Korte 1998: 170).

$\mathrm{Ob}$ die spezifischen Entwicklungsbedingungen und die politischen Lagertendenzen innerhalb der südafrikanischen Presse Einfluss auf die Entwicklung der Filmkritik genommen haben, wurde exemplarisch anhand zweier ausgewählter Kapstädter Tageszeitungen untersucht (Eckardt 2005: 18-27). Das Ergebnis dieser Detailbetrachtung gibt die nachstehende Tabelle wieder (Eckardt 2005: 27, Tabelle 2.1).

Tab. 10: Publizistische Eigenschaften ausgewählter Kapstädter Tageszeitungen

\begin{tabular}{|l|l|l|}
\hline \multicolumn{1}{|c|}{ Charakteristika } & \multicolumn{1}{|c|}{ Cape Times } & \multicolumn{1}{c|}{ Die Burger } \\
\hline Sprache & Englisch & Afrikaans \\
\hline Zeitungsgruppe & $\begin{array}{l}\text { South African Morning Newspa- } \\
\text { pers Ltd. }\end{array}$ & Nasionale Pers Bpk. \\
\hline Allgemeine Orientierung & liberal, pro-Britisch, & national, unabhängig \\
\hline Hauptinteresse neben Nachrichten & $\begin{array}{l}\text { Wirtschaft, Außenpolitik des } \\
\text { British Empire }\end{array}$ & $\begin{array}{l}\text { Innenpolitik, Sprachfrage, } \\
\text { kulturelle Eigenständigkeit }\end{array}$ \\
\hline $\begin{array}{l}\text { Allgemeine Tendenz der Filmbe- } \\
\text { richterstattung }\end{array}$ & $\begin{array}{l}\text { umfassend, informierend, } \\
\text { unterhaltend }\end{array}$ & selektiv, erzieherisch, anleitend \\
\hline $\begin{array}{l}\text { Ausrichtung der Filmkritik neben } \\
\text { der Inhaltswiedergabe }\end{array}$ & $\begin{array}{l}\text { deskriptiv, formal, funktionalis- } \\
\text { tisch }\end{array}$ & $\begin{array}{l}\text { normativ, ideologisch, sendungs- } \\
\text { bewusst }\end{array}$ \\
\hline
\end{tabular}

Oben stehende Tabelle verdeutlicht abermals die Polarität zwischen der englischen und der afrikaansen Presse. Die vor allem kommerzielle Ausrichtung der Cape Times wird auch in Bezug auf die Filmkritik, verstanden als Verkaufsförderungsinstrument, deutlich. Die Burger hingegen, als politisches Sprachrohr der Afrikaaner-dominierten National Party fungierend, ließ zuweilen erzieherische Tendenzen und einen mehr oder weniger deutlich vernehmbaren Standpunkt in ihren Filmkritiken erkennen. Zwar reagierten beide Tageszeitungen mit einer unterschiedlichen Ausrichtung ihrer Filmpublizistik auf die geänderte Marktsituation 1928 (Brechung des African-Theatres Monopols, höheres Filmaufkommen, Tonfilme), blieben jedoch ihrer Grundausrichtung treu. Die Cape Times bemühte sich mittels einer quantitativen Strategie möglichst alle Filme mit kürzeren inhaltlichen Besprechungen abzudecken. Die Burger beschränkte sich in einer qualitativen Strategie auf ausgewählte Filme, die mit längeren bewertenden Kommentaren versehen wurden.

Im Laufe der Untersuchung weiterer Periodika der einzelnen Zeitungsgruppen hat sich zudem gezeigt, dass die vorgenommene Charakterisierung 
für den größten Teil der südafrikanischen Presse zutraf und aus diesem Grund als hinreichend repräsentativ angesehen wird.

Im Gegensatz zu überregionalen deutschen Tageszeitungen der Weimarer Republik war die Filmpublizistik in der Cape Times bzw. in Die Burger nicht in den täglichen Kulturteil der Zeitung eingebettet, sondern erfolgte meist nur an ausgewählten Wochentagen auf einer Unterhaltungsseite bzw. in Unterhaltungskolummnen. Diese Praxis lässt die Vermutung zu, dass der Übergang der Filmberichterstattung in Südafrika vom Lokalnachrichtenteil in das Feuilleton zu diesem Zeitpunkt, anders als in Deutschland, noch nicht gänzlich vollzogen war. Der Anspruch des europäischen Feuilletons, alltagskulturelle, künstlerische und wissenschaftliche Vermittlungsaufgaben wahrzunehmen und ein öffentliches Nachdenken über ästhetische oder gesellschaftspolitische Innovationen anzuregen (Todorow 1996: 4), musste in der südafrikanischen Presse zwangsläufig andere Formen annehmen. Die Filmpublizistik im Hin und Her zwischen Nachrichtenteil und feuilletonnahen Darstellungsformen zielte sicher auch auf eine „effektive Vermittlung der gesellschaftlichen Alltagspraxis (...), mittels der aber auch komplexe Anliegen der Gesellschaft wie Kontinuitäten und Wandlungen, Stile, Moden, Erfahrungen und Widersprüche, Macht und Abhängigkeiten, soziale Rollen, Selbstverständigung und Ideologien erörtert werden" (ebd.) konnten. Ein solches Bemühen stieß jedoch im Rahmen des Nachrichtenjournalismus an seine Grenzen, da dort Neuigkeiten dramatisiert werden müssen und der sozioökonomische Alltag als Kontext keinen Neuigkeitswert besitzt (Tomaselli 1989: 99). Eine übergeordnete und selbstkritische Feuilletonkonzeption hatte daher im Gegensatz zu deutschen überregionalen Tageszeitungen kaum Entwicklungschancen (Todorow 1988 bzw. 1996).

Aus den genannten Gründen und durch das Fehlen einer eigenen Filmindustrie, sowie eines branchen- und leserspezifischen Zeitschriftenmarktes, kann ein direkter Vergleich mit Konzepten der Filmkritik zu Zeiten der Weimarer Republik nicht ohne Weiteres erfolgen (Dunger 1978). Mit der Tageszeitung als Hauptmedium der Filmpublizistik entfiel beispielsweise eine interessengruppenspezifische bzw. selbstreferenzielle Unterteilung des Schreibens über Filmkritik, nach welcher sich z.B. die Filmkritik der Weimarer Republik entweder für die Belange der Filmbranche, der Presse selbst oder dem Publikum verpflichtet sah (ebd.: 129).

In Bezug auf die Medienrezeption von Spielfilmen, untersucht anhand der Filmbesprechungen in Tageszeitungen, muss die Spezifik der südafrikanischen Filmpublizistik nicht zwangsläufig als ein Nachteil angesehen werden. Der Mangel an ausgewiesenen Filmpublizisten bei Tageszeitungen und die 
trotz allem permanent erfolgte Berichterstattung stützt die These des ,Journalisten als Teil des Publikums'. Ebenso wie der Durchschnittszuschauer rezipiert auch der Journalist einen Film und versucht seine Wahrnehmung sinnhaft-reflexiv zu strukturieren. Die zeitnah nach der Filmvorführung entstandenen Texte geben somit eher eine Publikumsrezeption wieder als intellektuell reflektierte, mit zeitlichem Abstand verfasste Filmkritiken. Die Dimensionen professioneller Filmkritik finden sich in der Tagespresse daher nur mittelbar in vergleichenden Formulierungen wieder, in denen der Rezensent das eben Gesehene mit Erfahrungen der Vergangenheit vergleicht und gegebenenfalls eine Wertung vornimmt.

Im vorgenannten Spannungsfeld bewegen sich die Erkenntnisinteressen und -möglichkeiten dieser Studie. Zusammenfassend gibt Tabelle 11 einen Überblick der südafrikanischen Zeitungslandschaft wieder. Die in dieser Studie ausgewerteten Zeitungen sind jene, für die in der nachfolgenden Tabelle eine Abkürzung mit angegeben ist. Ausgewählt wurden in erster Linie Zeitungen, die für ihr geographisches Verbreitungsgebiet maßgeblich waren, um eine möglichst hohe Repräsentativität der Materialauswahl zu sichern. Die Nichtberücksichtigung einiger Zeitungen resultierte entweder aus dem festgestellten Fehlen einer kontinuierlichen Filmberichterstattung, der Existenz anderer dominierender Zeitungen im Verbreitungsgebiet oder schlicht aus der nicht vorhandenen physischen Verfügbarkeit.

Die Vernachlässigung der Presse in Pretoria - immerhin Regierungssitz der Südafrikanischen Union - mag etwas überraschen. Dieser Umstand wird allerdings durch die Einschätzung relativiert, dass Pretoria als die einzige afrikanische Hauptstadt ohne eine Tageszeitung von politischer Bedeutung angesehen wurde (Zapp 1938: 25). Die Gründe dafür liegen zweifellos in der übermächtigen Stellung der Presse des bevölkerungsreichen Wirtschaftszentrums Johannesburg, in welcher die dortigen Minen- und Finanzkonzerne ihren Einfluss auf Politik und Berichterstattung geltend machten. 
Tab. 11: Die südafrikanische Zeitungsgruppen in den 1920er und 1930er Jahren

\begin{tabular}{|c|c|c|c|}
\hline Name (Gründungsjahr), Periodizität & Abk. & Ort, Provinz & Auflage ${ }^{36}$ \\
\hline \multicolumn{4}{|l|}{$\begin{array}{l}\text { Gruppe der südafrikanischen Morgenzeitun- } \\
\text { gen und assozierte Zeitungen (The South } \\
\text { African Morning Newspapers, Ltd.) }\end{array}$} \\
\hline Cape Times (1876), t & CT & Kapstadt, West-Kap & 25.- 30.000 \\
\hline Daily Dispatch (1872), t & & East London, Ost-Kap & \\
\hline Eastern Province Herold (1845), t & EPH & Port Elizabeth, Ost-Kap & \\
\hline Evening Post (1850), $t$ & & Port Elizabeth, Ost-Kap & \\
\hline Natal Mercury (1852), t & NM & Durban, Natal & 22.- 25.000 \\
\hline Rand Daily Mail (1902), t & RDM & Johannesburg, Transvaal & 32.- 40.000 \\
\hline Sunday Times (1906), w & ST & Johannesburg, Transvaal & 90.000 \\
\hline \multicolumn{4}{|l|}{$\begin{array}{l}\text { Argus-Gruppe mit Kooperationspartnern } \\
\text { (Argus Printing \& Publishing Co. Ltd.) }\end{array}$} \\
\hline Cape Argus (1857), t & CA & Kapstadt, West-Kap & 25.- 32.000 \\
\hline Diamond Fields Advertiser (1875), t & DFA & Kimberly, Nord-Kap & \\
\hline The Friend (1850), t & TF & Bloemfontein, OFS & \\
\hline Natal Advertiser (1887), t & NA & Durban, Natal & \\
\hline Natal Witness (1846), t & NW & Pietermaritzburg, Natal & 14.000 \\
\hline Pretoria News (1876/1897), $\mathrm{t}^{37}$ & & Pretoria, Transvaal & \\
\hline The Star (1886), t & TS & Johannesburg, Transvaal & 45.- 50.000 \\
\hline \multicolumn{4}{|l|}{ Nationale Presse (Nasionale Pers, Bpk.) } \\
\hline Die Burger (1914), t & DB & Kapstadt, West-Kap & 10.- 20.000 \\
\hline Die Volksblad (1912/14), t & VB & Bloemfontein, OFS & 12.000 \\
\hline Die Huisgenoot (1914), w & $\mathrm{HUI}$ & Kapstadt, West-Kap & \\
\hline \multicolumn{4}{|l|}{ Afrikaanse Presse (Afrikaanse Pers Bpk.) } \\
\hline Ons/Die Vaderland (1914), 2x pro Woche ${ }^{38}$ & & Rand-Region, Transvaal & 10.000 \\
\hline \multicolumn{4}{|l|}{ Unabhängige Zeitungen } \\
\hline Die Volkstem (1873), 2x pro Woche & & Pretoria, Transvaal & \\
\hline Die Afrikaner (1886), 2x pro Woche & DA & Pietermaritzburg, Natal & \\
\hline
\end{tabular}

${ }^{36}$ Die differierenden Angaben stammen aus Bömer 1934: 123 und Lawson 1936: 21.

${ }^{37} \mathrm{Vgl}$. Behrens 1955: 25.

${ }^{38}$ Die Vaderland erschien nur im Zeitraum 1929-1930 als Tageszeitung (Behrens 1955: 32f.). 


\section{Der Filmexport nach Südafrika in den Jahren 1928 bis} 1933

Ausgehend von der Überlegung, eine Außenperspektive auf das Weimarer Kino als Rezeptions- und Wirkungsanalyse am Beispiel Südafrikas für einen bestimmten historischen Zeitabschnitt in den Mittelpunkt des Vorhabens zu stellen, schließt eine solche Untersuchung neben den technischen, ästhetischen, psychologischen und soziologischen Aspekten die Betrachtung ökonomischer Aspekte zwingend mit ein (Mikos 1993: 157).

Da die Produktionsbedingungen oder Filmförderungsmaßnahmen deutscherseits allenfalls nur einen mittelbaren Einfluss auf den südafrikanischen Filmmarkt hatten, bietet es sich an, stellvertretend für die Entwicklung der deutschen Filmindustrie deren Exportbemühungen genauer zu untersuchen. Bislang existieren neben einer Vielzahl ästhetischer oder soziologischer Abhandlungen zum Spielfilm der Weimarer Republik nur wenige ökonomische Analysen. Die exemplarisch für die Universum Film Aktiengesellschaft (UFA), Deutschlands bedeutendsten Filmproduzenten, in kulturgeschichtlicher Perspektive angelegte Studie von Kreimeier, streift ökonomische Belange lediglich am Rande und konzentriert sich auf die Hauptmärkte der UFA in Europa und den USA (Kreimeier 1992: 146-157). Die strukturelle Untersuchung von Mühl-Benninghaus zur Entwicklung der Massenkommunikationsmittel Film, Presse, Hörfunk und Tonträger in der Weimarer Republik geht zwar dezidiert auf den Zusammenhang von Ökonomie und Kultur ein, detaillierte Aussagen zum Filmexport finden sich dennoch kaum (Mühl-Benninghaus 1987/1: 139163 und 1987/2: 7-8), Angaben zum Filmexport nach Südafrika überhaupt nicht; das gleiche gilt für ältere Abhandlungen wie die von Andersen (1929: 69-72) und Rathgeb (1935: 113-129).

Es darf an dieser Stelle nicht unerwähnt bleiben, dass es sich bei der Gesamtheit des deutschen Filmschaffens der Weimarer Jahre nicht etwa nur um die wert- und mengenmäßig geringe Produktion einer experimentierfreudigen Filmwerkstatt, sondern um eine in der Stummfilmperiode hochproduktiven Traumfabrik von Weltgeltung handelte, über deren volkswirtschaftliche Dimension nicht ohne weiteres hinweggesehen werden kann. Das Kinogeschäft alleine spülte jährlich etwa 40 Millionen Reichsmark an Lustbarkeitssteuer in die kommunalen Kassen (Rathgeb 1935: 115). Mit zeitweise rund 47.600 unmittelbar im Filmgeschäft tätigen Personen (Wolffsohn 1930: 406) und einem Ausstoss von 200 bis 500 Produktionen pro Jahr avancierte die Filmindustrie zum drittgrößten Industriezweig Deutschlands und wurde nur von Hollywood übertroffen (Kaes 1993: 46). 
Die medienhistorische Bedeutung Südafrikas, u.a. als Filmexportmarkt, ist bisher ebenso kaum erkannt worden. Immerhin existierten in Südafrika allein mehr Radioempfänger als in allen anderen Staaten Afrikas (Vaessen 1938: 55). Desweiteren wurden ca. 65 Prozent aller in den Jahren 1925-1934 nach Afrika exportierten US-Filme nach Südafrika geliefert, was 1929 der Exportregion ,Britisch Südafrika' Platz 15 in der Reihenfolge der USamerikanischen Filmexportmärkte einbrachte (Wolffsohn 1930: 583). ${ }^{39}$ Der Wertumfang betrug für ganz Afrika pro Jahr durchschnittlich etwa 5,9 Millionen US\$ (ebd.).

Für den deutschen Filmexport nach Südafrika könnte von Belang gewesen sein, dass im Zuge der Normalisierung der politischen Beziehungen mit Großbritannien und seinen Besitzungen 1928/1929 ein Handelsabkommen zwischen dem Deutschen Reich und Südafrika zustandekam, ${ }^{40}$ in dem festgelegt wurde, dass für deutsche Waren keine höheren Zölle erhoben werden sollten als für Waren aus anderen Ländern. Dafür gewährte die deutsche Seite den Südafrikanern Meistbegünstigung (Gerich 1937: 101).

Vergegenwärtigt man sich die politische und wirtschaftliche Situation der Weimarer Republik von 1918 bis 1933 lässt sich feststellen, dass mehrfach Phasen der politisch-wirtschaftlichen Unsicherheit auf Phasen relativer Stabilität folgten, was zu gesamtwirtschaftlichen Schwankungen führte. Diese wiederum beeinflusste die Entwicklung der deutschen Filmindustrie und somit auch den Filmexport. Für eine ausgewogene Betrachtung des Filmexports ist es daher vertretbar, die Phase der durch die Hyperinflation der Jahre 1922/1923 verstärkten Ausfuhrbemühungen (ausgelöst durch die gesteigerte Produktion infolge gesunkener Personalkosten und Ertragsunsicherheit auf dem Inlandsmarkt) auszuklammern. Stattdessen bietet sich mit der Annahme des Dawes-Planes und seinen die Wirtschaft belebenden Millionenkrediten die nachfolgende Phase der wirtschaftlichen Normalisierung ab 1925 als Beginn für eine eingehendere Untersuchung an (Murray 1982: 28). Die Betrachtung der Entwicklung der folgenden zehn Jahre bis 1935 ist u.a. darauf angelegt, die Auswahl des Untersuchungszeitraumes 1928-1933 zu kontextualisieren.

\footnotetext{
${ }^{39}$ Aufgrund der schlechten Vergleichbarkeit der in Südafrikanischen Pfund und US-Dollar geführten Statistiken wurde für die Jahre 1925 bis 1934 die ein- bzw. ausgeführte Filmmenge (gemessen in britischen Fuß) als Parameter herangezogen. Für die Jahre 1925 bis 1929 wurden die Mengen der Positivund Negativfilme zusammengerechnet, für die Jahre 1930 bis 1934 wurden die getrennt aufgelisteten Werte der Positiv- und Negativfilme, unterschieden in Stumm- und Tonfilme, addiert. Die Angaben wurden aus den Annual Statements der Jahre 1925 bis 1935 und aus Thompson 1985: 218-219 entnommen.

${ }^{40} \mathrm{Vgl}$. German-Union Treaty of Commerce and Navigation, in: Official Yearbook 13(1930/31), 516-518.
} 
Tab. 12: Gesamte Filmausfuhr des Deutschen Reiches 1928 - 1933 (in Mio RM)

\begin{tabular}{|c|c|c|c|c|c|c|}
\hline Jahr & 1928 & 1929 & 1930 & 1931 & 1932 & 1933 \\
\hline Betrag & 39,3 & 52 & 38 & 35,9 & 30,3 & 28 \\
\hline
\end{tabular}

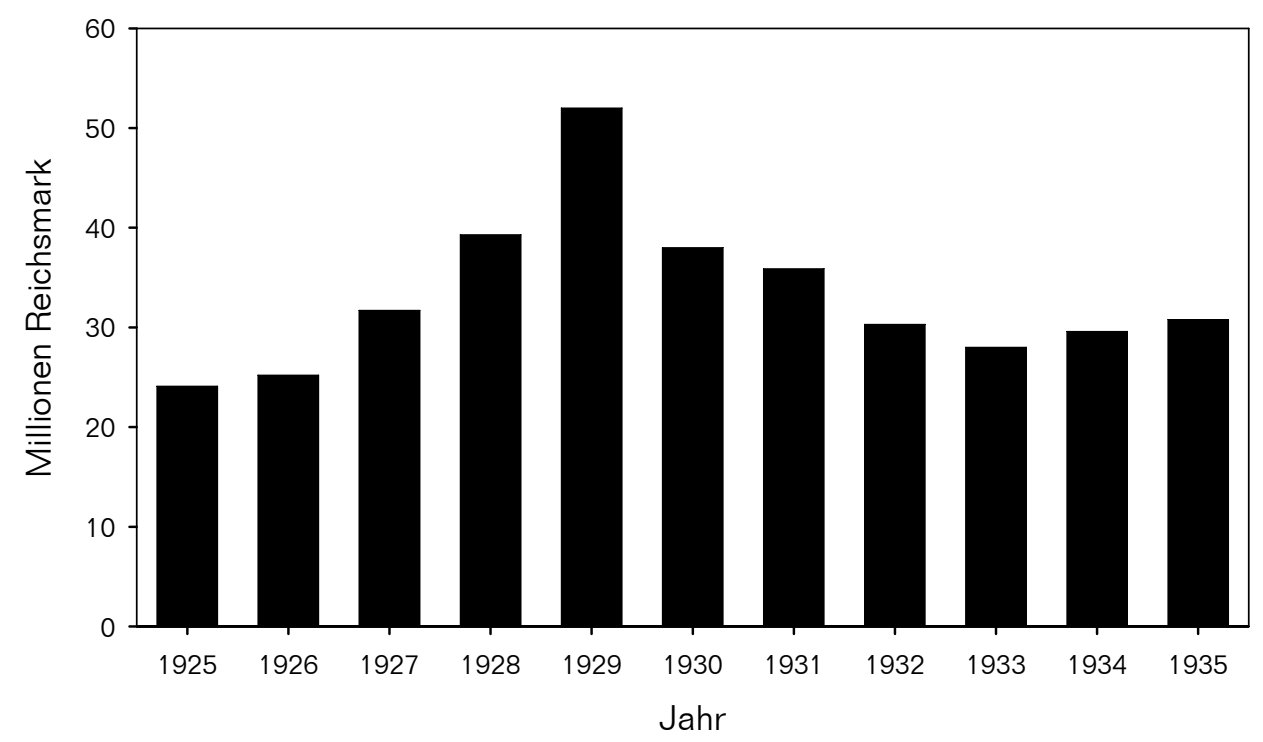

Abb. 4: Deutsche Filmausfuhr $1925-1935$

Aus Abbildung 4 und den Angaben in Tabelle 12 wird deutlich, in welchem Wertumfang sich der Filmexport des Deutschen Reiches in den Jahren 19251935 bewegte. Das Jahr 1929 stellt einen Höhepunkt des Filmexports, das Jahr 1933 hingegen den Tiefpunkt eines Abwärtstrendes dar. Ob ihrer länderspezifisch nicht aufgeschlüsselten Darstellung sollen die obenstehenden Angaben lediglich einen Orientierungsrahmen für die nachfolgende Untersuchung zum Filmexport nach Südafrika liefern.

Bei der Erfassung der quantitativen Dimension des deutschen Filmexports nach Südafrika stellt sich das Problem, dass bisher keine Einzeluntersuchungen zum deutsch-südafrikanischen Filmexport vorliegen. Ein Grund dafür ist das Fehlen von zwischenstaatlichen Handelsverträgen in Bezug auf filmwirtschaftliche Interessen, wodurch keine exakten Daten zur Verfügung stehen (Rathgeb 1935: 128). Die Aussagefähigkeit der vorhandenen Daten ist aufgrund der verschiedenen Erhebungsmethoden stark eingeschränkt, was die Vergleichbarkeit der jeweiligen nationalen Statistiken zusätzlich erschwert.

Die Differenzen in der deutschen und südafrikanischen Handelsstatistik lassen sich z.B. nicht nur auf die angefallenen Transportkosten reduzieren. Bei verschifften Waren ist ebenso der Zeitfaktor zu berücksichtigen, welcher am Jahresende in Deutschland verschiffte Waren statistisch zum alten Jahr, 
die südafrikanischen Statistiken die Ankunft der Ware zum neuen Jahr hinzuzählten. Daraus resultiert eine gewisse zeitliche Verschiebung bei den Werten der südafrikanischen Einfuhrstatistik. Ein weiterer Unterschied in den nationalen Statistiken ist der Umstand, dass die deutsche Handelsstatistik das Gebiet ,Britisch Südafrika' erfasst. Dazu gehörten nach deutscher Lesart neben der Südafrikanischen Union auch die Gebiete des heutigen Lesotho, Swasiland, Botswana, Simbabwe, Sambia und Malawi (in der damaligen Bezeichnung Basuto-, Swazi- und Betschuanaland, Süd- und Nordrhodesien sowie Njassaland). Die südafrikanischen Erhebungen erfassen hingegen nur die Südafrikanische Union, Botswana, Lesotho und Swasiland. Für die Zahlen zum Filmexport dürfte dieser Unterschied allerdings kaum ins Gewicht fallen, da sich die Mehrzahl der Spielstätten in Südafrika befand. In Ermangelung direkt vergleichbarer Zahlen eines Jahres sei darauf verwiesen, dass im Jahre 1926 in ganz Afrika etwa 644 regelmäßig betriebene Spielstätten existierten (Rathgeb 1935: 67), während im Jahre 1930 in Südafrika allein ca. 480 permanent betriebene Lichtspielhäuser gezählt wurden (Wolfsohn 1930: 618). ${ }^{41}$

Unterschiedliche Werte im Vergleich der beiden nationalen Statistiken ergeben sich auch durch den auf deutscher Seite den Wertanmeldungen zugrundegelegten Grenzwert, im Gegensatz zum von südafrikanischer Seite gelisteten handelsüblichen Engroswert im erzeugenden Land. Zudem listeten die südafrikanischen Statistiken meist die Werte ohne Einberechnung der gewährten Exportrabatte, was zu einer geringfügigen Verzerrung geführt haben kann (Mertsch 1935: 46). Die Vergleichbarkeit wird zusätzlich durch die zwei verwendeten Verrechnungseinheiten Reichsmark und Südafrikanisches Pfund erschwert. Exporte über Drittländer ohne Nennung des Ursprungslandes sind zwar denkbar, dürften aber vom Umfang kaum ins Gewicht gefallen sein.

Ein weiteres Hindernis für die Darstellung der deutschen Filmausfuhr nach Südafrika stellt der Umstand dar, dass die auf deutscher Seite erhobenen und im Statistischen Jahrbuch für das Deutsche Reich (im Folg. Statistisches Jahrbuch) veröffentlichten Daten keine Unterscheidung zwischen belichtetem, unbelichtetem und Rohfilm vornehmen (z.B. Positivfilme für Filmvorführungen und Negativfilme zur Herstellung von Positivkopien auf Rohfilm). Verzeichnet ist lediglich der Warenwert der ausgeführten Filme und deren Anteil an der Gesamtausfuhr. Durch die Zusammenfassung der Zahlen

${ }^{41}$ Ein Jahr später 1931 sollen es bereits 690, davon 280 für Tonfilme, gewesen sein (Wolfsohn 1933: 615). 
von unbelichtetem und belichtetem Film ist es nicht möglich, Rückschlüsse auf die Anzahl der ausgeführten Kinofilme zu ziehen. Selbst bei einer Trennung der beiden Filmarten wäre eine entsprechende Statistik von geringem Gebrauchswert, da jene bei den Filmen lediglich den Waren- bzw. Zollwert wiedergeben würde, was bei den Herstellungskosten eines Spielfilmes jedoch kaum ins Gewicht fällt. ${ }^{42}$ Zudem lässt die Nennung des Warenwertes keine Rückschlüsse darauf zu, ob es sich bei den Filmen um abendfüllende Spielfilme oder nur um Kurzfilme handelt. Aus den Angaben über die Länge der ausgeführten Filme lassen sich ebenfalls keine gesicherten Erkenntnisse über die durchschnittliche Anzahl der gelieferten Kinofilme gewinnen, da die Längenangaben aller Filmarten (z.B. Kurzfilme, Lehrfilme, Filmreklame, Spielfilme etc.) addiert wurden.

Entscheidend für den Filmaußenhandel ist ohnehin nicht der Warenwert des Films an sich, sondern der Wert der vergebenen immateriellen Vorführlizenzen. Auf diese Problematik wurde bereits in zeitgenössischen Untersuchungen hingewiesen, wenn bemerkt wurde: „Solange es nicht gelingt, diese Lizenzbeträge statistisch zu erfassen, muss jede auch noch so genau aufgestellte amtliche Außenhandelsstatistik für Filme illusorisch und ohne den geringsten praktischen Wert sein." (Olimsky 1931: 7). Die Schwierigkeit der Zusammenstellung einer solchen Statistik wird deutlich, wenn man bedenkt, dass es sich beim Kinofilm nicht einfach um ein technisches Produkt handelt, dessen Wertdeklaration z.B. von den Zollbehörden durch einfaches Abgleichen mit den Marktpreisen zu überprüfen wäre. Als Mischform von materiellem und immateriellem Wert, bedingt durch die Praxis der prozentualen Gewinnbeteiligung in Vertrieb und Verleih, ist der Wert eines Filmes erst nach Beendigung des Verleihs errechenbar (Rathgeb 1935: 108). Vor diesem Hintergrund wird deutlich, welch eingeschränkte Aussagekraft die existierenden Statistiken haben. Dennoch lassen sich mit den herkömmlichen Erhebungen auch ohne die Erfassung der tatsächlich gezahlten Lizenzgebühren Tendenzen sichtbar machen, welche Rückschlüsse auf die südafrikanische Filmeinfuhr zulassen.

Während die deutschen Ausfuhrdaten lediglich keine Trennung zwischen belichtetem und unbelichtetem Film ausweisen, vereint das Official Yearbook of the Union of South Africa and of Basutoland, Bechuanaland Protectorate and Swaziland (im Folg. Official Yearbook) die Werte von belichtetem und

${ }^{42}$ Etwa 5 Prozent der Produktionskosten entfielen Ende der 1920er Jahre in den USA auf das Filmmaterial für die Negativkopie (Wolffsohn 1930: 587). Die durchschnittlichen Herstellungskosten für einen abendfüllenden Stummfilm betrugen im Zeitraum um 1929 ca. 175.000 Reichsmark, durch den Mehraufwand für die entsprechenden Lizenzen wurden für einen Tonfilm ca. 275.000 Reichsmark veranschlagt (Jason 1932: 20 und Mühl-Benninghaus 1987/II: 7). 
unbelichtetem Film und fasst jene mit den Werten der eingeführten Vorführapparate (,Bioscopes') zusammen. Um eine aussagefähige Aufstellung der südafrikanischen Spielfilmeinfuhr zu erhalten, sind daher von den Angaben für ,Bioscopes and Films' des Official Yearbook die Werte für den Rohfilm und der Vorführapparate abzuziehen. Dies ist möglich, in dem man die Daten des Annual Statement of the Trade and Shipping of the Union of South Africa, Southern and Northern Rhodesia, and Terretory of South-West Africa (im Folg. Annual Statement) heranzieht, welches die Zollwerte für Vorführapparate (Posten 964. ,Bioscopes, Cinematographs, and Magic Lanterns'), unbelichteten und ,anderen Film' (Posten 971. ,Other' [Films, Anm. ME]) einzeln auflistet. Da sich die Daten des Annual Statement auch auf Süd- und Nordrhodesien (Simbabwe und Sambia) und Südwestafrika (Namibia) beziehen, könnten die Werte wie im Falle des Statistischen Jahrbuches einige Verzerrungen aufweisen. Auch hier sei erneut auf die geringe Kinodichte außerhalb Südafrikas verwiesen, was die Angaben als hinreichend zuverlässig erscheinen lässt. Während die amtlichen deutschen Statistiken den Filmexport nach Südafrika nicht gesondert ausweisen, listet das Annual Statement für die Filmeinfuhr und die Einfuhr von Filmprojektoren die Haupthandelspartner Südafrikas, unter denen sich auch das Deutsche Reich befand.

Unter Berücksichtigung der obengenannten Einschränkungen wird im Folgenden versucht, im Vergleich mit den anderen Haupthandelspartnern Südafrikas - an erster Stelle Großbritannien (GB), an zweiter Stelle die USA und an dritter Stelle das Deutsche Reich (D) - die Einfuhr von Filmen und Filmprojektoren nach Südafrika zur rekonstruieren. Im Verlauf dieser Darstellung soll weiters auch auf eine zweckmäßige Beschränkung des Untersuchungszeitraumes hingearbeitet werden. Um die gesamtwirtschaftliche Tendenz des Warenaustausches aufzuzeigen, erfolgt an dieser Stelle zunächst eine nach den Haupthandelspartnern geordnete Übersicht der südafrikanischen Importe, einschließlich der jährlichen Steigerungsraten gegenüber dem Vorjahr. 
Tab. 13: Gesamteinfuhr Südafrikas $1928-1933$ (in Mio SA £) ${ }^{43}$

\begin{tabular}{|l|c|c|c|c|c|c|c|c|c|c|c|c|}
\hline & 1928 & $\%$ & 1929 & $\%$ & 1930 & $\%$ & 1931 & $\%$ & 1932 & $\%$ & 1933 & $\%$ \\
\hline Total & 79,1 & +7 & 83,5 & +6 & 64,6 & -23 & 53 & -18 & 32,8 & -38 & 49,4 & +51 \\
\hline GB & 34,4 & +4 & 35,9 & +4 & 29,7 & -17 & 23,6 & -21 & 15,1 & -36 & 24,7 & +64 \\
\hline USA & 12,9 & +13 & 15,0 & +16 & 9,3 & -38 & 7,0 & -25 & 4,2 & -40 & 6,0 & +43 \\
\hline D & 5,9 & +11 & 5,3 & -10 & 4,4 & -17 & 3,6 & -18 & 2,5 & -31 & 3,2 & +28 \\
\hline
\end{tabular}

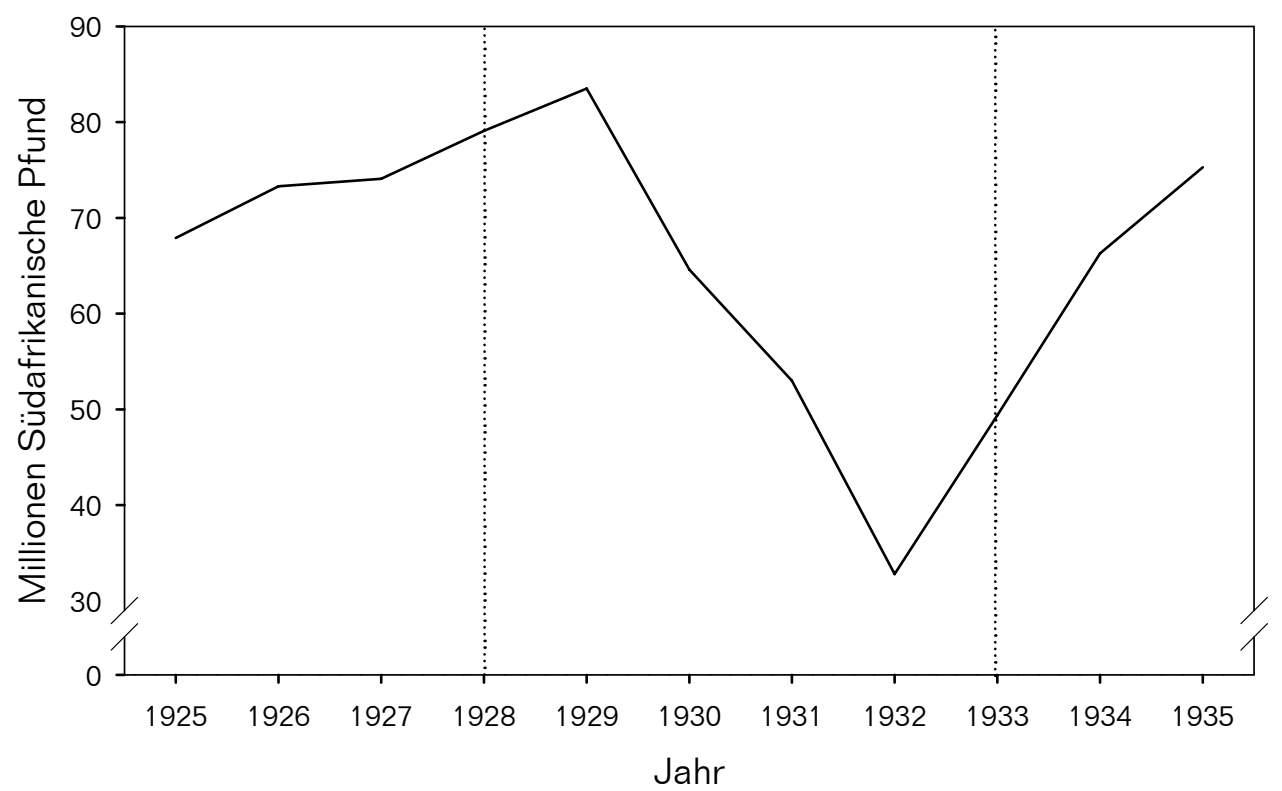

Abb. 5: Gesamtwareneinfuhr nach Südafrika 1925 - 1935

In der obenstehenden Tabelle bzw. Abbildung wird sichtbar, dass bis zum Jahr 1929 ein moderates Wachstum der südafrikanischen Importe zu verzeichnen war und ab 1929 ein Abwärtstrend einsetzte, der 1932 seinen Tiefpunkt erreichte. Für die Haupthandelspartner Südafrikas erfolgte diese Entwicklung uneinheitlich. Der Rückgang der deutsch-südafrikanischen Handelsbeziehungen setzte bereits 1929 und somit ein Jahr früher als bei den anderen Haupthandelspartnern ein. Dafür fällt der Rückgang der Importe nach 1929 aus deutscher Sicht weniger gravierend aus. Mit dem Einsetzen der wirtschaftlichen Erholung ab 1933 verzeichnete Südafrika wieder einen Zuwachs der Importe. Da die Gesamteinfuhr höchst unterschiedliche Warenund Gütergruppen zusammenfasst, haben die aufgezeigten Tendenzen für

${ }^{43}$ Die Daten dieser und der folgenden Tabellen und Abbildungen wurden aus dem Official Yearbook für die Jahre 1928-1933 entnommen und mit denen der Annual Statements abgeglichen, wobei sich keine gravierenden Unterschiede ergaben. Für schwer zugängliche Jahrgänge der Handelsstatistik wurde Sekundärliteratur auf Basis der amtlichen Statistik herangezogen; fehlende Angaben wurden entsprechend ergänzt (Gerich 1937: 3, 26, 48, 50; Mertsch 1935: 43; Klein 1929: 66). 
den Filmimport zunächst nur einen beschränkten Aussagewert, geben dafür aber den gesamtwirtschaftlichen Kontext der damaligen Entwicklung wieder. Den Import von Filmen und Filmprojektoren nach Südafrika zeigt Tabelle 14.

Tab. 14: Südafrika: Einfuhr von Filmen bzw. Filmprojektoren 1928 - 1933 (in 1000 SA £)

\begin{tabular}{|l|c|c|c|c|c|c|c|c|c|c|c|c|}
\hline & 1928 & $\%$ & 1929 & $\%$ & 1930 & $\%$ & 1931 & $\%$ & 1932 & $\%$ & 1933 & $\%$ \\
\hline $\begin{array}{l}\text { 'Bioscopes } \\
\text { and Films' }\end{array}$ & 213 & +35 & 229 & +8 & 324 & +42 & 324 & 0 & 163 & -50 & 228 & +40 \\
\hline Projektoren & 20 & 0 & 26 & +30 & 61 & +135 & 37 & -39 & 11 & -70 & 7 & -36 \\
\hline Rohfilm & 4,2 & +24 & 7,6 & +81 & 7,3 & -4 & 12,4 & +70 & 4,5 & -64 & 5,5 & +22 \\
\hline Differenz & 188,8 & +40 & 195,4 & +4 & 255,7 & +31 & 274,6 & +7 & 147,5 & -46 & 215,5 & +46 \\
\hline Filme & 188 & +40 & 195 & +4 & 256 & +31 & 274 & +7 & 147 & -46 & 212 & +44 \\
\hline
\end{tabular}

Bei einem Vergleich der Werte von Tabelle 13 und Tabelle 14 wird deutlich, wie notwendig eine Einzelbetrachtung der im Official Yearbook zusammengefassten Werte für ,Bioscopes and Films' ist, um die tatsächliche Entwicklung des Filmimports rekonstruieren zu können. Dabei wird erkennbar, dass der Rückgang des Imports von Filmprojektoren bereits 1931 einsetzte, während im gleichen Jahr der Filmimport noch Zuwachsraten verzeichnete. Die Einfuhr von Filmprojektoren war noch bis zum Jahr 1933 rückläufig, der Filmimport hatte seinen Tiefststand 1932 erreicht und erholte sich bereits im folgenden Jahr. Auffällig ist darüber hinaus, dass für den Import von Filmprojektoren die Jahre 1927, 1930 und 1934 von herausragender Bedeutung waren. Für den Import von Filmen waren dies hingegen die Jahre 1928, 1930 und 1933. Die getrennt erfassten Werte für Projektoren, Rohfilm und belichteten Film veranschaulicht Abbildung 6. 


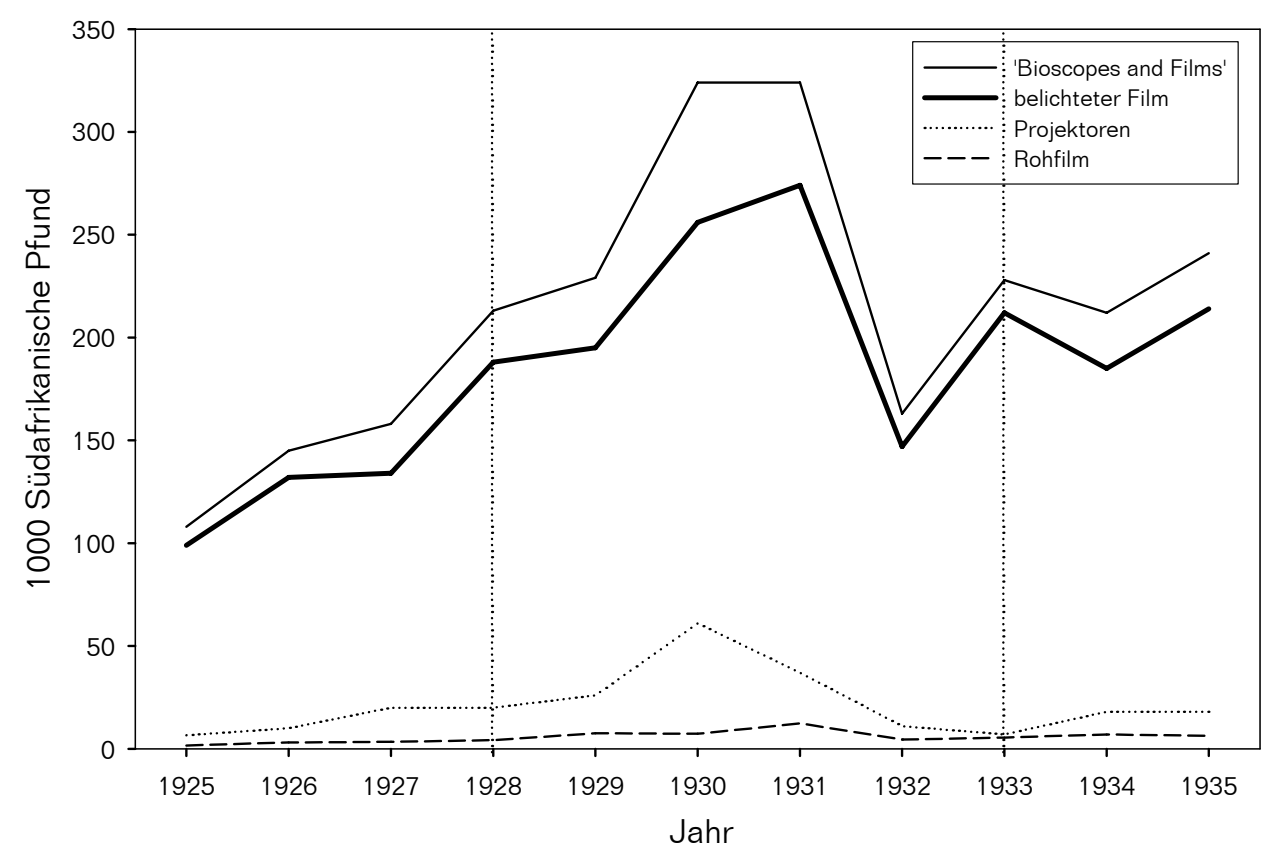

Abb. 6: Einfuhr von Filmprojektoren, Filmen und Rohfilm 1925 - 1935

Die graphische Darstellung des Imports von Projektoren, belichtetem Film und Rohfilm macht deutlich, dass diesen drei Gütern höchst unterschiedliche Wertangaben zugrundeliegen und die statistische Zusammenfassung jener Angaben leicht zu Fehlinterpretationen führen kann. Der Wertumfang des importierten belichteten Films übersteigt die Summe aus Rohfilm und Projektoren um ein Vielfaches. Der Import von Rohfilm scheint in keinem messbaren Verhältnis zum Import von belichtetem Film zu stehen, der Höchststand des Imports von belichtetem Film folgte zeitlich um ca. ein Jahr verschoben dem Höchststand der eingeführten Filmprojektoren. Im Vergleich mit der Gesamteinfuhr (Abb. 5) fällt auf, dass sich der Import von Filmen und Projektoren in den Jahren 1929 bis 1931 gegenläufig zur abnehmenden Tendenz der Gesamteinfuhr verhielt. 1932 sanken jedoch alle Importe als Folge der Weltwirtschaftskrise auf einen historischen Tiefststand (Kelly 1954: 76).

Auch bei der Herkunft der eingeführten Filme und Projektoren lohnt eine getrennte Betrachtung geordnet nach den Haupthandelspartnern. Danach ergibt sich die in Tabelle 15 und Abbildung 7 dargestellte Aufgliederung. 
Tab. 15: Einfuhr von Filmprojektoren 1928 - 1933 (in 1000 SA £)

\begin{tabular}{|l|c|c|c|c|c|c|c|c|c|c|c|c|}
\hline & 1928 & $\%$ & 1929 & $\%$ & 1930 & $\%$ & 1931 & $\%$ & 1932 & $\%$ & 1933 & $\%$ \\
\hline Total & 20 & 0 & 26 & +30 & 61 & +135 & 37 & -39 & 11 & -70 & 7 & -36 \\
\hline USA & 5,5 & -19 & $11^{44}$ & +100 & 4945 & +345 & 25 & -49 & 7,7 & -69 & 2,9 & -62 \\
\hline GB & 9,5 & -10 & 6,6 & -31 & 4,6 & -30 & 5,7 & +24 & 1,2 & -79 & 2 & +67 \\
\hline D & 4,7 & +147 & 7 & +49 & 6,6 & -6 & 5,7 & -14 & 1,2 & -80 & 1,2 & 0 \\
\hline
\end{tabular}

Neben der weitgehend uneinheitlichen Entwicklung der Einfuhr von Filmprojektoren aus den Ländern der Haupthandelspartner wird erkennbar, dass lediglich in den Jahren 1927, 1932 und 1934 eine gleiche Tendenz in Bezug auf den südafrikanischen Filmimport aus den USA, Großbritannien und Deutschland vorlag. 1928 fängt der gesteigerte Import von deutscher Seite die Rückgänge der anderen auf, die Steigerung der Einfuhr im Jahre 1930 wird ausschließlich von den USA bestritten, für die Jahre 1926, 1929, 1931 und 1933 ist im Vergleich der Importe von Großbritannien und dem Deutschen Reich eine gegenläufige Tendenz erkennbar. Der gestiegene Import von deutschen Projektoren im Jahre 1929 steht im Kontrast zu den gesunkenen Gesamtimporten aus dem Deutschen Reich. Für den Zeitraum 1931 bis 1933 mussten vor allem die USA geringere Exporte nach Südafrika hinnehmen. In Abbildung 7 wird sichtbar, dass eine spürbare Veränderung des Imports von Filmprojektoren in den Jahren 1928 bis 1933 stattfand, was eine genauere Untersuchung dieses Zeitraums nahelegt. In Bezug auf etwaige zolltarifliche Importanreize in der genannten Periode ist zu bemerken, dass sich der Importzoll für Filmprojektoren nicht änderte und konstant bei 25 Prozent des Warenwertes lag. ${ }^{46} \mathrm{Im}$ Vergleich mit dem fallenden Gesamtimport Südafrikas ab 1929 macht der Import von Projektoren dahingehend eine Ausnahme, da er erst ab 1930 eine Abwärtstendenz aufweist, mit der Weltwirtschaftskrise 1932 aber ebenso auf einem Tiefpunkt anlangt.

\footnotetext{
44 US-Amerikanische Quellen beziffern den Wert der 1929 nach Südafrika eingeführten Projektoren auf 24.607 US\$ (Cooper in Golden 1930: I).

451930 schloss diese Zahl den Gegenwert von 76 Tonfilmapparaturen ein (Wolffsohn 1933: 593).

${ }^{46} \mathrm{Vgl}$. Official Yearbook 11(1928/29): 601 und Official Yearbook 12(1929/30): 590.
} 


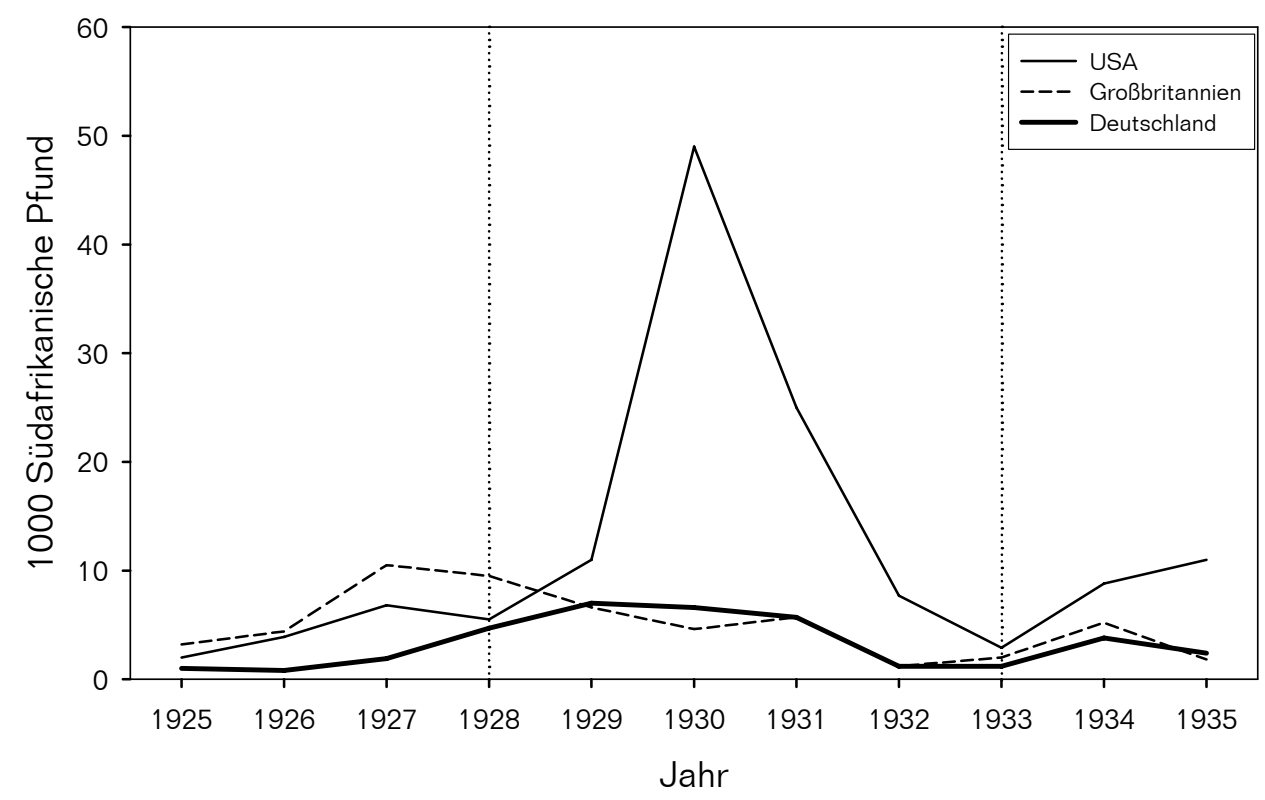

Abb. 7: Einfuhr von Filmprojektoren $1925-1935$

Es bedarf sicher keiner weiteren Erklärung, dass bei entsprechendem Bedarf, z.B. durch die Eröffnung einer größeren Anzahl von Spielstätten, zuerst ein gesteigerter Import von Filmprojektoren erfolgt und danach die Auslastung der Apparate mit einem erhöhtem Filmimport sichergestellt wird. Für die Jahre 1925 bis 1928 und nach 1933 weist der Import von Filmprojektoren keine dramatische Veränderung auf, was auf eine relativ stabile Marktsituation hindeutet. Eine signifikante Steigerung des Imports von Filmprojektoren fand hingegen im Zeitraum 1928-1932 statt, wobei auffällig ist, dass 1928 und 1929 der Import aus Deutschland, 1929 und 1930 der aus den USA und 1931 jener aus Großbritannien spürbare Steigerungsraten verzeichnete. Wie bereits erwähnt, kann dies nicht auf eine zolltariflich abweichende Behandlung der einzelnen Importländer zurückgeführt werden. Während der Höhepunkt der gesteigerten Einfuhr 1930 von den USA fast alleine (+345\%) getragen wurde, traf der Tiefpunkt 1932 gleichsam alle drei Haupthandelspartner. 
Tab. 16: Einfuhr von belichtetem Film 1928 - 1933 (in 1000 SA £) $)^{47}$

\begin{tabular}{|l|c|c|c|c|c|c|c|c|c|c|c|c|}
\hline & 1928 & $\%$ & 1929 & $\%$ & 1930 & $\%$ & 1931 & $\%$ & 1932 & $\%$ & 1933 & $\%$ \\
\hline Total & 188,3 & +40 & 195,3 & +4 & 255,5 & +31 & 274,3 & +7 & 147,2 & -46 & 212,6 & +-44 \\
\hline USA & 141,6 & +42 & 140,8 & -1 & 200,9 & +43 & 211,6 & +5 & 125,3 & -41 & 152 & -21 \\
\hline GB & 42 & +30 & 50,6 & +20 & 52 & +3 & 60 & +15 & 20,6 & -66 & 59,3 & +188 \\
\hline D & 0,5 & -17 & 2,4 & +380 & 1,3 & -46 & 1,5 & +15 & 0,7 & -53 & 0,3 & -57 \\
\hline
\end{tabular}

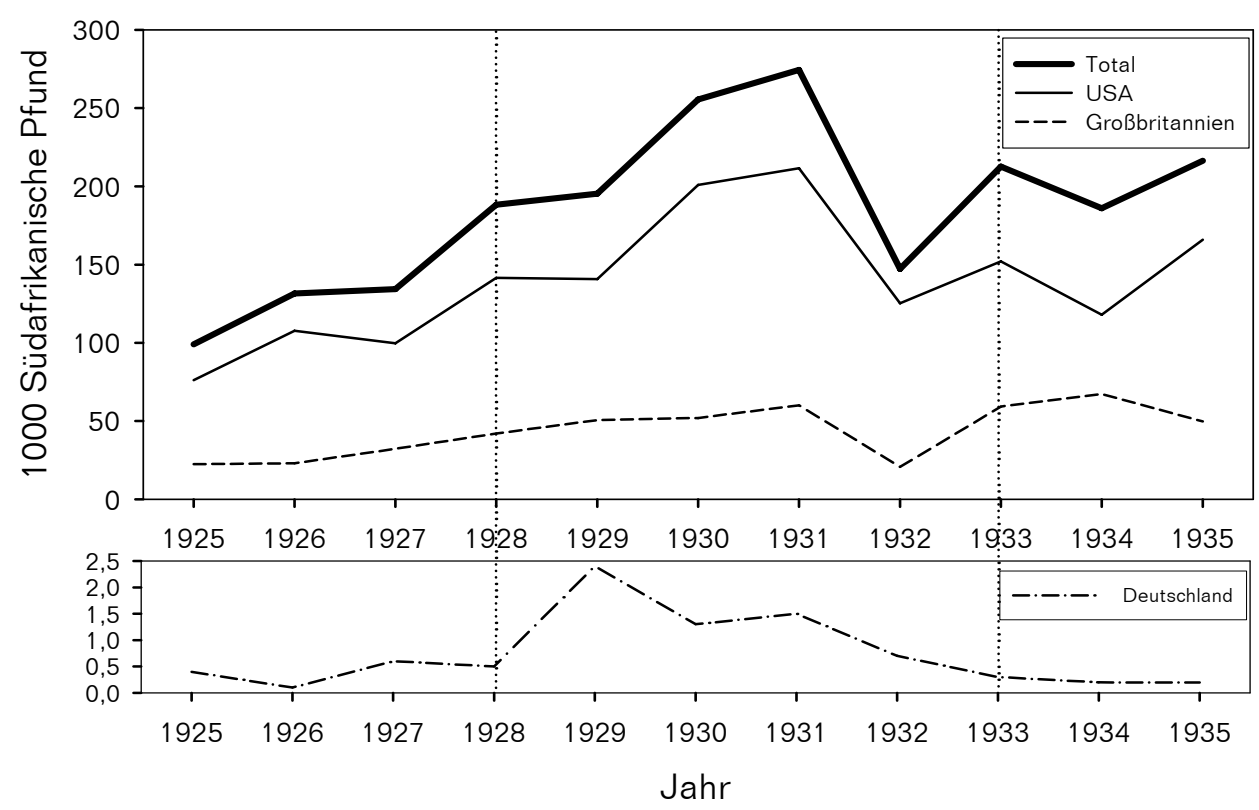

Abb. 8: Filmeinfuhr $1925-1935$

In Tabelle 16 und Abbildung 8 wird erkennbar, dass der Filmimport aus Großbritannien bis 1931 stetig zunahm, während die Einfuhr aus den USA einigen Schwankungen unterlag, aber dennoch unbestritten den wertmäßig größten Anteil ausmachte. Im Vergleich zum gesamten Filmimport kann festgestellt werden, dass Südafrikas Filmimporte fast ausschließlich von den drei Haupthandelspartnern stammten. Der Wertumfang des Filmimports aus Deutschland ist verglichen mit dem der USA oder Großbritanniens relativ gering, eine deutliche Steigerung (+380 Prozent) ist allerdings für das Jahr $1929 \mathrm{zu}$ verzeichnen. Die Steigerung der aus Deutschland nach Südafrika exportierten Filme korrespondiert mit dem Höhepunkt der deutschen Filmausfuhr im gleichen Jahr (Tabelle 12), verhielt sich aber gegenläufig zur seit $1928 \mathrm{sin}$ kenden deutschen Gesamtausfuhr nach Südafrika (Tabelle 13). Bei der zu unterschiedlichen Zeitpunkten ansteigenden Filmeinfuhr aus den einzelnen

${ }^{47}$ In US\$ geführte Statistiken geben den Filmexport der Jahre 1928-1929 nach British Südafrika wie folgt an: 1928: 113.446 US\$, 1929: 130.394 US\$ (Wolffsohn 1930: 583). 
Staaten liegt die Vermutung nahe, dass geänderte Zolltarife die Ursache sein könnten. Die neuen Zolltarife des Jahres 1929/30 unterschieden zwar von nun an zwischen Stumm- (2 Pence je Fuß) und Tonfilmen (3 Pence je Fuß) und bei Tonfilmen zwischer der ersten ( 3 Pence je Fuß) und jeder weiteren Kopie (nur 2 Pence je Fuß). Spürbare Handelshemmnisse im Vergleich zum vorherigen Tarif (30 Prozent auf den Warenwert oder 3 Pence je Fuß) konnten damit jedoch nicht auftreten (Official Yearbook 1928/29: 602 und Official Yearbook 1929/30: 590). ${ }^{48}$ Die Marktdominanz der Haupthandelspartner verdeutlicht Tabelle 17 mit dem Anteil der einzelnen Länder am südafrikanischen Filmimport des Zeitraumes 1928 bis 1933.

Tab. 17: Länderanteile der Filmeinfuhr 1928 - 1933

\begin{tabular}{|c|c|c|}
\hline & Betrag & Prozentualer Anteil \\
\hline Gesamteinfuhr & 1.273 .250 SA£ & \\
\hline Haupthandelspartner insgesamt & 1.263 .396 SA£ & $100 \%$ \\
\hline USA & 972.361 SA£ & $77 \%$ \\
\hline GB & 284.400 SA£ & $22,5 \%$ \\
\hline D & 6.635 SA£ & $0,5 \%$ \\
\hline
\end{tabular}

Die angegebenen Werte zeigen deutlich, dass Filme aus den USA, Großbritannien und dem Deutschen Reich den südafrikanischen Filmmarkt beherrschten. Die dominierende Rolle der US-Filme ist unbestreitbar, wenngleich der für die 1920er und 1930er Jahre vielfach unterstellte USMarktanteil von 80-90\% (Golden 1929: 29, Wolffsohn 1930: 618 und Thompson 1985: 221) durch die vorliegenden Zahlen nicht bestätigt werden kann. Ebenso konnte nicht nachgewiesen werden, dass bei der Versorgung des südafrikanischen Filmmarktes Deutschland an zweiter bzw. Frankreich an dritter Stelle gestanden hätten (Wolfsohn 1930: 618). Der quantitativ einzig ernstzunehmende Konkurrent der US-Filme auf dem südafrikanischen Markt waren die Filme aus britischer Produktion.

Wie in den vorangegangenen Überlegungen ausgeführt, fiel der Import deutscher Filme im Vergleich zu den Einfuhren aus den USA und Großbritannien verhältnismäßig gering aus. Dennoch nahmen Filmimporte aus Deutschland im Untersuchungszeitraum den dritten Platz auf dem südafrikanischen Filmmarkt ein. Betrachtet man nun die Veränderung des Umfanges im deutsch-südafrikanischen Filmhandel (Abbildung 9) fällt auf, dass vor 1928 und nach 1933 relativ wenige Filme importiert wurden, die Einfuhr 1929

${ }^{48}$ Die Wahlmöglichkeit zwischen den beiden Zolltarifen war insofern eingeschränkt, dass der tatsächlich zu begleichende Zoll immer jener war, welcher den höheren Betrag auswies (Official Yearbook 1928/29: 602). 
nahezu explodierte (+380\%), um bis 1933 auf einem Tiefstand anzulangen. Für den Zeitraum von 1928 bis 1933 ist daher anzunehmen, dass eine auch für das südafrikanische Publikum spürbar gestiegene Anzahl von deutschen Filmen zur Aufführung gekommen sein muss.

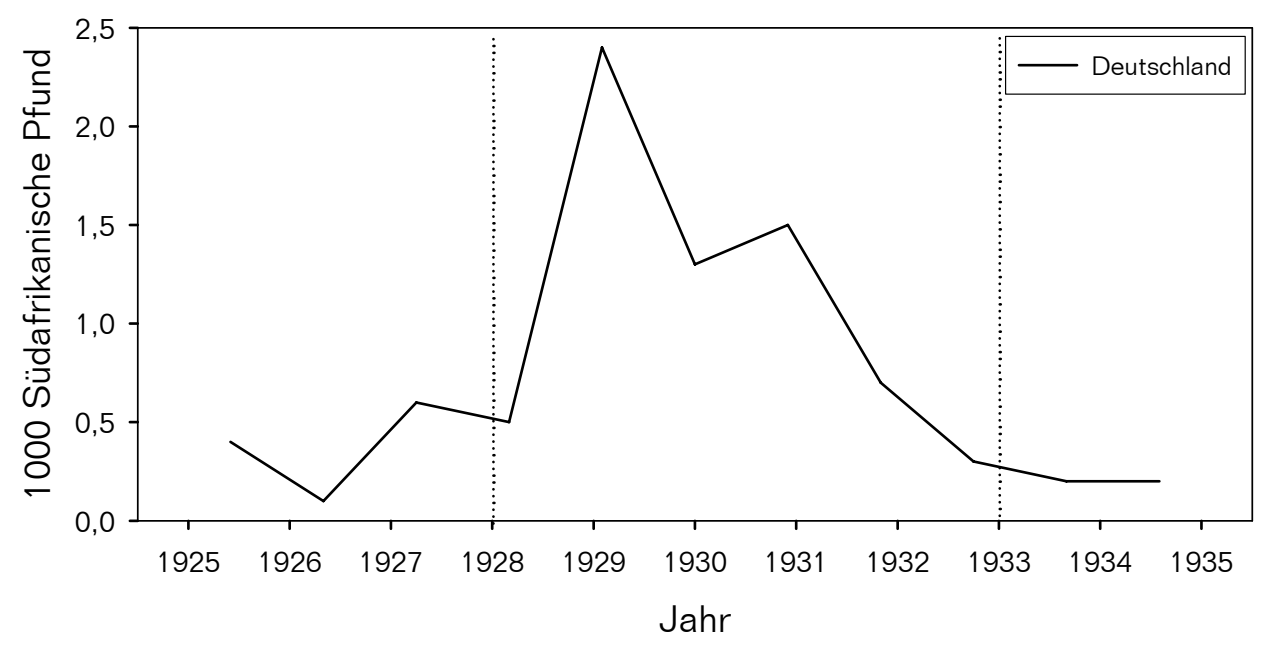

Abb. 9: Einfuhr deutscher Filme $1925-1935$

Stand bei der Beschreibung der ökonomischen Aspekte im Rahmen des rezeptions- und wirkungsgeschichtlichen Ansatzes die Einzelanalyse des Filmimportes im Vordergrund, kann die Auswertung der vorgefundenen Daten nur im Zusammenhang mit einigen der anderen (z.B. technischen) Aspekte erfolgen. An dieser Stelle gibt die technologische Entwicklung im ausgewählten Untersuchungszeitraum die entscheidenden Hinweise zur Interpretation der erhobenen Daten.

Der ab 1928 rapide Anstieg der nach Südafrika eingeführten Filmprojektoren ist die Reaktion auf die erfolgende Umstellung des gesamten internationalen Film- und Kinowesens vom Stumm- auf den Tonfilm seit dem Jahre 1927. Wurden ab 1928 zunächst nur die profitabelsten Premierenhäuser der Kinoketten mit Tontechnik ausgerüstet, fand im Verlauf des Jahres 1930 die Umrüstung der meisten Lichtspielhäuser der ersten Kategorie in den urbanen Zentren Südafrikas statt (du Wayne 1930: 425). Am Beispiel von Kapstadt lässt sich belegen, dass im Laufe des Jahres 1930 auch der größte Teil der Spielstätten der zweiten Kategorie von African Theatres Ltd. auf Tonfilmwiedergabe umgestellt wurde (Eckardt 2005: 33). Zusätzlich dazu erweiterte sich die Kapazität des südafrikanischen Filmmarktes mit den Expansionsplänen des neuen Wettbewerbes im Kinogeschäft, Kinemas Ltd., dem die 
Schlesinger-Organisation als etabliertem Monopolisten nachzog und immer neue Spielstätten errichtete (Kilcoin 1929: 101). Die gestiegene Zahl von Vorführmöglichkeiten förderte einen verstärkten Filmimport unter den Bedingungen des südafrikanischen Kinosektors als eines Anbietermarktes mit Wachstumspotential. Die Auswirkungen der Weltwirtschaftskrise in Europa und den USA nach dem ,Schwarzen Freitag' (25. Oktober 1929) trafen Südafrika mit einer etwa zweijährigen Verzögerung und sorgten für einen Tiefpunkt der Filmeinfuhr um 1932. Die Umstellung der südafrikanischen Kinoketten vom Stumm- auf den Tonfilm war bis Ende 1930 größtenteils abgeschlossen, lediglich in kleineren Lichtspielhäusern sah man von USSeite noch Absatzpotential für neue Projektoren (Golden 1930: 45).

Eine Ursache des Tiefpunktes des gesamten Filmimports im Jahre 1932 waren die Folgen der Weltwirtschaftskrise. Anders als die meisten Staaten Europas und die USA, die aus wirtschaftlichen Gründen vom Goldstandard (fixierte Umtauschoption einer Währung in Gold) abgingen und ihre Währungen abwerteten, behielt die südafrikanische Regierung als Demonstration ihrer Unabhängigkeit gegenüber Großbritannien und gestützt auf ihre hohen Goldexporte den Goldstandard bei (Gilliomee 2003: 404). Da vor allem Südafrikas Haupthandelspartner Großbritannien vom Goldstandard abging und das Britische Pfund stark abwertete, sanken die Preise für alle britischen Güter.

Die hohe Kaufkraft des Südafrikanischen Pfundes führte zu einer massiven Kapitalflucht, da vielfach die Gelegenheit genutzt wurde, Schulden in Großbritannien günstig zu begleichen, Guthaben in London für zukünftige Zahlungen zu schaffen und durch die vorübergehend niedrigen Preise an den britischen Wertpapierbörsen, Käufe in Goldaktien zu tätigen. Zudem ließen viele Exporteure die für ihre Waren erzielten Erlöse in London stehen, anstatt sie nach Südafrika zurückfließen zu lassen. Dadurch musste die Südafrikanische Staatsbank (South African Reserve Bank) etwa 13 Millionen SA£ abgeben und verlor durch das Abgehen Großbritanniens vom Goldstandard den Großteil ihres Kapitals. Die fatalen Folgen dieser Wirtschaftspolitik waren 1932 ein Rückgang der Industrieproduktion um ein Fünftel im Vergleich zu 1929 und eine Arbeitslosenquote von 22 Prozent unter der europäischen bzw. farbigen Bevölkerung (ebd.).

Als verspätete Gegenmaßnahme beschloss die Regierung erst im Oktober 1931 eine zehnprozentige Exportsubvention, die durch einen Extrazoll von 5 Prozent auf alle eingeführten Waren finanziert wurde. Diese Subventionsrate wurde später auf 25 Prozent bzw. 30 Prozent erhöht, was eine Steigerung des Zollzuschlages auf sieben Prozent nach sich zog (Mertsch 1933: 49). 
Somit ergab sich für deutsche Filmimporte eine Zollbelastung von 269,2 Prozent für jede erste Filmkopie bzw. 182,1 Prozent für jede weitere (Wolffsohn 1933: 348). Durch die Zollerhöhungen und die einsetzende Geldknappheit wurde die Einfuhr so stark gehemmt, dass ein drastischer Rückgang einsetzte, was für den Filmmarkt im Jahre 1932 fast einer Halbierung des Importumfangs im Vergleich zum Vorjahr gleichkam (Tabelle 16). Die Einführung von Dumpingzöllen auf Waren aus Ländern mit abgewerteter Währung verstärkten diese Tendenz zusätzlich.

Im Dezember 1932 gestattete die Regierung schließlich der Staatsbank vom Goldstandard abzurücken und die Einlösepflicht für Papiergeld in Gold wurde aufgehoben. Im Januar 1933 wurden die Zuschlags- und Dumpingzölle wieder aufgehoben und die Einfuhr von Waren aus Ländern mit entwerteter Währung wurde begünstigt, jedoch erschwerte sich die Einfuhr aus den an der Goldwährung festhaltenden Staaten (ebd.). Daraus lässt sich auch die Wiederbelebung des Filmimportes im Jahre 1933 und in den Folgejahren erklären (Abbildungen 6 und 8), teilweise auch das Ausbleiben der Erholung des Filmimports aus Deutschland, da die Reichsmark als Goldwährung davon nicht profitierte. ${ }^{49}$

Den Rückgang des deutschen Filmimports allein mit den Auswirkungen der Weltwirtschaftskrise zu erklären, wäre jedoch verfehlt. Die frühe und ausgedehnte Umstellung des südafrikanischen Kinowesens vom Stumm- auf den Tonfilm brachte es mit sich, dass der vorher für alle Produzenten vorhandene Weltmarkt ohne nationale Sprachbarrieren wegbrach und sich die Absatzgebiete auf Sprachgebiete reduzierten. War die Umstellung der Filmproduktion auf Tonfilme bereits ungeheuer kostspielig, bereitete die Synchronisation von Filmen in andere Sprachen auch noch technische Probleme. Waren die USA und Großbritannien durch ihre gemeinsame Sprache und ihr ungleich größeres Sprachgebiet ohnehin schon im Vorteil, verschlechterte die Umstellung auf den Tonfilm und die noch mangelhafte Synchronisationstechnik die Marktchancen des deutschen Films zusätzlich. Die bis dahin einzigen Möglichkeiten qualitativ zufriedenstellende Filme in anderen Sprache zu drehen, waren ein kostenaufwendiger zweiter Dreh des Films mit den gleichen Darstellern, welche die Dialoge nun in einer anderen Sprache sprachen, oder eine Neubesetzung mit fremdsprachigen Darstellern war erforderlich (etwa 30-50 Prozent Mehrkosten pro Sprachfassung; Mühl-Benninghaus 1999: 242). Die Amortisation der zusätzlichen Kosten hing ob des begrenz-

\footnotetext{
${ }^{49}$ Eine Reichsmark entsprach 1/2790 kg Gold oder 0,358423 g Feingold (Gablers Wirtschaftslexikon, Band 3, Wiesbaden 1988: 2188).
} 
ten deutschsprachigen Absatzgebietes wesentlich von der Exportfähigkeit des neuen Mediums ab (ebd.). Die technischen Synchronisationsprobleme waren aber schon gegen Ende des Jahres 1931 gelöst, ebenso verminderten sich die Akzeptanzschwierigkeiten von Seiten des Publikums. Wurden in Deutschland 1929 noch 175 Stummfilme und nur acht Tonfilme (davon zwei in drei Fremdsprachenfassungen) produziert, so waren es ein Jahr später nur noch 45, aber schon 101 Tonfilme, davon wiederum 26 in sechs Fremdsprachenfassungen (Jason 1932: 24). Im Jahre 1932 stellte die deutsche Filmindustrie die Stummfilmproduktion nahezu vollständig ein (Mühl-Benninghaus 1987: 186).

Durch den Rückgang des Angebotes von europäischen Stummfilmen und die verhältnismäßig geringe Anzahl englischer Sprachversionen könnte für Südafrika eine Angebotslücke entstanden sein. Dieser stand jedoch im Jahre 1929 die 755 Filme umfassende US-Produktion (neue Tonfilme, nachvertonte Stummfilme und letzte Stummfilmproduktionen) gegenüber, die jede Nachfrage ohne Zeitverzug befriedigen konnte (Wolffsohn 1930: 586). Auch nutzten die britischen Produzenten die fehlende Sprachbarriere als Chance und steigerten die Exportbemühungen ihrer quantitativ geringen Produktion.

Bis auf weiteres besteht noch keine Klarheit darüber, ob der massive Anstieg des Filmimports aus Deutschland 1928-1929 eine Folge des gegenseitigen Handelsabkommens und der zolltariflichen Normalbehandlung war, oder diese auf verstärkte Exportbemühungen deutscherseits zurückzuführen ist. Der südafrikanische Markt war durch die jahrelange US-Dominanz Hollywood-übersättigt und bot auch für den deutschen Stummfilm kurz vor dem Durchbruch des Tonfilms noch ausreichende Absatzchancen, da das Publikum nach neuen Gesichtern, Themen etc. verlangte. Vor diesem Hintergrund ist es denkbar, dass deutsche Produzenten oder Vertriebe südafrikanischen Verleihern günstige Konditionen einräumten, um sich die Chance einer letztmaligen Verwertung der Stummfilmrechte zu sichern und um künftig den Fuß zu einem Millionenmarkt in der Tür zu haben.

Wie gezeigt, geben die offiziell erhobenen Zahlen der Zollwerte des importierten Films nicht den realen Gegenwert der Kinofilme wieder, da weder die Höhe der Lizenzgebühren, noch die Einnahmen aus den Vorführungen der Filme statistisch erfasst wurden. Bei einer Zollbelastung von 269,2 Prozent für jede erste (Ton-) Filmkopie bzw. 182,1 Prozent für jede weitere (Wolffsohn 1933: 348) liegt zudem der Verdacht nahe, dass die Importeure ihre zu meldenden Zahlen bewusst möglichst niedrig ansetzten, um die im Vergleich zu allen anderen Auslandsmärkten höchste Zoll- und Steuerbelastung für den deutschen Film zu vermindern (ebd.). 
Diese und andere offenen Fragen lassen sich nur bei einer genaueren Betrachtung der tatsächlich in Südafrika gezeigten deutschen Spielfilme klären, da Angaben zu deren Produktionsjahr, Herstellern, Produzenten, Hauptdarstellern etc. möglicherweise Rückschlüsse darauf zulassen, warum und unter welchen Bedingungen gerade diese Spielfilme in Südafrika gezeigt wurden. 


\section{Deutsche Spielfilme als Teil der Programmgeschichte}

\subsection{Deutsche Spielfilme im südafrikanischen Kino}

Unter Programmgeschichte lässt sich ganz allgemein die Summe des Gesendeten (Hickethier 1993b: 22) - im Falle des Kinos also die Summe der gezeigten Filme - verstehen. Dem Zuschauer präsentiert sich die Programmgeschichte oft als ein heterogen gestaltetes (audio-) visuelles Angebot (ebd.: 23). Die Rekonstruktion dieses Angebots als Programmgeschichtsschreibung ist ob dieser Heterogenität am ehesten in einer Art Bausteinverfahren denkbar (ebd.: 22).

Dabei steht vollkommen außer Frage, dass die untersuchten deutschen Spielfilme neben den US-amerikanischen und britischen nur einen verhältnismäßig kleinen Teil der Programmgeschichte des südafrikanischen Kinos ausmachten, was in den Ausführungen zum Filmimport auch besonders deutlich wurde. Zweifellos hat die jahrelange Dominanz des Hollywoodkinos die Programmgeschichte derart geprägt, dass, wie es in Thelma Gutsches Grundlagenstudie (1972) mehr oder weniger offen beschrieben wird, von einer gewissen kulturellen Programmierung gesprochen werden kann, in deren Kontext die Rezeption der deutschen Filme betrachtet werden müsste. Da die gewünschte lückenlose Rekonstruktion der Programmgeschichte bisher nicht vorliegt und den Rahmen dieser Untersuchung sprengen würde, soll als Kompromislösung auf die exemplarische Rekonstruktion des Kapstädter Kinoprogramms der Jahre 1928 bis 1930 hingewiesen werden (Anhang I). Doch selbst diese Auflistung stellt nur einen Baustein oder eine Art Grundstruktur des zeitgenössischen visuellen Angebots dar. Etwaige Querverbindungen zwischen einzelnen Filmen, Zyklen, thematischen Gruppierungen, Moden, Starphänomene o.ä. bleiben notgedrungen unberücksichtigt oder müssen mit Hilfe von Thelma Gutsches fragmentierten Ausführungen (1972) hergeleitet werden.

Für die Programmgeschichte des Kinos kann jedoch allgemein festgestellt werden, dass es der stärker wirksame Werkcharakter des einzelnen Films trotz Wochenschau und Kultur-Vorfilm tendenziell verhindert hat, das Programm als Gesamtangebot gegenüber dem einzelnen Spielfilm als dominant erscheinen zu lassen (Hickethier 1993c: 174 bzw. Ludes 1999: 255). Nicht zuletzt aus diesem Grund erfolgt im Fortgang der Studie die Konzentration auf die deutschen Spielfilme, um innerhalb dieses speziellen Gesamtangebotes so etwas wie eine „partielle Programmgeschichte“ entwerfen zu können. 
Zur Rekonstruktion der Programmgeschichte des deutschen Spielfilms im südafrikanischen Kino können verschiedene Wege beschritten werden. Grundsätzlich bestehen zwei Möglichkeiten: eine produktionsseitige Recherche in deutschen und eine rezeptionsseitige Recherche in südafrikanischen Quellen. Auf deutscher Seite müssten dazu Dokumente der Verleihorganisationen der Filmhersteller gefunden werden, dass Gleiche gilt für entsprechende Unterlagen der südafrikanischen Filmvertriebe.

Die UFA als größter deutscher Filmexporteur vor dem Zweiten Weltkrieg hat zwar einen reichen archivalischen Bestand hinterlassen, jedoch stellt sich dessen mangelhafte Erschließung als größtes Problem einer systematischen und zielgerichteten Recherche dar. Die bloßen Geschäftsberichte des UFAVorstandes enthalten z.B. keinerlei detaillierte Angaben zum Auslandsgeschäft, diese sind nur als Beträge unter dem Posten ,Erlöse' summiert. ${ }^{50}$ Auch konnten etwaige Verträge zwischen deutschen und südafrikanischen Handelspartnern im Filmverleih bisher nicht gefunden werden.

Einen möglichen Anhaltspunkt bietet eine Liste für ein anderes Absatzgebiet (Ägypten, Syrien und Palästina), auf die später noch eingegangen werden soll. ${ }^{51}$ In der deutschen Filmpresse des Jahres 1928 wurde lediglich gemeldet, dass Kinemas Ltd. sechs deutsche Filme erworben habe, „[...] darunter zwei Greenbaum-Produktionen, drei Olga Tschechowa-Filme und den Hegewald-Film ,Zarewitsch' mit Iwan Petrowitsch“ (FK 17.12.28, 3) und dass in der letzten Saison neben britischen auch deutsche Filme in erhöhtem Maße erschienen (LBB 11.1.29, 16). ${ }^{52}$

Recherchen in südafrikanischen Archiven zu den Unterlagen von Kinemas Ltd. oder der Schlesinger-Organisation verliefen weitgehend erfolglos. Darüber hinaus ist es sehr wahrscheinlich, dass die Geschäftspapiere der genannten Unternehmen längst makuliert wurden und für Forschungszwecke unwiederbringlich verloren sind.

Somit verbleibt als einzige Möglichkeit zur Rekonstruktion der Programmgeschichte die systematische Auswertung der Kinowerbung in den südafrikanischen Tageszeitungen. Dabei ergibt sich die Schwierigkeit, dass für die deutschen Spielfilme oft verschiedene englische Verleihtitel in einem Land zirkulierten. Diese konnten wiederum mit US- oder britischen Produktionen gleichen Titels verwechselt werden, da die Werbeannoncen nur selten auf

$50 \mathrm{Vgl}$. Geschäftsberichte der Universum-Film Aktiengesellschaft für die Geschäftsjahre 1927/28 bis 1930/31; in: Universitätsbibliothek Heidelberg, Kalbus-Stiftung, Sign. Kalbus 732.

${ }^{51} \mathrm{Vgl}$. Unverbindliche Liste für Ägypten, Syrien und Palästina vom 10.10.1929, Anhang zum Vertrag der UFA mit der Mamatis \& Co./Alliance Cinematographique Egyptienne, Alexandria; in: Bundesarchiv Berlin, R 109/I, 5430, pp. 517-520 (Abk. UFA/Mamatis) und Anhang III.

${ }^{52} \mathrm{Vgl}$. auch Filmkurier 17.12.1928: 3. 
das Herstellungsland hinwiesen und dies auch nicht in allen Filmbesprechungen erwähnt wurde. Besonders nachteilig wirkt sich aus, dass trotz intensiver Forschung zum Spielfilm der Weimarer Republik kein verbindliches Register vorzuliegen scheint, welches den deutschen Filmen ihre internationalen Verleihtitel zuordnet. Die aus mehreren Publikationen und deren Übersetzungen entnommenen Angaben sind zum Teil widersprüchlich und müssen ständig geprüft werden (z.B. Eisner 1955, Kracauer 1995 und Kreimeier 1996).

Den einzig noch verbliebenen Ausgangspunkt für die angestrebte Rekonstruktion einer partiellen Programmgeschichte bietet wiederum Thelma Gutsches Standardwerk und dessen höchst selektive Angaben. Es soll allerdings nicht verschwiegen werden, dass auch in Hans Rompels filmhistorischen Darstellungen viele deutsche Filme genannt werden (Rompel 1942a: 92ff.). Dabei wird jedoch durch das Fehlen von Quellenangaben nicht klar, ob er seine Ausführungen auf persönliche Kinobesuche in Südafrika stützte, Filmschriften ausgewertet hat, oder, wie er selbst andeutet (Rompel 1942b: 33), Sondervorstellungen des deutschen Klubs oder der Botschaft in Pretoria besuchte, die nicht Teil des normalen Kinoprogrammes waren. ${ }^{53}$

Neben den im Abschnitt 2.1 genannten deutschen Filmen listet Thelma Gutsche in ihren jeweils am Kapitelende beigefügten Aufstellungen "outstanding films of each year" im Zeitraum 1927 bis 1932 weitere Produktionen, die als deutsche Spielfilme identifiziert werden konnten. Es handelt sich insgesamt um die folgenden elf Filme: VAUDEVILLE (dt. VARIETÉ, 1925, E.A. Dupont), FAUST (1926, F.W. Murnau), THE EMDEN (dt. DIE EMDEN, L. Ralph), THE TRIAL OF DONALD WESTHOF (dt. DER KAMPF DES DONALD WESTHOF, 1927, F. Wendhausen), THE WONDERFUL LIE (dt. DIE WUNDERSAME LÜGE DER NINA PETROWNA, 1928, $\mathrm{H}$. Schwarz), ATLANTIC (dt. ATLANTIK 1929, E.A. Dupont), THE BLUE ANGEL (dt. DER BLAUE ENGEL, 1929/30, J. v. Sternberg), THE LOVE WALTZ (dt. LIEBESWALZER, 1930, W. Thiele), THE WHITE HELL OF PITZ PALU (dt. DIE WEISSE HÖLLE VOM PITZ PALÜ, 1929, A. Fanck), CONGRESS DANCES (dt. DER KONGRESS TANZT, 1931, E. Charell) (Gutsche 1972: 228ff. und 251). An anderer Stelle erwähnt sie den Erfolg des Films MÄDCHEN IN UNIFORM (1931, L. Sagan) (Gutsche 1972: 238). Durch was sich diese Filme allerdings als "outstandig films of each year" qualifizierten, wurde nicht dargelegt.

\footnotetext{
${ }^{53}$ Rompel arbeitete von 1936 bis 1939 für das ,Staatsvertaalingsburo' in Pretoria, welches die Übersetzung von Lehrbüchern und Fachliteratur koordinierte (Ohne Autor 1941: 17).
} 
Mit Hilfe dieser ersten Zusammenstellung lässt sich der Zeitraum für weitere Recherchen in den Tageszeitungen sinnvoll auf die Jahre 1927 bis 1932 beschränken. Zur Sicherheit wurden in ausgwählten Zeitungen, der Cape Times (Kapstadt) und dem Natal Advertiser (Durban, Provinz Natal), die Jahre 1925 bis 1927 auf deutsche Titel in den Filmprogrammen untersucht. In diesen Jahrgängen wurden keine Hinweise auf deutsche Filme gefunden. Anschließend wurden die Ergebnisse einer umfassenden Detailstudie in drei ausgewählten Tageszeitungen (Natal Advertiser, Natal Witness und Natal Mercury $)^{54}$ zum Filmprogramm des Jahres 1928 in Durban ausgewertet (Eckardt 2000). Mit diesen konnte belegt werden, dass in Durban 1928 mindestens sechs der bei Gutsche erwähnten Filme gezeigt wurden. ${ }^{55}$ Alle sechs Filme wurden in Lichtspielhäusern der African Theatres-Kette aufgeführt, Kinemas Ltd. scheinen zu dieser Zeit noch über kein eigenes Kino in Durban verfügt zu haben.

Mit der relativen Gewissheit des Beginns einer permanenten Aufführung deutscher Spielfilme ab dem Jahre 1928 wurden ca. 20 südafrikanische Tagesblätter, Wochenzeitungen und Zeitschriften (Tabelle 11) systematisch nach Hinweisen auf die gesuchten Filme in den Werbeanzeigen der Kinoketten durchgesehen. Darüber hinaus wurde auch nach anderen Filmtiteln Ausschau gehalten, die eine deutsche Produktion hinter dem englischen Verleihtitel vermuten ließen. Da im Verlauf der Recherche auch einige neue Titel als deutsche Spielfilme identifiziert werden konnten, die Nachforschungen sich aber über ca. 18 Monate an verschiedenen geographischen Orten erstreckten, konnte am Ende der Recherche nicht nach allen als deutsch identifizierten Filmen in jedem Presseorgan gesucht werden. ${ }^{56}$ Durch gezielte nachträgliche Recherchen und die Auswertung verschiedener Zeitungsausschnittsammlungen sollte diesem Mangel abgeholfen werden. Es ist davon auszugehen, dass mit diesem Verfahren ca. 95 Prozent der tatsächlich in Südafrika gezeigten deutschen Spielfilme erfasst wurden. Für alle bei Gutsche genannten Filme konnten Belege gefunden werden, im Jahre 1933 gelangte nur noch ein deutscher Spielfilm (MÄDCHEN IN UNIFORM) zur Aufführung.

Betrachtet man die Ergebnisse der Recherche, lässt sich eine deutliche Dreiteilung in Bezug auf die Filmvertriebs- und Aufführungsgesellschaften feststellen. Die Programmgeschichte des südafrikanischen Kinos ist dem-

${ }^{54}$ Natal Advertiser, Natal Witness und Natal Mercury.

${ }_{55}$ Diese waren: FAUST, THE WALTZ DREAM, METROPOLIS, THE EMDEN, THE STUDENT OF PRAGUE und VAUDEVILLE.

${ }^{56}$ So konnten z.B. „Grabmahl einer großen Liebe - Shiraz“ (1928, F. Osten), „Der Geisterzug - Ghost Train" (1927, G. v. Bolvary) und "Geheimnisse des Orients - Secrets of the East" (1928, A. Volkoff) nicht mit in die Materialsuche einbezogen werden. 
nach eine Kombination, welche die bei African Theatres Ltd., Kinemas Ltd. und unabhängigen Lichtspielhäusern zur Aufführung gekommenen Filme umfasst, unter denen sich auch eine gewisse Anzahl deutscher Produktionen befand..$^{57}$

\subsubsection{Deutsche Spielfilme in den Kinos von Kinemas}

Ohne eigene Spielstätten mussten die Filme im Vertrieb von Kinemas Ltd. anfangs noch in gemieteten Stadthallen oder Räumlichkeiten anderer Institutionen gezeigt werden. Mit der Errichtung und dem Ausbau einer eigenen Kinokette zielten Kinemas darauf ab, in direkte Konkurrenz zur SchlesingerOrganisation zu treten, um mit einer ähnlich strukturierten Kinokette aus Premierenhäusern und Nachspielkinos den südafrikanischen Markt nach Schlesingers Vorbild durchdringen zu können. Die deutschen Spielfilme fielen nicht mehr in diese Frühphase von Kinemas, die meisten Produktionen konnten in eigenen Lichtspielhäusern vorgeführt werden. In der südafrikanischen Presse ließen sich folgende deutsche Spielfilme im Programm von Kinemas nachweisen:

Tab. 18: Deutsche Spielfilme im Programm der Kinokette Kinemas 1928 - 1931 (chronologisch)

\begin{tabular}{|l|c|c|c|}
\hline \multicolumn{1}{|c|}{ Filmtitel (D) - Verleihtitel (SA) ${ }^{58}$} & UA $^{59}$ & Erstbeleg (SA) & Regie \\
\hline An der schönen blauen Donau - Blue Danube (I.) & 16.08 .26 & 30.10 .28 CT & F. Zelnik \\
\hline Spione - The Spy & 22.03 .28 & 01.02 .29 DB & F. Lang \\
\hline Angst-Die schwache Stunde einer Frau - Fear & 22.08 .28 & 04.02 .29 RDM & H. Steinhoff \\
\hline Heimkehr - Homecoming * & 29.08 .28 & 08.02 .29 NA & J. May \\
\hline Die Liebe der Jeanne Ney - The Loves of Jenny Ney & 06.12 .27 & 25.03 .29 RDM & G.W. Pabst \\
\hline Am Rande der Welt - At the Edge of the World & 19.09 .27 & 25.03 .29 DFA & K. Grune \\
\hline Der Kampf des Donald Westhof - The Trial of Donald Westhof & 29.09 .27 & 16.04 .29 DB & F. Wendhausen \\
\hline Die Apachen von Paris - Apaches of Paris & 19.12 .27 & 27.04 .29 DB & N. Malikoff \\
\hline Die Todesschleife - Looping the Loop & 15.09 .28 & 14.05 .29 CT & A. Robison \\
\hline Die Leibeigenen - Bondage & 11.01 .28 & 26.05 .29 ST & R. Eichberg \\
\hline Mann gegen Mann - For Men Only & 14.05 .28 & 15.06 .29 EPH & H. Piel \\
\hline Die Carmen von St. Pauli - The Water Rat & 10.10 .28 & 10.08 .29 NM & E. Waschneck \\
\hline Die Jacht der sieben Sünden - Yacht of Seven Sins & 06.08 .28 & 05.10 .29 NM & J. \& L. Fleck \\
\hline Asphalt - Temptation* & 12.03 .29 & 16.10 .29 CT & J. May \\
\hline
\end{tabular}

57 Um die später erfolgenden Kategorisierungen und auch die Nachvollziehbarkeit der weiterführenden Überlegungen zu erleichtern, sollen die Titel der gezeigten Filme an dieser Stelle und nicht erst im Anhang tabellarisch wiedergegeben werden. Im Anhang werden dafür die technischen Daten, Inhaltssynopsen und Quellenverweise zu den Filmen ausführlich gelistet.

${ }^{58}$ Bei den mit einem * gekennzeichneten Filmen handelt es sich um Erich Pommer-Produktionen.

${ }^{59}$ Die Daten der Premiere beziehen sich auf die Uraufführung in Deutschland. 


\begin{tabular}{|l|c|c|c|}
\hline \multicolumn{1}{|c|}{ Filmtitel (D) - Verleihtitel (SA) ${ }^{58}$} & UA $^{59}$ & Erstbeleg (SA) & Regie \\
\hline Das letzte Fort - The Last Fort & 09.07 .29 & 19.10 .29 NM & K. Bernhardt \\
\hline Der geheime Kurier - The Secret Courier & 25.10 .28 & 19.11 .29 DB & G. Righelli \\
\hline Das tanzende Wien - Dancing Vienna (Blue Danube, II.) & 01.10 .27 & 04.07 .30 CT & F. Zelnik \\
\hline Ungarische Rhapsodie - Hungarian Rhapsody & 06.11 .28 & 23.04 .30 CT & H. Schwarz \\
\hline Skandal in Baden-Baden - A Society Scandal & 18.01 .29 & 22.03 .30 CT & E. Waschnek \\
\hline Die blaue Maus - The Blue Mouse & 16.11 .28 & 12.05 .30 DFA & J. Guter \\
\hline Der blaue Engel - The Blue Angel (T)* & 01.04 .30 & 16.01 .31 CT & J. v. Sternberg \\
\hline Frau im Mond - The Girl in the Moon & 15.10 .29 & 13.02 .31 CT & F. Lang \\
\hline Hokuspokus - Temporary Widow (T)* & 11.07 .30 & 13.07 .31 DB & G. Ucicky \\
\hline Liebeswalzer - The Love Waltz (T)* & 07.11 .30 & 16.05 .31 NA & W. Thiele \\
\hline Total: Filme im Vertrieb von Kinemas & 24 & & \\
\hline
\end{tabular}

Mit Ausnahme von AN DER SCHÖNEN BLAUEN DONAU (1926) stammten alle Filme aus den Produktionsjahren 1927 bis 1930. Aus der zeitlichen Differenz zwischen dem Herstellungsjahr und dem auf eine tatsächliche Aufführung hinweisenden Erstbeleg in Südafrika kann nicht generell darauf geschlossen werden, dass nur ältere oder nichtaktuelle Filme nach Südafrika gelangten. Nur äußerst selten ließ sich das Datum von Uraufführungen deutscher Filme in Südafrika feststellen. Ein Zeitraum von zwölf Monaten zwischen der Premiere in Deutschland und dem Auftauchen in Südafrika kann jedoch als aktuelle bzw. zeitnahe Verwertung angesehen werden, eine Konzession, welche an die geographische Randlage Südafrikas gemacht werden musste. Von den in der deutschen Fachpresse erwähnten und angeblich durch Kinemas zur Aufführung erworbenen Spielfilme konnte nur die Greenbaum-Produktion DER GEHEIME KURIER nachgewiesen werden, der Hegewald-Film "Zarewitsch" oder Olga Tschechowa-Produktionen fanden sich hingegen nicht im Programm von Kinemas wieder.

Etwaige Präferenzen für Filme bestimmter Regisseure lassen sich nicht schlüssig belegen. Nur jeweils zwei Filme entfallen auf die Regisseure Fritz Lang, Joe May und Erich Waschneck. Bei insgesamt sechs Filmen zeichnete jedoch Erich Pommer als Produzent verantwortlich (HOKUSPOKUS, LIEBESWALZER, HEIMKEHR, ASPHALT, UNGARISCHE RHAPSODIE und DER BLAUE ENGEL), 18 der insgesamt 24 Filme wurden von der UFA oder mit ihr assozierten Produktionen hergestellt, die übrigen stammten von unterschiedlichen Filmproduktionen. Der überwiegende Anteil bestand aus Stummfilmen, unter den 24 durch Kinemas vertriebenen Filmen waren nur drei Tonfilme vertreten (DER BLAUE ENGEL, HOKUSPOKUS und LIEBESWALZER). In Bezug auf die Zeit der Spielhandlung kann festgestellt werden, dass thematisch gegenwartsbezogene Sujets dominierten (17 Fil- 
me), während historische deutlich seltener (sechs Filme) zur Aufführung kamen; einzig AM RANDE DER WELT entzieht sich einer klaren Einordnung.

Betrachtet man die Rollenbesetzung der einzelnen Filme ist feststellbar, dass eine gewisse Häufung bestimmter Darsteller vorkommt. Als männlicher Star ist Willy Fritsch in fünf Produktionen (SPIONE, LIEBESWALZER, DIE CARMEN VON ST. PAULI, UNGARISCHE RHAPSODIE, FRAU IM MOND) und Gustav Fröhlich in drei Filmen vertreten (HEIMKEHR, ASPHALT, ANGST-DIE SCHWACHE STUNDE EINER FRAU). Ob Fritsch auch in der in Südafrika gezeigten Version des Tonfilms LIEBESWALZER mitspielte, kann anhand der Aufzählung noch nicht zweifelsfrei belegt werden. Von diesem Film existierte auch eine Fassung in englischer Sprache, in der anstelle von Fritsch John Batten die männliche Hauptrolle spielte (Kayser 1983: 185). Möglicherweise ist diese Version in den südafrikanischen Kinos zu sehen gewesen.

Als weibliche Protagonisten sind Brigitte Helm (AM RANDE DER WELT, DIE JACHT DER SIEBEN SÜNDEN, DIE LIEBE DER JEANNE NEY, SKANDAL IN BADEN-BADEN), Jenny Jugo (DIE TODESSCHLEIFE, DIE CARMEN VON ST. PAULI, DIE BLAUE MAUS) und ferner Lilian Harvey (LIEBESWALZER und HOKUSPOKUS) identifizierbar. Willy Fritsch ist oft zusammen mit einer weiblichen Hauptdarstellerin in einer Paarkonstellation besetzt (z.B. mit Jenny Jugo, Lil Dagover, Gerda Maurus, Lilian Harvey), wobei das Paar Fritsch/Harvey in den deutschsprachigen Versionen der Filme LIEBESWALZER und HOKUSPOKUS zusammenspielte und gemeinhin als das Traumpaar des deutschen Films der 1920er und 1930er Jahre galt (Kayser 1983). Über inhaltliche Vorlieben des Importeurs kann erst nach einer genaueren Betrachtung der Filmbesprechungen eine Aussage getroffen werden. Eine über die genannten Gemeinsamkeiten hinausgehende Strategie bei der Auswahl deutscher Filme durch Kinemas scheint nach den bisherigen Erkenntnissen nicht bestanden zu haben.

\subsubsection{Deutsche Spielfilme in den Kinos der Schlesinger-Organisation}

Als langjähriger Monopolist konnte die Schlesinger-Organisation auf eine nahezu perfekt funktionierende Kinoinfrastruktur mit mehreren Verwertungsstufen zurückgreifen. Die Monopolsituation wurde dazu genutzt, jeden an Vorführungen in Südafrika interessierten Vertrieb jenseits der eigenen African Films Ltd. Konditionen zu diktieren, welche entweder auf eine Zwangskooperation oder eine Neueröffnung von Spielstätten hinausliefen, was lange 
Zeit (bis auf Kinemas) kein Konkurrent infolge der hohen Anfangsinvestitionen wagte. Auch das 1931 gestartete Unternehmen von Metro-GoldwynMeyer und deren Vertrieb Union Theatres änderte nichts grundsätzliches an dieser Situation. In den südafrikanischen Printmedien wurde auf die folgenden deutschen Spielfilme im Programm von African Theatres hingewiesen:

Tab. 19: Deutsche Spielfilme im Programm von African Theatres 1927 - 1932

\begin{tabular}{|l|c|c|c|}
\hline \multicolumn{1}{|c|}{ Filmtitel (D) - Verleihtitel (SA) ${ }^{60}$} & UA & Erstbeleg (SA) & Regie \\
\hline Ein Waltzertraum - The Waltz Dream* & 18.12 .25 & 01.05 .27 TS & L. Berger \\
\hline Varieté - Vaudeville* $^{*}$ & 16.11 .25 & 11.09 .27 ST & E.A. Dupont \\
\hline Faust* $^{*}$ & 14.10 .26 & 07.12 .27 SCL & F.W. Murnau \\
\hline Metropolis* $^{*} 10.01 .27$ & 22.01 .28 ST & F. Lang \\
\hline Eifersucht - Jealousy & 17.09 .25 & 19.03 .28 CT & K. Grune \\
\hline Kreuzer Emden (Die Emden) - The Emden (Our Emden) & 22.12 .26 & 17.04 .28 TS & L. Ralph \\
\hline Der Student von Prag - The Student of Prague & 25.10 .26 & 20.04 .28 OUT & H. Galeen \\
\hline Der letzte Walzer - The Last Waltz & 19.08 .27 & 29.12 .28 CA & A. Robison \\
\hline Die wunderbare Lüge der Nina Petrowna - The Wonderful Lie* & 15.04 .29 & 02.10 .29 CT & H. Schwarz \\
\hline Manon Lescaut - Manon Lescaut* & 15.02 .26 & 08.06 .29 CT & A. Robison \\
\hline Jugendrausch - Nemesis & 15.06 .27 & 26.02 .29 DB & G. Asagaroff \\
\hline Wolga Wolga - Volga, Volga & 15.11 .28 & 19.07 .29 CT & V. Turschanski \\
\hline Alraune - Daughter of Destiny & 25.01 .28 & 04.09 .29 NW & H. Galeen \\
\hline Soldat der Marie - Young Romance & 13.10 .27 & 23.02 .29 NW & E. Schönfelder \\
\hline Atlantik - Atlantic (T) & 28.10 .29 & 26.06 .30 CT & E.A. Dupont \\
\hline Manolescu-Der König der Hochstapler - Manolescu & 22.08 .29 & $26.07 .30 ?$ NA & V. Turschansky \\
\hline Die weiße Hölle vom Piz Palü - The White Hell of Pitz Palu & 11.10 .29 & 18.06 .31 CT & A. Fanck, \\
\hline Der Kongreß tanzt - Congress Dances (T)* & & & G.W. Pabst \\
\hline Total: Filme im Vertrieb der African Theatres & 18.09 .31 & 19.11 .32 CT & E. Charell \\
\hline
\end{tabular}

Bei einer Betrachtung der insgesamt 18 Titel fällt auf, dass meist nicht ganz aktuelle Produktionen zur Aufführung kamen. Eine Ausnahme bildete hingegen DIE WUNDERBARE LÜGE DER NINA PETROWNA, ein Film der bereits sechs Monate nach seiner Deutschlandpremiere in Südafrika gezeigt wurde. Bei den meisten anderen lag mindestens ein Jahr zwischen der Uraufführung in Deutschland und dem Erstbeleg in Südafrika. Aufgrund der geschilderten Patentlage und der Tatsache, dass sich Kinemas die Alleinvertriebsrechte für die De-Forrest-Tonfilme gesichert hatten, verwundert es nicht, dass African Theatres nur zwei deutsche Tonfilme im Programm hatten (ATLANTIK und DER KONGRESS TANZT), wobei ATLANTIK eine deutsch-britische Kopro-

\footnotetext{
${ }^{60}$ Bei den mit einem * gekennzeichneten Filmen handelt es sich um Erich Pommer-Produktionen.
} 
duktion war und in Südafrika die englischsprachige Version zur Aufführung kam.

Wie auch für Kinemas festgestellt, konnte die Bevorzugung von Filmen bestimmter Regisseure nicht belegt werden, nur Ewald André Dupont, Viktor Turschanski und Arthur Robison waren mit je zwei Filmen mehrfach vertreten. Unter den von African Theatres ins Programm genommenen deutschen Spielfilmen befanden sich allerdings sieben Erich Pommer-Produktionen (EIN WALZERTRAUM, VARIETÉ, FAUST, METROPOLIS, DIE WUNDERBARE LÜGE DER NINA PETROWNA, MANON LESCAUT und DER KONGRESS TANZT). Im Gegensatz zu Kinemas dominieren im Programm von African Theatres in Bezug auf die Zeit der Spielhandlung die historischen Sujets (elf Filme), während gegenwartsbezogene nur halb so häufig (sechs Filme) vertreten waren. Durch das futuristische Sujet konnte METROPOLIS keiner der beiden Zeitschemen zugeordnet werden.

Von den 18 durch die Schlesinger-Organisation importierten deutschen Spielfilmen entstammten zwölf der UFA oder mit ihr assoziierten Produktionen, zwei von der H.R. Sokal-Film (DER STUDENT VON PRAG und DIE WEISSE HÖLLE VOM PIZ PALÜ), die restlichen von einzelnen Produktionen wie z.B. der Stern-Film- (EIFERSUCHT), Ama-Film- (ALRAUNE), PeterOstermeyer-Film- (WOLGA WOLGA) oder der Asta-Film-Produktion (SOLDAT DER MARIE), die im Übrigen alle in Berlin angesiedelt waren. Eine Ausnahme stellte der Kriegsfilm DIE EMDEN dar, welcher von der in München ansässigen EMELKA (Münchner Lichtspielkunst) produziert wurde.

Ein Blick auf die Hauptdarsteller in den von African Theatres ausgewählten Filmen macht deutlich, dass in mehreren Fällen dieselben Schauspieler wie in den von Kinemas importierten Filmen vertreten waren. So z.B. Willy Fritsch in DER LETZTE WALZER und EIN WALZERTRAUM, Gustav Fröhlich in METROPOLIS sowie JUGENDRAUSCH. Desweiteren spielten Warwick Ward in DIE WUNDERBARE LÜGE DER NINA PETROWNA, JUGENDRAUSCH und VARIETÉ, Emil Jannings in VARIETÉ und FAUST, Werner Krauss in DER STUDENT VON PRAG und EIFERSUCHT sowie Hans Brausewetter in EIN WALZERTRAUM und SOLDAT DER MARIE.

Übereinstimmungen zwischen der Auswahl von Kinemas und African Theatres sind auch in Bezug auf die weiblichen Hauptdarsteller zu verzeichnen. Brigitte Helm spielt in METROPOLIS, DIE WUNDERBARE LÜGE DER NINA PETROWNA, ALRAUNE und MANOLESCU-KÖNIG DER HOCHSTAPLER, Lilian Harvey lediglich in DER KONGRESS TANZT. Von letztgenanntem gab es ebenfalls eine englische Sprachversion, in der die männliche Hauptrolle nicht von Willy Fritsch sondern von Henri Garat ge- 
spielt wurde (Kayser 1983: 189). Zusätzlich kamen mehrere Filme mit Lya de Puti (MANON LESCAUT, VARIETÉ und EIFERSUCHT), Camilla Horn (FAUST und JUGENDRAUSCH) und Xenia Desni (EIN WALZERTRAUM und SOLDAT DER MARIE) zur Aufführung. Bei den von der SchlesingerOrganisation importierten deutschen Spielfilmen wird die Tendenz sichtbar, dass die Auswahlkriterien für die Filme wahrscheinlich von der Besetzung der Hauptdarstellerrollen anhängig waren.

\subsubsection{Deutsche Spielfilme in unabhängigen Spielstätten}

Bei den sogenannten unabhängigen Spielstätten handelte es sich entweder um Kinos die nicht zu einer der nationalen, regionalen oder lokalen Kinoketten gehörten (z.B. Wolframs Bioscope in Kaptstadt) oder es waren Veranstaltungsräumlichkeiten von verschiedenen Organisationen (z.B. der Eisenbahnerklub in Kapstadt) oder Institutionen (Stadthallen, Gemeindehäuser etc.). Die unabhängigen Kinos waren meist mit älterer Technik ausgestattet und konnten durch die Monopolverträge der Kinoketten nicht immer zeitnah die aktuellsten Produktionen aufführen. Entschied sich eine Organisation wie z.B. der Deutsche Klub in Kapstadt eine spezielle deutsche Produktion zu zeigen, fungierte er als unabhängiger Importeur und musste die vollen Zölle und Steuern dafür entrichten. Viele Importeure oder Kleinvertriebe konnten der etablierten Konkurrenz nicht standhalten und schieden schon nach wenigen Filmen aus dem Markt aus. Da sich die Auswahl auf jene Filme beschränken musste, deren Vertrieb sich die großen Kinoketten noch nicht oder nicht mehr gesichert hatten, kamen eher ältere Produktionen zur Vorführung (Eckardt 2005: 104ff.). Durch den geringen Werbeetat der unabhängigen Veranstalter wurde für diese Filme viel weniger Reklame geschaltet als dies die großen Kinoketten taten. Demzufolge ließ sich auch nur eine geringe Anzahl von Belegen in den südafrikanischen Printmedien dazu finden. Die Berichterstattung darüber war eher sporadisch, da die Zeitungen nicht fürchten mussten, wichtige Werbekunden zu verlieren. In den unabhängigen Kinos konnten die folgenden deutschen Filme nachgewiesen werden: 
Tab. 20: Deutsche Spielfilme im Programm unabhängiger Lichtspielhäuser 1928 - 1933

\begin{tabular}{|l|c|c|c|}
\hline \multicolumn{1}{|c|}{ Filmtitel (D)- Verleihtitel (SA) } & UA & Erstbeleg (SA) & Regie \\
\hline Das Cabinett des Dr. Caligari & $1919 / 20$ & 1927 TG: 237 & C. Wiene \\
\hline Die Wiskottens - The Wiskottens & 09.04 .26 & 05.08 .29 DB & A. Bergen \\
\hline Soll und Haben & 10.10 .24 & 05.09 .29 DB & C. Wilhelm \\
\hline Luther & 16.02 .28 & 17.10 .29 DDA & H. Kyser \\
\hline Der Alte Fritz (1. Der Friede) - The Old Fritz (I.) & 03.01 .28 & 13.06 .30 CT & G.Lamprecht \\
\hline Der Alte Fritz (2. Der Ausklang) - The Old Fritz (II.) & 20.01 .28 & 18.06 .30 DB & G.Lamprecht \\
\hline Mädchen in Uniform - Maidens/Maedchen in Uniform & 27.11 .31 & 23.03 .33 RDM & L. Sagan ${ }^{61}$ \\
\hline Total: Filme bei unabhängigen Vertrieben & 7 & & \\
\hline
\end{tabular}

Die Vorführung des in Deutschland bahnbrechenden Films DAS CABINETT DES DR. CALIGARI konnte nur durch eine Erwähnung bei Thelma Gutsche belegt werden (Gutsche 1972: 237), Presseberichte o.ä. fanden sich leider nicht. Wahrscheinlich war es dem Vertrieb Anglia Films Ltd. nicht möglich, genügend Vorführungen zu organisieren, um ausreichend von der Presse wahrgenommen zu werden. Bei den zuerst in Kapstadt nachgewiesenen Filmen DIE WISKOTTENS, SOLL UND HABEN und DER ALTE FRITZ (Zweiteiler) handelt es sich um Filmvorführungen die von deutschen Kulturvereinigungen organisiert und im Klubhaus der Eisenbahner gezeigt wurden. DER ALTE FRITZ wurde danach auch im Grand vorgeführt, ein Kino das zu Schlesingers African-Theatres-Kette gehörte (CT 9.7.1930: 7). DIE WISKOTTENS wurden nicht nur vom Deutschen Klub in Kapstadt, sondern auch von jenem in Johannesburg gezeigt, eine weitere Vorführung fand in der Stadthalle zu Pretoria statt (DDA 19.9.1929: 4 bzw. 3.10.1929: 2f.). Eine ganz ähnliche Aufführungsgeschichte in Kapstadt, Johannesburg und Pretoria konnte für die Verfilmung des Gustav Freytag Romans SOLL UND HABEN nachgewiesen werden (DB 5.9.1929: 9, DDA 19.10.1929: 4).

Als ein besonderer Ausnahmefall kann der Film LUTHER angesehen werden. Ursprünglich von der Deutschen Martini-Gemeinde in Kapstadt zur Vorführung ausgewählt, konnte der Film durch Einsprüche des Zensurkomitees der Kapprovinz dort zunächst nicht aufgeführt werden, gelangte aber in Johannesburg zur Vorführung (CT 2.11.1929: 17 und DDA 17.10.1929: 3). Die religöse Thematik brachte es mit sich, dass auch in konfessionellen Zeitungen über Filme diskutiert wurde, was sonst sehr selten war.

Eine Ausnahme anderer Art stellte der 1933 in Südafrika gezeigte deutsche Spielfilm MÄDCHEN IN UNIFORM dar. Importiert von der British Universal Pictures Ltd. kam der Film vorwiegend jenseits der etablierten

\footnotetext{
${ }^{61}$ Die künstlerische Oberleitung hatte Carl Froehlich inne.
} 
Lichtspielhäuser in Stadthallen u.ä. zur Aufführung. Die deutschösterreichische Regisseurin Leontine Sagan verbrachte einen Teil ihrer Jugend in Südafrika, worauf in einigen Besprechungen auch hingewiesen wurde (ST 26.3.1933: 5). Von den in Südafrika unabhängig gezeigten deutschen Produktionen war MÄDCHEN IN UNIFORM der einzige Tonfilm.

Bei der Diversität der Importeure verwundert es nicht, dass die Auswahl der deutschen Filme in unabhängigen Spielstätten mehr oder weniger durch Zufall zusammenkam und keine UFA-Filme gezeigt wurden. Dadurch erübrigt es sich auch, nach Gemeinsamkeiten in Bezug auf Regisseure oder Darsteller zu suchen. Unterschieden werden kann lediglich zwischen den von verschiedenen unabhängigen Vertrieben importierten Filmen und jenen, welche die deutschen Vereinigungen für ihre Klubabende jenseits des normalen Kinoprogramms organisierten.

\subsection{Schlussfolgerungen aus der Programmgeschichte}

\subsubsection{Programmkontext, Erfolgsfilme, Kategorisierungen}

Wie im Eingangskapitel angekündigt, hatte die Aufarbeitung der Programmgeschichte des südafrikanischen Kinos das Ziel, eine Liste der tatsächlich vorgeführten deutschen Filme zusammenzustellen. Damit sollte umgangen werden, einen nach persönlichen Vorlieben gestalteten Kanon zu präsentieren, dessen Abarbeitung dann nach Kriterien jenseits der südafrikanischen Kinogeschichte hätte erfolgen können. Entstanden ist eine hinreichend vollständige Auflistung der deutschen Produktionen, die nach Südafrika exportiert und dort aufgeführt wurden. Diese ca. 50 Filme bilden die Stammuntersuchung und werden in Anlehnung an die maßgebliche Forschungsliteratur "S-Filme" genannt (Korte 1998: 132).

Bevor auf die Struktur des Kanons an deutschen Filmen eingegangen wird, muss erneut darauf hingewiesen werden, dass eine ausschließliche Beschränkung auf die deutschen Filme innerhalb der Programmgeschichte des südafrikanischen Kinos zu Verzerrungen führen könnte, die durch das Ausblenden der nicht-deutschen Konkurrenz im Kinoprogramm unweigerlich entstehen würde. Um den Aufwand für die Kontextualisierung der deutschen Filme im südafrikanischen Kinoprogramm auf ein erträgliches Maß zu reduzieren, wird im Anhang eine für Südafrika repräsentative Liste der in den Lichtspielhäusern Kapstadts im Zeitraum 1928 bis 1930 gezeigten Filme beigefügt (Anhang I). Die Auswahl des Zeitraums ergibt sich aus den Beleg- 
daten für die deutschen Filme. In den Jahren nach 1930 wurden nur noch wenige deutsche Produktionen gezeigt, was eine Vollerfassung des Restprogramms bis 1933 unnötig machte. Eine weitere Einschränkung stellt die Konzentration auf die beiden Premierenhäuser Alhambra und Astoria-Kinema der Kinoketten African Theatres bzw. Kinemas dar. Auch diese Begrenzung scheint durchaus berechtigt, da in unabhängigen Kinos (wie z.B. Wolframs Bioscope in Kapstadt) nicht durchgängig aktuelle Filme gezeigt wurden. Ab dem Jahre 1930 konnte zudem festgestellt werden, dass viele Produktionen erst nach Durchlaufen des Verwertungskreislaufs der großen Kinoketten bei Wolframs Bioscope ins Programm kamen (Eckardt 2005: 34). Aus diesen Gründen ist das Programm des Alhambra und des Astoria-Kinema als repräsentativ für Südafrika anzusehen. Die Gesamtheit der Filme des Zeitraums 1928 bis 1930 in Kapstadt soll hier als Kontext zur Einordnung in die Programmgeschichte als „K-Filme“ bezeichnet werden.

Tab. 21: Gesamtanzahl der „K-Filme“ in den Premierenkinos in Kapstadt 1928 - 1930

\begin{tabular}{|c|c|}
\hline Jahr & Anzahl der Spielfilme in Kapstadt \\
\hline 1928 & 74 \\
\hline 1929 & 115 \\
\hline 1930 & 79 \\
\hline Total & 268 \\
\hline Durchschnitt pro Jahr: & ca. 90 \\
\hline
\end{tabular}

Die notwendige Binnenkontextualisierung der Programmgeschichte soll allerdings nicht dazu verleiten, unendlichen Vergleichen den Vorrang gegenüber der Konzentration auf die deutschen Filme einzuräumen. Die Dominanz der Hollywoodproduktionen und der steigende Anteil britischer Produktionen durch die neu entstandene Konkurrenzsituation bilden den programmgeschichtlichen Rahmen für die Rezeption des deutschen Spielfilms.

Die vertriebsorientierte Gliederung der Programmgeschichte sollte in erster Linie den Überblick der empirischen Daten ermöglichen. Für das zeitgenössische Publikum war die Zweiteilung zwischen Kinemas und African Theatres in Bezug auf die deutschen Filme zu Anfang sicherlich bemerkbar, allerdings könnten diese Unterschiede mit der zunehmenden Anzahl deutscher Produktionen in den Programmen beider Kontrahenten geringer geworden sein. Die Filmabende der deutschen Vereinigungen zielten natürlich auf ein überwiegend deutsches oder des Deutschen kundigen Publikums ab. Aus diesem Grunde war es für die südafrikanische Presse eher von untergeordneter Bedeutung. 
Betrachtet man zunächst die Daten der Erstbelege für Südafrika fällt auf, dass die Schlesinger-Organisation bereits vor Kinemas mit der Aufführung deutscher Spielfilme begann. Selbst eingedenk des lückenhaften Überlieferungszusammenhangs der Rezeptionsdokumente kann angenommen werden, dass es bei einem zeitlichen Unterschied von 15 Monaten African Films Ltd. waren, die deutsche Filme zuerst importierten und diese dann in den Kinos der African Theatres Ltd. liefen. Damit müsste die weiter oben getroffene Annahme, dass es vor allem Kinemas waren, die zuerst deutsche Filme importierten, um das Publikum mit anderen Inhalten als dem Hollywoodstandard anzulocken, korrigiert werden. Durch die Marktsituation des Duopols und der unmittelbaren Konkurrenz war es für jeden Marktteilnehmer wichtig, auf den Erfolg des Konkurrenten damit zu reagieren, die eigene Nachfrage durch Abgrenzung bzw. Nachahmung des Konkurrenzangebotes zu stimulieren. Bezogen auf die deutschen Filme könnte Kinemas auf deren Erfolg bei African Theatres mit der genannten Ankündigung des Ankaufs des gesamten UFA-Programms des Jahres 1928 reagiert haben (Gutsche 1972: 205). Mit Blick auf die älteren UFA-Produktionen des Konkurrenten konnten Kinemas brandneue Filme ankündigen und sich so besser im Wettbewerb positionieren. Das Beobachten des Publikumserfolgs der Konkurrenz dürfte sich auch auf die Filmauswahl der Importeure ausgewirkt haben. Erwiesen sich bestimmte Filme thematisch oder darstellerisch als Flop, wurden Filme mit ähnlicher Konstellation nicht in den Vertrieb aufgenommen. Für den Spielfilm der Weimarer Republik in Südafrika ergab sich daraus eine konkurrenzübergreifende Koalition für die deutschen Produktionen, da nicht schematisch ganze Programmblöcke nach Art des ,block-booking' importiert wurden, sondern nur erfolgversprechende Filme ausgewählt und gezeigt wurden. Diese Praxis konnte sich verständlicherweise erst nach einer gewissen Anfangserfahrung einstellen. Diese Periode bis Ende 1928 wurde maßgeblich von der Schlesinger-Organisation getragen, erst danach traten Kinemas mit eigenen deutschen Verleihtiteln auf den Plan.

Diese Konstellation macht es interessant, nach Gemeinsamkeiten in den Programmen der beiden Kinoketten zu suchen. Betrachtet man nur die Filmtitel, fällt sofort auf, dass bei African Theatres mit EIN WALZERTRAUM und DER LETZTE WALZER, Filme gezeigt wurden, die als Tanz- bzw. Operettenfilme charakterisiert werden können, in denen das Traumbild von Wien als Stadt voller ,Wein, Weib und Gesang' bzw. die ,K.u.K.-Romantik' thematisiert wurden. Ähnlich verhält es sich mit DER KONGRESS TANZT, der aber als Tonfilm etwas aus dem Schema fällt. Auf den Erfolg des ersten Walzerfilms aufbauend, folgten demnach weitere Filme mit einer ähnlichen Thema- 
tik. Bei Kinemas scheint man sich ebenfalls an dieser Strategie orientiert zu haben. Mit AN DER SCHÖNEN BLAUEN DONAU, dessen Fortsetzung DAS TANZENDE WIEN und LIEBESWALZER kamen Filme mit der gleichen thematischen Ausrichtung in die Kinos. In dieses Schema fallen ferner die Filme UNGARISCHE RHAPSODIE (K) und SOLDAT DER MARIE (A), die entweder auf einer Operettenvorlage basieren oder die K.u.K.- bzw. Balkanromantik zum Sujet haben. Hier liegt die Vermutung nahe, dass die beim Konkurrenten beobachteten Publikumspräferenzen einen direkten Einfluss auf die Programmgestaltung ausgeübt haben. Die Beliebtheit dieser Inhalte beim südafrikanischen Publikum könnte demnach für jene Nachfrage gesorgt haben, auf welche die Kinoketten mit ihren Angeboten aus deutscher Produktion reagiert haben.

Auf einer tieferen Ebene, nämlich bei den Darstellern der Walzerfilme, gibt es weitere Gemeinsamkeiten. Wie in Tanzfilmen üblich, steht zumeist ein Paar (oder mehrere) im Mittelpunkt der Handlung. In den Tonfilmen LIEBESWALZER (K) sind dies Lilian Harvey und John Batten (NA 16.5.1931: 10), in DER KONGRESS TANZT (A) Lilian Harvey und Henri Garat (DB 22.11.1932: 2). Wie bereits erwähnt, spielte in den deutschen Versionen der letztgenannten Filme Willy Fritsch die männliche Hauptrolle. In den Stummfilmen EIN WALZERTRAUM (A) und DER LETZTE WALZER (A) sieht man inn an der Seite von Xenia Desni bzw. Suzy Vernon. In AN DER SCHÖNEN BLAUEN DONAU $(K)$ und DAS TANZENDE WIEN $(K)$ übernahmen Lya Mara und Harry Liedke bzw. Lya Mara und Kurt Gerron die Rolle des tanzenden Paares. Die positive Aufnahme der Darsteller aus den Tanz- und Operettenfilmen lässt weiters danach fragen, ob dieselben Schauspieler nicht auch in anderen Filmen der beiden Kinoketten vertreten waren.

Die am Beispiel der Erstbelege in Zeitungen und Zeitschriften getätigten Zuschreibungen der Aufführungsdaten sind an dieser Stelle eher als Orientierung zu verstehen, als dass daraus exakte Angaben darüber gemacht werden könnten, ob dieser oder jener Film zeitlich dem einen oder anderen vorrausging. Von einer Rekonstruktion der diesbezüglichen Reihenfolge kann sicher abgesehen werden, da sich die Programmgestaltung eher am Erfolg der Filme mit den entsprechenden Darstellern ausgrichtet haben dürfte, als nur an bestimmten Filmthemen.

Wie bereits erwähnt, war Willy Fritsch dem südafrikanischen Publikum auch als Darsteller in den von Kinemas importierten Filmen SPIONE, DIE CARMEN VON ST. PAULI, HOKUSPOKUS und FRAU IM MOND bekannt. Betrachtet man die Gesamtzahl der gezeigten deutschen Filme wird deutlich, dass Willy Fritsch in sieben der gezählten ca. 50 Produktionen zu sehen war. 
Zu noch mehr Leinwandpräsenz brachte es einzig Brigitte Helm, die in acht Filmen mitspielte (AM RANDE DER WELT, DIE JACHT DER SIEBEN SÜNDEN, DIE LIEBE DER JEANNE NEY, SKANDAL IN BADEN-BADEN, METROPOLIS, DIE WUNDERBARE LÜGE DER NINA PETROWNA, ALRAUNE und MANOLESCU-DER KÖNIG DER HOCHSTAPLER). Vergleichsweise häufig war noch Gustav Fröhlich in fünf Produktionen (METROPOLIS, HEIMKEHR, ASPHALT, ANGST-DIE SCHWACHE STUNDE EINER FRAU und JUGENDRAUSCH) zusehen, ebenso Heinrich George (DAS LETZTE FORT, DIE LEIBEIGENEN, METROPOLIS, MANOLESCU-DER KÖNIG DER HOCHSTAPLER und dem unabhängig vertriebenen SOLL UND HABEN). Ferner kann Lya de Puti mit drei Filmen (VARIETÉ, MANON LESCAUT und EIFERSUCHT) als African Theatres' ,eigener' deutscher Filmstar angesehen werden, das Gleiche gilt für Kinemas' Jenny Jugo mit ebenfalls drei Filmen (DIE TODESSCHLEIFE, DIE CARMEN VON ST. PAULI und DIE BLAUE MAUS). Die thematische Vielfalt der mit den populären Schauspielern besetzten Filme macht deutlich, dass sich die Auswahl gerade dieser Filme am ehesten an jenen mit den Darstellern verknüpften Erfolgsaussichten orientierte als an Genres oder Ähnlichem.

Die obengenannte Aufzählung wäre allerdings unvollständig, wenn man zu Zeiten der Stummfilmära nicht die Möglichkeit in Betracht ziehen würde, dass manche Schauspieler auch aus nicht-deutschen Filmen bekannt sein könnten. Am ehesten würde man dies z.B. von der ursprünglich britischen Schauspielerin Lilian Harvey erwarten, die jedoch entgegen dieser Vermutung erst in Deutschland größere Filmerfolge erzielte. An dieser Stelle gewinnt die vergleichende Perspektive auf die Programmgeschichte erneut an Bedeutung, die jedoch aufgrund der lückenhaften südafrikanischen Überlieferung nicht in jedem Falle eingenommen werden kann. Isoliert betrachtet, könnte z.B. das Mitwirken von Emil Jannings in nur zwei von der SchlesingerOrganisation importierten Stummfilmen (FAUST und VARIETÉ), sowie im von Kinemas eingeführten Tonfilm DER BLAUE ENGEL, mehr oder weniger als Zufall abgetan werden, zumal gut vier Jahre zwischen der Aufführung der beiden Stumm- bzw. des einen Tonfilmes lagen. Jannings war dem südafrikanischen Publikum jedoch nicht vollkommen unbekannt, bereits 1926 konnte es sein schauspielerisches Talent in der italienischen Produktion "Quo Vadis" (1925, R: G. D'Annunzio/G. Jakoby) bewundern (Gutsche 1972: 197 und 376). Nachdem Jannings 1927 ein Angebot Hollywoods angenommen hatte, 
entstanden dort bis 1929 sechs Filme, ${ }^{62}$ die mit der Ausnahme von "Betrayal" (1929, L. Milestone) bereits ab 1928 durch die Schlesinger-Organisation nach Südafrika importiert wurden. Daraus lässt sich schlussfolgern, dass für das südafrikanische Publikum der Schauspieler Emil Jannings nicht erst mit dem Erscheinen deutscher Spielfilme bekannt wurde, sondern sich gewissermaßen eine ansteigende Bekanntheit von "Quo Vadis" (1926) über FAUST, VARIETÉ (1927), seinen Hollywoodfilmen (1928-1929) und dem BLAUEN ENGEL (1931) manifestierte.

Wie später noch erläutert werden wird, avancierte Jannings dadurch zu dem männlichen (deutschen) Filmstar der Jahre 1928 bis 1931 in Südafrika schlechthin. Dazu beigetragen haben könnte u.a. vielleicht eine die Medienrezeption beeinflussende Verleihung des ersten Academy-Award (,Oscar') 1928/29 für die beste schauspielerische Einzelleistung in den Filmen „The Way of all Flesh" und "The Last Command“ (Ihering 1941: 33). Vor diesem Hintergrund sollte eine Analyse der Rezeption der deutschen Jannings-Filme in Südafrika unter Berücksichtigung seiner Hollywoodfilme erfolgen. Ein vergleichbares Starpotential könnte man auch Brigitte Helm zubilligen, auch wenn sie in Südafrika ausschließlich mit den deutschen Produktionen bekannt wurde.

Zählt man die deutschen Filme zusammen, in denen die Hauptrollen von Emil Jannings, Willy Fritsch, Gustav Fröhlich, Brigitte Helm und Lilian Harvey gespielt wurden - insgesamt 22, also in fast der Hälfte aller "S-Filme" -, wird nachvollziehbar, welchen großen Einfluss die Vermarktung der von einem Filmstar dominierten Filme auf die Programmgestaltung gehabt haben dürfte. Für den deutschen Film könnte sich im Gegensatz zum Hollywoodfilm positiv ausgewirkt haben, dass durch ihn in den südafrikanischen Kinos trotz der wiederkehrenden Darsteller eine gewisse Themenneuheit bzw. -vielfalt Programm war.

Daraus ergibt sich jedoch die Schwierigkeit, dass ohne das Heranziehen weiterer Inhaltsangaben bzw. dem Rückgriff auf Rezeptionsdokumente kaum weitere Kategorisierungen vorgenommen werden können. Zudem existieren je nach Quelle unterschiedliche Genreabgrenzungen, die oft nur vage inhaltsübergreifende Rückschlüsse zulassen. Zeitgenössische Zuordnungen, wie jene in den vertriebsunabhängig herausgegebenen Paimann's Filmlisten, stellten den Filmen z.B. eine Art Schlagwort voran, welches den Kinobetreibern ermöglichen sollte, ihre Erwartung an den Film mit den Publikumserwar-

62 „Der Weg allen Fleisches/The Way of All Flesh“ (1927, V. Fleming); „Der König von Soho/The Street of Sin“ (1928, M. Stiller); „Der Patriot/The Patriot“ (1928, E. Lubitsch); „Sünden der Väter/Sins of Fathers" (1928, L. Berger) und "Sein letzter Befehl/The Last Command“ (1928, J.v. Sternberg). 
tungen der kinospezifischen Klientel abzugleichen, um daraus die Erfolgsaussichten des Films noch vor der Aufnahme ins Programm ableiten zu können. Für die als Walzer- und Operettenfilme charakterisierten Produktionen existierten z.B. die Charakterisierungen als Wiener Lebensbild (AN DER SCHÖNEN BLAUEN DONAU bzw. DAS TANZENDE WIEN), Liebesdrama (UNGARISCHE RHAPSODIE bzW. DER LETZTE WALZER), Tonfilmoperette (LIEBESWALZER), Komödie (EIN WALZERTRAUM), Schwank (SOLDAT DER MARIE) oder musikalische Ausstattungskomödie (DER KONGRESS TANZT) (Anhang IV).

Ein Vorschlag, um zu einer besseren Handhabbarkeit des Korpus der „SFilme" zu gelangen, besteht nun in einer zielgerichteten Operationalisierung der in Paimann's Filmlisten enthaltenen Verschlagwortung. Für den programmgeschichtlich vorgegebenen Filmkanon der Kinoketten African Theatres ( $A$ ) und Kinemas (K) ergibt sich die Möglichkeit der folgenden Kategorisierung:

Genre 1: Kriminal- und Abenteuerfilme (total: 18; sog. Kriminaldramen und komödien, Schwänke, Artistenkomödien, Abenteuer-, Hochstapler- und Katastrophendramen):

SPIONE, DIE LIEBE DER JEANNE NEY, DER KAMPF DES DONALD WESTHOF, DIE APACHEN VON PARIS, DIE TODESSCHLEIFE, MANN GEGEN MANN, DIE CARMEN VON ST. PAULI, DIE JACHT DER SIEBEN SÜNDEN, DAS LETZTE FORT, DIE BLAUE MAUS, HOKUSPOKUS (K); FAUST, VARIETÉ, DER STUDENT VON PRAG, WOLGA WOLGA, ATLANTIK, MANOLESCU, DIE WEISSE HÖLLE VOM PIZ PALÜ (A);

Genre 2: Liebes- und Sittenfilme (total: 12; sog. Liebesdramen, Sittenbilder, Lebensbilder, Kammerspiele):

ANGST-DIE SCHWACHE STUNDE EINER FRAU, HEIMKEHR, DIE LEIBEIGENEN, ASPHALT, DER GEHEIME KURIER, SKANDAL IN BADEN-BADEN, DER BLAUE ENGEL (K); EIFERSUCHT, DIE WUNDERBARE LÜGE DER NINA PETROWNA, MANON LESCAUT, JUGENDRAUSCH, ALRAUNE (A);

Genre 3: Walzer- und Operettenfilme (total: acht):

AN DER SCHÖNEN BLAUEN DONAU, DAS TANZENDE WIEN, UNGARISCHE RHAPSODIE, LIEBESWALZER (K); DER LETZTE 
WALZER, EIN WALZERTRAUM, SOLDAT DER MARIE, DER KONGRESS TANZT (A);

Genre 4: Science Fiction- und Kriegsfilme (total: vier; sog. utopische Dramen, Monumental- u. Kriegsfilme):

FRAU IM MOND, AM RANDE DER WELT (K); METROPOLIS, KREUZER $\operatorname{EMDEN}(A)$.

Die von den unabhängigen Vertrieben importierten Filme brauchen ob ihrer geringen Anzahl hier nicht kategorisiert zu werden. Durch deren Aufführungen für ein vorwiegend deutsches Publikum war die Einstufung als , deutscher Film' (z.B. mit deutschen Zwischentiteln) am Wichtigsten.

Selbstverständlich beruht auch diese zusammenfassende Einteilung auf einer Definition durch Selbstsetzung als forschungspragmatisches Werkzeug, die das Problem der schwierigen Binnendifferenzierung der als Basis dienenden Schlagworte nicht gänzlich aufhebt. So ist es beispielsweise einleuchtend, dass Filme wie LIEBESWALZER oder UNGARISCHE RHAPSODIE genauso gut auch in die Kategorie Liebes- und Sittenfilme hinpassen würden. Durch ihren Musikbezug bzw. durch die Anleihen der historischen Stoffe aus dem Fundus der „K.u.K.-Romantik“ weisen die als Genre-3 Filme zusammengefassten Produktionen allerdings mehr übergeordnete Gemeinsamkeiten miteinander auf, als mit den anderen Liebes- und Sittenfilmen. Aufgrund der geringen Anzahl der Genre 4- Filme und ihrer nur schwer vergleichbaren Inhalte, stellt diese Zuordnung die problematischste Kategorisierungsvariante dar. Da es sich aber um eine gut überschaubare Gruppe von Filmen handelt, soll diese in anderen Analysezusammenhängen kaum zu rechtfertigende gemeinsame Kategorisierung aus pragmatischen Gründen beibehalten werden.

Als Arbeitsgrundlage sind diese Kategorien insofern nützlich, da mit ihnen festgestellt werden kann, mit welchen Filmthemen die Vertriebe das südafrikanische Publikum bedienten. ${ }^{63}$ Über den Zeitraum von 1928 bis 1933 waren alle Kategorien etwa gleich oft vertreten, zeitliche Häufungen bestimmter Themen ließen sich nicht feststellen, beide Kinoketten hatten innerhalb der Kategorien etwa den gleichen Anteil an Filmen im Programm. Etwa ein Drittel der Filme basierte auf Literaturvorlagen wie Romanen oder Novellen (Anhang IV).

${ }^{63}$ Die Hollywoodproduktionen mit Emil Jannings sind, bis auf „Der König von Soho“ (Kriminal- u. Abenteurfilm), als der Kategorie Liebes- und Sittenfilme zugehörig anzusehen. Das die definitorische Abgrenzung der Genres nicht immer besonders trennscharf ist, liegt auf der Hand. 
Wie bereits im ersten Kapitel für die Marktsituation des Polypols bzw. Duopols angenommen, kann nicht von einem signifikanten Auftreten sozialkritischer Filme gesprochen werden. Am ehesten könnte man kontroversere Tendenzen in jenen den Krieg thematisierenden Filmen AM RANDE DER WELT oder KREUZER EMDEN vermuten. Mit der Kenntnis des literarischen Ursprungs des BLAUEN ENGELS, Heinrich Manns Roman „Professor Unrat", bietet sich jedoch bereits einiges Kontextwissen, welches diesen Film als ganz besonderes ,Sittendrama' ausweist (Glöckner/Lange 2002). Zur Überprüfung dieser Annahmen soll ein Vergleich mit einer anderen Kategorisierungsvariante herangezogen werden.

Für Untersuchungen zur NS-Filmpolitik wurden Klassifikationskategorien eingeführt, um Einschätzungen zur politischen Funktion der Filme abgeben zu können. Demnach wurde in „P-Filme“, manifest politisch-propagandistische Filme, und „nP-Filme“, latent politisch-propagandistische Filme, unterschieden (Albrecht 1969: 97f.). Die „nP-Filme“ untergliederten sich zusätzlich noch in heitere, ernste und aktionsbezogene Filme (Albrecht 1969: 104f.). Die Verschiedenheit der untersuchten Zeiträume lässt hier keine direkte Klassifizierungsübernahme zu. Weiters konnte anhand der genreähnlichen Zuordnungen festgestellt werden, dass politische Inhalte kaum vertreten waren bzw. nicht offen thematisiert wurden. Somit erscheint eine Übernahme der von Albrecht vorgeschlagenen Kategorisierung nicht zweckmäßig.

In Anlehnung und Erweiterung an Albrecht führt Korte (1998) für den Zeitraum 1930 bis 1933 eine weitere Kategorie ein, die als „Psoz-Filme“ jene Produktionen aufführt, die manifest demokratische, pazifistische oder sozialkritische Tendenzen aufweisen (Korte 1998: 124). Durch die zeitliche Überschneidung der Untersuchungsperioden besteht zunächst die Möglichkeit, einige der ab 1930 produzierten und in Südafrika gezeigten Filme gemäß der von Korte vorgeschlagenen Klassifizierung einordnen zu können. Zusätzlich werden insgesamt sieben Valenzklassen eingeführt, welche die handlungsprägenden Momente (z.B. Zeit/Ort der Handlung, Handlungsmuster, Situation, Ausgang/Ende, Charakter) systematisch für jeden Film erfassen und als Grundlage für die weitere Differenzierung der Aussagen im Rahmen einer breiteren interpretatorischen Auswertung heranzieht (Korte 1998: 147). Auch dabei steht die politische Valenz im Vordergrund, wenn wie folgt unterschieden wird (ebd.: 148ff.):

- V1: Filme mit eindeutig feststellbarer humanistisch-demokratischer, pazifistisch-antimilitaristischer, sozialkritischer oder sozialistischer Aussage; 
- V2: Filme mit tendenziell humanistisch-demokratischer, pazifistischantimilitaristischer, sozialkritischer oder sozialistischer Aussage;

- V3: Filme mit neutraler Aussage;

- V4: Filme mit offen ablenkender Aussage und Funktion (im zeitgenössischen Kontext);

- V5: Filme mit aufgesetzt optimistischer Aussage, mit offen eskapistischer Funktion;

- V6: Filme mit tendenziell militaristischer, nationalistischer, nationalsozialistischer Aussage;

- V7: Filme mit eindeutig militaristischer, nationalistischer, nationalsozialistischer Aussage.

Die beiden Kategorisierungsvarianten von Albrecht und Korte ergeben zusammenfassend folgende Überblicksklassifizierung:

Tab. 22: Kategorisierungsvarianten nach Korte (1998) und Albrecht (1969)

\begin{tabular}{|l|l|l|l|l|l|l|}
\hline V1 & V2 & V3 & V4 & V5 & V6 & V7 \\
\hline manifest/latente „Psoz-Filme“ & \multicolumn{2}{|c|}{ "unpolitische“ Unterhaltungsfilme (nP) } & manifest/latente „P-Filme“ \\
\hline
\end{tabular}

Durch die Beschränkung Kortes auf die Tonfilmproduktionen und die wenigen Überschneidungen der "S-Filme" dieser Untersuchung, ergeben sich nur wenige direkte Klassifizierungsübernahmen: V2: MÄDCHEN IN UNIFORM; V3: DER BLAUE ENGEL (Erf 1930), HOKUSPOKUS; V4: LIEBESWALZER (Erf 1930); V5: DER KONGRESS TANZT (Erf 1931). Wie erwartet tauchen keine Filme mit manifest bzw. latent politischer Aussage auf. Selbst wenn MÄDCHEN IN UNIFORM als V2-Film eingestuft wurde, ist dieser durch den Vertrieb jenseits der etablierten Kinoketten als Ausnahme unter den „SFilmen" anzusehen. Es überwiegen, wie auch in der Genrezuordnung bemerkbar, relativ unpolitische Unterhaltungsfilme. Bei einer summarischen Betrachtung der "S-Filme" wird deutlich, das bis auf die Filme mit Kriegssujet AM RANDE DER WELT und DIE EMDEN alle Produktionen in die Kategorien $\mathrm{V} 3$ bis $\mathrm{V} 5$ fallen, also mehr oder weniger allesamt als unpolitische Unterhaltungsfilme kategorisiert werden können. Wie bei MÄDCHEN IN UNIFORM bemerkt, trifft dies nicht auf die meisten der von unabhängigen Vertrieben importierten Filme zu, da diese oft zur Aufführung in deutschen Klubs bestimmt waren und somit ein hohes $\mathrm{Maß}$ an Identifizierbarkeit mit der alten Heimat ausdrücken sollten (z.B. DIE WISKOTTENS, LUTHER, SOLL UND HABEN oder DER ALTE FRITZ).

Die angenommene Zugehörigkeit der meisten Filme zu den Kategorien V3 bis $\mathrm{V} 5$ macht es erforderlich, einen genaueren Blick auf diese Untergruppen 
zu werfen. Bei V3 handelt es sich um Filme mit ausgeprägt ambivalenter, nicht eindeutig erkennbarer politischer Tendenz, also vor allem Kriminal- , Abenteuer-, Liebesfilme und Melodramen (Korte 1998: 149). Ähnlich verhält es sich auch mit den V4-Filmen, die sich jedoch durch ein erhöhtes Maß an menschlichen Gefühlen, Wünschen, Hoffnungen in der Handlung bzw. Darbietung auszeichnen (ebd.). In den V5-Filmen werden zwar die Bedürfnisse, Wünsche und Ängste des Publikums sichtbar, jedoch in eine euphemistische Traumwelt überführt und durch Gesang und Tanz aufgelöst. Paradebeispiel solcher Filme sind die sog. ,Depressionskomödien' die trotz gegenteiliger Erfahrungen des Publikums einen naiven, unbeschwert-fröhlichen Optimismus verbreiten (ebd.). Das formale Niveau (z.B. Ausstattung, Kameraführung etc.) vieler dieser Filme war recht hoch, das zentrale Abgrenzungskriterium zu V4 stellt der Aufstiegswunsch als dominierendes Moment der Handlung dar (ebd.: 150). Zu den Depressionskomödien muss gesagt werden, dass diese tatsächlich erst dann produziert wurden, als die Folgen der Weltwirtschaftskrise in Deutschland das Publikum erreichten, also vor allem nach 1930. Da das Gros der „S-Filme“ in den Jahren 1928 bis 1930 in Südafrika gezeigt wurde, kann nicht von einem vermehrten Auftreten dieser Filme ausgegangen werden. Der Großteil der „S-Filme“ wird demnach den Kategorien V3 und V4 zuzuordnen sein.

Die sowohl bei Korte (1998), als auch in dieser Untersuchung zu den „SFilmen" gehörenden Filme dienen als Orientierungsbeispiele für mögliche Kategorisierungsüberlegungen. Basis dieser Eingruppierungsvorschläge sind wiederum die Kurzeinschätzungen aus Paimann's Filmlisten, welche mit den zeitgenössischen Filmbesprechungen der Lichtbildbühne abgeglichen wurden. Die getätigten Kategorisierungen vermeiden an dieser Stelle bewusst den Zugriff auf die südafrikanischen Medienberichte zu den deutschen Filmen, um etwaige Unterschiede zwischen der in- bzw. ausländischen Medienrezeption nicht zu verwischen. Für alle Kategorisierungsvorschläge gilt, dass diese keine Einschätzung der künstlerischen oder filmhistorischen Bedeutung der Filme darstellen. Retrospektive, politisch-moralische Bewertungen sind damit ebenfalls nicht verbunden, vielmehr dienen die Kategorisierungen der Feststellung, welche zeitgenössisch feststellbare Funktion, die der Film für die politische Willens- und Bewusstseinsbildung des damaligen Publikums aufgrund der historischen Quellen gehabt haben muss (Korte 1998: 148). Für Südafrika bedeutet dies, dass abweichend von der getroffenen Einordnung viele Filme in der andersartigen historischen Situation, sowie unter den veränderten Rezeptionsbedingungen im Ausland eine deutlich verschiedene Wirkung gehabt haben können. 
Es stellt sich nunmehr die Frage, ob die sich abzeichnende Zweiteilung den gezeigten Filmen tatsächlich gerecht wird. Bei einer rezeptions- und wirkungsanalytischen Studie wie dieser sollte eine Kategorisierung auch in Bezug auf die Nachfrage des Publikums, also den kommerziellen Erfolg der Filme mit einbeziehen. In der Untersuchung von Korte wird diesem Anspruch dadurch Rechnung getragen, dass neben die Gruppe der "S-Filme“ eine weitere Gruppe tritt. Als "Erf-Filme“ werden die in den einzelnen Jahren besonders erfolgreichen Filme bezeichnet, deren Erfolgsgrad aus zeitgenössischen Umfragen und Statistiken abgeleitet wurde. Um den Zirkelschluss zu vermeiden, dass „Erf-Filme“ deshalb so erfolgreich waren, weil viel über diese geschrieben wurde, und die Frage nach dem Grund dafür, mit dem Erfolg dieser Filme erklärt wird, sollten noch weitere Parameter zur Kennzeichnung dieser Kategorie gefunden werden. Gerade weil diese Studie eine rezeptions- und wirkungsgeschichtliche Perspektive einnimmt, kann an dieser Stelle kein Vorgriff auf die Medienrezeption und die darin enthaltenen Aussagen über Zuspruch oder Ablehnung der Filme erfolgen. Daten zum Kassenerfolg einzelner Filme in Südafrika konnten ebenfalls nicht ermittelt werden. Unter Zuhilfenahme einiger Hinweise bei Thelma Gutsche soll diese Problematik verdeutlicht werden.

Wie bereits erwähnt, fügte Thelma Gutsche am Ende jedes Kapitels eine Liste an, welche die "outstanding films of each year" erfasste. Diese Bezeichnung scheint ganz bewusst gewählt, zumal herausragende Filme in den Augen eines Kritikers nicht in jedem Falle die erfolgreichsten sein müssen. Nach welchen Kriterien sich Gutsche bei ihrer Auswahl richtete, geht aus ihren Beschreibungen nicht hervor. Diese könnten filmästhetischen, darstellerischen, technischen oder ökonomischen Ursprungs gewesen sein. Ohne genauere Angaben ist davon auszugehen, dass es wohl eher Gutsches subjektivem Werturteil oblag, einen Film als herausragend einzustufen. Der Mangel an vergleichbaren Größen, wie z.B. der Gesamtanzahl der gezeigten Filme pro Jahr, macht es noch schwieriger einzuschätzen, ob es besonders viele oder nur wenige herausragende Filme in den entsprechenden Jahren gab. Für die Jahre 1928 bis 1930 bezeichnet Gutsche namentlich 78 Filme als herausragend (Gutsche 1972: 228ff.). Gemessen an den 268 „K-Filmen“, also der Anzahl in Kapstadt im gleichen Zeitraum gezeigten Filme, war demnach fast jeder dritte Film herausragend.

Eine recht zuverlässige Größe zur Bestimmung des Kassen- und Publikumserfolges ist die Dauer der Spielzeit einzelner Filme. Da für Kapstadt die durchschnittliche Spielzeit eines Filmes bei etwa einer Woche lag, kann angenommen werden, dass sich der positive Publikumszuspruch in einer 
längeren Spielzeit niedergeschlagen hat. Die „Erf-Filme“ aus den „K-Filmen“ wären somit all jene, die länger als fünf Tage gezeigt wurden. Insgesamt traf dies auf 41 Filme zu (Tabelle 23), wobei die Bandbreite zwischen 45 und sechs Tagen lag. Von diesen 41 Filmen sind allerdings nur 20 bei Thelma Gutsche als herausragend aufgeführt, was den Verdacht bestätigt, das nicht der in Spieltagen messbare Publikumserfolg zu der entsprechenden Einschätzung führte, sondern noch andere (subjektive) Kriterien herangezogen wurden. Unter den so ermittelten „Erf-Filmen“ befinden sich fünf deutsche bzw. deutsch-ausländische Koproduktionen: ATLANTIK, SHIRAZ, METROPOLIS, SPIONE und DIE CARMEN VON ST. PAULI, wobei einzig letzterer nicht bei Gutsche genannt wird. Der Unterschied zwischen den 78 von Gutsche genannten herausragenden Filmen und den nach der Spieldauer ermittelten 41 „Erf-Filme“, von denen nur die Hälfte bei ihr genannt wird, lässt vermuten, dass Gutsche ihre Einschätzungen auch an den ihr vorliegenden Materialumfang zu den einzelnen Filmen festmachte. Trotz der erwähnten Gefahr eines Zirkelschlusses kann davon ausgegangen werden, dass in der Presse neben den üblichen Premierenberichten häufiger über die Filme geschrieben wurde, die besonders lange im Kino liefen, Erfolg beim Publikum hatten und sich auch durch eine gewisse kontextuelle Berichterstattung (z.B. über die Hauptdarsteller, technische Tricks, kontroverse Zensurentscheidungen o.ä.) auszeichneten. Deshalb soll den recherchierten Rezeptionsdokumenten ein Materialindikator hinzugefügt werden, der besagt, wieviele filmbezogene Dokumente in den südafrikanischen Printmedien gefunden werden konnten.

\subsubsection{Ein Filmkanon und seine Systhematisierung}

Wie vermutet, unterscheidet sich die Anzahl (Quantität) der für die einzelnen Filme aufgefundenen Dokumente unabhängig von deren Qualität beträchtlich. Die Spanne reicht dabei von Filmen mit nur einem Quellenbeleg (z.B. DIE BLAUE MAUS oder SOLDAT DER MARIE) bis zu Produktion mit mehr als 30 Rezeptionsdokumenten (z.B. DER BLAUE ENGEL oder METROPOLIS). Mit Ausnahme von LUTHER als religiös kontroversem Film, konnten für die Filme unabhängiger Filmvertriebe nur unterdurchschnittlich wenige Belege gefunden werden. Dies verwundert nicht, da die infragekommende Zielgruppe - vorwiegend Deutsch-Südafrikaner - durch ihre eigenen deutschsprachigen Medien (z.B. Der Deutsch-Afrikaner, Abk. DDA) hinreichend informiert wurde. Desweiteren konnte festgestellt werden, dass sich 
für Filme der beiden großen Kinoketten ein quantitativ ähnlicher Materialkorpus zusammentragen ließ. Fügt man alle zu einer Systematisierung heranziehbaren Parameter zusammen, ergibt sich folgende Übersicht:

Tab. 23: Liste der „S-Filme" nebst Qualitätseinstufung und Standardreferenzen ${ }^{64}$

\begin{tabular}{|c|c|c|c|c|c|c|c|}
\hline MI & PFL & FK & Filmtitel & Erf-Film & VK & $\mathrm{HR}$ & TG \\
\hline & & & „Ml>10-Filme“ & & & & \\
\hline 48 & 1 & 10 & Der blaue Engel $(T)(K)^{*}$ & & V 3 & 100 & 224 \\
\hline 34 & 1 & 4 & Metropolis $(A)^{*}$ & 9 & V 5 & 107 & 217 \\
\hline 27 & - & & Mädchen in Uniform (U) & & $\vee 2$ & & 238 \\
\hline 26 & 1 & & Faust $(A) *$ & & V3 & 99 & 228 \\
\hline 25 & 4 & & Der letzte Walzer (A) & & V 4 & & \\
\hline 24 & 1 & 7 & Atlantik (T) (A) & 12 & V 4 & 8 & 229 \\
\hline 21 & 0 & & Luther (U) & & V 3 & & \\
\hline 19 & 2 & 6 & Die wunderbare Lüge der Nina Petrowna $(A)^{*}$ & & $\vee 4$ & 100 & 217 \\
\hline 18 & 1 & & Spione (K) & 6 & V 3 & 107 & 217 \\
\hline 18 & 0 & 6 & Kreuzer Emden (Die Emden) (A) & & V 6 & & 228 \\
\hline 18 & 1 & 7 & Heimkehr $(\mathrm{K})^{\star}$ & & V 4 & 100 & \\
\hline 17 & 1 & & Varieté $(A)^{\star}$ & & V 3 & 100 & 228 \\
\hline 17 & 1 & 2 & Die weiße Hölle vom Piz Palü (A) & & V3 & & 228 \\
\hline 16 & 1 & 9 & Asphalt $(\mathrm{K})^{*}$ & & V 4 & 32 & \\
\hline 15 & 2 & 1 & Der Kongreß tanzt $(T)(A)^{*}$ & & $\vee 5$ & & 251 \\
\hline 14 & 1 & 10 & Liebeswalzer $(\mathrm{T})(\mathrm{K})^{\star}$ & & V 4 & & 220 \\
\hline 13 & 5 & & Die Apachen von Paris (K) & & V 3 & & \\
\hline 13 & 3 & & Die Todesschleife (K) & & V 4 & 99 & \\
\hline 12 & 4 & & Am Rande der Welt (K) & & $\mathrm{V} 2$ & & \\
\hline 12 & 5 & & Die Carmen von St. Pauli (K) & 7 & V 4 & & \\
\hline \multirow[t]{3}{*}{11} & 0 & & $\begin{array}{l}\text { Der Alte Fritz (1. Der Friede) (U); Der Alte } \\
\text { Fritz (2. Der Ausklang) (U) }\end{array}$ & & V 3 & & \\
\hline & & & $\Sigma 22=1: 10,2: 2,3: 1,4: 2,5: 2,0: 4,-: 1$ & & & & \\
\hline & & & "MI<10-Filme“ & & & & \\
\hline 9 & 1 & & Manon Lescaut $(A)^{*}$ & & $\vee 4$ & & \\
\hline 8 & 6 & & Jugendrausch (A) & & V 3 & & \\
\hline 7 & 5 & & Die Jacht der sieben Sünden (K) & & $\vee 5$ & & \\
\hline 6 & 4 & & Die Leibeigenen (K) & & V 3 & & \\
\hline 6 & 1 & 3 & Ungarische Rhapsodie (K)* & & V 3 & & \\
\hline
\end{tabular}

${ }^{64}$ Abkürzungen: MI: Materialindikator, PFL: Paimann's Filmlisten, FK: Filmkurier, VK: Valenzklasse, HR: Hans Rompel (Rompel 1942), TG: Thelma Gutsche „outstanding films of each year“ (Gutsche 1972). Den Bewertungen in Paimann's Filmlisten wurde zur Vereinfachung ein Zahlenwert zugeordnet. Die vergebenen Qualitätsbezeichnungen sind: 0: ohne Bewertung (meist für Kultur- oder Historienfilme), 1: Schlager, 2: fast ein Schlager, 3: stark über dem Durchschnitt, 4: über dem Durchschnitt (Exklusivbild), 5: guter Mittelfilm, 6: passabler Mittelfilm, 7: unter dem Durchschnitt. Bei den „Erf-Filmen“- Erfolgsfilmen handelte es sich um die nach der Dauer der Spielzeit (Tage) in den Premierenhäusern Alhambra (A) bzw. Astoria (K) in Kapstadt im Zeitraum 1928 bis 1930 überdurchschnittlich lange gezeigten Filme (Eckardt 2005: 101f.). Erich Pommer-Produktionen wurden mit einem * gekennzeichnet. 


\begin{tabular}{|c|c|c|c|c|c|c|c|}
\hline $\mathrm{Ml}$ & PFL & FK & Filmtitel & Erf-Film & VK & $\mathrm{HR}$ & TG \\
\hline 5 & 1 & & Der Student von Prag (A) & & $\vee 5$ & 68 & 218 \\
\hline 4 & 4 & & Angst-Die schwache Stunde einer Frau (K) & & $\vee 4$ & & \\
\hline 4 & 1 & 1 & An der schönen blauen Donau (1. Teil) (K) & & $\vee 3$ & & \\
\hline 4 & 4 & 3 & Das tanzende Wien (2. Teil) (K) & & V3 & & \\
\hline 4 & 1 & 1 & Frau im Mond (K) & & $\vee 5$ & 107 & \\
\hline 3 & 4 & & Eifersucht (A) & & $\vee 3$ & & \\
\hline 3 & 3 & 2 & Wolga Wolga $(A)$ & & V3 & & \\
\hline 3 & 4 & & Das letzte Fort (K) & & V3 & & \\
\hline 3 & 4 & & Die Liebe der Jeanne Ney (K) & & V 3 & & 228 \\
\hline 3 & 2 & & Hokuspokus $(T)(K)^{*}$ & & $\vee 4$ & & \\
\hline 3 & 4 & & Die Wiskottens (U) & & V3 & & \\
\hline 3 & 4 & & Soll und Haben (U) & & $\vee 3$ & & \\
\hline 2 & 2 & & Alraune (A) & & $\vee 4$ & & \\
\hline 2 & 2 & & Manolescu-Der König der Hochstapler (A) & & $\vee 4$ & & \\
\hline 2 & 1 & 10 & Ein Walzertraum $(A)^{*}$ & & V 5 & & \\
\hline 2 & 4 & & Der Kampf des Donald Westhof (K) & & $\vee 4$ & & 229 \\
\hline 2 & 2 & & Mann gegen Mann $(\mathrm{K})$ & & $\vee 3$ & & \\
\hline 1 & 2 & & Der geheime Kurier (K) & & V 3 & & \\
\hline 1 & 5 & & Skandal in Baden-Baden (K) & & $\vee 3$ & & \\
\hline 1 & 4 & & Die blaue Maus $(\mathrm{K})$ & & V3 & & \\
\hline 1 & 4 & & Soldat der Marie (A) & & $\vee 3$ & & \\
\hline \multirow[t]{3}{*}{1} & 1 & & Das Cabinett des Dr. Caligari (U)* & & $\vee 3$ & 99 & \\
\hline & & & $\sum 27=1: 7,2: 5,3: 1,4: 11,5: 2,6: 1$ & & & & \\
\hline & & & Nichtdeutsche Filme mit Emil Jannings & & & & \\
\hline 22 & 1 & & The Way of all Flesh(A) & 10 & $\vee 4$ & & 218 \\
\hline 19 & 1 & 8 & The Last Command (A) & & $\vee 4$ & 108 & 229 \\
\hline 10 & 2 & & Sins of the Fathers (A) & & $\vee 4$ & & \\
\hline 9 & 1 & & The Patriot (A) & & $\vee 3$ & & 229 \\
\hline 9 & 4 & & Streets of $\operatorname{Sin}(A)$ & & $\vee 4$ & & \\
\hline
\end{tabular}

Aus der obenstehenden Tabelle wird eine Zweiteilung sichtbar, für die der Materialindikator "Ml $>10$ “ bzw. „Ml<10" maßgeblich ist. Beide Gruppen sind quantitativ ähnlich verteilt (27:22), es lässt sich auch nicht nachweisen, dass bestimmte Filme einer der konkurrierenden Kinoketten von der Presse bevorzugt wurden.

Für die "Ml>10-Filme“ ist augenfällig, dass sie in Bezug auf die in sieben Stufen unterteilten Qualitätsbezeichnungen in Paimann's Filmlisten, nicht schlechter als 5 bewertet wurden, mehr als die Hälfte der 22 Filme erhielten die Bestnoten 1 bis 3, nur zwei Filme wurden mit 5 (,passabler Mittelfilm') bewertet. Vier Filme wurden nicht bewertet, MÄDCHEN IN UNIFORM konnte in den PFL nicht nachgewiesen werden. Mit Ausnahme von DIE 
EMDEN (A) verteilten sich die nicht bewerteten Filme auf die der unabhängigen Vertriebe, was die Vermutung bestätigt, dass es sich eher um Historien- oder Kulturfilme gehandelt hat, als um Spielfilme mit Unterhaltungscharakter. Da die stark unterschiedliche Zugänglichkeit zu den einzelnen Printmedien die Aussagekraft des Ml einschränkt, soll versucht werden, die Filme mit hohem MI mit jenen Filmen abzugleichen, die sich durch eine überdurchnittliche Spielzeit in Kapstadt auszeichneten, ebenso, ob sie bei Thelma Gutsche als "outstanding" geführt wurden. Für die Filme METROPOLIS, ATLANTIK und SPIONE korreliert ein hoher MI mit einer längeren Spielzeit und einer Erwähnung bei Thelma Gutsche. Insgesamt werden sieben der 22 „Ml>10-Filme“ bei Gutsche als „outstanding“ geführt, vier hatten eine überdurchschnittliche lange Spielzeit in Kapstadt. Die "Ml>10-Filme" sind also am ehesten mit den „Erfolgsfilmen“ („Erf-Filme“) der als Beispiel benutzten Studie von Korte (1998) vergleichbar. Zur Absicherung dieser Einschätzung sind die aus Leserumfragen der Zeitschrift Filmkurier ermittelten Platzierungen der beliebtesten Filme im Zeitraum 1925 bis 1932 ebenfalls gelistet (Garncarz 1994: 122f.).

Die getätigten Beobachtungen lassen somit den Schluss zu, dass eine umfangreiche Medienrezeption (hoher MI) jenen Filmen zuteil wurde, die infolge des Publikumszuspruches länger als gewöhnlich (>5 Tage) gezeigt wurden, filmisch-darstellerisch hervorragend waren (Gutsches „outstanding“) und in der Einschätzung der Publikumsattraktivität durch unabhängige Dienstleister für die Filmvertriebe (PFL-Qualitätsbewertung) weit vorne lagen. Gut die Hälfte der „Ml>10-Filme“ fand sich auch unter den vom Leserpublikum des Filmkuriers zu den zehn besten Filmen in Deutschland gekürten Produktionen (Garncarz 1994: 122ff.). Somit kann der relativen Willkürlichkeit des Materialindikators zugute gehalten werden, dass tatsächlich nur außergewöhnlich erfolgreiche Filme eine gesteigerte Medienrezeption nachsichzogen und der $\mathrm{Ml}$ als geeignetes Hilfsmittel zur Einschätzung der Bedeutung einzelner Filme innerhalb der Programmgeschichte verwendet werden kann. Ganz am Rande muss noch bemerkt werden, dass der von Erich Pommer produzierte Anteil der „S-Filme" (*, 14 Filme) durchweg als sehr erfolgversprechend eingeschätzt wurde (PFL stets $\geq 2$ ) und sich neun der 14 Pommer-Produktionen unter den „Ml>10-Filme“ befanden.

Die als Sonderfall auch verzeichneten Hollywood-Filme mit Emil Jannings können den „Ml>10-Filmen“ zugeordnet werden, da sie im Wesentlichen die aufgeführten Kriterien erfüllen.

In Abgrenzung zu den genannten Filmen der ersten Gruppe stellen die "Ml<10-Filme" Produktionen dar, die bis auf die unterste PFL- 
Qualitätsbezeichnung (7: unter dem Durchschnitt) alle Kategorien umfassen, wobei der größte Anteil auf die Note 4 (,über dem Durchschnitt') entfällt und mit Note 1 bis 3 bewertete Filme deutlich seltener auftreten als in der Gruppe der "Ml>10-Filme“. Von den Filmen der zweiten Gruppe werden lediglich zwei Produktionen bei Gutsche als ,outstanding' erwähnt, keiner der Filme hatte eine längere Spielzeit in den Kapstädter Lichtspielhäusern der Jahre 1928 bis 1930. Für ca. die Hälfte der „Ml<10-Filme“ konnten lediglich bis zu fünf Pressebelege gefunden werden. Für diese Gruppe ist anzunehmen, dass sie vom Publikum nur mit einem durchschnittlichen Zuspruch bedacht wurden (durchschnittliche Spielzeit <5 Tage), dies von unabhängigen Dienstleistern für die Filmvertriebe ähnlich gesehen wurde (schlechtere PFL-Bewertung), qualitativ-filmisch nicht herausragend waren (keine ,outstanding'-Nennung bei Gutsche) und dadurch ein entsprechend geringes Medienecho hervorrief. Der niedrige Materialindikator als quantitatives Hilfsmittel lässt auch in diesem Falle den Schluss zu, dass es sich bei den „Ml<10-Filmen“ um Filme handelt, deren programmgeschichtliche Bedeutung als eher nebensächlich einzuschätzen ist.

Mit Blick auf die Kategorisierung der Filme überrascht es nicht, dass sich diese (ausnahmenbereinigt) auf die Valenzklassen V3 bis V5 verteilen. Bestimmte Genrepräferenzen lassen sich aus der aufgestellten Rangliste nicht ableiten. Versucht man beispielsweise die auf Basis der Verschlagwortung in Paimann's Filmlisten durchgeführte Genrekategorisierung auf jene zehn "Ml>10-Filme" mit den höchsten MI-Werten anzuwenden, wird keine eindeutige Genrepräferenz sichtbar. Die auftretenden Häufungen der Genre 1- und Genre 2-Filme spiegeln lediglich die höhere Gesamthäufigkeit dieser Genrezuordnungen wider. Nimmt man die zehn Filme mit den niedrigsten MIWerten aller "Ml<10-Filme“, ergibt sich (ausnahmenbereinigt) eine ähnliche Verteilung.

\subsubsection{Anschlussmöglichkeiten}

Wie aus den vorangegangenen Darlegungen hervorgeht, konnte durch die systematische Auswertung der Printmedien die Rekonstruktion der Programmgeschichte des deutschen Spielfilms in Südafrika erstellt werden („SFilme“). Unter Zuhilfenahme weiterer quantitativer („K-Filme“, MI) und qualitativer (PFL, Gutsche, Rompel) Parameter konnte ein Kanon an Filmen identifiziert werden, dem eine umfangreichere Medienrezeption zu Teil wurde. In manchen Fällen könnte dies auf einen quantitativ überdurchschnittli- 
chen Publikumszuspruch zurückgeführt werden, worauf die längere Spielzeit dieser Filme in den Kapstädter Kinos hindeutet. Durch die Einordnung in bestimmte Klassen politischer Valenz wurde deutlich, dass überwiegend neutrale, politisch indifferente oder nicht eindeutig zuschreibbare Filme gezeigt wurden. Ob der unzureichenden Binnendifferenzierung soll diese Kategorisierungsmöglichkeit im Verlauf der Studie nicht weiter verfolgt werden.

Ob die unterstellten und vor allem auf quantitativ feststellbaren Tendenzen beruhenden Annahmen über die Bedeutung der Filme zutreffend sind, kann nur in einer qualitativ-vergleichenden Analyse der Rezeptionsdokumente festgestellt werden. Dazu soll aus den identifizierten Filmgruppen („Ml>10-Filme“, Genre 1 bis 4 etc. ) summarisch die Medienrezeption untersucht werden, um die Auffassungen der südafrikanischen Medien und der Zuschauer in Bezug auf die Genrezuordnungen und Kategorisierungen überprüfen zu können. Unter Beachtung der in den Medien widergespiegelten historischen Dualität der beiden vor allem sprachlich unterscheidbaren dominanten Bevölkerungsgruppen soll deren Einstellung zum deutschen Film rekonstruiert werden. Im Abgleich mit zeitgenössischen deutschen Beurteilungen (z.B. in der Lichtbildbühne) ${ }^{65}$ wird angestrebt, auf textueller Basis die erwähnten Wirkungsfaktoren zu identifizieren und vor dem spezifisch südafrikanischen Rezeptionshintergrund nachvollziehbar zu machen. Anhand eines noch zu bestimmenden Filmes könnte zudem nach den rezeptionsleitenden Signalen gesucht und diese mit den Aussagen der Rezeptionsdokumente kontrastiert werden. Durch die Synthese des verfügbaren Materials soll das zeitgenössische Rezeptionsspektrum, die dafür ursächlichen Wirkungsfaktoren und eine Differenzierung der kollektiven Rezeptionen, bezogen auf die relevanten Teilpublika (Englisch vs. Afrikaans), angestrebt werden (Korte 1998: 43).

\footnotetext{
65 „Lichtbildbühne (LBB), eine 1908 gegründete und ab 1923 täglich erscheinende ,Illustrierte Tageszeitung' mit Beilagen [...]. Die Zeitschrift bringt neben vielen Hintergrundinformationen und offiziellen Erklärungen (meist im Wortlaut abgedruckt) in der Rubrik ,Filmbesprechung' täglich drei bis vier unterschiedlich lange Rezensionen, die jeweils mit einem Namenskürzel versehen sind. [...] Der politische Standpunkt ist in Abhängigkeit von den Rezensenten betont pluralistisch: neben deutlich sozial engagierten und liberal-kritischen Positionen sind betont ,neutrale' Einschätzungen zu finden, die vorwiegend das geschäftliche Interesse der Filmindustrie im Auge haben. Auffallend ist das durchgängige Engagement für Filminhalte und -gestaltung in einem bürgerlich-liberalem Sinne, auch wenn dieses vielfach den möglichen Erfolgsaussichten (des Films) untergeordnet wird“ (Korte 1998: 136f.).
} 


\section{Ausgewählte Rezeptionsanalysen: Dokumente, Meinun- gen, Vergleiche}

Die beschriebenen Anschlussmöglichkeiten im Rahmen einer Rezeptionsanalyse sollen nun an den nach verschiedenen Kriterien kategorisierten Filmen geprüft werden. Dabei wird je nach Materiallage, Genreeinordnung, film- und kinohistorischer Relevanz ein repräsentativer Querschnitt an zu analysierenden Filmen ausgewählt, um das zeitgenössische Rezeptionsspektrum rekonstruieren zu können. Besondere Ausnahmefilme erfahren eine Detailanalyse, in welche auch die deutsche bzw. die internationale Rezeption mit eingehen. Eine exemplarische Filmanalyse wird in den Fällen vorgenommen, in denen die südafrikanische Rezeption zu Bewertungen geführt hat, die an den rezeptionsleitenden Merkmalen der Filme selbst überprüft werden müssen.

\subsection{Rezeptionsdokumente zu Filmen unabhängiger Veranstalter}

Da für die von den unabhängigen Vertrieben importierten Filme durch ihre geringe Anzahl eine tiefergehende Kategorisierung nicht zweckmäßig war, entfällt in diesen Fällen eine subsummierende Genrezuordnung. Wie bereits erwähnt, fallen die Filme MÄDCHEN IN UNIFORM und LUTHER durch ihren hohen Materialindikator unter die "Ml>10-Filme“, was eine zusammenfassende Analyse mit den übrigen Filmen der unabhängigen Importeure erschwert. Aus diesem Grund können diese zwei, ebenso wie DAS CABINETT DES DR. CALIGARI (ohne Rezeptionsdokumente), als Ausnahmen gelten und nicht an dieser Stelle mit ausgewertet werden.

Tab. 24: Filme in unabhängigen Spielstätten (ausnahmebereinigt)

\begin{tabular}{|c|c|c|l|c|}
\hline MI & PFL & FK & \multicolumn{1}{|c|}{ Filmtitel } & Erstbeleg SA \\
\hline 11 & 0 & - & Der Alte Fritz (1. Der Friede), & 13.06 .30 CT \\
& 0 & - & Der Alte Fritz (2. Der Ausklang) & $18.06 .30 \mathrm{DB}$ \\
\hline 3 & 4 & - & Die Wiskottens & $05.08 .29 \mathrm{DB}$ \\
\hline 3 & 4 & - & Soll und Haben & $05.09 .29 \mathrm{DB}$ \\
\hline
\end{tabular}

Aus den Rezeptionsdokumenten zu den drei bzw. vier Filmen geht zweifelsfrei hervor, dass die genannten Filme durch die deutschen Klubs in Kapstadt, Johannesburg bzw. Pretoria zur Aufführung kamen und hauptsächlich in deren eigenen Räumlichkeiten gezeigt wurden. Über alle drei Filme wird in der deutsch-südafrikanischen Wochenzeitung Der Deutsch-Afrikaner (DDA) berichtet, auch nehmen die einzelnen Artikel untereinander Bezug auf diese 
deutschen Filme. Von DIE WISKOTTENS und SOLL UND HABEN nahm zusätzlich nur die afrikaanse Presse Notiz, die englische Presse wiederum bedachte nur DER ALTE FRITZ mit einer ausführlicheren Berichterstattung.

Bei SOLL UND HABEN handelt es sich ebenso wie bei DIE WISKOTTENS um Literaturverfilmungen, die auf den gleichnamigen und damals sehr populären Romanen von Gustav Freytag bzw. Rudolf Hertzog basieren. Beide gelten als typische Kaufmannsromane des 19. Jahrhunderts (Pohl 1988), deren Kenntnis die Besprechungen als selbstverständlich voraussetzten (DDA 19.9.1929: 4 bzw. DDA 10.10.1929: 4) und deshalb nur kursorisch auf den Inhalt eingegangen wurde (DDA 3.10.1929: 2). Im Mittelpunkt der Besprechungen stand vor allem der Unterschied zwischen dem deutschen und dem US-amerikanischen Film (behutsamer Handlungsaufbau vs. Aktionsbezogenheit und ,sex-appeal'), die überzeugende Natürlichkeit der schauspielerischen Leistung und die außerordentliche gute Schilderung des deutschen Familienlebens, welche die Sehnsucht nach der alten Heimat weckte. Bei SOLL UND HABEN erwähnt die deutsch-südafrikanische Filmkritik die virtuose Darstellung der verschiedenen jüdischen Typen, die in Paul Graetz (,Veitel Itzig') als besten Schauspieler des Films ihren Höhepunkt findet.

Die afrikaanse Filmkritik zu SOLL UND HABEN, für die kein geringerer als Hans Rompel seine Besprechung mit H.R. initialisierte, berichtete über einen altmodisch-romantischen Film, der zwar gut bebildert sei, die Regie aber nur eine bruchstückhafte Produktion auf die Beine stellte, die zudem durch eine schier unendliche Anzahl neu auftauchender Personen die eigentliche Erzählhandlung verdunkelte (DB 5.9.1929: 9). Rompel erkannte aber die Mühe der Darsteller Heinrich George und Mady Christians an, sich für ihre Rollen vollkommen aus der sonst für sie gewohnten Schauspielerei zu lösen. Auch für DIE WISKOTTENS machte der Rezensent deutlich, dass er den Film nicht für einen der besten deutschen Filme hielt, die in Südafrika gezeigt wurden (DB 5.8.1929: 8). Für ihn gab es zu viele (deutsche) Zwischentitel und Textpassagen, die Erzählung entwickele sich zu langsam und zur psychologisierenden Darstellung eigne sich eben nicht jeder Stoff. Hervorstechendes Merkmal aller deutschen Filme, und so auch dieses, sei jedoch die Natürlichkeit mit der das menschliche Leben dargestellt werde, in der kein Platz für die kreischend-unechte Abgeschmacktheit der amerikanischen Filme ist. Die Photographie besteche durch die typisch warmen Töne, welche die UFA das südafrikanische Publikum schätzen gelehrt habe. Harry Liedtkes einfaches aber durch und durch gefühlvolles Schauspiel werde noch lange in Erinnerung bleiben. Einzig die Rolle der Mabel White als leichtsinniges Frau- 
chen in Schauspielermanier, entspreche so nicht der Figur aus Herzogs Roman.

Abgesehen von den etwas euphorischen Kommentaren zu SOLL UND HABEN bzw. DIE WISKOTTENS aus der deutschsprachigen Presse, deckt sich die südafrikanische Rezeption mit der Einschätzung der Filme aus Paimann's Filmlisten als „über dem Durchnitt“. Die Eingruppierung als V3-Film mit neutraler Aussage kann anhand der südafrikanischen Rezeptionsdokumente zu SOLL UND HABEN voll und ganz bestätigt werden. Gustav Freytags Romanvorlage, bestehend aus drei sich am Scheitelpunkt der Handlung kreuzenden Dramen eines Aristokraten, eines Kaufmanns und eines Juden, gilt durch seine dramaturgische Schwarzweißmalerei und die Überlegenheitsdemonstration des deutschen Nationalcharakters mittels eines negativen Gegenüber in Gestalt des Judentums als klischeehaft und tendenziell antisemitisch (Jens 1989: 822). Diese konfrontative Überzeichnung kritisierte Theodor Fontane bereits bei Erscheinen des Romans (1855: 63). Später auch als ,deutsche Ideologie' bezeichnet, wurde diese Dramatisierung nach den Erfahrungen der NS-Diktatur als problematisch angesehen (Hubrich 1974). Die zeitgenössische Kritik sah in der Romanverfilmung jedoch eher die Darstellung eines interesseverdienenden historischen Dokumentes, die jüdische Komponente des Films wurde nur beiläufig und ohne wahrnehmbare Tendenz erwähnt.

Der als Zweiteiler produzierte und aufgeführte Film DER ALTE FRITZ wurde im Juni/Juli 1930 in Kapstadt ${ }^{66}$ gezeigt und besonders von der englischsprachigen Presse ausführlich besprochen. ${ }^{67}$ Bereits in der ersten Vorführungsankündigung wurde Otto Gebühr in der Hauptrolle (Friedrich II. von Preußen) als ausgezeichneter Darsteller erwähnt (CT 13.6.1930: 9). Auch der unidentifiziert gebliebene Rezensent der Cape Times initialisierte seine Besprechung und lobte den Film als gelungene Charakterstudie in der trotz dreier Erzählstränge (Friedrich II, seine Ehefrau und sein Neffe) keine unecht wirkenden Akteure vertreten seien (CT 17.6.1930: 7). Hollywood könne zudem von DER ALTE FRITZ lernen, wie man eine königliche Hofgesellschaft in Szene setzt, ohne pompös zu wirken. Den deutschen Zwischentiteln war leicht zu folgen, auch reichte die Handlung alleine aus, um die Aktionen der Charaktere zu begreifen. Während der erste Teil des Films als heiter und humorvoll wahrgenommen wurde, schätzte man den zweiten Teil als ernst

\footnotetext{
${ }^{66}$ Am 20.6.1930 wurde der Film auch an der benachbarten Universität Stellenbosch (ca. 30 km entfernt) gezeigt (CT 19.6.1930: 7).

${ }^{67}$ CT 13.6.1930: 9; DB 14.6.1930: 8; CT 17.6.1930:7; DB 18.6.1930: 9; CT 19.6.1930: 7; CT 23.6.1930:

7; СT 7.7.1930: 7; 8.7.1930: 7; 9.7.1930: 7.
} 
und nachdenklich ein (CT 19.6.1930: 7). Die dramaturgische Umsetzung von Leben und Altern des Königs, dargestellt durch einzelne unbedeutende Vorfälle, die erst in ihrer Gesamtheit das Bild des einsamen, mürrischen und vom Volk immer weniger geschätzten Monarchen ergeben, wurden unübertrefflich durch Otto Gebühr verkörpert. Im Kommentar zur Schlussszene drückt der Rezensent unmissverständlich seine Begeisterung für diesen Film aus:

„In Frederik, Otto Gebühr has created a character that is among the finest I have met with in life and in literature, and certainly loveable. It was something more than mere film sentiment that made the closing scenes of Frederick's life not the easiest. I have had to watch, though they were handled delicately and with a restraint that comes from a genius. It was a tribute to some of the finest acting I have ever seen. [...] I shall look forward to the next German film from the same studio" (ebd.).

In einer längeren Besprechung wurde DER ALTE FRITZ mit der ebenfalls in Kapstadt gezeigten französischen Produktion „Napoleon“ (1927, A. Gance) verglichen (CT 23.6.1930: 7). Der für Hollywoodprodukte üblichen Unterscheidung in Unterhaltungsfilme und pseudo-künstlerische Unternehmungen entzögen sich beide Filme, stattdessen böten beide Unterhaltung und künstlerischen Anspruch. Auffallend war jedoch die konträre Umsetzung dieser Kombination durch den französischen Regisseur in Abgrenzung zu seinem deutschen Gegenüber. In „Napoleon“ bemerkte der Rezensent den von Beginn an etwas bemüht wirkenden Anspruch, einen künstlerischen Film schaffen zu wollen, während bei DER ALTE FRITZ, wie auch bei anderen in Kapstadt gezeigten deutschen Filmen, die Thematik im Vordergrund stand, aus deren Umsetzung der Film als Kunstwerk entstehen solle. Daher bestehe der echte Kunstwert des deutschen Films darin, zunächst pure Unterhaltung zu sein und in dieser Einfachheit bestehe bereits seine Kunst. Während der französische Film die künstlerischen Ambitionen der Produzenten sichtbar mache, verschwanden diese in DER ALTE FRITZ hinter der überwältigenden Bedeutung der darstellerischen Fähigkeiten. Als überaus naiv und primitiv wurde der in viragierten Bildern daherkommende Symbolismus in "Napoleon" bezeichnet, der nur übertrieben pathetisch wirke. Die zahlreichen Wiederholungen von Napoleons Kriegserfolgen langweilten den Rezensenten, der extensive Farbeinsatz wurde als wenig gelungen eingeschätzt, allein in zwei Szenen (der ,junge Napoleon' während einer Strafe in der Kadettenanstalt und der ,Befehlshaber Napoleon' bei seiner Flucht von Korsika) verwandele sich das Farbenspiel in ungekünstelte Schönheit. Im Gegensatz zu Otto Gebührs ,Friedrich', als unglaublich lebendiger Person, präsentiere sich Abel 
Gance' ,Napoleon' als Puppe mit nur zwei Gesichtsausdrücken. Der ,Friedrich' aus DER ALTE FRITZ hingegen wäre eine Figur von alltäglicher Köperlichkeit und schlichter Expressivität, überführt in etwas unglaublich kraftvolles und dominierendes. Dieser ,Friedrich' übe einen unwiderstehlichen Reiz auf die Vorstellungskraft aus: „Here, indeed, was a King who was a King“ (ebd.).

Im direkten Vergleich des französischen mit dem deutschen Film fiel der krasse Unterschied im Anspruch der einzelnen Regisseure und ihrer Produkte auf. Der fränzösische Film beeindrucke durch seine totale Subjektivität, während der deutsche als vollkommen objektiv eingeschätzt wurde. In letzterem gingen gewöhnliche Leute ihren normalen Tätigkeiten nach, die jedoch dadurch nicht abgedroschen wirkten, da sie der Regisseur als notwendige und aussagekräftige Details seiner Produktion anerkannt hatte. Eigentlich habe der Regisseur seinen Leuten einfach gestattet, sich wie das gemeine Volk aufzuführen, er habe bloß die Details weggelassen, die für seine Zwecke irrelevant waren. Die geistige Einstellung der Regisseure reflektiere sich so in ihren Filmen, dass in "Napoleon" das von allen anderen verschiedene Individuum im Mittelpunkt stehe, in DER ALTE FRITZ hingegen das Allgemeingültige: „The former emphasises individuality and subjectivity, whereas the latter is content to derive from what is common to all men and hence is immessureably more honour winning work" (ebd.).

Die durchgehend hohe Meinung zu DER ALTE FRITZ wird in den späteren Ankündigungen der Cape Times mehrfach wiederholt, selbst das Problem der deutschen Zwischentitel wird als unerheblich angesehen, die Darstellung im Film spreche für sich (CT 30.6.1930: 7). Zur zweiten Aufführung des Filmes in Kapstadt wurden beide Teile hintereinander gezeigt, auch wurde ob des erwarteten guten Publikumszuspruchs ein Lichtspielhaus der African Theatres-Kette, das Grand, angemietet (CT 9.7.1930: 7).

Die afrikaanse Filmkritik beschränkte sich auf zwei Berichte die vor der Aufführung des Films abgedruckt wurden und deshalb nicht als vollwertige Filmkritiken angesehen werden können. Betont wurde in beiden das außergewöhnliche Schauspieltalent Otto Gebührs und die vollkommen authentische Verfilmung der historischen Figur Friedrich II. Otto Gebühr könne in einem Atemzug mit Emil Jannings genannt werden, was allein genommen schon die Garantie böte, dass es die Mühe Wert sei, den Film anzusehen (DB 14.6.1930: 8). Die deutschen Zwischentitel seien für afrikaanse Zuschauer kein sprachliches Problem, auch sei der Film vom kulturellen Standpunkt aus wertvoll (DB 18.6.1930: 9). Die Aufführung diene nebenbei dazu, die finanzielle Ausstattung der deutschen Kirche und der deutschen Schule 
zu stärken und gleichzeitig den Deutschen und ihren Freunden die Möglichkeit zu geben, gute deutsche Filme zu sehen, die nicht in den normalen Kinos gezeigt würden (ebd.).

Der Hinweis auf die historische Authentizität verwundert nicht, in Deutschland war DER ALTE FRITZ auch als Lehrfilm für den Unterricht zugelassen (Lamprecht 1969a: 6), ebenso ist die Kategorisierung als Historien- bzw. Kulturfilm in Paimann's Filmlisten gut nachvollziehbar. Für alle drei Filme gilt, dass sie für die deutsche Gemeinschaft in Südafrika eine größere Bedeutung hatten, als nur Unterhaltung bzw. heimatverbundene Themen jenseits von Hollywood zu bieten:

„Wir sehen selten in Südafrika gute deutsche Kulturfilme. Wenn jetzt der Versuch gemacht wird, typisch deutsche Filme bei uns aufzuführen, so soll hiermit auch ein Stück Werbearbeit für unser altes Vaterland geleistet werden. Im Deutsch-Afrikaner wurde oft genug darauf aufmerksam gemacht, wie notwendig Kulturpropaganda für die deutsche Weltgeltung ist. Es darf darum erwartet werden, daß dieser erste Versuch beim deutschen Publikum Pretorias jene Unterstützung findet, die er im Interesse unserer Sache verdient, damit auch in Zukunft deutsche Filmaufführungen stattfinden können" (DDA 3.10.1929: 3).

Um voreilige Schlüsse aus Begriffen wie ,Kulturpropaganda' oder ,deutsche Weltgeltung' zu vermeiden bzw. die Unterstellung reaktionärer Tendenzen überprüfen zu können, ist eine zeitgenössische Kontextualisierung unabdingbar. Während und nach dem Ersten Weltkrieg wurde durch die britische Propaganda alles Deutsche als barbarisch und kulturlos dargestellt (Niedhardt 2006). Die Mehrzahl der Südafrika-Deutschen ohne südafrikanische Staatsbürgerschaft wurde wie Kriegsgefangene interniert (Van Dijk 2003), deutsche Waren wurden boykottiert, es kam wiederholt zu Übergriffen auf Deutsche (besonders nach dem ,Lusitania-Zwischenfall', s. Bailey/Ryan 1975) und deren Eigentum wurde geplündert (Van Dijk 2004). Die aufgehetzte Stimmung gipfelte darin, dass selbst jiddischsprachige Südafrikaner durch den ähnlichen Klang der Sprache für Deutsche gehalten wurden und von Plünderern bedroht wurden. Bei Kriegsausbruch sei die Bevölkerung Johannesburgs u.a. auch vor das Haus I.W. Schlesingers gezogen und wollte es ob seiner angeblichen Deutschfreundlichkeit anzünden, da auch sein Familienname auf eine deutsche Herkunft schließen ließ (Zapp 1938: 53). Nach Kriegsende blieb das Bild des barbarischen kriegslüsternen Deutschen (,Hunnen') in vielen Köpfen präsent. Eine Normalisierung dieser Situation erhoffte man sich durch positive Beispiele (,Kulturpropaganda') wie qualitativ 
hochwertige deutsche Filme, in denen nach der Vorstellung der SüdafrikaDeutschen die eigene Kultur unverzerrt und auf der Höhe der Zeit dargestellt wurde.

In diesem Zusammenhang soll kurz auf einen zentralen Aspekt im Rahmen der Gründungsbemühungen einer zentralgesteuerten deutschen Filmproduktion durch das deutsche Militär im Ersten Weltkrieg hingewiesen werden. Demnach galt bei der UFA-Gründung der Leitsatz „Die beste Art die Häuser zu füllen ist: Die Massen fröhlich zu unterhalten. Jeder zu absichtliche Versuch politischer und wirtschaftlicher Belehrung erreicht in der Regel das Gegenteil" (Dokumentenauszug in: Mühl-Benninghaus 2004: 301). In diesem Sinne sind auch die Ausführungen zur „Kulturpropaganda“ zu verstehen, da man es im Fall von LUTHER mit einem international attraktiven historischen Stoff zu tun hatte, über den sich ein positives Bild der Deutschen als der Nation transportieren ließ, die einen der einflussreichsten Glaubensreformer hervorgebracht hatte.

Die dem Film unterstellten Einflussmöglichkeiten auf die potentiellen Rezipienten lösten einen entscheidenden Handlungsdruck auf die aktive deutsche Filmpolitik aus. Das politische Kulturverständnis in Deutschland war damals untrennbar mit diesem Aspekt verbunden. Der Film zählte in der von deutschen Intellektuellen entwickelten Kategorisierung von Kultur und Zivilisation eindeutig zur Kategorie Zivilisation. Mit der inhaltlichen Beeinflussung des Films verbanden die Verantwortlichen gleichsam die Hoffnung, die Zuschauer aus dem „überaus unerfreulichen Zustand der Verpöbelung und Verameisung" herauszuheben (ebd.: 303f.). Als Resultat dieser Bemühungen sollte der Film dem nationalen, wie auch dem internationalen Publikum deutsche Kultur und Kunst näher bringen, also nach außen einheitlich und nach innen vereinheitlichend wirken. Die mit der UFA-Gründung verfolgte Filmpolitik bildete also vor allem einen langfristig angelegten Gegenentwurf zu den demokratischen Kulturtraditionen des Westens (ebd.).

Von einem übergeordneten politischen Standpunkt aus besehen, der die kommerziellen Aspekte des Filmgeschäfts deutscherseits als eher randständig einschätzt, könnte der Eindruck entstehen, dass die UFA als Zentralinstanz des deutschen Films das Ziel verfolgte, aus den einzelnen Spielfilmen ein unterschwelliges Programm zu formen, dessen intendierte Wirkung generell auf die Darstellung deutscher Vitalität und Stärke trotz des verlorenen Krieges hinauslief. Während sich diese Intention im Einzelwerk noch hinter der dominanten Botschaft des Films verbergen konnte oder entsprechend kontextualisiert als ausgehandelter Kode nur in abgeschwächter Form rezipiert war, könnte eine Gesamtschau des verwirklichten Filmprogramms als 
Teil des jeweiligen nationalen Kinoprogramms offenlegen, mit welchen Mitteln auf die angestrebten Ziele hingewirkt werden sollte.

Stützen lassen sich derartige Vermutungen durch Äußerungen aus den die Zentralisierung des deutschen Filmgeschäfts im Ersten Weltkrieg propagierendn Kreisen, die mit dem Film eine "nationale Selbstdarstellung" und Sympathiewerbung im Ausland „mit dem Ziel der Wiedereroberung, Sicherung und Ausbreitung der durch den Krieg verlorenen Wirtschaftsgebiete" durch „Beeinflussung der Volksstimmung" der betreffenden Länder in einer sorgfältig abgestimmten Kombination von „Kultur-, Industrie- und Verkehrspropaganda" erreichen wollten (Klitzsch in Korte 1978: 67f.). Nach Ludwig Klitzsch, 1916 Mitbegründer der Deutschen-Lichtbild-Gesellschaft, war dies nur dann erfolgreich möglich,

„Indem man den ernsten Kern der deutschen Propagandafilme mit dem üppig wuchernden Beiwerk von Dramen, Lustspielen usw. verbrämt, so daß das ausländische Publikum solange um der angenehmen Hülle willen den einstweilen noch recht fremd anmutenden Kern annimmt, bis es sich an ihn gewöhnt hat und bis der stete Tropfen den Stein gehölt hat. [...] Diese Filme müssen erheitern und nebenbei, also nicht aufdringlich belehren. Es ist das Kunststück des Regisseurs, die Handlung des Films so interessant zu gestalten, daß seine Aufführung von den Kinematographentheatern des In- und Auslandes begehrt wird" (ebd.)

Die Frage, ob dem deutschen Film damit für die kommenden Jahre ein „ideologisches Programm" vorgegeben wurde (Korte 1978: 68), lässt sich im Kontext Südafrikas erst nach einer Untersuchung des deutschen Spielfilms als geschlossenem Programmbestandteil beantworten, in dem die Filme der unabhängigen Spielstättenbetreiber nur eine marginale Rolle spielten. Wenn man in Bezug auf die Rezeption eines einzelnen Films nicht von determinierenden, sondern nur von in ihn eingeschriebenen dominanten kulturellen Ordnungen sprechen kann, „weil es immer möglich ist, ein Ereignis mittels mehr als einer ,Markierung' [...] zu klassifizieren [...] und zu dekodieren“ (Hall 1999: 103), lässt sich möglicher Weise am Filmprogramm belegen, ob der Eindruck einer ideologisch übergeordneten Programmierung wahrgenommen wurde. Dass den einzelnen Filmen ein Muster von Lesarten zugrunde lag, in welches eine bestimmte institutionelle, politische und ideologische Ordnung eingeschrieben war (ebd.), steht dabei außer Frage.

Vor dem genannten Hintergund ist auch mit ,deutscher Weltgeltung' im südafrikanischen Kontext die Frage des Umgangs mit den deutschen Kolonien gemeint gewesen. Da Deutsch-Südwestafrika (das heutige Namibia) 
seit 1919 unter südafrikanischer Verwaltung stand, die Mandatsmacht sich jedoch als neuer Kolonialherr aufspielte und die deutschstämmige Bevölkerung drangsalierte, wünschte man von deutscher Seite etwas mehr Respekt vor der ehemaligen Kolonial- und wiedererstarkten Wirtschaftsmacht. Die Hoffnung, mit der Aufführung von deutschen Filmen auf das Interesse des deutsch-südafrikanischen Publikums zu stoßen, hatte sich jedenfalls erfüllt, berichtete die Presse doch über dicht gedrängte Zuschauermassen (DB 17.6.1930: 8).

Die deutsche Rezeption von DER ALTE FRITZ war der südafrikanischen nicht unähnlich. Die Leistung Otto Gebührs wurde als überragend eingeschätzt, die Authentizität der Kameraarbeit sei eine „Art Tatsachenphotographie" (FK 4.1.28). Das Überragende der ,Friedrich'-Figur sei mehr dem Drehbuch als dem Regisseur geschuldet, darstellerisch liege Einzigartiges vor (LBB 4.1.1928). Auch der zweite Teil wurde durchgehend positiv bewertet, Otto Gebühr habe keine applausheischende Fridericus-Maske lebendig gemacht, sondern eine darstellerische Schöpfung von vollendeter Eindringlichkeit und Überzeugungskraft geboten (LBB 21.1.1928). Mögliche politische Tendenzen im Sinne einer ,deutschen Ideologie' wurden klug vom Regisseur umschifft:

„Es macht Gerhard Lamprechts Charakter alle Ehre, daß er sich durch die in diesem Stoff liegenden Lockungen zu billigen und billigsten Effekten nicht von der künstlerischen Aufgabe hat ablenken lassen, ein großartiges und geschlossenes Porträt des alternden Friedrichs zu geben, seinen Film ganz auf die Charakterstudie einzustellen" (LBB 23.1.1928).

Die Einschätzung der schauspielerisch-künstlerischen Qualität des Films gleicht in der Besprechung durch die Lichtbildbühne auffällig jener in der Cape Times beim Vergleich mit der zu „Napoleon“ geäußerten Meinung:

„Kein noch so kleiner Auftritt ohne eine persönliche Nuance und ohne eine innere Notwendigkeit und Beziehung zum Ganzen. [...] Die Personen flieBen mit der Szene zusammen, werden mit ihr und in ihr zum farbigen, atmenden Bild. Selten sah man in einem Film durchweg eine Bildgestaltung von dieser Vollkommenheit, von dieser Kultur" (ebd.).

Die Kategorisierung des Films in Valenzklasse V3 als neutralen Film wird sowohl durch die südafrikanische, als auch die deutsche Medienrezeption („Beschreibung ohne Tendenz - das ist der Kern.“ FK 21.1.1928) bestätigt. Selbst innerhalb der sprachlich getrennten südafrikanischen Rezeption bestand darüber Einigkeit, dass ein qualitativ hochwertiger Film gezeigt wurde, 
eine Art Film die man gerne öfter in Südafrika sehen würde und von der Hollywood einiges lernen könne.

Diese auf jedes vorliegende Rezeptionsdokument eingehende Analyse ist nur bei einer deutlich beschränkten Anzahl von Filmen (3 bzw. 4) und einem überschaubaren Materialfundus (17 Dokumente) möglich. Die Ausnahme der in unabhängigen Spielstätten aufgeführten deutschen Filme erlaubte dieses Vorgehen jenseits der Genrezuordnung bzw. des Materialindikators, es muss allerdings auf diesen Sonderfall beschränkt bleiben.

\subsubsection{Ausnahmefilm I: MÄDCHEN IN UNIFORM}

Die bedeutendste Ausnahme unter den von unabhängigen Veranstaltern aufgeführten Filmen stellt das von der Deutschen Filmgemeinschaft produzierte Jugenddrama MÄDCHEN IN UNIFORM dar. ${ }^{68}$ Der Film verfügt über den dritthöchsten MI-Wert (27) aller „S-Filme“, nach Korte fiel der Film mit pazifistisch-antimilitaristischer Tendenz eindeutig in die Valenzklasse V2 (Korte 1998: 192). Folgt man den Einschätzungen Siegfried Kracauers, hielt man den Film in Deutschland für den besten des Jahres 1931, in den USA sprach man begeistert von einem der humansten Filme die je gedreht wurden (Kracauer 1995: 239).

Tab. 25: Ausnahmefilme unabhängiger Veranstalter

\begin{tabular}{|c|c|c|l|c|}
\hline MI & PFL & FK & \multicolumn{1}{|c|}{ Filmtitel } & Erstbeleg SA \\
\hline 27 & - & & Mädchen in Uniform & 08.03 .33 CT \\
\hline 21 & 0 & & Luther & 05.09 .29 DB \\
\hline
\end{tabular}

Mit dem Aufführungsjahr 1933 ist MÄDCHEN IN UNIFORM der letzte in Südafrika gezeigte Film aller "S-Filme“, da sich im Programm der Kinoketten für die folgenden Jahre keine deutschen Filme mehr nachweisen ließen. Bereits für das Jahr 1932 ließ sich nur DER KONGRESS TANZT (Erstbeleg 19.11.32) als einziger deutscher Film im Programm der südafrikanischen Kinoketten belegen. Diese Rechercheergebnisse können als zuverlässig angesehen werden, was darüber hinaus durch den Einbruch des deutschen Filmexports nach Südafrika bestätigt wird (s. Kapitel 4).

Eine weitere Besonderheit bei MÄDCHEN IN UNIFORM stellt die Tatsache dar, dass der Film durch den neuen unabhängigen Verleih „British Universal Pictures" vertrieben wurde (CT 8.3.33: 7) und die Aufführungen vor-

${ }^{68}$ CT 8.3.33: 7, RDM 23.3.33: 7, ST 26.3.33: 5, NA 3.4.33: 9, NM 1.4.33: 21, TF 21.4.33: 9, VB 21.4.33:

7, DB 2.5.33: 2, CT 2.5.33: 7 (Kapstadt, Johannesburg, Durban, Bloemfontein, Kapstadt). 
zugsweise außerhalb der organisierten Lichtspielhäuser in angemieteten Stadthallen oder Ähnlichem stattfanden (RDM 23.3.33: 6). „British Universal Pictures" gelang es indes nicht, sich am Markt zu etablieren und stellte seine Bemühungen infolge finanzieller Schwierigkeiten nach MÄDCHEN IN UNIFORM ein (Gutsche 1972: 238).

Der Film selbst erzählt die Geschichte der verwaisten Manuela, die in ein Mädchenstift für adlige Offiziers- und Soldatenkinder aufgenommen wird. Unter preußischer Zucht und Strenge droht das sensible Mädchen innerlich zu zerbrechen, bis es Hoffnung in der mütterlichen Zuneigung einer der Erzieherinnen erfährt. Im Überschwang ihrer Gefühle nach einem erfolgreichen Theaterstück und berauscht vom Alkohol, gesteht sie ihre von Pubertätsleidenschaft getragene Verehrung, was von der Stiftsoberin als ein Skandal angesehen wird. Angsichts der zu erwartenden drakonischen Strafen (Isolation) und des angedrohten Verweises der verständnisvollen Erzieherin, unternimmt Manuela einen Selbstmordversuch, der durch ihre Mitschülerinnen vereitelt wird.

Die Öffentlichkeit erfuhr zuerst durch die angekündigte Absicht des neuen Filmverleihs, dass MÄDCHEN IN UNIFORM nach Südafrika importiert werden sollte (CT 8.3.33: 7). Besonders interessant für die Presse war der Umstand, dass die Regisseurin des Films, Leontine Sagan (Reisepass ausgestellt auf ,Medi Schlesinger', DB 9.5.33: 7), in Südafrika aufgewachsen war und als "South African woman, formerly of Johannesburg" (CT 8.3.33: 7) angekündigt wurde. Nachdem der Film fest für Südafrika gebucht war, erfolgten die üblichen Anleihen bei der britischen Presse, wonach der Film drei Monate erfolgreich in London gelaufen sei (NA 18.3.33: 7). ${ }^{69}$ Die Kritiker verschiederner Länder seien voll des Lobes gewesen und der französische Filmregisseur René Clair bzw. sogar George Bernhard Shaw hätten den Film als das Großartigste, was sie bisher gesehen, bezeichnet (ebd.).

Der Film wurde auch in Südafrika in der Version mit deutschen Dialogen wiedergegeben, allerdings hatte man erklärende englische Untertitel beigefügt. Nach der anfänglichen Enttäuschung darüber berichtete die Presse, dass die Untertitel hätten entfallen können, da die charakterstarken Bilder allein die Geschichte für jedermann verständlich erzählten (RDM 23.3.33: 6). Das dieser Film von einer Frau produziert wurde sei etwas, worauf jede Frau

${ }^{69}$ Z.B.: "Sunday Express: A great emotional experience ... I have tried to detect any flaw ... I have failed" oder "Film Weekly: One of the outstanding films of the year ... one entertainment for all discerning film fans.” (NA 18.3.33: 7) oder „Note the following: 1. Was produced by a South African woman. 2. There are no men in the cast. 3. Was awarded First Place as the World's Best Film in 1932. 4. The Prince of Wales went specially to see it. 5 . has been running for: 32 weeks in New York, 36 weeks in Paris, 30 weeks in London and 12.000 saw it Johannesburg" (NA 30.3.33: 8). 
stolz sein könne, der Film sei mehr als nur ein Film, sondern „a slice of life itself" (ebd.).

Neben der Darstellung der harten Disziplinierungsmethoden wurde die Verehrung Manuelas für ihre Erzieherin als die „emotionalen Tiefen eines sensiblen Kindes" umschrieben (ebd.). Ob das glückliche Ende des Films - im Gegensatz zum Bühnenstück - wirklich die beste Wahl war, ließ der Rezensent zwar offen, er war jedoch von der Zustimmung des Publikums überzeugt. Andere Kritiker sprachen hingegen von einer Verfälschung, die dem Stück die Wahrheit raube (NA 3.4.33: 9). Die meisten Besprechungen erwähnten auch, dass das Darstellerensemble vollkommen ohne Männer auskomme, ebenso die Bedeutung der psychologischen Komponente: „The strenght and beauty of the film depend upon its fidelity to the incalculable nuances of feminine psychology [...]" (ST 26.3.33: 5).

Die direkte Erzählweise des Films ohne die Schockeffekte eines Pudowkin oder Fritz Lang (CT 2.5.33: 7) und die übliche Gefühlsduselei wurde honoriert (NA 3.4.33: 9), ein Film ganz ohne Morde, Prügeleien und Unfälle (VB 21.4.33: 7), der den Zuschauer durch seine starke Handlung und ausgezeichnete Fotografie dennoch packe und festhalte (DB 2.5.33: 2). Das Verbot des Films in einigen Ländern Europas erklärte man mit den psychologischen Aspekten der Handlung, gleichwohl sei nichts Anstößiges zu sehen gewesen (NM 3.4.33: 7).

Hinter den ,psychologischen Aspekten' wird verdeckt auf die emotional aufgeladene Lehrer-Schüler Beziehung hingewiesen, die mit der Schilderung der ,stahlharten Strenge, ${ }^{70}$ des Alltages im Mädchenstift das zweite Hauptmotiv des Films bildet (Toeplitz 1985: 218f.). Der Film MÄDCHEN IN UNIFORM trage das Siegel der Ernsthaftigkeit und Kunstfertigkeit, da er auf hoher Ebene ein menschliches Problem behandele, welches die, die es trifft, hochgradig aufwühle und jede Frau und jeden Mann mit menschlichen Gefühlen anspreche (CT 2.5.33: 7). Den zeitgenössischen Kritikern blieb die Brisanz des persönlichen Verhältnisses eines weiblichen Zöglings mit dessen Lehrerin nicht verborgen, was folgende Stellungnahme belegt:

„In a note on the programme, I notice, it is stated that Manuela [...] falls in love with the one humane mistress [...]. This is a crude way of expressing the actual human reaction. Love, as the authoress herself carefully points out, taken many forms and 'girls of that age and type need an object for their affection'. Manuela turns to Fräulein von Bernburg as a flower towards the sun. It is a deep instinctive necessity of her being. The distinc-

70 „In die staalharde strengheid van 'n adelike meisieskool in Potsdam [...]“ VB 21.4.33: 7. 
tion is important for otherwise the true point of this memorable film is lost. That is why MÄDCHEN IN UNIFORM has such a wide appeal in that it catches up something of the age-old war between rule by love and rule by force. This is far more than a study in adolescence. There is a very real human message in this story which the producer has treated with such tenderness and a rare delicacy of understanding" (NA 3.4.33: 9).

In den wenigen Bemerkungen der südafrikanischen Filmkritiker, die über eine Inhaltsangabe und das Hervorheben der filmischen Qualität hinausgehen, fällt auf, dass das Hauptmotiv des emotionalen Leidens des Mädchens eher angesprochen wird, als die gesellschaftliche Problematik des soldatischen Erziehungsideals der konservativen Kreise in Deutschland. Letzere wird allenfalls genannt „The picture portrays the effects, moral and mental, of stern, almost military discipline and repression upon girls of impressionable age" (TF 21.4.33: 9), eine weitere Problematisierung bleibt allerdings vollkommen aus. Die bildlich umgesetzte Anspielung auf die Kasernierung der Schülerinnen, z.B. durch die streng gestreifte uniformähnliche Kleidung der Mädchen, auf die der Titel anspielt, die Darstellung des Internats als eine Art Gefängnis, in der ,Zucht' herrscht und das Kommando einer Vorsteherin obliegt, die als „Friedrich der Große in Frauengestalt" (Siegfried Kracauer) versinnbildlicht wird, wurden von der südafrikanischen Kritik nicht wahrgenommen. In der stark patriarchalischen Gesellschaft Südafrikas verwundert dieses Faktum nicht, Schuluniformen gehörten damals wie heute zum Alltag und können eher als verbindendes Element des deutschen und südafrikanischen Erziehungsstils rezipiert worden sein.

Auch die deutsche Rezeption begrüßte die großartige Leistung des Regieund Produzentenkollektivs Leontine Sagan und Carl Froehlich, sprach von erfreulichem Geschmack und Anstand, sowie von spontan einsetzendem Beifall während der Uraufführung (Kracauer 1995: 516). Erstaunlicherweise blieben Kracauers Ausführungen neben dem Lob der produktionstechnischen Seite weitgehend deskriptiv (Kracauer 1995: 518). Außer einer Erwähnung der ,Pubertätsleidenschaft' und der Entthronung der Vorsteherin beschrieb er keinen der vorkommenden psychologischen und sozialen Konflikte mit dem inn sonst auszeichnenden kritischen Tiefgang. Erst in seinen Nachkriegsschriften erkannte er plötzlich „die verheerenden Auswirkungen des Preußentums auf ein sensibles junges Mädchen“ (Kracauer 1995: 237). Die 1931 noch „entthront" und als „weichendes Gespenst“ beschriebene Oberin (Kracauer 1995: 517), schmetterte Kracauer 1947 selbst mit Fanfahrenklängen ${ }^{71}$

${ }^{71}$ Bei Jerzy Toeplitz sind es Hornklänge (Toeplitz 1985: 218). 
als „unerschüttert gebliebenes Autoritätsprinzip“ zurück (Kracauer 1995: 240).

Laut einer Umfrage der Zeitung Der Deutsche hatte MÄDCHEN IN UNIFORM beim Publikum des Jahres 1931 den stärksten Eindruck hinterlassen (LBB 1.1.32):

„Es konnte ein Film das Rennen machen, der mit ganz geringen Mitteln auf Grund einer Beteiligungs-Gemeinschaft von Froelich geschaffen wurde, ein Film, der nicht einen einzigen Starnamen zeigt - und dennoch den stärksten Eindruck des Jahres hinterließ. Wenn man außerdem weiß, daß dieser Film, dem keine Riesenpropaganda zur Verfügung stand, überdies noch ein ausgezeichnetes Geschäft ist, so sind die praktischen Lehren für die Filmindustrie unschwer zu ziehen" (ebd.).

Auf eine andere Seite des Films wurde in der internationalen und vor allem der US-amerikanischen Rezeption hingewiesen:

"If you have heard that the film has Lesbian 'angles,' and expect to see a Freudian analysis, you will be disappointed. Not by the most violent stretch of the imagination can the relationship and attraction of Fräulein von Bernburg and Manuela be termed sexual. Also, there are no men in the picture and no chliches, to the relief of those who are old enough to realize that there are more potent and important problems in life than how to win a girl or lose your virginity in the manner made fashionable by popular magazines - and motion pictures" (Rodriguez 1932: 11)

Das Ausbleiben ähnlicher Bemerkungen in der südafrikanischen Rezeption legt die Vermutung nahe, dass die jene Problematik thematisierenden rezeptionsleitenden Signale im südafrikanischen Kontext keine Wirkung entfalten konnten.

MÄDCHEN IN UNIFORM attestierte man in der Sekundärliteratur bezüglich der filmischen Darstellung der gleichgeschlechtlichen Liebe eine „dezente, hundertprozentig künstlerisch empfundene Andeutung“ (Zglinicky 1956: 572). Andere sprachen von einer als lesbisch missverstandenen Beziehung zwischen einer besonders sensiblen Schülerin und einer Lehrerin (Bawden/Tichy 1977: 394f.). Die bis auf verhaltene Andeutungen zurückgenommenen lesbischen Akzente (Dahlke/Karl 1988: 278) bewahrten den Film davor, „[...] sich den unreifen Gefühlen seiner Hauptgestalt hinzugeben, wie es andere ,Triebfilme' taten" (Gregor/Patalas 1962: 148). Verfehlt wäre es auch, den Film als feministisch anzusehen, da er in einem vollkommen anderen kulturellen Zusammenhang stand und mit Filmen männlicher Filmemacher zum Thema ,weibliche Verhaltensweisen' oder ,weibliche Rollenspiele' grup- 
piert werden müsste, da die feministische Spielfilmtradition erst im Verlauf der 1960er Jahre entstand (Bawden/Tichy 1977: 202).

Aus der südafrikanischen Rezeption ließen sich ähnliche Überlegungen ohnehin nicht ableiten, da lediglich das menschliche Bedürfnis nach Zuneigung in einer als gefühllos empfundenen Umgebung aus Manuelas Verhalten geschlussfolgert wurde. Das Aufeinandertreffen der gegensätzlichen Disziplinierungsmaßnahmen ,Verständnis' vs. ,Zucht' wurden als „rule by love and rule by force" (NA 3.4.33: 9) umschrieben und nicht weiter problematisiert. Mögliche feministische Lesarten (Rich 1992) entsprechen nicht der zeitgenössisch geäußerten Medienrezeption, wenngleich es bemerkenswert ist, dass in einem ausschließlich mit Frauen besetztem Film nur Großaufnahmen der Gesichter und kaum solche von Beinen, Hüften oder anderen Körperteilen zu sehen sind (Thuleen 1994).

\subsubsection{Ausnahmefilm II: LUTHER}

Von der Existenz des Films LUTHER, in Deutschland teilweise mit den Untertiteln „Der Mönch von Wittenberg“ oder „Ein Film der deutschen Revolution“ versehen, ${ }^{72}$ erfuhr die südafrikanische Öffentlichkeit zuerst aus Korrespondentenmeldungen, wonach der Film von der britischen Zensurbehörde beanstandet und seine öffentliche Vorführung zunächst verboten wurde (CT 12.8.29: 7). Die Gründe dafür waren in den Animositäten der katholischen gegenüber der evangelischen Kirche und umgekehrt zu sehen, die vor allem auf die Darstellung des Ablasshandels bzw. die Überhöhung der Figur des Reformators beruhten (NA 4.9.29: 11). Als LUTHER nach Zensur und Schnittauflagen doch noch aufgeführt wurde, zeigten sich die Kritiker enttäuscht, interessant sei allenfalls die Darstellung des mittelalterlichen Lebens. Von der Zensur herausgeschnitten wurden vor allem die Gemetzel zeigenden Szenen:

"The general verdict of the critics is that it is a painstaking dull picture that would not have attracted much notice if there had not been a talk of banning it. The actor who plays Luther is a ponderous performer, and both he and the director have done little towards expressing the character of the great Reformer" (NA 25.9.29: 11).

Die Ankündigung der Aufführung von LUTHER in Südafrika fiel der deutschsüdafrikanischen Presse zu (DDA 17.10.29: 3), da die evangelisch-

\footnotetext{
${ }^{72}$ Vgl. Eintrag zu LUTHER unter http://www.filmportal.de.
} 
lutherische Kirche den Film privat eingeführt hatte und in ihren Gemeinden zu zeigen beabsichtigte. Für die Aufführung in Kapstadt wurde ob der deutschen Zwischentitel sogar die Bereitstellung eines Übersetzers für die des Deutschen nicht kundigen Zuschauer gemeldet (CT 30.10.29: 9). Die erste Vorstellung des Films fand am 23.10.1929 in der Stadthalle zu Pretoria ohne vor- oder nachzensierende Beanstandungen statt (DDA 31.10.29: 3 bzw. CT 8.11.29: 12). Bemängelt wurde allerdings, dass ohne landessprachliche Zwischentitel ein Teil des Publikums der Handlung nicht folgen konnte und die musikalische Begleitung eine Qual gewesen sei (DDA 31.10.29: 3). Wie wichtig der deutschen Gemeinde in Pretoria diese Vorstellung war, muss auch in Zusammenhang mit den weiter oben genannten Ausführungen zur ,Kulturpropaganda' und des Bemühens um eine vorurteilsfreie Darstellung der Auslandsdeutschen betrachtet werden:

„Parallel damit geht ein Streben von gleich großer Wichtigkeit, nämlich die Erziehung des nichtdeutschen Publikums, den deutschen Menschen durch eine nichtfeindliche Brille zu betrachten und inn in seinem wahren Wesen zu erkennen. [...] Wie der Besuch der beiden ersten deutschen Schaustellungen in Pretoria gezeigt hat, besteht ein Bedürfnis nach deutschen Filmen und ihre Vorführung kann zu einem kulturellen wie finanziellen Erfolg werden. Zu einem weiteren Gelingen ist es aber unerläßlich, daß in jeder Beziehung nur das Allerbeste geboten wird, sonst nützen wir der deutschen Sache nichts" (ebd.).

In Kapstadt hatte der Film das gleiche Schicksal wie zuvor in London. Zunächst konnte eine bereits angekündigte Aufführung durch den Einspruch der Zensurbehörde der Kapprovinz nicht stattfinden (CT 2.11.29: 17). Die Beanstandungen erfolgten durch den Druck verschiedener katholischer Organisationen, welche jedoch nur zu Zensurauflagen und nicht zu einem Verbot des Filmes führten (CT 9.11.29: 17). Um den Film entbrannte eine Kontroverse, die in den beiden konfessionellen Wochenzeitungen Kapstadts The Southern Cross (katholisch) und De Kerbode (evangelisch) mit ungewöhnlicher Härte geführt wurde. ${ }^{73}$ Dabei stand erfahrungsgemäß weniger der Film im Mittelpunkt der Debatte, dafür umso mehr die unterschiedlichen kirchenhistorischen Auffassungen über die Person Martin Luther. Die katholische Seite berief sich auf einen Passus des Zensurgesetzes ('Cinematograph Film Ordinance'), welches Eingriffe vorsah wenn „[...] scenes calculated to give offence to religious convictions or the feeling of any section of the public

${ }^{73} \mathrm{Vgl}$. The Southern Cross 6.11.29: 3f, 13.11.29: 1, 20.11.29: 3f. und De Kerbode 13.11.29: 823, 20.11.29: 869f., 4.12.29: 982. 
[...]" (Southern Cross 6.11.29: 3) gezeigt wurden. In der Kampagne gegen den Film wurden daher nur die negativen Berichte der britischen Presse zitiert und die historische Inkorrektheit des Films betont (ebd.). Bei der unvorteilhaften Darstellung von Luthers angeblichem lasterhaften Leben und dem ihn unterstellten Antisemitismus bezogen sich die Anschuldigungen eindeutig auf außerhalb der Filmhandlung liegende Begebenheiten, da der Film Luthers Entwicklung nur bis zur Bibelübersetzung führte und mit dem Abschluss von Luthers heroischer Periode endete (LBB 17.2.28: 2). Der Zensurausschuss legte Wert darauf, dass der geäußerte Verdacht von antideutschen Einstellungen seitens der Behörde unbegründet sei und schlicht nach dem Gesetz gehandelt wurde (CT 6.11.29: 10). Zur geführten konfessionellen Debatte in Südafrika lesen sich die einführenden Zeilen der Lichtbildbühne wie eine sich selbst erfüllende Prophezeiung:

„Ein Film vom kämpfenden Luthertum, ein Film, der ausschließlich auf das Werden des Reformators eingestellt ist. Das ist sein Vorzug in protestantischen Gebietsteilen Deutschlands, das ist sein Nachteil in katholischen Gebieten“" (LBB 17.2.28: 2).

Diese Einschätzung wird durch die dreimalige Zensurvorlage des Films in Deutschland unterstützt (Geller 1999: 327), für das breite Publikum wurde daher eine mit größter Vorsicht durchzuführende Umarbeitung des Titelsatzes empfohlen (PFL 1928: 83). Nach der tatsächlichen Aufführung des Films in Kapstadt berichtete die Presse, dass der Film zwar technisch gesehen klar über dem Durchschnitt liege, aber die Erwartung an etwas grundsätzlich Neues nur durch die unnötige Debatte im Vorfeld herbeigeredet wurde (CT 9.11.29: 17). Einen großen Eindruck machten die Fotografie und die Darsteller, die Effekte seien originell, die filmische Kunstfertigkeit erfrischend gewesen (ebd.).

Von deutscher Seite wurde bemerkt, dass die Fotografie sich von Experimenten ferngehalten und dadurch nirgends versagt hätte, auch wurde in den Kinobauten alles Konventionelle vermieden und das Charakteristische gesucht (LBB 17.2.28: 2). Vielleicht gelang es gerade deshalb auch dem südafrikanischen Publikum, dem Film trotz der starken Zensureingriffe zu folgen. Diese hätten den geschichtlichen Zusammenhang zwar häufig zerrissen, doch sei der Film so spannend und unterhaltsam gewesen, dass man sich nicht stets darum sorgen musste, was als nächstes passiert (DB 9.11.29: 9). Die Regie habe sowohl bezüglich der Hauptdarsteller, als auch in den Massenszenen Großartiges geleistet, auch sei das schauspielerische Können des 
Luther-Darstellers eine bemerkenswerte Leistung gewesen (ebd.). Die deutschsprachige Kritik schätzte dies weitgehend ähnlich ein:

„Die Darstellung ist in allen Rollen ausgezeichnet, Klöpfer eine Prachtgestalt, die stilgetreuen Bauten und die rein bildhafte Wirksamkeit vieler Szenen eine nachhaltige Unterstreichung der Geschehnisse. Auch die Photographie ist gut. Die Zwischentexte hingegen genügen im Vereine mit dem bildlich Dargestellten nur durch den protestantischen Religions- oder Geschichtsunterricht Vorgebildeten zum Verständnis des Ganzen“ (PFL 1928: 83).

Die letztgenannten Einschränkungen monierte auch die katholische Presse in Kapstadt und fragte sich, ob dem Durchschnittszuschauer bei den Namen der deutschen Mitstreiter Luthers und deren Schlagworte überhaupt irgendwelche Gedanken kämen, die sein Interesse am Geschehen befördern würden (Southern Cross 6.11.29: 3).

Die Wirkung von LUTHER auf das Premierenpublikum in Berlin war angeblich so stark, dass es fast zu einer Demonstration gekommen wäre (LBB 17.2.28: 2). Im Kontext der ausgehenden 1920er Jahre verwundert es nicht, dass der Film den Reformator als deutsch-nationale Symbolfigur zur Einigung des Nachkriegs-Protestantismus zeigt, der kämpferisch versucht, die reine Lehre des Evangeliums in einer neuen Kirche zu verwirklichen (Geller 1999: 327).

Bedenkt man die Entstehungszeit der in Paimann's Filmlisten als Historienfilm klassifizierten Produktion (1928) und die starke Betonung Luthers als deutsche Symbolfigur, könnte man den auf deutscher Seite unterstellten "nationalistischen Tendenzen" zwar zustimmen, diese waren aber nur im Kontext der Weimarer Republik um 1928 als solche auch wahrnehmbar. Insofern verwundert es nicht, dass LUTHER aus südafrikanischer Sicht als politisch neutraler Film eingeschätzt wurde. Die Tatsache, dass politisch stark tendenziöse Filme in Deutschland erst ab ca. 1932 in zunehmender Zahl produzier wurden (Korte 1998: 150), bestätigt diese Einschätzung.

Um alle „S-Filme“ vergleichend analysieren zu können, soll im Folgenden ein systematischeres Analyseschema zur Anwendung kommen, welches zielgerichtet nach Gemeinsamkeiten und Unterschieden in der englischsprachigen bzw. afrikaansen Medienrezeption sucht. Als Grundlage dieses Analyseschrittes dient die vorgenommene Genreeinordnung, wobei sich die gewählte Aufzählung in Genre 1 bis 4 lediglich an der Anzahl nach Genres klassifizierten Filme in den „S-Filmen“ bezieht. Die den einzelnen Genres zugeordneten Filme werden je nach Materiallage summarisch behandelt, 
wobei ein ausgewählter, für das Genre typischer Film eingehender untersucht werden soll.

\subsection{Rezeptionsdokumente zu Genre 1-Filmen: Kriminal- und Aben- teuerfilme}

Zum Genre mit der höchsten Anzahl an Filmen ließen sich für die „Ml>10Filme" 140 Rezeptionsdokumente ermitteln, für die zahlenmäßig etwa gleich starke Gruppe der „Ml<10-Filme“ 31 Dokumente. Unter den Genre 1-Filmen befinden sich zwei Tonfilme, ATLANTIK und HOKUSPOKUS, die Verteilung aller Filme unter den dominierenden Kinoketten ist etwa gleich stark. Bei einer Betrachtung der Qualitätseinschätzungen wurde die Mehrzahl der "Ml>10-Filme" mit der höchsten PFL-Wertung bedacht, von den „Ml<10Filmen" erreichte dies nur ein einziger. Da insgesamt nur drei der Genre 1Filme in den Ranglisten des Filmkuriers genannt wurden, kann die Bewertung dieses Merkmal vernachläßigt werden. Auffällig ist allerdings, dass mit den aus dem Jahre 1927 stammenden Erstbelegen für die Filme FAUST und VARIETÉ augenfällig wird, dass die Schlesinger-Organisation mit der Aufführung deutscher Produktionen damals begonnen hat. Mehr als die Hälfte der Genre 1-Filme wurden 1929 gezeigt, nach 1931 ließen sich keine weiteren deutschen Filme dieses Genres mehr nachweisen. Unter den Genre 1-Filmen befanden sich die drei Erich Pommer-Produktionen FAUST, VARIETÉ und HOKUSPOKUS. Anhand der deutschen Rezeptionsdokumente sind die Genre 1-Filme als unpolitische Unterhaltungsfilme einzuschätzen.

Tab. 26: Genre 1-Filme: Kriminal- und Abenteuerfilme 1927 - 1931

\begin{tabular}{|c|c|c|l|c|}
\hline MI & PFL & FK & \multicolumn{1}{|c|}{ Filmtitel } & Erstbeleg SA \\
\hline & & & "Ml>10 Filme“ & \\
\hline 26 & 1 & - & Faust (A)* & 07.12 .27 SCL \\
\hline 24 & 1 & 7 & Atlantik (T) (A) & 26.06 .30 CT \\
\hline 18 & 1 & - & Spione (K) & 01.02 .29 DB \\
\hline 17 & 1 & - & Varieté (A) & 11.09 .27 ST \\
\hline 17 & 1 & 2 & Die weiße Hölle vom Piz Palü (A) & 18.06 .31 CT \\
\hline 13 & 5 & - & Die Apachen von Paris (K) & 27.04 .29 DB \\
\hline 13 & 3 & - & Die Todesschleife (K) & 14.05 .29 CT \\
\hline 12 & 5 & - & Die Carmen von St. Pauli (K) & 10.08 .29 NM \\
\hline & & & "Ml<10 Filme“ & 05.10 .29 NM \\
\hline 7 & 5 & - & Die Jacht der sieben Sünden (K) & 20.04 .28 OUT \\
\hline 5 & 1 & - & Der Student von Prag (A) & 19.07 .29 CT \\
\hline 3 & 3 & 2 & Wolga Wolga (A) & \\
\hline
\end{tabular}




\begin{tabular}{|c|c|c|l|c|}
\hline 3 & 4 & - & Das letzte Fort (K) & 19.10 .29 NM \\
\hline 3 & 4 & - & Die Liebe der Jeanne Ney (K) & 25.03 .29 RDM \\
\hline 3 & 2 & - & Hokuspokus (T) (K)* & 13.07 .31 DB \\
\hline 2 & 2 & - & Manolescu-Der König der Hochstapler (A) & $26.07 .30 \mathrm{NA}$ \\
\hline 2 & 4 & - & Der Kampf des Donald Westhof (K) & $16.04 .29 \mathrm{DB}$ \\
\hline 2 & 2 & - & Mann gegen Mann (K) & $15.06 .29 \mathrm{EPH}$ \\
\hline 1 & 4 & - & Die blaue Maus (K) & $12.05 .30 \mathrm{DFA}$ \\
\hline 171 & & $\Sigma$ & 18 Filme & \\
\hline
\end{tabular}

\subsubsection{Exemplarische Dokumentenanalyse von FAUST}

Der unter der Regie von Friedrich Wilhelm Murnau gestaltete Film FAUST war zusammen mit VARIETÉ und EIN WALZERTRAUM einer der ersten deutschen Filme die von der Schlesinger-Organisation eingekauft und bereits 1927 in Südafrika vorgeführt wurden. Die Handlung des Films orientiert sich eher an der Volkssage „Faust“ bzw. Goethes „Urfaust“ (1772-1775), als an dem zweiteiligen Dramenklassiker (1808 bzw. 1832) aus der Feder Goethes. In FAUST wird der Pakt des alternden Gelehrten mit dem Teufel erzählt, wobei letzterer dem zweifelnden Faust Weisheit und Jugend verspricht, um als Gegenleistung Fausts Seele zu erlangen. Als jugendlich verwandelter Faust kann der Gelehrte die junge Margarethe verführen, nachdem Mephisto deren Mutter und Bruder aus dem Weg geräumt hat. Die Verwerflichkeit seiner Taten erkennt Faust erst, als die von ihm schwangere Margarethe wegen Kindsmordes verurteilt wird und verbrannt werden soll. Geläutert steigt der wieder zum Greis gewordene Faust auf den Scheiterhaufen, um sich gemeinsam mit seiner Geliebten dem Herrgott zu überantworten.

In Südafrika wurde FAUST $^{74}$ zuerst durch das zur SchlesingerOrganisation gehörende Branchenblatt Stage, Cinema and Listener vorgestellt, welches die Pressephotos des UFA-Verleihs bzw. der PARUFAMET mit kurzen Bildunterschriften veröffentlichte (SCL 7.12.27: 13). Vom Hauptquartier der Schlesinger-Organisation in Johannesburg gelangte der Film zuerst in die Johannesburger Kinos, worauf die Kritikerin „Treble Violl“ der dortigen Tageszeitung The Star aufmerksam machte. Ob FAUST tatsächlich ein ,super-film' sei, ${ }^{75}$ könne das Publikum Johannesburgs nun endlich selber feststellen, wobei das Markenzeichen „UFA“ bereits für Großartigkeit stehe

${ }^{74}$ SCL 7.12.27: 13, TS 12.12.27: 8, NA 31.12.27: 10, VB 12.1.28: 6, TF 13.1.28: 6, OUT 2.3.28: 56, CT 21.3.28: 10, DB 27.3.28: 8, CA 27.3.28: 9, EPH 6.4.28: 11, NW 12.5.28: 16, NM 20.4.29: 23, EPH 24.7.31: 15 (Joahnnesburg, Durban, Bloemfontein, Pretoria, Kapstadt, Port Elizabeth, Pietermaritzburg, Durban, Port Elizabeth).

${ }^{75}$ Als deutsches Äquivalent dürfte die Bezeichnung ,Großfilm', also ein abendfüllender Spielfilm, dem ,super-film' entsprochen haben. 
(TS 12.12.27: 8), da jeder UFA-Film eine unglaubliche Stärke in Sachen Filmtechnik und Handlungsführung zeige (TS 13.12.27: 10). Mit immenser Gedanken- und Vorstellungskraft habe Regisseur F.W. Murnau eine Atmosphäre verbildlicht, die in ihrer Güte nur mit Gustave Doré's Illustrationen zu Dantes Inferno vergleichbar wären (ebd.). Schauspielerisch sei Camilla Horn die größte Entdeckung dieses Films, sie habe die Jugend und genau jenen "Teutonic sentimentalism", den die Rolle erfordere. Als junger Faust sei Gösta Ekman der rechte Darsteller, als Greis aber ähnele er einem „King Lear crazed with misery“ (ebd.). Emil Jannings sei aber eine Enttäuschung, oder erwarte man von diesem begabten Schauspieler einfach zu viel (ebd.)? Die musikalische Begleitung des Films, vor allem bestehend aus Adaptionen von Gounods Oper „Faust" und anderen klassischen Kompositionen, wurde als kraftvolle Unterstützung der Filmhandlung eingeschätzt (ebd.).

Ein ganz besonderes Publikum wohnte der Premiere von FAUST in Durban bei. Der lokale Manager des zu African Theatres gehörenden „Prince of Wales"-Kinos, Mr. Moylan, hatte neben dem Kritiker des Natal Advertiser „T.J.H.“ auch Joseph Albrecht (1893-1977), den späteren Regisseur des ersten afrikaansen Tonfilms „Moedertjie“ (1931) und Begründer der südafrikanischen Filmindustrie, eingeladen. Ohne im Einzelnen auf den Inhalt des Films einzugehen - die Geschichte von „Faust" sei ohnehin jedem bekannt zählt die recht enthusiastische Besprechung des Natal Advertisers zu den seltenen Beispielen echter Filmkritik in der südafrikanischen Presse:

„To say we were amazed and delighted with the film is to put it very mildly. There where so many novell effects, so much real art in setting and photography, that the three of us, Mr. Albrecht, Mr. Moylan and I agreed that we had seen nothing so remarkable on the screen before. [...] And now for the marvellous lighting effects, no strained hard photography, but pictures which look like Rembrandt or Velasquez paintings. I have seen nothing to equal the lighting in this photoplay - it was a revelation to me. It marked that definite advance in photoplays which remove them from the arena of a cheap amusement into the higher regions of impressionistic art. [...] FAUST is more than a photoplay, it is an achievement, a definite step forward" (NA 31.12.27: 10).

Gerade der Verweis auf die der Malerei ähnliche Bildqualität von FAUST und der Vergleich mit Gemälden von Rembrandt oder Velasquez zeigt das Verständnis des Kritikers für die ästhetische Dimension von FAUST. In Lotte Eisners Standardwerk zum deutschen Filmexpressionismus „L'ecran démoniaque" (dt. "Die dämonische Leinwand“), 1952 zuerst auf Französisch erschienen, heißt es dazu ganz ähnlich: 
"The forms come through the misty light gently, opalescent. If Murnau is recalling the light-quality in Rembrandts Faust etching, he interprets it in his own fashion. Here the imprecise contours take up the supernatural theme of the opening, its resonance developing as if controlled by the pedal of a invisible pianist" (Eisner 1969: 286).

Die englische Presse fand durchgehend lobende Worte für FAUST, der Film sei "a triumph of artistic production from every conceiveable point of view" (NW 16.5.28: 7), die szenischen Effekte seien unbeschreiblich „and added to make the whole work a piece art superior to anything we have had from America since 'Intolerance'" (South African Nation 31.3.28: 17). Kritik gab es einzig zur Schneesturmszene am Ende des Films:

"Once, and once only, is the film in danger of decending to pathos. The snowstorm scene, after the betrayal of Marguerite, might have been beter managed, but that of course, is practically at the end, and is redeemed by the realistic burning at the stake with which the picture ends" (CA 27.3.28: 9).

Die geradlinig und einfach gehaltene Erzählung sei im Vergleich zu diversen Hollywoodproduktionen grundsätzlich anders (CA 27.3.28: 9). Gemessen am Publikumszuspruch war FAUST außerordentlich erfolgreich, die Presse berichtete durchgehend von vollen Lichtspielhäusern (z.B. TF 13.1.28: 6, CT 27.3.28: 10, EPH 11.4.28: 14 etc.). Obwohl das Szenario von Goethes Meisterwerk stamme, müsse man dem Regisseur und Emil Jannings dafür danken, dass es gelungen sei, das neue Medium Film an die literarische Vorgabe anzupassen (South African Nation 31.3.28: 17):

"The grandeur of the work, the imaginative terror of the conception, the katharsis of pity, none are lost in the change from poetic presentment to film picturisation. [...] This is a rare occasion for those who believe in the higher artistic future of the cinema picture" (ebd.)

Die Kritik der afrikaansen Presse hingegen machte von Beginn an deutlich, dass die Ankündigung einer Verfilmung von Goethes Meisterwerk einfach nur lächerlich sei und der Film für all jene Zuschauer eine Enttäuschung wäre, die eine werkgetreue literarische Verfilmung erwartet hätten (DB 29.3.28: 8 bzw. VB 13.1.28: 6). Dennoch könne der Films als ein ergreifendes Drama gelten, welches man nicht verpassen solle. Die Deutschen verzichteten zwar auf die Schärfe der sonst gewohnten amerikanischen Technik, aber eben dadurch wirke der Film viel künstlerischer (ebd.). 
Eine recht ausführliche Kritik von FAUST findet sich in der Kapstädter Tageszeitung Die Burger, die höchstwahrscheinlich auf Hans Rompel zurückgeht. Da FAUST gegenüber den US-amerikanischen Filmen, die man gewöhnlich in Kapstadt zu sehen bekomme, dermaßen heraussteche, wäre es schon die Mühe wert, herauszufinden, woran dies eigentlich liege (DB 27.3.28: 8). Man wisse ja, dass die UFA, Fritz Lang und seine Drehbuchschreiberin Thea von Harbou schon lange von einem ,idealen Film' träumen würden und METROPOLIS die Verwirklichung dessen wäre. In FAUST hingegen sei dies noch nicht ganz gelungen, aber bewunderswürdig sei die Anpassung des Materials an das Medium Film allemal (ebd.). Viele amerikanische Filme erinnerten noch an photographierte Theateraufführungen, die Handlung sei theatermäßig und die Erzählungen erweiterte Theaterstücke. Auch in FAUST gebe es noch Augenblicke, die stark an die Bühne erinnerten, die Schlusssequenz sei wohl nur deshalb so verändert worden, um sie packender zu machen. Den Grund dafür sieht der Rezensent im Einfluss der amerikanischen Regisseure, die wohl sogar bis in die UFA-Ateliers durchdringe (ebd.). Besonders die etwas übertrieben wirkende Schlussszene stelle ein typisch ,amerikanisches Ende' dar (DB 30.3.28: 8). Auch ein Teil der deutschen Filmkritik sah darin die Entsprechung der Wirtschaftsstruktur einer Nation, die im ,struggle for life' jedermann eine Chance zum Vorwärtskommen geben wolle (Feld 1926). Der ganze Film war aber aus südafrikanischer Sicht ein hervorragendes Beispiel einer neuen Kunst, mit neuen Ansprüchen und Möglichkeiten, eine vollkommen neue Kunsttechnik (DB 27.3.28: 8).

Als Beispiel wurde die Szene mit den vier apokalyptischen Reitern genannt, die pure Symbolik sei, verstärkt durch die zwei Lichtstrahlen, durch jene man die Reiter erst sehen könne. In der US-amerikanischen Produktion "The Four Horsemen of the Apocalypse" (1921, Rex Ingram) habe man nur die adrett photographierten Reiter gesehen - sonst nichts (ebd.). Alles überragend wäre auch die darstellerische Leistung von Emil Jannings, welcher der ideale Filmschauspieler sei. Sein Gesicht, das jede Emotion, jede Abstufung der Gefühle wiedergeben könne, sei unvergleichlich. Dass Jannings jetzt in die Hände der Yankees gefallen sei, werde inn sicher total verderben, schließlich sei er kein Mann für "heart-stirring dramas of society sins, flapping flappers and jazzing mothers" (ebd.). Er sei grandios und gehöre in die richtig große Kunst so wie die hier in FAUST. Sein Mephisto sei einer, wie man ihn noch nie gesehen habe, eine Meinung, der sich auch die englische Presse anschloss (TF 13.1.28: 6). Zu recht werde er als bester lebender Filmschauspieler gehandelt, er spiele die Rolle exzellent (NW 16.5.28: 7), 
auch Gösta Ekman, Camilla Horn und Yvette Guilbert (Martha) seien vortrefflich (DB 29.3.28: 8 bzw. EPH 11.4.28: 14). FAUST rangiere auf der selben Höhe wie VARIETÉ und METROPOLIS (NW 16.5.28: 7), Emil Jannings beweise wie in "Der letzte Mann" und "The Way of All Flesh", dass er derzeit einer der weltbesten Filmschauspieler sei (EPH 11.4.28: 14).

In mehreren englischsprachigen Rezensionen ist auffällig, dass statt echter Kritiken Textvorgaben aus Werbematerialien der Filmvertriebe oder Agenturberichte wiedergegeben wurden (z.B. EPH 6.4.28: 11, NM 20.4.29: 23, EPH 24.7.31: 15). Nicht um eine kritisch-anerkennende Bewertung verlegen, schrieb stattdessen Die Burger:

„Der Film FAUST ist keine Übertragung von Goethes Meisterwerk, aber für sich genommen ist er wieder ein Beweis dafür, dass die ,Hunnen', so wie auf mehreren Gebieten, auch in der Filmwelt einen Ehrenplatz verdienen. Wie fein wird da jede Kleinigkeit ausgearbeitet, wie grandios etliche Szenen und dabei doch nie mit amerikanischer Unmöglichkeit. Man fühlt, daß wir hier näherkommen an die scheinbare Unmöglichkeit zu vergessen, dass wir einen Film sehen" (DB 29.3.28: 8). ${ }^{76}$

In den USA wurde FAUST als ein außergewöhnlicher Film eingeschätzt, „one of the really fine things of the screen" (Photoplay 2/1927: 52 in Slide 1982: 96f.). Regisseur Murnau beweise mit diesem Film, dass „Der letzte Mann“ kein Zufallserfolg war. Gösta Ekman und Camilla Horn hätten unter seiner Regie dem gefürchteten Jannings einen Film gestohlen, was seine Verdienste allerdings keinesfalls schmälern würde (ebd.). Ähnlich wie der Bezug auf "Intolerance” (South African Nation 31.3.28: 17) wurde in den USA ein weiterer Film von D.W. Griffith zum Vergleich mit Murnaus FAUST herangezogen:

„Murnau has develeoped any number of scenes extraordinary in directorial technique and photography. The opening curiously parallels the start of the Griffith film, 'Sorrows of Satan' (1926, Anm. ME), with Lucifer at the gates of heaven. The Murnau handling is vastly superior, however" (Photoplay 2/1927: 52 in Slide 1982: 96f.).

${ }^{76}$ „Die rolfilm FAUST is geen vertolking van Goethe's meesterwerk nie, maar op homself geneem is dit weer ' $n$ bewys dat die ,Hunne' soos op menige gebied, ook in die rolprent wereled, ' $n$ ereplek verdien. Hoe fyn word elke kleinigheid uitgewerk, hoe groots sommige tonele, en daarby tog nooit Amerikaansonmoontlik nie. ' $n$ Mens voel dat ons hier nader kom by die skynbare onmoontlikheid om te vergeet dat ons 'n rolprent sien." 
Ähnlich positiv wurde der Film auch in Frankreich aufgenommen, wo man wie in der südafrikanischen Rezeption die gänzlich neuartige Qualität der filmischen Umsetzung schätzte:

„Bis auf den heutigen Tag hat kein einziger Film den Eindruck einer vom ersten bis zum letzten Bild so leidenschaftlich erfühlten Kraft und Bewegung vermittelt. Darüber hinaus ist der Beweis erbracht, daß ein Werk der Leinwand ein rein visuelles und plastisches Werk sein kann, und nur, wenn wir diesen Film so sehen, enthällt er uns seinen wahren Sinn und seine tiefste Philosophie. Der Schöpfer dieses FAUST vollbringt das Wunder, uns in jeder Minute, jeder Sekunde die komplette und persönliche Vision seiner Welt zu präsentieren" (L'Europe Nouvelle 2/1927 in Brennicke/Hembus 1983: 133).

In der deutschen Kritik hingegen war man von FAUST weniger begeistert. Die meisten literatur- oder theaterorientierten ,Großkritiker' bemängelten entweder die starken Abweichungen vom literarischen Drama, den Theaterstücken, der Oper oder den fehlenden Respekt vor Goethes Meisterwerk (Haas 1926). Zu zerfahren, ohne Spannung, mit zu vielen Wiederholungen geriete FAUST zu einer tödlichen Langeweile für den Zuschauer (Eggebrecht 1926):

„Von den Schauspielern ist gleich der wichtigste, Gösta Ekman als Faust, ganz undiskutabel schlecht. Als Greis mit wallendem Bart und ÖldruckPatriarchengesten, als Liebhaber ein blasser weichlicher Junge ohne Ausdruck, manchmal peinlich steif wie ein Anfänger. Jannings ist noch nie so von allen seinen Gaben verlassen gewesen wie hier: ein Opernmephisto, übertrieben, mit so unbeherrschten, wilden Gebärden, daß er zuweilen wie eine Karikatur seiner Rolle wirkt" (ebd.).

Gerade in Bezug auf Emil Jannings steht diese Auffassung im krassen Gegensatz zum Tenor der südafrikanischen Rezeption die bemerkte:

„The acting is magnificient. Jannings as Mephisto, gives a performance that is the very incarnation of sin itself. He is not the handsome baritone masquerading as sin - he is wickedness and evil personified. In the earlier stages of the photoplay, he plays the Evil One in a manner that makes one believe in his vileness. He makes Satan a horribly repellant figure - a compound of horror and loathing" (NA 31.12.27: 10).

Weitgehend einig war sich die Filmkritik in Bezug auf die Anfängerin Camilla Horn, die als "Gnaden-Geschenk der Natur" (LBB in Brennicke/Hembus 1983: 132) und als eine der wenigen schauspielerischen Hoffnungen des 
weiblichen deutschen Nachwuchses bezeichnet wurde (Eggebrecht 1926). Die in der südafrikanischen Kritik zu keinem Zeitpunkt thematisierte Zweiteilung des Films wurde in Deutschland als ein ernstes Problem erachtet:

„Es ist der große Fehler des Kyserschen Manuskripts, daß es in zwei fast gleichgroße Teile, den Teil ,Zauberer Faust' und den Teil ,Liebhaber Faust' zerfällt; nicht wegen irgendwelcher Regeln dramaturgischer Mathematik, die hier durchbrochen wurden; sondern wegen der Unmöglichkeit, beide Teile bildhaft-musikalisch gegeneinander zu ,temperieren', wie man in der Harmonielehre sagt: Die grundsätzlich unbewegte, gemäldehafte Fassung der magischen Szenen, die erst mimisch fortzubilden, und die grundsätzlich bewegte, dramatische Fassung der Gretchenszenen, die erst in Bildkomposition umzusetzen war. Das Resultat ist: mimische Unfülle der Mephisto-Faust-Szenen, denen die Sorge um die realistische Dramatik das volle Ausschwingen stilmäßiger Schönheit behindert hat" (Haas 1926).

Im Widerstreit der deutschen Kritiker, die sich in die Lager der Werktreue fordernden Oberlehrer und jenes der filmbegeisterten Journalisten zweiteilen ließen, obsiegte mehrheitlich die von teutonischer Philologen-Quängelei geprägte Medienrezeption (Brennicke/Hembus 1983: 133): Der Stoff sei durch Goethes meisterhafte Vorlage einfach unverfilmbar, eine Art Angstpsychose, die ein einmal von Goethe geformter Stoff ausstrahle (Haas 1926). Filmenthusiasten wie die der Lichtbild-Bühne sprachen dennoch von einer Meisterleistung deutscher Filmkunst, wobei im ersten Teil die schöpferische Phantasie, befruchtet wahrscheinlich durch altes Quellenmaterial, frei gewaltet habe (Wollenberg 1926). Die Bilder erinnerten an alte Holzschnitte, die Gestalten träten als individualistische Charaktere zurück und würden zu Symbolen vergrößert, Emil Jannings, Camilla Horn und Yvette Guilbert spielten stark und vollendet, einzig Ekmans Spiel leide etwas am passiven Manuskript (ebd.).

Die durch die hohen Standards der deutschen Filmpublizistik deutlich kritischere Bewertung von FAUST wird erkennbar, wenn man sich die FAUSTBegeisterung der südafrikanischen Presse ins Gedächtnis ruft, für welche das alltägliche Programm weit von den Qualitäten des Murnau-Films entfernt war. Anders lassen sich die doch recht konträren Auffassungen der deutschen und südafrikanischen Kritik zu FAUST kaum erklären:

„Murnau hat in diesem Film Überragendes geschaffen, jedoch lässt auch er mitunter zwingende Notwendigkeit vermissen und man sagt sich: um wieviel schöner und festlicher hätte dieser Film sein können, wenn, bei aller Hochachtung vor dem Werk, auf der ganzen Linie letzte künstlerische Forderungen erfüllt worden wären“" (o.A. 1926). 
Bei der kontroversen Bewertung von FAUST in der deutschen Kritik muss allerdings beachtet werden, dass der zeitgenössische Kontext - hier die Situation der Filmindustrie - einen wesentlichen Anteil am Zustandekommen der doch recht überkritischen Reaktionen hatte. Die nachfolgende Pressenotiz fasst die Stimmung abschließend zusammen:

„Der FAUST-Film der UFA ist ein großangelegter, klein endender Film. Die Kinomüdigkeit ist in diesem Jahr groß, die amerikanische Politik verhängnisvoll geworden. Wenn auch FAUST das Publikum nicht fesseln sollte, so ist das keine Niederlage des deutschen Films, sondern eine Aufforderung, ihn zu schaffen. Gleichgültig, woher die Stoffe kommen" (Berliner Börsen-Courier 15.10.26; in: Jacobsen 1989: 66).

Gestützt auf die überdurchschnittlich zahlreichen und auch qualitativ hochwertigen südafrikanischen Rezeptionsdokumente zu FAUST kann festgestellt werden, dass der Film überaus erfolgreich war und dadurch sowohl die UFA als auch Emil Jannings dem Publikum in positiver Erinnerung blieben. Besonders Jannings, der vielen Zuschauern bereits aus anderen Filmen bekannt war, konnte seine Popularität weiter ausbauen. Die Einschätzung der den Kinobetreibern nahestehenden Paimann's Filmlisten, wonach FAUST als ein ,Schlager' eingeschätzt und auch sonst nur Positives dazu geäußert wurde (PFL 1926: 154), zeigt, dass die deutsche Medienrezeption oft weniger die Vorlieben des Publikums einzuschätzen versuchte, als dass sie ihre eigene, oft literarisch geprägte Expertise in den Vordergrund stellte und damit dem Zuschauer kaum filmbezogene Rezeptions- oder Konsumempfehlungen gab. Ein direkter Vergleich mit dem positiven Tenor der südafrikanischen Rezeption und der Einschätzung aus den PFL legt offen (s. Anhang IV), dass diese kommerzielle Liason der Filmpublizistik im Falle von FAUST dem Publikum eine bessere Entscheidungshilfe bot, als die ,teutonischen PhilologenQuängeleien'. Politisch oder gar ideologische Tendenzen konnten in diesem historischen Drama nur schwerlich untergebracht und damit auch nicht erwähnt werden. 


\subsubsection{Untersuchung weiterer „MI>10-Filme“}

ATLANTIK/ATLANTIC ist einer der wenigen Tonfilme unter den S-Filmen. ${ }^{77}$ Als deutsch-britische Koproduktion wurde der Film von Regisseur Ewald André Dupont in drei Sprachversionen (deutsch, englisch, französisch) in den Elstree-Studios nahe London produziert. Mit ATLANTIK wurde die Schiffskatastrophe der „Titantic" aus dem Jahre 1912 zum ersten Mal in einem Tonfilm auf die Leinwand gebracht. In die Rahmenhandlung des Unglücks eingepasst, wurde zum einen die Aufnahme des Unglücks bei den verschiedenen Passagieren und zum anderen deren Verhalten im Angesicht des Todes. Eine weitere Personalisierung erfuhr die Erzählung durch das Vorstellen von drei Paaren und deren Umgang mit der Katastrophe.

Tab. 27: „MI>10-Filme“ unter den Genre 1-Filmen

\begin{tabular}{|c|c|c|l|c|}
\hline MI & PFL & FK & \multicolumn{1}{|c|}{ Filmtitel } & Erstbeleg SA \\
\hline 24 & 1 & 7 & Atlantik (T) (A) & 26.06 .30 CT \\
\hline 18 & 1 & - & Spione (K) & $01.02 .29 \mathrm{DB}$ \\
\hline 17 & 1 & - & Varieté (A)* & 11.09 .27 ST \\
\hline 17 & 1 & 2 & Die weiße Hölle vom Piz Palü (A) & $18.06 .31 \mathrm{CT}$ \\
\hline 13 & 5 & - & Die Apachen von Paris (K) & $27.04 .29 \mathrm{DB}$ \\
\hline 13 & 3 & - & Die Todesschleife (K) & $14.05 .29 \mathrm{CT}$ \\
\hline 12 & 5 & - & Die Carmen von St. Pauli (K) & $10.08 .29 \mathrm{NM}$ \\
\hline
\end{tabular}

Nach der ersten Pressevorführung von ATLANTIK in Kapstadt äußerte sich vor allem die englischsprachige Presse enthusiastisch:

„Although the film was made at the Elstree studios, it was produced, characteristically enough by E. A. Dupont, who is a German, though his name is French. This picture is supremely interesting as an example of a big British film, because it explains, to a great extent, the superiority of Elstree over Hollywood, Berlin and Paris" (CT 26.6.30: 7).

Die Anfangssequenz sei nicht einfach nur eine Einführung in die Filmhandlung, der Regisseur lasse vielmehr durch seinen Sinn für das psychologische Element die Möglichkeit zu, dass sich die Zuschauer als Teil der Passagiere des Luxusschiffes verstünden (ebd.). Während ein Hollywoodfilm sicher eine Masse von schreienden Frauen und Männern gezeigt hätte, habe es Dupont mit geschickter Hand vermocht, den gleichen Eindruck durch die gezielte

${ }^{77}$ CT 26.6.30: 7, CT 28.6.30: 9, CA 1.7.30: 15, DB 1.7.30: 10, DB 2.7.30: 10, CT 4.7.30: 9, DB 9.7.30: 8, ST 27.7.30: 7, RDM 28.7.30: 5, NA 22.8.30: 9, NM 26.8.30: 14, EPH 2.9.30: 12, NW 6.9.30: 9, NW 10.9.30: 8, DFA 29.9.30: 3, TF 30.9.30: 6, VB 30.9.30: 9, DB 6.12.30: 8, TF 17.2.33: 5 (Kapstadt, Johannesburg, Durban, Port Elizabeth, Pietermaritzburg, Kimberley, Bloemfontein, Kapstadt, Bloemfontein). 
Auswahl einzelner Persönlichkeiten zu erzeugen. Der Zuschauer verlasse das Kino überwältigt von dieser unbeschreiblichen Produktion (ebd.), der man ohne zögern zubilligen könne, der effektivste Tonfilm gewesen zu sein, den Kapstadt bis jetzt gesehen habe (CT 28.6.30: 9).

Die meisten Rezeptionsdokumente berichten von einem enormen Publikumserfolg des Films, in Johannesburg waren am 26.7.1930 alle fünf Aufführungen im Kinotheater Bijou ausverkauft (RDM 28.7.30: 5), in Kapstadt wurde ob des großen Publiumszuspruches beschlossen, die Spielzeit des Films zu verlängern (DB 9.7.30: 8). Zur eher passiven Darstellung des Pfarrers im Film veröffentlichte die Cape Times einen Leserbrief, der von einem Bekannten der zwei damals auf dem Schiff befindlichen Geistlichen stammte und deren aktive Rolle während der Katastrophe hervorhob (CT 4.7.30: 9).

Die englischsprachige Presse betonte sehr auffällig, dass es sich um einen großartigen britischen Film handele (z.B. CT 8.7.30: 7 und NW 8.9.30: 6), der leicht die Erinnerung an all die US-amerikanischen Produktionen verblassen ließe (ST 27.7.30: 7). Die Tatsache, dass der Film aus einer deutschbritischen Zusammenarbeit hervorging, wurde mit Verweisen auf eine zweisprachige Produktion oder hinter Bemerkungen wie "took Berlin by storm" (NW 6.9.30: 9) eher versteckt als offengelegt. Lediglich die Kritikerin der Rand Daily Mail sprach von der Produktion in Deutschland und in England, jeweils mit einem brillianten Darstellerensemble (RDM 28.7.30), die Regieleistungen Duponts bei anderen Filmen wie z.B. VARIETÉ und „Piccadilly" (1929, A. Bennett) wurden nur vereinzelt erwähnt (NW 6.9.30: 6). Nur eine einzige Besprechung bezeichnete den Film als abscheulich, die Darstellungen seien einfach zu wahr und grausam, Szene für Szene werde die nackte Wahrheit gezeigt, die durch ihren Schrecken krank mache (TF 30.9.30: 6).

Folgt man nur den Ausführungen der englischsprachigen Presse, musste man unweigerlich zu dem Schluss kommen, dass es sich um einen durch und durch britischen Film gehandelt habe. Aus diesem Grund verwundert es auch nicht, dass die anderen Ortes vorgebrachte Kritik, wonach Thelma Gutsche die Erwähnung der deutsch-britischen Koproduktion von ATLANTIK unterschlagen habe (Eckardt 2005: 10), wie dieses Detail übersehen werden konnte. Mit der Aufführung der englischen Sprachversion von ATLANTIK und der , patriotischen' Berichterstattung der englischsprachigen Presse musste für das südafrikanische Publikum fast zwangsläufig der Eindruck entstehen, dass es sich um einen rein britischen Film handelte.

In der afrikaansen Presse betonte man hingegen, dass dies der erste Film in Kapstadt gewesen sei, der mit einer deutschen und einer englischen Besetzung gedreht wurde (DB 2.7.30: 8). Die ganze Spiel- und Aufnahmelei- 
tung habe sich in den Händen der Deutschen befunden und es sei klar ersichtlich, wie sehr die Engländer von ihren deutschen Kollegen gelernt hätten (ebd.). Das Schauspiel der Deutschen sei im Allgemeinen menschlicher in seiner Charakterdarstellung, suche keine Effekte durch Übertreibung, sondern vielmehr durch eine gewisse Verhaltenheit und Natürlichkeit (ebd.). Die Darstellung der Engländer in ATLANTIK sei viel tiefgründiger und natürlicher als sonst, ein Beweis dafür, das jene damit anfangen würden, sich dies von den Deutschen abzuschauen (ebd.).

Auch die afrikaanse Presse bezeichnete ATLANTIK als einen ausgezeichneten („skitterend, kolossaal“) Film (DB 1.7.30: 10), alles werde so echt und lebendig vorgestellt, dass es wirklich den Anschein habe, als befinde sich der Zuschauer zwischen den Unglücklichen der Schiffskatastrophe (DB 3.7.30: 8). Eine tiefergehende Einschätzung der Tonfilmqualitäten von ATLANTIK findet sich ebenfalls nur in der afrikaansen Presse. Unter dem Pseudonym "Silentium" beschrieb Hans Rompel (Eckardt 2005: 73) den Film als einen perfekten Tonfilm und idealen Film des Jahres 1930 überhaupt (DB 6.12.30: 8):

„Unerschütterliche Einheit und Logik; absolute Abwesenheit von ,Tricks', Manieriertheiten oder Künstlichkeit; strenge Einfachheit und ein vollkommenes Verständnis für die Bedeutung von Ton und Stummheit - das sind die Dinge die ATLANTIK zu dieser glänzenden Leistung machen, die der Film ist" $[\ldots]^{78}$

Als Beispiel führte Rompel die Szene an, in welcher dem Pfarrer erzählt wird, das die Lage ernst sei, jedoch nicht wie ernst. Als er dennoch nachfragt, wie ernst die Lage wirklich sei, erhält er keine Antwort. Als der Pfarrer schließlich die abgeschossenen Signalraketen durch das Fenster sieht, hat er seine Antwort. Genau darin, einem ausgeglichenem Verhältnis von Ton- und Stummanteilen, sah Rompel auch die Zukunft des Tonfilmes, einer Technik, die sowohl auf der Bild-, als auch auf der Tonebene nicht von dem hohen Standard abweichen solle, den der Stummfilm mit seiner Symbolik in dessen goldener Ära erreicht habe (ebd.). ATLANTIK sei auch deswegen ein echter Tonfilm, da er ohne Ton undenkbar wäre, ja nicht einmal als gefilmtes Theaterstück durchgehen würde (ebd.).

Ein direkter Vergleich mit der Rezeption der deutschen Sprachfassung erscheint einigermaßen schwierig, da es in den Rollenbesetzungen kaum Über-

78 „Onwrikbare eenheid en logika; absolute afwesigheid van ,tricks', gemaniereerdheidjies of kunsmatigheid; strenge eenvoud en ' $n$ perfekte begrip van die waarde van geluid en stilte - dit is die dinge wat ATLANTIC tot die skitterende prestasie maak wat dit is $[\ldots]^{\prime \prime}$. 
schneidungen gab. In einer 1930 durchgeführten Umfage nach den geschäftlich erfolgreichsten Tonfilmen der Spielzeit 1929/30 wurde ATLANTIK von den deutschen Filmtheatern an erster Stelle genannt (Bauer 1950: 1). Die sarkastische Einschätzung von Teilen der deutschen Filmkritik, wonach die "Betonung seelischer Lappalien angesichts des Todes" (Ihering in Dahlke/Karl 1988: 198) im Mittelpunkt von ATLANTIK stehe, weicht von den Eindrücken der südafrikanischen Rezeption recht stark ab. In der filmhistorischen Sekundärliteratur wird der Film ob seiner experimentellen Geräuschdramaturgie als ein ,Wegweiserfilm' der frühen Tonfilmkunst angesehen (Dahlke/Karl 1988: 199). Die gleichzeitig bemängelte statische Handlungsführung (ebd.) wurde in der südafrikanischen Presse nicht moniert. Von den drei parallel hergestellten Sprachversionen gilt die deutsche als die Beste, der englischen und französischen warf man mangelnde Kompaktheit vor (Kramer 1995: 37f.).

In den USA stieß der Film auf ein geteiltes Echo. Als Duponts bester Film bezeichnet, fehle ATLANTIK trotzdem das gewisse Etwas, um als ein ebenso exzellenter Film zu gelten, wie Hitchcocks „Murder!“ (1930) (Shelley 1930 in Slide 1992: 7). Einige der Szenen kurz vor dem Abtauchen des Schiffes seien von einer typisch britischen Bedächtigkeit gekennzeichnet, die für die weniger stoischen Amerikaner völlig unbegreiflich sei. Gerade in solchen Szenen ausgedehnten Schweigens fühlte sich ein großer Teil des Publikums ausgesprochen unwohl (Blaisdell 1931 in Slide 1982: 8). Der Film sei dennoch seheneswert:

„Inquiry [...] brings to light that ATLANTIC was the first multilingual picture to be made. It was recorded in English, French and German and was photographed not in 1930 but in 1929, making the recording all the more remarkable in quality in view of the primitive conditions prevailling in the sound field at the period" (ebd.).

Bei SPIONE/THE SPY handelt es sich um ein Kriminaldrama, in dem ein skrupelloser Bankier hinter der Fassade seiner Bank einen Spionagering betreibt und sogar Teile der Kriminalpolizei unterwandert hat. Auf den Verbrecher wird ein junger Polizist angesetzt, woraufhin Ersterer ein weibliches Mitglied seiner Bande zur Abwehr des Beamten abstellt. Allerdings verlieben sich die beiden in einander, was für beide zu Interessenkollisionen zwischen den rivalisierenden Gruppen führt. Als der Bandenchef einen Anschlag auf 
ihren Geliebten verüben lässt, verrät die Dame ihre Organisation, dass Verbrechernest wird ausgehoben und sie selbst in letzter Minute gerettet. ${ }^{79}$

Laut Die Burger war das Astoria-Kino zur Aufführung von SPIONE ausverkauft, der Film selbst liefere eine Sensation nach der anderen bis schließlich der Höhepunkt darin erreicht werde, dass die Identität des 'Meisters' endlich aufgedeckt werde (DB 1.2.29: 8). SPIONE sei ein fabelhaftes Beispiel für melodramatischen Sensationalismus, eine Spion-DetektivGeschichte, welche die Kunst der Handlungserzählung nur durch filmische Mittel meistere (CT 2.2.29: 11). Wie üblich erwähnte die englischsprachige Presse, dass der Film in Londons Marble Arch Pavillion für ganze drei Wochen zu sehen war und baute Teile der Agenturmeldung zum Film in die Besprechung mit ein (z.B. RDM 25.2.29: 4).

In Johannesburg war der Andrang im Astoria-Kino so groß, dass ob der ausverkauften Vorstellung hunderte Kinogänger zurückgewiesen werden mussten (ebd.). In Kimberley verlängerte das Management des TheatreRoyal-Kinema die Spielzeit des Films aufgrund der starken Nachfrage um einen Tag (DFA 11.3.29: 8), in Kapstadt wurde eine zweite Spielzeit für den Film gefordert (DFA 4.3.29: 8). Ähnlich wie die in Deutschland empfohlenen spektakulären Reklamemaßnahmen, ${ }^{80}$ wurde der Film auch in Südafrika durch Kinemas beworben. So wurden z.B. in Kimberley zu einer bestimmten Zeit an drei Tagen ,echte Spione' in verschiedenen Straßen angekündigt, die es an einer bestimmten Zigarettenmarke zu erkennen galt (ebd.). Wer den Spion zu erst sah, sollte inn mit "Excuse me, are you the spy?" ansprechen und konnte damit drei Kinokarten und 500 der besagten Zigaretten gewinnen.

In einigen Filmvorbesprechungen wurden Teile der Agenturmeldung zu SPIONE abgedruckt, ergänzt um Schlagzeilen aus der englischen Presse, die allesamt die außerordentliche Qualität dieses Thrillers rühmten (NA 16.3.29: 7). ${ }^{81}$ Verweise auf die UFA, Fritz Lang und Thea von Harbou oder METROPOLIS gehörten ebenfalls zu den Standardelementen der Filmvorbesprechungen, an gleicher Stelle wurde SPIONE als erster von Kinemas gezeigter UFA-Film bezeichnet (z.B. NM 16.3.29: 23). Ebenso wie in Kapstadt, Johannesburg und Kimberley stand der Film auch in Durban und Bloemfontein sehr hoch in der Zuschauergunst (NA 19.3.29: 11 und TF 9.7.29: 10). Keine der dargestellten Sensationsszenen sei unglaubwürdig (NM 19.3.29:

${ }^{79} \mathrm{Vgl}$. Reklame-Ratschläge des UFA-Leih für SPIONE, Berlin 1927/28, 23 S.

${ }^{80} \mathrm{Vgl}$. Reklame-Ratschläge des UFA-Leih für SPIONE 1928: $15 \mathrm{ff}$.

81 Z.B. Sunday Graphic: This is a film that will appeal to all classes of audience; Liverpool Post: Held an audience for over two hours; Manchester Daily Dispatch: You must not hesitate to stand in a queue for this picture; Sunday Pictorial: As a shocker it leaves anything yet seen on the screen miles behind (NA 16.3.29: 7). 
6), bis zum Schluss befinde sich der Zuschauer in einer Atmosphäre der Verunsicherung über die Identität des Meisterspions (DA 22.3.29: 6). Ende August 1929 kehrte der Film in die Nachspielkinos der Kinemas-Kette nach Kapstadt zurück (CT 24.8.29: 11), ebenso im Jahre 1930 (29.8.30: 7). In Durban war SPIONE 1931 erneut zu sehen (NA 17.1.31: 8), in Port Elizabeth sogar noch im Jahre 1932 (EPH 20.10.32: 14).

Die deutsche Filmkritik zu SPIONE war überwiegend positiv. Der Filmkurier sprach von einem ,hundertprozentigen Weltwurf', Der Film von einem über alle Zweifel erhabenen Geschäftsfilm, die Berliner Börsen-Zeitung von einem ,Reißer', die Deutsche Zeitung von einem Massenerfolg. ${ }^{82}$ Die Lichtbildbühne beschrieb SPIONE wie folgt:

„[...] er ist der erste deutsche Spannungsfilm, der über die Leinwand rollt. Hier ist die Synthese von starkem, stärkstem Stoff, mit moderner, modernster Ausdrucksgebung versucht [...] Fritz Lang hat dieses Geschehnis in einem hinreißenden Tempo inszeniert [...] vor allem aber die geradezu grandiose, an den Nerven reißende Eisenbahnkatastrophe [...] Zum Schluß gab es rauschenden Beifall - und immer wieder Beifall [...] ein entscheidender Erfolg [...] ein Geschäftsfilm großen und edlen Stils." 83

Ganz anders äußerte sich Rudolf Arnheim in einer zeitgenössischen Kritik:

„Fritz Lang dreht das alles geschickt und sauber herunter, aber ohne daß man auch nur einen Augenblick auf den Gedanken käme, es könne sich hier um Filmkunst handeln. Die Luxusausgabe eines ZehnpfennigDetektivschmökers, nicht mehr!" (Arnheim in Brennike/Hembus 1983: 149).

Auch die Tendenzpresse am linken Rand des politischen Spektrums bescheinigte dem Film ein großer Krampf „[...] und trotz knalligster und kostspieligster Effekte von tödlicher Langeweile" zu sein (Film und Volk in: Kreimeier 1992: 199). In Deutschland konnte sich auch, im Gegensatz zur südafrikanischen Rezeption, zur in SPIONE verwirklichten Ästhetik der Neuen Sachlichkeit geäußert werden. So seien die vielen kleinen Episoden des Films wie:

„[...] exakt ineinandergreifende Räder eines überkomplizierten Handlungswerkes [...] Kompliziertheit und Ausdehnung lassen hier jede Szene allein eine bestimmte Bewegungstatsache zur Aufgabe übrig. Es ist wie in der ultramodernen Fabrik, durch die ein hastig laufendes Band der Handlung rollt und in der am Rande des Bandes einzelne Bildabschnitte wie

82 Vgl. Reklame-Ratschläge des UFA-Leih für SPIONE 1928: $13 \mathrm{ff}$.

${ }^{83} \mathrm{Ebd}$. 
mechanisierte Arbeiter stehen, um einen raschen Handgriff zu tun. Rasch, ohne sich um Zusammenhänge zu kümmern, ohne über Motive und Zweckmäßigkeit des Ganzen nachdenken zu können oder zu wollen“" (Filmtechnik-Filmkunst in: Kreimeier 1992: 207).

An eine derartige Deutung war ob der nicht vorhandenen Wahrnehmbarkeit der Neuen Sachlichkeit in Südafrika nicht zu denken, auch gab es keine Fachblätter, in denen solche Gedanken in Bezug auf den Film hätten geäuBert werden können. In seiner posthistorischen Projektion kritisierte Siegfried Kracauer SPIONE als sinnentleerte Sensationen, die den Anschein substantieller Enthüllungen annahmen und zudem im pompösen Stil von METROPOLIS inszeniert seien (Kracauer 1995: 160). Die zeitgenössische Kritik betonte nach den Problemen mit METROPOLIS gerade das Gegenteil, wonach kein monumentaler Film entstanden und es gelungen sei, das Sekundäre dem Primären unterzuordnen, die Aufmachung wäre zwar großzügig, erstarre aber nicht in Überdimensioniertheit (PFL 20.4.28: 68).

Innerhalb von Fritz Langs Trilogie aus METROPOLIS, SPIONE und FRAU IM MOND können die ersten beiden als zwei der erfolgreichsten aller „SFilme" gelten. Die Orientierung von Drehbuch und Handlung an wahren Begebenheiten war in Südafrika nicht wahrnehmbar und wurde somit auch nicht in den Rezensionen geäußert. Als spannender Unterhaltungsfilm voller Effekte und virtuoser Filmkunst konnte SPIONE vor dem südafrikanischen Publikum bestehen und bestärkte den exzellenten Ruf der UFA-Produktion.

In VARIETÉ NAUDEVILLE, ${ }^{84}$ in Südafrika als "one of the screen wonders of the world" (ST 11.9.27: 7) angekündigt, wird die Geschichte eines nur noch im Jahrmarktprogramm auftretenden Artisten (Boss Huller) erzählt, der ein elternloses Mädchen (Bertha-Marie) bei sich aufnimmt, sich in sie verliebt, dafür Frau und Kind verläßt, um fortan mit dem Mädchen in einer Truppe von Hochseilartisten wieder vor großem Publikum zu spielen. Das Mädchen betrügt ihren Gönner allerdings schon bald mit einem Rivalen, dessen Tod während der Vorstellung der Betrogene leicht als Künstlerpech kaschieren könnte. Stattdessen stellt er sich ihm im Hotel und tötet ihn blind vor Wut im Handgemenge. Trotz seiner Untat stellt die Frau des Inhaftierten ein Gnadengesuch, worauf ihn der Gefängnisdirektor zu einem Gespräch bittet, nach welchem er anschließend begnadigt wird.

Die in der Sunday Times veröffentlichte Rezension des Filmkritikers „Gadabout" stellt unter den englischsprachigen Filmkritiken in Südafrika eine

${ }^{84}$ ST 11.9.27: 7, RDM 20.9.27: 9, EPH 7.2.28: 7, NW 18.2.28: 4, NW 20.2.28: 6, NW 22.2.28: 7, NM 16.6.28: 27, NM 22.6.28: 10, NM 8.12.28: 5, ST 12.7.31: 12 (Johannesburg, Port Elizabeth, Pietermaritzburg, Durban, Johannesburg). 
absolute Ausnahme dar (ST 11.9.27: 7). Entstanden nach einer Privatvorführung von VARIETÉ am 7.9.27, ging die Kritik ausführlich auf den Film selbst, die Zensur und den Hollywoodfilm im Allgemeinen ein. Desweiteren konnte der Kritiker auf Erfahrungen einer früheren Vorführung von VARIETÉ in der Konzernzentrale von African Films zurückgreifen.

Für jede einzelne Rolle dieses Films sei mit Sicherheit mehr Hirn verbraucht worden, als für jede andere amerikanische Produktion (ebd.). Die Betonung liege dabei auf Hirn, nicht auf Geld oder Arbeit. Zwar kenne man aus Amerika manchen spektakulären Film, jedoch sei es kennzeichnend für die amerikanische Filmkunst, dass ein Mindestmaß an Analphabetentum zu dessen unausrottbaren Qualitätseigenschaften gehöre. Für den Durchschnittskinogänger sei dies verschmerzbar, aber für jene die etwas von historischen Orten, Perioden, Kostümen und Benehmen verstünden - ganz zu schweigen von Literaturkennern - wirke dies fast schon anstößig. In den USA war der Film derart erfolgreich, dass er täglich zwischen 6000 und 7000 Dollar einspielte und alle Rekorde brach. Es müsse also bestimmte Gründe für diesen Erfolg in den USA, England und Deutschland gegeben haben, die es wert seien, die Kunst dieses Films eingehender zu studieren.

Unmittelbar nach Bekanntwerden des Erfolgs von VARIETÉ sei der Film zur Vorführung in Südafrika erworben worden und der Zensurbehörde in Kapstadt gezeigt worden. Durch diese erhielt er auch prompt einen KOSchlag. Tatsächlich ließen sich zu VARIETÉ keine Rezeptionsdokumente in der sonst so filminteressierten Kapstädter Tagespresse finden. In der Provinz Transvall (Johannesburg etc.) muss der Film erneut begutachtet worden sein, sonst hätte er kaum gezeigt werden dürfen. Der Kritiker zeigte sich überrascht von der Entscheidung der Kapstädter Zensurbehörde, wo doch in der Vergangenheit viel fragwürdigere amerikanische Filme ohne jede Beanstandung gezeigt werden konnten. Doch durch die Schnittauflagen der Behörden in Transvaal sei der Film seiner Hauptaussage beraubt worden, was die Zensur aus ,moralischen Gründen' ad absurdum führe. Welche Szenen herausgeschnitten wurden, offenbaren die aktuellen Filmbesprechungen leider nicht. Aus einer Notiz zur Zensurpraxis aus dem Jahre 1931 lässt sich jedoch entnehmen, wie der Film verändert wurde. Durch das Wegkürzen der Anfangsszene wurde der Ehemann in einen Junggesellen verwandelt, so dass die Moral des Films, dass man Ehefrau und Kind nicht für Lust und kurzweiligen Erfolg im Stich lassen solle, vollkommen verloren ging (ST 12.7.31: 12).

Doch selbst in der verstümmelten Fassung ziehe der Film alle künstlerischen Register und stimmuliere die visuelle Einbildungskraft (z.B. durch die Verbildlichung der Totschlagsszene ohne Blut und Mordlust) (ST 11.9.27: 7). 
Einige Gefängnisszenen erinnerten in ihrer Bildlichkeit an die Illustrationen von Gustav Doré, ein Vergleich der auch in Zusammenhang mit METROPOLIS gezogen wurde und sowohl für die Popularität der Doréschen Zeichnungen, als auch die Verwendbarkeit dieser Bildideen im Film spricht.

Die Flankierung der eigentlichen Geschichte mit einem Vorspann (inhaftierter Huller beim Gefängnisdirektor) und einem als Happy End ausgehenden Abspann (Gefängnisdirektor verkündet Hullers Begnadigung) wurde als typisch deutsche ,In-Klammer-Setzung' angesehen (RDM 20.9.27: 9). Den stärksten Eindruck neben der ausgezeichneten Regieführung und Kameraarbeit hinterlasse jedoch Emil Jannings in der Hauptrolle (NW 20.2.28: 6), dessen Natürlichkeit nichts melodramatisches enthalte (NM 22.6.28: 7). Die üblichen Studiokonventionen habe der Film einfach hinweggefegt, allein für sein ausgezeichnetes Schauspiel sei er bereits sehenswert (NW 22.2.28: 7). Zur Verdeutlichung des internationalen Erfolgs des Films druckte der Natal Witness acht Schlagzeilen US-amerikanischer Zeitungen zu VARIETÉ in Seitenbreite über dem Kinoprogramm der Woche ab (NW 18.2.28: 4).

Die US-amerikanische Kritik bezeichnete den Film als einen Kritiker-Film par excellence (Photoplay 9/1926; in: Slide 1982: 304), die New York Times listete ihn unter den besten zehn des Jahres 1926. ${ }^{85}$ Der Film besitze größere Publikumsqualitäten als jede andere in die USA importierte Produktion seit „Madame Dubary“ (1919, E. Lubitsch). VARIETÉ sei fast so, wie ein Film eigentlich sein müsse:

„It is a simple story told without wandering and it as grown up. It concerns itself with triangles among sideshows and vaudeville folk. There isn't any originality to the plot, but there is in the straightforward and mature handling of it. The acting, with fleeting exceptions, is perfect, Emil Jannings standing out as usual" (The New Yorker 3.7.26 in: Slide 1982: 305).

Die deutschsprachige Filmkritik schätzte VARIETÉ als einen ,Schlager' ein (PFL 15.1.26: 3) und sprach von einem der besten Filme, die je in Deutschland gedreht wurden:

„Eine technisch glänzend gearbeitete Mischung aus Kammerspielfilm und Sensationsfilm.[...] Dies Raffinement im Aufbau des Films, dessen Manuskript der Regisseur selbst schrieb, ist charakteristisch [...]. Wieviele neue und bezaubernde Wirkungen sind zum Beispiel aus dem unzählige Male gezeigten Varietémotiv herausgepeitscht. [...] Die Photographie von Karl Freund und die Tricktechnik geben schließlich unserem Auge Entzücken

${ }^{85} \mathrm{Vgl}$. http://www.silentsaregolden.com/DeBartoloreviews/rdbvariete.html [18.12.06]. 
und unserem Herzen Atembeklemmendes. [...] Jannings zeigt manchmal nicht nur das Spiel des Helden, sondern Studien über dies Spiel" (Stürmer 1925).

Filmhistorische Einschätzungen sahen vor allem in der formalen Umsetzung die Gründe, welche den Film zu einem Meisterwerk machten (Kramer 1995: 321). Extreme Perspektiven, subjektive Einstellungen verschmolzen zu einem virtuosen Strom von Licht und Bewegung (ebd.). Der Filmkurier feierte Regisseur Dupont mit den Worten: „Sein Gehirn ist ein großer Nachzeichner seiner atmosphärischen Impressionen" (Filmkurier in Dahlke/Karl 1988: 122).

Der einzige ,Bergfilm' unter den in Südafrika gezeigten deutschen Filmen stellte die gemeinschaftlich von Arnold Fanck und Georg Wilhelm Pabst verantwortete Produktion DIE WEISSE HÖLLE VOM PIZ PALÜ/THE WHITE HELL OF PITZ PALÜ dar. ${ }^{86}$ Der Film erzählt die Geschichte eines Dr. Johannes Krafft, der bei der Besteigung des Berges Piz Palü einst seine Braut verlor und zu einem Einsiedler wurde. Mit einem jungen Paar wiederholt er zehn Jahre nach dem Unglück die Tour und auch diesmal gerät er in Bergnot. Sein ganzer Einsatz gilt der Rettung des Paares, welches später von einer Expedition befreit wird, er selber aber ums Leben kommt. Für einige spektakuläre Luftbilder konnte der Kunstflieger Ernst Udet gewonnen werden.

Der „Film Critic” der Cape Times begann seine Ausführungen mit der Feststellung, dass der Film der beste gewesen wäre, der je in Kapstadt gezeigt wurde (CT 18.6.31: 5). Weiters bemerkte er:

„This triangular drama with Pitz Palü as the fourth protagonist is lifted out of the ordinary by the simplicity and sincerity of the players and the wonder of the mountain scenes in a glittering waste before which adventure turns to terror" (ebd.).

Die Bilder der Schneelandschaften seien sogar eindrucksvoller als in Filmen mancher Polarexpeditionen, der Effekt der sanft flackernden Fackeln vor dem schneeweißen Hintergrund führe hin zu einer Steigerung, die lediglich in der Fackelszene von DER ALTE FRITZ gewagt wurde (ebd.). Als Inbegriff der Wahrhaftigkeit im eigentlichen Sinne beeindrucke der Film durch die Großartigkeit der Handlung, der Inszenierung, Fotografie und der Filmkunst (CT 23.6.31: 5): „It is a film that grips and holds one both by thrill of ist beauty,

${ }^{86}$ CT 18.6.31: 5, CT 20.6.31: 9, CT 23.6.31: 5, DB 23.6.31: 9, CT 23.6.31: 5, DB 24.6.31: 8, CT 13.7.31: 9, EPH 7.10.31: 18, NM 21.11.31: 25, NA 21.11.31: 7, NA 24.11.31: 11, NM 24.11.31: 14, TF 16.3.32: 8, VB 17.3.32: 10 (Kapstadt, Port Elizabeth, Durban, Bloemfontein). 
the danger to the actors and the horror of the power of height and depth" (ebd.). Die in den Film gesetzten Erwartungen wurden nicht enttäuscht, sondern übertroffen (DB 24.6.31: 8), der Film sei von einem Draufgänger und Künstler aufgenommen worden (DB 23.6.31: 9). Aus nicht nachvollziehbaren Gründen gab die sonst so korrekte Filmkritik in Die Burger an, dass der Film von Carl Lämmle produziert worden sei, obwohl H.R. Sokal dafür verantwortlich zeichnete.

Eine Sondervorführung mit Orchesterbegleitung wurde in der Stadthalle von Kapstadt vor einem außerordentlich zahlreichen Publikum arrangiert (CT 13.7.31: 9). Die Fotografie sei unbeschreiblich gut, die Fackelszene bei Nacht eine der besten die je gemacht wurden (NM 21.11.31: 25). Wenn die Produzenten das Wort ,unglaublich' für den Film gebraucht hätten, würden sie nicht einmal besonders falsch liegen (NA 24.11.31: 11). Vom technischen Standpunkt aus sei die Leistung der Kinematographen unfassbar, deren Bilder unter so schwierigen Bedingungen ein Triumph an menschlicher Ausdauer und Erfindungsgeist (NM 24.11.31: 14). Der auch in Deutschland als ,volksbildend' prädikatisierte Film wurde in Bloemfontein von einigen Schuldirektoren in einer Privatvorstellung darauf untersucht, ob er im Unterricht eingesetzt werden könne (TF 16.3.32: 3):

„[...] it can be stated, at the very outset, that there is not a single objectionable incident in it. It is indeed, cleaner and more wholesome than one might have been led to expect, and children, in the viewing of it, instead of suffering harm, will gain in knowledge; for it shows them scenes and a mode of life with which few of them are likely to come in contact unless they travell widely" (ebd.).

In den USA erstellte die den Film vertreibende „Universal“ eine 16 mm Kopie, die speziell für den Schulgebrauch vorgesehen war (Blaisdell 1930). Der Kinoversion in den USA wurde mit einer ,vocal dramatization' versehen, die manche Kritiker an Kommentare während eines Boxkampfes erinnerte und damit einen wunderschönen Film ruiniert hätte (Hamilton 1930).

Die deutsche Filmkritik sprach hingegen von einer glänzenden fototechnischen Leistung in einem langweiligen Film und das dem Regisseur das Motiv, die Antithese Element - Mensch, entglitten sei (Frankfurter Zeitung 15.11.29 in: Gandert 1993: 700):

„Dr. Krafft ist der gute Cowboy im Gebirge, das Bergseil ist das Lasso, das Flugzug Udets ist das Heldenpferd. Im Sturm und Rasen zeigt sich der zornerfüllte und doch gerechte Gott. Das Happy End stellt sich mit Klischeepräzision ein" (ebd.). 
Andere Kommentare bezeichneten den Film als ein "Musterbeispiel von Werktreue“" (Berliner Börsen-Courier vom 17.11.29 in: Gandert 1993: 701), vollends begeistert zeigte sich die Kritik in der Vossischen Zeitung:

„Hier ist nichts gestellt, nichts präpariert. Man sieht keine Pappe. Was sind die Dekorationen der FRAU IM MOND gegen diese Naturpracht, und wie unsagbar langweilig war der dreistündige Schiffsuntergang im ATLANTIK-Film gegenüber dieser Eis- und Schneekatastrophe. Hier wird der Zuschauer mitgerissen, hier ist er von der Natürlichkeit der Geschehnisse und der Echtheit des Entsetzens überzeugt" (Vossische Zeitung 17.11.29 in: Gandert 1993: 701).

Als einer der besten deutschen Filme wurde DIE WEISSE HÖLLE VOM PIZ PALÜ sogar von der politischen Tendenzpresse gelobt, noch nie sei ein deutscher Film mit so kühner Realistik gezeigt worden, die Filmoperateure hätten Glanzleistungen von unerhörter Schönheit und mitreißender Spannung vollbracht (Die Rote Fahne vom 19.11.29 in: Gandert 1993: 702).

Die Gesamttendenz der Kritik an DIE WEISSE HÖLLE VOM PIZ PALÜ wies in die selbe Richtung wie spätere filmgeschichtliche Abhandlungen, die den Erfolg des Films auf die Kombination von schlichter Handlungskonstruktion und Darstellerqualitäten mit den spektakulären Naturaufnahmen aus dem Hochgebirge zurückführten (Dahlke/Karl 1988: 203). Ohne filmische Beweisführung diffamierte Siegfried Kracauer die Bergfilme hingegen als eine Welle von Pro-Nazitendenzen (Kracauer 1995: 271). Aus der zufälligen Übernahme der dramatisierten Wolkendarstellungen in vielen Bergfilmen und so auch in DIE WEISSE HÖLLE VOM PIZ PALÜ - in die Anfangssequenz von „Triumph des Willens“ (1935, L. Riefenstahl), leitete Kracauer eine Verschmelzung von Gebirgskult und Hitlerkult ab (ebd.). Unter den ausgewerteten zeitgenössischen Rezeptionsbelegen findet sich jedoch kein einziger Hinweis auf diese wohl nur durch Kracauer nachvollziehbare Lesart. Mit der in dieser Studie angestrebten Kinogeschichte als Rezeptions- und Wirkungsgeschichte lässt sich nachweisen, dass Kracauers posthistorische Projektionen eher persönlichen Motiven folgten, als dass diese film- und kinohistorisch belegbar wären.

Die nur als ,guter Mittelfilm' (5) bewertete Produktion APACHEN VON PARIS ${ }^{87}$ handelt von einem der amerikanischen „Moral Uplift League“ ange-

${ }^{87}$ DB 27.4.29: 8, CT 27.4.29: 11, CT 29.4.29: 9, DB 1.5.29: 9, DB 3.5.29: 8, NM 18.5.29: 23, NA 18.5.29: 6, RDM 3.6.29: 12, NW 22.6.29: 13, NW 24.6.29: 4, EPH 6.7.29: 17, TF 13.12.29: 17, VB 12.12.29: 8 (Kapstadt, Durban, Johannesburg, Pietermaritzburg, Port Elizabeth, Bloemfontein). 
hörendem Ehepaar nebst Tochter, die nach Paris reisen, um die Europäer vor Alkoholmissbrauch und Sittenverfall zu retten. Von einer Verbrecherbande (,Apachen') bedroht, entgehen sie ihrem Schicksal nur durch den Umstand, dass sich der Bandenchef in die Tochter verliebt, diese später heiratet und sein Vagabundendasein aufgibt. ${ }^{88}$

Die Pressevorführung des Films in Kapstadt bewog den Kritiker von Die Burger dazu, APACHEN VON PARIS als einen würdigen Nachfolger von SPIONE und einen weiteren Beleg für die beispiellose Tüchtigkeit der UFA zu bezeichnen (DB 27.4.29: 8). Selbst an belangloseren Filmen wie DER KAMPF DES DONALD WESTHOF werde immer noch deutlich, wie überlegen die UFA ihren Mitbewerbern und Nachahmern sei, von den mächtigen Fritz Lang Produktionen wie METROPOLIS oder FAUST ganz zu schweigen. Die Bewunderung der UFA-Filme rühre vor allem von deren Kunstfertigkeit her, jede Szene sei im Hinblick auf ihre Komposition perfekt, immer auf ein Maximum an Kunstsinnigkeit ausgerichtet. Als Erzählung sei APACHEN VON PARIS nicht von besonderem Interesse, allein der höhere Kunstwert dieses Films werde das Publikum schon anziehen, immerhin genössen die UFA-Produktionen eine riesige Popularität (ebd.). Diese Einschätzung sah der Rezensent nach der ersten Publikumsvorstellung als bestätigt an, an den beiden vergangenen Tagen lief der Film in vollen Sälen, ein Beweis dafür, dass die Zuschauer den Kunstwert der UFA-Filme zu schätzen wüssten (DB 1.5.29: 9). Selbst wenn der Film durch seine Art nicht auf der höchsten Stufe der UFA-Filme stehe, sei er immer noch ein herausragender Film seiner Klasse (DB 3.5.29: 8).

Auch die englische Presse betonte, dass die UFA für ihre großartigen und modernen Produktionen bekannt sei (CT 29.4.29: 9) und der Film vor allem jene zufriedenstellen würde, denen spannendes und abwechslungsreiches Geschehen wichtiger sei als die wenigen Unwahrscheinlichkeiten (NM 18.5.29: 23). Nicht zuletzt die Anspielungen auf die "geheimnisvolle Pariser Unterwelt" sorgten dafür, dass der Film an der Kinokasse sehr erfolgreich war und offenbar den Geschmack des Publikums traf (EPH 6.7.29: 17 und TF 13.12.29: 17).

Auch in der deutschen Kritik wurde diese deutsch-französische Gemeinschaftsproduktion recht wohlwollend besprochen, jedoch eher als Posse abgetan. Als Literaturverfilmung erinnere der Film an Berliner Milieufilme à la Zille, aber die zur „Unwirklichkeit aufgepulverte Kaschemmen-Romantik“

\footnotetext{
${ }^{88}$ Vgl. Reklame-Ratschläge des UFA-Leih für DIE APACHEN VON PARIS, Berlin 1927/28, 14 S.
} 
verschaffe nun einmal dem Bürger jenen angenehmen Hautkitzel, den man in der Zerstreuung suche (LBB 20.12.27: 2):

„Alles in allem ein Film, der durch seine optische Sauberkeit und handwerkliche Akkuratesse die Anspruchsvolleren ebenso befriedigen wird wie das breitere Publikum, das Effekte, Spannung und eine gute Dosis Leidenschaft nicht missen will" (ebd.).

Bei DIE TODESSCHLEIFE/LOOPING THE LOOP handelt es sich um einen der wenigen Filme, welcher auch im deutschsprachigen Verleihgebiet mit einem englischen Titel vertrieben wurde. ${ }^{89} \mathrm{Im}$ Zirkusmillieu spielend, handelt der Film von einer Liebesbeziehung eines Mädchens mit einem Clown, welcher seine wahre Identität aus Angst vor einer Zurückweisung des Mädchens zunächst verschweigt. Trotz eines Verlöbnisses der beiden zerstreiten sie sich und finden erst wieder zueinander, nachdem der Clown das Mädchen unerkannt vor den Zudringlichkeiten eines Akrobaten schützt.

LOOPING THE LOOP wurde von der südafrikanischen Kritik vor allem dafür gelobt, dass der Film Einblicke hinter die Kulissen der Zirkuswelt ermöglichte (DB 17.6.29: 8, NA 22.6.29: 6 und NW 3.8.29: 9). Regisseur Arthur Robison wurde als Schöpfer von DER LETZTE WALZER und "Schatten" (1923) erwähnt, ebenso das Mitwirken Warwick Wards in VARIETÉ (RDM 17.6.29: 12). Unter den anderen bereits gezeigten Zirkusfilmen wie VARIETÉ, "Life's a Circus" und "Ghosts of the Night" ${ }^{90}$ rage LOOPING THE LOOP eindeutig hervor. Beschrieben als „Exciting sequences of events culminating in an intensely dramatic climax, straightens matters out and brings to a close one of the most exciting films that has been booked for Durban" (NM 22.6.29: 24), gab der Rezensent die Vorabinformationen des Verleihs unmittelbar an die Leser weiter. Die englische Presse kam in ihren Besprechungen kaum über unverbindliche Gemeinplätze wie „Extremely well acted and produced in the best UFA manner" (CT 18.6.29: 7) oder "one of the most striking and vivid pictures that has ever been screened" (NA 22.6.29: 6) hinaus.

Im Gegensatz dazu stand die afrikaanse Presse, die den Film zwar ebenfalls in den höchsten Tönen lobte, aber dem Schauspieler Warwick Ward in der Rolle des André die Fähigkeit absprach, seine Rolle mit Tiefe und stark emotionalem Spiel auszufüllen (DB 18.6.29: 9). Jenny Jugo hingegen wurde

\footnotetext{
${ }^{89}$ RDM 17.6.29: 12, CT 18.6.29: 7, DB 18.6.29: 9, DB 21.6.29: 9, NA 22.6.29: 6, NM 22.6.29: 24, NM 25.6.29: 9, NW 3.8.29: 13, NW 10.8.29: 9, EPH 3.8.29: 7, TF 19.12.29: 5, VB 21.12.29: 8 (Johannesburg, Kapstadt, Durban, Pietermaritzburg, Port Elizabeth, Bloemfontein).

${ }^{90}$ Die genannten Filme konnten bisher nicht identifiziert werden.
} 
zugebilligt, dass sie tief, feinsinnig und stark temperamentvoll spiele und ihre Trauermiene hätte sie sich wohl von Pola Negri abgeschaut (ebd.). Die kleinen Manieriertheiten, über die man sich noch in AM RANDE DER WELT habe ärgern können, seien verschwunden (ebd.), die weiche Fotografie der UFA, die nicht mit amerikanischer Nebelhaftigkeit zu verwechseln sei, besitze die angenehme Eigenschaft, die Augen nicht zu ermüden, der ganze Film stelle einen Meilenstein in der Filmwelt dar (DB 21.6.29: 9). Besonders auffällig sind die Vergleiche des Rezensenten mit Werken aus der Malerei, so z.B. könne die Symbolik der Spiegelrefektion einer Szene an Goyas Gemälde „Maya im Spiegel“ erinnern, rembrandtartig wären einige Fensterdurchsichten gestaltet (DB 18.6.29: 9). ${ }^{91}$

Ein interessantes Detail zur später noch ausführlich behandelten Zensurpraxis in Südafrika offenbart die Besprechung des Films im Natal Witness, wonach zwei Mitglieder des Stadtrates von Pietermaritzburg an der Vorstellung teilnahmen, um zu entscheiden, ob der Film auch für Nachmittagsvorstellungen geeignet sei (10.8.29: 9). Es wäre allerdings schwer zu sagen, welche Einsprüche - wenn überhaupt - gegen den Film erhoben werden könnten (ebd.). Die meisten Besprechungen belegen einen guten Publikumszuspruch für LOOPING THE LOOP. Bei den Berichten der engschlische Presse fiel zudem auf, dass Teile aus den (meist agenturvermittelten) Filmvorbesprechungen als eine Art Textbausteine in die Rezensionen miteingingen. Den darin enthaltenen Rezeptionsempfehlungen scheint also weitgehend gefolgt worden zu sein.

Die deutsche Kritik bemängelte u.a. die realitätsfremde Darstellung des Artistenmilieus, obschon trotz dieses Fehlers die ganze Handlung spannend genug sei, „um den Beschauer dauernd in Atem zu halten, zu interessieren und zu fesseln" (LBB 17.9.28: 2). Von Jenny Jugo bleibe fast nur der überwiegend weinerliche Gesichtsausdruck im Gedächtnis, Warwick Ward hätte man schon besser gesehen, Werner Krauß hingegen wurde eine Leistung attestiert, die ihn kaum ein deutscher Darsteller nachmachen könne (ebd.). Dieser Einschätzung wurde auch in Paimann's Filmlisten gefolgt (PFL 4.1.29: 2). Ressumierend schrieb die Lichtbildbühne:

„Die Regieleistung Arthur Robisons, [...], stellt sich bei einer kritischen Würdigung wie ein Januskopf dar: vorzüglichen Einzelleistungen, die gewiß auf sein Konto zu buchen sind, steht das unzulängliche Spiel zweier Hauptdarsteller gegenüber" (LBB 17.9.28: 2).

${ }^{91}$ Hier könnte auch eine Verwechslung vorliegen, gemeint war sicher die „Venus vor dem Spiegel“ (164951) von Diego Velázquez. 
Die Geschichte von DIE CARMEN VON ST. PAULI/THE WATER RAT ${ }^{92}$ erzählt von einem Seeoffizier, der durch ein verführerisches Mädchen von seinem Dienst abgelenkt wird, woraufhin ein Einbruch auf seinem Schiff geschieht und er entlassen wird. Durch diesen Absturz wird er fast zum Verbrecher, ein Mord wird inm ebenfalls unterstellt, der nur durch die Zeugenschaft des Mädchen aufgeklärt wird. Am Ende verlassen beide als freies Liebespaar den Gerichtssaal. ${ }^{93}$

Die Mehrzahl der englischsprachigen Rezeptionsdokumente basiert größtenteils auf einer Agenturmeldung, die von einem Liebesdrama im Hamburger Hafenmillieu spricht, welches von Regisseur Erich Waschneck inszeniert wurde, der auch mit "Jackals" einen der besten Filme der vergangenen zwei Jahre produziert habe (NM 10.8.29: 23, NA 10.8.29: 6, NW 7.9.29: 13, CT 21.9.29: 11). DIE CARMEN VON ST. PAULI sei zwar nicht so ein schweres Drama wie "Jackals", aber auch nicht weniger effektiv umgesetzt und sehr interessant produziert. ${ }^{94}$ Die beiden Hauptdarsteller Willy Fritsch und Jenny Jugo seien dem Publikum noch aus EIN WALZERTRAUM und SPIONE bekannt (ebd.), der Film wurde als durch und durch "romantic and thrilling" eingeschätzt (CT 14.9.29: 10). Aus ihrer schwierigen Rolle mache Jenny Jugo trotz einer gewissen Künstlichkeit noch das Beste, Fritschs Rolle wäre nichts Großartiges aber er beherrsche sie (CT 24.9.29: 7).

Wesentlich kritischer war wiederum die afrikaanse Presse, welche den Film in Die Burger als voller Fehler und Ungereimtheiten bezeichnete (DB 24.9.29: 9). Was den Film trotzdem anziehend mache, sei die durchweg glänzende Fotografie, auch die Straßenszenen und jene in der Hafenkneipe seien auf dem hohen Niveau, was man von den besten Arbeiten der UFA zu erwarten gewohnt sei (ebd.). Dies entschädige in jeder Hinsicht für die schwache Handlung, die der Film mit hunderten anderen Filmen teile. Das Schauspiel von Willy Fritsch und Jenny Jugo sei sehr ansehnlich, der Realismus der Darstellungen war mit Vergnügen anzusehen, auch werde der Zensor wohl bei einigen Aufnahmen zugeschlagen haben (ebd.). In einer zweiten Besprechung in Die Burger wird der Rezensent genauer und benannte einige der von ihm identifizierten Ungereimtheiten (DB 26.9.29: 8). Warum solle

\footnotetext{
${ }^{92}$ NM 10.8.29: 23, NA 10.8.29: 6, NW 14.9.29: 10, CT 21.9.29: 11, DB 24.9.29: 9, EPH 17.12.29: 8 (Durban, Pietermaritzburg, Kapstadt, Port Elizabeth).

${ }^{93} \mathrm{Vgl}$. Reklame-Ratschläge des UFA-Leih für DIE CARMEN VON ST. PAULI, Berlin 1928/29, 18 S.

${ }^{94}$ Um welchen Film es sich bei „Jackals“ tatsächlich handelte, konnte leider nicht festgestellt werden. Die zeitliche Nähe des Jahres 1928 lässt vermuten, dass es sich vielleicht um „Die Geheime Macht" gehandelt haben könnte, der allerdings unter den alternativen Verleihtiteln „Sajenko the Soviet" (USA) und „Secret Power" (UK) gezeigt wurde.
} 
z.B. eine Reederei wertvolle Güter in einem Schiff lagern, welches gar nicht benutzt werde und wieso steht unmittelbar nach dem Raub die komplette Firmenleitung der Reederei in der Kajütte des Schiffes? Trotzdem sei der Film ein typisches UFA-Produkt, was in vielerlei Hinsicht dem guten Namen der Produzenten zur Ehre gereiche (ebd.).

Die deutsche Rezeption sprach von einem sauberen Geschäftsfilm, er profitiere besonders vom erotischen Spiel Jenny Jugos und sei eine saubere, fleißig durchgearbeitete Leistung (LBB 11.10.28: 2). Die Einschätzung aus Paimann's Filmlisten als ,guter Mittelfilm' verstärken den eher belanglosen Charakter von DIE CARMEN VON ST. PAULI, größere Abweichungen zwischen der südafrikanischen und der deutschen Medienrezeption konnten nicht festgestellt werden. ${ }^{95}$ Dass der Film im Drehort Hamburg besonders gut ankam, bedarf sicher keiner weiteren Erklärung, über die spezielle Picanterie des St. Pauli-Milieus schrieb der in der Hafenstadt Durban angesiedelte Natal Advertiser, "The plot is laid in Hamburg, known to the travelled as the naughtiest city in the world" (NA 13.8.29: 12).

\subsubsection{Untersuchung der „MI <10-Filme“ unter den Genre 1-Filmen}

\section{Zu DIE YACHT DER SIEBEN SÜNDEN/THE YACHT OF THE SEVEN SINS} liegt nur eine Filmrezension vor, die anderen Texte sind Filmvorbesprechungen, also Rezeptionsempfehlungen. Für eine Luxuskreuzfahrt seiner Yacht „Yoshiwara“ heuert ein Mädchenhändler Tänzer- und Sängerinnen an. An Bord befinden sich noch weitere dubiose Gestalten, was dem Verlobten einer der Tänzerinnen merkwürdig vorkommt, er aber unter Mordverdacht gerät und auf der Yacht Zuflucht suchen muss. Doch auch die Behörden sind misstrauisch geworden und halten das Schiff auf See an, nehmen die Kriminellen gefangen und finden die Mörderin.

Tab. 28: „Ml<10-Filme“ unter den Genre 1-Filmen

\begin{tabular}{|c|c|c|l|c|}
\hline MI & PFL & FK & \multicolumn{1}{|c|}{ Filmtitel } & Erstbeleg SA \\
\hline 7 & 5 & - & Die Jacht der sieben Sünden (K) & 05.10 .29 NM \\
\hline 5 & 1 & - & Der Student von Prag (A) & 20.04 .28 OUT \\
\hline 3 & 3 & 2 & Wolga Wolga (A) & 19.07 .29 CT \\
\hline 3 & 4 & - & Das letzte Fort (K) & $19.10 .29 \mathrm{NM}$ \\
\hline 3 & 4 & - & Die Liebe der Jeanne Ney (K) & 25.03 .29 RDM \\
\hline 3 & 2 & - & Hokuspokus (T) (K)* & $13.07 .31 \mathrm{DB}$ \\
\hline
\end{tabular}

${ }^{95}$ Vgl. auch die Pressestimmen zu DIE CARMEN VON ST. PAULI in den Reklame-Ratschlägen des UFALeih 1928: $16 \mathrm{ff}$. 


\begin{tabular}{|c|c|c|l|c|}
\hline MI & PFL & FK & \multicolumn{1}{|c|}{ Filmtitel } & Erstbeleg SA \\
\hline 2 & 2 & - & Manolescu-Der König der Hochstapler (A) & $26.07 .30 \mathrm{NA}$ \\
\hline 2 & 4 & - & Der Kampf des Donald Westhof (K) & $16.04 .29 \mathrm{DB}$ \\
\hline 2 & 2 & - & Mann gegen Mann (K) & $15.06 .29 \mathrm{EPH}$ \\
\hline 1 & 4 & - & Die blaue Maus (K) & $12.05 .30 \mathrm{DFA}$ \\
\hline
\end{tabular}

Ausnahmslos alle Besprechungen erwähnen die Hauptdarstellerin Brigitte Helm, die bereits aus METROPOLIS, THE WONDERFUL LIE und AT THE EDGE OF THE WORLD bekannt sei und wieder in einer Rolle als Vamp besetzt wäre (NM 5.10.29: 23). Auch die hervorragende Fotografie des Films wird in den meisten Besprechungen herausgestellt (NM 7.10.29: 4, NW 12.10.29: 13). Besonders an der afrikaansen Besprechung des Films in Die Burger fällt auf, dass anscheinend ein und derselbe Werbetext verarbeitet wurde, die Formulierungen wirken sehr standardisiert (DB 25.10.29: 8). Ihre Besetzung als Vamp, eine Rolle die sie eigentlich hasse, sei diesmal vollkommen anders: als strahlende, selbstbewusste, philosophische und vornehm gekleidete Persönlichkeit entspreche sie nicht den üblichen Filmtypen (ebd.). Ungewöhnlich ist auch die Bemerkung in Die Burger, das ohne Pressevorführung die Besprechung nur sehr kurz ausfallen könne, da man es nicht schätze, nur mitgeteilte „Meinungen“ wiederzugeben (ebd.). Die einzige echte Filmbesprechung in der Cape Times lobte den Film als simpel erzählt und voller feinsinniger Charakterisierungen, genauso wie man es von einer UFA-Produktion erwarte:

„A UFA film is always interesting from one angle or another. If the story is thin, the production is sure to recompense one for the poverty of plot, and if the production should by some wild chance fail, there is pretty certain to be compensation in fine photography (CT 30.10.29: 9).

Die deutsche Filmkritik bezeichnete den Film als einen recht bescheidenen Film, „[...] den auch seine äußere Aufmachung nicht über die Ansprüche der Vorstadt hinaus steigert" (LBB 7.8.28: 2). Der wertsteigernde Faktor sei allein Brigitte Helm gewesen, allerdings bei dem die Regie führenden Ehepaar Fleck in den falschen Händen gelangt. Die Gesamtqualifikation aus Paimann's Filmlisten als ,guter Mittelfilm' wird mit den Aussagen aus der Lichtbildbühne bestätigt. Die auf einer Luxusyacht spielende erotisch angehauchte Handlung, der Einbau von Mörder- und Gaunergeschichten um eine Mädchenhändlerbande, sowie die herausragende Positionierung von Brigitte Helm als Vamp verstärken die offen ablenkende Tendenz dieses Films. 
Als "The story of a man who sold his soul" wurde DER STUDENT VON PRAG/THE STUDENT OF PRAGUE angekündigt (Outspan 20.4.28: 52). Ein armer Student erhält von einem Fremden 600.000 Gulden, als Gegenleistung verlangt dieser dessen Spiegelbild. Das Geld verschafft ihm Zugang zur Gesellschaft und er versucht, eine bereits verlobte Comtesse zu gewinnen, wird aber von seiner ehemaligen Geliebten verraten, worauf sich der Verlobte zum Duell ankündigt. Dem Vater des Mädchens verspricht der Student die Verschonung des künftigen Schwiegersohnes, was jedoch durch das Auftauchen des Doppelgängers und einem Mord am gegnerischen Duellanten endet. Die Comtesse versagt ihm daraufhin seine Zuneigung, ein Unglück, was er mit Glücksspiel zu kompensieren sucht. Sein ständiges Glück entfremdet ihn von seinen Kameraden, am Ende spielt er gegen seinen Doppelgänger, der ihn ständig verfolgt. Um ihm zu entkommen, schießt der Student auf sein Spiegelbild und tötet sich damit selbst.

Neben der Nacherzählung der Handlung bieten die Filmbesprechungen kaum wertende Äußerungen. Erwähnt wurde die gute Presse für den Film in Übersee (TS 23.4.28: 8), das gute Schauspiel Conrad Veidts und Werner Krauss' (ST 22.4.28: 7), die Ähnlichkeit des Filmstoffes mit „Faust“ (NM 12.5.28: 23) und das der ganze Film irgendwie unheimlich wirke (TF 26.6.28: $10)$.

Die unter dem Titel WOLGA, WOLGA/VOGA, VOLGA verfilmte Geschichte des russischen Volkshelden Stepan Rasin zeigt die Kämpfe der Aufständischen mit den Truppen des Zaren. Für ein Bündnis mit dem Schah segelt er nach Persien, wo er vom persischen Statthalter verraten wird, fliehen muss und sich in dessen Tochter verliebt. Trotz Verbotes bringen seine Leute das Mädchen an Bord, woraufhin eine Meuterei ausbricht, die zum Tod des Mädchens durch Rasin selbst führt. Erneut verraten geht er auf dem brennenden Schiff unter.

Nach einer Pressevorführung stimmte der Rezensent der Cape Times den Meldungen aus London zu, die WOLGA, WOLGA als eine moderne, fast schon impressionistische Produktion bezeichneten (CT 19.7.29: 11). Der sparsame Einsatz von Großaufnahmen (,close-ups') habe, anders als bei Hollywood, dieser Darstellungsmethode eine doppelte Effektivität verliehen.

Das Wüstendrama DAS LETZTE FORT/THE LAST FORT stellt das Schicksal dreier von Frauen enttäuschter Kameraden in den Mittelpunkt, die auf der Seite der Araber in Nordafrika gegen die Franzosen kämpfen. Die Tochter eines gefangenen Offiziers sorgt kurzzeitig für Verwirrung. Als das Fort in Pflichterfüllung fällt, gelingt nur einem der Kameraden zusammen mit den Gefangenen die Flucht. 
Als ,maskulines' Drama profitiere der Film von der Energie der Darsteller (NM 19.10.29: 24), allen voran Heinrich George und Maria Paudler (NM 21.10.29: 5). Die erfolgreich kreierte Atmosphäre des Films und dessen Psychologie stellten eine seiner Attraktionen dar (NW 16.11.29: 13).

Die Literaturverfilmung von Ilja Ehrenburgs gleichnamigem Roman DIE LIEBE DER JEANNE NEY/THE LOVES OF JEANNY NEY handelt von einer jungen Französin, die während der Wirren der russischen Revolution ihren Vater verliert, nach Paris flieht und dort den jungen Sowjetagenten wiedertrifft, in welchen sie sich in Moskau verliebt hatte. Als ein Spitzel ihren Onkel ermordet, wird versehentlich ihr Geliebter verhaftet. Am Ende gelingt es ihr, den Spitzel als wahren Täter zu überführen und ihren Geliebten zu entlasten.

Der Film sei von G.W. Pabst mit dem gleichen genialen Touch wie „Secrets of a Soul" (1926, dt. "Geheimnisse einer Seele") produziert worden, das Sujet komplex und die Innenaufnahmen kubistisch (RDM 25.3.29: 11). Das Talent von Brigitte Helm in ihrer ersten Rolle nach METROPOLIS als blinde Cousine wirke wie verschwendet (ebd.), der Hauptdarstellerin Edith Jehanne zuzusehen sei hingegen ein Vergnügen (NW 8.6.29: 31). In der deutschen Presse wurde der Film als Triumph der Regiekunst und Bildgestaltung bezeichnet (LBB 6.12.27: 2).

Ein Film der äußerst erfolgreichen Darstellerpaarkonstellationen um Lilian Harvey ist HOKUSPOKUS/THE TEMPORARY WIDOW (mit L. Harvey und Laurence Olivier). In dieser Kriminalkomödie wird eine Frau des Gattenmordes angeklagt, jedoch nach der Selbstbezichtigung eines jungen Mannes freigelassen. Dieser ist schließlich der vermeintlich Ermordete selbst, der als Künstler eine Möglichkeit suchte, seine Bilder besser verkaufen zu können.

Dieser possenhafte Tonfilm um einen Scheinprozess wurde als eine Mischung aus Lust- und Trauerspiel in der afrikaansen Presse angekündigt (DB 14.7.31: 9). Sehr realistisch und voller Humor von Anfang bis Ende strotze der Film voller unerwarteter Wendungen. Der Film sei die englische Fassung einer der mehrsprachigen UFA-Produktionen, die jetzt wohl zur Gewohnheit würden (CT 14.7.31: 5). Die in Deutschland lebende Engländerin Lilian Harvey habe einen starken Akzent, ihre Persönlichkeit sei der von Greta Garbo nicht unähnlich, sonst aber eher unbeachtlich. Der Humor des Films sei etwas für die Teile des Publikums, die lieber schmunzeln als laut lachen würden (ebd.).

Die Abenteuer eines Diebes stehen im Mittelpunkt MANOLESCU. Um seiner kostspieligen Partnerin Willen, begeht er diverse Betrügereien, bekommt Gewissensbisse und wird dafür von einem ehemaligen Freund seiner Gespielin niedergeschlagen. Im Krankenhaus verliebt er sich in seine Pflege- 
rin, die verspricht, auf ihn zu warten, nachdem er durch Verrat in die Hände des Gesetzes fällt.

Der Erstbeleg zu diesem Film ist eine Produktionsnotiz der UFA, welche diesen teilweise in St. Moritz und Monte Carlo gedrehten Film entsprechend bekanntgemacht hat (NM 16.3.29: 23). Der Natal Advertiser war sich sicher, dass ein Film mit dem UFA-Gütesiegel und dem hervorragenden Zusammenspiel von Brigitte Helm und Iwan Mosjukin nur sein Geld wert sein kann (NA 26.7.30: 11). Brigitte Helm spiele die für sie typische Unterwelt-Eva, eine Besetzung für die sie seit Beginn ihrer Karriere immer wieder ausgewählt wurde. Der Film hätte ein eleganter Gaunerfilm werden können, wenn die Produzenten ihn nicht mit einer Moral aus dem Durchschlagsheft versehen hätten (ebd.). Die deutsche Kritik urteilte recht hart gegen den Film und vermerkte, dass er ein Musterbeispiel dafür sei, wie ein dankbarer Stoff durch Fehler in der Grundanlage geschädigt werde: „Ein Gaunerfilm, bei dem man zur idyllischen Besinnung kommt, ist keiner" (Ihring 1929a in Gandert 1993: 419).

In DER KAMPF DES DONALD WESTHOF/THE TRIAL OF DONALD WESTHOF muss ein unter Mordverdacht an seinem Arbeitgeber stehender Sekretär seine Unschuld beweisen, ein Verdacht durch welchen er als Folge seiner Beziehung zu dem jungen Mädchen geraten ist, welches sein Chef heiraten wollte. Da das Mädchen schweigt, rettet ihn erst die Aussage einer Jugendfreundin vor der erwarteten Strafe.

Der Kommentar aus Die Burger hebt die Besonderheit der meisten deutschen Filme hervor, in denen vor allem die Wirklichkeit so dargestellt werde, wie sie ist, und nicht so wie dies die meisten Hollywoodfilme dem Zuschauer weißmachen wöllten (DB 16.4.29: 8). Wie in UFA-Filmen üblich, folge ein fotografisches Wunder auf ein anderes. Besonders typisch seien auch die symbolische Darstellung der Großstadt und die Auswahl einer temperamentvollen Filmheldin. Wenn die UFA nur wöllte, könnte sie immer Detektivdramen produzieren, die genausogut wären, wie die von jeder amerikanischen Firma, oder besser gesagt: noch besser wären, da sich die UFA nicht der Schwachsinnigkeiten der amerikanische Regisseure schuldig mache (ebd.). In der Bewertung des Natal Witness wurde die „außergewöhnlich dramatische UFA-Produktion" vor allem für ihre Kameraarbeit und das ausgezeichnete Schauspiel von Imre Raday gewürdigt (NW 13.7.29: 13). Die deutsche Medienrezeption äußerte sich recht positiv und bemerkte, dass „[...] bei aller Feinheit der Mittel, bei aller Zurückhaltung von groben Effekten doch ganz starke und publikumswirksame Werk [...] ohne Bedenken einer der besten 
Filme, die uns bis jetzt die Saison bescherte, genannt werden" darf (LBB 30.9.29: 2).

Als Stunt-Film wurde Harry Piels MANN GEGEN MANN/FOR MEN ONLY angekündigt (EPH 15.6.29: 15), ein Film der als Nicht-UFA-Film über den UFA-Vertrieb nach Südafrika gelangte. Zwischen Harry Piel und einer Detektivin entbrennt ein Wettkampf um die Jagd nach einer Bande von Geldfälschern, deren Oberhaupt ein Bankkassier ist. Die Verhaftung des letzteren überlässt Piel der Detektivin, nachdem er die Bande bereits festgesetzt hat und die Blüten der Grenzpolizei in die Hände spielt.

Als ,Stuntman Nummer Eins' bezeichnet der Diamond Fields Advertiser den Hauptdarsteller und Regisseur Harry Piel, der ein spannungsgeladenes Detektivmelodram in verschneiter Hochgebirgslandschaft zelebriert. Die Titelgebung spielt angeblich auf die Schlussszene an, in der Piel die Schurken seiner Konkurrentin mit den Worten "this kind is a job for men only" überlässt (ebd.).

Bei DIE BLAUE MAUS/THE BLUE MOUSE, zu dem nur ein Textbeleg vorliegt, handelt es sich um einen Schwank, in dem ein auf beruflichen Aufstieg hoffender lediger Sekretär eine Bartänzerin als seine Frau engagiert, damit diese ihre Reize zur Beförderung des Sekretärs bei dessem Vorgesetzten zum Einsatz bringt. Am Ende wird der Sekretär befördert und heiratet die Tänzerin.

Die Besprechung des Diamond Field Advertisers hob vor allem das Talent der beiden Hauptdarsteller Jenny Jugo und Harry Halm hervor (DFA 12.5.30: 3). Die UFA bestätige mit diesem Film, dass sie auf Schauspieler zählen könne, die vom Charakter her nicht zu kontinentaleuropäisch geraten wären, sondern durch ihr komödiantisches Talent auch auf internationalen Erfolg hoffen könnten.

Wie sich anhand der Medienrezeption der „Ml<10-Filme“ unter den Genre 1 -Filmen belegen lässt, kann einer Analyse der wenigen und qualitativ schwachen Rezeptionsdokumente (meist Agenturmeldungen) kaum mehr als die Funktion einer programmgeschichtlichen Flankierung der erfolgreicheren deutschen Filme zugewiesen werden. Die Ergebnisse dieser exemplarisch an den „MI $<10$-Filmen“ unter den Genre 1-Filmen durchgeführten Analyse sind teilweise banal und kommen selten über Vergleiche der Inhaltsbeschreibungen in den verschiedenen Zeitungen hinaus. Selbst das gelegentliche Hinzuziehen von deutschen Filmkritiken bietet kaum Aufschluss darüber, ob die Filme in Südafrika im Vergleich zu Deutschland unterschiedlich rezepiert wurden oder nicht. Aus diesen Gründen kann bei den verbleibenden Genres weitgehend auf eine Auswertung der Rezeptionsdokumente zu den „Ml<10- 
Filmen" verzichtet werden, selbst wenn dies die angestrebte Vollständigkeit der quellenmäßig möglichen Dokumentenanalysen einschränkt.

\subsection{Exkurs: Filmzensur in Südafrika}

Den folgenden Ausführungen zur südafrikanischen Zensurpraxis muss vorangestellt werden, dass es nicht möglich war festzustellen, welche der „SFilme" zensiert wurden und ob die gefällten Zensurentscheidungen Ähnlichkeiten mit denen der deutschen Prüfstellen aufwiesen. Im Gegensatz zu den gut dokumentierten Zensurentscheidungen der Berliner Filmoberprüfstelle aus den Jahren 1920 bis $1938^{96}$ existiert keine vergleichbare südafrikanische Zusammenstellung für den Untersuchungszeitraum. Trotz der kontinuierlichen und spätestens seit 1948 auch politisch motivierten Filmzensur liegen nur wenige Abhandlungen dazu vor. Zur Frühgeschichte der Filmzensur wird deshalb fast durchgängig auf die Ausführungen Thelma Gutsches (1972) zurückgegriffen, eine Praxis, die bisher eher Plagiate als tatsächliche Forschungsergebnisse entstehen ließ (Druker 1979). Erschwerend kommt hinzu, das Studien zur jüngeren Zensurgeschichte aus rechtlichen Gründen bzw. dem Einspruch der damals Verantwortlichen nicht veröffentlicht werden können (z.B. Moses 2007). Die einzige noch verwertbare Quelle stellt abermals Keyan Tomasellis Dissertation (1983) dar, welche für die Frühgeschichte ebenfalls auf Thelma Gutsches Daten zurückgreift.

Ohne eine entsprechende Gesetzgebung können die Anfänge der Filmzensur allenfalls als eine Art Vorgeschichte gelten, die meist nur aus Pressekritiken, Petitionen gesellschaftlicher Organisationen (z.B. Social Reform Association, National Council of Women etc.) oder Protesten verschiedener Religionsgemeinschaften bestand. Im Vordergrund standen dabei zunächst aber eher Fragen der Aufführungssicherheit (z.B. Brandschutzbestimmungen), später dann Belange des Jugendschutzes, da man dem Kinoprogramm einen negativen moralischen Einfluss zubilligte. Zur Qualität der damaligen Filme bemerkte Thelma Gutsche:

„The universally low quality of films of about 1911, 1912 and 1913 made it difficult to identify objectionable tendencies other than vulgarity, suggestivness, morbid sensationalism and an utter absence of taste. Frequent instances of these tendencies were scenes showing men rushing out of

\footnotetext{
${ }^{96} \mathrm{Vgl}$. Verbotene Bilder, manipulierte Filme $(I+I I)$. Zur Edition der Zensurentscheidungen der Berliner Film-Oberprüfstelle aus den Jahren 1920 bis 1938; unter: http://www.deutsches-filminstitut.de/dframe 12.htm [20.1.2007].
} 
restaurants or bedrooms holding their stomachs and, obviously in search of lavatories, bursting into women's rooms etc.; men in the last stages of intoxication pawing women; lascivious dances, suggestive décolltage, etc. etc. Added to these obviously unsavoury scenes were others showing criminal acts which, themselves practicable, were liable to inspire emulation in impressionable youth" (Gutsche 1972: 285).

Den Ausschlag zur tatsächlichen Einführung einer Zensurregelung gab die Aufführung des religiösen Films "From Manger to Cross" (1912, S. Olcott) (TF 7.6.13: 4). Nach dem Einspruch verschiedener religiöser Körperschaften, einer regen Presseberichterstattung und Petitionen an den Administrator (=Gouverneur) erließ man in Kapstadt zum 31. März 1913 die „Religous Performance Prevention Ordinance“ (Nr. 3/1913) „to provide for the prohibition of certain performances and exhibitions of a religous character" (Gutsche 1972: 289). Betroffen waren allerdings nur Filme, „calculated to give offence to religious convictions or feelings of any section of the public" (ebd.), die der Administrator einfach per Brief oder Telegramm verbieten konnte. Diese besonders für die Filmvertriebe willkürliche Regelung wurde unverzüglich kritisiert. Im Einvernehmen mit den an einer Besserung des Kinos interessierten gesellschaftlichen Organisationen, den Filmvertrieben und der Standesvertretung der Kinoeigentümer (Western Province Cinematograph Association) wurde eine freiwillige Kontrollinstanz, das „Bioscope Advisory Committee“, geschaffen (Gutsche 1972: 290).

Alle vertretenen Parteien stimmten der Praxis zu, dass zwölf Filme pro Woche von zwei Mitgliedern des Komitees zu sichten seien, diese per Postkarte eine Empfehlung an den Sekretär des Komitees richteten, welcher die Empfehlung an die Filmvertriebe bzw. Kinos weiterleitete und diese in der Regel auch befolgten. Da durch ein freiwilliges Komitee keine Strafen für Zuwiderhandlungen festgelegt werden konnten, bestand keine rechtliche Handhabe gegen Verstöße des Übereinkommens, zumal die Regelung nur für die Kapprovinz galt und in Kapstadt beanstandete Filme in den anderen Provinzen gezeigt wurden.

Den Anlass zur Einführung einer offiziellen Zensurverordnung gab die Verfilmung von Richard Dehans Burenkriegsroman „The Dop Docter“, von der man aus England hörte, dass sie die Buren (=Afrikaaner) recht unvorteilhaft darstellen würde und man von deren Seite wünschte, den Film zu verbieten (ebd.: 291f.). Da der Film keinen religiösen Inhalt hatte oder anzügliche Szenen enthielt, bestand keine rechtliche Handhabe den Import des Films zu verweigern. Eigens für diesen Zweck musste Premierminister Louis Botha in 
London intervenieren und man erkannte endlich die Notwendigkeit einer Zensurverordnung.

Tatsächlich wurden derartige Regularien dann auch in mehreren Provinzen erlassen, so z.B. als „Public Performance Control Ordinance“ (Nr. 9/1916) in der Kapprovinz, deren Geltung sich auf „the prohibition of performances and exhibitions calculated to bring any section of the public into ridicule or contempt" beschränkte, welches der Administrator per Mitteilung verhängen konnte (ebd.). In der gleichartigen Verordnung der Provinz Oranje-Freistaat wurden fünf Beanstandungskriterien genannt:

$\S 5$. Objectionable pictures shall be deemed to be pictures representing -

a) Scenes suggestive of immorality or indecency;

b) Executions, murders or other revolting scenes;

c) Scenes of debauchery, low habits of life or other scenes such as would injuriously affect the minds of young persons;

d) Successful crime or violence such as would injuriously affect the minds of young persons;

e) Scenes calcualted to give offence to the religious convictions of the feelings of any section of the public ${ }^{97}$

Die Verordnung des Oranje-Freistaates enthielt auch Strafen für die Missachtung der Vorgaben. Die Höchststrafe wurde mit 20 Pfund, drei Monaten Haft oder drei Monaten Zwangsarbeit für Zuwiderhandlungen festgelegt. Da sich die Regelung an jener der Kapprovinz orientierte, verwundert es etwas, dass Thelma Gutsche in diesem Zusammenhang von fehlenden Beststrafensmöglichkeiten spricht. Wahrscheinlicher ist hingegen, dass diese recht selten genutzt wurden und man deshalb auch die Empfehlungen des „Bioscope Advisory Committee" wiederholt ignorierte. Als trotz der negativen Stellungnahmen der ,Aufklärungsfilm' „Enlighten Thy Daughter” (1917, Ivan Abramson) in Kapstadt gezeigt wurde, verfügte der Administrator der Kapprovinz eine permanente Filmzensur in Gesetzesform (ebd.: 293).

Die "Cinematograph Film Ordinance" (Nr. 21/1917) hob die beiden Vorgängerregelungen auf und war dazu bestimmt, „to regulate and control places of recreation and amusement by prohibiting the exhibition therein of any cinematograph film not approved and to provide for the granting or refusal of such approval" (ebd.). Diese etwas umständliche Formulierung weist bereits auf die eigentliche Rechtsgrundlage dieser regionalen Verord-

${ }^{97}$ Ordinance No. 3 of 1916: Ordinance: To provide for the Inspection of Pictures; and to prohibit the Exhibition of objectionable Pictures; in: Ordinances of the Province of the Orange Free State 1916. Bloemfontein, 4-6. 
nung hin. Die Unionsregierung hatte es den Provinzen zugestanden, im Rahmen der Finanzverfassung (Financial Relations Act, Nr. 10/1913) eine Vergnügungssteuer (,Amusement Tax') zu erheben, die alle „places of amusement and recreation within the province" umfasste, unter die auch die Lichtspielhäuser fielen. Diese Kompetenzübertragung war ursächlich für die dezentrale und nach Provinzen unterschiedene Zensurgesetzgebung, die das Zustandekommen einer zentralen Filmzensur lange verzögern sollte.

Obwohl das Prinzip der Zensur von allen Seiten befürwortet wurde, erregten die allzu genauen Details eine kontroverse Debatte. Ganz allgemein legte es fest: „Approval shall not be given in the case of any film which depicts any matter that is against the safety of the realm or is likely to offend against the public order or common decency [...]” (ebd.: 293). ${ }^{98}$ Kriterien wie „improper impersonations of the King "legen nahe, dass bei diesen Regelungen die britische Gesetzgebung (1909, Cinematograph Act) als Vorbild gedient haben könnte. Bei einem Vergleich mit den vom British Board of Film Censors im Zeitraum 1914 bis 1938 angewandten Verbotskriterien fällt auf, dass sich die Regelungen der Kapstädter Zensurbehörde wie eine präzisiertere Auswahl der britischen Bestimmungen lesen lassen (Robertson 1985: 7).

Als in Südafrika besonders wirksam können folgende Zensurkriterien gelten: $\S 5$ : f) scenes containing reference to controversial international politics; g) scenes representing antagonistic relations of Capital and Labour; I) scenes calculated to bring any section of the public to ridicule or contempt; n) pugilistic encounters between Europeans and non-Europeans (ebd.). Weitere Besonderheiten bestanden in den dem Jugendschutz dienenden Altersbeschränkungen (älter als 12 Jahre bzw. älter als 16 Jahre). Ebenso gab es ethnische Kriterien, wonach folgende Freigaben erteilt werden konnten: nur für Europäer; nur für Europäer und Nicht-Europäer (Schwarzafrikaner ausgeschlossen) und nur für Europäer und Nicht- Europäer älter als 12 Jahre (Gutsche 1972: 302f.).

Das Hauptverdienst der neuen Regelung war die Ernennung eines permanenten „Board of Inspectors“ durch den Administrator, welches die Vorführgenehmigung durch die Vergabe eines Zertifikates erteilte. Bei unentschiedenen Voten entschied der Administrator. Obwohl verschiedentlich Anstren-

${ }^{98}$ Ergänzend folgte ein Katalog detaillierter Regelungen der vorsah "[...] approval shall not be given to films depicting: a) improper impersonations of the King; b) irreverent treatment of death; c) Nude figures; d) excessivly love scenes; e) scenes purporting to illustrate 'night life'; f) scenes containing reference to controversial international politics; g) scenes representing antagonistic relations of Capital and Labour; h) scenes tending to disparage public character or to create public alarm; I) Vampire Women, the Drug Habit, White Slave Traffic; j) materialisation of the conventional figure of Christ; k) scenes holding up the King's uniform to ridicule or contempt; I) scenes calculated to bring any section of the public to ridicule or contempt; n) pugilistic encounters between Europeans and non-Europeans (Gutsche 1972: 293f.). 
gungen zur Etablierung eines zentralen Zensurrates unternommen wurden, bestand die ungewöhnliche Provinzenregelung noch bis zum Jahr 1931 fort (ebd.: 294).

Während in der Kapprovinz ein ernannter Zensurrat die Filme bewertete, oblag es in Transvaal der Polizei, einen Film zuzulassen oder Auflagen zu erteilen. Falls ein Film in Kapstadt verboten wurde, arrangierte die Schlesinger-Organisation für die Aufführung in Transvaal eine Sondervorführung für den Beauftragten des dortigen Administrators, der nicht selten seine Freigabe entgegen des Verbotes aus Kapstadt erteilte (ebd.: 294). Das „Transvaal Board of Censors" (Public Entertainments Ordinance, Nr. 1/1920) bestand nur aus einem Polizeioberst und zwei Assistenten, die ihre Entscheidung oft an den Pressekritiken ausrichteten. Dabei bewertenten sie einen Film eher danach, ob er eine Gefahr für die öffentliche Ordnung darstellte und nicht als moralische Instanz.

Im Oranje-Freistaat delegierte man die Zuständigkeit an die Stadtverwaltungen, die in der Regel den Entscheidungen aus Kapstadt folgten. In Transvaal und dem Oranje-Freistaat begründete man vom Kapstädter Votum abweichende Entscheidungen damit, dass dort viele Verbote aus Vorsicht vor den schwer abzusehenden Reaktionen der farbigen Bevölkerungen getroffen würden, die es aber in den anderen beiden Provinzen gar nicht gäbe (ebd.: 295). In Natal scheiterte die Etablierung eines provinzweiten Zensurrates (NW 19.6.29: 8) und so folgten die Stadtverwaltungen bzw. die Polizei ebenfalls meist den Vorgaben aus Kapstadt (Gutsche 1972: 295).

Besonders für die Filmvertriebe war diese Situation ein großes Ärgernis, welche mit handfesten finanziellen Nachteilen verbunden war. Der Einfuhrzoll wurde für die ganze Südafrikanische Union erhoben und ein Filmverbot in einer Provinz verringerte die Einnahmen nicht selten bis zu einem Punkt, an dem kaum noch Gewinne zu erzielen waren (ebd.). Um die finanziellen Verluste zu begrenzen, vereinbarten die Filmimporteure mit ihren überseeischen Partnern Rückgabemöglichkeiten für den Fall negativer Zensurentscheidungen. Da die vor allem von Kinemas eingeführten britischen Filme bereits von den dortigen Behörden zensiert wurden, empfand man die doppelte Zensur als wettbewerbsverzerrende Benachteiligung (Tomaselli 1983: 347). Hinzu kam noch die von der Kapstädter Zensurbehörde verlangte Gebühr von einem Sechstel Penny pro Fuß jedes begutachteten Films. Man fürchtete sogar, dass die anderen drei Provinzen ebenso verfahren und damit die Steuern pro Film auf 2 Shilling und 57 Pence hochschrauben würden, was etwa dem doppelten Preis des Films selbst entsprach (ebd.: 346). Diese Befürchtung scheint sich allerdings nicht bewahrheitet zu haben. 
Bevor auf die Einführung und die Debatte um die zentrale Zensurgesetzgebung eingegangen wird, soll an dieser Stelle an Hand der spärlich verfügbaren Daten ein kurzer quantitativer Überblick der Filmzensurpraxis gegeben werden. Da die Gesamtanzahl der begutachteten Film nicht bekannt ist, kann hier nur die Zahl der zurückgewiesenen Film angegeben werden. Um welche Filmtitel es sich handelte, gibt das im Anhang beigefügtes Dokument wieder (Anhang II). Aufgrund des Umstandes, dass weder etwas zum Entstehungsnoch zum Überlieferungszusammenhang dieses Dokumentes bekannt ist, können dessen Angaben nur unter Vorbehalt herangezogen werden. Vergleicht man die nach Thelma Gutsche vom Zensurverbot betroffenen Filme mit der aufgefundenen Titelliste, ergeben sich jedoch Übereinstimmungen (Gutsche 1972: 295). In Ermangelung anderer Belege soll daher angenommen werden, dass es sich bei den Angaben des Archivdokuments um hinreichend belastbare Aussagen handelt. Gelistet wurden zwar überwiegend USamerikanische Produktionen, allerdings waren auch die zwei deutschen Spielfilme „Mr. Wu“ (1919, L. Pick) und „Die Straße“ (1923, K. Grune) vertreten.

Tab. 29: Anzahl der im Zeitraum 1917 - 1926 in Kapstadt verbotenen Filme ${ }^{99}$

\begin{tabular}{|c|c|c|c|c|c|c|c|c|c|c|}
\hline Jahr & 1917 & 1918 & 1919 & 1920 & 1921 & 1922 & 1923 & 1924 & 1925 & 1926 \\
\hline Anzahl & 3 & 10 & 12 & 14 & 8 & 7 & 11 & 13 & 18 & 5 \\
\hline
\end{tabular}

Die Ablehnungsgründe der einzelnen Filme können ohne das Vorliegen der Zensurkarten nicht geklärt werden. Bei einer großen Anzahl dürften die Gründe dafür den ,Night Life'-Szenen, Nacktaufnahmen oder ,Vamp'Charakteren geschuldet sein (z.B. bei „What Do Men Want?“, „Enlighten Thy Daughter" oder „The Sin Woman“). ${ }^{100}$ Bei dem nicht näher identifizierbaren Film „What the German Emperor Forgot in His Memoirs“ könnten die befürchteten politischen Verwicklungen für ein Aufführungsverbot gesorgt haben. Da für den Untersuchungszeitraum 1928 bis 1933 keine Titellisten der zensierten Filme nachgewiesen werden konnten und oft nur über die spektakuläre Zensur im Ausland besonders erfolgreicher Filme berichtet wurde, geben die vereinzelten Nennungen bei Thelma Gutsche nur einen begrenzten Einblick in die tatsächliche Zensurpraxis.

\footnotetext{
${ }^{99}$ Siehe Anhang III.

100 Bei der nicht identifizierbaren Produktion „Where are Thy Children“ könnte es sich vielleicht um den von Carl Laemmle produzierten Film „Where are my Children?“ (1916, P. Smalley/L. Weber) gehandelt haben, der sich dem heiklen Thema Abtreibung annahm, sich zwar grundsätzlich dagegen, aber für Geburtenkontrolle aussprach (Beller 1995: 111). Diese Annahme wird durch Thelma Gutsche's Ausführungen bestätigt (Gutsche 1972: 143).
} 
In Bezug auf die deutschen Spielfilme finden sich bei Gutsche drei Produktionen, die zensiert worden sein sollen: VARIETÉ (VAUDEVILLE), LUTHER und DER BLAUE ENGEL (1972: 295ff.). Alle drei Fälle können bestätigt werden, da sich für VARIETÉ keine Rezeptionsbelege in der Kapstädter Presse finden ließen (6.2.2), um LUTHER ein Streit zwischen den Konfessionen geführt wurde (6.1.1.) und die abweichenden Zensurentscheidungen zu DER BLAUE ENGEL der Diskussion um die Einführung einer zentralen Zensurgesetzgebung neues Leben einhauchte (s. weiter unten). Die britische Produktion "Dawn“ (1928, H. Wilcox), die filmische Version eines Romans über das Schicksal der Krankenschwester Edith Cavell im Ersten Weltkrieg, wurde gemäß $\S 5 d$ ) verboten, da man die guten Beziehungen zu Deutschland nicht belasten wollte (Gutsche 1972: 296). In Großbritannien selbst wurde der Film nach deutschen Protesten nur unter Schnittauflagen zugelassen (CT 16.3.28: 14). Einen teilweise auf Hochrechnungen (für 1928/29) beruhenden quantitativen Überblick für den Zeitraum 1927 bis 1935 bietet Tabelle 30 .

Tab. 30: Quantitativer Umfang der Filmzensur 1927 - $1935^{101}$

\begin{tabular}{|l|c|c|c|c|c|c|}
\hline & $1927^{102}$ & $1928-29^{103}$ & $1931^{-32^{104}}$ & $1932-33^{105}$ & 1934 & 1935 \\
\hline $\begin{array}{l}\text { Zensierte Gesamtmenge } \\
\text { (in Fuß) }\end{array}$ & - & - & 4.833 .256 & 5.272 .710 & 3.736 .664 & 3.875 .288 \\
\hline Gebühren (in SA £) & - & - & 3374 & 3664 & 2595 & 2691 \\
\hline $\begin{array}{l}\text { Genehmigt ohne } \\
\text { Schnittauflagen }\end{array}$ & 1166 & 752 & 2007 & 2166 & 1443 & 1565 \\
\hline $\begin{array}{l}\text { Vorführung ohne } \\
\text { Auflagen }\end{array}$ & 249 & 19 & 111 & 206 & 161 & 160 \\
\hline $\begin{array}{l}\text { Vorführung unter } \\
\text { Auflagen 106 }\end{array}$ & 40 & 37 & 12 & 28 & 41 & 24 \\
\hline $\begin{array}{l}\text { Genehmigt nach } \\
\text { Schnittauflagen }\end{array}$ & 33 & 17 & 6 & 26 & 29 & 41 \\
\hline $\begin{array}{l}\text { Vorführung ohne } \\
\text { Auflagen }\end{array}$ & 32 & 8 & 11 & 46 & 26 & 27 \\
\hline $\begin{array}{l}\text { Vorführung unter } \\
\text { Auflagen }\end{array}$ & 1520 & $\begin{array}{c}933 \\
(2000)^{107}\end{array}$ & 2147 & 2472 & 1700 & 1817 \\
\hline Abgelehnt & & & & & & \\
\hline Gesamt & & & & & & \\
\hline
\end{tabular}

\footnotetext{
101 Vgl. CT 4.6.29: 7, Official Yearbook 1936: 328 und Gutsche 1972: $302 f$.

$102 \mathrm{Vgl}$. Gutsche 1972: 302f

${ }^{103}$ Zeitraum 30.11.1928 bis 30.4.1929, vgl. CT 4.6.29: 7

104 Zeitraum 15.7.1931 bis 14.7.1932

${ }^{105}$ Zeitraum 15.7.1932 bis 31.12.1933

106 Z.B.: Nicht für Nachmittagsvorstellungen geeignet.

107 Schätzung, basierend auf einer Hochrechnung anhand der Zahlen für die zugrundeliegenden fünf Monate 1928-1929 und der Anzahl der im Zeitraum von zwölf Monaten 1931-1932 zensierten Filme.
} 
Bei den angegebenen Gesamtzahlen der Filme muss allerdings beachtet werden, dass es sich nicht durchgängig um abendfüllende Spielfilme handelte. Von den 1520 im Jahre 1927 durch die Kapstädter Zensurbehörde gesichteten Filme wurden 347 als Drama, 395 als Komödie, 486 als Wochenschauen oder Nachrichten und 292 als Programmwerbefilme (,trailer') klassifiziert (Gutsche 1972: 302).

Die ungewöhnliche Situation der dezentralen Filmzensur bewirkte teilweise das Gegenteil der eigentlich mit der Regelung verbundenen Intention. Oftmals fungierte die negative Entscheidung der Kapstädter Zensurbehörde für das Publikum der anderen Provinzen als ein zusätzlicher Ansporn, die betreffende Vorführung zu besuchen, zumal Filmvertriebe und Presse mit dem Zensurvermerk Werbung machten (ebd.: 294). In der Filmreklame konnte darüber hinaus mit den fragwürdigen Szenenbildern und Untertiteln geworben werden, welche die Zensur hatte entfernen lassen (ST 26.5.29: 12). Diese Praxis wurde erst mit einer Erweiterung des Financial Relations Act (Nr. 4/1922) unterbunden (ebd.).

Die öffentliche Diskussion spektakulärer Zensurfälle wie LUTHER (CT 4.9.29: 7) oder die als dramatisch empfundene Häufung von ,sex-appeal'Filmen um 1930 (Gutsche 1972: 217ff.) verschärfte die Unzufriedenheit über die bestehende dezentrale Zensur und sensibilisierte den Gesetzgeber für die notwendige Einführung einer einheitlichen Regelung (CT 7.12.29:13).

Folgerichtig reichte Innenminister D.F. Malan im März 1930 eine Gesetzesvorlage ein, welche für ein Ende der je nach Provinz beliebigen Entscheidungen sorgen und die gesamte Zensur einer zentralen Behörde obliegen sollte (Gutsche 1972: 297). Geplant war ein "Union Board of Censors", dessen Entscheidungen für das ganze Land bindend sein sollten. Inhaltlich glich das neue Gesetz weitgehend den Regelungen der "Cinematograph Film Ordinance" der Kapprovinz. Der detaillierte Katalog der Verbotsgründe wurde jedoch als zu weitgehend und unpraktikabel eingeschätzt:

„'Indecent scenes in general', for example, could be made of almost anything in existence, from mixed bathing to assault. What it does mean will depend entirely on the mentality of the individual who interprets it and not on the clause itself. What, too, is a 'vampire women?' or 'undesirable intermingling of Europeans and non-Europeans'? Somebody raised in the backveld might quite easily regard as a vampire a woman who, to the average town dweller, would seem a harmless and perhaps rather attractive lounge-lizzard. [...] At any rate, there is nothing in the clause to suggest what a vampire woman precisely is. As for the undesirable intermingling of Europeans and non-Europeans, there are many people in this country who 
think it undesirable that Europeans and coloured should mingle on the same pavement. [...] These illustrations are probably extreme, but the point is that there is nothing in the Bill to prevent any Board of Censors from interpreting it in this fashion or any other fashion they like. If these provisions were literaly enforced, there are many books that are given out as Sunday-School prizes that would be banned on the screen" (CT 24.4.30: 7).

Nach der ersten Lesung am 17. Januar 1930 wurde eine zweite Lesung für den 10. März angekündigt, das Gesetzesvorhaben später aber aufgrund dringlicherer Regierungsangelegenheit bis zum Februar 1931 hintangestellt. ${ }^{108}$ Besonders der Kriterienkatalog wurde dahingehend bemängelt, dass es ein Fehler sei, schon im Voraus so detailliert festlegen zu wollen, was erlaubt sei und was nicht (Gutsche 1972: 297).

Zwischenzeitlich gab die sich überfordert fühlende Polizei in der Provinz Transvaal ihre Zensurbefugnisse zurück und die Einrichtung eines eigenen Zensurkomitees wurde beschlossen (CT 1.8.30: 9). Dieses Vorhaben konterkarierte die Bemühungen des Innenministers, was vor allem in der afrikaansen Presse kritisiert wurde (DB 2.8.30: 6). Als Begründung für die Einrichtung eines solchen Komitees in Johannesburg wurde ausgeführt, dass Johannesburg eines der Zentren der Erstaufführung von Filmen in Südafrika sei, da die beiden maßgeblichen Filmvertriebe African Theatres und Kinemas ihre Hauptquartiere in der Stadt hätten. Deshalb sei es von großer Bedeutung, das ein Komitee dort eingerichtet werde, wo sich das Zentrum der Filmerstaufführungen befinde (CT 13.8.30: 7). In der zweiten Lesung der Provinzgesetzgebung wurde das Vorhaben bereits als absurd kritisiert, da es den Plänen der Unionsregierung zuwiderlaufe und nur Zusatzkosten entstehen würden, welche die Kinobetreiber auf das Publikum abwälzen müssten (CT 20.8.30: 7). Schließlich wurde das Vorhaben zurückgezogen, jedoch nicht ohne noch mehr Verwirrung in die ganze Angelegenheit gebracht zu haben (Gutsche 1972: 297).

Noch vor der Wiedereinreichung der unionsweiten Gesetzesvorlage zensierte das Cape Board of Censors die deutsche Produktion DER BLAUE ENGEL und verhängte ein Vorführverbot. Da sich diesem Verbot nur der Oranje-Freistaat, nicht aber die Provinzen Transvaal und Natal anschlossen, demonstrierte die daraus entstandene Diskussion erneut die Notwendigkeit

108 Vgl. Unie van Suid-Afrika, Debatte van die Volksraad, Deel 14 (6de Parlament, 17.1.-28.3.30). Kaapstad: 1454. 
einer zentralen Gesetzgebung, was dem Vorhaben des Innenminister in die Hände spielte.

In der ersten Lesung am 19. Februar 1931 wurde die Vorlage besprochen und nach zahlreichen Einsprüchen eine zweite Lesung verfügt, in der ein Bericht eines extra eingerichteten Ausschusses zur Zensurgesetzgebung gehört werden sollte. ${ }^{109}$ Der Bericht des Komitees lag zum 25. März vor und dessen Empfehlungen wurden zur Kenntnis genommen (ebd.: 298). ${ }^{110}$ In einer dritten Lesung am 26. März wurden weitere Änderungswünsche vorgetragen und der Entwurf an die zweite Kammer des Parlaments, den Senat, überwiesen. ${ }^{111}$ Das neue Gesetz, der sogenannte „Entertainment (Censorship) Act", wurde als Act No. 28 of 1931 am 3. Juni 1931 beschlossen und zum 15. Juli im Gesetzblatt veröffentlicht. ${ }^{112}$

Dem Gesetz war eine kontroverse, teils voller Sarkasmus geführte Debatte vorangegangen, welche der sachlichen Arbeit an einer zweckmäßigen Zensurgesetzgebung nicht immer förderlich war. In den Debatten diskutierten Zensurbefürworter und -gegner heftig miteinander, wobei deutlich wurde, dass die afrikaansen Parlamentarier eher zu den Befürwortern, die englischen eher zu den Kritikern der Neuregelung gehörten bzw. Filmzensur als solche ganz ablehnten. Das Gesetz selbst beruhte im Wesentlichen auf der Zensurverordnung der Kapprovinz, von der es auch den Katalog der Verbotskriterien übernahm. Dabei regte besonders $\S 5 \mathrm{I}$ ), das zeigen von ,Vampire Women' zu Hohn und Spot über das Vorhaben an. Bevor ein solcher Unsinn im Gesetz festgeschrieben werde, solle der Innenminister zunächst ein solches Exemplar dem Parlament vorstellen, (RDM 20.2.31: 10f.). Ohne die zahlreichen Einwürfe und Diskussionen zu wiederholen, gibt die Einschätzung des Abgeordneten Deneys Reitz (Barberton, Natal) nach dem Lesen der Vorlage einen Eindruck der allgemein geäußerten Kritik wieder:

„When I read this Bill for the first time, I wondered what sort of soured bigot, what sort of joyless zealot, was responsible for it, and naturally my thoughts wandered to the Minister of the Interior, but I found it was to a large extent based on the Cape provincial provisions of 1917. It proves

\footnotetext{
${ }^{109}$ Vgl. Unie van Suid-Afrika, Debatte van die Volksraad, Deel 16 (6de Parlament, 30.1.-6.6.31). Kaapstad: 657.

$110 \mathrm{Vgl}$. Union of South Africa, House of Assembly Debates, Part16 (6 $6^{\text {th }}$ Parliament, 30.1.-6.6.31).Cape Town: 1760, 2053-2062.

$111 \mathrm{Vgl}$. Union of South Africa, Minutes of proceedings of the Senate from January the 30th 1931 to June the 6th 1931 (Third Session, 6 ${ }^{\text {th }}$ Parliament, Third Senate) Cape Town: 106f., 111-113, 123, 146, 156f., 179.

${ }^{112} \mathrm{Vgl}$. Statutes of the South African Union 1931. Cape Town: 132-143.
} 
what a limited outlook, what a parochial mind is bred by provincial councils. The Bill is a string of absurdities." ${ }^{113}$

Diese Bemerkung soll als Beispiel für die kontroverse Diskussion über das Gesetz genügen, um es nachfolgend in seinen Grundzügen vorzustellen.

Die Regelungsbreite des Gesetzes bestand in der Aufgabe "To regulate and control the public exhibition and advertisment of cinematograph films and of pictures and the performance of public entertainments". Der Zensur unterlagen also nicht nur die Filme, sondern auch die Filmwerbung und Bilder aus den Filmen, sofern die Vorführungen öffentlich waren. Ein aus sieben Mitgliedern bestehendes, vom Innenminister einberufenes Komitee hatte die Zensurentscheidungen zu treffen. Bei unentschiedenem Urteil gab die Stimme des Ausschussvorsitzenden den Ausschlag, mit zensierten Filmbildern durfte nicht geworben werden. Das erste Union Board of Censors bestand ausschließlich aus den ehemaligen Mitgliedern des Kapstädter Zensurkomitees (Gutsche 1972: 301). Der Wunsch der Kinoketten bzw. sozialer Organisationen, Mitglieder entsenden zu dürfen, wurde nicht berücksichtigt (Gutsche 1972: 304).

Der Katalog der Verbotskriterien war im Wesentlichen Derselbe wie jener der "Cinematograph Film Ordinance", hinzugefügt wurde jedoch, dass eine Darstellung in ,beleidigender Weise' vorgelegen haben musste. Die Erwähnung von ,Vampire Women' entfiel. Die von 14 auf 19 erweiterten Tatbestände ${ }^{114}$ lassen sich auch in dieser Fassung wieder als Auswahl der 1926 vom British Board of Film Censors festgelegten Verbotsgründe lesen (Robertson 1985: 180-182). ${ }^{115}$ Wie unsinnig die Festlegung kontextunabhängiger Verbotskriterien tatsächlich war, verdeutlicht eine Persiflage der Cape Times auf die entsprechenden Regelungen:

„The case against the censorship has never been presented more convincing than by Dr. Malan (Innenminister, Anm. ME) when, in the House of Assembly last week, he paraded his fantastic code of critics - an index expurgatorius under which 'Romeo and Juliet' would have been banned on account of 'excessivly passionate love scenes'; 'Othello' prohibited be-

\footnotetext{
${ }^{113} \mathrm{Vgl}$. Union of South Africa, House of Assembly Debates, Part16 (6 ${ }^{\text {th }}$ Parliament, 30.1.-6.6.31). Cape Town: 580

114 Die Kriterien der alten Zensurverodnung wurden geringfügig überarbeitet, einige entfielen, hinzugefügt wurden „b) scenes holding up to ridicule or contempt any member of the King's military or naval forces; $\mathrm{n}$ ) scenes of juvenile crime and, in the case of older persons, scenes of the technique of crime and of criminality; o) scenes of brutal fighting; $p$ ) scenes of drunkenness and brawling; s) scenes of rough handling or ill-teatment of women and children" (Statutes of the South African Union 1931. Cape Town: 137f.)

${ }^{115}$ Diese waren in sieben Gruppen unterteilt: Religious, Political, Military, Social, Questions of Sex, Crime und Cruelty.
} 
cause of the 'undesirable intermingling of Europeans and non-Europeans' or, alternativly, the 'excessiv rough handling or ill-treatment of women'; the grave-digger in 'Hamlet' warned off for 'irreverent treatment of death'; and a 'talkie' of proceedings in Parliament forbidden as being likely both 'disparage public characters' and 'to create public alarm'" (CT 27.2.31: 8).

Für jeden begutachteten Film war eine Gebühr von nicht mehr als einem Sechstel Penny je Fuß zu entrichten, Strafen bei Zuwiderhandlungen konnte die Gerichte festlegen. Da die Möglichkeit bestand, Aufführungsverbote für Kinder oder Nichteuropäer getrennt zu erlassen, kamen praktisch keine Totalverbote mehr vor. ${ }^{116}$ Das neue Gesetz verhinderte zwar die unhaltbaren Zustände der dezentralen Zensur, scheiterte aber strukturell an der Missachtung der Kontextbedingungen der Zensur. Zensur als solche ist immer abhängig vom aktuellen Zeitgeschehen, den Lebensverhältnissen, der öffentlichen Meinung etc. und kann kaum mit einem feststehenden Katalog abgeprüft werden, sei er auch noch so umfangreich (Gutsche 1972: 303). Den Kinoketten selbst eröffnete die gestufte ,ethnische' Zensur die Möglichkeit, ihre Filme noch länger im dreistufigen Aufführungskreislauf („1st-, 2nd- and 3rd run cinemas") zirkulieren zu lassen, da man die Kinos und Vorstellungen für Europäer, Nicht-Europäer und Kinder separieren konnte. ${ }^{117}$

Die Filmreklame konnte beanstandet werden, wenn a) religiöse Gruppen beleidigt oder Gefühle von Teilen der Öffentlichkeit verletzt, b) Teile der Öffentlichkeit lächerlich oder verächtlich gemacht und c) gegen das öffentliche Interesse und die Moral verstoßen wurde. Das zu erteilende Freigabezertifikat sollte auf die Bilder gestempelt werden, Filme hatten es im Vorspann zu zeigen.

Nach der Gründung privater Filmklubs (z.B. in Kapstadt) wurde man darauf aufmerksam, dass man mit dem neuen Gesetz nur öffentliche, also keine privaten Vorführungen untersagen konnte. Dieses Schlupfloch wurde 1934 mit einer Gesetzesänderung geschlossen, nach der nun alle Filmvorführungen unter das Gesetz fielen. Mit der Änderung wurde aber auch erlaubt, dass vor Programmbeginn - und nicht mehr vor jedem Film - daraufhingewiesen wer-

\footnotetext{
116 Eine Ausnahme bildete im August 1939 die US-Produktion „Confessions of a Nazi Spy“ (1939, A. Litvak), für den der Verbotsgrund „reference to controversial or international politics“ bemüht wurde. Nach Kriegsausbruch wurde das Verbot aufgehoben (Gutsche 1972: 266).

${ }^{117}$ Am Beispiel Kapstadts und für eine spätere aber vergleichbare Periode (1945-1960) beschreibt David Gainer die praktischen Auswirkungen dieser Zensurpraxis: „First, it played at the largest European-only cinemas in Central Cape Town. Then, after 3-6 months on the circuit, the film returned to Cape Town to play the second-run European cinemas, the first-run Non-European cinemas, and the suburban cinemas. After another 6-12 months on the circuit, the film returned to Cape Town's smaller Non-European cinemas, third-rate European cinemas, and if appropriate, to a Saturday morning children's show (musicals and westerns were deemed appropriate)" (Gainer 2000: 114f.).
} 
den musste, dass eine Freigabe der Zensurbehörde vorlag. Oftmals lag es dann im Ermessen der Veranstalter, welcher nicht begutachtete Film unbemerkt ins Programm aufgenommen wurde (Gutsche 1972: 304).

Neben den in Pressemeldungen genannten Filmen tauchten auch in der Parlamentsdebatte einige Filmtitel auf, die man in der südafrikanischen Zensurgeschichte als Schlüsselfilme bezeichnen kann. Wie bereits erwähnt, spielten Produktionen wie „From Manger to Cross“, „Enlighten Thy Daughter" und "The Dop Docter" eine entscheidende Rolle in der vor allem in der Kapprovinz verangetriebenen Zensurgesetzgebung. Die Überlegungen zur Zentralisierung der Filmzensur hingegen wurden maßgeblich durch die Kontroversen um die Filme LUTHER, DER BLAUE ENGEL und „All Quiet at the Western Front“ (1929, L. Milestone, dt. „Im Westen nichts Neues“) beeinflusst.

Ohne auf die Dokumentenanalyse zu LUTHER oder ausführlich auf Pressekritiken zu „All Quiet at the Western Front“ zurückzugreifen sei bemerkt, dass auf diese Filme in der Zensurdebatte ausdrücklich verwiesen wurde. So wurde am Beispiel von LUTHER durch den Abgeordneten Swart (Ladybrand, Oranje-Freistaat) illustriert, was eine zu wortgenaue Zensurregelung bewirken könnte:

„We have had the case here of the film ,Martin Luther', which was prohibited in Cape Town because the Catholics raised objections thereto, while the film was made and shown in Germany, where a third of the population are Roman Catholics. Such things we must leave to the common sense of the board of censors, and we must not tie them up too much, because otherwise a small section may come along and on account of these provisions claim that a film be disapproved. I should be inclined rather to insert a general clause that the board is to take care that films which are not in the public interest or offensive or immoral shall not be exhibited." 118

Im Streit zwischen Regierung und Opposition polemisierte man darüber, was unter ,public policy' zu verstehen sei, da darüber nur der jeweils politische Standpunkt entschied. In diesem Sinne war auch die Frage des englischsprachigen Abgeordneten Coulter (Gardens, Kapstadt) an den afrikaansen Innenminister zu verstehen, ob man "All Quiet at the Western Front“ im Sinne der öffentlichen Ordnung nun aufführen oder verbieten müsse. ${ }^{119}$ Dahinter

\footnotetext{
${ }^{118} \mathrm{Vgl}$. Union of South Africa, House of Assembly Debates, Part16 (6 ${ }^{\text {th }}$ Parliament, 30.1.-6.6.31). Cape Town: $583 f$.

${ }^{119} \mathrm{Vgl}$. ebd. $586 f$.
} 
verbarg sich selbstverständlich das Ringen einer tendenziell deutschfreundlichen Regierung mit einer tendenziell deutschlandkritischen Opposition.

Auch in Südafrika hatte man sehr wohl zur Kenntnis genommen (DB 15.12.30: 6 oder CT 31.12.30: 7), dass um die Uraufführung von „All Quiet at the Western Front" in Deutschland die nach der Macht strebende NSDAP alle Kräfte mobilisierte, um die Aufführung und somit auch die öffentliche Ordnung mit „tumultatorischem Terror“ massiv zu stören (Beller 1995: 119). Dazu führte Innenminister Malan aus:

„It is easy that an incident may occur as happened overseas with the performance of 'All Quiet at the Western Front'. We will have agitation and rows in connection with them if we don't make provisions to stop them. That film is perhaps not against public policy and public morality but it causes dissatisfaction and encourages agitation and therefore there must be supervison and control so that such circumstances we can say that the performance or exhibition must stop." ${ }^{120}$

Auch in einer weiteren Lesung des Gesetzes wurden die Vorgänge um „All Quiet at the Western Front" in Deutschland als Grund für eine möglichst umfassende und rigide Zensur bemüht. Ob der Innenminister damit auch jede gegen seine Partei gerichtete Karrikatur verbieten wolle, beantwortete Minister Malan u.a. wie folgt:

„The idea is that pictures or representations of plays which are produced in the theatre may be of such a kind as possibly to create a commotion, that one section of the population might get excited against another section and that all sorts of troubles might arise. I said [...] that that had already happened in some parts of the world, e.g., in connection with 'All quiet at the Western Front'. Then there must be a machinery to stop it in the interests of peace and order." 121

Trotz der vorgebrachten Einsprüche wurde das Gesetz weitgehend in der vom Innenminister favorisierten, allumfassenden Ausrichtung verabschiedet. Da nur einer der in dieser Studie behandelten "S-Filme“, MÄDCHEN IN UNIFORM, nach Inkraftreten des Gesetzes aufgeführt wurde, fielen alle anderen "S-Filme“ noch unter die Regelungen der dezentralen Zensur. Wie am Beispiel von LUTHER oder „All Quiet at the Western Front" gezeigt werden konnte, gab die öffentliche Diskussion solcher Schlüsselfilme u.a. dazu Anlass, die Gesetzgebung zur Filmzensur zu ändern. Da es sich, wie

\footnotetext{
120 Vgl. ebd. $593 f$.

${ }^{121} \mathrm{Vgl}$. ebd. $2059 f$.
} 
weiter unten noch am BLAUEN ENGEL belegt werden wird, um eine sich wechselseitig beeinflussende Debatte gehandelt hat, soll für diese Situation abschließend ein theoriegeleitetes Interpretationsangebot kurz umrissen werden.

Die Beeinflussung der Filmzensur durch sogenannte Schlüsselfilme, ebenso wie der Einfluss der Filmzensur auf die tatsächlichen Zensurmaßnahmen könnte man als ,Moderatoreffekt' umschreiben. Noch vor der Erläuterung dieses Erklärungsansatzes muss allerdings bemerkt werden, dass mit der Verwendung der Begriffe ,Moderatorfunktion' bzw. ,Moderatoreffekt' keinesfalls der Anschein einer empirisch-sozialwissenschaftlichen Exaktheit dieser Begrifflichkeit in Bezug auf das festgestellte Phänomen suggeriert werden soll. Es handelt sich vielmehr um ein vereinfachtes Modell dieses Ansatzes, welches versucht, die Ambivalenz zwischen fachwissenschaftlicher Terminologie und alltagssprachlicher Erklärungstauglichkeit in medienhistorischer Perspektive zu nutzen.

Ein Moderator ist eine Drittvariable, die die Stärke einer Wirkbeziehung zwischen zwei Variablen beeinflusst (Baron/Kenny 1986: 1174). Eine Moderatorvariable soll also erklären, unter welchen spezifischen Bedingungen ein bestimmter Effekt zustandekommt. Ganz allgemein wird untersucht, ob ein unabhängiges Merkmal ein anderes (abhängiges) Merkmal beeinflusst. Ein Moderatoreffekt besteht, wenn ein drittes Merkmal - der ,Moderator' - beide untersuchten Merkmale beeinflusst. Im vorliegenden Fall könnten demnach die (dezentrale) Zensur als unabhängige Variable und der Film als abhängige Variable modelliert werden. Als einflussnehmende Drittvariable könnte die geplante Einführung der zentralen Filmzensur angenommen werden. Um nun die Notwendigkeit oder Nichtnotwendigkeit der zentralen Zensur zu demonstrieren, könnte die dezentrale Filmzensur geneigt gewesen sein, ihre Entscheidungen nach der jeweiligen Prämisse auszurichten, um den gewünschten Effekt herbeizuführen. Da die Zensurverordnung der Kapprovinz nach dem Willen des Ministers in eine zentrale Gesetzgebung überführt werden sollte, könnten genau jene Zensurentscheidungen herbeigeführt worden sein, welche die Schwächen der bisherigen Regelung und die Stärken der Neuregelung unterstrichen. In diesem Falle käme dem zentralen Regelungsvorhaben die Moderatorfunktion zu, Einfluss auf die dezentrale Zensur auszuüben, was sich letztendlich auch auf den zu zensierenden Film auswirken würde.

Der Gegensatz zwischen der sozialwissenschaftlich bedeutsamen Unterscheidung in Moderator- und Mediatorfunktion (ebd.: 1177) soll an dieser Stelle aus pragmatischen Gründen unbeachtet bleiben. Die Entscheidung für 
,Moderator' resultiert aus dem allgemeinbegrifflichen Verständnis von ,mäßigen' und ,etwas (mit Worten) begleiten', wohingegen ,Mediator' eher auf ein Aushandeln oder eine Einigung hinweist, was im vorliegenden Fall aber nicht angestrebt wurde.

Die Ambivalenz dieser Situation bestand aber auch darin, dass den Schlüsselfilmen selbst eine Moderatorfunktion zukam, da deren Inhalt Einfluss auf die zentrale Gesetzgebung in den Debatten festgestellt werden konnte. Somit moderierte das Vorhaben der zentralen Gesetzgebung die dezentrale Zensurpraxis und die davon abhängigen Filmvorführungen, gleichzeitig moderierten die Schlüsselfilme die Ausgestaltung der zentralen Gesetzgebung und die Ausschaltung der Zensur auf Provinzebene. Die Schlüsselfilme hatten also einen Moderatoreffekt in Bezug auf die Gesetzgebung, die Gesetzgebung wiederum eine Moderatorfunktion gegenüber der Zensurpraxis, welche die tatsächliche Filmaufführung regulierte.

Für die Schlüsselfilme unter den „S-Filmen“ wie LUTHER oder DER BLAUE ENGEL bedeutet dies, dass sie nur in der konkreten zeitgeschichtlichen Situation, der Umstellung einer dezentralen auf eine zentrale Zensurgesetzgebung, den Status von Schlüsselfilmen erlangen konnten, welcher das Wechselspiel von Moderatorfunktion bzw. -effekten herbeiführte. Man könnte auch von einem kontextabhängigen Moderatoreffekt sprechen, der die Funktion der Filme und somit auch deren Medienrezeption beeinflusst hat.

Sowohl das Interpretationsangebot, als auch die medienhistorische Trägfähigkeit des gewählten Begriffs stehen selbstverständlich zur Disposition, einen temporären Erklärungswert kann man diesem Konstrukt hingegen kaum absprechen.

\subsection{Zum Starphänomen}

Wie bereits angedeutet, gehört zu einer die 1920er und 1930er Jahre umfassenden kinogeschichtlichen Untersuchung auch die Betrachtung des Starphänomens. In der Epoche des klassischen Hollywood-Studiosystems, dessen Produkte den südafrikanischen Markt mehr oder weniger dominierten, war das Starsystem eines der wesentlichen Marketinginstrumente um den Erfolg der Filme und so auch der Studios zu garantieren. Bis etwa 1913 wurde die Filmwerbung noch von der Betonung des Markennamens des jeweiligen Studios dominiert, bei der durch die Nennung der Marke auf eine gewisse Uniformität und qualitative Einordnung des hergestellten Films geschlossen werden sollte (Bowser 1990: 118): 
"The popularity of any one brand of pictures will be found on analysis to depend almost altogether on the one point ... how nearly the average output approaches dependable uniformity of excellence. Nearly every manufacturer has at some time or other produced a notable film - one that can compare favorably with the world's best - but not every manufacturer makes a practice of getting out films of this class, or anything like that. In the case of some makers the great films are few and far between. In other cases they come with uncertain frequency, but it is only in a very few instances that they can be said to approach dependable uniformity of excellence. Any manufacturer who desires to establish his trademark at the top can better afford to throw a film, that he knows is not up to the mark, into the scrap heap, than to issue it and thus injure his reputation with the public" (New York Dramatic Mirror 9.4.1910: 17 in ebd.)

Um die Sicherheit dieser "dependable uniformity of excellence“ zu gewährleisten, kam dem zum Zentrum der Filmproduktion aufgestiegenen Hollywoodstudios die Entstehung des (,abendfüllenden') Spielfilms gerade recht. Mit der Möglichkeit einer erweiterten Aufmerksamkeit für den einzelnen Spielfilm durch eine darstellerbezogene Personifizierung sah man eine Gelegenheit, sich von den Mitkonkurrenten wirksam abzugrenzen und legte damit die Grundlagen für das Starsystem Hollywoods. Um einen langfristigen Erfolg zu gewährleisten, band man die zu Stars gewordenen Schauspieler mit Knebelverträgen für eine bestimte Anzahl von Filmen alternativlos an die Studios. Diese Verträge gaben den studioeigenen PR-Abteilungen genügend Zeit, entsprechende Images aufzubauen, die jeweiligen Stars als ein Kunstprodukt der Traumfabrik Hollywood zu , pushen' und zu vermarkten.

Durch die planmäßige Schaffung von Aufmerksamkeit sollte das Publikum zielgerichtet zur entsprechenden Konsumptionsentscheidung geführt werden. Den sozio-ökonomischen Rahmen bildete die damals verfügbare Medientechnik:

„Das Geschäft mit der Aufmerksamkeit hatte seine frühindustrielle Phase in der Periode der analogen Informations- und Kommunikationstechniken. Mit Presse, Rundfunk und Tonfilm kamen erstmals die für die Geburt von Stars kritischen Mengen anonym gespendeter Aufmerksamkeit zusammen. Das Geschäft der Attraktion wurde in dieser frühen Phase professionalisiert, die gezielte Jagd auf die Aufmerksamkeit des allgemeinen Publikums entwickelte sich mit der Werbung zur eigenen Industrie" (Frank 1998: 147)

Wie jede allgemeine Betrachtung des Starphänomens steht auch die Betrachtung dieses Phänomens in Südafrika unter dem Vorbehalt, dass 
„[...] der Versuch einer rein typologischen, primär inhaltlich begründeten, überzeitlich gültigen und medienübergreifenden Definition von Starcharakteristiken aufgrund der Komplexität und Vielfältigkeit des Starphänomens zum Scheitern führen muß" (Korte/Lowry 2000: 20).

Für den relativ kurzen Zeitraum von 1928 bis 1933 in Südafrika gilt dies umso mehr, da sich nur Stars von ihrer Struktur sowie ihrer Funktion her für die jeweiligen Publika in bestimmten historischen Phasen definieren lassen (ebd.: 21), der ausgewählte Untersuchungszeitraum aber den Übergang vom Stumm- zum Tonfilm umfasst und somit gerade in Bezug auf den Filmstar zwei unterschiedliche Startypologien abgedeckt werden. Da das Hauptinteresse dieser Studie auf die deutschen Spielfilme abzielt, der deutschen Filmindustrie die Hollywood'sche Art der Starfabrikation aber eher fremd war, müssen andere Analyseschritte getätigt und erweiterte Vergleichsgrundlagen herangezogen werden.

Die zentralen Aspekte des Startums lassen sich in den Komponenten Erfolg, Imagekontinuität und Wirkung erfassen (Korte/Strake-Behrendt 1991: 14ff.). Selbst wenn damit höchst unterschiedliche Dimensionen des Phänomens angesprochen werden, dürfte klar sein, dass sich beim Fehlen nur einer Komponente kaum eine Starwirkung einstellen würde. Vor dem Hintergrund einer zu erzeugenden Imagekontinuität und der überschaubaren Zahl aller "S-Filme“ (ca. 50) wird deutlich, dass nur solche Schauspieler Starruhm erlangen konnten, die dem südafrikanischen Publikum mit einer gewissen Anzahl von Filmen präsent waren und somit ein Wiedererkennungswert gegeben war. Dazu stellt die folgende Übersicht jene Schauspieler zusammen, die in mindestens fünf Filmen in prominenter Rolle zu sehen waren. 
Tab. 31: Schauspieler in mindestens fünf „S-Filmen“ nebst Filmtiteln

\begin{tabular}{|c|c|c|c|c|c|}
\hline MI & PFL & FK & Schauspieler bzw. Filmtitel & $\mathrm{HR}$ & TG \\
\hline & & & Emil Jannings (9), Ml: 160 & & \\
\hline 48 & 1 & 10 & Der Blaue Engel $(\mathrm{T})(\mathrm{K})^{\star}$ & 100 & 224 \\
\hline 26 & 1 & & Faust $(A)^{*}$ & & \\
\hline 22 & 1 & & Der Weg allen Fleisches (A) & & 218 \\
\hline 19 & 1 & 8 & Sein letzter Befehl (A) & 108 & 229 \\
\hline 17 & 1 & & Varieté $(A)^{*}$ & & \\
\hline 10 & 2 & & Sünden der Väter (A) & & \\
\hline 9 & 1 & & Der Patriot (A) & & 229 \\
\hline 9 & 4 & & Der König von Soho (A) & & \\
\hline- & - & - & Quo Vadis (A) & & 197 \\
\hline & & & Brigitte Helm (8), MI: 80 & & \\
\hline 34 & 1 & 4 & Metropolis $(A)^{*}$ & 107 & 217 \\
\hline 19 & 2 & 6 & Die wunderbare Lüge der Nina Petrowna $(A)^{*}$ & 100 & 217 \\
\hline 12 & 4 & & Am Rande der Welt (K) & & \\
\hline 7 & 5 & & Die Jacht der sieben Sünden (K) & & \\
\hline 3 & 4 & & Die Liebe der Jeanne Ney (K) & & 228 \\
\hline 2 & 2 & & Alraune $(A)$ & & \\
\hline 2 & 2 & & Manolescu-Der König der Hochstapler (A) & & \\
\hline 1 & 5 & & Skandal in Baden-Baden (K) & & \\
\hline & & & Willy Fritsch (7), MI: 85 & & \\
\hline 25 & 4 & & Der letzte Walzer (A) & & \\
\hline 18 & 1 & & Spione (K) & 107 & 217 \\
\hline 18 & 1 & 7 & Heimkehr $(\mathrm{K})^{\star}$ & 100 & \\
\hline 12 & 5 & & Die Carmen von St. Pauli (K) & & \\
\hline 6 & 1 & 3 & Ungarische Rhapsodie $(\mathrm{K})^{*}$ & & \\
\hline 4 & 1 & 1 & Frau im Mond (K) & 107 & \\
\hline 2 & 1 & 10 & Ein Waltzertraum $(A)^{*}$ & & \\
\hline & & & Gustav Fröhlich (5), MI: 80 & & \\
\hline 34 & 1 & 4 & Metropolis $(A)^{*}$ & 107 & 217 \\
\hline 18 & 1 & 7 & Heimkehr $(\mathrm{K})^{\star}$ & 100 & \\
\hline 16 & 1 & 9 & Asphalt $(K)^{*}$ & 32 & \\
\hline 8 & 6 & & Jugendrausch (A) & & \\
\hline 4 & 4 & & Angst-Die schwache Stunde einer Frau (K) & & \\
\hline & & & Heinrich George (5), Ml: 46 & & \\
\hline 34 & 1 & 4 & Metropolis $(A)^{*}$ & 107 & 217 \\
\hline 6 & 4 & & Die Leibeigenen (K) & & \\
\hline 3 & 4 & & Das letzte Fort (K) & & \\
\hline 3 & 4 & & Soll und Haben (U) & & \\
\hline 2 & 2 & & Manolescu-Der König der Hochstapler (A) & & \\
\hline
\end{tabular}


Betrachtet man nur die zur Systematisierung herangezogenen Parameter leuchtet ein, dass auf jene Schauspieler mit einer größeren Anzahl von Filmen in der Regel auch ein höherer Materialindikator entfällt. Aus der Größe Materialindikator als quantitativem Gradmesser der Medienrezeption Aussagen über die Wirkung der Filme bzw. den Filmstar ableiten zu wollen, wäre jedoch verfehlt. Viele Belegdokumente transferierten oftmals nur den Inhalt von Agenturberichten über Filme und Stars, so dass es einem Zirkelschluss gleichkäme, daraus eine direkte Wirkung abzuleiten. Allein die Aufmerksamkeit des Zeitungslesers und nicht des Kinozuschauers wurde damit auf den jeweiligen Film bzw. Star gelenkt.

Auf eine erhöhte Aufmerksamkeit für die Filme mit Emil Jannings und Brigitte Helm kann man allerdings aus den Verweisen in der südafrikanischen Sekundärliteratur schließen, die nur bei diesen beiden Schauspielern ins Gewicht fällt. Rein quantitativ könnte man annehmen, dass Starzuschreibungen eher zu den Darstellern Emil Jannings, Brigitte Helm, Willy Fritsch und Gustav Fröhlich zu erwarten sein müssten, da zu jenen im Vergleich mit den übrigen Schauspielern eine signifikant größere Anzahl von Rezeptionsdokumenten vorliegt. Doch auch diese Aussage hat nur eine beschränkte Erklärungskraft, denn nicht in jedem Falle berichteten die Pressebelege der Filme auch über die Schauspieler, gleichwohl stellte es den Regelfall dar. Aus der Zusammenstellung direkt ablesbar ist hingegen die Tatsache, dass es keine Schauspieler gab, deren Filme auf nur eine der südafrikanischen Kinoketten festgelegt waren, so dass diese eventuell von ,ihren Stars' hätten sprechen können. Aufgrund der rein quantitativen Betrachtung soll daher mit der Vermutung abgeschlossen werden, dass eine Starzuschreibung am ehesten bei den Darstellern Emil Jannings und Brigitte Helm zu erwarten ist.

Allein durch die größere Anzahl an Filmen mit Emil Jannings und Brigitte Helm war eine häufigere Berichterstattung über beide Schauspieler gegeben, was sich u.a. auch darin niederschlug, dass von beiden viel öfter Abbildungen in der Presse wiedergegeben wurden, als von allen anderen deutschen Schauspielern. Bei Brigitte Helm lag dies vor allem an den spektakulären Bildern aus METROPOLIS, bei Emil Jannings an seinem kontinuierlichen Erfolg in Europa und den USA. Selbstverständlich taten sowohl die Reklameabteilungen der UFA und der Hollywoodstudios, als auch die der südafrikanischen Kinoketten ihr Bestes, um beiden ein ganz eigenes Starimage zu verschaffen. So kursierte über Jannings die Legende, dass er in Brooklyn als Kind deutsch-amerikanischer Eltern geboren wurde (RDM 8.7.29: 5). Jannings beförderte diese Legendenbildung mit einem erfundenen Lebenslauf, wobei er sich zunutze machte, dass sein Vater tatsächlich ein deutsch- 
amerikanischer Kaufmann war und er selbst nicht in Deutschland, sondern der Schweiz zur Welt kam (Holba 1979: 6f.). Über Brigitte Helm wurde verbreitet, sie sei im Alter vom 16 Jahren von Fritz Lang und seiner Ehefrau adoptiert und von beiden heimlich zwei Jahre lang auf die Rolle in METROPOLIS vorbereitet worden (ST 11.3.28: 6).

Zu Zeiten des ,klassischen Hollywood Studiosystems' wurde für die so vermarkteten Schauspieler eine möglichst publikumswirksame Identität erdacht, die sich bis in alle Lebensbereiche erstreckte, um eine möglichst hohe Übereinstimmung der Filmrollen mit dem jeweiligen Image des Schauspielers zu gewährleisten (Bawden/Tichy 1977: 732). Dazu wurden bestimmte Startypen (,typage') mit dem Ziel kreiert, dass sich mit der Nennung bestimmter Darsteller beim potentiellen Kinobesucher bereits eine Idee des Filminhaltes einstellen sollte (ebd.).

Im Unterschied zum Starsystem Hollywoods basierte der Erfolg der deutschen Stars auf den durch sie repräsentierten kulturellen Traditionen, die vom einheimischen Publikum geteilt und geschätzt wurden (Garncarz 2004: 392). Die deutschen Stars definierten sich nicht wie ihre US-Kollegen durch bestimmte Persönlichkeitsmerkmale, sonder durch ihre Arbeit als Schauspieler und ihrem Berufsethos als Künstler. Die Bezeichnung "Star" hatte in ihren Augen den Beigeschmack von Selbstsucht, Mangel an Talent und aufgebauschtem Medienrummel. Die Ursache für die Zurückweisung des USStarkultes lässt sich dadurch erklären, dass viele Filmschauspieler die Grundlagen ihres Könnens beim Theater erlernt hatten. Sie wollten als kreative Künstler respektiert werden, deren Qualitätsanspruch sich aus der Fähigkeit einer künstlerisch hochstehenden Darstellung der verschiedensten Rollen ableitete (ebd.). In starkem Kontrast zu Hollywood, das seine Stars vor allem durch die Verbreitung von Nachrichten aus dem Privatleben in der Öffentlichkeit platzierte, war die Privatsphäre der Künstler für die Medien weitgehend Tabu. Die meisten deutschen „Filmlieblinge“ lehnten derartige Nachfragen von Fans oder der Presse ab. Ohne an weitreichende Knebelverträge wie die der US-Studios gebunden zu sein, konnten sie die Reklame über sich selbst effektiv kontrollieren und banden sich meist nur von Film zu Film an die produzierenden Studios (ebd.). In dieser Hinsicht wurden von der deutschen Filmindustrie und den Medien trotz starker Publikumsnachfrage keine dem US-Publicity-Rummel gleiche Kampagnen geführt, um die Privatsphäre der Schauspieler zu schützen. Ein weiteres Beispiel für den grundsätzlich anderen Umgang der deutschen Filmindstrie mit dem Starkomplex war die konstante Verweigerung der Schaffung von Kinderstars, die zwar in US-Filmen auch in Deutschland erfolgreich waren, es jedoch als ein Tabu angesehen 
wurde, Kinder wie Erwachsene arbeiten zu lassen und ins Rampenlicht der Öffentlichkeit zu stellen (ebd.). Im Zuge der Reorganisation der UFA durch den Hugenberg-Konzern um 1928/29 veränderten sich zwar diese Vermarkungsstrategien und die Präsentation der Stars wurde den Publikumswünschen angepasst. In einigen der von der UFA betreuten Publikationen bzw. in der Presse war fortan mehr über das Privatleben der „Filmlieblinge“ zu lesen, jedoch drehte sich nach wie vor alles um die Person des Schauspielers als Künstler, eine Skandalberichterstattung wie in den USA blieb tabu (ebd. 397f.):

"The new form of reporting stayed true to the basic cultural consensus between producers and audience that was the condition for stars to be accepted in Germany, but it als narrowed the gap between supply and demand that had existed before" (ebd.: 398).

Da eine synthetisierende, konsistente Theorie des Stars bisher nur selten zur Untersuchung der Vielzahl historischer Filmstars angewandt wurde, soll an dieser Stelle in Anlehnung an Korte (2000) der ,Komplex Filmstar' näher erläutert werden. Demnach lässt sich der Filmstar als ein komplexes Phänomen denken, bei dem ästhetische, ökonomische, kulturelle und pragmatische Aspekte interagieren und sich vier zentrale Dimensionen unterscheiden lassen: 1.) der Star als ,Image', 2.) der Star als Wirtschafts- und Produktionssfaktor, 3.) der Star in Rezeption und Wirkung und 4.) der Star im Kontext seiner soziokulturellen Bedeutung (Korte/Lowry 2000: 8).

Dem Konzept des ,Starimage' kommt dabei eine zentrale Bedeutung zu, da es die Schnittmenge zwischen der realen Person, dem Schauspieler und dem Publikum darstellt und der Star als ein Ergebnis der Interaktion zwischen dem Image und den kulturellen Diskursen der Zeit aufgefasst werden kann (ebd.: 9). In zeitgenössischen deutschen Filmdebatten sprach man vom Zwang zum Erfolg und der Nötigung, sich im Anspruch auf die Massenwirkung auf wenige immer wiederkehrende Typen beschränken zu müssen (Bie 1936: 21f.). In der Filmkunst verwandele sich das Massenwunschbild zum Starkult, „der jeden echten Charakterzug allmählich verwischt und vom ursprünglichen Gesicht nur die Maske übrig lässt" (ebd.). Der Filmstar muss eine bestimmte Leistung als Darsteller, oft aber auch die Verkörperung kultureller Stereotypen erbringen, um die gewünschte Imagezuschreibung als ein Zeichenkomplex beim Publikum zu bewirken:

„Der Star, mit dem die Zuschauer und Fans interagieren, ist [...] immer ein Konstrukt, das auf den in den Medien verbreiteten Informationen und 
Zeichen aufbaut. [...] Wichtig ist aber auf jeden Fall, das innerfilmische Image (,Rolle', ,Leinwandimage') vom außerfilmischen Image (verschiedentlich auch ,Person', ,Persönlichkeit', ,Erscheinung' [...]) zu unterscheiden, auch wenn beide Aspekte des Images in ständiger Wechselwirkung stehen" (Korte/Lowry 2000: 10f.).

„Auch wenn authentische biographische Fakten die Basis des Images bildeten, wurden sie für die Öffentlichkeit so aufbereitet, daß sie ein bestimmtes, durchgängiges, in sich konsistentes Image propagierten, das darüber hinaus zu den Filmrollen paßte" (Harris in Korte/Lowry 2000: 11).

Weiters schlägt Korte vor, dem Starimage ob der enormen Bandbreite möglicher Elemente mittels zeichentheoretischer Überlegungen die Eigenschaft einer ,strukturierten Polysemie' zuzubilligen und in Anlehnung an Faulstich als „Brennpunkt hochkomplexer Bezugssysteme und allgemeingesellschaftlicher Verhältnisse und Prozesse" zu verstehen (Korte/Lowry 2000: 12f. bzw. Faulstich 1990/91: 50). Zu bedenken sei dabei allerdings, dass eine Analyse des Starimages durch die Fülle signifikanter Einzelheiten stets eine relativ offene interpretative Prozedur bliebe, da sie sich kaum formalisieren lasse und das Image sich aus dem jeweiligen Kontext und den Assoziationen der Rezipienten ergäbe (Korte/Lowry 2000: 13). Aus einigen zentralen Eigenschaften und Charakterzügen konstruiert sich demnach ein organisiertes Bild vom Star als Person, wobei diese Vorgänge nicht als Eigenschaft, sondern als Prozess aufzufassen sind. Dadurch wäre es möglich, das Zusammenspiel der einzelnen Momente zu analysieren und auch die Brüche und Veränderungen im Image einzuordnen (ebd.: 13f.).

Als Zusammenfassung des zeichentheoretischen Ansatzes zur Imagebildung lässt sich das ,Image' als ein Superzeichen, also als Zeichen eines höheren Komplexitätsgrades begreifen. Aus mehreren Zeichen zusammengesetzt, reduziert es die Komplexität und aus vielen Merkmalen wird eines. ${ }^{122}$ Zum Superzeichen Starimage gehört auch das Spannungsverhältnis bzw. die Dialektik von Typik (Darstellertypus) und Individualität (z.B. reale Person):

„Um seine Funktion für die Filmindustrie und auch das Publikum zu erfüllen, muß der Star das Publikum ansprechen, d.h. auch als herausragendes, besonderes Individuum erscheinen. Andererseits, muß er auch - soll er ein breites Publikum ansprechen und seine Interessen bzw. gesellschaftlichen relevante Fragen verkörpern - durchaus typisch sein. Auf ähnliche Art muß das Image konstant bleiben, und die ,Persönlichkeit' und

\footnotetext{
122 So z.B. kann aus einer Vielzahl von Eigenschaften das Image bzw. Superzeichen ,Latin Lover' entstehen, welches in der Filmgeschichte je nach Epoche verschiedene Schauspieler trugen (z.B. in der Stummfilmzeit Rudolph Valentino, nach dessen Tod Ramon Novarro oder seit den 1980er Jahren Antonio Banderas).
} 
,Präsenz' des Stars zu etablieren, die Wiedererkennung zu garantieren und eine längerfristige Interaktion mit ihm zu ermöglichen, aber zugleich genug Variationen und sogar überraschende oder rätselhafte Momente bieten, um das Interesse längerfristig zu erhalten“ (ebd.: 14).

Da in dieser Studie Rezeption und Wirkung von Filmen und so auch von Filmstars im Vordergrund stehen, kann die ökonomische Seite des Starsystems auf das Notwendigste verkürzt werden. Im Wesentlichen steuerten dabei die ,Publicity Departments' der Filmstudios oder Vertriebe das für die Öffentlichkeit aufbereitete Privatleben der Filmstars, um deren Leinwandrollen zu unterstützen (ebd.). Dabei bestand das Ziel in der Aufgabe, mit einer Starbesetzung sozusagen automatisch einen erfolgreichen Film zu garantieren. Der durch stereotypisierende Vereinfachungen geschaffene Star senkt in ökonomischer Hinsicht die Transaktionskosten des Kinobesuchers als Konsumenten (z.B. Informationsbeschaffungskosten für Filminhalte), in dem er inm ein festes Vorstellungsbild liefert, das bereits mit bestimmten Qualitätserwartungen oder -erfahrungen verbunden ist und somit durch Reduktion der Marktkomplexität Kosten senkt. Dies gilt ebenso für den Filmproduzenten, der über den Markenwert des Stars sein unternehmerisches Risiko besser kalkulieren kann und mit dem Starimage gleichzeitig eine Art Versicherungsoption für den Erfolg des Films parat hat:

„Whatever change of emphasis from actor to play which the future may hold, the 'stars' are today an economic necessity to the motion picture industry. In the 'star' your producer gets not only a 'production' value in the making of his picture, but a 'trademark' value and an 'insurance' value, which are very real and very potent in guaranteeing the sale of this product to cash customers at a profit. It has been amply demonstrated that the actual salaries [...] paid to motion picture actors, [...], are determined by the law of supply and demand in exactly the same way as the rewards of executives in the business world" (Prospektauszug 1927 in Koszarski 1990: 262).

Die potentiellen Bedeutungen eines Starimages erschließen sich hingegen erst in der Rezeption, da die Letztentscheidung, ob jemand ein Star wird oder nicht, trotz aller Medienunterstützung letztendlich allein beim Publikum liegt. Das Starimage besteht nicht nur aus medienvermittelten Informationen (einschließlich Bildern), sondern ist vielmehr ein Produkt der Verarbeitung all dieser Zeichen und Aussagen (Korte/Lowry 2000: 16). Als Konstrukt entsteht jene ,Starqualität', die aus der Interaktion zwischen den Rezipienten und dem Bedeutung tragenden Material ein ganz spezifisches Image gene- 
riert. Die interpretatorische Arbeit der Rezipienten am Starimage wird darüber hinaus noch von subjektiven Faktoren wie Identifikation, Projektion etc. beeinflusst, ebenso vom kulturellen Kontext, da die gesellschaftlich akzeptierten Werte, Diskurse und Codes den Verstehenshorizont kontextuell strukturieren:

„Erst das Publikum macht den Star. Erfolg ist ein konstituierendes Kriterium für Stars. Die Bedeutung des Stars wird erst in der Rezeption realisiert und individuell aktualisiert. Ein Star kann für verschiedene Publika unterschiedliche, sogar entgegengesetzte Bedeutungen haben. [...] Starimages sind offene Texte, deren Bedeutung in besonderem Maße vom jeweiligen kulturellen, historischen und gesellschaftlichen Kontext abhängig, also einem zeitlichen Wandel unterzogen ist. Sie sind Indikatoren sowohl für die vorherrschenden historisch-kulturellen Strömungen (,Zeitgeist') ihrer Entstehungssituation als auch für die Rezeptionsveränderungen in den folgenden Phasen" (ebd.: 22).

Dem kulturellen Kontext kommt bei dieser Studie eine besondere Bedeutung $z u$, da es sich bei einem Star nicht um eine einmalig festgelegte Qualität handelt, sondern sich diese im Rahmen verschiedener Interpretationskontexte wandeln kann. Es kann davon ausgegangen werden, dass in Südafrika andere Publiumspräferenzen, Marktmechanismen etc. zum Tragen kamen, welche die Rezeptionsausrichtung abweichend zur deutschen Rezeption beeinflusst haben:

„Weder die Filme noch die sekundären Texte über den Star bestimmen seine Bedeutung allein. Vielmehr sind diese in größere Zusammenhänge eingebettet. Die Intertextualität des Images erstreckt sich bis hinzu allgemeinen kulturellen Texten [...]. Eine kritische Interpretation ist also auf die Vermittlung der scheinbar getrennten Bereiche Text - Kontext - Rezipient durch die kulturellen Diskurse gerichtet, in denen sich der Erwartungshorizont des jeweiligen Publikums manifestiert. [...] Stars haben häufig die Funktion, als Kristallisationspunkte für die populärkulturelle Diskussion und die kollektive oder individuelle Ausformung aktueller kultureller Fragen zu dienen" (ebd.: 20).

Da im konkreten Fall nur fünf Produktionen unter allen „S-Filmen“ keine Stummfilme waren, die Umstellung von Stumm- auf den Tonfilm um 1930 stattfand und die Mehrzahl der „S-Filme“ vor 1930 gezeigt wurde, empfiehlt es sich, die Stars des Stummfilms stärker in den Blick zu nehmen als die des sich gerade entwicklenden Tonfilms. 
Durch die lang andauernde Vorherrschaft des US-amerikanischen Films dominierten auch in Südafrika die Hollywoodstars der entsprechenden Periode. Thelma Gutsche führt dazu aus, dass vor der Einführung längerer Spielfilme vor allem die Komödianten der wöchentlichen Abenteuerstreifen zu Stars wurden, die ab 1911 mit der Etablierung des Starsystems in Hollywood von den diversen Studiostars abgelöst wurden (Gutsche 1972: 122). ${ }^{123}$ Für das Nachkriegskino 1920er Jahre konstatiert Thelma Gutsche das Entstehen eines ,Starkomplexes':

"The most enduring and powerfull feature of the post-war cinema was the supervention of ,stars', the inculcation of the ,star-complex' and the infection of a certain proportion of the public with 'film-fanatism'. 'Glamour' did not properly belong to the cinema until after the Great War when the public was most susceptible to it. Where previously high-speed acting, excitement, sensation and perpetual movement had held audiences entranched, now emotional appeal or erotic order was exploited" (ebd.: 177).

Für die Zeitspanne zwischen Kriegsende und Tonfilmumstellung lassen sich aus den bei Thelma Gutsche gelisteten „outstanding films of each year" und der Vollerfassung des Kinoprogrammes in Kapstadt für die Jahre 1928-1930 (Anhang I bzw. Eckardt 2005: $101 \mathrm{ff}$.) einige Annahmen über zeitgenössisch populäre Filmstars herleiten. Demnach waren die Filmstars der frühen 1920er Jahre Mary Pickford, Theda Bara, Lon Chaney, Thomas Meighan, Jackie Coogan, Tom Mix, Douglas Fairbanks, Harold Lloyd, Larry Semon, Buster Keaton, Charlie Chaplin, Pola Negri, Alla Nazimova, Rudolph Valentino u.a. (Gutsche 1972: 177). ${ }^{124}$ Eine ganz ähnliche Nennung ergaben Umfragen von Filmfachzeitschriften in den USA (z.B. Photoplay oder Film Daily), wobei sich ein Unterschied in der Einschätzung der Popularität durch die Fans im Vergleich zu den eindeutig abrechenbaren Zuschauerzahlen der Kinobetreiber beobachten ließ (Koszarski 1990: 262). ${ }^{125}$ Die Übereinstimmung der in den USA und Südafrika populären Filmstars belegt erneut die Dominanz des Hollywoodfilms im südafrikanischen Kino.

123 Z.B. Mary Fuller, Maurice Costello, Marc Mcdermott, Florence Lawrence, G.M. Anderson, Helena Gardener, Alice Joyce, Carlyle Blackwell, Hobart Bosworth, Julia Swayne, Asta Nielsen (Gutsche 1972: 122-123).

${ }^{124}$ Oder zusätzlich Sally O'Neil, Jack Holt, Gloria Swanson, Joan Bennett, Clara Bow, Ivor Novello, Greta Garbo etc. (Gutsche 1972: 228ff.).

125 Rangliste laut Photoplay 1924 (Fanzeitschrift): 1. Mary Pickford, 2. Douglas Fairbanks, 3. Gloria Swanson, 4. Pola Negri, 5. Thomas Meighan, 6. Norma Talmadge, 7. Harold Lloyd, 8. Tom Mix; Rangliste laut Film Daily 1924 (Fachzeitschrift): 1. Harold Lloyd, 2. Gloria Swanson, 3. Tom Mix, 4. Thomas Meighan, 5. Norma Talmadge, 6. Rudolph Valentino, 7. Douglas Fairbanks, 8. Mary Pickford etc. (Koszarsky 1990: 262). 
In einer Phase, in der viele Filmstars "Sirens, sheiks, vampire women” darstellten, führte die Rezeption dieser Filme zu einem vorher nicht gekannten Film- bzw. Starkult:

„During the twenties, John Gilbert's barber was said to have offered $£ 1000$ for the clippings of his hair to retail to female fans. The vogue for Rudolph Valentino first brought this unhealthy pre-occupation with screen personalities to the fore and his death in 1926 revealed to what extent 'film fanatism' had depraved feminine taste and upset its sense of value. Excellent for publicity and trade generally (during the twenties, sales of picture postcards of the stars, screen journals, pocket-biographies etc. rose to remarkable heights), the star complex at one time represented a serious menace to adolescent psychology at least. Its encouragement of silly sentimentality and its inculcation of false standards were undoubtedly harmful but it nonetheless represented a definite development of the cinema and one that was maintained" (Gutsche 1972: 177f.)

Programmgeschichtlich dominierten demnach vor allem jene USamerikanischen Filmstars, die seit dem Wegfall der nicht US-Filme nach Kriegsausbruch verstärkt im südafrikanischen Kino zu sehen waren. Stars wie z.B. Mary Pickford, Charlie Chaplin oder Theda Bara waren dem einheimischen Publikum also schon seit mehr als zehn Jahren bekannt (Gutsche 1972: 162ff.), andere wie Thomas Meigham, Lon Chaney, Gloria Swanson oder Lillian Gish seit mehr als fünf Jahren (ebd.: 195f.). Das es dadurch zu gewissen Gewöhnungseffekten gekommen und der Wunsch nach neuen unverbrauchten Darstellern gewachsen sein könnte, ist durch diese Konstellationen nicht von der Hand zu weisen.

Die bei Thelma Gutsche genannten deutschen Schauspieler in der erwähnten Auflistung sind Emil Jannings (4x), Brigitte Helm (3x), Marlene Dietrich (2x), ${ }^{126}$ Lilian Harvey (1x), Leni Riefenstahl (1x) und Conrad Veidt (1x) (Gutsche 1972: 228f.). Die Übereinstimmung dieser Nennungen mit der aus den „S-Filmen“ erstellten Rangfolge bestätigt die Annahme, dass ein mögliches Starpotential durch die größere Anzahl der Filme mit Emil Jannings und Brigitte Helm am ehesten zu finden sein dürfte.

Ein weiteres Indiz für die Richtigkeit dieser Annahme stellen die Erwähnung der beiden Schauspieler in den Schriften des südafrikanischen Filmkritikers Hans Rompel dar. Die für den Zeitraum 1928-1933 vollständig erfassten Artikel in der Zeitschrift Die Huisgenoot spiegeln die eingehende Beschäftigung mit der Filmstarthematik wieder (Eckardt 2007), jedoch widmete

${ }^{126}$ Marlene Dietrich wird auch bei der US-Produktion „Morocco“ (1930, J. v. Sternberg) gelistet, die nicht Teil der "S-Filme“ ist. 
er nur drei Filmstars exklusive Beiträge: Brigitte Helm (Rompel 1929), Emil Jannings (Rompel 1931a) und Charlie Chaplin (1931b). Die über die Reklamemeldungen der Tagespresse hinausgehenden Ausführungen zu den genannten Stars verdeutlichen deren Sonderstellung, selbst wenn die Berufung auf nur einen Filmkritiker etwas willkürlich erscheint. Die Übereinstimmung mit den empirisch erhobenen Daten und die subjektive Einschätzung des einzigen zeitgenössischen südafrikanischen Filmkritikers mit theoretischem Reflexionsvermögen stützen die getroffenen Annahmen. Selbst wenn vereinzelt auch andere deutsche Schauspieler als ,Stars' bezeichnet wurden, z.B. Jenny Jugo als "Continental Clara Bow“ (NA 24. 4.29: 11), Betty Amann und Gustav Fröhlich nach ihrem Erfolg mit ASPHALT (CT 4.6.29: 7) oder auch Elisabeth Bergner (Theron 1932), kann man sich hinsichtlich der beim Publikum erreichbaren Popularität aufgrund der Kontinuität der Filme mit Emil Jannings und Brigitte Helm auf diese beiden Stars konzentrieren.

\subsubsection{Filmstar I: Emil Jannings}

In seiner ausgewogenen, Hochachtung und Kritik gleichermaßen enthaltenden Analyse der schauspielerischen Qualitäten von Jannings, verglich Rompel dessen deutsche Produktionen mit jenen seines Hollywoodengagements. Betrachte man Jannings' deutsche Filme werde deutlich, dass diese eine Reihe gut balancierter, vom Regisseur als Ganzes entworfener Filme darstellten, in der sich Jannings und seine Mitspieler unter die Ganzheit des Films unterordneten (Rompel 1931: 49). Jannings verfüge über die besondere Gabe, sich einem solchen Ganzen so zu unterwerfen und sein Schauspiel derart zu beherrschen, dass es das Ganze zu einer nahezu perfekten, logisch geschlossenen Einheit mache. Gerade dadurch steche er so heraus, er fühle die Bedeutung für das Ganze und zugleich könne man sein individuelles Spiel bewundern, welches die Ganzheit zur Vollendung bringe (ebd.).

Vollkommen anders verhalte es sich mit seinen US-Produktionen, da Drehbuch und Regie darauf ausgerichtet wären, Jannings die Chance zu geben, sich selbst voll ausspielen zu können. Individuell bewundern könne man wieder sein brilliantes Spiel, sein wunderbares Ausdrucksvermögen und sein fabelhaftes Gespür dafür, welche Effekte man mit Hilfe der Kamera erzielen könne. Doch im Hinblick auf die Regie seien diese Filme unkünstlerisch, die Filmkompositionen von typisch amerikanischer Nachlässigkeit in Bezug auf Details, die ganze Umgebung, Gegenstände und Figuren, alles in allem eine unwirkliche Angelegenheit, so wie in einer Puppenstube (ebd.). In „Der Patriot“ (1928, E. Lubitsch) könne man Jannings Verkörperung der 
Figur Paul I. zweifellos bewundern, doch das ganze Szenario wirke unecht, nur sein direkter Gegenspieler Graf Pahlen (Lewis Stone) besitze menschliche Qualitäten, alle anderen seien einfach nur Puppen. Die entstandene Hochachtung gelte allein Jannings, nicht dem Film. Der normale Zuschauer wisse bereits, dass - außer Jannings und Stone - keine Nebenrolle oder Schauplatz dem Ganzen auch nur die kleinste Bedeutung einflößen könne. Das Publikum sei sich aber nicht bewusst, dass dieser Interessenmangel eigentlich der Verurteilung des Films als Ganzem gleichkomme. In jeden Film gehöre eine absolute Einheit aus dem Thema, den Darstellern und dem Schauplatz, gleichfalls eine logische Entfaltung des Ganzen, welche diese Einheit ununterbrochen bewahrt. Dafür sei einzig und allein der Regisseur verantwortlich, deshalb sei dessen Name auch viel wichtiger für den Film als der einiger Schauspieler.

Darin lag für Rompel auch einer der Hauptunterschiede zwischen dem deutschen und dem US-amerikanischen Film. Während man deutsche Filme nach dem Namen der Regisseure aussuche, weil man ein kunstvolles, ausgewogenes und akkurat entworfenes Ganzes suche, mache der Hollywoodfilm nur mit seinen Filmstars Reklame. Genau darin liege der größte Fehler, da der Film nur zusammengehämmert werde, um die Fertigkeiten der Darsteller zu zeigen, genauso wie in einem Zirkus die Tiere ihre Kunststückchen aufführten (Rompel 1931: 51). Dies gebe manchem Schauspieler den Vorwand, sich permanent in den Mittelpunkt zu stellen, was in der Regel auf Kosten des Themas, des Zusammenhangs, der ursprünglichen Intention des Regisseurs und natürlich der Mitdarsteller geschehe. Mit den Ausführungen zur Wichtigkeit des Regisseurs kann man bei Rompel vermuten, dass seiner Meinung nach auch dem erfolgreichen Regisseur ein Starimage zukommen könne.

Der qualitative Unterschied zwischen Jannings' deutschen und seinen Hollywoodfilmen beruhe genau auf diesen gegensätzlichen Produktionsbedingungen. Da Jannings gegenüber sich selbst nicht besonders kritisch sei, brauche er Regisseure, die ihn besser unter Konrolle hielten, da er schnell dazu neige, die Grenzen seiner Rolle zu überschreiten, um das ganze Filmgeschehen zu beherrschen. Diese Gefahr entstehe immer dann, wenn Jannings' Regisseure ihm zu viel freie Hand ließen (ebd.). Diese Einschätzung teilte neben Rompel auch Regisseur Sternberg, der Jannings attestierte, stets mit fairen oder unfairen Mitteln die ganze Aufmerksamkeit auf sich ziehen zu wollen (Holba 1979: 27).

Ein zweiter Kritikpunkt an Jannings war seine Neigung, gewisse Bewegungen bzw. ein bestimmtes Gebaren in Manieriertheiten degenerieren zu 
lassen. Es wäre leichtsinnig, das in einer Situation passende Gebaren in der nächstpassenden zu wiederholen, da es zu schnell Gewohnheit würde; ein Fehler, der in so manchem Jannings-Film erkennbar sei (Rompel 1931: 51). Das größte Ärgernis sei jedoch sein Hang zum ,über-spielen' oder übertreiben. Da ihm klar wäre, dass das Publikum die feinen schauspielerischen Nuancen kaum wahrnehmen könne, neige er dazu, sein Spiel großspurig zu konstruieren, Besonderheiten unnötig stark zu betonen, um unter allen Unständen die Aufmerksamkeit des Publikums zu gewinnen. Das diese Eigenschaft von Jannings in seinen US-Filmen durch die gelockerte Regieführung viel stärker ausgeprägt sei als in seinen deutschen Filmen, verstehe sich fast von selbst (ebd.).

Diesen Kritikpunkten stehe seine Fähigkeit gegenüber, einen wunderbaren Einblick in die von ihm dargestellten Charaktere zu gewähren, wie tief er sich selbst in die Rollen hineinversetzen könne und wie überzeugend er diese ausgestalte. Zwischen der größtmöglichen Bestialität und der liebenswürdigsten Gutmütigkeit besitze sein Schauspiel unzählige Schattierungen und Nuancierungen. In VARIETÉ zeige er eine ganz unamerikanische, psychologische Charakterstudie, in der auch jeder Gegenstand so platziert wird, dass er Leben gewinnt. Im Wechselspiel aus Rohheit und Feinsinnigkeit sei Jannings dennoch ein untergeordneter Teil des Ganzen, eine Spitzenleistung, die Regisseur Dupont vollbracht habe. Ebenso janusköpfig gelinge die Darstellung des Mephisto in FAUST, als Fürst der Finsternis und als adrett kostümierter Schalk gleichermaßen überzeugend.

In seinem ersten Hollywoodfilm, „The Way of All Flesh“, beginne Jannings zwar ganz typisch und überzeugend mit der Darstellung eines biederen deutschen Hausvaters, doch mit dem Übergang zur amerikanischen Schnulze verliere er sein künstlerisches Gleichgewicht und das ganze Szenario werde unüberzeugend (ebd.). ${ }^{127}$ "The Street of Sin" sei eine ebenso schematische Produktion, in der Jannings vor allem durch seine Darstellung als AusgestoBener und durch das kurze Aufblitzen animalischer Leidenschaft beim Publikum einen bleibenden Eindruck hinterlassen habe. Mit ihm geriet „The Patriot" zu einer Studie über den Wahnsinn, allerdings etwas übertrieben und sich selbst zu stark in den Vordergrund stellend, woran Regisseur Lubitsch aber die Schuld trage. Den jeweiligen Gemütszustand des wahnsinnigen Zaren, seine Wut, seinen Kummer, seine Eitelkeit, gebe er mit unvergesslichen Gesichtsausdrücken wieder. Unter seinen US-amerikanischen Filmen sei aber „The Last Command" eindeutig der beste, die Verkörperung des unter

\footnotetext{
${ }^{127}$ „The plot is simple and the settings are good without being remarkable" (CT 15.3.29: 11).
} 
geist-igem und körperlichem Schock stehenden Generals gebe nicht mal einem Psychiater Anlass zur Kritik. ${ }^{128}$ Gleichwohl sehe man ihn zum ersten Mal in einer neuen Situation, in der er einen körperlich und seelisch gebrochenen Mann darstelle, in welchem ab und an noch die Überbleibsel einstigen Stolzes bemerkbar wären. Obwohl der Film unausgeglichen und schlecht komponiert wäre, sei ihm ob des tüchtigen Jannings eine prächtige Schlußszene gelungen:

„Sowas ist irgendwie [typisch] Emil Jannings: Künstler bis in die Fingerspitzen - aber ein Künstler der einen guten Regisseur verlangt; ein Darsteller für die Massen, und deshalb ein Abgott für das Publikum. Wir vermissen ihn im Augenblick. Mögen wir nicht allzu lang auf seinen Tonfilm warten müssen! Und hoffentlich macht er - sobald die Tonfilmkrankheit vorüber ist - noch so manchen Stummfilm unter den deutschen Regisseuren" (ebd.) $)^{129}$

Die Gesamteinschätzung von Jannings durch Hans Rompel deckt sich in vieler Hinsicht mit den Einschätzungen der südafrikanischen Tagespresse, gleichwohl erreichen Rompels Ausführungen eine analytische Tiefe, welche die Filmkritiken ob ihres oft werbenden Grundcharakters gar nicht erreichen konnten. In seinen US-Rollen variierte Jannings jedoch nur das in „Der letzte Mann“ (1924, F.W. Murnau) voll ausgespielte Motiv des gebrochenen alten Mannes. Da dieser Film in Südafrika nicht gezeigt wurde und DER BLAUE ENGEL, in dem dieses Muster wiederkehrt, von Rompel noch nicht berücksichtigt wurde, kann die Nichtidentifikation dieses Leitmotivs auch nicht überraschen. Wie in den USA machte die pathetische Ausstrahlungskraft von Emil Jannings ihn auch in Südafrika zu einem populären, kassenträchtigen Star (Bawden/Tichy 1977: 378). Selbst die in der Cape Times kontrovers ausgetragene Debatte um "The Way of All Flesh“ kritisierte nicht das schauspielerische Können Jannings, sondern vielmehr die Trivialität des Themas und dessen vulgäre Bearbeitung, welche den Film ruiniere (Eckardt 2005: 73ff.). Trotz der Kritikerschelte waren die konventionellen Themen der Janningsfilme beim Publikum überaus erfolgreich, auch die Presse feierte inn als "One of the films greatest character actors" (NA 26.10.29: 6). Für seine "distinguished performances" in „The Way of All Flesh" und „The Last Com-

\footnotetext{
${ }^{128}$ Rompel selbst war ein ausgebildeter Psychiater, obwohl er nach seinem Studium zuerst für die Presse arbeitete.

129 „Sulks, enigsins, is Emil Jannings: kunstenaar tot aan die tippe van sy vingers - maar 'n kunstenaar wat 'n goeie regisseur eis; die speler vir die massa, en derhalwe die afgod van die publiek. Ons mis hom op die oomblik. Mag ons nie alte lank op sy praatprent moet wag nie! En mag - as die praatprentmalheid verby is - Jannings nog menige stil prent maak onder die Duitse regisseurs".
} 
mand“ erhielt Jannings den ersten Academy Award („Oscar”) der Filmgeschichte für die beste Hauptrolle (Ihrering 1941: 139). Das dieses Faktum in in keinem der Rezeptionsdokumente erwähnt wurde, ist ein überraschender Befund.

Aus welchen Gründen Emil Jannings beim südafrikanischen Publikum zu dem Filmstar der späten 1920er Jahre avancierte, lässt sich aus der Berichterstattung nur unzureichend erklären. Eine Ursache war mit Sicherheit seine durchgängige Leinwandpräsenz, weiters sein unbestrittenes schauspielerischen Können und die Imagekontinuität des einst starken Mannes, dem das Schicksal seine Kräfte nimmt (Weniger 2001/4: 200). Einen Unterschied in der englischsprachigen bzw. der afrikaansen Medienrezeption lässt sich ebenfalls nur schwer ausmachen, da erstere durch ihre kommerzielle Orientierung mit echter Kritik eher zurückhaltend war und zweitere durch die Einschätzungen von Hans Rompel dominiert wurde. Rompel selbst präzisierte in seinem Zeitschriftenaufsatz die Aussagen der eigenen Filmkritiken und reicherte sie um sein filmhistorisches Kontextwissen an. Da er generell dem europäischen und speziell dem deutschen Film sehr positiv, dem USamerikanischen jedoch kritisch gegenüberstand, schränkt dies die Aussagekraft seiner Werthaltungen gelegentlich ein.

Dass in diesem Abschnitt die Interaktion von Emil Jannings und seiner Rolle in DER BLAUE ENGEL nicht näher untersucht wird, liegt in der besonderen Ausnahmestellung des Films. Als Jannings' erster Tonfilm bietet er zu wenige Vergleichsmöglichkeiten mit seinen Stummfilmen, obwohl sich die Typologie der Rolle noch stark an den von ihm verkörperten Charakter á la „Der letzte Mann“ orientiert. DER BLAUE ENGEL stellt allerdings in Jannings' Schaffen eine Art Übergangsfilm dar (Bie 1936: 72), in dem sich seine Suche nach einem zeitgemäßeren Leinwandimage mit einer gewissen tonfilmbedingten darstellerischen Unsicherheit paart (Bawden/Tichy 1977: 378). Dies brachte es mit sich, dass Jannings Tonfilmqualitäten ob seiner immer noch theatralischen Darstellungsweise als wesentlich schlechter eingeschätzt wurden (ebd.). Um eine ausgewogen Vergleichsgrundlage zu haben, wurde sich deshalb auf sein Stummfilmimage beschränkt.

Da alle Janningsfilme (bis auf FAUST) keine phantastischen Themen aufgriffen und eher in der Gegenwart spielten, könnte seine Popularität auch mit einer Änderung des Publikumsgeschmacks zum Ende 1920er Jahre zusammenhängen, der realistischeren Charakteren eher als phantastischen zugeneigt war (Gutsche 1972: 217). Programmgeschichtlich lässt sich seine Popularität u.a. damit erklären, dass er als ,neues Gesicht' dem Wunsch des Publikums nach unverbrauchten Darstellern entgegenkam. Im Gegensatz zu 
vielen Hollywoodstars war er dem Publikum erst seit 1926 (in „Quo Vadis?, 1925, G. D'Annunzio/G. Jacoby) bekannt. Desweiteren waren seine USKonkurrenten wie Rudolph Valentino, Douglas Fairbanks oder Lon Chaney auf bestimmte Genres festgelegt, die das Publikum nur zu gut kannte und in der Anpassungsfähigkeit von Jannings an seine verschiedenen Rollen eine Art neuen, europäischen Schauspielertypus erkannte (,Schauspieler als Künstler, nicht Star'). Bis auf seine Rollen in „Quo Vadis?", FAUST und „The Patriot" stellte er zudem zeitgenössische Figuren dar, wohingegen direkte Konkurrenten wie Douglas Fairbanks auf historische Rollen ,abonniert' schienen ${ }^{130}$ oder wie Rudolph Valentino den immergleichen androgynen, aber trotzdem ,frauenverschlingenden' Liebhaber in Kostümfilmen abgaben. ${ }^{131} \mathrm{Im}$ Sinne des Selbstverständnisses der deutschen Schauspieler als Künstler, die durch ihre Theaterausbildung auch im Film für verschiedene Rollen jenseits des "Hollywood-Typage" besetzt wurden, konnte Jannings dieses Talent sowohl in seinen Rollen als Familienvater ("The Way of all Flesh“ und „Sins of the Fathers"), Ganove und Liebhaber („Varieté" und „Street of Sin“), alternder Machtmensch („The Last Command“ und DER BLAUE ENGEL) sowie als Geist oder Wahnsinniger (FAUST, "Quo Vadis“ und „The Patriot“) anscheinend überzeugend umsetzen.

\subsubsection{Filmstar II: Brigitte Helm}

Brigitte Helm war ohne Zweifel der weibliche deutsche Filmstar in Südafrika, wobei sie durch ihre ausschließlich in deutschen Filmen erfolgten Auftritte anders als bei Emil Jannings - vor allem als europäischer Filmstar (,continental') wahrgenommen wurde. Spricht bereits ihre überdurchschnittliche Leinwandpräsenz in acht Filmen für eine durch das Publikum wahrnehmbare Kontinuität, verstärkt die Imagekontinuität ihrer exponierten Frauenrollen die Starqualität der Darstellerpersönlichkeit.

Die von Brigitte Helm verkörperten Frauenrollen lassen sich in zwei Gruppen unterscheiden: zum einen in die des ,Vamp' in den Filmen METROPOLIS, ALRAUNE, JACHT DER SIEBEN SÜNDEN, MANOLESCU und zum anderen in die der ,tragischen Geliebten' in DIE WUNDERBARE LÜGE DER NINA PETROWNA, SKANDAL IN BADEN-BADEN und AM

\footnotetext{
130 Z.B. in „The Three Musketeers“ (1921, F. Niblo), „Robin Hood” (1922, A. Dwan), The Black Pirate” (1926, A. Parker), „The Gaucho” (1927, F.R. Jones), „The Iron Mask” (1929, A. Dwan) (Gutsche 1972: 196 und 228f.)

131 Z.B. in "The Sheik" (1921, G. Melford), „Monsieur Beaccaire“ (1924, S. Olcott) oder "The Eagle” (1925, C. Brown) (Gutsche 1972: 196 bzw. Eckardt 2005: 102).
} 
RANDE DER WELT. Eine Ausnahme stellt die Produktion DIE LIEBE DER JEANNE NEY dar, in der sie nicht die Hauptrolle spielt, keinen Vamp oder eine Heroine darstellte, sondern als blindes Mädchen die reine Unschuld verkörpert. Da sie mit ihrer außergewöhnlichen Doppelrolle in METROPOLIS bereits einen sensationellen Erfolg hatte, bemühte sich die UFA, der Schauspielerin das Image eines Vamps anzuheften, besetzte sie in entsprechenden Rollen und ließ spektakuläre Reklamebilder zirkulieren.

Ebenso wie bei Emil Jannings umschreibt Hans Rompel bereits mit dem Titel seines Schauspielerporträts seine Sicht auf Brigitte Helm als "die Sphinx unter den Filmschauspielerinnen" (Rompel 1929: 37) und spielt zweifellos auf ihre ambivalenten Qualitäten als Filmstar an. Die Bezeichnung als 'Sphinx' hat inzwischen einen überzeitlichen Charakter angenommen, wie Jubiläumsartikel in der Tagespresse belegen (Müller 2006).

Gleichermaßen als Engel und als Teufel war sie in METROPOLIS zu bewundern. Fritz Lang gestaltet ihre Rolle als Wechselspiel von reiner weiblicher Güte und seelenloser mechanischer Kälte meisterhaft aus. Der Eindruck dieser Rolle war so stark, dass ihr Kritiker und Regisseure die Fähigkeit einer perfekte Verkörperung des Filmvamps zusprachen, eine Zuschreibung die sie selbst unter allen Umständen vermeiden wollte und die UFA später auf andere Rollen verklagen musste (Weniger 2001/3: 628).

Danach sei für Brigitte Helm einiges schief gelaufen, so käme z.B. ihr Mitwirken in JACHT DER SIEBEN SÜNDEN einer skandalösen Verschwendung ihres Talents gleich (Rompel 1929: 37ff.). In Bezug auf Ihre Ausdruckskraft könne man sie in einer Reihe mit Pola Negri und Theda Bara nennen, ihr Gesichtsausdruck und vor allem die Wirkung ihrer Augen sei betörend. Durch ihren starren undurchdringbaren Blick wirke sie so rätselhaft, wie kaum eine andere Schauspielerin. Leider sei sie in JACHT DER SIEBEN SÜNDEN in die falschen Hände geraten, genauso wie in SKANDAL IN BADEN-BADEN, ein Film der klar unter ihrem Niveau läge. Für MANOLESCU hatte sie wieder als Vamp auftreten müssen, gegen die unanständigen Szenen hätte sie zwar erfolgreich protestiert, der Vamp sei sie aber geblieben. Das sie auch positiv besetzte Rollen spielen könne, bewies sie zum Teil schon in METROPOLIS, noch stärker aber in AM RANDE DER WELT und DIE WUNDERBARE LÜGE DER NINA PETROWNA. In letzterem spiele sie tiefgründiger und gefühlvoller, benutze ihre Augen in einem Moment um fröhlich-verliebt zu schauen und schon im nächsten den Eisesblick der Maschinen-Maria aus METROPOLIS annehmen zu können (Rompel 1929: 39). Selbst Verführungsszenen, die in anderen Händen vielleicht unanständig wirken würden, gelängen ihr so geschickt, dass nichts anderes als ein Kunstwerk daraus werden könne. Sie 
habe den angeborenen guten Geschmack der verhindere, dass etwas hässliches in ihr Schauspiel eindringt, es sei denn der Regisseur zwänge es einfach hinein (ebd.). Solange sie diese Eigenschaft bewahren könne und nicht zu einer Routineschauspielerin würde, bliebe sie so rätselhaft, wie man es eben von einer "Sphinx unter den Filmschauspielerinnen“ erwarte.

Neben der offensichtlichen Bewunderung für einen attraktiven Filmstar legte Rompel wie schon bei Jannings seine Auffassung dar, dass ein talentierter Darsteller erst durch die Hand des richtigen Regisseurs jene Starqualitäten ausspielen könne, die vielleicht in ihm ruhten. Da es sich ausschließlich um Stummfilme handelte, überrascht die Betonung der schauspielerischen Mimik gerade nicht, da diese neben der Körperbewegung als das Stilmittel galt, um dem Zuschauer Gefühle und Gedanken (ohne Zwischentitel) zu vermitteln. Weil Rompel ohnehin nichts vom Tonfilm hielt und für ihn ein perfekter Stummfilm am besten ohne Zwischentitel auskommen sollte, stellte die Nuancierung der Gesichtsausdrücke bei Brigitte Helm ein ideales Demonstrationsobjekt für seine Expertenmeinung dar. Dass sie als ,Vamp' zum Star anvancierte, ist natürlich der erotischen Aufladung ihrer Rollen geschuldet, die in ALRAUNE zumindest in Südafrika ihren Höhepunkt hatte. Leider äußert sich Rompel nicht kontinuierlich zu eventuellen Zensureingriffen bei diversen Szenen in ihren Vampfilmen. Erstaunlicherweise wurde in METROPOLIS die Transformationsszene, in der die gute in eine böse Maria verwandelt wird, vom Zensurkomitee der Kapprovinz beanstandet und entfernt (Rompel 1929: 37).

Neben der Aufführungs- war es, wie belegt werden konnte, auch eine spezielle Imagekontinuität, die Brigitte Helm beim südafrikanischen Publikum zum Star werden ließ. Unterstellt man z.B. überwiegend männliche Kinobesucher wird auch deutlich, welchen Einfluss die erotische Komponente als Erfolgsfaktor auf die Festigung der Filmstarpersönlichkeit gehabt haben dürfte. Die Personalisierung Brigitte Helms als Vamp steht allerdings im Widerspruch zu der bei Emil Jannings konstatierten Änderung des Publikumsgeschmacks zum Ende der 1920er Jahre. Daraus könnte man schließen, dass die Attraktivität des Vampmotivs an sich noch nicht völlig erschöpft war, sondern lediglich neue Gesichter für die entsprechenden Rollen gewünscht wurden. Da in den Rezeptionsanalysen ausführlich auf die darstellerischen Qualitäten von Brigitte Helm eingegangen wird, sollen die kurzen Bemerkungen zu ihrer Starqualität an dieser Stelle genügen. 


\subsection{Rezeptionsdokumente zu Genre 2-Filmen: Liebes- und Sit- tenfilme}

Für die vier „Ml>10-Filme“ konnten insgesamt 101 Rezeptionsdokumente gefunden werden, für alle "Ml<10-Filme" wurden 31 Belege recherchiert. Die Mehrzahl der „Ml>10-Filme“ wurde von Paimann's Filmlisten als ,Schlager' eingeschätzt, ebenso waren alle vier unter den vom Filmkurier ermittelten erfolgreichsten Filmen eines Jahrganges vertreten. Nur beim BLAUEN ENGEL handelte es sich um einen Tonfilm, das Verhältnis zwischen den Filmen der Schlesinger-Organisation und Kinemas war weitgehend ausgeglichen. Von den "Ml<10-Filmen“ erreichte nur einer die PFL-Bestnote, die schlechteste Einschätzung aller „S-Filme“ erhielt JUGENDRAUSCH mit der Gesamtqualifikation 6: ,passabler Mittelfilm'. Auch bei den Genre 2-Filmen fällt auf, dass die „MI>10-Filme“ häufig wesentlich bessere PFLBewertungen erhielten als die „Ml<10-Filme“. Besonders auffällig ist, dass es sich bei den fünf Filmen mit den höchsten PFL-Gesamtqualifikationen und den höchsten MI-Werten allesamt um Produktionen des Starproduzenten Erich Pommer handelt, die zudem in vier von fünf Fällen auf der Bestenliste des Filmkuriers zu finden waren. Die Mehrzahl der Filme wurde 1929 gezeigt, für den Zeitraum vor 1929 bzw. nach 1931 konnten keine Genre 2-Filme ermittelt werden.

Tab. 32: Genre 2-Filme: Liebes- und Sittenfilme 1928-1931

\begin{tabular}{|c|c|c|l|c|}
\hline MI & PFL & FK & \multicolumn{1}{|c|}{ Filmtitel } & Erstbeleg SA \\
\hline & & & "Ml>10-Filme" & \\
\hline 48 & 1 & 10 & Der blaue Engel (T)(K)* & 16.01 .1931 CT \\
\hline 19 & 2 & 6 & Die wunderbare Lüge der Nina Petrowna (A)* & 02.10 .1929 CT \\
\hline 18 & 1 & 7 & Heimkehr (K)* & 08.02 .1929 NA \\
\hline 16 & 1 & 9 & Asphalt (K)* & 16.10 .1929 CT \\
\hline & & & "Ml<10-Filme" & \\
\hline 9 & 1 & - & Manon Lescaut (A)* & 08.06 .1929 CT \\
\hline 8 & 6 & - & Jugendrausch (A) & 26.02 .1929 DB \\
\hline 6 & 4 & - & Die Leibeigenen (K) & 26.05 .1929 ST \\
\hline 4 & 4 & - & Angst-Die schwache Stunde einer Frau (K) & 04.02 .1929 RDM \\
\hline 3 & 4 & - & Eifersucht (A) & 19.03 .1928 CT \\
\hline 2 & 2 & - & Alraune (A) & 04.09 .1929 NW \\
\hline 1 & 2 & - & Der geheime Kurier (K) & 19.11 .1929 DB \\
\hline 1 & 5 & - & Skandal in Baden-Baden (K) & 22.03 .1930 CT \\
\hline 135 & & $\Sigma$ & 12 Filme & \\
\hline
\end{tabular}




\subsubsection{Auswahlanalyse von DER BLAUE ENGEL}

Wie bereits erwähnt, ließ sich zu DER BLAUE ENGEL die höchste Anzahl an Rezeptionsdokumenten recherchieren ( $\mathrm{Ml}$ 48), auch die anderen zur Systematisierung verwendeten Parameter lassen den Schluss zu, dass es sich um einen außergewöhnlich populären Film gehandelt hat. Aus diesen Gründen ist der Film für eine Produktanalyse geradezu prädestiniert, da es mittels der Vielzahl an Rezeptionsdokumenten am ehesten gelingen dürfte, die in der Produktanalyse zu identifizierenden Wirkungsfaktoren entsprechend zu kontextualisieren und das zeitgenössische Rezeptionsspektrum (,Lesarten') zu umreissen. Im Vorgriff auf die avisierten Detailanalysen muss jedoch bemerkt werden, dass trotz der Vielzahl von Belegdokumenten eine Nachzeichnung der Medienrezeption des Films in Südafrika durch zeitgenössischkontextuelle Einflüsse außerordentlich erschwert wird.

Bei diesen Einflüssen handelt es sich zum einen um die zeitgleich stattgefundene Debatte über die erstmalige Einführung einer zentralen Gesetzgebung zur Filmzensur (1930-31) und zum anderen um die massive, meist agenturgesteuerte Berichterstattung $z u$ den mitwirkenden Filmstars Emil Jannings und Marlene Dietrich. Letztere erlangte zwar erst durch ihre Rolle in DER BLAUE ENGEL den Status eines Filmstars, allerdings sorgte der zeitliche Abstand zwischen der Uraufführung in Deutschland und dem Eintreffen in Südafrika dafür, dass die Reklameabteilungen der Filmvertriebe das neu entstandene Image unverzüglich für den südafrikanischen Markt nutzten.

Um dieser Problematik Rechnung zu tragen, sei auf die Abschnitte zur Zensurgesetzgebung bzw. zum Starphänomen verwiesen. Obwohl die Rezeptionsgeschichte von DER BLAUE ENGEL fast untrennbar mit diesen beiden Themenfeldern verbunden ist, soll in der angestrebten Auswahlanalyse versucht werden, die unvermeidlichen Redundanzen auf das notwendige Maß zu reduzieren und sowohl die tatsächlich vorgebrachten Kritikpunkte der Zensur, als auch die feststellbaren Andeutungen der Medienrezeption am Film zu belegen. Das Aufführungsverbot in Kapstadt hat jedoch dazu geführt, dass die sonst so meinungsfreudige afrikaanse Presse daselbst fast nichts über den Film berichten konnte. Dadurch wird die vergleichende Beschreibung des spezifischen Rezeptionshintergrundes der afrikaansen Zuschauer (die es in den nicht von der Zensur betroffenen Provinzen ja auch gab) bedauerlicherweise erschwert, was sich komplizierend auf die Rekonstruktion der Zuschauergeschichte auswirkt. 
Auf die teilweise kontroverse Rezeptionsgeschichte der Literaturvorlage muss an dieser Stelle nicht eingegangen werden, da sie für die Filmrezeption in Südafrika unerheblich war. ${ }^{132}$ Die Romanvorlage, Heinrich Manns „Professor Unrat oder der Tod eines Tyrannen“ (1905), war in Südafrika kaum bekannt, in der englischen Tonfassung ergaben sich zudem keine wortspielerischen Anknüpfungspunkte zwischen dem Romantitel und der Hauptfigur im Film (Prof. Rath). Folgerichtig taucht die Bezeichnung „Unrath“ weder akustisch noch visuell im Film auf.

Für die konsequent internationale Ausrichtung dieses zweisprachig (deutsch/englisch) produzierten Filmes ist von Bedeutung, dass die UFA ein fast durchgängig hollywooderfahrenes Kollektiv für diesen finanziell kostspieligen Film verpflichtete, um dessen Erfolg zu garantieren: als Produzent fungierte der in Deutschland und den USA bekannte Erich Pommer, die Regie übernahm der von der Paramount ,ausgeliehene' Joseph von Sternberg, der bereits in den USA erfolgreich mit dem als sehr schwierig anleitbar geltenden Emil Jannings zusammengearbeitet hatte (Prawer 2002: 19ff.). Auch der übrige Stab bestand aus den besten Filmleuten, welche die UFA aufbieten konnte (Zucker 1930: 118). ${ }^{133}$

$\mathrm{Da}$ in Südafrika eine englische Sprachversion des Films gezeigt wurde, wäre zunächst zu klären, um welche Fassung es sich gehandelt hat. Abgesehen von einer durch die diverse Zensurmaßnahmen möglichen Vielzahl von Versionen existiert neben der deutschen Fassung eine englische Fassung der Paramount, sowie eine weitere Variante mit englisch-deutschem Dialog im Besitz des British Film Institute (Prawer 2002: 73f.). Die mit deutschem bzw. deutsch-englischem Dialog parallel abgedrehten Versionen unterscheiden sich nur geringfügig voneinander, ebenso die britische von der ParamountFassung (ebd.). Da aus den Rezeptionsbelegen nicht rekonstruierbar ist, welche Fassung tatsächlich in Südafrika gezeigt wurde, soll für die Analyse die rekonstruierte englische Fassung mit herangezogen werden, die 2001 im Rahmen der UFA-Klassiker Edition veröffentlicht wurde. ${ }^{134}$ Die 1930 zwei mal zensierte deutsche Version (Jugendverbot) gilt in Übereinstimmung mit Regisseur Sternberg als die beste Version und auch international als belieb-

\footnotetext{
132 Vgl. dazu Holba 1979: 30ff, Brennike/Hembus 1980: 16-18 und Glöckner/Lange 1998.

133 Z.B. Kamera: Günther Rittau, Ton: Fritz Thierry, Bauten: Otto Hunte, Drehbuch: Robert Liebmann Musik: Friedrich Holländer, Szenario: Heinrich Mann, Carl Zuckmayer, Karl Vollmöller etc. Vgl. UFA Reklame-Ratschlag zu DER BLAUE ENGEL, Berlin 1929: 9ff.

${ }^{134}$ DER BLAUE ENGEL. UFA-Klassiker Edition DVD, München 2001.
} 
tere (ebd.). Die englische Fassung ist ob des starken Akzents der deutschen Darsteller zuweilen nur schwer verständlich. ${ }^{135}$

Wie von Baxter (2001: 65f.) und Prawer (2002: 73f.) dargelegt und anhand des als DVD-Bonusmaterial beigefügten Vergleichs der Schulszene in der deutschen bzw. englischen Fassung ( E 26ff.) exemplarisch nachvollziehbar, differieren die Versionen kaum voneinander, die filmische Botschaft wird durch das gleiche visuelle Material transportiert. Lediglich einige marginal abgeänderte Schnittfolgen und Änderungen der Einstellungsdauer sind zu vermerken. ${ }^{136}$ Was die visuelle Erzählstrategie der englischen Fassung angeht, ist nicht davon auszugehen, dass durch die genannten Abweichungen in die Struktur der rezeptionsleitenden Signale eingegriffen wurde, so dass keine argumentativen Verzerrungen entstehen, wenn die deutsche Version, einschließlich der daran gebundenen Sekundärliteratur, zur Analyse mit herangezogen wird. Die maßgeblichen Abweichungen betreffen in erster Linie die Tongestaltung der englischen Version. Aufgrund der verkürzten Dialoge und der in Übersetzung dargebotenen Chansons könnte eine von der Originalfassung abweichende Interpretationslenkung entstanden sein.

Der Film beschränkt sich auf die Darstellung des sittenstrengen, unverheirateten Gymnasialprofessors Immanuel Rath (Emil Jannings), der durch die nächtlichen Besuche seiner Schüler bei einer Varietédarbietung deren Moral bedroht sieht. Zur Bekämpfung dieses Übels sucht er das zwielichtige Hafenlokal "Blauer Engel“ auf, um sich ein Bild des frivolen Treibens zu machen und seine Schüler zu disziplinieren. Von der sexuellen Übermacht der Sängerin Lola-Lola (Marlene Dietrich) überwältigt, findet er sich zuerst unverhofft in ihrem Ankleidezimmer wieder, um nach dem nächsten Besuch festzustellen, dass er die Nacht in ihrem Bett verbracht hat. Diese Umstände kommen auch dem Direktor des Gymnasiums zu Ohren, der nach Raths bekundeter Heiratsabsicht aus Sorge um seine Schüler den Professor aus dem Schuldienst entlässt. Als Ehemann folgt er von nun an Lola-Lola als Teil der Varietétruppe und tritt später selbst als Clown auf. Nach einer demütigenden Vorstellung in seinem ehemaligen Wirkungsort erwischt Rath seine Frau mit dem neuen Liebhaber Mazeppa (Hans Albers), woraufhin Rath versucht, Lola zu erwürgen. Das Vorhaben scheitert jedoch, er wird überwältigt und in eine Zwangsjacke gesteckt. Wieder befreit, flüchtet er vom Ort seiner Demüti-

\footnotetext{
${ }^{135} \mathrm{Vgl}$. Beilage zur DVD.

${ }^{136}$ Etwas irritierend wirkt lediglich die Einstellungsfolge im Zusammenhang mit Raths Entlassung aus dem Schuldienst (E 325 bis 329). In der englischen Fassung fehlt die Dialogszene, in der Rath dem Direktor empört seine Heiratspläne mitteilt. Für den englischsprachigen Zuschauer kommt daher der Satz des Direktors „I'm sorry my friend, but you've left me no choice. I must request your resignation." etwas unvermittelt. Siehe auch Krützen 1996: 138-142.
} 
gung, irrt durch der Stadt und sucht seine alte Schule auf. Dort verschafft er sich Zutritt und bricht in jenem Klassenzimmer, in dem er einst unterrichtete, tot auf einem Katheder zusammen. ${ }^{137}$

Als erste Eindrücke nach der Filmsichtung bleiben besonders die polarisierende Darstellung der Hauptakteure Prof. Rath und Lola-Lola, der häufige Musikeinsatz sowie das deprimierende Schicksal des Professors in Erinnerung. Dabei scheint die Schematisierung auch auf den Gegensatz männlich/weiblich und alt/jung übertragen worden zu sein. Ähnliches kann auch über die akustische (Ruhe/Lärm) und die Lichtgestaltung (weich, hell/hart, zwielichtig) geäußert werden. Bei der Darstellung der weiblichen Hauptperson fallen deren offensichtliche erotische Aufladung sowohl durch die Kleidung, die dargebrachten Liedtexte und Posen auf. Die unausgesprochene Charakterisierung von Lola-Lola als einer Prostituierten tut ihr Übriges. Ergänzend zu den polarisierten Hauptcharakteren verstärken die entsprechend zugeordneten Raumkonzepte den Eindruck des Gegensätzlichen (Ordnung vs. Unordnung). Neben Rath und Lola-Lola ist Varietédirektor Kiepert (Kurt Gerron) die einzige handelnde Person im engeren Sinne. Die anderen männlichen (z.B. Schüler Angst, der Wirt oder Mazeppa), wie auch die weiblichen Nebenfiguren (z.B. Guste oder Raths Wirtschafterin), wirken als seien sie lediglich eine Rahmung der beiden Erstgenannten. Ganz allgemein schildert die Handlung den totalen Niedergang einer ehemaligen Autoritätsperson, die scheinbar selbstverschuldet ins Unglück rennt, da sie ihr Wohl und Wehe an die Launenhaftigkeit einer Frau und eine gesellschaftlich unerwünschte Beziehung bindet. Eine irritierende Nebenrolle nimmt ein stummer und namenloser Clown ein, dessen Auftreten zwar willkürlich, aber dennoch einer subtilen Dramaturgie folgend, erscheint.

Gerade vor dem Hintergrund des BLAUEN ENGELS als Teil der Programmgeschichte des südafrikanischen Kinos müssten dem Publikum die Parallelen zu den bereits vor 1931 gezeigten Hollywoodfilmen mit Emil Jannings aufgefallen sein. In "The Way of All Flesh“, „The Patriot" und „The Last Command" ereilt Jannings als Hauptfigur ein ähnlich tragisches Schicksal. In der letztgenannten Produktion spielte er zudem unter der Regie Joseph von Sternbergs die Rolle einer Autoritätsperson, die vom Schicksal erniedrigt in den Tod getrieben wird. Als verbindendes Element kann die Thematik von Pflichterfüllung und -verletzung angesehen werden, die auch im BLAUEN ENGEL dargestellt wird.

${ }^{137}$ Vgl. UFA-Reklame-Ratschlag zu DER BLAUE ENGEL, Berlin 1929: 3-5. 
Durch die zeitliche Distanz der Aufführung von Jannings Hollywoodfilmen (1928/29/30) und dem BLAUEN ENGEL (1931) fällt es schwer, von einer programmgeschichtlichen Konstanz zu sprechen, zumal die letztgenannte Produktion als Ton- bzw. Gesangsfilm im Rahmen eines gänzlich anderen Konkurrenzangebotes wahrgenommen wurde. ${ }^{138}$ Die Kontinuität des Hauptdarstellers Jannings und seine damit gewachsene Popularität sprechen hingegen für einen durch das Publikum deutlich wahrnehmbaren Programmbestandteil (,Jannings-Film'). Die an sich wünschenswerte programmhistorische Einbettung wird leider durch den Umstand erschwert, dass die vollständige Programmerfassung durch die geringe Anzahl deutscher Filme im Jahre 1931 (fünf) nur für den Zeitraum 1928 bis 1930 vorliegt. Zieht man die lückenhafte Aufstellung der Erfolgsfilme des Jahre 1931 durch Thelma Gutsche (1972: 230) ersatzweise heran wird deutlich, dass mit Filmen wie "The Love Parade" (Lubitsch, 1930), LIEBESWALZER oder "Broadway Melody“ (Beaumont, 1929) Gesangsfilme bzw. Musicals besonders populär waren. In diesem Kontext könnte der Import des BLAUEN ENGELS von Seiten des südafrikanischen Vertriebs erwogen worden sein, da die Beliebtheit von Musikfilmen 1931 gute Zuschauerzahlen versprach und ein bekannter Filmstar wie Jannings für zusätzliche Attraktivität sorgte.

Durch den von der Romanvorlage unbeeinflussten Rezeptionskontext in Südafrika kann die Frage angeschlossen werden, ob die dargestellte Trägödie als individuelles Einzelschicksal oder als gesellschaftlich bedingt aufgefasst wurde. Desweiteren muss vor dem Hintergrund der Zensurproblematik gefragt werden, welchen Eindruck die erotischen Darstellungen beim Publikum hinterlassen haben. Die Thematisierung des männlichen Autoritätsverlustes, herbeigeführt durch eine Frau jenseits der bürgerlichen Ordnung, dürfte im patriarchal-religiösen Kontext der südafrikanischen Gesellschaft zu anderen Bewertungen geführt haben als in Deutschland. Im Rückgriff auf die bereits erwähnte Zensurdiskussion soll rekonstruiert werden, vor welchen Gefahren man den Rezipienten durch die Zensurmaßnahmen schützen wollte und welche zeithistorischen Umstände (Bezugsrealität) diesen Bemühungen zugrundelagen. Der geistig-kulturelle Gegensatz zwischen dem englischsprachigen und dem afrikaansen Teil der südafrikanischen Bevölkerung soll dabei im Sinne der Wirksamkeit des filmischen Problems und dessen Bedeutung für die Lebenswirklichkeit des Publikums besonders berücksichtigt werden

\footnotetext{
138 Z.B. in Zusammenhang mit „The Jazz Singer” (Crossland, 1927), „The Singing Fool“ (Bacon, 1928), „Rio Rita“ (Reed, 1929) oder „King of Jazz“ (Anderson, 1930). Siehe dazu auch Anhang I.
} 
(Korte 1998: 43). Um dies anhand des Films überprüfen zu können, erfolgt zunächst eine ausführliche formal-inhaltliche Bestandsaufnahme.

Die vorliegende restaurierte DVD-Fassung vermerkt eine Untergliederung des Films in 21 Kapitel, die auch auf die englische Fassung übertragen wurde. Letztere wird dem tabellarischen Sequenzprotokoll zur Seite gestellt. Die Dialoge der englischen entsprechen als Übersetzung weitgehend der deutschen Fassung. Dabei wurden nur die Hauptdialoge übersetzt, die meisten Nebendialoge sind entweder auf Deutsch wiedergegeben oder wurden eingespart. Zur weiteren Argumentation am Film soll hier zunächst ein tabellarisches Sequenzprotokoll die Orientierung erleichtern, desweiteren sei auf das Filmprotokoll (Schmidt 1965: 47-60 und Glöckner/Lange 1998: 21-29) bzw. das Filmtranskript (Schramme 1985) verwiesen. ${ }^{139}$

Tab. 33: Tabellarisches Sequenzprotokoll zu DER BLAUE ENGEL ${ }^{140}$

\begin{tabular}{|c|c|c|c|c|c|}
\hline Zeit & Sequenz/Handlung & Dr. & Nr. & Zeit & DVD: English Chapters \\
\hline \multirow[t]{2}{*}{0.00} & 1. Schwarzfilm, Titelvorspann & & 1 & 0.00 & Opening Titles \\
\hline & 2. Darstellung des Schulmorgens & I. & 2 & \multirow[t]{2}{*}{1.58} & \multirow[t]{2}{*}{ Prof. Dr. Rath } \\
\hline 3.24 & 2.1. Tagesbeginn von Prof. Rath & & & & \\
\hline 5.56 & 2.2 Schulklasse vor Raths Eintreffen & & 3 & \multirow[t]{2}{*}{7.36} & \multirow[t]{2}{*}{ "To be or not to be" } \\
\hline 8.09 & $\begin{array}{l}\text { 2.3 Rath trifft ein, straft Schüler, zieht Lola- } \\
\text { Karte ein }\end{array}$ & & & & \\
\hline \multirow[t]{2}{*}{14.51} & 2.4 Klassenprimus erklärt Lola-Postkarte & & 4 & 13.49 & The Postcard \\
\hline & 3. Begegnung mit Lola im "Blauen Engel" & II. & 5 & \multirow[t]{2}{*}{16.57} & \multirow[t]{2}{*}{ The Blue Angel } \\
\hline 20.37 & 3.1 Rath triff im „Blauen Engel“ ein & & & & \\
\hline 27.16 & 3.2 Rath trifft Lola \& Direktor in der Maske & & 6 & 21.58 & Lola Lola \\
\hline \multirow[t]{2}{*}{29.31} & 3.3 Schüler üben Rache an Klassenprimus & & 7 & \multirow[t]{2}{*}{28.37} & \multirow[t]{2}{*}{ The Next Day } \\
\hline & 4. Konfrontation Rath vs. Schüler & & & & \\
\hline 33.16 & 4.1 Schule am folgenden Tag & & 8 & 33.28 & "I knew you'd come back“ \\
\hline 36.36 & $\begin{array}{l}4.2 \text { Rath besucht Lola/Schüler verstecken } \\
\text { sich }\end{array}$ & & 9 & 39.24 & The Dispute \\
\hline 42.11 & $\begin{array}{l}\text { 4.3 Rath schützt Lola, Polizei greift ein, Rath } \\
\text { entdeckt Schüler }\end{array}$ & & 10 & 44.19 & A Little Shot \\
\hline 49.21 & $\begin{array}{l}\text { 4.4 Rath wird betrunken gemacht, Ehren- } \\
\text { gast bei Lola-Auftritt }\end{array}$ & & 11 & 48.44 & Falling in Love again \\
\hline 54.59 & $\begin{array}{l}\text { 4.5 Rath erwacht in Lolas Bett, gemeinsa- } \\
\text { mes Frühstück }\end{array}$ & & 12 & 52.21 & A Sweet Breakfast \\
\hline
\end{tabular}

\footnotetext{
139 Die Nebeneinanderstellung des tabellarischen Sequenzprotokolls der deutschen Fassung, der Kapiteleinteilung der englischen Version sowie die Einarbeitung der Dramenstruktur (Dr.) geht leider zu Lasten der chronologisch-maßstäblichen Übersichtlichkeit dieses Hilfsmittels. Zur besseren Vergleichbarkeit der beiden Versionen scheint diese Einschränkung jedoch vertretbar.

140 Vgl. Schmidt 1965: 47ff., Schramme 1985 (Filmtranskript), Widera 1999: 97f., Beiheft zur DVD DER BLAUE ENGEL der UFA-Klassiker Edition 2001 bzw. Kloppenburg/Panchyrz/Ruprecht 2005: 6 (Seminararbeit "Krisen des Bürgertums“, Seminar "Träume und Alpträume der Moderne“ im Sommersemster 2005, Universität Göttingen).
} 


\begin{tabular}{|c|c|c|c|c|c|}
\hline Zeit & Sequenz/Handlung & Dr. & Nr. & Zeit & DVD: English Chapters \\
\hline 59.59 & $\begin{array}{l}\text { 4.6 Unterricht bei Rath, verhöhnende } \\
\text { Tafelbilder, unruhige Schüler }\end{array}$ & & 13 & \multirow[t]{3}{*}{56.17} & \multirow[t]{3}{*}{ Resignation } \\
\hline \multirow[t]{2}{*}{60.51} & 4.7 Raths Entlassung durch den Direktor & & & & \\
\hline & 5. Hochzeit & III. & & & \\
\hline 65.45 & 5.1 Heiratsantrag Raths an Lola & & 14 & 61.48 & The Proposal \\
\hline 67.20 & 5.2 Hochzeitsfeier & & 15 & \multirow[t]{2}{*}{64.33} & \multirow[t]{2}{*}{ Festivities } \\
\hline \multirow[t]{2}{*}{69.38} & 5.3 Hochzeitsnacht & & & & \\
\hline & 6. Niedergang & IV. & & & \\
\hline \multirow[t]{2}{*}{72.08} & \multirow{2}{*}{$\begin{array}{l}\text { 6.1 Rath hilft beim Varieté aus, verkauft } \\
\text { Lola-Postkarten }\end{array}$} & & 16 & 68.37 & "I can't stand it" \\
\hline & & & 17 & 73.56 & A Big Attraction \\
\hline 78.39 & 6.2 Varieté an Raths altem Wirkungsort & & 18 & \multirow[t]{2}{*}{76.56} & \multirow[t]{2}{*}{ Sold out } \\
\hline 78.55 & 6.3 Mazeppa, neuer Verehrer von Lola & & & & \\
\hline \multirow[t]{2}{*}{83.11} & 6.4 Varietéprogramm, Rath als Clown & & 19 & \multirow[t]{2}{*}{82.15} & \multirow[t]{2}{*}{ Before the Show } \\
\hline & 7. Katastrophe & V. & & & \\
\hline 92.57 & 7.1 Mazeppa küsst Lola & & 20 & \multirow[t]{2}{*}{86.44} & \multirow{2}{*}{$\begin{array}{l}\text { The Sorcerer's Appren- } \\
\text { tice }\end{array}$} \\
\hline 93.56 & $\begin{array}{l}\text { 7.2 Rath versucht Lola zu erwürgen, wird } \\
\text { von Mazeppa überwältigt }\end{array}$ & & & & \\
\hline 95.14 & 7.3 Rath überwältig in Zwangsjacke & & 21 & \multirow[t]{3}{*}{93.05} & \multirow[t]{3}{*}{ The End (Final) } \\
\hline 97.45 & 7.4 Lolas Auftritt, Rath schleicht davon & & & & \\
\hline 100.11 & $\begin{array}{l}\text { 7.5 Rath dringt in alte Schule ein, bricht tot } \\
\text { auf Katheder zusammen }\end{array}$ & & & & \\
\hline 102.02 & Schluss & & & 100.12 & End \\
\hline
\end{tabular}

Unter Zuhilfenahme einiger Standardinstrumente der systematischen Filmanalyse soll anhand des BLAUEN ENGELS eine exemplarische Produktanalyse erfolgen, in welcher der formale Aufbau des Films und die filminhärenten rezeptionsleitenden Signale zur Ermittlung der filmisch dominanten Rezeptionsangebote deutlich werden (Korte 1998: 43).

Als ein hilfreicher Ausgangspunkt für eine formal-inhaltliche Bestandsaufnahme hat sich die Untersuchung der Einstellungsgrößen erwiesen. Einstellungsgrößen bestimmen sich entweder nach dem realen Abstand der Kamera zum Aufnahmeobjekt oder durch die Wahl des Objektivs. Der Objektdistanz werden neben den Konsequenzen für die Verständlichkeit der Handlung vor allem atmosphärische und emotionale Qualitäten zugeschrieben, die z.B. durch Nähe oder Abstand zu den Akteuren den Einfühlungsprozess steuern können (Korte 2001: 25). Die gewählte Einstellungsgröße ist auch deshalb zur Beeinflussung von Aufmerksamkeit und Identifikationsbereitschaft des Publikums von zentraler Bedeutung (ebd.), weil der Betrachter wahrnehmungspsychologisch von den Entfernungsverhältnissen und den Perspektiven im Sehen, Verhalten und Deuten des Geschauten mitbestimmt ist (Beicken 2004: 35). In der Produktions- bzw. der Analysepraxis hat sich dazu eine 
gestufte Skala herausgebildet, welche die generischen Einstellungsgrößen in Weit (W), Total ( $T$ ), Halbtotal ( $H T)$, Halbnah (HN), Amerikanisch (A), Nah (N), Groß (G) und Detail (D) klassifiziert (ebd.: 35f. bzw. Korte 2001: 25f.). Es wäre jedoch verfehlt anzunehmen, dass mittels der Einstellungsgrößen eine gleichsam mechanistische Interpretation von Nahaufnahmen als stets identifikationsfördernd oder der Einsatz von Totalen immer auf eine gewollte Distanz zum Dargestellten hinweisen würde (Korte 2001: 27). Zusätzlich zur Einstellungsgröße sind die Bildinhalte, Dialog und Ton von Bedeutung und machen erst im Zusammenwirken das Besondere einer Einstellung aus (Beicken 2004: 35).

Betrachtet man die Gesamtzahl der vorfindlichen Einstellungen fällt auf, dass sich mehr als die Häfte der Einstellungen (313 von 508) auf die Größen Amerikanische und Halbnah verteilen. ${ }^{141}$ Dies ist insofern überraschend, als dass man ob der erwähnt starken erotischen Komponente hätte erwarten können, dass nähere Einstellungen (Nah, Groß) häufiger verwendet werden würden, um die emotionalen Qualitäten visuell entsprechend umzusetzen. Die dominante Verwendung der Einstellungen Amerikanische und Halbnah belegen ein eher ambivalent gesteuertes Nähe/Distanz-Verhältnis, der sehr sparsame Einsatz von Groß- und Detailaufnahmen deutet auf eine stark konzentrierte Publikumslenkung durch diese besonderen filmischen Mittel hin. Daraus kann die Frage abgeleitet werden, auf welche Weise die „erotische Atmosphäre" hergestellt wird, wenn der Rückgriff auf Groß- und Detailaufnahmen weitgehend unterbleibt.

\footnotetext{
141 Als Basis der Ausführungen dienen sowohl das im Anhang von Schramme (1985) beigefügte Filmtranskript, als auch das Filmprotokoll von Schmidt (1965) zur deutschen Version des BLAUEN ENGELS. Beide Quellen wurden mittels der DVD-Version des Films aus der UFA-Klassiker Reihe (2001) abgeglichen, wonach sich keine wesentlichen Unterschiede feststellen ließen. Das benutzte Filmprotokoll von Schmidt (1965: 47ff.) ist weitgehend identisch mit dem Filmtranskript von Schramme 1985 (508 vs. 511 Einstellungen). Als veröffentlichter Quelle soll dem Schmidtschen Filmprotokoll dort der Verzug gewährt werden, wo es förderlich ist. Für bestimmte Angaben musste jedoch auf das Filmtranskript zurückgegriffen werden, da das Filmprotokoll einige Fehler enthält (z.B. den Zählfehler bei E 329). Weiters konnte eine abweichende Einstellungskategorisierung festgestellt werden, die sich in unterschied lichen Angaben für die Anzahl der Einstellungsgrößen Halbtotale und Halbnah niederschlägt. Die Grundtendenz bleibt aber in beiden Darstellungen die Gleiche. Für die Einstellungsgrößen wird sich daher an der eigenen Nachkategorisierung orientiert, welche die Angaben von Schramme im Wesentlichen bestätigt. Die Angaben zu Handlung und Dialog hingegen beziehen sich auf die Ausführungen von Schmidt (1965).
} 


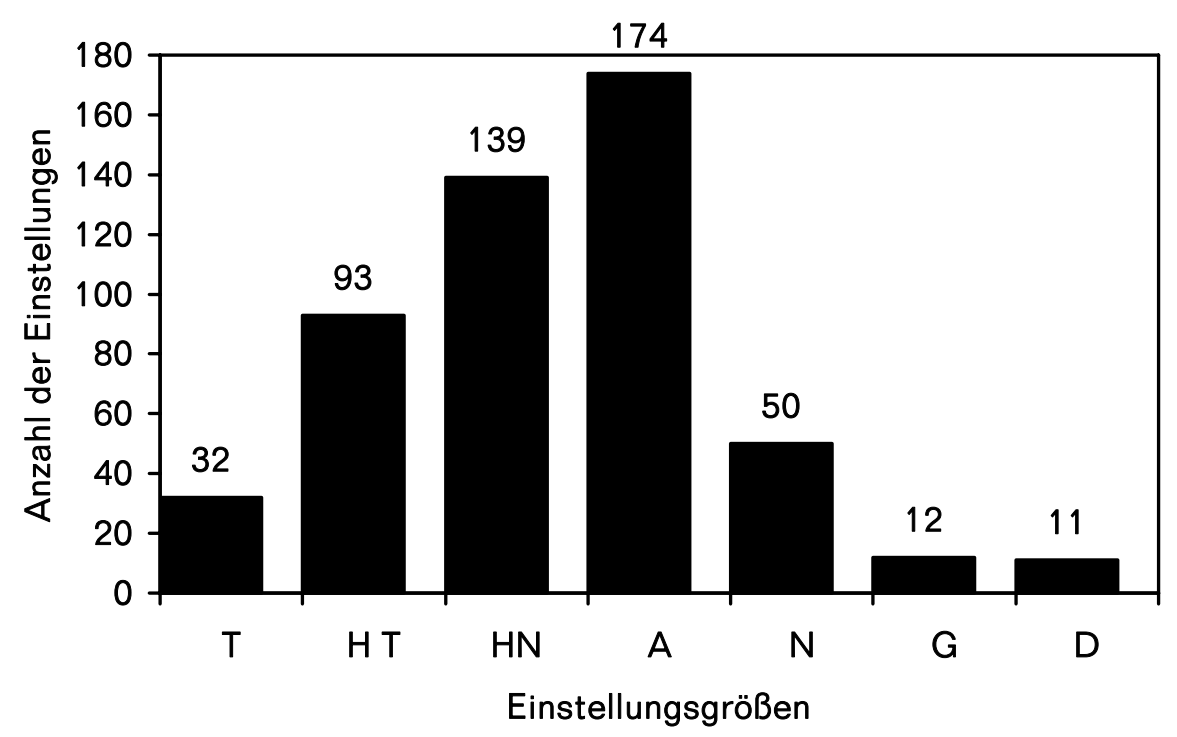

Abb. 10: Verteilung der Einstellungsgrößen in DER BLAUE ENGEL

Untersucht man die identifizierten Groß- und Detailaufnahmen kann man feststellen, dass diese nur selten die Hauptfiguren der Handlung, Prof. Rath (E 421, 476, 506) und Lola (E 82, aber als Starpostkarte) abbilden, sondern in der Regel unbelebte Gegenstände (z.B. E 10 und 308 Vogelkäfig, E 176 Zifferblatt, E 370-374 Kalender) deren handlungsleitende Funktion kontrastierend in die Sequenzen eingebaut erscheint, in einer Gesamtschau jedoch mehrheitlich eine unterschwellige Botschaft transportieren. ${ }^{142}$

Ein weiteres hilfreiches Analyseinstrument ist die Feststellung der Schnittfrequenz, welche die zeitliche Dauer der einzelnen durch Schnitte getrennten Einstellungen in Bezug auf die Gesamtdauer des Films wiedergibt.

Die filmhistorisch als „Montage“ bezeichnete und besonders eng mit der Stummfilmästhetik der 1920er Jahre assoziierte Schnittechnik ermöglicht es, einzelne Einstellungen ihrer Länge nach durch Schnitte zu verbinden, um somit einen bestimmten filmischen Rhythmus zu schaffen (Beicken 2004: 43). Als eigenständiges Gestaltungselement eingesetzt, lässt sich bspw. durch ,harte' Schnitte das präsentierte Geschehen rhythmisieren, „durch gezielte Kombination verschiedener Vorgänge und Handlungsorte spannungssteigernd zuspitzen (...), verschiedene Einstellungsgrößen oder gegensätzliche Bildinhalte zu einer gemeinsamen Aussage (...) oder Metapher vereinigen“" (Korte 2001: 28). Der sogenannte unsichtbare ,weiche' Schnitt

${ }^{142}$ So z.B. Gefangenschaft in E 10 und 308 (Vogelkäfig) sowie E 476 (Rath in Zwangsjacke). 
hingegen bietet einen unmerklichen Übergang zwischen den Einstellungen und dient dem kontinuierlichen Erzählfluss (Beicken 2004: 43). Anhand der Bevorzugung der jeweiligen Schnittechnik lässt sich nebenbei meist auch die filmhistorische Entwicklungsstufe der einzelnen Produktionen feststellen, da mit der Verbesserung der Schnittechniken erweiterte Möglichkeiten entstanden, die Übergänge zwischen den Einstellungen immer weiter zu verfeinern und für das Auge ,unsichtbar' zu machen. Die Betrachtung der zeitlichen Dauer der Einstellungen stellt dabei gewissermaßen nur eine reduzierte Analyseebene dar, da die unterschiedlichen Arten der Einstellungsverbindung hier nicht untersucht werden sollen.

Die durchschnittliche Einstellungslänge des in 508 Einstellungen unterteilten Films beträgt 11,8 Sekunden. Damit gilt die Produktion als ein eher bedächtig geschnittener Spielfilm. ${ }^{143}$ Sehr kurze Einstellungen von 1 bis 2,5 Sekunden kommen insgesamt 79 mal zum Einsatz. Diese verteilen sich auf ganz bestimmte Phasen, die Rückschlüsse auf die Dramaturgie der Filmhandlung zulassen. Überlange Einstellungen, deren Variationsbreite zwischen $\mathrm{E}$ 405 mit 64 Sekunden und E 314 mit 94 Sekunden schwankt, wurden insgesamt nur sieben mal gebraucht. Alle überlangen Einstellungen fanden erst in der zweiten Hälfte des Films Verwendung (E 282 mit 75,5 s nach 49:21 min). Die auf fünfminütige Blöcke verdichtete Schnittfrequenzgraphik hat die in der folgenden Abbildung dargestellte Struktur.

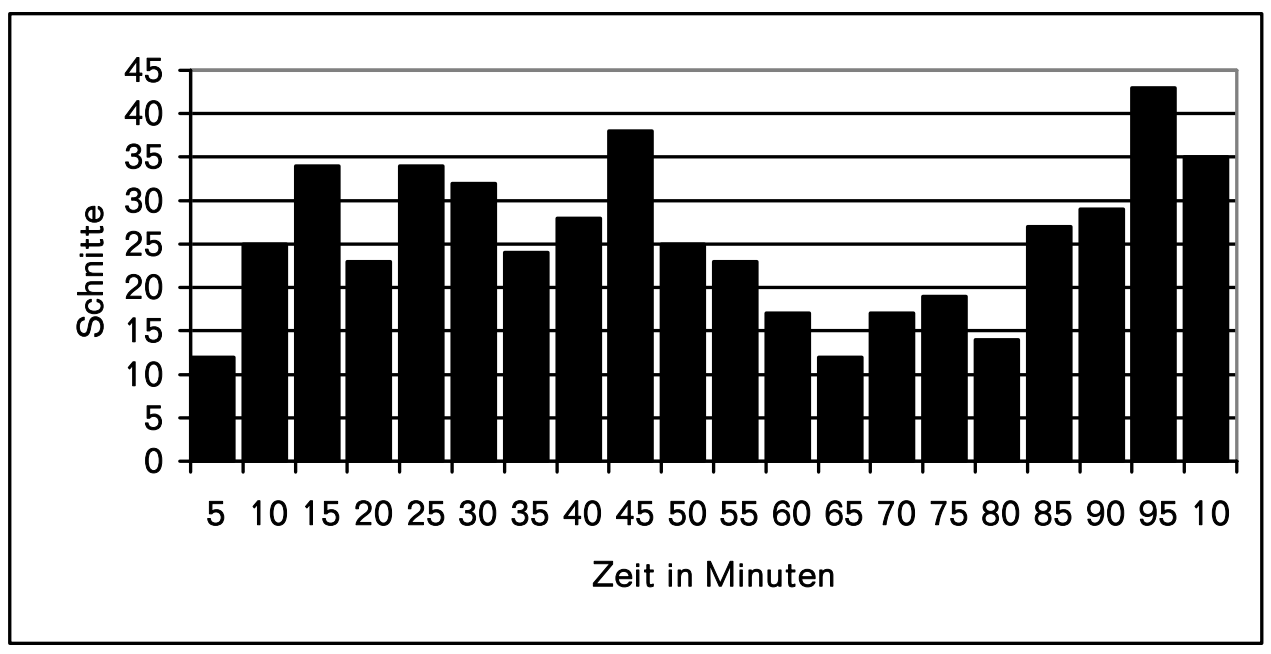

Abb. 11: Schnittfrequenzgraphik von DER BLAUE ENGEL

\footnotetext{
143 Zum Vergleich: In S.M Eisensteins Feuerwerk der Stummfilmmontage „Panzerkreuzer Potjomkin“ (1925) erfolgt durchschnittlich alle 2,8 Sekunden ein Schnitt (Korte 2001: 48).
} 
Wie im tabellarischen Sequenzprotokoll bereits angedeutet, lehnt sich DER BLAUE ENGEL trotz des stark reduzierten Handlungsstranges als Literaturverfilmung an die klassische Dramenstruktur an. Stellt man der Schnittfrequenzgraphik das Schema der Handlungstruktur gegenüber, wird klar, welches Kalkül sich hinter den variierenden Einstellungslängen verbirgt.

Tab. 34: Anlehnung des BLAUEN ENGELS an die klassische Dramenstruktur ${ }^{144}$

\begin{tabular}{|c|c|c|c|c|}
\hline \multicolumn{2}{|c|}{$20: 37$} & $5: 45$ & $2: 08$ & $93: 56$ \\
\hline I & ॥ & III & IV & V \\
\hline 1. Exposition & 2. Steigerung & 3. Krise & 4. Retardierung & 5. Katastrophe \\
\hline $\begin{array}{l}\text { Darstellung } \\
\text { des Schul- } \\
\text { morgens }\end{array}$ & $\begin{array}{l}\text { Begegnung mit Lola im „Blauen } \\
\text { Engel”; Konfrontation Rath vs. } \\
\text { Schüler; Entlassung }\end{array}$ & Hochzeit & $\begin{array}{l}4 \text { Jahre später: Rath } \\
\text { als Clown, persönli- } \\
\text { cher Niedergang }\end{array}$ & $\begin{array}{l}\text { Mordversuch an } \\
\text { Lola; Raths Tod }\end{array}$ \\
\hline
\end{tabular}

Mittels der getätigten Beobachtungen und den genutzten Standardinstrumenten der systematischen Filmanalyse wird erkennbar, dass sich die Dramaturgie des Films an den klassischen, pyramidalen Dramenaufbau aus fünf Akten anlehnt. Die Exposition (I) bilden dabei die Sequenzen 1 und 2, die steigende Handlung (II) wird durch die Schulszenen und die Bekanntschaft mit Lola formiert, wobei die erste persönliche Begegnung Raths mit Lola als erregendes Moment angesehen werden kann. Als Höhepunkt und Peripetie (III) fungieren die Hochzeit und die Degradierung des Gymnasialprofessors zum Hilfsarbeiter einer Schaustellertruppe. Der persönliche und gesellschaftliche Abstieg von Professor Rath stellt die fallende Handlung (IV) dar, als verzögerndes Moment kann Raths Clownnummer angesehen werden. Die Katastrophe (V) dieser Tragödie stellt der Mordversuch Raths an Lola dar, die allerdings weiter verzögert mit Raths eigenem Tod im Gymnasium endet.

Tendenziell lässt sich diese Struktur auch aus der Schnittfrequenzgraphik herauslesen. Die ansteigende Formalspannung im Film wird in der Regel durch eine erhöhte Schnittfrequenz deutlich. Dies geschieht auch im vorliegenden Beispiel, bei dem in der Exposition die Häufigkeit der Schnitte zum Vorantreiben der Handlung zunimmt, auf einem gewissen Niveau bleibt und sich bis zum Höhepunkt bzw. Umschwung steigert. Demnach wäre der Höhepunkt etwa die Phase die mit Einstellung 214 (39:40) beginnt, als Rath unter Lolas Tisch knieend ihre Zigaretten aufsammelt, also von Lola „um den

${ }^{144}$ Die gleiche klassische Dramenstruktur weisen übrigens auch Jannings' Hollywoodfilme „The Way of All Flesh", „Sins of the Fathers“, „The Patriot“, „The Last Command“ und „The Street of Sin“ auf. Ein direkter Vergleich von DER BLAUE ENGEL und dem vom Sujet ähnlichen „The Way of All Flesh“ konnte leider nicht durchgeführt werden, da der US-Film als historisches Dokument nicht überliefert ist. 
kleinen Finger gewickelt" wird. Zusätzlich nutzt Rath seine Autorität bzw. Männlichkeit zu Lolas Schutz, was anschließend zu einem grundsätzlichen Autoritätsverlust gegenüber seinen Schülern führt, weil er im Lokal „Blauer Engel" genau das Gleiche suchte wie seine Schüler (Erotik und Zerstreung), denen er die dortigen Besuche ursprünglich austreiben wollte (E 270, 47:21). Sehr deutlich wird die fallende Handlung mit Raths Abstieg nach der Hochzeit (ab E 358, 71.11) und seiner jämmerlichen Existenz als Bühnenclown. Die Katastrophe bahnt sich etwa ab der 90. Filmminute mit erneut gesteigerter Schnittfrequenz an, als Rath in seiner alten Heimatstadt gegen seinen Willen auftreten muss, Lola mit Mazeppa anbandeln sieht und sie aus Wut umzubringen versucht.

Die zunächst eine absolute Autorität darstellende Hauptfigur Prof. Rath wird in Subsequenz 2.3 (E 25 bis 73) in der Klassenraumszene unmissverständlich ins Bild gesetzt. Von der Perspektive Raths, also erhöht vom Katheder aus (leichter Kameraschwenk nach unten), erfolgt ein hauptsächlich im Schuss-Gegenschuss-Verfahren und in Halbnah visualisierter Schlagabtausch mit den Schülern. Zur Spannungssteigerung und damit an dieser Stelle auch zur Betonung der verbildlichten Autorität Raths sind 14 der 48 Einstellungen sehr kurz (weniger als 2,5 Sekunden) und gegeneinander geschnitten. Die ca. 7-minütige Subsequenz ist mit einer durchschnittlichen Einstellungsdauer von ca. 8 Sekunden deutlich dramatisiert. Eine ähnlich dramatisierte Einstellungsfolge mit schnellen Schnitten findet sich auch am Ende des Films in Subsequenz 6.4f. (E 454-478), in der Rath seine letzte Kraft zusammennimmt, sich den Anweisungen des Varietédirektors widersetzt und versucht, eine gewaltsame Lösung der Situation zu erwirken.

Als bewusster Gegensatz zur sich mit der Schnittfrequenz steigernden Formalspannung ist der Einsatz überlanger Einstellungen (,Plansequenzen') während der fallenden Handlung anzusehen. Hier wird die Handlung weniger durch Schnitte sondern inhaltlich (z.B. durch Dialoge) vorangetrieben, in dem für Rath schicksalhafte Szenen als eine Art Gradation des Autoritätsverlustes ausführlich geschildert werden. Mit Ausnahme von E 381, in der drei Kamerafahrten enthalten sind, bleibt die Kamera in den anderen überlangen Einstellungen in statischer Position. 
Tab. 35: Überlange Einstellungen zur Verdeutlichung des Autoritäsverlustes

\begin{tabular}{|c|c|}
\hline Einstellung, Zeit, Dauer & Handlung, Konsequenz \\
\hline $\begin{array}{l}\text { E } 282 \text { Amerikanische } \\
49: 21 ; 75,5 s\end{array}$ & $\begin{array}{l}\text { Rath nach Schwächeanfall; akzeptiert alkoholisches Getränk zur Stärkung von } \\
\text { Varietédirektor Kiepert; wird betrunken (willenlos) gemacht, erhält Logenplatz } \\
\text { zur Beobachtung von Lola; Rath ordnet sich Kieperts Autorität unter }\end{array}$ \\
\hline $\begin{array}{l}\text { E 314, Halbnah } \\
56: 59,94 s\end{array}$ & $\begin{array}{l}\text { Rath bei Lola nach gemeinsamer Nacht am Frühstückstisch; indirekte Offerte } \\
\text { von Lola, Raths Junggesellenleben zu beenden; Rath ist nicht abgeneigt; } \\
\text { Aufgabe seiner Unabhängigkeit um Lolas Gunst zu erhalten }\end{array}$ \\
\hline $\begin{array}{l}\text { E } 349 \text { Halbtotale bis } \\
\text { Amerikanische } \\
67: 20,67,5 s\end{array}$ & $\begin{array}{l}\text { Rath, Lola und Schaustellertruppe bei Raths Hochzeit; Kiepert führt an Rath } \\
\text { lächerliche Zaubertricks vor, Rath spielt mit, Selbstdegradierung Raths zum } \\
\text { Clown; sich ankündigender Ausstieg aus der bürgerlichen Gesellschaft }\end{array}$ \\
\hline $\begin{array}{l}\text { E 370, Halbtotale } \\
74.17,71 \mathrm{~s}\end{array}$ & $\begin{array}{l}\text { Rath bei Lola im Ankleidezimmer, hilft ihr die Strümpfe anzuziehen, bringt die } \\
\text { Brennscheere zum frisieren; Rath ist zum wortlosen Diener Lolas geworden }\end{array}$ \\
\hline $\begin{array}{l}\text { E 377, Nah } \\
75.59,70,5 s\end{array}$ & $\begin{array}{l}\text { Rath vor dem Schminktisch, legt sich Clownmaske an; endgültiger Abstieg der } \\
\text { ehemaligen Autoritätsperson Rath zum Bühnenclown }\end{array}$ \\
\hline $\begin{array}{l}\text { E 381, Amerikanische } \\
78: 55,68,5 \mathrm{~s}\end{array}$ & $\begin{array}{l}\text { Schaustellertruppe nach Jahren erneut im „Blauen Engel“, Kiepert als } \\
\text { skrupelloser Geschäftemacher; Eintritt von Mazeppa als Konkurrent für Rath, } \\
\text { der um Lolas Gunst buhlen wird; Ankündigung der Tragödie; Autoritätsverlust } \\
\text { führt zu Machtlosigkeit gegenüber jüngerem Konkurrenten }\end{array}$ \\
\hline $\begin{array}{l}\text { E 405, Amerikanische } \\
84: 33,64 \mathrm{~s}\end{array}$ & $\begin{array}{l}\text { Rath in der Garderobe des „Blauen Engels“; herablassende Bemerkungen } \\
\text { Lolas zu Rath; Demonstration der Überlegenheit Mazeppas („Kraftakt“ vs. } \\
\text { Clown); Ausweglosigkeit von Raths Situation, Bestätigung des vollkommenen } \\
\text { Autoritätsverlustes }\end{array}$ \\
\hline
\end{tabular}

Wie bereits deutlich wurde, zielt der gesamte Handlungslauf darauf ab, den Autoritätsverlust der Hauptperson audio-visuell so darzustellen, dass die „kausal gegliederten Vorgänge deutlich artikulieren, wie der Held eine Verbotsgrenze überschreitet und daran zugrunde geht" (Wuss 1999: 107). Der Versuch einer immanenten Bestandsaufnahme des Films sollte vor allem der Rekonstruktion der Filmrealität im BLAUEN ENGEL dienen (Korte 2001: 21), die als eine Dimension der Filmanalyse und somit als Baustein zur Erfassung der filmischen Botschaft entsprechend zu kontextualisieren ist.

Um die eingangs an den Film herangetragene Fragestellung weiter zu konkretisieren, soll im Folgenden gezielt daraufhingearbeitet werden, wie die noch herauszuarbeitende ,intendierte Wirkung' des Films beim Zuschauer hervorgerufen werden sollte. Dazu ist es zunächst notwendig, ausgewählte Kontextfaktoren (Bezugs- und Bedingungsrealität) der Filmentstehung grob zu umreissen.

Als deutsche Produktion des Jahres 1929/30 reagierte DER BLAUE ENGEL indirekt auf die schweren Krisensymptome der Weimarer Republik im Nachgang der Weltwirtschaftskrise (Winkler 2000: 484). Dabei steht Rath als gealterter Beamter stellvertretend für jenen Teil der ehemals gutsituierten bürgerlichen Bevölkerungsschicht, die durch die verordneten Gehaltskürzungen der Regierung Brüning direkt betroffen war (ebd.: 496). Durch 
Pflichterfüllung und Disziplin hatte es diese Schicht im Wilhelminischen Kaiserreich zu etwas gebracht, drohte jedoch im Strudel der Nachkriegsereignisse unter den Verhältnissen der noch nicht gefestigten Demokratie ihren sozio-ökonomischen Status zu verlieren. Im Sinne restaurativer Vorstellungen wurden die bestehenden Chancen der Weimarer Republik (z.B. politische Partizipation) verkannt und deren Fehlentwicklungen nicht in der mangelnden aktiven Identifikation mit der Demokratie gesehen, sondern als ein dem ungeliebten ,Parlamentarismus' geschuldeter Geburtsfehler. Im Sinne eines abschreckenden Beispiels wird im BLAUEN ENGEL der Niedergang des Gymnasialprofessors thematisiert um zu belegen, dass die Katastrophe hätte vermieden werden können, wenn Rath alles beim Alten gelassen und den gesellschaftlichen Konventionen gehorcht hätte. Genau diese Beharrungskräfte symbolisiert Rath als weitgehend passive Figur.

Als Gegenpol zu den Beharrungskräften ist die Figur der Lola-Lola gestaltet, die für die potentiellen Gewinner der neuen Demokratie steht, da sie aktiv das eigene Schicksal in die Hand nimmt und die neuen Freiheiten jenseits der klassischen Rollenzuweisungen zu nutzen sucht. Als wesentlich dynamischere Figur akzeptiert sie nicht die noch in der Tradition des Kaiserreichs verwurzelten Autoritäten (,Rangfolgen'), wie der respektlose Umgang mit ihrem Chef, Varietédirektor Kiepert, oder Prof. Rath, den sie kaum ernstzunehmen scheint, belegt. Andererseits verkörpert sie auch die Risiken der neuen Zeit, denn als „Frau ohne Vergangenheit" führt sie vor, welche neuen Abhängigkeiten sich durch die allgemeine sozio-ökonomische Unsicherheit ergeben können (z.B. Zuhälterei) und das gesellschaftliche Veränderungen nicht zwangsläufig in gesellschaftliche Akzeptanz münden müssen. Beide Charaktere stehen sinnbildlich für die fast schizophrene Situation zu Zeiten des beginnenden Endes der Weimarer Republik, in der sich die Kräfte der Beharrung (,der alte Rath') und der Veränderung (die junge Lola') fast unvermittelt gegenüberstanden und eine gesellschaftliche Lähmung herbeiführten, die keiner Seite von Nutzen war.

In dieser kurzen kontextualisierten Gegenüberstellung der beiden Hauptpersonen lässt sich bereits erahnen, welche intendierte Wirkung der Film (Autorintention') haben sollte und welche Variationsbreite durch die strukturierte Polysemie der Bilder im Sinne möglicher unterschiedlicher Lesarten haben konnte. Dem Film selbst ist eine deutliche Parteinahme für Rath anzumerken, was sich bereits quantitativ daran festmachen lässt, dass Rath in 
wesentlich mehr Einstellungen zu sehen ist als Lola. ${ }^{145}$ Die dominante Bedeutungsstruktur des Films zielt zum einen klar auf die Verurteilung von Raths Grenzübertretung, zum anderen auf die Ablehnung von Lolas gefühllosem Eigennutzverhalten ab. Man könnte auch von einer Mitleidsidentifikation mit Rath sprechen, da sein Schicksal als unverdient und fremdbestimmt wahrgenommen werden soll. Dies wird u.a. durch eine perspektivbildende Variation des Kamerawinkels bewerkstelligt, die vorwiegend Raths Sichtweise aufgreift. So wird beispielsweise Lola mehrfach in leichter Untersicht gezeigt, als Rath zum ersten Mal den „Blauen Engel“ betritt, m.a.W. Raths Blick von unten nach oben auf die Bühne (E 98, 101, 104, 106) rekonstruiert und als Blicklenkungsvorgabe verwendet wird (Schramme 1985: 185). Als Übernahme von Raths Blickwinkel ist ebenfalls die leichte Aufsicht auf Lola in Subsequenz 6.4f. (z.B. in E 432, 442, 449, 454, 456, 460) zu werten, die Rath während seines Bühnenauftritts mit Kiepert und Lola mit Mazeppa flirtend an der Bühnentreppe zeigen (ebd.: 185f.). Eine Identifikation mit Lola-Lola wird zwar durch ihre scheinbare Gefühlosigkeit erschwert, jedoch wird sie auch als überaus attraktiv, erotisch und begehrenswert dargestellt, was zu keinem eindeutigen Negativimage führt und durchaus auch positive Interpretationen nachsichgezogen haben könnte.

Hinter dieser zwar polarisierenden, aber dennoch ausbalancierten Figurengestaltung kann die auf einen breiten Publikumserfolg angelegte Strategie der Filmproduzenten vermutet werden, die Zuschauer aus den zwei großen gesellschaftlichen Lagern gleichermaßen anzusprechen und ins Kino zu locken. Im südafrikanischen Kontext zu Anfang der 1930er Jahre musste demnach mit einer gänzlich anderen Interpretation gerechnet werden, da die zeithistorische Situation eine andere war bzw. sich die skizzierte Lagermentalität unter den Zuschauern entlang anderer Trennlinien manifestierte.

Die dominante Botschaft des Films (im Sinne der, Autorintention') stellt demnach die affirmative Botschaft eines "Status-quo-Erhalts“ dar, der durch das Nichtüberschreiten gesellschaftliche Grenzen gewahrt und somit auch kein existenzgefährdender Autoritäsverlust eintreten würde. Wie diese Botschaft im Film transportiert wird, soll mit Hilfe einiger Beispiele verdeutlicht werden.

Dass die gewünschte Wirkung hauptsächlich durch audio-visuelle Strategien zur Darstellung des Autoritätsverlustes und dessen Folgen erreicht werden sollte, wurde bereits weiter oben festgestellt. Auf die Autorität der

\footnotetext{
145 So ist z.B. Rath in gut 20 der 50 Nahaufnahmen und in zwei Großaufnahmen (E 421 und 476) zu sehen, während Lola nur in 10 Nah- und keiner Großaufnahme zu sehen ist.
} 
Person Rath wird schon in Einstellung E 4 durch eine Detailaufnahme seines Emailletürschildes mit vollem Titel „Professor Dr. Rath“ unmissverständlich hingewiesen. In Subsequenz 2.3 (E 27-73) wird dies abermals (zudem noch in leichter Untersicht) demonstriert und Rath als herrische, stets selbstsicher auftretende Person präsentiert. Dies ändert sich in Subsequenz 3.1 (ab E 98) mit dem Auftauchen Raths im „Blauen Engel“ und der ersten Begegnung mit Lola. Durch den von Lola geführten Scheinwerfer geblendet, wirkt Rath plötzlich unsicher, schaut fast ängstlich über seine Schulter und wendet sich irritiert hin und her. Die gleiche Unsicherheit ist in der ersten direkten Konfrontation mit Lola (ab E 119) zu spüren, in der er außer Atem und mit seinem Gehstock fuchtelnd, Lola zu Rede stellen will. Diese jedoch verweigert inm trotz genanntem Titel, also der Betonung seines gesellschaftlichen Ranges, den geforderten Respekt und weist ihn unbeeindruckt an, zunächst seinen Hut abzunehmen. Damit wiederum fordert Lola von Rath den Respekt ein, den er einer Dame zu zollen hat, obwohl er ihr durch die Anrede „Fräulein" diesen Rang eben nicht einräumen wollte. Verunsichert kommt Rath dieser Aufforderung nach, bezichtigt Lola jedoch sogleich, seine Schüler zu verführen. Diesem Anwurf entgegnet sie mit einer wirschen Abfuhr (E 122), bleibt jedoch ansonsten unbeeindruckt und beginnt stattdessen, sich ungerührt von Raths Anwesenheit aus- bzw. umzukleiden (E 125 bis 133). Den Höhepunkt der Autoritätsdekonstruktion bildet Einstellung 133 (24:54), in der Lola sich die Wendeltreppe hinauf begibt und Rath in eine außerordentlich priviligierte, wenngleich nicht genutzte, Beobachterposition manövriert. Zwischen oberem Schlafzimmer und Wendeltreppe sind nur noch ihre Beine zu sehen, bis sie schließlich ihr Spitzenhöschen abstreift und mit einer spöttischen Bemerkung auf Raths Schultern fallen lässt. Von diesem Augenblick an ist Rath Lola mehr oder weniger willenlos verfallen, die von Rath unterstellten Verführungskünste an seinen Schülern hat sie an ihm selbst erfolgreich demonstriert.

In Bezug auf die weiter oben aufgeworfene Frage der visuellen Inszenierung von Erotik wird mit Blick auf die genannte Einstellungsfolge beispielhaft deutlich, warum mit einer verstärkten Verwendung der Einstellungsgrößen Halbnah und Amerikanische gearbeitet wurde (vgl. Abb. 10). Die durch Andeutungen, Posen und gezielte Aussparungen bewerkstelligte ,erotische Interpretationslenkung' entsteht im BLAUEN ENGEL oft situations- oder raumbezogen, wozu sich die Verwendung der Einstellungsgröße Halbnah besonders gut eignet (Beicken 2005: 36). Die vor allem auf der gestischen und nicht auf der mimischen Handlungsebene angesiedelten Posen usw. werden gerne mittels der Amerikanischen Einstellung verbildlicht (ebd.). 
Die geschilderte Passage kann als eine Schlüsselszene des Films angesehen werden, da sie den Beginn des Autoritäsverlustes von Prof. Rath markiert. Filmisch umgesetzt wird dies durch eine Kette schneller Einstellungsfolgen zur Steigerung der Formalspannng (vgl. Abb. 11), nach der mit einer zeitlich gedehnten Einstellung (E 133 ca. 43 s) die Bedeutung der Subsequenz für die Gesamthandlung des Films unterstrichen wird. Diese Strategie wird besonders im zweiten Teil des Films (vgl. Tab. 35) zur Verdeutlichung des fortschreitenden Autoritätsverlustes eingesetzt. Im übertragenen Sinne begibt sich Rath aus seiner von Ordnung und Disziplin dominierten Umgebung in die von Lola, die durch Unübersichtlichkeit, Lärm etc. gekennzeichnet ist. Am deutlichsten wird dies durch die polarisierend gegenübergestelten und klar abgegrenzten Raumkonzepte der Hauptfiguren:

Tab. 36: Polarisierende Raumkonzepte in DER BLAUE ENGEL

\begin{tabular}{|c|c|c|c|}
\hline \multicolumn{2}{|c|}{ Rath } & \multicolumn{2}{|c|}{ Lola } \\
\hline Raum & Charakteristik & Raum & Charakteristik \\
\hline Raths Wohnung & $\begin{array}{l}\text { ärmlich (Dachwoh- } \\
\text { nung), funktional, viele } \\
\text { Bücher, für nur eine } \\
\text { Person eingerichtet; } \\
\text { passiver Schauplatz }\end{array}$ & Lolas Garderobe & $\begin{array}{l}\text { dekoriert, diverse } \\
\text { Utensilien, Verkehr } \\
\text { unterschiedlicher } \\
\text { Personen; } \\
\text { aktiver Schauplatz }\end{array}$ \\
\hline Schule & $\begin{array}{l}\text { Ruhe, Ordnung, } \\
\text { Übersichtlichkeit, } \\
\text { Arbeit, Disziplin, } \\
\text { Strafen, Hierarchien, } \\
\text { "Reih und Glied“, } \\
\text { weiches gleichmäßiges } \\
\text { Licht }\end{array}$ & „Blauer Engel“ & $\begin{array}{l}\text { Lärm, Unordnung, } \\
\text { Durcheinander, } \\
\text { Zerstreuung, Verkehr, } \\
\text { Vergnügen, Respetlo- } \\
\text { sigkeiten, Tanz, hartes } \\
\text { Licht }\end{array}$ \\
\hline \multicolumn{2}{|c|}{ strikte Trennung von Privat- und Arbeitssphäre } & \multicolumn{2}{|c|}{ keine Trennung von Privat- und Arbeitssphähre } \\
\hline \multicolumn{2}{|c|}{ "Gesellschaftsmodell/Lebenswelt Rath“ } & \multicolumn{2}{|c|}{ "Gesellschaftsmodell/Lebenswelt Lola“ } \\
\hline
\end{tabular}

Während also Lola keine Probleme aus der fehlenden Trennung von Privatund Arbeitssphäre erwachsen, führt Raths Grenzüberschreitung in die Katastrophe, indem er nach Schulschluss in "amtlicher Eigenschaft" (E 122) seinen Schülern nachstellt und so die klare Trennung von privat und beruflich aufhebt. Die daraus resultierenden Probleme könnten demnach auch als eine versteckte Kritik an der übereifrigen Pflichterfüllung Raths verstanden werden.

Aus der Gegenüberstellung der Handlungsräume wird ersichtlich, dass die Rath zugeordnete Raumkonstellation seine statisch-passive Rolle innerhalb der Handlungsdarbietung unterstützt und schon bald keinen Schauplatz mehr darstellt. Im Gegensatz dazu ist die Lola zugeordnete Raumkonstellation dynamisch-aktiv angelegt, in ihrem Wirkungsbereich wird Rath verführt, der 
Heiratsantrag gemacht, die Hochzeitsnacht angedeutet, der Konkurrenzkampf mit Mazeppa ausgetragen, sowie der finale Autoritätsverlust erfahren. Auffällig ist dabei, dass die Raumkonzepte an ein nach Geschlecht getrennten gut/böse-Schema angelehnt scheinen, welches die intendierte Botschaft, d.h. die Mitleidsidentifikation mit Rath, unterstützt:

„In der hier belegten Polarität dieser räumlichen und figuralen Konstellationen reproduzieren sich ein ungebrochenes geschlechtspolares Denken, und die [...] dargestellten polaren ,Geschlechtscharaktere' sind hier manifest vorhanden. Die Bewertung des dem männlichen Protagonisten zugeordneten Handlungsraumes als übergordnet ist deutlich geworden. Der Handlungsbereich der weiblichen Figur ist eindeutig negativ besetzt" (Schramme 1985: 102f.)

Vergegenwärtigt man sich die weiter oben gestellte Frage, mit welchen Bildstrategien die erotische Komponente ohne den häufigen Einsatz von Nah- und Großaufnahmen umgesetzt wurde, findet man im Vergleich der beiden Raumkonzepte die entsprechende Antwort. Durch die Gegenüberstellung eines „männlichen“ und eines „weiblichen“ Raumkonzeptes wird die Aufmerksamkeit des Zuschauers auf die vergleichsweise exotische und viel dynamischere Atmosphäre von Lolas Umgebung gerichtet. Diese besondere Atmosphäre wird durch ein unruhiges, kontrastreiches, hartes Licht mit ausgeprägten Schattenwirkungen, hohem Geräuschpegel sowie der ein ,distanziertes Begehren' unterstützenden Kameraführung geschaffen, die erotische Posen und Gesten in Amerikanischer oder Naheinstellung zeigt, um dem Zuschauer einen Imaginationsraum zu eröffnen, dessen Grenzen er gedanklich selbst aufheben kann, ohne auf fragmentierende Vorgaben (in Groß- oder Detailaufnahme) angewiesen zu sein. Zusätzlich dazu werden diese Orte als ,verrucht', d.h. halblegal aber attraktiv, dargestellt und durch eine ,Verbotene Früchte'-Strategie interessant gemacht. Dazu zählt auch der an die Raumkonzepte angelehnte Einsatz der als akustische Gestaltungsmittel gebrauchten Lied- und Gesangseinlagen. Durch die frivolen Liedinhalte wird der ,Raum Lola' weiter erotisiert, während im ,Raum Rath' alte Volksweisen wie „Üb immer Treu und Redlichkeit“, „Ännchen von Tharau“ oder das Glockenspiel der Turmuhr Beständigkeit und Tradition betonen. In der englischen Version sind ausschließlich die Lieder Lolas übersetzt und konnten somit textlich auch zur Vorwegnahme des weiteren Geschehens eingesetzt werden. Die Tongestaltung von Raths Spähre hingegen konnte durch die Unbekanntheit der Melodien beim südafrikanischen Publikum kaum eine ähnliche Funktion wie im Falle Lolas einnehmen. 
Die als irritierend wahrgenomme Rolle des namen- und sprachlosen Clowns erfüllt, obwohl zur Sphäre Lolas gehörig, eine Art Warnfunktion für Rath in Bezug auf sein weiteres Schicksal. ${ }^{146} \mathrm{Er}$ nimmt gewissermaßen die Zukunft Raths im zweiten Akt (E 111 bei 21.48 und E 296 bei 52.56) vorweg und fungiert als ein Sendbote, in dem er fiktionsintern die Darstellung eines zum Zeitpunkt der Präsentation noch nicht geschehenen Ereignisses verkörpert, welches für die Haupthandlung noch von Bedeutung sein wird (Huber/Böhm 2005).

Da das Geschehen zur Identifikationslenkung fast durchgängig aus der Perspektive Raths dargestellt wird, dessen Grenzüberschreitung (,Eindringen in Lolas Lebenswelt') aber als negativ empfunden werden soll, lohnt sich ein Blick auf die dazu notwendigen Umsetzungsstrategien. Am Beispiel des Weges von Rath zum „Blauen Engel“, kontrastiert mit seiner Flucht aus dem „Blauen Engel“ in seine alte Schule, soll diese Strategie mittels einer Feinanalyse verdeutlicht werden.

Um die nötige Kontextualisierung nicht zu erschweren, wurde zunächst geprüft, ob die entsprechenden Einstellungsfolgen auch in der englischsprachigen Fassung vorhanden sind. Dies konnte bestätigt werden, die Einstellungen ohne Sprache und Musik scheinen mit denen der deutschen Fassung identisch zu sein. Zur besseren Orientierung am Film soll zur Analyse wieder auf die deutsche Fassung und das dazugehörige Einstellungsprotokoll zurückgegriffen werden (Schmidt 1965). Die ausgewählte Subsequenz „Raths Weg zum ,Blauen Engel'“ findet sich zu Beginn von Sequenz 3 und umfasst die Einstellungen E 89 (18.07) bis E 98 (20.27). Die Schlusssequenz „Raths Flucht aus dem ,Blauen Engel'“ (Subsequenz 6.7/6.8) beginnt mit Einstellung $E 490$ (97.45) und endet mit E 508 (102.14). ${ }^{147}$

Tab. 37: Zeitliche Einordnung der Auswahlsequenzen

\begin{tabular}{|c|c|c|c|c|}
\hline \begin{tabular}{|c|} 
E $89 \mathrm{ff}$. \\
$18.07-$ \\
20.27
\end{tabular} & & & & $\begin{array}{c}\text { E } 490 \mathrm{ff} . \\
97.45- \\
102.14\end{array}$ \\
\hline 0 & \multicolumn{2}{|c|}{$65: 45$} & $92: 5$ & 102 \\
\hline I & II & III & IV & V \\
\hline 1. Exposition & 2. Steigerung & 3. Krise & 4. Retardierung & 5. Katastrophe \\
\hline $\begin{array}{l}\text { Darstellung des } \\
\text { Schulmorgens }\end{array}$ & $\begin{array}{l}\text { Begegnung mit Lola im } \\
\text { "Blauen Engel”; Konfrontation } \\
\text { Rath vs. Schüler; Entlassung }\end{array}$ & Hochzeit & $\begin{array}{l}4 \text { Jahre später: Rath } \\
\text { als Clown, persönli- } \\
\text { cher Niedergang }\end{array}$ & $\begin{array}{l}\text { Mordversuch an } \\
\text { Lola; Raths Tod }\end{array}$ \\
\hline
\end{tabular}

\footnotetext{
${ }^{146}$ Der Clown ist in insgesamt 22 Einstellungen (E 111, 112, 116, 121, 122, 130, 162, 164, 198, 200, 203 , $204,205,240,242,256,263,271,277,280,284,296)$ zu sehen.

${ }^{147}$ In Anhang $\vee$ ist für beide Einstellungsfolgen ein Auszug aus dem Filmprotokoll wiedergegeben.
} 
Die Auswahlsequenz „Weg zum ,Blauen Engel'“'gehört demnach zur ansteigenden Handlung (II), welche auf die Begegnung Raths mit Lola hinarbeitet. In dieser knapp zwei Minuten langen Einstellungsfolge wird keiner der eindeutig Prof. Rath $\left(R / R^{\star}\right)$ zugeordneten Räume gezeigt, der Weg durch die Gassen zählt dennoch zu Raths Handlungsraum. Bis zu Raths Ankunft im „Blauen Engel“ markieren sechs von zehn Einstellungen Räume, die entweder Lola (L) oder ihrer Sphäre $\left(L^{*}\right)$ zugewiesenen sind (z.B. E 96, Schüler mit Blick zur Bühne). Dadurch wird Lola zwar mehr Zeit (88 s) als Rath (45 s) eingeräumt, allerdings wird Rath durch Schwenk und Kamerafahrt in E 89 in Akteursperspektive gezeigt, während die konstant statische Kamera Lola als passives Objekt darstellt. ${ }^{148}$

Tab. 38: Auswahlsequenz I „Weg zum ,Blauen Engel'“

\begin{tabular}{|c|c|c|c|c|c|c|c|c|c|c|c|}
\hline E-Nr. & 89 & 90 & 91 & 92 & 93 & 94 & 95 & 96 & 97 & 98 \\
\hline Zeit & 18.20 & 25 & 26 & 11 & 8 & 10 & 4 & 15 & 5 & 23 & 6 \\
\hline Dauer & $\mathrm{HT}$ & $\mathrm{T}$ & $\mathrm{A}$ & $\mathrm{T}$ & $\mathrm{T}$ & $\mathrm{A}$ & $\mathrm{T}$ & $\mathrm{A}$ & $\mathrm{T}$ & $\mathrm{N}$ \\
\hline Größe & $\mathrm{R}$ & $\mathrm{L}$ & $\mathrm{L}$ & $\mathrm{L}$ & $\mathrm{R}$ & $\mathrm{R}^{\star}$ & $\mathrm{L}$ & $\mathrm{L}^{*}$ & $\mathrm{~L}$ & $\mathrm{R}$ \\
\hline Raum &
\end{tabular}

Von besonderem Interesse in dieser Subsequenz ist vor allem der Standpunkt der Kamera in Bezug auf Rath. Die Lola bzw. den „Blauen Engel“ zeigenden Einstellungen geben das Ziel von Raths Weg an. In Einstellung $E$ 89 ist Rath von rechts aus einer schlecht beleuchteten Gasse kommend und von hinten zu sehen, er dreht sich suchend nach dem Weg um, die Kamera folgt ihm in die von einer Laterne beleuchtete, enge und schiefe Gasse. Vor und in der Gasse sorgt das Licht für eine starke Schattenwirkung. Rath passiert in der Gasse zwei eindeutig als Prostituierte charakterisierte Frauen, die eine stehend mit Zigarette, die andere sich aus einem Fenster lehnend und ihm nachschauend. Dazu ertönen Schifferklavier und Gesang („Es war einmal ein treuer Husar...") sowie schrilles Gelächter.

In E 93 kommt Rath wiederum von rechts aus einer dunklen Gasse mit schrägen Häusern ins Bild und geht in Richtung einer Laterne, deren Licht seinen Schatten auf die Hauswand wirft. Der Weg führt leicht bergab auf die Bildmitte zu, akustisch ist der dumpfe Ton eines Schiffsnebelhorns zu hören.

In beiden Einstellungen kommt Rath stets von rechts vorne ins Bild und geht auf die Mitte, also nach links, zu. Ein derartiger Kamerastandpunkt wird

\footnotetext{
148 Die Abweichungen zwischen der Gesamtzeit der Auswahlsequenz und der Summe der einzelnen Einstellungen geht höchstwahrscheinlich auf Anzeigetoleranzen des benutzten DVD-Geräts zurück.
} 
gewöhnlich dazu benutzt, um zu zeigen, dass eine Figur von etwas ,weg' geht. Der Weg Raths zum „Blauen Engel“ wird demnach als eine Art Wegführen dargestellt. Die dunklen Gassen, die Schatten, die Prostituierten und die Geräuschkulisse einer Hafengegend machen deutlich, in welcher zwielichtigen und schlecht beleumundeten Gegend sich der Professor aufhält und er dort - er blickt sich suchend nach dem Weg um - nicht zu Hause ist und auch nichts zu suchen hat. Verstärkt wird dieser Eindruck noch durch die folgende Einstellung (E 94), die einen in ähnlich dunkler Umgebung postierten Polizisten vor einem Lola-Lola-Plakat zeigt. Damit wird klar, dass in dieser Umgebung „Recht und Ordnung“ keine Selbstverständlichkeit sind und auf ein kriminelles Millieu geschlossen werden soll.

Zur besseren Einprägsamkeit und wohl auch zur Betonung der besonderen Funktion dieser Szene wurden zwei fast indentische Einstellungen ( $E$ 191-192) von der gleichen Kameraposition aus in die 4. Sequenz (34.39) einmontiert. Zur dramatischen Aufladung wird auf der Tonebene noch ein jaulender Kater hinzugefügt, der ebenfalls von rechts nach links durchs Bild springt. In der nachfolgenden Einstellung ist auch das Nebelhorn wieder zu hören.

Die Kombination aus der wegführenden Route in den „Blauen Engel“, den am Straßenrand stehenden Prostituierten und dem eingeschnitten Polizisten machen klar, dass Raths Ziel negativ konnotiert und er dabei ist, seine ihm angestammt Spähre zu verlassen und eine gefährliche Grenze (,Warnsignal Nebelhorn') überschreitet. Der Kamerastandpunkt liefert in dieser Subsequenz Bilder mit wertendem bzw. urteilenden Charakter (Schramme 1985: 187), da Raths Weg zum „Blauen Engel“ eindeutig negativ konnotiert ist. Die eingestreuten Szenen aus dem Hafenlokal (E 90-92 und 95-97) suggerieren das scheinbar lohnende Ziel des Weges, mögliche erotischer Abenteuer, die in den Liedern der weiblichen Interpreten auf der Bühne offen besungen werden (Guste bzw. Lola „Give me the man“). Die Liedtexte haben sogar eine die kommende Entwicklung vorwegnehmende Funktion, z.B. in dem nach der Liedzeile "Just a man who can cover me and kiss me too" in Einstellung $E$ 98 auf Raths Gesicht in Nahaufnahme vor der Glastür des „Blauen Engels“ umgeschnitten wird. Diese vorausdeutende Funktion haben im übrigen alle Lieder des Films, da sie im Text auf die künftige Handlung anspielen (Schramme 1985: 35). In der letzten Einstellung der Sequenz wird durch die Nahaufnahme nochmals die auf Rath abzielende Identifikationslenkung betont. Als Fazit der Feinanalyse kann somit festgehalten werden, dass die sich abzeichnende Grenzüberschreitung als gefährlich dargestellt wird und das 
von ihm ins Auge gefasste Ziel seines Wegs nicht mit dem ihm zugedachten Raumkonzept übereinstimmt.

Die zweite Auswahlsequenz „Raths Flucht aus dem ,Blauen Engel'“ (E 490 bis E 508) kann als Gegenstück zur ersten Auswahlsequenz angesehen werden. In 19 Einstellungen, die sich über etwa 4,5 Minuten erstrecken, wird das Hinausschleichen Raths aus dem „Blauen Engel“ und sein Weg zur Schule, an der er einst unterrichtete, gezeigt.

Tab. 39: Auswahlsequenz II „Flucht aus dem ,Blauen Engel'“

\begin{tabular}{|c|c|c|c|c|c|c|c|c|c|c|}
\hline E-Nr. & 490 & 491 & 492 & 493 & 494 & 495 & 496 & 497 & 498 & 499 \\
\hline Zeit & 97.45 & \multicolumn{6}{|c|}{99.57} \\
\hline Dauer & 6,5 & 27,5 & 5,5 & 10 & 31,5 & 7,5 & 7,5 & 1,5 & 10,5 & 12,5 \\
\hline Größe & HT & A & HN & A & T & T & A & D & A & HT \\
\hline
\end{tabular}

\begin{tabular}{|c|c|c|c|c|c|c|c|c|c|}
\hline E-Nr. & 500 & 501 & 502 & 503 & 504 & 505 & 506 & 507 & 508 \\
\hline Zeit & 100.11 & \multicolumn{7}{|c|}{102.14} \\
\hline Dauer & 8 & 10,5 & 14 & 9,5 & 9 & 17,5 & 2 & 21 & 32 \\
\hline Größe & $\mathrm{A}$ & $\mathrm{A}$ & $\mathrm{HT}$ & $\mathrm{HT}$ & $\mathrm{A}$ & $\mathrm{A}$ & $\mathrm{D}$ & $\mathrm{A}$ & HT-T \\
\hline
\end{tabular}

Auswahlsequenz II „Flucht aus dem ,Blauen Engel'“ gehört zum letzten Akt (V) innerhalb der Dramenstruktur und bildet das Ende der Katastrophe. Während in den Subsequenzen 7.1/7.2 noch eine hohe Schnittfrequenz dominiert, liegt sie in Auswahlsequenz II nur bei durchschnittlichen $14 \mathrm{Se}$ kunden. Da Lola lediglich in E 491 und E 493 gezeigt wird, konnte auf einen Vermerk des Raumbezuges verzichtet werden. Auffällig ist zunächst, dass bis auf eine Naheinstellung alle Einstellungsgrößen vertreten sind.

In E 490 sieht man Rath von links kommend an der Wand einen Flur mit starker Schattenwirkung entlangschleichen, zu hören ist „Falling in Love again“. Danach wird auf die Bühne mit Lola umgeschnitten (E 491), sie singt die Zeilen "Men close up to me, like moths around a flame, and if they are burning, I know I'm not to blame". Rath schleicht von links kommend gebückt und sich ängstlich umschauend weiter an einer Wand entlang (E 492) und vernimmt den Applaus nach dem Ende von Lolas Lied. Diese reagiert fast emotionslos auf die Gunstbezeugung (E 493). In E 494 gelangt Rath von hinten links ins Bild, er ist von vorne zu sehen und kommt aus einer schiefen engen Gasse zu einer Ecke, die von einer Laterne beleuchtet wird und starke Schatten wirft (wie E 89). Wankend und sich ängstlich umdrehend bewegt er sich in Richtung Bildmitte, vom Tuten eines Schiffsnebelhorns begleitet, wendet er sich nach rechts, die Kamera schwenkt mit ihm. Zunächst noch 
von vorne, dann von der Seite zu sehen, streift Rath taumelnd die verschneiten Häuser entlang, bis er rechts aus dem Bild verschwindet bzw. durch die Überblendung auf E 495 aufgefangen wird. In Aufsicht findet er sich vor dem Schultor wieder, auf das sein übergroßer Schatten fällt. Vom Schatten kaum zu unterscheiden, wankt er zur Türe (E 496), betätigt eine Glocke (E 497, Groß) und wartet dann vor der Pforte auf Einlass (E 498). Ein Schuldiener, von dem zunächst nur der runde Lichtkegel seiner Lampe sichtbar ist ( $E$ 498), kommt durchs Treppenhaus und öffnet Rath die Tür (E 499). Der Lichtkegel zeigt nun Rath von hinten und von links kommend eine Treppe aufsteigend (E 500). Ebenfalls von links in einem Korridor angelangt (E 501), schleppt er sich die Wand entlang, öffnet eine Türe und geht zögerlich hinein. Der Schuldiener kommt mit seiner Lampe die Treppe hinauf (E 502), leuchtet die offene Türe an (503) und tritt kurz darauf durch selbige ins Klassenzimmer. Zuerst noch im dunkeln, dann vom Lichtkegel erfasst, wird Rath schräg liegend auf seinem Katheder (E 504) gezeigt, an der linken Seite der Pultkante hält sich seine Hand fest, die der Schuldiener vergeblich zu entfernen versucht (E 505). E 506 zeigt die festgekrallte Hand im Detail, dann in E 507 wieder die hilflosen Versuche des Schuldieners, Rath vom Katheder zu lösen. In der letzten Einstellung (E 508) sieht man Rath in Halbtotale und von einem Lichtkegel umgeben, tot auf dem Katheder liegen. Die Kamera fährt zurück in die Totale und zeigt den Klassenraum fast von der selben Position aus wie nach Raths Entlassung (E 332).

Besonders interessent ist in dieser Subsequenz die Einstellungen E 494, die Rath von links zur Bildmitte kommend mit dem Gesicht zur Kamera zeigt, genau entgegengesetzt zu E 93, der Signalton des Schiffsnebelhorns ist ebenfalls zu hören, dauert aber länger und wird noch einmal wiederholt. In dieser und den folgenden Einstellungen kommt Rath stets von links hinten ins Bild und geht auf die Mitte, also nach rechts vorne, zu. Ein derartiger Kamerastandpunkt wird gewöhnlich dazu benutzt, um zu zeigen, dass eine Figur zu etwas ,hin' geht oder heimkehrt. Das Wiederaufgreifen der fast gleichen Wegmarken wie auf der Route zum „Blauen Engel“ endet nun vor Raths ehemaliger Schule. Diese Strecke steht für das Verlassen des weiblichen, von Lola dominierten, Raumkonzepts und die Heimkehr in die angestammte „männliche“ Handlungssphäre. Etwas abgeschwächt wird diese ,Heimkehrerperspektive' nach dem Eintritt in das Schulgebäude, wo Rath zwar immernoch von links kommend, aber öfter seitlich oder von hinten gezeigt wird. Die letzte ,lebende' Einstellung zeigt inn von rechts vorne in den Klassenraum eintreten, wo er dann später leicht links von der Bildmitte tot auf der Pultplatte zu sehen ist. Die letzten Einstellungen ab E 501 Schwächen die ,Heim- 
kehrperspektive' etwas ab, vielleicht um zu verdeutlichen, dass er eben doch nicht mehr wie einst dazu gehört. Die Identifikationslenkung erfolgt in Auswahlsequenz II, wie schon in Auswahlsequenz I, fast ausschließlich über den Kamerastandpunkt und nicht durch besondere Nähe oder Distanz suggerierende Einstellungsgrößen.

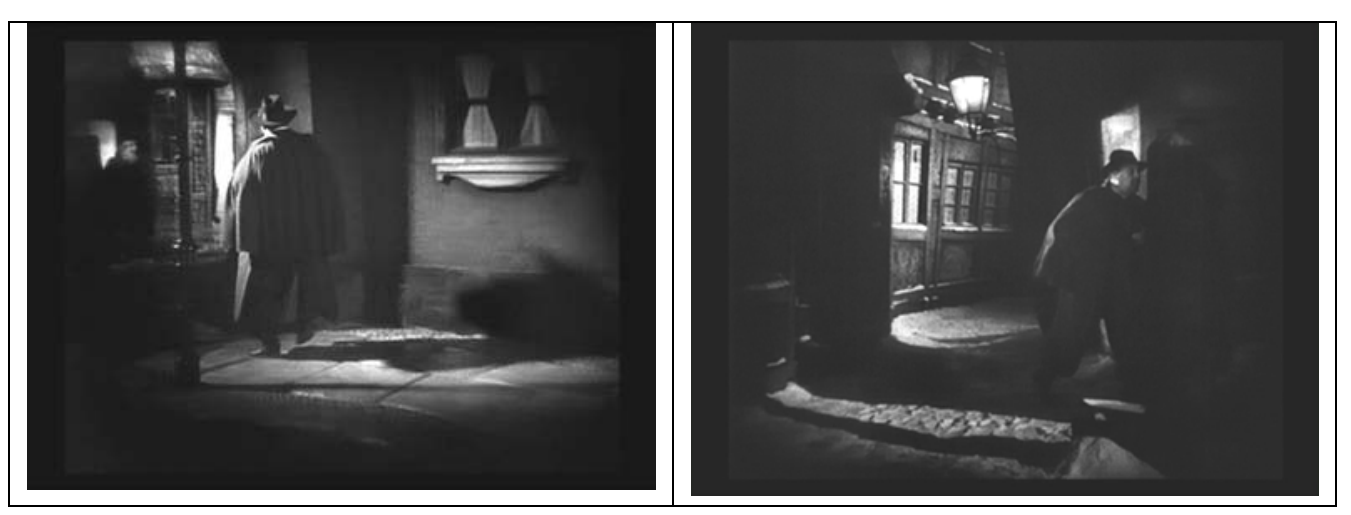

Abb. 12: E 93: „Weg zum ,Blauen Engel'“ und E 494: „Flucht aus dem ,Blauen Engel'“

Der wertende Charakter des Kamerastandpunktes wird auch in dieser Subsequenz sichtbar, wonach die Rückkehr an seinen alten Wirkungsort positiv als Heimkehr - an den Platz wo er eigentlich hingehört - konnotiert ist. Besonders deutlich wird an dieser Stelle die Bestimmung des Standpunktes der Erzählinstanz durch die Wahl des Kamerstandpunktes und die Bewegung der Figur im Verhältnis dazu (Schramme 1985: 187).

Die beiden Auswahlsequenzen stellen einen punktuellen Einblick in die verschiedenen Strategien der filmischen Umsetzung der dominanten Botschaft dar. Es dürfte jedoch schon anhand dieser beschränkten Auswahl klar geworden sein, dass die intendierte Wirkung des Films darauf abzielte, dem Publikum die Grenzübertretung Raths als nicht nachahmenswert zu vermitteln und das ein Verlassen der zugeschriebenen gesellschaftliche Spähre unkontrollierbare Gefahren birgt, die zu Rangverlust, Existenznot, Erniedrigung und Tod führen.

Ruft man sich das in Kapitel 1 beschriebene Verständnis des in den Cultural Studies entwickelten Analysekonstrukts des ,dominanten Kodes' in Erinnerung, wird nachvollziehbar, dass die intendierte Wirkung des Films mittels der exemplarisch vorgestellten Strategien genau jene ,bevorzugten Lesarten' nahelegt, denen die gewünschte institutionelle, politische und ideologische Ordnung bereits eingeschrieben ist, die durch den produzierenden Filmkonzern (die UFA) selbst schon institutionalisiert wurde (Hall 1995: 103). 
Selbst wenn dadurch produktionsseitig eine Wirkung im Sinne der ,Autorintention' gezielt hervorgerufen werden soll, heisst dies auf der Rezipientenseite noch lange nicht, dass sich nicht doch mehrere potentielle Lesarten bilden können, die wiederum erst durch die stark kontextbeeinflussten dominanten Rezeptionsangebote entstehen. Im Falle Südafrikas hieße dies nun, ausgehend von den in der Produktanalyse ermittelten Wirkungsfaktoren in den Rezeptionsdokumenten danach zu suchen, wie die intendierte Wirkung in einen ausgehandelten Kode, also dem dominantem Kode unter lokalen Bedingungen, überführt wurde (Hall 1995: 108). Die einzige Möglichkeit dies tatsächlich auch feststellen zu können, besteht in der vergleichenden Auswertung der südafrikanischen Medienrezeption des BLAUEN ENGELS. Daraus soll eine Art Rezeptionsgeschichte rekonstruiert werden, die es ermöglicht, aus den dort vertretenen Meinungen Antworten auf die weiter oben gestellten Fragen abzuleiten.

Der Umstand, dass für den BLAUEN ENGEL die meisten Pressebelege (MI 48) gefunden wurden, ist zu gleichen Teilen Chance und Bürde der nachfolgenden Auswertung. Chance, weil sich aus der Vielzahl der Texte vielleicht am ehesten so etwas wie eine Rezeptions- und Zuschauergeschichte generieren lässt. Bürde, weil hier eine Kernerarbeit zu leisten ist, da die Textdokumente in diesem Falle so vollständig wie möglich ausgewertet werden müssen, um auf diesem Umweg generelle Rückschlüsse auf das Rezeptionspotential deutscher Filme zu erhalten. Es ist ob der Materiallage bereits abzusehen, dass sich viele Fragen eher auf Basis der Belege zum BLAUEN ENGEL beantworten lassen werden, als mit Hilfe der wesentlich spärlicheren Überlieferung zur Mehrzahl der anderen Filme. Aus diesem Grund wird nachvollgend sehr ausführlich auf die südafrikanische Medienrezeption eingegangen werden müssen, auch um die übrigen Auswertungen entsprechend straffen zu können.

Zunächst muss jedoch ein weiterer Umweg eingeschlagen werden, um im Zuge der angestrebten vergleichenden Rekonstruktion der zeitgenössisch dominanten Rezeptionsangebote über eine entsprechende Grundlage zu verfügen. Dazu soll ein kurzer Auszug der Rezeption des BLAUEN ENGELS in Deutschland der Auswertung der südafrikanischen Medienrezeption vorangestellt werden. ${ }^{149}$ Die ermittelte dominante Botschaft dürfte in erster Linie auf ein deutsches Publikum abgezielt haben, dessen potentielle Lesarten bzw. die zeitgenössisch dominanten Rezeptionsangebote sich in den

149 In Ermangelung US-amerikanischer Rezeptionsdokumente beschränkt sich der Vergleich auf die südafrikanische und die deutsche Rezeption. 
deutschen Rezeptionsdokumenten am eindeutigsten belegen lassen müssten.

Selbstverständlich steht auch diese kursorische Sichtung vor dem Problem der repräsentativen Quellenauswahl, das sich aus dem Umstand einer mehr als 4000 Zeitungen umfassenden deutschen Presselandschaft speist. Da sich selbst thematisch enger gefasste Studien (z.B. Korte 1998) dieser Problematik ausgesetzt sehen, die Auslassungen aber nachvollziehbar sind, soll dieser Umstand mit der nie wieder erreichten Mannigfaltigkeit der Filmpresse der Weimarer Republik entschuldigt werden (Haacke 1970: 300), die eine allumfassende Berücksichtigung auch nur der führenden Zeitungen enorm erschwert.

Da der Film in der Umfrage der Zeitschrift Filmkurier Rang 10 unter den besten Filmen des Kinojahres 1930 einnahm, kann immerhin von einer breiten Zuschauer- und Medienrezeption ausgegangen werden, die Sekundärliteratur dazu füllt ebenfalls Bände (z.B. Schmidt 1965, Sternberg 1967, Sudendorf 1980, Bandmann/Hembus 1980: 16ff., Schramme 1985, Frewin 1992, Wehnert 1996, Dietrich 1997, Glöckner/Lange 1998, Widera 1999, Dirscherl/Nickel 2000, Prawer 2002 etc.).

Allgemein lässt sich die deutsche Kritik zu DER BLAUE ENGEL in zwei Schwerpunkte gliedern. Zum einen wurde entweder Kritik an der Romanverfilmung als solcher geübt, zum anderen bewertete man die Qualitäten des Films als Tonfilm. Diese Fokussierungen überlagerten die sonst üblichen Bemerkungen zur Regie, Schauspielerei, Kameraarbeit etc. In Sachen einer politischen Wertung ergibt sich kein eindeutiges Bild, was allerdings nicht verwundert und auf die meisten Unterhaltungsfilme zutreffen dürfte.

Freilich wurde der Standpunkt des Mann'schen Romans je nach politischer Couleur hinterfragt, wodurch Meinungen entstanden, es handele sich um einen Film gegen Heinrich Mann (Hussong 1930: 112). Auf der anderen Seite äußerte man, dass das Vorbild des Romans selbstverständlich verändert wurde und es lächerlich wäre, irgendwelche Vergleiche, die Werturteile enthielten, zu ziehen (Zucker 1930: 118). Die UFA, obwohl sie zum Hugenberg-Konzern gehöre, ${ }^{150}$ habe sich in ihrer Produktion sehr wenig in die parteipolitischen Ziele des Konzerns einspannen lassen. Allerdings bekam man es wohl im Hause Hugenberg ob der eindeutig ,links' orientierten Persönlichkeit Heinrich Manns etwas mit der Angst zu tun, so dass man in den kon-

\footnotetext{
150 Zum Hugenbergkonzern s. Bernhard 1928; zur Person des deutschnationalen Politikers Alfred Hugenberg (1865-1951) siehe Wernecke/Heller 1982.
} 
zerneigenen Blättern Beschimpfungen organisierte, was nur als ein ekelhaftes Doppelspiel bezeichnet werden könne (ebd.: 118f.).

Enttäuschend sei der Film vor allem deshalb, weil der im Roman entfesselte Schultyrann zu einem wehleidigen Clown geschrumpft, der grandiose Filmstoff einem sentimentalen Handlungsklischee zum Opfer gefallen sei (Sahle 1930: 123f.). Für Siegfried Kracauer war der Film ein Musterbeispiel an Substanzlosigkeit, eine Privattragödie zur Wirklichkeitsflucht (Kracauer 1930: 125). In Verkennung der auf Unterhaltung ausgerichteten Romanverfilmung erwartete er eine Einbettung der Personen in den gesellschaftlichen Raum, was verdeutlichen sollte, „dass die individuellen Abläufe wo nicht bedingt, so doch mitbedingt sind von der jeweiligen ökonomischen und sozialen Situation" (ebd.). Die gezeigte Art der Fluchtversuche führten nach seiner Meinung nur in eine gähnende Leere.

Zu einer ähnlichen Einschätzung kam auch „Celsus" (Carl von Ossietzky) in der Weltbühne, der den Film als larmoyantes, unintelligentes Spießerstück abtat (Celsus 1930: 128). Schematisch gerierte sich auch die linksgerichtete Kritik in der Roten Fahne, die den gesellschaftskritisch aggressiven Vorkriegsroman von Heinrich Mann als "verzuckmayert" diffamierte, worunter man die Verschiebung des „kämpferischen“ in die schiefe Ebene des „dichterisch-schicksalhaften“ verstand, was nur zu einem Erfolg der größtmöglichen Gesinnungslosigkeit geführt hätte (Kemmeny 1930: 130f.).

Die mehr auf die filmischen Qualitäten und den Unterschied zwischen Roman und Film anerkennende Kritik schätzte hingegen die filmische Individualisierung des Stoffes, da

„[...] der Film das Schicksal eines vom ersten Augenblick an unserer Teilnahme sicheren, eines im Gemüt Vereinsamten, der mit tragischer Folgerichtigkeit an sich und in sich zugrunde geht von der Stunde an, da er unerfahren und ahnungslos dem Irrlicht nachgeht, das er für Frauenliebe hält, und das doch nichts als Dirnentum [ist]" (Hussong 1930: 112).

In Sachen Tonfilmqualität beweise DER BLAUE ENGEL, dass künftig, „Ein Wasserstoffsuperoxidköpfchen und ein gemaltes Mäulchen [...] keinen Beruf zur Diva mehr bedeuten; [...]. " werde (ebd.). Teilweise war man geneigt, den BLAUEN ENGEL als besten deutschen Tonfilm zu nennen, zum ersten Male habe man ohne jede Kritik die Möglichkeit der neuen Kunstgattung des Tonfilms erkannt (Zucker 1930: 117). Regisseur Sternberg verstünde es vorzüglich, sinnvolle Dialoge und tonfilmgemäße Musik zu gestalten, auch zwänge er die Schauspieler zu fast ungewohnten Höchstleistungen (ebd.). Im Gegensatz zum frühen Tonfilm bilde sich, 
„ein Tonfilmdialog [...] heraus, in dem bereits nicht mehr etwas gesagt wird, um zu zeigen, dass etwas gesagt werden kann, sondern in dem wirklich, in jedem knappen Satz, etwas Charakterisierendes oder Handlungsweitertreibendes gesagt werden muss. [...] Mit dem Tonfilm DER BLAUE ENGEL rückt also die deutsche Produktion, nach den in ihrer Starrheit so filmfremd albernen Liederbildern und nach den soldatischen Tonfilmen aus Ungar- und anderem Operettenland, in die Weltproduktion ein durch technische wie [...] durch geistige Qualität, nämlich der Motive, Menschenschilderung, Milieuzeichnung" (Pinthus 1930: 120).

Für Herbert lhering stellte DER BLAUE ENGEL sogar den „Einbruch des Geistes in den Film" dar, was das Verdienst von Heinrich Mann und Erich Pommer sei (Ihering 1930: 121). An den filmischen Konventionen - also wohl an der Unterhaltungsorientierung - kritisierte er aber den Umschlag vom epischen Ensemblefilm zum dramatischen Starfilm, der zu einer Solonummer für Jannings würde (Ihrering 1930: 122). Auch sei die Durchkomponierung der einzelnen Situationen stärker als in der Gesamtkomposition. Das wirkliche Ereignis dieser Produktion sei eigentlich Marlene Dietrich:

„Sie singt und spielt fast unbeteiligt, phlegmatisch. Aber dieses sinnliche Phlegma reizt auf. Sie ist ordinär ohne zu spielen. Alles ist Film, nichts Theater. Zum erstenmal kommt eine Frauenstimme im Tonfilm mit Timbre, Klangfarbe, Ausdruck heraus" (ebd.)

„Das Ereignis dieses Films ist aber nicht Sternberg, auch nicht Emil Jannings, der als Unrat noch einmal die Galerie seiner gedemütigten, deklassierten, vom Leben zersägten Mitleidsattrappen um ein neurasthenisches Prachtexemplar vermehrt - so überwältigend, so großartig diese Leistung auch angelegt ist, sie wiederholt, nur in anderem Kostüm, ein Wirkungsschema, von dem sich Jannings endlich befreien müsste. Nein, das Ereignis dieses Films ist Marlene Dietrich. [...]: das ist keine falsche Garbo mehr, alles an ihr ist neu und aufreizend; dieser lockende, einladende Gang, diese kühle Verdorbenheit, diese sinnliche Aggressivität in Ton und Bewegung - [...] (Sahl 1930: 124).

Die gleiche Meinung drückte auch die Weltbühne aus. Man war sich zwar unsicher, ob Marlene Dietrich dies auch ein zweites Mal gelingen werde, aber dies mache ihr in den Filmateliers einiger Kontinente niemand nach, „Dieses herrliche laszive Gesicht, diese hagere stelzende Gestalt mit den schäbigen Seidenhöschen und den unwahrscheinlichen schwarzen Gummistrumpfbändern gehört zu den wenigen wirklich großen Filmeindrücken seit Jahren " (Celsus 1930: 130). Laut der Roten Fahne sei DER BLAUE ENGEL als Film 
sehr gelungen, der erste in Deutschland aufgeführte künstlerisch gestaltete Tonfilm. Regisseur Sternberg wäre genial, Jannings habe man noch nie so stark, so überwältigend, so wahr gesehen wie hier. „Eine glänzende Regie, eine glänzende Photographie. Aber der Inhalt ist: Kitsch, ist: 00“ (Kemmeny 1930: 131).

Die ausgewählten Rezeptionsdokumente machen deutlich, dass sich die intendierte Wirkung des Films - also grob gesagt die Mitleidsidentifikation des Zuschauers mit der Figur Prof. Rath - auch in den Pressebelegen niedergeschlagen hat. Die Konzentration der Kritik auf die zu großen Abweichungen von der Romanvorlage stehen paradigmatisch für die auch vom Film erwartete Gesellschaftskritik des Romans, die im Film stattdessen auf eine persönliche Leidensgeschichte (,Privattragödie') reduziert wird. Der als schicksalshaft empfundene Niedergang des Professors wurde dadurch bewusst von der allgemeinen sozio-ökonomischen Situation abgekoppelt, um die zeitgenössisch dominanten Rezeptionsangebote zu kanalisieren und in die gewünschte Richtung zu lenken. Obwohl sich die UFA mit der Produktion augenscheinlich nur „wenig in die parteipolitischen Ziele des (Hugenberg-) Konzerns einspannen" liess (Zucker 1930: 118f.), vermittelte der Film doch als die zu bevorzugende Lesart die Dominanz des Individuellen über das Gesellschaftliche, welche die durch die UFA repräsentierte politische und ideologische Ordnung stützt. Die ebenso geführten Diskussionen über die tontechnischen Qualitäten des Films oder die herausragende Rolle von Marlene Dietrich gehören zu den die intendierte Wirkung flankierenden Strategien, die weitere potentielle oder gar oppositionelle Lesarten an den Rand drängen sollten. Selbstverständlich wurde die intendierte affirmative Wirkung des Films in den Rezeptionsbelegen von den Rändern des politischen Spektrums kritisiert, die Mehrheit der Medienberichte stützte jedoch die intendierte Wirkung des Films und redete e i n e $r$ potentiellen Lesart (individuelle $>$ gesellschaftliche Probleme) als zeitgenössisch dominant das Wort. Ob diese Lesart auch in der südafrikanischen Rezeption vorherrschte, soll in der folgenden Auswertung geklärt werden.

Die Medienrezeption von DER BLAUE ENGEL begann in Südafrika wie üblich mit einem Rückgriff auf Meldungen der britischen Presse, die als Filmankündigungen vor der eigentlichen Aufführung fungierten. Gemäß der Einschätzung des britischen Sunday Express könne Deutschland mit DER BLAUE ENGEL seine vergangene Vormachtstellung in Sachen Filmkunst wiederherstellen, selbiges gelte für die Bedeutung der deutschen Filmkunst für die europäische Filmindustrie (NA 9.5.30: 11). Der Inhalt sei geprägt vom Spiel Emil Jannings', er spiele eine typische Jannings Rolle, nämlich „that of 
an old teaching college professor who, bewitched by an fascinating slut, loses his respectability, his reason and finally dies in degradation" (ebd.). ${ }^{151}$ Mit der Betonung von Jannings tragender Rolle in einer Pressevorbesprechung wird seine Status als Filmstar hervorgehoben und werbewirksam eingesetzt. Die Geschichte des Films wurde als nach den Wünschen der Filmproduzenten etwas zu sehr hingebogen eingeschätzt, dass was Professor Rath da passiere, könne sich im wirklichen Leben wohl kaum ereignet haben (NA 4.8.30: 11). Neben der Erwähnung von Jannings' und von Sternbergs Hollywoodqualitäten wurde auch das Schauspiel von Marlene Dietrich gelobt:

„In the English version of THE BLUE ANGEL she talks and sings with scarcly the trace of an accent. German and English are cleverly blended in this version and since all the characters and settings maintain their German origin, the 'local colour' is, of course, more convincing than it usually is in films 'edited' for foreign marktes" (ebd.).

In einer der Vorbesprechungen erfolgte eine zu diesem Zeitpunkt eher nebensächlich Bemerkung, die eine Ursache der Gründe des späteren Zensurverbots von DER BLAUE ANGEL gewesen sein könnte. Wenn die Cape Times bemerkt, „The middle aged pedagogue, indistinguishable from many South African professors whom we bless for the things they failed to teach us [...]" (CT 30.8.30: 11), kann davon ausgegangen werden, dass auch andere südafrikanische Beobachter die gleichen Assoziation gehabt haben könnten. Der Erfolg des Films in Berlin und vor allem in London wird dazu geführt haben, dass sich Kinemas die Vertriebsrechte für Südafrika frühzeitig sicherten (NA 20.11.30: 11).

Bereits wenige Monate später erschien eine erste Filmbesprechung in der Cape Times. In Europa und America habe DER BLAUE ENGEL einen sensationellen Erfolg und diejenigen, die Emil Jannings noch aus „The Last Command" in bester Erinnerung haben, sollten sich auf den ersten Tonfilm dieses großartigen Schauspielers freuen (CT 16.1.31: 7). Ähnlich wie in „The Way of All Flesh" und "Sins of the Fathers" strapaziere Jannings ein thematisch ähnliches Sujet, eben jene ,backstage'-Atmosphäre, welche den Hollywoodregisseuren so lieb und teuer geworden sei. Neben Jannings beeindrucke Marlene Dietrich durch ihr Talent und ihre körperliche Anziehungskraft, welche den unwahrscheinlichen Niedergang des Professors wenigstens etwas plausibel mache. Die darin liegende Gefahr wurde jedoch klar erkannt:

\footnotetext{
151 Es bleibt zu bemerken, dass sich ohne die britische Vorlage keine südafrikanische Zeitung zu dieser drastischen Wortwahl (engl. ,slut': dt. ,Hure' oder ,Schlampe') hätte hinreißen lassen.
} 
„In her physical attraction lies a possible danger to the film in countries which still, rightly or wrongly, suppport censorship. It is understood that the Cape Board of Censorship will see the film this morning. If they take a superficial or a hasty view of it, it will be easy for them to suggest a number of cuts [...]. This is not a 'leg show', with a 'sex appeal interest' dragged in for the benefit of the box-office. It is a serious work of art, and a work of art cannot be cut about without being damaged" (CT 16.1.31: 7).

Allerdings benehme sich Marlene Dietrich nicht anders als sonst, auch ziele ihr Schauspiel keinesfalls auf die niederen Instinkte des Publikums ab. Selbst ihre Kleidung wäre auch nicht anders, als man dies von den 50 bis 60 Revuetänzerinnen gewohnt sei, die in einem spektakulärem Film wie z.B. „Movietone Follies" (1929, David Buttler) zu sehen waren (ebd.):

„It will be a very pitty if, because she unites brains to beauty, any part of her remarkable performance is interfered with, and the unity of a very admirable film destroyed in however small a degree" (CT 16.1.31: 7)

Trotz der Vielzahl der nachweisbaren Pressebelege für DER BLAUE ENGEL trat in den Rezeptionsbelegen zwischen dem 16. und dem 26. Februar 1931 eine Art semantischer Bruch ein. Die bis dahin filmzentrierte Medienrezeption wurde durch die Entscheidung des Cape Board of Film Censors, den Film in der Kapprovinz nicht zur Aufführung zuzulassen, überschattet (CT 26.2.31: 9). Diese Problematik wurde bereits im Exkurs zur Filmzensur mit dem Erklärungsansatz des ,Moderatoreffekts' beschrieben.

Durch diesen Umstand fällt die bisherige, weitgehend materialbezogene Berichterstattung ausgerechnet in der durch die Sprachgruppengegensätze besonders urteilsfreudigen Presse Kapstadts aus. Im Vorgriff auf die Aufführungschronologie von DER BLAUE ENGEL muss ebenso bemerkt werden, dass sich der Kapstädter Zensurentscheidung auch die Verwaltung der Provinz Oranje-Freistaat anschloss, was einen zusätzlichen Einfluss auf die Medienrezeption ausübte (TF 14.3.31: 9). Da die allgemeine Zensurproblematik in einem Exkurs dieser Studie eingehender behandelt wurde, die Rezeption von DER BLAUE ENGEL aber wesentlich von der Zensurentscheidung beeinflusst wurde, soll im Folgenden der Versuch unternommen werden, die Diskussion des Aufführungsverbots zunächst hintanzustellen, und mit der Medienrezeption in den verbotsfreien Provinzen Transvaal und Natal fortzufahren. Das auch dort die Zensurentscheidung wahrgenommen wurde und in der Folge mit in die Bewertung des Films einging, steht außer Frage. 
Zur Verdeutlichung der unverständlichen Zensurentscheidung wurde in Kapstadt intensiv aus der Johannesburger Presse zitiert. Die Filmkritikerin der Rand Daily Mail, „Treble Viol“, bemerkte dazu, dass die Geschichte um die erschreckende Leidenschaftlichkeit eines in die Jahre gekommenen Mannes, dessen bisheriges Leben von sexueller Unbedarftheit gezeichnet war, sicher nicht nach jedermanns Geschmack sei (CT 2.3.31: 11). Wahrscheinlich sei es die vollkommene Ernsthaftigkeit der Thematisierung, die hier missverstanden werde. Der Film sei ohne Zweifel ein Kunstwerk, nichts Unmoralisches zum Zwecke irgendwelcher Anstößigkeiten sei zu sehen. Eine Ausnahme sei vielleicht das unerträgliche Pathos von Jannings' Darbietung, der dramatische Höhepunkt des mitleiderregenden Wahnsinns sei dennoch fantastisch (ebd.). Besonders in Kapitel $\bigvee$ mache die Darstellung von Jannings vollkommen vergessen, dass es sich nur um eine Schauspiel handele. Zudem habe Regisseur Sternberg eine clevere Ökonomie der Worte für Jannings' ersten Tonfilm arrangiert, in seiner Rolle als Professor für englische Sprache und Literatur spreche er wirklich English, das Gleiche gelte für die englischsprechende Tänzerin Lola. Besonders die Eigenschaft des BLAUEN ENGELS als überaus gelungener Tonfilm wurde als ein wesentliches Erfolgsmerkmal der Produktion angesehen, da er den Ton der Handlung Untertan mache:

"The picture, too, sets a new standard in cinema art. Von Sternberg has broken away from the tyranny of sound, and made it subservient to action. THE BLUE ANGEL, as a whole, may be taken as a revelation of the highest art of the talking screen" (CT 2.3.31: 11).

Wie in der südafrikanischen Filmkritik allgemein üblich, wurde zum Herausstreichen der außerordentlichen Qualität eines Filmes auf den großen Erfolg des Films in Großbritannien oder den USA hingewiesen, eine Strategie, die auch beim BLAUEN ENGEL angewandt wurde (RDM 2.3.31: 3). Tatsächlich lief der Film für zwölf Wochen in den Kinos des Londoner West-End, obwohl er bereits vor dem Ende der Saison dort zur Aufführung im ganzen Land freigegeben wurde (NW 28.3.31: 7).

Einzig in der Vorbesprechung des Films im Natal Advertiser wurde vermerkt, dass DER BLAUE ENGEL eine Adaption von Heinrich Manns Roman "Professor Unrat" - einer eher düsteren Erzählung - wäre und dass Emil Jannings auch in diesem Tonfilm sein schon zu Stummfilmzeiten bewiesenes Talent voll ausspiele (NA 21.3.31: 7). Nach der Unsicherheit über die zu erwartende Zensurentscheidung (NA 23.3.31: 9) gelangte die Presse der Provinz Natal zu vollkommen gegensätzlichen Einschätzungen. Die in Durban 
erscheinenden Blätter Natal Mercury und Natal Advertiser sprachen von einem langweiligen Film, Marlene Dietrich sei zwar recht hübsch, aber als Vamp nicht besonders überzeugend (NM 24.3.31: 9). Wenn nicht bereits die suggestivsten Szenen entfernt worden seien, wären vor diesem Hintergrund die Zensurverbote noch unerklärlicher (ebd.). Seine Enttäuschung über DER BLAUE ENGEL fasste der Natal Advertiser in wenigen Zeilen zusammmen:

„THE BLUE ANGEL impresses me personally, and I think the opinion is shared by many others, as an over-boosted picture, and one that fell flat so far as a large section of Kings (Kino in Durban, ME) audience was concerned. I, and I daresay many others, formed the opinion that the only people likely to enjoy it would be persons under 21 . The story is depressing and the speech of the principal actor is at times hard to follow" (NA 24.3.31: 11).

In Pietermaritzburg warb der Natal Witness mit dem Verweis auf die Zensur des Films in Kapstadt und Durban, ebenso mit dem Schauspiel von Jannings, welches seine Stummfilmrollen noch übertreffe (NW 28.3.31: 7). Selten sei er in so guter Form gewesen wie in diesem Film, auch Marlene Dietrich spiele außergewöhnlich gut. Für diesen konsequent internationalen Film sei auch keine Synchronisation nötig gewesen, da er ein englisches und ein deutsches Publikum gleichermaßen anspreche. Der Professor spreche natürlich Englisch mit seinen Schülern und auch zu Lola, die als Engländerin dargestellt werde. In den anderen Fällen werde Deutsch benutzt, allerdings nur wo die Verbildlichung des Geschehens die Worte vollkommen verständlich mache (ebd.). Der Ton sowie die gelegentlichen Geräusche seien gut gelungen, Marlene Dietrich singe sehr ansprechende Lieder und die ganze Produktion sei trotz ihres leichten Hollywoodeinschlages durch die bekannten UFAStudios und Jannings' Rolle hervorragend umgesetzt (ebd.).

Die folgende Besprechung derselben Zeitung beginnt mit dem Hinweis, das der Film in der Kapprovinz verboten, in Durban drastisch gekürzt und in Pretoria nur für Erwachsene zugelassen wurde (NW 1.4.31: 9). Diejenigen, die den Film gesehen hätten, verstünden die ganze Aufregung allerdings nicht. Auch sei vollkommen unverständlich, warum der Film in Großbritannien und Kontinentaleuropa einen so ausgezeichneten Ruf genieße. Sicher zeige er einiges an feinem Schauspiel, besonders jenes von Emil Jannings und Marlene Dietrich, aber das ganze Thema des Films wäre zu schäbig (ebd.). Die Produktion sei zwar überaus gelungen, aber wie auch schon das Schauspiel an eine erbärmliche Geschichte verschwendet worden. Emil Jannings habe man schon öfter in Rollen dieser Art gesehen, er spiele wieder den 
Niedergang eines ehedem respektierten Mannes, der immer tiefer sinke und schließlich wahnsinnig werde. Die Darstellung der Tragödie sei zwar durchaus gutes Schauspiel, aber eben doch keine Unterhaltung. Marlene Dietrich hingegen sei ohne Zweifel ein toller ,Fund', selbst in ihrer mitleidslosen Rolle sei sie noch ansprechend, sie habe eine Art verführerischen Charme, der für die Leinwand höchst selten sei (ebd.).

Beim Vergleich der beiden gegensätzlichen Besprechungen aus dem Natal Witness wird deutlich, dass es sich bei der ersten um die Übernahme einer Agenturmeldung handelte und nur die zweite als echte redaktionelle Filmkritik angesehen werden kann. An dieser Stelle wird einmal mehr deutlich, welchen Einfluss die Werbeabteilungen der Filmvertriebe mit ihren Rezeptionsempfehlungen hatten. Im Falle des BLAUEN ENGELS kommt noch erschwerend die Zensurproblematik hinzu, welche die Medienrezeption auf Fragestellungen richtet, die ohne die Zensureingriffe wahrscheinlich nicht entstanden wären.

Im einzigen afrikaansen Rezeptionsdokument aus der Provinz Natal berichtete Die Afrikaaner von einem vollen Kino und besorgten Zuschauern (DA 3.4.31: 6). Dieser erste Tonfilm mit Emil Jannings sei der erste Deutsche Tonfilm in Pietermaritzburg überhaupt gewesen, die Szenen lauter Prachtstücke, besonders am Schluss, der sehr tragisch gestaltet wäre (ebd.).

Für die Medienrezeption zu DER BLAUE ENGEL lässt sich mittels der bis jetzt herangezogenen Materialien eine Zweiteilung beobachten, die sich nicht einfach in Ablehnung oder Zustimmung erschöpft. Auf der einen Seite werden die technischen und schauspielerischen Qualitäten des Films durchaus begrüßt, auf der anderen jedoch die Schwächen des Drehbuchs und der erzählten Fabel kritisiert. Da diese Werthaltungen wesentlich von den Zensurentscheidungen beeinflusst wurden, soll im Folgenden die Zensurgeschichte des Films kurz umrissen werden, um zu einem abschließenden Urteil zu gelangen.

Da die Aktenlage zum Zensurfall BLAUER ENGEL nicht geklärt werden konnte, lässt sich nur anhand der Presseberichterstattung rekonstruieren, welche Gründe zum Aufführungsverbot geführt haben könnten. Am 26. Februar 1931 wurde bekanntgegeben, dass das Cape Board of Censors der Kinokette Kinemas untersagte, den Film aufzuführen (CT 26.2.31: 9). Diese Nachricht löste besonders im Finanzzentrum Johannesburg Verwunderung aus, da die Behörden der Provinz Transvaal die Aufführung gestattet hatten. Der zuständige Polizeioffizier konnte sich auch nicht vorstellen, aus welchen Gründen der Film zensiert wurde: „The film contains nothing objectionable, $[\ldots]$. There is no orgy in it, and not the remotest suggestion of anything 
offensive in the cabaret or, in fact, elsewhere in the film" (CT 26.2.31: 9). Einige der Szenen seien emotional sehr anstrengend, auch in Deutschland fanden viele Zuschauer den Film so erschütternd, dass sie die Vorstellung verlassen mussten. Selbst die Tatsache dass Teile des Films auf Deutsch waren, behinderte nicht den großen Erfolg des Films in London und New York, wo man sehr wohlwollend über den Film rede. Die gewöhnlich von der Zensur beanstandeten Dinge seien in diesem Film einfach nicht enthalten (ebd.).

Als Grund für das Aufführungsverbot gab die Zensurbehörde keine konkreten Angaben, sondern berief sich auf einen der Verbotsgründe im Zensurgesetz, wonach Filme nicht genehmigt würden, die „suggestive of immorality and offensive to public decency" wären (CT 27.2.31: 9). DER BLAUE ENGEL regte demnach angeblich zur Sittenlosigkeit an und beleidigte den öffentlichen Anstand. Wahrscheinlich regte auch diese undurchsichtige Informationspolitik die Presse in Kapstadt an, besonders kritisch über diesen Fall zu berichten. Als allgemeine Breitseite gegen die Zensurbehörde kann bereits die Veröffentlichung der Namen und Tätigkeiten der vier die Entscheidung tragenden Mitglieder angesehen werden. Unter diesen vier Mitgliedern befanden sich ein ehemaliger Amtsrichter ( $F$. Howe-Brown), ein Makler und Vertreter (D.F. Bosman), ein Buchhalter (B. Dods) und eine Vertreterin der Nederduits Gereformeerde Kerk ${ }^{152}$ bzw. Vertreterin des christlichen Frauenbundes (Frau Du Toit, Witwe des verstorbenen Prof. du Toit). Diese hatten den Film bereits am 16. Februar begutachtet. Inoffiziell wurde einem Vertreter von Kinemas angeblich bereits vor der Vorführung zu verstehen gegeben, dass der Film wohl verboten würde (ebd.). Gleichwohl sei das abgegebene Votum nicht einstimmig gewesen.

Nach der Pressevorführung und vor dem Verbot äußerte ein Kritiker der Cape Times, dass der Film thematisch nichts besonderes sei, man kenne dies bereits von Jannings' Filmen „The Way of all Flesh" und „Sins of the Fathers" (ebd.). Auch sei der Film mit Zurückhaltung und Anstand produziert worden, sicher nichts für Kinder, aber „it is certainly not a play which preaches, as do so many American films, that all that matters in life is , a good time'“ (ebd.). Zusammen mit dem Cape Argus war man sich einig, ,'The Blue Angel' is the finest film of its kind that I have ever seen. The theatre has given us no more powerful drama, the silent film no more convincing spectacle" (CT 27.2.31: 9).

${ }^{152}$ Dutch Reformed Church. 
Der Kommentar der Cape Times führte das Verbot direkt auf die zur gleichen Zeit stattfindende Debatte um ein neues zentrales Zensurgesetz zurück (CT 27.2.31: 8). Der beste Beweis dafür, dass ,alberne' Gesetze auch ,albern' ausgeführt würden, böten die vier Mitglieder des Cape Board of Censors. Mit innen brauche man gar nicht um den künstlerischen Wert des Films zu streiten, denn, wie auch immer sie zu ihren Posten gekommen wären, beruhe deren Meinung über ein Kunstwerk offensichtlich weder auf Vorbildung noch Kompetenz, und so sei deren Einschätzung, ob nun individuell oder gemeinschaftlich, absolut wertlos (ebd.). Natürlich wüssten sie, was ihnen gefällt, aber es sei ja lautbar geworden, dass sie ihre Entscheidung bereits getroffen hätten, bevor sie das Kino verließen. Vielleicht wäre DER BLAUE ENGEL ja wirklich „suggestive of immorality and offensive to public decency“, aber davon abgesehen hätten fast alle Filmkritiker in Europa und Amerika sowie eine beachtliche Zahl an Kinogängern den Film als bewegend und meisterhaft eingeschätzt, ein Film in dem der großartigste lebende Schauspieler den vielleicht besten Auftritt seiner Karriere biete (ebd.):

„If so, it would not be the first film , suggestive of immorality and offensive to public decency' which the Cape Board has passed without protest. Hollywood inanities, offensive in their vulgarity to any civilised human being, are exhibited nearly every week, presumably with its approval" (ebd.).

Besonders bedenklich sei die Tatsache, dass ein Unterkomitee sich anmaße zu entscheiden, was die Bewohner von Kapstadt sehen dürften und was nicht, ohne in diesem wichtigen Fall eine Vollversammlung aller acht Mitglieder des Ausschusses einberufen zu haben (ebd.).

Leicht spöttisch bemerkte man zur Entscheidung der Kapprovinz, dass der Film doch in Transvaal als harmlos eingestuft wurde und aus diesem Grunde wohl kaum sittliches Verderben ins Kap bringen werde (RDM 27.2.31: 6). Die künftige Gefahr durch das neue Zensurgesetz schätzte man jedoch realistisch ein, ohne Änderungen fiele es übereifrigen Zensoren nur allzu leicht, Filme zu verbieten, die anderswo keinerlei Restriktionen ausgesetzt wären (ebd.). Wenn der Öffentlichkeit schon Zensoren aufgehalst würden, dann sollte wenigstens darauf geachtet werden, dass es sich bei jenen um Leute von Verstand und Klugheit handele und nicht nur um irgendwelche Naseweise (ebd.). Besonders negativ fiel auch die Verweigerung der Angabe der Verbotsgründe auf, die Zensur beruhe ja doch auf einer gemeinsamen Basis und außerdem sei die Angabe der Gründe nur fair gegenüber den Kinoketten, so dass diese ihr künftiges Programm daran ausrichten könnten (RDM 2.3.31: 3). 
Nach dem Eintreten der Presse für den Film und gegen die Zensur erfolgten mehrere Publikumsreaktionen, die als Leserbriefe abgedruckt wurden. Nach dem viele Einwohner Kapstadts in der Vergangenheit einige der großartigen UFA-Stummfilme gesehen hatten, sei es nun besonders enttäuschend, dem Publikum ein Meisterwerk vorzuenthalten, welches der Rest der Welt sehen dürfe (CT 3.3.31: 8). Was könne die Öffentlichkeit also in Zukunft erwarten? Vor einiger Zeit hätte die Cape Times noch von einer neuen Niederlassung nahmhafter Filmproduzenten in Kapstadt gesprochen, die eine Reihe von Spitzenfilmen nach Südafrika bringen wollten. ${ }^{153}$ Wieviele davon wohl das Cape Board of Films Censors freigeben würde, wäre äußerst fraglich (ebd.).

In einem Leserbrief des Unterzeichners „Pro-Censor Board“ ergriff dieser offen Partei für das Komitee und verlangte für deren Entscheidung die Rükkendeckung des Administrators der Kapprovinz (CT 3.3.31: 8). Wenn dies nicht geschehe, wäre die Position der Zensurbehörde nur noch ein Witz, denn die beiden konkurrierenden Kinoketten würden sonst in jedem Falle alle Entscheidungen in Frage stellen, die Zeitungen mobilisieren und auf den Einspruch des Administrators hoffen. Das einzige was bei dieser Sache herauskomme, wäre noch mehr Reklame für Kinemas, was im Gegenzug die nachfolgenden Entscheidungen des Komitees beeinflusse. Die ganze Bewegung sei nur ein Ausdruck der finanziellen Interessen von Kinemas, denn wenn diese Herren den Anspruch hätten, unerwünschtes Amüsement zu unterbinden, bräuchte man auch keine Zensurgesetze, die so kostspielig überwacht werden müssten. Es wäre doch interessant, dazu die Meinung von Kinemas und African Theatres direkt zu hören (ebd.). Nach dieser auch die Haltung der Cape Times kritisierenden Stellungnahme stellte die Zeitung folgendes klar:

"The case against the Cape Board of Censors is that four members of it, without refering the matter to the full Board, took upon themselves to ban a film which has been passed by censors in every civilised country and acclaimed by critics and public alike in England, Germany and the United States as the masterpiece of perhaps the greatest living actor, and that they did so without giving it any adequate consideration. 'Pro-Censor Board' merely begs the question when he speaks of 'undesirable entertainment'. Has he seen ,The Blue Angel'?" (CT 3.3.31: 8).

153 Damit dürften die Anstrengungen von Metro-Goldwyn-Mayer gemeint sein, die Ende 1930 auf dem südafrikanischen Markt tätig wurden (Gutsche 1972: 213). 
Ein weiterer Leserbrief von "Britisher" mahnte ebenfalls die Wachsamkeit von Presse und Öffentlichkeit in dieser Sache an, denn man könne zwar davon ausgehen, dass das Komitee bei unbedeutenderen Filmen wisse, was es tue, aber bei Filmen die in Europa und Amerika als Meisterwerke eingestuft würden, könne man die Kompetenz der Zensoren durchaus beargwöhnen (CT 5.3.31: 8). Er sei jedenfalls davon überzeugt, dass das Zensurkomitee keine Ahnung hätte, sonst wären in der Vergangenheit nicht Filme gezeigt worden, deren Freigabe fast einem Verbrechen nahegekommen sei (ebd.).

Das gescholtene Zensurkomitee sah sich nun seinerseits zu einer Stellungnahme genötigt. Zunächst bezichtigte man die Cape Times einer fehlerhaften Berichterstattung, leitete eine Stellungnahme an den Administrator weiter und bat gleichzeitig um die Veröffentlichung des Briefs, welchen der Administrator vorher abgesegnet hatte (CT 6.3.31: 10).

Der Film sei von vier Mitgliedern des Komitees zurückgewiesen worden, unter ihnen war der Ausschussvorsitzende. Man habe nach der Vorführung eine ganze halbe Stunde darüber diskutiert ob der Film 1. unanständiger und immoralischer Art sei, der eine völlige Ablehnung rechtfertige, und 2. ob die fragwürdigen Teile eliminiert werden könnten, ohne ihn komplett zu verderben. Danach entschied man sich für das Totalverbot. Interessanter Weise lässt das Totalverbot darauf schließen, dass eher die sich durch den ganzen Film ziehende Darstellung des Autoritäsverlustes als problematisch angesehen wurde, als die "freizügigen“ Bilder von Marlene Dietrich. Letztere hätte man ohne viel Aufwand und mit vertretbaren Einschränkungen für die Spielfilmhandlung herausschneiden können, den geschilderten Autoritätsverfall hingegen nicht.

Auch in England sei der Film vor der Freigabe drastisch gekürzt worden. ${ }^{154}$ Trotz seiner negativen Entscheidung sei das Komitee von der schauspielerischen Leistung Emil Jannings' und der übrigen Besetzung beeindruckt gewesen, in keinem seiner vorherigen Filme sei die Personifikation mit dem dargestellten Charakter so ausgezeichnet gewesen (ebd.). Dies bewirkte jedoch keine Beeinflussung des abgewogenen Urteils der Zensoren in Bezug auf die wirklichen Sachverhalte der präsentierten Geschichte. In Zukunft wünsche man sich von der Cape Times, dass diese vor dem Ergreifen irgendwelcher Maßnahmen das Zensurkomitee nach den Fakten befrage.

\footnotetext{
${ }^{154}$ Für die Richtigkeit dieser Annahme sprechen die unterschiedlichen Längen der verschiedenen Fassungen: erste deutsche Zensurfassung: 2965m, deutsch/englische Fassung: 2856m, in den USA registrierte Länge: 2797m (Die Top 100 des deutschen Films, Platz 7, DER BLAUE ENGEL, CD bzw. Bauer 1950: 14 und Sudendorf 1980: 132).
} 
Gegen den Vorwurf der Falschinformation wehrte sich die Cape Times nachdrücklich, tatsächlich wiederholt die Stellungnahme des Zensurausschusses lediglich die Fakten, welche bereits in den Artikeln der Cape Times angesprochen wurden (CT 26.2.31: 9 und CT 27.2.31: 9). Dass die Verbotsentscheidung noch vor dem Verlassen des Theaters klar war, traf ebenfalls zu, da sich dass Zensurkomitee noch im Kino gerade mal ein halbe Stunde beriet, um zu einem Entschluss zu kommen. Nach der Sichtung des Films könne man die Entscheidung des Ausschusses nur als absurd ansehen (CT 6.3.31: 10). Wer auch immer behaupte, er könne ein fundiertes Urteil über diesen Film nach ein paar Minuten oder sogar einer "vollen halben Stunde“ fällen, sei entweder vollkommen unzugänglich für die Wirkungen dieses ausgezeichneten emotionalen Schauspiels oder ignorant gegenüber den Grundbestandteilen echter Kritik. Warum dem Totalverbot gegenüber partiellen Schnittauflagen der Vorzug gegeben wurde, sei nicht nachvollziehbar. Die Entschuldigung des Zensurausschusses, dass der Film auch in England zensiert wurde, verfange überhaupt nicht:

„But if it could be cut in England and still win the approval of critics and public, why did not the sub-commitee have it shown again and settle down to earn their fees by doing a little work at cutting it, instead of forming a snap judgement and taking the easy path of total rejection?" (ebd.)

Die Cape Times sah keinen Grund, ihre Meinung zu ändern: den Film nach einem einfachen Mehrheitsvotum zu verbieten ohne inn dem vollzähligen Komitee vorzulegen zeige, dass die vier Mitglieder eine krasse Vernachlässigung ihrer Pflichten und der Belange sowohl gegenüber der Öffentlichkeit, als auch den Unternehmen an den Tag legten, von deren Steuergeldern sie schließlich bezahlt würden (ebd.). Auf die ,wahren Fakten' vom Zensurausschuss zu warten, habe die Cape Times nicht nötig gehabt, man habe stets wahr berichtet, obwohl trotz aller Bemühungen keine individuellen Stellungnahmen von einzelnen Komiteemitgliedern zu vernehmen waren. Der verspätete Brief deute im Gegenteil darauf hin, dass man Angst vor der Veröffentlichung der ganzen Wahrheit habe. An den Vorsitzenden richte man deshalb die Frage,

„[...] whether THE BLUE ANGEL was banned at the instigation and on the insistance of a female member of the quorum of four, on the ground, not that it was 'offensive to public deceny', but that it was likely to bring into contempt members of the teaching profession?" (ebd.) 
Im Analogieschluss müsste man dann wohl schlussfolgern, dass, angenommen, der Administrator würde einen professionellen Clown in den Zensurausschuss berufen, dann alle Zirkuskomödien mit Charly Chaplin verboten würden? Wäre dem so, würde sich die Öffentlichkeit Kapstadts sicher der Meinung der Cape Times anschließen, nach der das in Transvaal praktizierte Zensursystem, welches allein in den Händen der Polizei lag, die bessere Alternative böte (ebd.).

Noch vor der Auswertung der Pressebelege zur Zensur des Films in der Provinz Oranje Freistaat und einigen Leserbriefen sollen an dieser Stelle die versteckten Hinweise zu den wahren Verbotsgründen gesammelt werden, um eine begründete Vermutung äußern zu können. Die Cape Times fragte demnach, ob nicht vielleicht auf Betreiben des einzigen weiblichen Mitgliedes des Ausschusses, mit dem nur die Witwe von Professor Du Toit gemeint sein konnte, mit Nachdruck auf ein Verbot gedrängt wurde, da der Film möglicherweise Anlass zu einer Geringschätzung des Lehrerstandes gegeben hätte und dies bloß hinter der Standardformel "offensive to public deceny" verdeckt worden wäre. In einer der Meldungen über den Erfolg des BLAUEN ENGELS in London hieß es sinngemäß, dass der Pädagoge mittleren Alters ununterscheidbar von jenen südafrikanischen Professoren wäre, denen man vor allem für die Dinge zu danken habe, die man von jenen nicht gelernt habe (CT 30.8.30: 11).

Aus der Kombination dieses Eindruckes, dem Verdacht der Cape Times und dem persönlichen Hintergrund eines der Ausschussmitglieder lässt sich schlussfolgern, dass möglicherweise der Hauptgrund für die negative Zensurentscheidung in der Darstellung des Gymnasialprofessors Rath zu suchen ist. Die Darstellung der Beziehung einer Prostituierten mit einem Lehrer, neben dem Pfarrer oftmals die einzige wirkliche Respektsperson im rauhen Alltag vieler Südafrikaner, wurde mit Sicherheit in vielen konservativen Kreisen, vor allem unter den Afrikaanern, ablehnend bewertet. Nur vor diesem Hintergrund wird einigermaßen verständlich, warum ähnlich anzügliche Szenen in anderen Unterhaltungsfilmen nicht zensiert wurden, sobald aber eine Respektsperson wie ein Lehrer darin vorkam, die öffentliche Moral als bedroht angesehen wurde. Szenen wie z.B. in Sequenz 3.2, in der Lola-Lola ihre Unterwäsche abstreift und selbige dann von oben dem verdutzten Professor zum Fangen auf die Schultern fallen lässt, wären sicher auch ohne Totalverbot mit Schnittauflagen belegt worden.

Durch die Zensurentscheidung in Kapstadt entstand die ungewöhnliche Situation, dass DER BLAUE ENGEL in den Provinzen Transvaal, Natal und in Südrhodesien (das heutige Simbabwe) zugelassen war, nicht jedoch in der 
Kapprovinz. Gewöhnlich folgte die Provinz Oranje-Freistaat den Entscheidungen aus Pretoria oder Kapstadt, in diesem Falle orientierte man sich am Cape Board of Censors und so verhängte der Administrator in Bloemfontein ein Aufführungsverbot für den Film (TF 14.3.31: 9). In der Presse fragte man sich, warum gerade der drittbeste Film der Welt, der in Johannesburg für volle Lichtspielhäuser gesorgt habe und dort in verlängerter Saison laufe, unmoralisch und anstößig sein solle, sogar die Deutschen in Johannesburg seien voll des Lobes (ebd.). Vielleicht habe bei der Entscheidung in Kapstadt eine Rolle gespielt, dass der Zensor negative Wirkungen des Films auf die Farbigen und die Asiaten im Kap befürchtet habe, dieses Problem existiere aber im Freistaat und Transvaal nicht (ebd.). ${ }^{155}$ Das lokale Zensurkomitee in Bloemfontein stellte jedoch eine private Vorführung in Aussicht, nach der entschieden werden sollte, ob das Verbot nicht vielleicht aufgehoben werden könnte. Der Entscheidung aus Kapstadt schloss sich der örtliche Zensurrat jedoch an, besonders die weiblichen Mitglieder (Maynie Fleck, Frau D.F. Malherbe und Kitty Papenfus) bezeichneten den Film als „too depressing and unpleasant for public consumption" (TF 6.5.31 in Schoeman 1980: 269).

Eine nachträgliche Verbotsanfrage in Pretoria wurde negativ beschieden, das Jugendverbot aber aufrechterhalten (CT 17.3.31: 9). Bis auf ein, zwei Schnitte wurde der Film für Transvaal genehmigt, wenngleich die Vorführungen nur von Südafrikanern europäischer Herkunft besucht werden durften (CT 25.3.31: 7). Die in Durban (Natal) für die Filmzensur zuständige Polizei machte sich in den Augen der Presse mit ihren Schnittauflagen lächerlich, da man ausgerechnet eine Szene herausschnitt, die im Werbevorspann für den Film bereits überall zu sehen war (NM 24.3.31: 9).

Der lächerliche Zustand der unterschiedlichen Zensurentscheidungen wurde auch von der afrikaansen Presse des Freistaates bemängelt (VB 17.3.31: 7). Dieses Durcheinander erwecke den Eindruck, als ob die Sittlichkeit in einer Provinz leichter nachteilig zu beeinflussen wäre als in einer anderen. Die Zensurentscheidung in Kapstadt war auch für den Kritiker des Volksblad unverständlich, er habe den BLAUEN ENGEL in Pretoria gesehen und dort schon viel zweifelhaftere Film mit ansehen müssen. Jede Person die den Film ohne Vorurteil gesehen habe, werde erkennen, dass die Szenen nichts außergewöhnliches seien und auch niemandem die Schamesröte ins Gesicht treiben würde (ebd.). Im Freistaat selbst gab es Proteste gegen die Entscheidung des Administrators und man fragte selbstbewusst, warum der

\footnotetext{
155 Die genannten Bevölkerungsgruppen waren hauptsächlich in der Kapprovinz ansäßig, mit Asiaten waren die sogenannten Kap-Malaien gemeint.
} 
Freistaat mit der Kapprovinz die zweifelhafte Entscheidung teilen müsse, einen Film zu verbannen, der als beste Tonfilmkunst gepriesen werde (TF 7.5.31: 8). Einige Deutsche im Freistaat sahen den Beschluss als eine gezielte Benachteiligung der deutschen Produzenten an (ebd.). Unverständlich sei darüber hinaus, wie dann ein Film wie "The Way of all Flesh" habe freigegeben werden können, ein Film dessen deprimierenden Eindruck man nie vergessen werde (TF 19.5.31: 9).

In einem weiteren Leserbrief wurde der Bemerkung widersprochen, dass die Handlung des Films am Lieblingsort des Bösen schlechthin stattfinde (CT 19.3.31: 8). Das ganze Szenario könne man sich auch in Südafrika vorstellen, man müsse sich die Hafenstadt nur als Kapstadt und Prof. Rath als einen alternden Professor aus Stellenbosch vorstellen, der dasselbe erlebe und an der gleichen Tragödie zugrundegehe wie im BLAUEN ENGEL. In Deutschland diskutiere die Jugend ganz offen darüber und zeige ein erstaunliches Verständnis für die aufgeworfenen Probleme. Auch in Südafrika habe die Jugend einen sauberen, freimütigen und wissbegierigen Geist, so dass einzig die großartige Darstellung eines Leidenden in Erinnerung bleiben wird, alles andere versinke in Bedeutungslosigkeit. Den Zensoren und Nörglern wird die Jugend als Beispiel empfohlen, damit sie ihre altmodischen Unaufrichtigkeiten des letzten Jahrhunderts loswerden können:

„Middle-aged critics and carpers, having clouded minds, seek sly allusion to condem - after enjoying it. Their eyes and senses ferret out wrong where none was intended clinging to the out-moded dishonesties of the last century. Let them learn of the young, to see and think with clarity and honesty. Though their motives may appear pure to themselves, it is sometimes difficult to deny the quip that to the pure all things are impure" (ebd.).

Trotz der Tatsache, dass die Presse mehrheitlich zensurkritische Artikel und Leserbriefe veröffentlichte, kamen beide Seiten gleichberechtigt zu Wort. Das Zensurkomitee habe schließlich auf eine Art ,gesunde Unterhaltung' zu achten, „Have not indecent and suggestive sex plays and films had a long enough innings?" (CT 17.3.31: 8), es wäre höchste Zeit, dass jene unterstützt würden, die auch in Kino und Theater für ein lehrreiches und erbauliches Programm sorgen wöllten (ebd.). Warum man diese Fähigkeit ausgerechnet dem BLAUEN ENGEL absprechen wollte, bemängelte ein anderer Leserbrief: 
"Critics throughout the world are unanimous that the film industry as a whole has produced little worthy of the name of art. The one notable exception is the work of Emil Jannings, and it is to his undying credit that, despite the ever-increasing public demand for sentimental love-sick trash, he has been responsible for the introduction of a little real life on the movies" (CT 17.3.31: 8).

Da das Zensurgesetz nur öffentliche Filmvorführungen verbieten konnte, kam Ende April eine Privataufführung von DER BLAUE ENGEL in Kapstadt zustande, an der sogar Vize-Premier Jan Smuts, der Innenminister Daniel Francois Malan (Initiator des zentralen Zensurgesetzes), die Bürgermeisterin, Parlamentsabgeordnete und weitere Persönlichkeiten des öffentlichen Lebens teilnahmen. Zum Schluss des Films spendierte die ausgewählte Runde anhaltenden Beifall (CT 27.4.31: 7).

Die Rezeptionsgeschichte von DER BLAUE ENGEL endete in Südafrika erst 1932, so wurde der Film im November erneut in Durban aufgeführt (NM 29.10.32: 21), wobei auffällig ist, dass nur die Pressebelege aus der Provinz Natal auf die Literaturvorlage von Heinrich Mann hinwiesen (NM 1.11.32: 9). In Kapstadt wurde der Film zusätzlich noch im Rahmen einer Privatveranstaltung des dortigen Filmklubs gezeigt, was wiederum die alten Beanstandungen reflexartig hervorrief (DB 24.11.32: 7).

Nach Sichtung und Gegenüberstellung der ausgewählten Filmkritiken wird deutlich, welche Gemeinsamkeiten sich zwischen der südafrikanischen und der deutschen Rezeption aufdrängen. Geschätzt wurde der virtuose Umgang mit dem neuen Medium Tonfilm, der sogar in der Fremdsprachenversion überzeugen konnte. Die in die Handlung eingepasste Berücksichtigung des bilingualen Dialogs (Rath ist Englischprofessor, Lola eine ausländische Künstlerin) wurde als eine gekonnte Authentisierungsstrategie wahrgenommen (NA 4.8.30: 11). Die schauspielerische Umsetzung des Themas durch das Ensemble um den vom Stummfilm- zum Tonfilmstar gereiften Emil Jannings stand in der südafrikanischen Rezeption eher im Vordergrund als in der deutschen. Da Jannings auch durch seine internationalen Erfolge in Südafrika bekannt und beliebt war, dominierte in der südafrikanischen Presse das Herausstreichen seines darstellerischen Talents. In der deutschen Presse dominierte der Eindruck, dass Jannings noch zu viel Pathos á la „Der letzte Mann" oder „The Way of all Flesh" mit sich herumschleppe und von Marlene Dietrich mehr oder weniger an die Wand gespielt werde.

Da Heinrich Manns Roman „Professor Unrat" in Südafrika weitgehend unbekannt war, obwohl dessen Autorschaft auch im Vorspann der englischen Version genannt wurde, enthielten die Rezeptionsdokumente bis auf zwei 
unbedeutende Ausnahmen keine Verweise auf die Literaturvorlage, so dass die Problematik der Literaturverfilmung, anders als in der deutschen Rezeption, nicht thematisiert werden musste. Aus diesem Grunde war es in Südafrika wesentlich unkomplizierter, den Film einfach als ein isoliertes Kunstwerk, denn als Verfilmung zu begreifen (Schmidt 1965: 39). Die südafrikanische Medienrezeption war vollkommen mit Sternbergs Bemühen einverstanden, die spätbürgerliche Welt Europas einfach nur darzustellen, während die deutsche vielfach unter Berufung auf die Romanvorlage deren Denunziation forderte (ebd.).

An dieser Stelle wird nun sichtbar, wie auf die intendierte Wirkung des Films im jeweiligen Rezeptionskontext reagiert wurde. Während die deutsche Rezeption die vom Roman vorgeschlagene gesellschaftskritische, vom Film aber nichteingelöste Lesart forderte, fand sie sich mehrheitlich (mit der Ausnahme der politischen Tendenzpresse wie z.B. der Roten Fahne), abgelenkt durch die Tonfilmproblematik und das gelungene Schauspiel, mit der Darstellung des individuellen Versagens eines Einzelnen (,Grenzüberschreitung') ab. Eine an den Roman angelehnte kritische Lesart wurde jedoch durch den Film gekonnt ausgeschlossen, was durch die Presse mit Bemerkungen wie ,substanzloses, Spießerstück' oder ,verzuckmayerte Gesinnungslosigkeit' angeprangert wurde. Als zeitgenössisch dominantes Rezeptionsangebot wurde die intendierte Wirkung im Wesentlichen vom Großteil der Filmpresse und so wahrscheinlich auch vom Publikum akzeptiert. Die angespannte sozio-ökonomische Situation der Jahre 1929/30, die ausgehend vom Roman des Jahres 1905 eine wesentlich kritischere Lesart des Films hätte hervorrufen können, wurde durch die bewusste Änderung des Drehbuchs verhindert, da die politisch konservativ gelenkte UFA kein Interesse daran hatte, die ,spätbürgerliche Welt Europas' noch weiter bzw. wenigstens nicht ,von links' zu demontieren.

Im Gegensatz dazu schwenkte die südafrikanische Presse voll auf die dominante Lesart ein, unterstützte aber wie ihre deutschen Kollegen auch die Lesart des individuellen und nicht des gesellschaftlichen Versagens. Durch die andersartige sozio-ökonomische Situation in Südafrika, d.h. der verzögerten Auswirkungen der Weltwirtschaftskrise, ebenso wie durch die Nichtbekanntheit der Romanvorlage, konnte in Südafrika keine ähnlich gesellschaftskritische Lesart in Bezug auf den Film entstehen. Gleichwohl gab es eine andere Art von Kritik, welche sich auf ganz andere zeitgenössisch dominante Rezeptionsangebote bezog. In diesem Zusammenhang ist die regionale Zensurentscheidung als Maßnahme zur Vermeidung nichtintendierter potentieller Lesarten zu verstehen. Ruft man sich in Erinnerung, dass die Verbots- 
entscheidung wahrscheinlich auf die Initiative der weiblichen Mitglieder der Zensurkommitees in Kapstadt zurückging und diese von den weiblichen Mitgliedern des Zensurrates in Bloemfontein ausdrücklich unterstützt wurde, wird klar, dass hier stellvertretend für eine mögliche weibliche Lesart gehandelt wurde. Die auf einer gut/böse-Polarisierung beruhende negative Darstellung der weiblichen Hauptfigur, die starke sexuelle Aufladung der Figur Lola-Lola und der angedeutete Ehebruch dürften das Missfallen der betreffenden Zensurratsmitglieder gefunden haben. Hinter der formaljuristischen Standardfloskel "suggestive of immorality and offensive to public decency" wird auch die Befürchtung gestanden haben, dass jene im Varieté-Millieu tätigen Frauen generell als Prostituierte anzusehen wären und das eindeutige Angebote der männlichen Zuschauer eine logische Reaktion wären. Allerdings konnte durch die Darstellung des relativen Erfolgs von Lola-Lola ebenso suggeriert werden, dass sich eine solche Tätigkeit vielleicht zeitweise lohnen würde. Immerhin mündete die Präsentation von Lolas Reizen in einer Ehe mit einem Gymnasialprofessor.

Die genannten Erklärungsansätze erschließen sich am besten mit einem Rekurs auf die südafrikanische Zuschauergeschichte. Die wirtschaftlichadminstrative Dominanz des englischen Establishments in Kapstadt - und somit auch in der Zensurbehörde - darf nicht darüber hinwegtäuschen, dass es sich bei der Mehrzahl der europäischstämmigen Bewohner der Kapprovinz um Afrikaaner handelte, deren vielfach prekäre sozio-ökonomische Situation sich wesentlich von jener der englischstämmigen Südafrikaner unterschied. Gleichzeitig war in der Kapprovinz die intellektuelle Elite der Afrikaaner beheimatet und aktiv bestrebt, Strategien zur Verbesserung der Situation auf politischem Wege herbeizuführen. Oberstes Ziel war dabei, die durch den Urbanisierungsprozess proletarisierten „Arm-Blankes/Poor Whites“, 1932 immerhin ca. 300.000 von 1,8 Millionen ,weißen' Südafrikanern (Standish 1985: 141), eine sozio-ökonomische Perspektive zu geben und den Verarmungs- bzw. Verwahrlosungsprozess umzukehren. Als besonders schützenswert wurden dabei die traditionell hochgeschätzten Familienstrukturen angesehen, die im Zuge der Landflucht immer mehr erodierten. Die als Gefahr wahrgenommene gesellschaftliche Modernisierung (Industrialisierung etc.) wurde für die schwächsten Teile der afrikaansen Bevölkerung (Jugendliche und junge Frauen) als besonders bedrohlich eingeschätzt:

„Not infrequently poor white youths and girls migrate to the city alone before the rest of the family and without having made certain of employment beforehand, and so become more easily subjected to immoral influences. 
Low wages are a source of danger to the girls as is also employment in a certain class of café, and hence parents of poor families who have migrated to the cities are often opposed to their girls being engaged in this type of work. Poor whites are subject to the demoralising influences of life in the city all the more easily because of the uprooting effects of leaving their old environment with its sanctions and customs. They become acquainted with a new mode of life and with temptations which the weaker cannot withstand" (Wilcocks 1932: 83).

Genau dieses als voller ,Verführungen' und ,unmoralischer Einflüsse' geltende Millieu wurde jedoch im BLAUEN ENGEL thematisiert. Zwar wurde es als negativ, aber dennoch als gesellschaftlich weitgehend toleriert dargestellt. Gleichzeitig wurde vermutet, dass vor allem die jungen Frauen als entwurzelte neue Großstadtbewohner in erhöhtem Maße ins Kino gehen würden („Plenty of pleasure such as dancing and bioscopes“, Rothmann 1932: 202). Dort hätten sie dann Filme wie den BLAUEN ENGEL sehen können, der das ganze Gegenteil von jener moralischen, wie auch sozio-ökonomischen Auferstehung darstellte, die sich die Afrikaaner-Intellektuellen und auch die einflussreichen Frauenverbände wünschten. Zum Schutz dieser Bevölkerungsteile dürfte die Zensurmaßnahme durchgesetzt worden sein, da man im Falle des Kinos immer von einem direkten Einfluss der im Film gezeigten Inhalte (,Reiz-Reaktions-Schema') auf die Zuschauer ausging. Die potentielle Lesart der Figur Lola-Lola als erfolgreiche Prostituierte wurde im südafrikanischen Kontext demnach als Teil des zeitgenössisch dominanten Wirkungsangebotes eingeschätzt, welches in keinem Falle rezipiert werden sollte.

Ganz ähnlich dürfte auch im Fall der unvorteilhaften Darstellung des Lehrerstandes im Film argumentiert worden sein. Einen wesentlichen Teil zur Verbesserung der Lebenssituation der ,Arm Blankes/Poor Whites' stellten die Maßnahmen zur Hebung des Bildungsniveaus dar. Dabei kam dem Lehrer die entscheidende Rolle zu, selbst ein gutes Vorbild zu sein, um dadurch die Lernmotivation seiner Schüler zu fördern:

„Now, if it is true that the teacher, his qualifications and power of leadership constitute the most potent single factor in the rehabilitation of the poor white, does it not, therefore, follow that if we wish to seek the uplift of our people by means of education, we should concern ourselves above all with the selection and training of our teachers?" (Malherbe 1932: 321).

Der Lehrer in DER BLAUE ENGEL hingegen wird zunächst als ein unbarmherziger Tyrann dargestellt, der zwar Disziplin und Ordnung exzerziert, aber schon bald von der Neugierde des Verbotenen angezogen und ins Unglück 
gestürzt wird. Dass eine gesellschaftlich respektierte Persönlichkeit eine Beziehung mit einer Prostituierten eingeht, konnte kaum als vorbildlich gelten und sprach auch nicht für die Willensstärke des Pädagogen. Die potentielle Lesart der Figur Prof. Rath als einer individuelle Fehler machenden Autoritäsperson, wurde demnach im südafrikanischen Kontext als Teil des zeitgenössisch dominanten Wirkungsangebotes eingeschätzt, welches ebenfalls unter keinen Umständen rezipiert werden sollte.

Die Zensurmaßnahmen orientierten sich also an der als unbedingt schutzbedürftig eingeschätzten verarmten afrikaansen Stadtbevölkerung, die man ob ihrer geringen Bildung nicht in der Lage wähnte, die ,richtigen' Schlüsse aus der Filmrealität ableiten zu können. Dass sich die etablierten Zeitungen Kapstadts und deren wohlsituierte Leser gegen diese Bevormundung wehrten, ist deshalb nur allzu verständlich. Folgt man der Logik der Zensurentscheidung, hätte in der viel stärker von den Urbanisierungsprozessen betroffenen Provinz Transvaal (Johannesburg etc.) die geschilderte Gefahr eine ungleich größere Wirkung entfalten müssen. Dort wurde der Film jedoch nur mit einem Jugendverbot belegt, da die Filmzensur in dieser Provinz von der Polizei ausgeübt wurde, die Auflagen oder Verbote nur aussprach, wenn sie die öffentliche Sicherheit bedroht sah.

Da die geschilderten Gefahrenpotentiale in Deutschland nicht existierten, spielte die Zensur nur eine untergeordnete Rolle, in Südafrika hingegen dominierte sie die Rezeption des BLAUEN ENGELS. Als Ursache dafür kann der generelle Gegensatz zwischen der städtisch modernen und experimentierfreudigen Gegenwart der Weimarer Republik und der noch immer stark vom 18. Jahrhundert geprägten, extrem konservativen und ruralpaternalistisch strukturierten Lebenswelt Südafrikas angesehen werden. In letzterer konnte die Darstellung einer selbstbewussten, sich im Grenzbereich von Tingel-Tangelmilieu und Prostitution behauptenden Frauenfigur nur auf Unverständnis stoßen. Das Sendungsbewusstsein der AfrikaanerIntellektuellen in der Kapprovinz verstärkte dabei die Tendenz, die unter lokalen Bedingungen ausgehandelte Lesart des Films („dominantem Kode unter lokalen Bedingungen“, Hall 1999: 108) als gefährlich einzuschätzen, was für die verhängte Verbotsentscheidung ausschlaggebend gewesen sein dürfte. Der in der Presse geäußerte Verdacht, dass ein weibliches Mitglied des Kapstädter Zensurkomittees maßgeblich am Zustandekommen des ablehnenden Votums beteiligt gewesen sei, bestätigt diese Einschätzung, ebenso die negative Einschätzung der Frauenvertreterinnen im Zensurrat des Oranje-Freistaates. Die unterstellte Herabwürdigung des Lehrerstandes im BLAUEN ENGEL klingt als Verbotsgrund ebenso plausibel. 
Betrachtet man die vorgefundenen Phänomene und stellt sie in einen übergeordneten kulturell-gesellschaftlichen Zusammenhang, drängt sich folgende Deutung auf, die maßgeblich durch die Verschiedenheit der Bezugsbzw. der Bedingungsrealitäten verursacht erscheint. Sowohl im südafrikanischen, als auch im deutschen Rezeptionskontext stellt die in DER BLAUE ENGEL dargestellte Thematik eines sozio-ökonomisch bedingten Autoritätsverlustes ein aktuelles Problem dar (,Bezugsrealität'). Für das deutsche Publikum wurde eine Lösung im Sinne der damaligen immer konservativer werdenden Politik nahegelegt, die mit Autorität, Pflichtbewusstsein und Disziplin die alten Werte der Monarchie beschwor und die neuen Werte der Weimarer Republik wie Pluralismus, Mitbestimmung und Freiheit als Bedrohung der Ordnung dämonisierte. In diesem Sinne könnte man den im Film vermittelten Ausweg als „restaurative Lösung“ umschreiben. Es wird suggeriert, dass sich ohne die Grenzüberschreitung des Professors die aufgetretenen Probleme nicht ergeben hätten und generell die alte Situation, bezogen auf den Film also der strikte Nichtkontakt zum „weiblich“ konnotierten Raumkonzept, als die stabile und wünschenswerte dargestellt wird („Gesellschaftsmodell/Lebenswelt Rath").

Eine gänzlich andere Bedingungsrealität stand hinter den südafrikanischen Reaktionen auf den Film. Für einen Großteil der Bevölkerung stellte sich das "Gesellschaftsmodell Lola" als aktuell bzw. prekär und nicht als die Verkörperung demokratischer Freiheiten dar. Da man politisch bestrebt war, diese Notsituation zu verbesseren, wurde die nicht grundsätzlich negative konnotierte Figur Lola als gefährlich und zu realitätsnah eingeschätzt. Eine „restaurative Lösung“ des Problems wie im "Gesellschaftsmodell Rath“ konnte es in Südafrika so nicht geben, weil eine gesellschaftlich rückwärts gewandte Politik im Sinne der Afrikaaner genau die erträumte pastoral-agrarische Lebenswelt des 18. Jahrhunderts war, die durch den Burenkrieg und die beginnende Industrialisierung unwiederbringlich zerstört war. Einer ähnlich geordneten Gegenwart wie im "Gesellschaftsmodell Rath" entsprachen sicher auch einige Zukunftsvisionen der Afrikaaner-Intellektuellen, jedoch durften diesen nicht als Rückkehr in eine alte Ordnung daherkommen, da sich die Beharrungskräfte in Südafrika als sozio-ökonomisch unterlegen erwiesen hatten. Das "Gesellschaftsmodell Rath" stellte vielleicht einen Wunschzustand dar, jedoch durfte dieser nicht durch Negativkonnotationen oder die Zuschreibung menschlicher Schwächen gefährdet werden, um die Hoffnung auf positive Veränderungen durch eine gesellschaftliche Modernisierung nicht zu gefährden. Die offene Kritik der südafrikanischen Zensurverantwortlichen an der Darstellung der Lebenswelt Lolas als „suggestive of immorality 
and offensive to public decency" war demnach nicht durch die offensive Erotik der Figur, sondern durch die vermittelte Toleranz gegenüber dieser gesellschaftlichen Wirklichkeit begründet. Dass es diese Lebenswirklichkeit in Südafrika gab, stand außer Frage. Bei der stets als Vorbild dienenden europäischen Kultur wollte man es aber in Bezug auf deren propagierte Überlegenheit offenbar nicht riskieren, durch eine zu genaue Hinterfragung der dortigen Zer- und Verfallsprozesse das Konzept der europäischen Kulturdominanz auch nur in irgendeiner Weise zur Disposition zu stellen. Insofern verwundert es nicht, dass eingedenk der fragmentierten südafrikanischen Zuschauergeschichte der Tenor der dortigen Medien in etwa so ausfiel, wie es produktionsseitig angedacht war. Als ausgehandelter Kode, und somit die Dominanz der individuellen Schicksalserfahrung vor der Gesellschaftskritik festschreibend, lässt sich die Äußerung der Cape Times deuten, wonach die großartige Darstellung eines Leidenden in Erinnerung bleiben und alles andere in Bedeutungslosigkeit versinken werde (CT 19.3.31: 8).

\subsubsection{Exemplarische Dokumentenanalyse von ASPHALT}

In ASPHALT/TEMPTATION ${ }^{156}$ wird das dramatische Aufeinandertreffen eines pflichtbewussten Polizeiwachtmeisters mit einer professionellen Diebin geschildert, wobei es Letzterer gelingt, den Staatsdiener für sich einzunehmen, um einer Strafe zu entgehen. Im Streit um die Gunst der Halbweltdame erschlägt der Polizist einen ihrer kriminellen Komplizen. In seiner Gewissensnot offenbart er sich seinem ebenfalls bei der Polizei angestelltem Vater und wird von diesem dem Gesetz überstellt. In Reue gesteht die Geliebte des jungen Polizisten den wahren Tathergang und muss selber eine Haftstrafe antreten. Das getrennte Liebespaar verspricht sich dennoch in Treue aufeinander zu warten.

Nach einer speziellen Pressevorführung in Kapstadt sprach die Cape Times von einer „[...] slight human story, so cleverly unfolded that the drama consistently maintains a very high level" (CT 16.10.29: 7). Auch von der technischen Seite sei die Produktion sehr interessant, die individuelle Charakterisierung der Handelnden durch die beiden Hauptdarsteller, gepaart mit der cleveren Kameraarbeit, schaffe eine überaus realistische Atmosphäre. In Kapstadt wurde der Film zum einjährigen Jubiläum des Astoria-Kinos gezeigt

${ }^{156}$ CT 16.10.29: 7, CT 19.10.29: 13, CA 22.10.29: 13, DB 22.10.29: 8, CT 22.10.29: 7, DB 23.10.29: 8, NM 9.11.29: 23, NM 12.11.29: 7, NW 16.11.29: 13, TF 23.12.29: 15, RDM 30.12.29: 5, EPH 14.1.30: 6, EPH 15.1.30: 20, EPH 18.1.30: 5, EPH 8.9.32: 5 (Kapstadt, Durban, Pietermaritzburg, Bloemfontein, Johannesburg, Port Elizabeth). 
und trug somit zur bereits bestehenden hohen Reputation der kontinentaleuropäischen Produktionen bei (CA 22.10.29: 13).

Wesentlich enthusiastischer sprach man in der afrikaansen Tageszeitung Die Burger über ASPHALT. Der Film sei einer der ,größten' der UFA (DB 22.10.29: 8). Durch die vielen kleineren mit der UFA verbundenen Produzenten kämen zwar gelegentlich unbedeutendere Filme wie DIE LEIBEIGENEN, HEIMKEHR oder AM RANDER DER WELT nach Südafrika, aber DIE WUNDERBARE LÜGE DER NINA PETROWNA und ASPHALT hielten den Standard der UFA in Ehren (ebd.). Die Photographie sei wunderbar, die Regie gebe ein prächtiges Beispiel dafür ab, was ein guter Regisseur mit einem erstklassigen Schauspieler wie Gustav Fröhlich machen könne. In HEIMKEHR habe Fröhlich noch eine untergeordnete Rolle gespielt, aber in ASPHALT könne er endlich zeigen was er kann; genauso tiefsinnig wie temperamentvoll sei es ein Genuss, seinem Schauspiel zu zusehen. Seine Partnerin Betty Amann stehe ihm in nichts nach, auch nicht in den feinsten Nuancen des Ausdrucksvermögens. Produzent Erich Pommer ertrage nur Filme, die wirkliche Kunstwerke seien, Zweitklassigkeit lasse er gar nicht zu. Mit Regisseur Joe May habe er zudem einen erstklassigen Partner gefunden. So wäre es auch kein Wunder, das ASPHALT einer der besten Filme der letzten Monate gewesen sei, zumindet seit DIE TODESSCHLEIFE (ebd.). Auch sei der Film besser als DIE WUNDERBARE LÜGE DER NINA PETROWNA, Regie und Handlung seien einfach besser, außerdem sei letzterer nur ein ,ein-Personen-Film' gewesen.

Die überdurchschnittlich häufigen Vergleiche mit anderen deutschen Produktionen lassen sich programmhistorisch darauf zurückführen, dass die genannten Filme im gleichen Halbjahr wie ASPHALT zu sehen waren, im Falle von DIE WUNDERBARE LÜGE DER NINA PETROWNA betrug der zeitliche Vorlauf nur etwa zwei Wochen (Eckardt 2005: 115f.). Durch die zeitliche Konzentration dieser Filme in den Lichtspielhäusern von Kinemas konnte das Publikum die deutschen Spielfilme als einen wesentlichen Programmbestandteil des Kinojahres 1929 wahrnehmen.

Im Astoria-Kino Kapstadts lief der Film vor einem zahlreichen Publikum (CT 22.10.29: 7) und wurde als hochentwickeltes Filmdrama von heute eingeschätzt, dessen Erfolg nicht so sehr von der Ausarbeitung des Themas abhänge, sondern vielmehr seiner künstlerischen Produktion und psychologischen Wahrheit geschuldet sei. Trotz der pathetischen Schlußszene und minimaler Konstruktionsdefekte sei der Film mit seinen zweifellos guten Darstellern und der äußerst gelungenen Produktion spannende Unterhaltung (ebd.). In der zweiten Besprechung von Die Burger fiel dem Rezensenten 
besonders positiv auf, dass in der siebenminütigen Eröffnungssequenz (Kamerafahrt mit Drehkran) keine Zwischentitel vorkamen und dadurch die Verbildlichung viel eindrucksvoller wirke (DB 23.10.29: 8). Die UFA habe sich erfolgreich vom Theater gelöst und sich den Anforderungen des Films gestellt und Lösungen dafür gefunden. Die Rückkehr zu Rafinesse und in der Wirklichkeit des Seins dargestellten Menschen hob auch der Natal Mercury positiv hervor. Zu oft habe man Filme mit unechten Puppen und unreifer Bösartigkeit ertragen müssen (NM 9.11.29: 23).

Die gleiche Zeitung begrüsste ASPHALT als einen Film, der wie die meisten ,Teutonic films' einen ungewöhnlichen Beginn und eine starke Handlung habe und ganz im Gegensatz zu DIE WUNDERBARE LÜGE DER NINA PETROWNA stehe, welcher dem guten Ruf des Kings-Kinema in Durban letzte Woche merklich geschadet habe (NM 12.11.29: 7). Die Dreiecksgeschichte profitiere vom fast bis zum Ende aufgesparten Hinzukommen der dritten Partei, erst zum Höhepunkt der Handlung sei dies nötig gewesen. Sowohl der aus HEIMKEHR bekannte Hauptdarsteller Gustav Fröhlich, als auch der die Vaterrolle spielende und in AM RANDE DER WELT mitwirkende Albert Steinrück spielten mit bemerkenswerter Leidenschaft, Betty Amann als Femme fatale wurde mit der US-Amerikanerin Clare Bow verglichen (ebd.). Der Natal Witness schloss sich diesen Einschätzungen an, bezeichnete den Film aber ganz offen als "sex and murder drama" (NW 16.11.29: 13). Bei guten Publikumszuspruch lief der Film auch in Port Elizabeth, welcher als „especially remarkable for its display of character acting and for the technical excellence of the production" angepriesen wurde (EPH 14.1.30: 6), der Film steigere ebenso das ohnehin hohe Ansehen der kontinental-europäischen Produktionen (EPH 15.1.30: 20). Formulierungen wie "highly emotional acting“ (ebd.) oder „a film which has caused a lot of discussion wherever it has been shown" (EPH 18.1.30: 5), deuten lediglich zwischen den Zeilen darauf hin, dass der Film eine starke erotische Komponente enthielt, die nur der Natal Witness offen als "sex and murder drama" bezeichnete (NW 16.11.29: 13).

Die deutschsprachige Filmkritik ging mit ASPHALT hart ins Gericht, schon der Titel stünde zur Handlung in einem etwas losem Zusammenhang (PFL 1929: 35f. bzw. Vogt 2001: 191). In Südafrika konnte diese Kritik nicht entstehen, da mit dem Verleihtitel TEMPTATION ${ }^{157}$ das Leitmotiv der Handlung präzise umschrieben wurde. Ganz allgemein bemängelte man trotz guter technischer Umsetzung die zu flache Botschaft des Films: „Man hat die

${ }^{157}$ Engl. für Versuchung, Verlockung. 
äußere Vervollkommnung, die technischen Effekte gelernt, aber die inhaltliche Substanz einschrumpfen lassen“" (Berliner Boersen-Courier 12.2.29 in: Gandert 1993: 29). Ganz ähnlich äußerte sich 1929 auch Siegfried Kracauer, der konstatierte: „Schade, daß wie so oft in Deutschland das technische Verständnis sich auf Kosten des Wissens um die geistige Bedeutung auslebt" (Kracauer 1995: 413).

In Bezug auf das Schauspiel wurde wie in der südafrikanischen Kritik bemerkt: „Man sieht den Einfluß des Regisseurs auch bei einem Schauspieler wie Gustav Fröhlich, der noch nie so einfach und gehalten war" (Berliner Boersen-Courier 12.2.29 in: Gandert 1993: 29). Dem Drehbuch wurde vorgehalten, dass es voller billig moralisierender Wandsprüche sei (Die Welt am Abend 12.3.29 in: Gandert 1993: 29), der packend beginnenden großstädtischen Version Berlins folge das Erleben eines Polizisten mit Pflicht, Verführung, Reue und Buße, ein Volksstückinhalt von ärmlichstem Geschmack (Berliner Tageblatt 17.3.29 in: Gandert 1993: 29).

Von Interesse ist auch die Tatsache, dass die Umsetzung der erotischen Komponente als vertane Chance angesehen wurde: „Und die Verführungsszene, bei der der blonde Gustav Fröhlich seine polizeilichen Pflichten vergisst, ist beträchtlich naiv. So ein Anspringen, so eine Umklammerung. So ein Nichtloslassen ist des Guten zuviel. Es muß eher abstoßend wirken [...]“ (ebd.). Dieser Hinweis wirft die Frage auf, warum die südafrikanische Rezeption auf diese Szene scheinbar überhaupt nicht einging. Ein Grund könnte in der strengen Zensurpraxis der Kapprovinz zu sehen sein, die für eine solche Szene Schnittauflagen erteilt hätte. Dieses Nichterwähnen in der Filmkritik der Kapstädter Tagespresse lässt tatsächlich eine derartige Zensurpraxis vermuten, da die Presse in der Provinz Natal, die gar kein spezielles Zensurgesetz hatte, offen von einem "sex and murder drama" sprach (NW 16.11.29: 13). Auch in Deutschland wurde der Film mit einem Jugendverbot belegt, weil angeblich unmoralische Darstellungen zu sehen seien (Vogt 2001: 188). ${ }^{158}$ Filmhistorische Einschätzungen sprechen wiederum davon, dass die Verführungsszene in ihrer stofflichen und atmosphärischen Sinnlichkeit zu den Höhepunkten der deutschen Filmkunst gehören würde (Kramer 1995: 37).

Anders als in der südafrikanischen Filmkritik wurde Betty Amann mit Dita Parlo und nicht mit Clara Bow verglichen (Berliner Tageblatt 17.3.29 in: Gandert 1993: 29), allerdings wirke Betty Amann wie aus dem Titelblatt

${ }^{158} \mathrm{Vgl}$. zusätzlich die Zensurentscheidung der Oberfilmprüfstelle Berlin Nr. 743 vom 9.8.1930; unter: http://www.deutsches-filminstitut.de/zengut/df2tb008z.pdf [13.12.2006]. 
eines amerikanischen Magazins ausgeschnitten (Berliner Boersen-Courier 12.2.29 in: Gandert 1993: 29). Technisch sei zwar in der Rhythmik des Bildablaufs, in den Kontrastierungen, Übergängen und Entsprechungen der Bilder Meisterliches erreicht worden (Berliner Boersen-Courier 12.2.29 in: Gandert 1993: 28), allerdings würde man doch niemals die Ursprünglichkeit und Unmittelbarkeit der technischen Wirkungen wie die Amerikaner erreichen (ebd.: 29), zumal sich gerade vom Inhaltlichen her der deutsche Film seine Eigenart erobert habe (ebd.). Diese Gefahr der Hollywoodanbiederung, genährt durch die auf Unterhaltung und internationalen Erfolg abzielenden Produktionen eines Erich Pommer, sah man in der südafrikanischen Kritik überhaupt nicht. Das technisch hohe Niveau, die spannende und leicht verständliche Handlung machten gerade bei der südafrikanischen Kritik den Reiz des Films aus, eine Tatsache, die durch Berichte über den guten Publikumszuspruch bestätigt werden kann.

Als ,Straßenfilm' dokumentierte ASPHALT die hohe Kunst des deutschen Stummfilms in seiner Endphase kurz vor dem Übergang zum Tonfilm. Dies wurde in der südafrikanischen Medienrezeption vor allem durch die Betonung der künstlerischen Überlegenheit gegenüber den US-Produktionen anerkannt. Die Straße als Symbol für die Chancen und Gefahren des neuartigen Großstadtlebens weiter Teile der deutschen Bevölkerung wurde in Südafrika wesentlich unkritischer aufgenommen als in Deutschland.

\subsubsection{Untersuchung der "MI >10-Filme“}

Der ebenfalls von Erich Pommer produzierte Film DIE WUNDERBARE LÜGE DER NINA PETROWNA/THE WONDERFUL LIE OF NINA PETROWNA schildert das Schicksal der Geliebten eines hohen russischen Offiziers, die sich in einen seiner Untergebenen verliebt und ersteren verlässt. Durch Geldnot getrieben, versucht der neue Liebhaber beim Kartenspiel sein Glück mit gefälschten Karten zu erzwingen, was jedoch von seinem Vorgesetzten entdeckt wird. Für sein Schweigen verlangt der Oberst die Rückkehr seiner vormaligen Geliebten, die daraufhin wieder in dessen Haus einzieht, sich jedoch kurz darauf durch Gift das Leben nimmt. 
Tab. 40: „Ml>10-Filme“ unter den Genre 2-Filmen

\begin{tabular}{|c|c|c|l|c|}
\hline MI & PFL & FK & \multicolumn{1}{|c|}{ Filmtitel } & Erstbeleg SA \\
\hline 19 & 2 & 6 & Die wunderbare Lüge der Nina Petrowna $(\mathrm{A})^{\star}$ & $02.10 .1929 \mathrm{CT}$ \\
\hline 18 & 1 & 7 & Heimkehr $(\mathrm{K})^{\star}$ & $08.02 .1929 \mathrm{NA}$ \\
\hline 16 & 1 & 9 & Asphalt $(\mathrm{K})^{\star}$ & $16.10 .1929 \mathrm{CT}$ \\
\hline
\end{tabular}

Das damals populäre zaristische Emigranten-Drama DIE WUNDERBARE LÜGE DER NINA PETROWNA ${ }^{159}$ variert das aus MANON LESCAUT bekannte Thema mit Brigitte Helm und Franz Lederer in den Hauptrollen. Auf die thematische Verwandtschaft mit dem im Sommer 1929 gezeigten Film MANON LESCAUT weisen folgerichtig auch einige Besprechungen hin (CT 5.10.29: 13 und CT 8.10.29: 7). Generell fällt bei den meisten Besprechungen auf, dass neben der Filmhandlung auf die Produzententätigkeit Erich Pommers (zuweilen auch als Regisseur genannt, DB 4.10.29: 9) hingewiesen wird und nicht auf die Regieleistung von Hanns Schwarz, sowie auf die auBergewöhnliche Darstellungsleistung von Brigitte Helm.

Als unzweifelhaft besten Film des Jahres beschreibt Die Burger DIE WUNDERBARE LÜGE DER NINA PETROWNA, mit dem Filme wie SPIONE, DIE TODESSCHLEIFE und METROPOLIS endlich ihresgleichen gefunden hätten (DB 4.10.29: 9). Besonders beachtlich sei die Art und Weise, wie in diesem Film alles im Bild ausgedrückt werde, die ersten sieben Minuten des Films kämen vollkommen ohne Text aus, eine echte UFA-Errungenschaft. Die Zuschauer hätten endlich Gelegenheit, die UFA-Methode in voller Anwendung zu sehen, was ihnen die Chance gebe, zu begreifen, um wieviel besser ein Film sein könne, der darauf ausgelegt ist, alles in Bildern und ohne die Hilfe von Worten auszudrücken (ebd.). Die Qualität des Films war für den Manager des Astoria-Kinema der Beweis, dass der Stummfilm wohl nie aussterben wird, was der Kommentator mit Wohlwollen vermerkte. Die entfaltete Uniformenpracht sei wohl den amerikanischen Einflüssen geschuldet, das zurückhaltende Spiel von Brigitte Helm hingegen einfach wunderbar (ebd.). Ungewöhnlicherweise folgen noch zwei Besprechungen in Die Burger (DB 8.10.29: 8 und DB 11.10.29: 9). Brigitte Helm sei eigentlich nicht besonders hübsch, ja eigentlich zu mager, aber ihr Gesicht so ausdrucksstark und ihre Bewegungen so elegant, was sie zu einer der bezauberndsten Weibsbilder der Leinwand mache (DB 8.10.29: 8). Die gekonnte Inszenesetzung der Handlung und die prächtige Kameraarbeit unterscheide den Film

${ }^{159}$ CT 2.10.29: 9, DB 4.10.29: 9, CA 5.10.29: 13, DB 8.10.29: 8, CA 8.10.29: 13, DB 11.10.29: 9, RDM 14.10.29: 5, NM 2.11.29: 23, NM 4.11.29: 6, NM 5.11.29: 14, EPH 5.11.29: 13, EPH 8.11.29: 18, NW 9.11.29: 13, NW 13.11.29: 7, TF 24.2.30: 14, VB 25.2.30: 9, CT 1.11.32: 7 (Kapstadt, Johannesburg, Durban, Port Elizabeth, Pietermaritzburg, Bloemfontein, Kapstadt). 
himmelhoch von ähnlichen Produktionen US-amerikanischer Herkunft. Über die wenigen im wirklichen Leben eher unwahrscheinlichen Begebenheiten könne man getrost hinwegsehen, auch hätten einige der dramatischen Effekte etwas natürlicher wiedergegeben werden können (DB 11.10.29: 9).

Ähnlich positiv äußerte sich auch die Cape Times, der Film sei originell (CT 2.10.29: 9), unter den vielen Durchschnittsproduktionen hervorstechend (CT 5.10.29: 13), das Wort „UFA“ habe sich zu einem Markenzeichen für exzellente Filme entwickelt, die selten enttäuschen und mit Recht als Stummfilmkunst bezeichnet werden könnten (CT 8.10.29: 7). Die Kombination aus Realismus und Symbolismus vereinige sich im Schauspiel Brigitte Helms (CA 8.10.29: 13), die ihren ,sex-appeal' jetzt im Gegensatz zu METROPOLIS voll ausspiele (RDM 14.10.29: 5).

Während die Filmvorbesprechungen im Natal Mercury noch positiv unkritisch ausfielen (NM 2.11.29: 23 und NM 4.11.29: 6), meldete man nach der ersten Aufführung, dass der Film wohl keine Zuschauerrekorde brechen werde, da er gerademal zweitklassig sei (NM 5.11.29: 14). Trotz dieser Einschätzung sorgte der Film für ausverkaufte Häuser (EPH 5.11.29: 13). Die mit UNGARISCHE RHAPSODIE geschaffene Erwartung an ausgezeichnete Filme erfülle das Duo Erich Pommer und Hanns Schwarz mit DIE WUNDERBARE LÜGE DER NINA PETROWNA und übertreffe alle Erwartungen (NW 9.11.29: 13). Besonders der Verzicht auf den als typisch amerikanisch kritisierten Schluss der Machart „they are married and lived happily for ever" wurde begrüßt (VB 25.2.30: 9).

In einer erneuten Aufführung des Films im Jahre 1932 kam die Cape Times ganz im Gegensatz zu ihren vorherigen Einschätzungen zu dem Schluss, dass der Film die enttäuschendste Produktion gewesen sein müsse, mit der Erich Pommer je etwas zu tun gehabt habe (CT 1.11.32: 7). Die Geschichte sei weder besser noch schlechter als die Mehrzahl der übrigen Filmthemen, nur die Präsenz von Brigitte Helm, noch bekannt aus DIE LIEBE DER JEANNY NEY, mache die Banalität erträglich. In letztgenanntem Film und in schäbiger Kleidung habe ihre Darstellung jedoch viel lebendiger und realistischer gewirkt, als in der aus Satinkopfkissen und Duftbädern bestehenden Atmosphäre von DIE WUNDERBARE LÜGE DER NINA PETROWNA.

Die Ursachen für diesen Stimmungswandel bei der Cape Times könnten zum einen in einer weniger an die Agenturtexte angelehnten Berichterstattung durch neue Filmkritiker liegen. Andererseits stellte die Aufführung des Films vor dem Publikum des Kapstädter Filmklubs eine gänzlich andere Rezeptionssituation dar, aus welcher anschließende Diskussionen mit in die Filmrezension eingeflossen sein könnten. Das war bei den vorherigen Auffüh- 
rungen im Jahre 1929 eher unwahrscheinlich. Ein Hinweis auf die inzwischen erreichte Reflektionsfähigkeit findet sich in der Bemerkung:

„Technically the film was interesting in that it showed the early use of staircases and steps and clocks and other inanimate objects, later to be perfected by the German and Russian film producers für conveying atmosphere" (CT 1.11.32: 7).

Der 1932 weitgehend abgeschlossene Übergang vom Stumm- zum Tonfilm dürfte ebenfalls veränderte Rezeptionsgewohnheiten hervorgebracht haben, die den Film im Nachhinein in einem vollkommen anderen Licht erscheinen ließen. Als zeitgenössische Kritik können diese Bemerkungen nurmehr bedingt gelten, da der Film in einem veränderten Überlieferungzusammenhang rezipiert wurde und die veröffentlichte Kritik keine unmittelbare Medienrezeption mehr darstellt.

HEIMKEHR ${ }^{160}$ thematisiert das durch gemeinsame Kriegs- und Gefangenschaftserlebnisse entstandene Vertrauensverhältnis eines ledigen und eines verheirateten Soldaten. Die Erzählungen des letzteren über dessen Frau schaffen bei seinem Kameraden eine Vertrautheit mit der Ehefrau, welche inn nach seiner Flucht in die Lage versetzt, an die Stelle seines Kameraden zu treten. Nach seiner Rückkehr erkennt der alte Ehemann die neue Situation und verzichtet darauf, sein Recht von einer Frau zu fordern, die seine Liebe nicht mehr erwidert und geht zur See.

In den Filmvorbesprechungen zu HEIMKEHR fällt auf, das sie sich im Wortlaut stark ähneln, selten über eine Inhaltsangaben hinausgehen und wohl auf eine Agenturmeldung zurückzuführen sind (z.B. CT 31.8.29: 11, NM 7.9.29: 27, NA 7.9.29: 6 etc.).

Die erste Notiz des Natal Advertisers berichtet von Erich Pommers Rückkehr aus Hollywood und seinem neusten für die UFA produzierten Film (NA 8.2.29: 9). Um einen Film auch international ansprechend zu machen, habe Pommer in Hollywood gelernt, dass die Story eines Filmes auf das einfachste mögliche Element reduziert werden müsse. Daraus sei HEIMKEHR entstanden, ein Film mit perfekten Details, sehenswert, weil er eben nicht auf Sensationen ausgerichtet sei (ebd.). Die meisten Rezensionen und Vorbesprechungen gingen nicht über Inhaltsangaben hinaus, vereinzelt war von einem

160 NA 8.2.29: 9, ST 25.8.29: 6, DB 31.8.29: 8, CT 31.8.29: 11, CA 3.9.29: 13, NM 7.9.29: 27, NA 7.9.29: 6, CT 3.9.29: 7, NM 10.9.29: 8, NA 10.9.29: 14, DFA 16.9.29: 3, NW 28.9.29: 13, EPH 30.9.29: 8, EPH 1.10.29: 12, EPH 2.10.29: 15, EPH 5.10.29: 15, TF 7.1.30: 5 (Johannesburg, Kapstadt, Durban, Kimberley, Pietermaritzburg, Port Elizabeth, Bloemfontein). 
zahlreichen Publikum und einer typischen UFA-Produktion mit perfekten Details und Fotografie die Rede (CA 3.9.29: 13).

Kritisch äußerten sich nur wenige Kommentatoren, wie z.B. jener in Die Burger, der den zu häufigen Einsatz gemalter Hintergrundkulissen bemängelte, eine Spielerei, von der Pommer auch manchen deutschen Kritikern zufolge schnellstens genesen möge (DB 31.8.29: 8). Nachdem die Handlung in Deutschland angelangt sei, wurde dieser Mangel aber abgestellt und der gewohnte, warme Ton der UFA-Fotografie sei wieder vorherrschend. Bei der Darstellung der Schauspieler rage Lars Hanson deutlich hervor, eine Tatsache die auf Pommer zurückgehe, der den Schweden nicht wie in seinen amerikanischen Rollen nur sentimental agieren lasse. In vieler Hinsicht sei der Film typisch deutsch, besonders in der einfachen Darstellung der europäischen Häuslichkeit und der gewohnten echten Menschlichkeit ohne amerikanisches Gehabe und ähnlichen Zierrat (ebd.).

Als „nicht vom üblichen Standard“ sprach hingegen der Natal Mercury, trotz des guten Schauspiels schleppe sich die Handlung an vielen Stellen nur dahin (NM 10.9.29: 8). Der einzige Fehler dieses großartigen Dramas bestand für den Natal Advertiser im Mangel an lichten Momenten, um die dramatische Intensität des Films zu entlasten (NA 10.9.29: 14).

In der deutschen Kritik wurde vor allem bemängelt, dass jene dem Kammerspiel zugrundeliegende Novelle „Karl und Anna“ (Leonhard Frank), als Stoff nicht recht zur Verfilmung tauge und die Bilder spürbar versagen, wenn sie die Bedeutung der Wörter, die sie illustrieren, treffen sollen (Kracauer 1995: 202):

„Fanatischer und kompromißreiner Wille zu höchstgesteigerter filmkünstlerischer Qualitätsleistung ist hier verwirklicht - jedoch an einen Stoff verwandt, der sich - grundsätzlich gesprochen - den spezifischen und ureigensten Ausdrucksmitteln und Möglichkeiten des Lichtspiels versagt versagen muß" (LBB 30.8.28: 2).

Da der Stoff sich thematisch der Formung durch filmische Ausdrucksmittel entziehe, hätte man höchstens mit revolutionär neuen manuskript- und regietechnischen Lösungen im „Sinne der Russenkunst“ etwas erreichen können, nicht aber mit einem Festhalten an den Traditionen des westeuropäischen Kammerspiels, die nur - und das mit den besten, genial beherrschten Mitteln von heute und morgen - einen Film von gestern entstehen lassen habe (ebd.). Der Höhepunkt des Films, das Erkennen der Liebe zwischen Anna und Karl durch Richard, sei mit novellistischer Psychologie überladen: 
„Mit respektheischendem Takt ringt Joe May um bildmäßige Lösungen für schwer ausdeutbare menschliche Beziehungen, die in einer restlos gültigen Sprache auch die gekonnteste Kammerfilmkunst nicht mit letzter Überzeugungskraft zu formulieren vermag. Auf eine simple Formel gebracht, kündte er den Sieg der Freundschaft über die Liebe, des Mannes über das Weib" (ebd.).

Angeblich sei die erste "Erich-Pommer-Produktion“ in Alfred Hugenbergs UFA vom hauseigenen Blatt „UFA-Dienst“ mit einer Inhaltsangabe versehen worden, die Uneingeweihten suggerieren könnte, dass es sich „um einen Film mit bolschewistischer Tendenz" handeln würde, was sogleich dementiert wurde (Kreimeier 1992: 202). Bis auf den Hinweis auf die während der Zeit des Zusammenbruchs und der Revolution spielenden Handlung ließ sich aus den UFA-Reklame-Ratschlägen jedoch kein Hinweis auf etwaige Tendenzen entnehmen, auch konnten in der südafrikanischen Rezeption ähnliche Auffassungen nicht nachgewiesen werden. ${ }^{161}$

Bei der Betrachtung der zeitgenössischen Rezeption in Südafrika wird deutlich, dass, wenn sich eine Vorführung bestimmter deutsche Filme abzeichnete, zuerst auf positive Meldungen britischer Medien zurückgegriffen wurde, um das Publikum auf die bevorstehende Premiere in Südafrika vorzubereiten. Die dortige Presse monierte zwar einige Besonderheiten der Filmbauten (auf Leinwand gemalte Natur- und Stadtlandschaften), erkannte diese jedoch nicht wie spätere Kommentare als oberflächliche Anleihen an den Expressionismus (Dahlke/Karl 1988: 171) und den Straßenfilm der frühen 1920er Jahre (Kracauer 1995: 202), da Filme dieser Epoche (mit der Ausnahme des „Caligari“-Films) in Südafrika nicht gezeigt wurden und somit auch keine Parallelen hergestellt werden konnten. Die Novelle schien ebenfalls nicht besonders bekannt gewesen zu sein, da der von der Literaturvorlage abweichende Ausgang des Films unerwähnt blieb. ${ }^{162}$

\subsection{Rezeptionsdokumente zu Genre 3-Filmen: Walzer- und Ope- rettenfilme}

Bei den Genre 3-Filmen fällt auf, dass sechs der acht Filme unter den besten zehn Filmen eines Jahres im Filmkurier gelistet, die Hälfte der Filme in Paimann's Filmlisten als ,Schlager' (1) eingestuft wurden und drei Filme zur Gruppe der „MI>10-Filme“ gehören. Die drei erwähnten Merkmale lassen

\footnotetext{
161 Vgl. UFA-Reklame-Ratschlag zu HEIMKEHR. Berlin 1928, 12 S.

162 Kreimeier spricht von einem „verfälschten Happy-End“ (1992: 202), ein Detail, auf das weder in der Lichtbildbühne noch bei Siegfried Kracauer (1995) eingegangen wurde.
} 
den Schluss zu, dass diese Filme von den deutschen Medien als sehr erfolgreich eingestuft wurden, rein quantitativ konnte für die drei "Ml>10-Filme" ein erhöhtes Interesse der südafrikanischen Medien festgestellt werden. Unter den Genre 3-Filmen befinden sich vier Erich Pommer-Produktionen, darunter zwei Tonfilme, nur die Hälfte der Filme konnte der Valenzklasse V3 („neutral“) zugeordnet werden. Die Genre 3-Filme wurden zu gleichen Teilen in den Kinos von Kinemas bzw. African Theatres aufgeführt, wobei die letztgenannten dieses Filmgenre zuerst auf die Leinwand brachten.

Tab. 41: Genre 3-Filme 1927 - 1931

\begin{tabular}{|c|c|c|l|c|}
\hline MI & PFL & FK & \multicolumn{1}{|c|}{ Filmtitel } & Erstbeleg SA \\
\hline 25 & 4 & - & Der letzte Walzer - The Last Waltz (A) & 29.12 .1928 CA \\
\hline 15 & 2 & 1 & Der Kongreß tanzt (T) - Congress Dances (A)* & 19.11 .1932 CT \\
\hline 14 & 1 & 10 & Liebeswalzer (T) - The Love Waltz (K)* & 16.05 .1931 NA \\
\hline 6 & 1 & 3 & Ungarische Rhapsodie - Hungarian Rhapsodie (K)* & 23.04 .1930 CT \\
\hline & & & & 30.10 .1928 CT \\
\hline 4 & 1 & 1 & $\begin{array}{l}\text { An der schönen blauen Donau (1. Teil) - The Blue } \\
\text { Danube (K) }\end{array}$ & 04.07 .1930 CT \\
\hline 4 & 4 & 3 & Das tanzende Wien (2. Teil) - Dancing Vienna (K) & 01.05 .1927 TS \\
\hline 2 & 1 & 10 & Ein Walzertraum - The Waltz Dream (A)* & 23.02 .1929 NW \\
\hline 1 & 4 & - & Soldat der Marie - Young Romance (A) & \\
\hline 71 & & $\Sigma$ & 8 Filme & \\
\hline
\end{tabular}

Trotz der Problematik des schwierigen Vergleiches zwischen Stumm- und Tonfilmen soll für die Genre 3-Filme DER KONGRESS TANZT/CONGRESS DANCES einer exemplarischen, dokumentenbasierten Rezeptionsananlyse unterzogen werden. Zum einen, weil zu diesem Film genügend südafrikanische Rezeptionsdokumente (15) vorliegen und im Gegensatz zu DER LETZTE WALZER keine ungünstige PFL-Einstufung (4 vs. 2) den Vergleich erschwert; zum anderen, weil für DER KONGRESS TANZT wenigstens zwei afrikaanse Besprechungen gefunden werden konnten (DB 22.11.1932: 11 und VB 3.1.1933: 6). Im Vergleich zur Gesamtzahl der vorliegenden Rezeptionsdokumente konnten für DER KONGRESS TANZT auch die meisten Filmkritiken (12, reviews' bei MI 15) gefunden werden, die tatsächlich nach der Aufführung des Films entstanden (,reviews' vs. ,previews') und dadurch eher repräsentative Rückschlüsse auf die Rezeption zulassen. Aus Sicht der Filmhistoriographie muss jedoch hinzugefügt werden, dass durch die eingeschränkte Materiallage der Ausnahmefall einer umgekehrten Chronologie der filmhistorischen Beweisführung praktiziert werden muss, um zu verwertbaren Ergebnissen zu gelangen. DER KONGRESS TANZT ist als die Vollendung 
des Genres Tonfilmoperette anzusehen, da jenem als Tonfilm endlich die Musik/Gesang-Komponente symbiotisch hinzugefügt werden konnte, die dem Genre als Stummfilm noch fehlte. Das optische Geschehen konnte jetzt den Ton oder die Musik unterstreichen, die Musik wiederum das Visuelle weitertreiben (Thiele 1930 in: Jakobsen 1989: 108). Erich Pommer betrieb durch seine Erfahrung mit Walzerfilmen konsequent die Auflösung der Operette zur musikalischen Komödie, zur Revue, die in DER KONGRESS TANZT meisterhaft umgesetzt wurde (Jakobsen 1989: 105). In dieser Hinsicht sind die anderen Walzer- und Operettenfilme als Wegmarken anzusehen, wobei sich in Südafrika anhand der vier Erich Pommer-Produktionen der Eindruck aufdrängen musste, eine zielgerichtete Entwicklung vor sich zu haben. ${ }^{163}$

\subsubsection{Exemplarische Dokumentenanalyse von DER KONGRESS TANZT}

Bei DER KONGRESS TANZT/CONGRESS DANCES ist zunächst zu beachten, dass von diesem Tonfilm mehrere Fremdsprachenversionen existierten (Englisch und Französisch) und die englische Fassung mit den Hauptdarstellern Lilian Harvey und Henry Garat in Südafrika gezeigt wurde. ${ }^{164}$ Die englische Sprachfassung (ca. $93 \mathrm{~min}$ ) unterschied sich geringfügig von der deutschen bzw. französischen Version (ca. $100 \mathrm{~min}$ ) (Jacobsen 1989: 186). Die sequenzierte Fernsehfassung hatte eine Spielzeit von ca. 93 Minuten und entsprach damit quantitativ etwa der englischen Version. ${ }^{165}$

Die Handlung spielt zur Zeit des Wiener Kongresses (1814/15), zu dessen Anlass sich der russische Zar in Wien aufhält, in den sich dann auch prompt eine kleine Wiener Handschuhverkäuferin verliebt. Der K.u.K.Außenminister Metternich versucht die amourösen Abenteuer des Zaren zu instrumentalisieren und ihn dadurch von der aktiven Teilnahme am Kongress abzuhalten. Nach anfänglichem Misserfolg gelingt der Plan schließlich, doch just zu diesem Zeitpunkt landet Napoleon wieder in Europa und der Kongress löst sich auf. Der Zar verlässt Wien, die Handschuhverkäuferin bleibt zurück.

\footnotetext{
163 Für Südafrika chronologisch nachvollziehbar als Abfolge von: EIN WALZERTRAUM (1927), UNGARISCHE RHAPSODIE (1930), LIEBESWALZER (1931) und DER KONGRESS TANZT (1932).

${ }^{164}$ CT 19.11.1932: 11, DB 22.11.1932: 2, CT 22.11.1932: 5, ST 22.11.1932: 5, RDM 26.11.1932: 13, NA 23.12.1932: 11, NM 24.11.1932: 21, TF 3.1.1933: 6, VB 3.1.1933: 6, EPH 30.1.1933: 7, EPH 31.1.1933: 12, EPH 1.2.1933: 16, EPH 2.2.1933: 3, EPH 3.2.1933: 14 (Kapstadt, Johannesburg, Durban, Bloemfontein, Port Elizabeth)

${ }^{165}$ Sendefassung des Mitteldeutschen Rundfunks vom 22.7.1995, 20.15 Uhr.
} 
Die filmische Struktur der Handlung wird durch untenstehende Sequenzgraphik deutlich: ${ }^{166}$

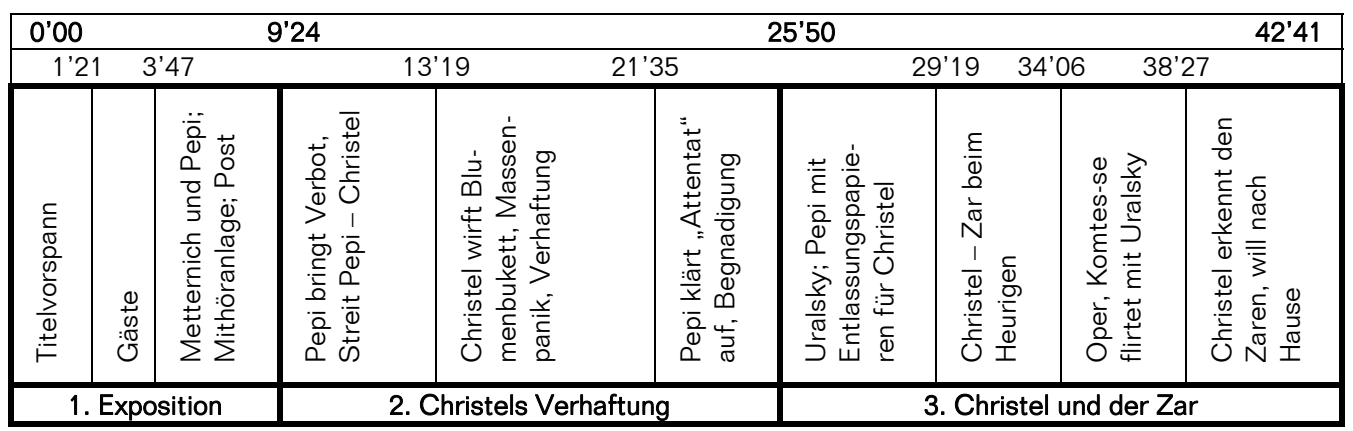

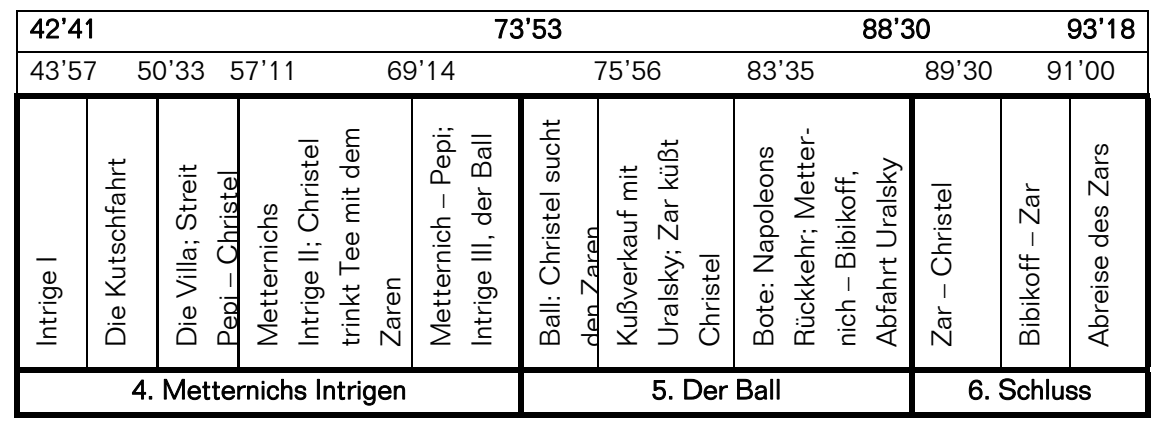

Abb. 13: Differenzierte Sequenzgraphik zu DER KONGRESS TANZT

In seinem Aufbau folgt der Film weitgehend dem klassischen Drama in fünf Akten, wobei die Sequenzen vier und fünf dem vierten Akt eines Dramas mit fallender Handlung und retardierendem Moment entsprechen (Biermann/Schurf 1990: 129f.). Bereits diese Strukturierung deutet darauf hin, dass in diesem Film keine filmischen Experimente angestrebt, sondern vielmehr bewährte Erfolgsformeln umgesetzt wurden.

Die südafrikanischen Rezeptionsdokumente lassen sich neben der sprachlichen Zweiteilung auch chronologisch in ,previews' und ,reviews' untergliedern, wobei die ,previews' als Rezeptionsempfehlungen der Produzenten bzw. des Verleihs aufzufassen sind. Sie sollten jedoch nicht vorschnell der unkritischen Verkaufsförderung zugeordnet werden. Bei den ,previews' folgte die Presse dem bekannten Schema, wonach zunächst über den Erfolg der Filme in London oder Europa berichtet und auf die baldige Aufführung in Südafrika hingewiesen wurde (ST 22.11.1932: 5 und NA 23.12.1932: 11). Beide Artikel gehen zunächst ausführlich auf den Produzenten Erich Pommer ein, dessen Mitwirken als eine Ursache für den Erfolg des Films angesehen

166 Kraus 2005: 8 (Seminararbeit „DER KONGRESS TANZT - ein Film über das Glück“, Seminar: Träume und Albträume der Moderne: Filme der 1920er und 1930er Jahre; SS 2005, Universität Göttingen). 
wurde, da unter seiner Leitung bewusst auf den populären Geschmack gezielt werde, ohne zu viel künstlerische Integrität zu opfern, mit welcher man die UFA seit ihrer Gründung assozierte. Für diesen neuen Typ von UFAFilmen stehe beispielhaft DER KONGRESS TANZT, der weltmarktgerecht in drei Versionen gedreht wurde. Dadurch entstünden zwar keine Meisterwerke, aber Bestnoten in Sachen Unterhaltungswert seien ihm sicher (NA 23.12.1932: 11). Besonders die Ausstattung des Films wurde gelobt, wenngleich darauf wert gelegt wurde, dass es sich nicht um ein historisches Dokument handele, sondern eine leichte musikalische Romanze könnerhaft umgesetzt werde und einen neuen Standard im Filmemachen setze (ebd.).

Als Agenturbericht bzw. Textübernahme entlarvt sich das ,preview' des Natal Advertiser, in dem das natürliche Spiel des männlichen Hauptdarstellers Henri Garat erwähnt wurde, welches er auch in Three Men at a Petrol Station gezeigt habe (ebd.). Eine Aufführung von DIE DREI VON DER TANKSTELLE (1930, W. Thiele) in Südafrika konnte allerdings nicht nachgewiesen werden. Ansonsten wird vor allem auf die Ebenbürtigkeit von DER KONGRESS TANZT mit Hollywood hingewiesen:

"This brief outline of the story fails to convey any idea of this glorious production; of how the imagination of the producers, the open purse of the UFA-company, the art of the camera and the artistry of the players have combined to make a picture which assuredly must be regarded as a landmark in the industry of the talkies" (ST 22.11.1932: 5).

Beachtung verdient die kurze Bemerkung des Sunday Times-Filmkritikers "Gadabout" zum eskapistischen Potential dieser Tonfilmoperette:

„The UFA-people provided him (Regisseur Erik Charell, Anm. ME) with unlimited ressources so that he was able to exploit the remarkable ability of his for creating atmosphere and making us forget completely this miserable twentieth century of ours, with its chronic slump ${ }^{167}$ and its unredeemed promises of 'turning the corner'" (ebd.).

Diese seltene Stellungnahme mit Aktualitätsbezug lässt sich vielleicht am ehesten aus dem Wunsch erklären, die um 1932 auch in Südafrika spürbaren Auswirkungen der Weltwirtschaftskrise (Kapitel 2.3) mit Hilfe des Films wenigstens für kurze Zeit vergessen zu können. Auch die deutsche Rezeption sprach in der wirtschaftlich angespannten Situation 1931 von einem „Bilderbuch für die illusionshungrigen, die im Zauberreiche Kino die fürchterliche

${ }^{167}$ Englisch für Rezession, Wirtschaftskrise, Abschwung. 
Realität dieser winterlichen Misere vergessen wollen [...]." (LBB 24.10.1931 in Korte 1998: 326). Noch deutlicher wurden Stimmen von den politisch jenseits der Mitte situierten deutschen Blättern, die entsprechende Schlagworte parat hatten: „'Opium für das Volk': in dieser Zeit tiefster schwärzester Not hat die UFA nichts Besseres zu tun, als ein historisches Feuerwerk von Uniformprunk, Luxus, Vergnügungen, Festen abzubrennen“ (Hieber 1931 in Jakobsen 1989: 107).

Abschließend wurde bemerkt, dass „The Smiling Lieutenant" (1931, R: Ernst Lubitsch) zwar clever und unterhaltsam, DER KONGRESS TANZT hingegen in jeder Hinsicht der größere Film war und dass die zwei „Eriks“ Erich Pommer und Erik Charell - etwas großartiges vollbracht hätten (ebd.). Merkwürdig ist jedoch, dass der Kritiker der Sunday Times (Johannesburg) noch bemerkt, er wüsste nicht genau wann der Film in Südafrika gezeigt werde, obwohl er bereits in Kapstadt angelaufen war (CT 19.11.1932: 11).

Die Filmbesprechungen (,reviews') der übrigen englischen Presse stimmen in der Einschätzung des Films mit den genannten positiven Attributen überein. Trotz der allgegenwärtigen Inflation der Superlative in der Filmpresse könne DER KONGRESS TANZT ein Triumph genannt werden (CT 22.11.1932: 5). Die Story des Films sei eigentlich unbedeutend, selbst wenn sie noch zehnmal unwahrscheinlicher gewesen wäre, könnte man dies dem Film ob seiner wunderbaren Nuancen bereitwillig vergeben (ebd.). Um die zweite weibliche Hauptdarstellerin, Lil Dagover, kreise die Handlung nur nebenbei, da sich der Regisseur anscheinend dafür entschieden habe, die Handlung über Bord zu werfen als er entdeckte, welch herrliche Unterhaltung er auch ohne daraus machen könne (ebd.). Der Film pulsiere förmlich vor Musik und Rhythmus, so dass das individuelle Schauspiel in einem Film solcher Dimension in den Hintergrund trete (RDM 26.11.1932: 13). Der Film tauge durch das Vermeiden jeglicher Theaterkonventionen als Vorbild für all jene Regisseure, die beharrlich nichts weiter als photographierte Bühnenstücke böten (NM 24.12.1932: 21). In Bloemfontein wurde der Film als der außergewöhnlichste, den die Besucher des örtlichen Plaza-Kinos je geboten bekamen, eingeschätzt (TF 3.1.1933: 6). Eine Bewertung die auch von der afrikaansen Presse der Stadt bestätigt wurde (VB 3.1.1933: 6). ${ }^{168}$ Ähnlich enthusiastisch wurde der Film in Port Elizabeth besprochen, wobei die fünf dazu veröffentlichten Texte den gleichen die Handlung beschreibenden Inhalt

\footnotetext{
168, „....] het die publiek van Bloemfontein ' $n$ vermaaklikheid ondervind wat nie maklik oortref sal word nie.“ Afrikaans für: „[...] hat das Publikum Bloemfonteins eine Unterhaltung erfahren, die nicht leicht zu übertreffen sein wird."
} 
lediglich in wechselnder Satzanordnung präsentierten (EPH 30.1.1933 bis 3.2.1933).

Zu einer gänzlich entgegengesetzten Einschätzung kommt die Kritik der afrikaansen Tageszeitung Die Burger (Kapstadt). Nach all der Reklame und den großen Erwartungen die man nun einmal an UFA-Filme habe, stelle der Film eine Enttäuschung dar (DB 22.11.1932: 2). Allein die Fotografie sei meisterhaft, jedoch werde mit ihr zuviel herumprobiert, um für die ansonsten schwache Bearbeitung des Szenarios zu entschädigen. Es gäbe nicht viel, was diesen Film von hunderten anderen unterscheide; sicher sei er ein Historienfilm, allerdings habe man von diesen aus England bereits bessere gesehen. Prächtige Kostüme und gute Effekte seien zwar ganz nett, aber der Rest des Films bestehe aus einer einzigen Parodie, die nicht einmal als besonders originell oder witzig bezeichnet werden könne (ebd.). Die Kamera hole heraus, was herauszuholen war, aber man gehe unzufrieden nach Hause und ohne aus dem Wirrwarr von Personen und Ereignissen irgendwie schlau geworden, gerührt oder besonders gut unterhalten worden zu sein; allerdings habe dies nicht an den Schauspielern gelegen (ebd.). „Dieser Tonfilm ist mittelmäßig, trotz seines Anteils an prächtigen Szenen und Melodien die hängenbleiben, er enttäuscht aber jene, die etwas besonderes erwartet haben (DB 22.11.1932: 2). ${ }^{169}$

In der dem deutschen Film eigentlich positiv gesinnten afrikaansen Presse Kapstadts kam diese Einschätzung eigentlich einen seltenen und unverblümten Verriss gleich. Die Bemerkung, dass man bessere englische Historienfilme kenne, stellt angesichts der offen antibritischen Haltung der afrikaansen Presse einen ungeheuren Affront dar. Während die englische Presse also weitgehend das technische Niveau und die darstellerischen Leistungen bejubelte, entging ihr die Ironie der dargestellten Überzeichnungen des erträumten Wien-Klischees; lediglich das satirische Potential der Metternich'schen Abhöranlage fand Erwähnung (RDM 26.11.1932: 13). In seiner filmischen Beispielhaftigkeit billigte ein Teil der deutschen Presse dem Film zu, dass er ein „Feuerwerk prasselnder Bildüberraschungen” böte, (Der Film 24.10.1931 in Korte 1998: 326) und aus der ganzen Tonfilmzeit schwerlich etwas ähnlich Verzauberndes hervorgegangen sei (Deutsche Filmzeitung 1931/Nr. 48 in Korte 1998: 326).

\footnotetext{
169 „Die klankprent is middelmatig met ' $n$ aantal pragtige toneeltjies en ' $n$ paar wysies wat bly hang, maar stel teleur as 'n mens iets besonders verwag het."
} 
Aus Großbritannien kamen überwiegend positive Stimmen, man erkannte aber trotz aller technischer Perfektion den grundsätzlich ablenkenden Charakter des Films als Höhepunkt des Walzerfilmgenres:

„The film wedded many styles of German film-making, being at once an historical pageant, a witty comedy and a popular operetta [...]. Above all, it was the epitome of all the escapist Vienese films, for which audiences still kept a warm place in their hearts in spite of the earlier socialrevelation of Stroheim and Pabst (O'Leary in Traubner 1996: 125).

"This fantasia on a historical theme is a lovely, lilting, intoxicating affair, sumptuously staged and perfect in its interpretation. In the case of CONGRESS DANCES the directorial throne is occupied by Mr. Erik Charell, whilst Mr. Pommer represents the power behind it" (London Times 1931 in Traubner 1996: 126).

Die afrikaanse Presse stimmte mit ihrer Meinung eher jener deutschen Medienrezeption zu, die von einer "Revue der unbegrenzten Möglichkeiten“, einem „Bildersturm“ oder einer „Materialschlacht” (FK 24.10.31 in Korte 1989: 325) sprachen und konstatierten, dass „das Äußerste an äußerlicher Wirkung herausgeholt" worden sei (Rote Fahne 27.10.1931 in: Korte 1998: 326). An der durch technische Raffinessen verdeckten Oberflächlichkeit nahm auch das stets kritische Feuilleton der Frankfurter Zeitung an dieser Erich Pommer-Produktion anstoß:

„Sie ist in Wirklichkeit eine sinnlose Häufung von Dekorationen: ein Produkt jener Zerstreuungskunst, zu der die UFA vor einiger Zeit die Parole ausgegeben hat; ein Leerlauf sämtlicher Motive, die das Publikum allmählich vergiften, indem sie ihm das billige Glück des Rausches verschaffen" (Kracauer 1931: 511).

Aus den gegensätzlichen Kommentaren zu DER KONGRESS TANZT sowohl in der deutschen, als auch in der südafrikanischen Presse lässt sich schlussfolgern, dass die im Film dargestellte Ablenkung von der Realität in einigen Medien nicht erkannt, in anderen begrüßt und wiederum von Dritten als Realitätsbewältigungsmodus strikt abgelehnt wurde. Die Einschätzung des Films als Aufstiegsmärchen bzw. ablenkende Sozialromantik in der deutschen Rezeption war daher folgerichtig. Selbst durch die wenigen kritischen Worte (ST 22.11.1932: 5 und DB 22.11.1932: 2), kann diese Einschätzung auch für die südafrikanische Rezeption übernommen werden. Der afrikaansen Presse kann man die Enttäuschung darüber anmerken, dass sie den Film im Vergleich zu anderen deutschen oder österreichischen Walzerfilmen (fast) als 
Parodie entlarven konnte, „[...] weil dieser Film sein Wien-Metier auf die Spitze treibt, wo Walzer-Seligkeit und Kronen-Kult in Selbstironie umschlagen" und Träume tatsächlich auch als Träume gezeigt werden (Karasek 1965: 45). Im Vorgriff auf die zeitlich vor DER KONGRESS TANZT gezeigten Walzer- und Operettenfilme wird deutlich, dass der zeitgeschichtliche Kontext, m.a.W. die wirtschaftlichen Härten in Südafrika um 1932, (vereinzelt) eine der in Deutschland um 1931 ähnliche Rezeption hervorgebracht hat. Für die nachfolgend abgehandelten Walzerfilme konnte folgerichtig eine derartige Rezeption nicht nachgewiesen werden, da der wirtschaftshistorische Kontext die rezeptionsleitenden Signale im Film nicht in diesem Sinne beeinflussen konnte.

\subsubsection{Untersuchung weiterer Genre 3-Filme}

Für die anderen zwei "Ml>10-Filme" DER LETZTE WALZER ${ }^{170}$ und LIEBESWALZER ${ }^{171}$ ist festzustellen, dass sich trotz hoher MI-Werte (23 bzw. 15) nur bedingt Aussagen zur tatsächlichen Medienrezeption ableiten lassen, da der Anteil echter Filmbesprechungen, d.h. Kritiken, die nach der Aufführung entstanden sind und keine Übernahmen von Werbetexten oder Agenturmeldungen darstellen, relativ gering ist (acht bzw. fünf). Auch bedienten sich diese beiden Filme eines sehr ähnlichen Sujets, welches am ehesten der Verwechselungskomödie nahekommt.

Tab. 42: Weitere Genre 3-Filme

\begin{tabular}{|c|c|c|l|c|}
\hline MI & PFL & FK & \multicolumn{1}{|c|}{ Filmtitel } & Erstbeleg SA \\
\hline 25 & 4 & - & Der letzte Walzer - The Last Waltz (A) & 29.12 .1928 CA \\
\hline 14 & 1 & 10 & Liebeswalzer (T) - The Love Waltz (K)* & $16.05 .1931 \mathrm{NA}$ \\
\hline 2 & 1 & 10 & Ein Walzertraum - The Waltz Dream (A)* & 01.05 .1927 TS \\
\hline
\end{tabular}

In der DER LETZTE WALZER tauscht eine zur Heirat bestimmte Prinzessin die Rolle mit ihrer besten Freundin, daraufhin verliebt sich der Adjutant des Bräutigams in die vermeintliche Prinzessin, was wiederum den Bräutigam auf

${ }^{170}$ CA 29.11.1928: 7, CT 1.1.1929: 7, CA 2.1.1929: 16, DB 4.1.1929: 8, CT 5.1.1929: 9, RDM 15.1.1929: 8, NA 2.2.1929: 7, NM 2.2.1929: 21, NA 4.2.1929: 9, NA 5.2.1929: 9, NW 16.2.1929: 13, TF 26.3.1929: 10, DFA 29.4.1929: 3, DFA 3.5.1929: 6, EPH 15.6.1929: 15, CT 16.8.1929: 9, CT 23.8.1929: 9, CT 24.8.1929: 11, CT 29.8.1929: 7, CT 31.8.1929: 11, CT 3.9.1929: 7 (Kapstadt, Johannesburg, Durban, Bloemfontein, Kimberley, Port Elizabeth, Kapstadt).

171 NA 16.5.1931: 10, NM 16.5.1931: 26, NA 19.5.1931: 9, NW 23.5.1931: 9, DA 25.5.1931: 5, NW 26.5.1931: 7, CT 30.5.1931: 9, CT 2.6.1931: 7, DB 3.6.1931: 9, EPH 5.6.1931: 8, EPH 6.6.1931: 19, DFA 29.6.1931: 3, TF 7.8.1931: 12, NA 20.11.1931: 11, EPH 21.12.1932: 18 (Durban, Kapstadt, Port Elizabeth, Kimberley, Bloemfontein, Durban, Port Elizabeth). 
den Plan ruft, dieser von seinem Adjutanten attackiert wird und ob dieses Ungehorsams erschossen werden soll. Der letzte Wunsch des Verurteilten ist ein Walzer mit der vermeintlichen Prinzessin, nach dem der Unglückliche schließlich begnadigt wird. In LIEBESWALZER schickt der erzherzogliche Bräutigam seinen Sekretär, woraufhin sich die Prinzessin in diesen verliebt. Der Rollentausch fliegt letztenendes doch auf, aber da der Sekretär Sohn eines reichen amerikanischen ,Autokönigs' ist, darf er die Prinzessin schließlich heiraten.

Die Mehrzahl der Besprechungen weist darauf hin, dass es sich um UFAProduktionen handelt, bei DER LETZTE WALZER wird auf den Vertrieb durch die Paramount (richtiger: PARUFAMET) und die internationale Besetzung der Rollen hingewiesen (CA 29.12.1928: 7). Die Besprechungen der Filme bieten neben den üblichen Inhaltsangaben nur positive Aussagen, das besondere Engagement der UFA, als deutsche Firma international auch mit verschiedenen Sprachversionen tätig zu werden, wurde lobend erwähnt (z.B. NM 2.2.1929: 21 und CT 16.8.1929: 9). Viele der Rezeptionsdokumente ähneln sich stark im Wortlaut und der Auswahl bestimmter Besonderheiten. Dies kann als Beleg für die redaktionelle Zusammenarbeit der verschiedenen Zeitungen innerhalb der dominierenden Zeitungsgruppen genommen werden. So formulierten z.B. die zur Gruppe der südafrikanischen Morgenzeitungen bzw. zur Argus-Gruppe gehörenden Blätter Natal Mercury und Natal Witness über LIEBESWALZER fast gleichlautend:

„According to a trade review, the story has plenty of sparkling comedy incidents and the characterisations, for the most part, are definitely amusing" (NM 16.5.1931: 26).

"This picture is described by one of the trade journals as excellent light entertainment $[\ldots]$. The story has plenty of sparkling comedy incident and the characterisations for the most part are definitely amusing" (NW 23.5.1931: 9).

Auch scheinen Agenturmeldungen oder Berichte des UFA-Auslandsdienstes direkt übernommen worden zu sein. Letztere erschienen auch fremdsprachig (auf Englisch, Französisch, Spanisch) und dürften inhaltlich im Wesentlichen den UFA-Reklame-Ratschlägen entsprochen haben (Olimsky 1931: 49). Südafrika als einziges Land mit einer entwickelten Unterhaltungsindustrie in Afrika wird mit Sicherheit einige der vier regelmäßig durch den UFAAuslandsdienst belieferten Fachblätter in Afrika gestellt haben (ebd.). Eine 
redaktionell weitgehend eigenständige Besprechung zu DER LETZTE WALZER verfasste der Filmkritiker „T.J.R.“ des Natal Advertiser:

„One of the most charming romantic pictures I have seen for a long time comes from the UFA studios and is now being shown at Prince's. Last weak I commented upon the fact that the British production of 'Madame Pompadour', while it possesed every spectacular quality, had an impoverished story as a basis and that lacking the essential of good drama, the film tamed to hold attention. THE LAST WALTZ possesses the very element that 'Madame Pompadour' lacked; for it has romance, pathos, adventure, humour - all the qualities that make for success. And with it all magnificent scenes and settings, splendid acting, excellent casting and intelligent production. The great quality of UFA productions - as FAUST, VAUDEVILLE and METROPOLIS - bore out was the wonderful lighting and the splendid grouping. The actors are not stilted, they do not stand unnaturally and pose, they are human beings and move in a human mannor. [...] There are few films which have given me such unnalloyed pleasure. It is light with the lightness of Strauss' music; it is entertaining, and it is a model of direction" (NA 5.2.1929: 9).

Die verschiedenen Paarkonstellationen der beiden Filme (Willy Fritsch \& Suzy Vernon bzw. John Batten \& Lilian Harvey) werden als überzeugend angesehen. Besonders überrascht zeigte sich die südafrikanische Presse über das gute Englisch der deutschen Darsteller im Tonfilm LIEBESWALZER, als besonders unterhaltsam wurde sogar George Alexanders „piquant Teutonic flavour of his accent“ eingeschätzt (NM 16.5.1931: 26). Der spezielle Humor des Films, der weder amerikanisch noch britisch sei, konnte wie auch die Musik bestens überzeugen (CT 2.6.1931: 7).

Aus der afrikaansen Presse liegen nur drei Rezeptionsdokumente vor. Zu DER LETZTE WALZER bemerkt der Kommentar in Die Burger, dass der ganze Film in einer leichtherzigen, rühmlich-unlogischen Art aufgebaut sei, wie er für Operetten typisch ist und man sich kaum eine bessere Unterhaltung für die Neujahrswoche vorstellen könne (DB 4.1.1929: 8): „Doch selbst bei einem solchen Thema legen die deutschen Regisseure an Kunstgefühl an den Tag, welches den Film meilenweit über alles, was Hollywood auf diesem Gebiet gebracht hat, heraushebt (ebd.)." ${ }^{172}$ Die Rollen seien exzellent besetzt, selbst die an sich unmögliche Geschichte werde durch die temperamentvolle Dramatik überzeugend gemacht. Und dies nicht in der oberflächlichen Manier wie es die ,Yankees' so trefflich beherrschten, sondern mit

172 „Selfs by 'n dergelyke onderwerp pas die Duitse regisseurs ' $n$ kunsgevoel toe wat die prent myle verhef bo einige ding wat Hollywood op dergelyke gebied gebring het." 
tiefer Menschlichkeit, was hauptsächlich eine Frage des Temperaments sei (ebd.). LIEBESWALZER wurde als ungewöhnlich gut produzierter Film eingeschätzt, ein vollbesetzter Kinosaal sah Lilian Harvey erfolgreich in der Hauptrolle und bewunderte George Alexanders ungekünstelten Humor (DA 25.5.1931: 5). Die Filmkritik in Die Burger bemerkte dazu:

„UFA-Filme sind bei uns bekannt für ihre meisterhafte Technik und die richtige Auswahl der Schauspieler. Dieser hohe Standard wird durchgängig in DER LIEBESWALZER gehalten, ein Tonfilm der diese Woche im Adelphi gezeigt wird. Dieser stellt jeden Geschmack zufrieden: da sind genügend romantische Spielchen, ausreichend Humor, genügend Musik und genug zusammenhanglose Liebesgeschichtchen drinn, um den Film ausgewogen und äußerst angenehm zu machen" (DB 3.6.1931: 9). ${ }^{173}$

Auch in der englischen Version kamen die Musikstücke in LIEBESWALZER wie "The Love Waltz" und "You're Just the One Girl for Me" gut bei Presse und Publikum an (EPH 5.6.1931: 8), was für die konsequente internationale Ausrichtung der Fremdsprachenversionen der UFA-Filme spricht. Dazu wurden die vier Schlager des Films durch die bekannten Jazzkapellen Paul Goldwin-Band und die Weintraub-Syncopaters eingespielt. Diese Lieder waren auch auf Schallplatte erhältlich und Teil der Werbekampagne für den Film. ${ }^{174}$

Im Vergleich zu allen anderen Genre 3-Filmen wurde in LIEBESWALZER eine zeitgenössische Geschichte mit Automobilen usw. erzählt, die dem depressionsgeprüften deutschen Publikum eher zugänglich war als die anderen Walzerfilme mit ihren ewigen ,Husar liebt Bauernmädchen'Geschichtchen (Traubner 1996: 89). Ob des unterschiedlichen sozioökonomischen Kontextes in Südafrika wurde diese Auffälligkeit wahrscheinlich nicht als Besonderheit artikuliert. Die sog. ,Husar liebt Mädchen'Geschichte dürften vom südafrikanischen Publikum eher als besonders ,exotisch' wahrgenommen worden sein, was z.T. den großen Erfolg des Genres begründen würde. Die romantischen Komödien können alle als unpolitisch charakterisiert werden.

Der als Verwechselungskomödie aufgebaute Film EIN WALZERTRAUM behandelt die Heiratsnöte eines Erzherzogs, der sich von seinem Adjutanten

\footnotetext{
173 „U.F.A.-rolprente is by ons bekend vir hul uitstekende tegniek en die regte keuse van spelers. Hierdie hoë standard word deurgaans gehandhaaf in THE LOVE WALTZ, die U.F.A.-praatprent wat hierdie week in die Adelphi vertoon word. Dit stel elke smaak tevrede: daar is genoeg romantiese voorvalletjies, genoeg humor, genoeg musiek en genoeg onsamehangende liefdesgeskiedenisse in om die rolprent goedgebalanseerd en uiters aangenaam te maak."

${ }^{174}$ Vgl. UFA-Reklame-Ratschlag zu LIEBESWALZER, Berlin 1929: 6 (24 S.).
} 
vertreten lässt und letzterer sich schließlich doch noch in die anfangs ungeliebte Prinzessin verliebt. Bei dieser Produktion handelt es sich höchstwahrscheinlich um eine der ersten von der Schlesinger-Organisation in Südafrika gezeigten deutschen Filme. Der Verweis auf die UFA als Produzent auch anderer beachtlicher Filme wie METROPOLIS und VARIETÉ erfolgt schon in den ersten Zeilen der Filmankündigung (TS 1.5.1927: 19). Die Filmbesprechung nach der ersten Vorstellung gibt einen guten Eindruck der Publikumsreaktionen und der Kritikermeinung wieder:

„A mild sensation among Rand (Gebiet um Johannesburg, Anm. ME) film enthusiasts was caused at the Bijou Theatre last night, when the first German production yet screened in Johannesburg was shown to a packed house. Oppinions expressed afterwards formed striking contrasts: some members of the audience condemmed the film wholeheartedly, while others stated that it was one of the finest exhibited for many month. [...] THE WALTZ DREAM may be described as a weak story exceedingly beautifully filmed" (TS 3.5.1927: 3).

Damit lässt sich belegen, dass zumindest in Johannesburg EIN WALZERTRAUM tatsächlich der erste deutsche Film war, der einem südafrikanischem Publikum gezeigt wurde. Auch erhärtet sich die weiter oben geäuBerte Vermutung, dass die Schlesinger-Organisation zuerst deutsche Filme nach Südafrika importierte. Einen Erfolg von EIN WALZERTRAUM an der Kinokasse kann man guten Gewissens unterstellen, die positiven Reaktionen darauf dürften bewirkt haben, noch weitere Walzer- und Operettenfilme nach Südafrika zu importieren.

Wenn der Film wie angenommen tatsächlich einer der ersten in Südafrika aufgeführten deutschen Filme war, so könnte diese Entscheidung maßgeblich vom Erfolg des Films in den USA beeinflusst gewesen sein. Der Film wurde im New Yorker Capitol-Filmtheater zwei Wochen lang gezeigt, was für einen ausländischen Film ohne US-amerikanische Filmstars sehr ungewöhnllich war. Die New York Times lobte EIN WALZERTRAUM, da er einem Hollywood-ähnlichen Kostümstück gleiche, dass gar nicht die Vermutung aufkommen ließe, dass der Film aus Deutschland sei (Traubner 1996: 78). Der letzte Vermerk spielte ironisch auf die v.a. expressionistischen, weniger unterhaltungsorientierten deutschen Produktionen wie „Das Cabinett des Dr. Caligari" an, die in den USA gezeigt wurden. Der Erfolg von EIN WALZERTRAUM ebnete Regisseur Ludwig Berger den Weg nach Hollywood, der nach dem Film ein entsprechend gutes Angebot akzeptierte (ebd.). 
Für alle Genre 3-Filme gilt, dass zwischen der deutschen und der südafrikanischen Medienrezeption keine relevanten Unterschiede festgestellt werden konnten. Die Auswahl gerade dieser Filme durch die Kinoketten dürfte ihre Ursache im beim Publikum relativ beliebten Genre der Walzer- und Operettenfilme haben, zumal in den Filmen eine Kontinuität der Hauptdarsteller zu bemerken ist, ${ }^{175}$ welche bei nur mäßigem Publikumszuspruch unterblieben wäre und auf eine gewisse Beliebtheit der Schauspieler schließen lässt. Obwohl von 1927 bis 1932 pro Jahr mindestens ein deutscher Walzerbzw. Operettenfilm gezeigt wurde, fällt es schwer, darin eine programmgeschichtliche Kontinuität auszumachen. Durch die gemeinsame Thematik, vielfach nur schwer vom Genre Liebesfilm bzw. -komödie zu trennen, und die historisch wie geographische klare Zuordnung dürfte das Publikum keine Schwierigkeiten damit gehabt haben, die Genre 3-Filme als deutsche Filme zu identifizieren. Im Kinoprogramm von 1928 fällt zwar eine bemerkbare Häufung von historischen Abenteuer- und Liebesfilmen auf, die der ,BalkanRomantik' der Genre 3-Filme recht nahe kamen, z.B. „The Eagle“ (1926, C. Brown), „Michail Strogoff“ (1926, V. Turschanski), „Don Juan“ (1926, A. Crossland) oder "Prince of Adventurers" (1927, A. Wolkoff) (Eckardt 2005: 102ff.), jedoch fehlt in selbigen der starke Musikbezug, den die Genre 3Filme trotz ihrer Stummfilmexistenz gemeinsam aufwiesen.

\subsection{Rezeptionsdokumente zu Genre 4-Filmen: Science Fiction- und Kriegsfilme}

$\mathrm{Zu}$ den Genre 4-Filmen ließen sich insgesamt 70 Rezeptionsdokumente ermitteln, einzig der Film FRAU IM MOND gehört zu den „Ml<10-Filmen“, für die übrigen lagen mindestens zehn Pressebelege vor. Mit der Ausnahme von AM RANDE DER WELT zählten alle Filme laut einer Erhebung des Filmkurier zu den zehn besten Filmen des Kinojahres der jeweiligen Uraufführung. Der Kriegsfilm UNSERE EMDEN wurde in Paimann's Filmlisten keiner Bewertung unterzogen, zwei Produktionen erhielten die Bestnote (,Schlager'), AM RANDE DER WELT wurde als ,über dem Durchschnitt' eingeschätzt.

\footnotetext{
175 Die vorherrschende Paarkonstellation bestand aus Willy Fritsch \& Partnerin, sowie Harry Liedtke \& Partnerin, wobei Xenia Desni für die beiden männlichen Hauptdarsteller in zwei Filmen abwechselnd deren weibliches Gegenüber verkörperte.
} 
Tab. 43: Genre 4-Filme $1928-1931$

\begin{tabular}{|c|c|c|l|c|}
\hline MI & PFL & FK & \multicolumn{1}{|c|}{ Filmtitel } & Erstbeleg SA \\
\hline 34 & 1 & 4 & Metropolis (A) & 22.01 .1928 ST \\
\hline 18 & 0 & 6 & Unsere Emden (Kreuzer Emden) (A) & 17.04 .1928 TS \\
\hline 12 & 4 & - & Am Rande der Welt (K) & 25.03 .1929 DFA \\
\hline 4 & 1 & 1 & Frau im Mond (K) & 13.02 .1931 CT \\
\hline 70 & & $\Sigma$ & 4 Filme & \\
\hline
\end{tabular}

Aus diesen Daten kann geschlossen werden, dass sowohl die deutschen, als auch die südafrikanischen Medien ein erhöhtes Interesse an einer Berichterstattung über diese Filme gehabt haben. Da nur vier Filme in dieses problematischste aller kategorisierten Genres fallen, können aus der Gleichverteilung der Filme unter den zwei großen Kinoketten keine thematischen Präferenzen abgeleitet werden. Aufgrund des hohen Materialindikators (34), dem Vorhandensein von einigen afrikaansen Filmbesprechungen (4) und der reichlichen Sekundärliteratur soll METROPOLIS für eine detailierte Dokumentenanalyse herangezogen werden.

\subsubsection{Exemplarische Dokumentenanalyse von METROPOLIS}

Bei einer Analyse der Medienrezeption von METROPOLIS muss zunächst darauf geachtet werden, dass durch die kontroverse Produktions- und Verwertungsgeschichte des Films die Gefahr besteht, lediglich eine weitere Nuance der nicht enden wollenden Rekonstruktionsgeschichte hinzuzufügen, als tatsächlich auf die Rezeption des Films einzugehen. Mit dem Verweis auf die dazu vorliegende umfangreiche Sekundärliteratur soll dieses Problem umgangen werden und nur dann Erwähnung finden, wenn es zum Verständnis der historischen Rezeption des Films beitragen kann (Gehler/Kasten 1990, Elsaesser 2001, Jakobsen/Sudendorf 2000, Patalas 2001).

METROPOLIS gehört zu den bekanntesten und auch umstrittendsten Produktionen der Filmgeschichte. Dies Einschätzung bestätigt bereits rein quantitativ die südafrikanische Medienrezeption, da für den Film der höchste MI-Wert aller „S-Filme“ (34) ermittelt werden konnte. ${ }^{176}$ Darüber hinaus erfüllt METROPOLIS auch alle Kriterien, um als „Erf-Film“ eingestuft zu

176 ST 22.1.1928: 6, SCL 25.1.1928: 14ff., TS 31.1.1928: 10, ST 5.2.1929: 6, NA 22.2.1928: 7, NM 11.2.1928: 24, NA 13.2.1928: 9, NA 14.2.1928: 9, NM 14.2.1928: 6, NA 16.2.1928: 9, EPH 17.2.1928: 5, EPH 22.2.1928: 11, TF 27.2.1928: 4, VB 28.2.1928: 8, OUT 2.3.1928: 56, NW 17.3.1928: 16, NW 20.3.1928: 5, DFA 26.3.1928: 7, OUT 20.4.1928: 52, CA 19.5.1928: 7, CT 21.5.1928: 5, DB 22.5.1928: 8, DB 23.5.1928: 8, NM 12.8.1928: 23, NM 21.8.1928: 9, NA 28.8.1928: 9, NA 6.10.1928: 7, NM 8.10.1928: 6, EPH 27.4.1929: 6 (Johannesburg, Durban, Port Elizabeth, Bloemfontein, East London, Pietermaritzburg, Kimberley, Potcheftstroom, Kapstadt, Durban, Port Elizabeth). 
werden. Mit einer als ,Schlager' eingeschätzen Gesamtqualifikation in Paimann's Filmlisten, Rang vier in der Bestenliste des Filmkuriers für das Jahr 1927, einer Nennung als "outstanding film of the year 1928" bei Thelma Gutsche und der Erwähnung durch Hans Rompel, gibt es kaum einen Film unter den „S-Filmen“, der eindeutiger als „Erf-Film“ eingestuft werden kann. Zu METROPOLIS konnten tendenziell mehr Filmvorbesprechungen als echte Filmkritiken recherchiert werden, was auf erhöhte Aktivitäten seitens der Filmvertriebe hinweist, auch ließen sich nur drei Besprechungen afrikaanssprachiger Zeitungen ermitteln.

Da von METROPOLIS - wie von den meisten für das Auslandsgeschäft vorgesehenen Filmen auch - verschiedene Kinofassungen existierten und die Premierenfassung unwiederbringlich zerstört wurde (Elsaesser 2001: 43-60), gilt es zunächst zu klären, welche Version in Südafrika gezeigt wurde. Ein Blick in die Rezeptionsdokumente zeigt recht eindeutig, dass es sich um eine der Verleihfassungen der Paramount gehandelt haben muss. Bei der Beschreibung der Filmhandlung wurden die Hauptcharaktere mit jenen Namen bezeichnet, die abweichend von der deutschen Fassung speziell für den englischsprachigen Markt ersonnen wurden (ST 22.1.1928: 7 und SCL 25.1.1928: 14ff.). ${ }^{177}$ In den beiden vom US-Theateregisseur Channing Pollock und der Paramount bearbeiteten Versionen wurde die Originalfassung beträchtlich gekürzt, teilweise ummontiert und mit neuen Zwischentiteln versehen. ${ }^{178}$ Damit entsprach der eigentlich überlange Film (ca. zweieinhalb Stunden Länge) der normalen Dauer der US-amerikanischen Langspielfilme von ca. eindreiviertel Stunden. Als weiteren Beleg für die Aufführung der USbzw. Commonwealth-Version kann hinzugenommen werden, dass durch den Wegfall einiger Handlungslinien in der südafrikanischen Rezeption weder auf die Beziehung zwischen John Masterman und Rotwang, noch auf Eric Masterman's Helfer eingegangen wurde.

Damit steht fest, dass in Südafrika nicht eine der deutschen Verleihkopien gezeigt wurde, sondern eine umgeschnittene Version, welche den heutzutage kommerziell aufgeführten Fassungen eher entspricht als die rekonstruierten aus den Filmarchiven. ${ }^{179}$ Diese Umstände erschweren die filmgerechte Analy-

\footnotetext{
177 Joh Fredersen $=$ John Mastermind, Freder Fredersen = Eric Mastermind, Maria = Mary etc.

${ }^{178}$ Die genauen Angaben dazu schwanken je nach benutzter Quelle. Während teilweise von Kürzungen um etwa die Hälfte gesprochen wurde (Dahlke/Karl 1988: 145), gilt inzwischen als allgemein anerkannt, dass mindestens 1000m beim Umschnitt verloren gingen (Elsaesser 2001: 43). Darüber hinaus können lokale Zensureingriffe zu völlig unterschiedlichen Spielfilmlängen geführt haben, welche die Diskussionen über die Länge der tatsächlich aufgeführten Fassung unsinnig machen.

179 Diese Tatsache ist bei der Sequenzanalyse zu beachten, weil für diese oft nur auf die allgemein zugänglichen Versionen, z.B. die 1984er Version von Giorgio Moroder, zurückgegriffen werden kann.
} 
se der Rezeptionsdokumente, da nicht immer zweifelsfrei festzustellen ist, welche Teile des Films nur deshalb unerwähnt blieben, weil diese in der Vorführversion nicht enthalten waren, oder aber vom Rezensenten bewusst ausgelassen wurden. Aus diesem Grund kann die beigefügte Sequenzgraphik auch nur einen beschränkten Erklärungswert bieten. ${ }^{180}$

\begin{tabular}{|c|c|c|c|c|c|c|c|c|c|c|c|c|}
\hline $\begin{array}{l}\text { 00: } \\
00\end{array}$ & $\begin{array}{l}\text { 03: } \\
30\end{array}$ & $\begin{array}{l}08: \\
20\end{array}$ & $\begin{array}{l}\text { 11: } \\
03\end{array}$ & $\begin{array}{l}12: \\
10\end{array}$ & $\begin{array}{l}\text { 18: } \\
08\end{array}$ & $\begin{array}{l}\text { 21: } \\
51\end{array}$ & $\begin{array}{l}23: \\
17\end{array}$ & $\begin{array}{l}29: \\
30\end{array}$ & $\begin{array}{l}31: \\
20\end{array}$ & $\begin{array}{l}38: \\
16\end{array}$ & $\begin{array}{l}40: \\
40\end{array}$ & $\begin{array}{l}42: \\
05\end{array}$ \\
\hline 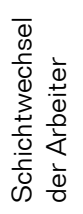 & 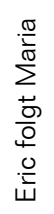 & 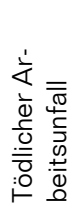 & 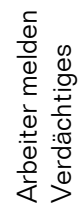 & 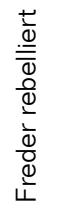 & 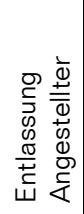 & 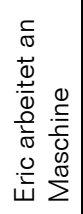 & 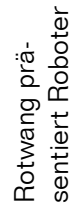 & 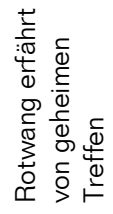 & 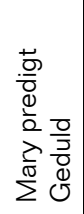 & 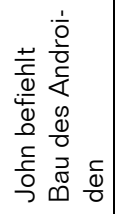 & 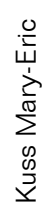 & 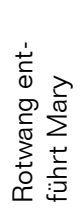 \\
\hline $\begin{array}{l}\text { I. } \\
\text { Exp. }\end{array}$ & \multicolumn{2}{|c|}{$\begin{array}{l}\text { II. } \\
\text { Eric \& Mary }\end{array}$} & \multicolumn{3}{|c|}{$\begin{array}{l}\text { III. } \\
\text { John Masterman's } \\
\text { Büro }\end{array}$} & \multicolumn{3}{|c|}{$\begin{array}{l}\text { IV. } \\
\text { John Masterman \& } \\
\text { Rotwang }\end{array}$} & \multicolumn{4}{|c|}{$\begin{array}{l}\text { V. } \\
\text { Marys Rede in den Katakomben }\end{array}$} \\
\hline
\end{tabular}

\begin{tabular}{|c|c|c|c|c|c|c|c|c|c|c|c|}
\hline $\begin{array}{l}47: \\
30\end{array}$ & $\begin{array}{l}54: \\
37\end{array}$ & $\begin{array}{l}57: \\
24\end{array}$ & $\begin{array}{l}60: \\
13\end{array}$ & $\begin{array}{l}64: \\
30\end{array}$ & $\begin{array}{l}69: \\
57\end{array}$ & $\begin{array}{l}73: \\
29\end{array}$ & $\begin{array}{l}77: \\
34\end{array}$ & $\begin{array}{l}82: \\
13\end{array}$ & $\begin{array}{l}86: \\
12\end{array}$ & $\begin{array}{l}87: \\
21\end{array}$ & $\begin{array}{l}\text { 89: } \\
04\end{array}$ \\
\hline 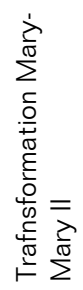 & 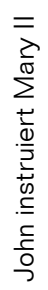 & 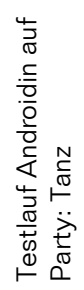 & 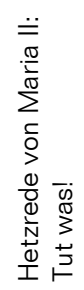 & 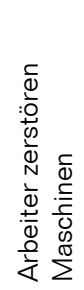 & 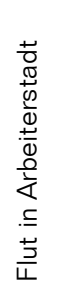 & 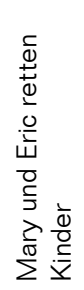 & 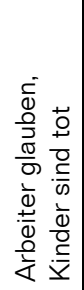 & 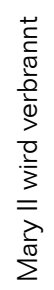 & 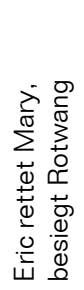 & 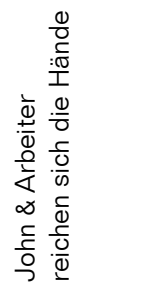 & $\begin{array}{l}\frac{0}{0} \\
\frac{5}{4}\end{array}$ \\
\hline \multicolumn{3}{|c|}{$\begin{array}{l}\text { VI. } \\
\text { Erschaffung der } \\
\text { Androidin }\end{array}$} & \multicolumn{4}{|c|}{$\begin{array}{l}\text { VIII. } \\
\text { Zerstörung der Maschinen }\end{array}$} & \multicolumn{3}{|c|}{$\begin{array}{l}\text { VIII. } \\
\text { Scheiterhaufen }\end{array}$} & $\begin{array}{l}\text { IX. } \\
\text { Versöhnung }\end{array}$ & $\begin{array}{l}X . \\
\text { Ende }\end{array}$ \\
\hline
\end{tabular}

Abb. 14: Differenzierte Sequenzgraphik zu METROPOLIS ${ }^{181}$

Wie bereits weiter oben erwähnt, folgte die südafrikanische Medienrezeption jener der britischen Presse und berichtete zuerst über den Erfolg des Films in London (ST 1.5.1927: 6). Ebenfalls geteilt wurde die Sorge über die enormen Produktionskosten des Films und die prekäre Finanzlage der UFA, die durch das angestrengte Ringen mit den USA um den britischen Markt bzw. den der britischen Besitzungen entstanden seien (ebd.). In der ersten ausführlichen und sich über drei Spalten erstreckenden Filmkritik der Sunday Times erfolgte eine eingehende Darstellung der Spielfilmhandlung (ST 22.1.1928: 7).

\footnotetext{
180 Die vorgenommene Sequenzeinteilung muss dabei nicht mit den einzelnen Akten des Films übereinstimmen. Die rekonstruierte DVD-Studienfassung des Films wählt in der Synopsis bspw. eine Untergliederung in 53 Kapitel (UdK 2005: 28).

181 Siehe Gischler 2005: 5f. bzw. Kater 2005: 6 (Seminararbeit „Utopien im Spielfilm der Weimarer Republik", Seminar: Träume und Albträume der Moderne: Filme der 1920er und 1930er Jahre; Sommersemester 2005, Universität Göttingen).
} 
In einer nicht allzu fernen Zukunft besteht die Welt nur noch als eine dreigeteilte „Metropolis": Von der Geschäftsstadt wird Macht ausgeübt, in der Arbeiterstadt geschuftet und in den Lustgärten über den Wolkenkratzern pflegen die Abkömmlinge der Geschäftsstadt den Müßiggang. Die maschinengleichen Arbeiter fristen ein elendes Dasein und betreuen die unterirdischen Apparate, welche die Stadt am Leben erhalten. Von ihrem Los gezeichnet, erhoffen sie ihre Errettung von einem Propheten, einem „Mittler zwischen Hirn und Hand". In dem Mädchen Mary sehen sie eine Art Lichtgestalt, die sie zum Ertragen des Schicksals ermutigt. Dem Beherrscher der Stadt missfallen die Umtriebe von Mary und mit Hilfe eines Wissenschaftlers wird eine künstliche Doppelgängerin von Mary hergestellt, welche die Arbeiter zur Rebellion anstiftet. Die Arbeiter zerstören die Maschinen und die Unterstadt wird überflutet. Eric, der in Mary verliebte Sohn des Stadtbeherrschers John Masterman, gelingt es zusammen mit dem Mädchen die Kinder der Arbeiter vor dem Ertrinken zu retten und die Rebellion zu beenden. Als Mittler zwischen den Arbeitern und seinem Vater sorgen Eric und Mary dafür, dass sich beide Seiten solidarisch die Hände reichen und versöhnen.

Bei der detaillierten Beschreibung des Films in der Sunday Times handelt es um die Filmkritik nach einer Sondervorführung am 17. Januar 1928 im Johannesburger Bijou-Lichtspielhaus, bei der lediglich der Kinomanager, zwei Musiker und der Filmkritiker „Gadabout" anwesend waren (ST 22.1.1928: 7). Das zur Schlesinger-Organisation gehörende und als Programmzeitschrift fungierende Branchenblatt Stage, Cinema and Listener brachte vier kritiklose Seiten Text und Bilder zu METROPOLIS, die offensichtlich aus dem ,Paramount Press Kit for Metropolis' oder dem Metropolis-Heft des UFAAuslandsdienstes entstammten (SCL 25.1.1928, 14-18). Dieser Text gab die offizielle Linie der Schlesinger-Organisation für die Pressereklame vor, der Text selbst stammt angeblich von einem „W.J. Makin“, welcher den Film in London gesehen haben soll. Inhaltlich stimmt dieser Artikel bis auf die geänderten geographischen Einschübe mit der Meldung des Natal Witness überein (NW 17.3.1928: 16), ebenso alle gefundenen Pressephotos.

Vollkommen ohne begründende Wertung stehen die Inhalte des Werbetextes im Gegensatz zu den Details des Artikels in der Sunday Times. Die Filmbesprechung beginnt mit der Spekulation, dass, wenn man Edgar Allen Poe, Gustav Doré, Herbert George Wells, Jules Verne und John Martin zu einer Kooperation für ein Filmdrehbuch zusammenbringen könnte, wohl etwas ähnliches wie METROPOLIS verfilmt worden wäre. Durch die gigantische Konzeption des Films entstehe ein vollkommen neuer Blick auf die 
Kinematographie. Die Ideen hinter den Hauptfiguren wurden schnell identifiziert:

„The chief characters, [...], are John Masterman, symbolising capital; his son, Eric, and Mary, a girl of the people, representing Heart and Sympathy; and Grot, the foreman, symbolising Labour. Rotwang, the inventor is only a jackal of Masterman's and indicates how science has been harnessed by the capitalist. And here I would like to point out that all the way through the film the spectator's sympathies are with the people, and it is only in the last moment of his remorse that Masterman triumphs over prejudice of those in front" (ST 22.1.28: 7).

Weiters vermerkt Filmkritiker "Gadabout” die Aufstellung der Maschinen erinnere an Illustrationen Heath Robinsons und die Symbolik an Ernst Tollers Schauspiel "Die Maschinenstürmer“. Der einhändige Rotwang scheine Edgar Allan Poes "Goetz of the Iron Hand" entsprungen zu sein, Marys Flucht vor inm übertreffe die Spannung in „The Pit and the Pendulum" bei Weitem. Der Film sei von Fritz Lang wunderbar produziert worden, kaum vorstellbar, dass jemand diesen Job besser hätte erledigen können. Die einzelnen Darsteller wurden für ihr Schauspiel gelobt, „But the character which stands out with unforgettable prominence is that of Grot - the burly, bearded, emphatic Grot, magnificantly played by Heinrich George“ (ebd.). Die Kreativität dieser UFA-Produktion sei etwas, was noch in keinem anderen Film zu sehen war, die Art und Weise wie Lang die Handlung präsentiere, sei ein Triumph der gezielten Bildauswahl (TS 31.1.28: 19). Eigentlich könne man den Film gar nicht adäquat beschreiben, "Metropolis is a film that has to be seen to believe it" (EPH 10.2.28: 6).

Abermals wird die britische Presse bemüht und aus den London Daily News zitiert, dass der Film in Londons Marble Arch Pavillon alle Rekorde gebrochen und in Johannesburg Filmgeschichte geschrieben habe (NA 11.2.28: 7). In diesem Film werde einfach alles durch das Medium Film selbst und durch die Filmtechnik ausgedrückt, keine Anleihen beim Theater waren nötig, der Film sei vollkommen unabhängig von verbalen Erklärungen. Die Geschichte des Films gerate zwar etwas sehr symbolisch als "drama of capital, or rather brains and labour" (ebd.), jedoch verfüge sie auch über alle "film thrills, fights, love making, even including a Cubist night club“ (ebd.). Die Neuartigkeit des Filmischen gegenüber dem Theater in METROPOLIS wurde besonders lobend erwähnt: „METROPOLIS interpreting the world today makes the frantic efforts of modern expressionist school of playwright seem like mildewed feeble drivel. METROPOLIS is something radically diffe- 
rent" (ebd.). ${ }^{182}$ Die inhaltliche und formale Essenz von METROPOLIS umschreibt der Natal Advertiser wie folgt:

„Not all have succeeded in dealing adequately with the eternal question of love in the midst of the imaginative foreshadowings of the ultra scientific and mechanical world of the future. In these works the elements of imagined futurity overshadow that of love. The superb blend of these two elements is in METROPOLIS, where we see that love, as in the past, will, in the world of the future, continue to be the power it is to-day" (NA 13.2.28: 9).

„It is impossible to describe adequately the varying and almost magical lighting effects, the gigantic sets used in the film, the extraordinary brilliance with which the plot is presented, and the scale with which the producer has drawn this city of the future. [...] Whether it will have a healthy influence on minds not attuned to disect the dramatic from the practical is hard to say, for it tells a terrible side in an awe inspiring prophetic and unorthodox way. The film casts an almost hypnotic spell in its influence and focuses excited imagination on a problem already assuming concernable proportions. With German thoroughness it probes mercylessly a weak link in our economic armour and spares neither the capitalist greedy for power, nor the workmens sullenness in his impotent misery" (NA 14.2.28: 9).

Als eher unwahrscheinlich wurde die Thematik von nur wenigen Kommentatoren bezeichnet (NM 14.2.28: 6), die Expressivität des Films zog viele Zuschauer derart in ihren Bann, dass viele nach der Vorstelllung froh waren, dass es sich nur um einen Film handelte (NA 16.2.28: 9). Die Großartigkeit des Filmischen wurde selbst durch leise Zweifel an der Thematik des Films kaum erschüttert, da die Andersartigkeit im Vergleich zu Hollywood höher bewertet wurde:

„Whatever the purport of the theme, many came away last night wondering if METROPOLIS was a plausible prophecy. All, however were deeply impressed by the magnificence of the production, the like of which has never been equalled and seldom approached by scheming Hollywood" (NA 16.2.28: 9).

\footnotetext{
182 Folgt man Thomas Elsaesser, ist man geneigt, dieses Zitat einem Artikel von Frank Vreeland aus dem New York Telegramm vom 7.3.27 zuzuschreiben, dessen Übersetzung dem Zitat aus dem Natal Advertiser/London Daily News sehr nahekommt: „In Metropolis entfaltet sich ein lebhaftes Panorama ..., das die fiebrigen Aktivitäten der Theaterautoren der modernen expressionistischen Schule wie angeschimmelten, schwachen Blödsinn aussehen lässt" (Elsaesser 2001: 128).
} 
Neben der Erwähnung der weiblichen Hauptdarstellerin Brigitte Helm als künftiger Star (TF 27.2.28: 4), war die südafrikanische Presse sicher, dass der Film die hohen Produktionskosten kaum wieder einspielen würde (EPH 22.2.28: 11). Dass der Film in Großbritannien und den USA sehr erfolgreich lief, wurde immer wieder betont (NW 20.3.28: 5 und CT 21.5.28: 5). In England galten die deutschen Filme des Jahres 1927 den einheimischen und den US-amerikanischen in Bezug auf Intelligenz und künstlerischer Gestaltung generell als weit überlegen:

„British and American films, however, considered from the twin standpoint of intelligence and artistry, sink almost into insignificance when compared with Germany's output, from which I choose the following ten films: , METROPOLIS, FAUST, MANON LESCAUT, THE STUDENT OF PRAGUE, „Out of the Mist“, „Bohemian Love“ (silly title), „A Daughter of the Hills", "The Queen of Spades" and "Dancing Maid". Germany's war drama THE EMDEN also ranks with the best ever produced in that class. This list of German films is all the more significant because German films almost without exception, are grotesquely maltreated by British distributors" (ST 5.2.28: 6).

Eine leichte Veränderung in der Einschätzung von METROPOLIS lässt sich nur aus den Besprechungen zur wiederholten Aufführung des Films in Durban herauslesen. Egal welche Verdienste die Produktion als Film auch habe, zur Anziehung des Publikums würden sie in jedem Falle reichen, und sei es nur deshalb, weil so viel für oder gegen den Film geschrieben wurde (NM 12.8.28: 23). Produktionstechnisch sei der Film seiner Zeit weit voraus, „but it is the subject matter which aroused the controversy which centred around it" (ebd.):

"The moral that neither brain nor brawn can do without the other and that the only mediator between them should be the heart, is a humane one. Whatever the opinions may be respecting this feature, the management (des Alhambra-Kinos, Anm. ME) is wise in securing it for three nights" (NA 6.10.28: 7).

Dies waren im Wesentlichen die einzigen ,kritischen' Stimmen zu METROPOLIS, nähere Erläuterungen zu diesen Einlassungen oder angedeuteten Tendenzen fanden sich nicht. Es ließen sich auch keine Berichte darüber nachweisen, dass der Film beim Zuschauer an Attraktivität eingebüßt hätte, im Gegenteil wurde meist von ausverkauften Häusern gesprochen (NA 28.8.28: 9 und NA 6.19.28: 7). 
In der afrikaansen Presse wurde der Film ebenso enthusiastisch aufgenommen wie in der englischsprachigen. Allerdings machte bereits das eher provinzielle Volksblad frühzeitig klar, dass zwar die Produktion als ein Höhepunkt der Filmgeschichte anzusehen sei, aber die Filmhandlung selbst nur die allergewöhnlichsten Banalitäten biete (VB 28.2.28: 8). Die Besprechung in Die Burger stellt die vom Umfang längste Filmkritik des Jahres 1928 dar (DB 22.5.28: 8). Sowohl in Sachen Ausführlichkeit, als auch der Tiefgründigkeit der vorgebrachten Bemerkungen ist anzunehmen, dass diese Kritik von Hans Rompel verfasst wurde (Eckardt 2005: 72). Rompel zog in seiner Besprechung eine direkte Linie von Samuel Butlers (1835-1902) Erzählung „Erewhon“, über Herbert George Wells (1866-1946) Roman „The Time Machine" sowie die ersten Roboterphantasien in Karel Capeks (1890-1938) Theaterstück „R.U.R.“" (=Rossums Universal Roboter) zu Thea von Harbous und Fritz Langs METROPOLIS. Die Begeisterung für die Regiearbeit Langs und die filmtechnische Umsetzung der Zukunftsphantasien kannte bei ihm kaum Grenzen. Selbst die gelegentlich etwas übertriebenen Gesten einzelner Darsteller trübten nicht deren prächtiges Schaffen, da selbst dies noch unendlich tief und kunstsinniger sei, als alles was Hollywood je geliefert habe (DB 22.5.28: 8). Die Fotografie mit ihren herrlichen Lichteffekten gleiche der Malerei eines Rembrandt, die Szene des Schichtwechsels der in Blöcken aneinander vorbei marschierenden Arbeiter war für Rompel von Van Goghs Gemälde „Die Runde der Gefangenen“ (1890) inspiriert (ebd.).

Dass die Bildkompositionen und deren Ästhetik in METROPOLIS mit Gemälden verglichen wurde, ist eine auffällige Gemeinsamkeit in mehreren Rezeptionsdokumenten: Während sich Rompel an Van Gogh erinnert fühlte, erkannte Filmkritiker "Gadabout" in der Szene, in welcher Mary den riesigen Gong läutet und die schreienden Kinder sich vor den Wassereinbrüchen zu retten suchen, eine Parallele zu Gustav Dorés Bibelillustrationen (ST 22.1.28: 7). Die oft mit christlicher Symbolik aufgeladenen Bilder (Jakobsen/Sudendorf 200: 26ff.) hätten etwas ganz besonderes, eine Art eschatologischer Weltuntergangsstimmung, die mehr seien, als „[...] daß hier ein Maler rein optische Reize von kaum vorstellbarer Großartigkeit gestaltet hat" (LBB 11.1.27: 2). Das gemeinsame Erwähnen von Langs Anleihen aus der Malerei ist eine der seltenen Gelegenheiten, in der sich die südafrikanische Filmkritik über ihren allgemeinen Standard erhob. Mit welcher Verbildlichungskraft der ehemalige Malereistudent Fritz Lang gearbeitet hat und dies sogar von den beiden genannten südafrikanischen Filmbesprechungen er- 
kannt wurde, wird in der Gegenüberstellung der Gemälde mit einigen Standbildern des Films deutlich. ${ }^{183}$

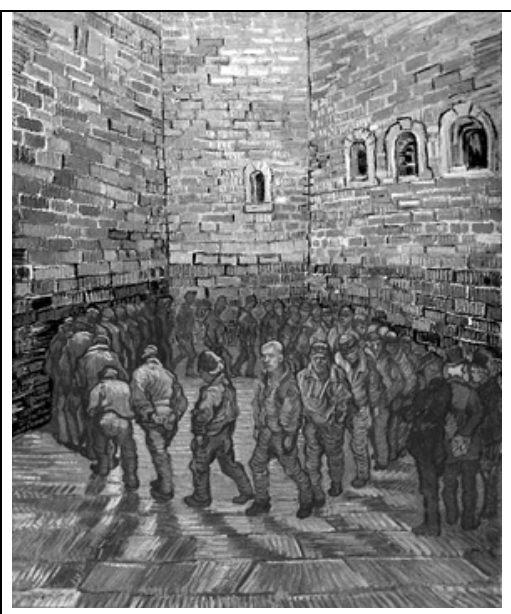

Vincent van Gogh: Die Runde der Gefangenen (1890)

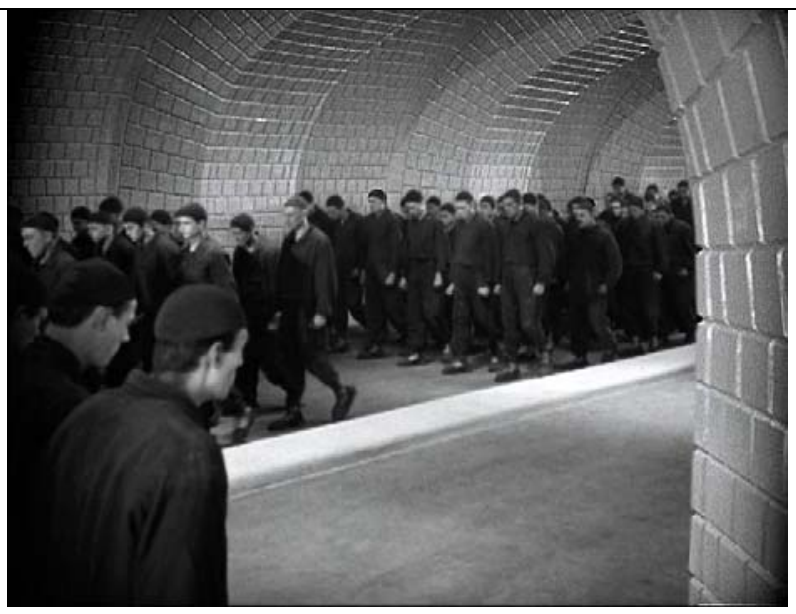

Metropolis: Sequenz I, Schichtwechsel (2:37)

Abb. 15: Szenische Gegenüberstellung von Malerei und Film I: Vincent van Gogh

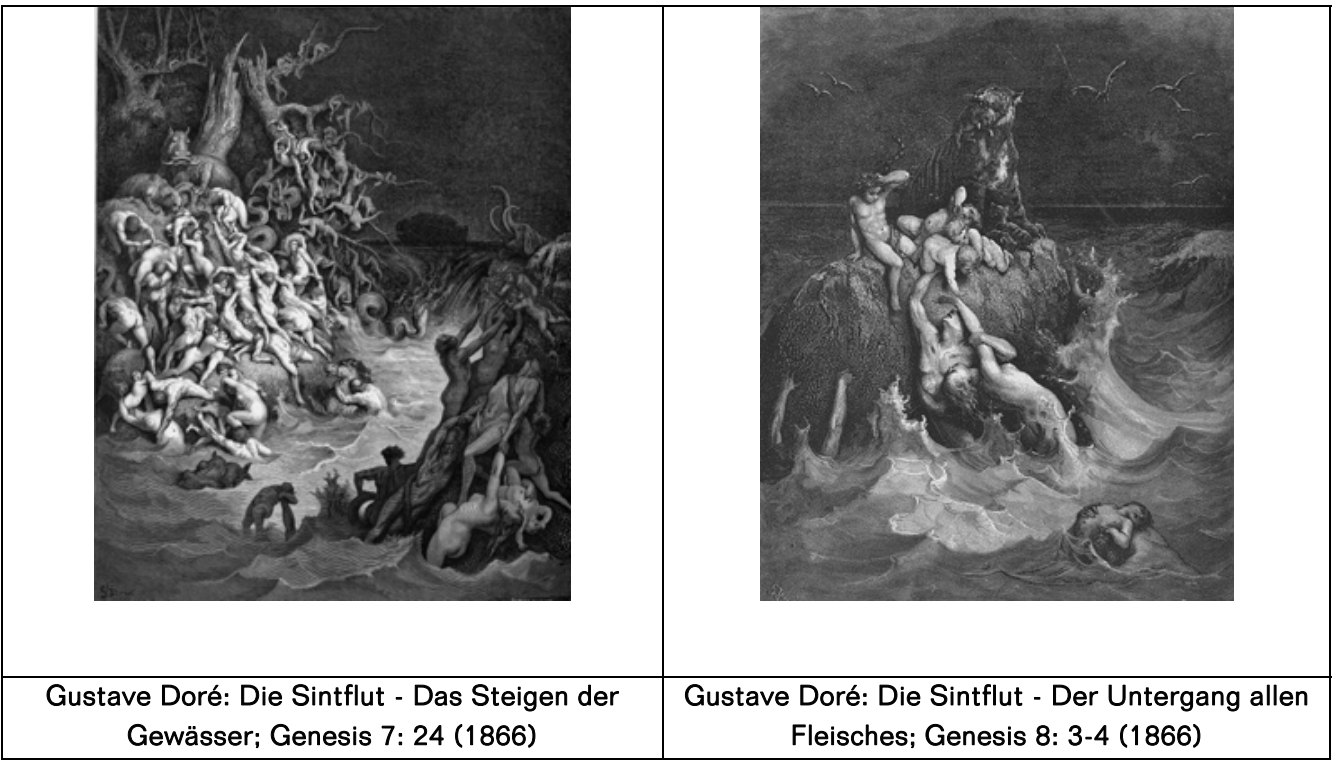

${ }^{183}$ Aufgrund der besseren Bildqualität wurden die Standbilder aus der Studienversion von METROPOLIS (UdK 2005) entnommen, auf welche sich auch die Zeitangaben beziehen. 


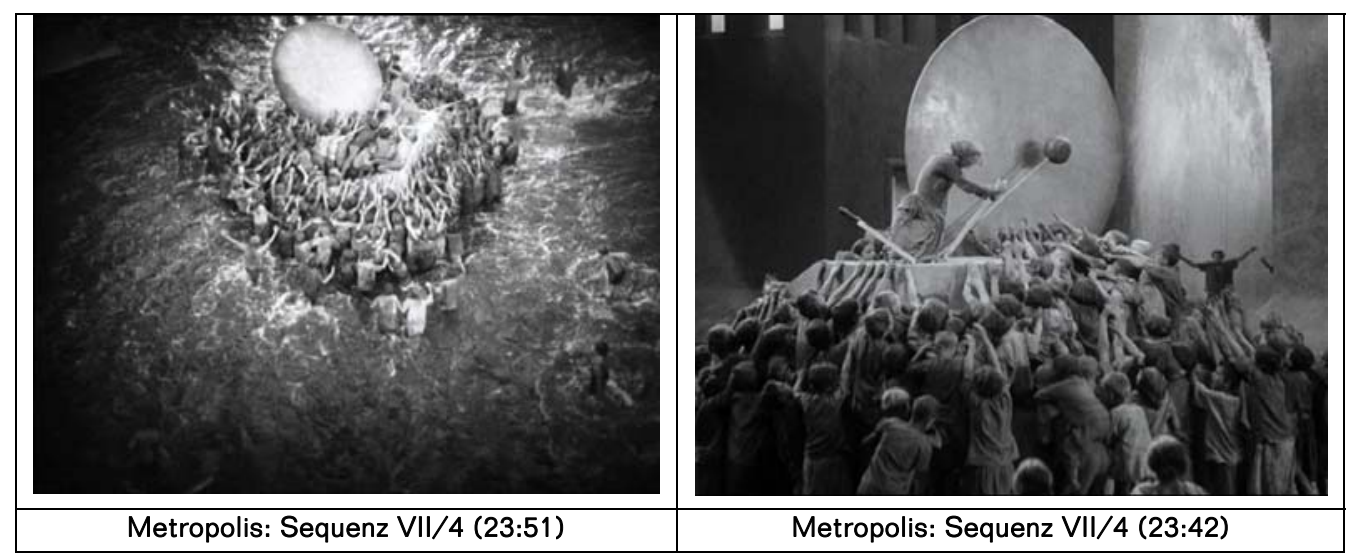

Abb. 16: Szenische Gegenüberstellung von Malerei und Film II: Gustave Doré

Alles in allem wurde METROPOLIS in Die Burger als bewunderungswürdig eingeschätzt, auch weil hier nicht jene krankhafte Art von Liebesvorstellung geboten werde, die man dem Publikum sonst im Übermaß auftische (DB 23.5.28: 8). Seine ganzen Sympathien abschließend für den deutschen Film ausdrückend, fragte Hans Rompel:

„Wo aber bleibt bei der tiefsinnigen Kunst dieses Films, seiner durchdringend an uns gerichteten Warnung und der deutschen Geringschätzung von oberflächlichen Effekten [eigentlich] der amerikanische Film, mit seinem flachen ,human interest', seinem ewigen ,love appeal' und seiner Aufeinanderstapelung mechanisch produzierter Drehbücher?" (DB 22.5.28: 8). ${ }^{184}$

Zusammenfassend kann also festgestellt werden, dass bis auf einige seltene Fragen nach dem eher unwahrscheinlichen Sujet des Films keine negativen oder zweifelnden Kritiken in der südafrikanischen Presse zu finden waren. Es überwogen eindeutig die begeisterten Stellungnahmen, die nicht selten an die positiven Stimmen aus Großbritannien anschlossen. Umso erstaunlicher ist diese Einschätzung, wenn man bedenkt, dass der bisherige Stand der Forschung die angeblich oft negativen Reaktionen der zeitgenössischen Kritiker in den Mittelpunkt stellte (Rotha 1930/1967: 274f.). Diese Negativzuschreibung rührt allerdings weniger aus tatsächlichen Rezeptionsanalysen, sondern vielmehr aus dem Wissen, dass mit der bis dahin „teuersten UFAProduktion in der Zeit der Weimarer Republik" (Kreimeier 1992: 18) die Filmindustrie in eine folgenschwere Finanzkrise geriet und dadurch ihren

184 „Waar bly by die diepgaande kuns van hierdie film, by die deurdringende waarskuwing wat dit ons bring, by sy Duitse minagting van oppervlakkige effek - die Amerikaanse rolprent met sy oppervlakkige „Human Interest", sy ewige „Love Appeal“ en sy opeenstapeling van meganies geproduseerde scenario's ?" 
Kampf mit Hollywood um die Filmmärkte der Welt vorzeitig aufgeben musste.

Die deutsche Filmkritik war METROPOLIS durchaus zugeneigt, bis auf das etwas schwache und zu symbolische Drehbuch, in dem „[...] das Spiel der toten Masse stärker als die menschlichen Vorgänge [...]" (LBB 11.1.27: 2) ausgeprägt war, wurde Fritz Langs Arbeit hoch geschätzt. Filmpolitisch stellte der Film jedoch ein Risiko dar, weil der ungeheure Aufwand in keinem gesunden Verhältnis zum fertigen Film stand und die Möglichkeit des Scheiterns auf dem US-Markt als ein zu hohes Risiko angesehen wurde (ebd.). Als Prestigeprojekt im Kampf mit Hollywood zählte man aber auf die internationale Strahlkraft des Films:

„Ein Film wie METROPOLIS wird in Deutschland so leicht nicht wieder gemacht werden. Da wir ihn haben, müssen wir hoffen, dass die aufgebrachten Leistungen sich wenigstens ideell rentieren: in einer Steigerung des Ansehens des deutschen Films in der Welt. Und wie auch immer das finanzielle Ergebnis sein wird - das ideelle ist uns nicht zweifelhaft. Denn METROPOLIS ist nicht nur ein in Deutschland, in Europa einziges Werk auch in der ganzen Welt, Amerikas Mammutfilme eingerechnet, haben wir bisher nichts Gleiches zu finden vermocht" (LBB 11.1.27: 2).

Warum METROPOLIS in den USA nicht den gewünschten Erfolg hatte, lässt sich nur äußerst mühsam rekonstruieren. Erschwerend kommt hinzu, dass der Film dort umgeschnitten wurde und damit ein kompliziertes Symbolsystem aus Bildern von fremder Hand verändert wurde, ohne dass der Intention der eigentlichen Macher Rechnung getragen wurde:

„Als ich mit meiner Arbeit begann, dem Film eine strukturierende Montage zu verleihen, hatte METROPOLIS weder Logik noch Maß. Es war ein wildgewordener Symbolismus, so daß die Zuschauer nicht sagen konnten, wovon der Film handelte. Ich habe ihm meine Bedeutung gegeben" (Pollock in Elsaesser 2001: 44).

Bei soviel Unverständnis verwundert es fast schon wieder, dass es nach der Neumontage noch möglich war, der Handlung des Films zu folgen und die Fabel zu erfassen. Die geänderten Zwischentitel hatten angeblich dazu geführt, dass man in den USA ,bolschewistische Tendenzen' in METROPOLIS zu erkennen glaubte. Da diese Zwischentitel aber vom USamerikanischen Vertrieb eingefügt wurden, bleibt die Frage bestehen, warum dieses Risiko geradezu herausgefordert wurde, wo doch die deutschen Zwischentitel diese Rückschlüsse bis dato nicht heraufbeschworen hatten. An 
dieser Stelle spielt wiederum die Kontextualisierung der Rezeptionsbedingungen eine entscheidende Rolle, die auch hier Erklärungen zum Erfolg oder Misserfolg des Films besteuern kann.

Die US-Rezeption bemerkte anfänglich nur „What a pity that American editors distort what is essentially a Jules Verne fantasy with preachy subtitles" (Photoplay 5/1927 in Slide 1982: 191), kein Wort von irgendwelchen Tendenzen, ,predigende Untertitel' allein waren noch lange nicht bolschewistisch. Negativ fiel bei METROPOLIS die weitgehend pessimistisch eingeschätzte Zukunft der Normalbevölkerung ins Gewicht, der ganze Trend der Zivilisationsentwicklung gehe in eine vollkommen andere Richtung als in Langs Film, keine seiner Zukunftsvorhersagen erschien dem USKommentator vernünftig (Beaton 1927 in Slide 1982: 192):

„It assumes also that men will work long hours, in spite of the fact that the tendency towards shorter hours is marked. None of the things that METROPOLIS says time will do to society seem reasonable to me. Capital will never make slaves of workingmen because it is no good business so to do. For all those reasons I could derive no satisfaction from following the story of the picture. But as a picture I found it fascinating. Let us consider it purely as a picture and not as a piece of literature" (ebd.).

Wenn Lang nur für die materiell-technische Seite der Produktion zuständig gewesen wäre und beispielsweise Lubitsch die Darstellerführung übernommen hätte, wäre sicher ein besserer Film entstanden, wenngleich es die Handlung eigentlich ausschließt, einen perfekten Film daraus machen zu können. Die US-Version hätte eine viel bessere Fassung werden können, wenn die menschliche Komponente des Films nicht so radikal herausgekürzt worden wäre. Außerdem sprach die UFA nur davon, einen Film über die Zukunft in 100 Jahren zu machen, daraus hätten aber die zu Übertreibungen neigenden Presseleute der Paramount 1000 Jahre gemacht, wodurch das Publikum etwas noch Unglaublicheres erwartet hätte (ebd.). Dennoch schließt der Bericht des Film Spectator mit einer Empfehlung:

„No matter what degree of entertainment you derive from METROPOLIS you must give it credit for being a great intellectual feat as well as an example of the extraordinary possibilities of the screen. It is to be hoped that some day Eric Pommer will find himself so situated in Hollywood that he can attempt something else equally daring and ambitious" (Beaton 1927 in Slide 1982: 193). 
Zur Sache kommt einzig die Rezensentin von The Nation, die bemerkte, dass "METROPOLIS, for all its thesis and its subtitular dialectic compound for American comprehension by the enlightend Channing Pollock [...]" (Gerstein 1927 in Slide 1982: 193), also die ,dialektischen' (oder einfach nur widersprüchlichen) Zwischentitel irgendwie durch Channing Pollock für das amerikanische Verständnis entschärft wurden. Eigentlich hätte dadurch eine eventuell vorhandene ,Tendenz' eliminiert sein müssen, obwohl durch Langs Überformalisierung der Film nicht über das revolutionäre Potential verfügte, welches man ihm offenbar zugetraut hatte:

„As Lang has directed it, METROPOLIS is more stylized fantasy than realism. Even in the torrential revolt of the workers as they pour through the machine-rooms, alive, demoniacal, there is an air of unreality. This is not the revolution as the Russians stage it. [...] It is the Metropolis itself, the city of doomed basements and curving machinerooms, of massed buildings that conceal the sky, of aeroplanes that ply their corner-to-corner traffic, of trains that seem to shoot into unmeasured and untracked space, that makes Fritz Lang's films so significant " (Gerstein 1927 in Slide 1982: 194f.)

Selbst wenn an dieser Stelle nur drei Rezeptionsdokumente aus den USA herangezogen werden konnten, entstand nicht der Eindruck, dass gravierende ideologische Unstimmigkeiten vorgelegen hätten. Vor einem zurechtgestutzten Jule Verne-Film mit Predigerqualitäten, ergänzt um verständlichere Zwischentitel, der revolutionäre Arbeiter in künstlichen Stilisierungen zeigt, hätte die US-amerikanische Zensur oder Öffentlichkeit sicher keine Angst gehabt. Die am Rande erwähnten revoltierenden Arbeiter geben aber schon einen Wink in die Richtung der unterstellten Tendenz. Vielleicht war dies neben den Zwischentiteln die Tendenz, vor der man sich fürchtete.

Diese Überlegungen als Fehlinterpretation abzutun wäre jedoch falsch, denn die polysemen Bilder des Films können unter den veränderten Rezeptionsbedingungen in den USA andere Lesarten hervorgerufen haben, die jenseits der Intention der Filmemacher lagen. Je nach historischer Situation und dem individuellen Rezeptionshintergrund können dabei ganz unterschiedliche Interpretationen entstanden sein. Dadurch wurde der Film auch als Projektionsfläche benutzbar, um ihm im jeweiligen ideologischen Lager einen Platz zu zuweisen. Wohl durch die unüberprüfbare Zukunftsthematik scheint sich METROPOLIS dafür besonders gut geeignet zu haben. Im Sinne einer Ideologiekritik des Films lässt sich die paradoxe Situation nachweisen, dass METROPOLIS von den jenseits der Mitte des politischen Spektrums stehen- 
den Kräften als Propaganda der Gegenseite gewertet und entsprechend angefeindet wurde.

Als ,protonationalsozialistisch' bezeichnete vor allem Siegfried Kracauer den Film in seiner 1947 erstmals erschienenen Studie „Von Caligari zu Hitler“ (Kracauer 1995). Für ihn schien „in METROPOLIS [...] das gelähmte Kollektivbewusstsein mit ungewöhnlicher Klarheit im Schlaf zu reden" (Kracauer 1995: 171). Vor allem in den geometrisch stilisierten Formalismen Langs wollte er politisch totalitäre Tendenzen entdeckt haben. Die vermittelnde Konfliktlösung im Film machte er als eine geschickte Beschwichtigungspolitik aus, welche die Arbeiter nicht nur davon abgehalten hätte, ihre Sache siegreich durchzufechten, sondern die es auch noch ermöglichte, sie fester in den Griff zu kriegen (ebd. 172). Zudem fand er noch ein den Schlussworten Marias ähnliches Goebbels-Zitat, um dem deutschen Publikum ein latentes Verlangen nach einer Festigung totalitärer Autorität nachzuweisen (ebd.).

Wie ahistorisch diese Art von 'Beweisführung' ist, wird klar, wenn man sich den Veröffentlichungszeitpunkt (1947) von Kracauers Bemerkungen in Erinnerung ruft. Im politischen Kontext der Jahre 1924-1928 wäre es der kommerziell ausgerichteten UFA nicht im Traum eingefallen, einen protonationalsozialistischen Film zu drehen, da bei den Wahlen des Jahres 1928 die NSDAP nur magere 2,6 Prozent der Stimmen erreichte (Dressel 1995: 74). Ferner dürfte die in METROPOLIS hineingelesene paternalistische Parabel der Klassenkollaboration kaum Teil der nationalsozialistischen Weltanschauung gewesen sein, oder entsprach es etwa dem ,Führerprinzip', dass der Führer aus Angst um seinen Sohn auf die Knie sinkt (Elsaesser 2001: 67)? Für die u.a. in den USA festgestellte ,bolschewistische Tendenz' und den großen Erfolg des Films trotz der ,Mängel' hatten ausgerechnet die ideologischen Gegenspieler Kracauers eine Erklärung:

„Die Reklame und die Neugier brachte dem Film volle Häuser in Deutschland und Frankreich. In den USA wurde er zusammengeschnitten. Das Unzulängliche der Auseinandersetzung mit den sozialen Problemen wurde drüben stärker empfunden als bei uns, weil man dort nur das, noch dazu in süßester Verkitschung, zu zeigen pflegte, was ungefährlich war. [...] Im damaligen Deutschland fragte man sich in allen Lagern vergeblich, was an diesem Film bolschewistisch sei. Heute sind wir klüger geworden. Wir wissen heute, daß, als dieser Film im Januar 1927 zur Uraufführung kam, sich in der Sowjetunion jene Entwicklung anbahnte, die wir heute als groBe technische Revolution und Voraussetzung für den rüstungsgewaltigen bolschewistischen Imperialismus erkannt haben. In den Köpfen der Männer um Stalin formten sich damals die ersten Vorstellungen von Rüs- 
tungsgiganten, in die man seelenlose Massen zwingt um mit ihnen Panzergeschütze und Flugzeuge für die wilden politischen Gelüste der kommunistischen Oberschicht zu bauen" (Kriegk 1943: 90f.).

Genauso wie bei Kracauer spielt auch bei Kriegk der Entstehungskontext der Ausführungen die entscheidende Rolle. In ihren Einschätzungen verarbeiteten sie eher politische Stimmungslagen ihrer jeweiligen Gegenwart, als dass sie den zeitgenössischen Entstehungs- bzw. Rezeptionskontext der Filme in den Mittelpunkt stellen. Wenn die Produktionsstätten der UFA „[...] in den Worten Blochs, ein ,Mischort' der Republik, ihres progressiven und regressiven Materials - und zugleich ,Hohlraum' und ,Abraumhalde', schutzlos offen gegenüber dem gewaltsamen Zugriff neuer Sinnstifter (waren), die bereitstanden, das Vakuum mit einer dubiosen Ersatzreligion zu füllen" (Kreimeier 1992: 132), dann gilt diese Einschätzung auch für die Filme selbst, wenn sie denn in die Hände posthistorischer Filmideologen gelangten.

Die Ambivalenz der Interpretationsmöglichkeiten wird besonders deutlich, wenn man die Verbindung aus den angeblich autoritativen Sozialismusklischees des Drehbuchs und Langs visionären Bilderwelten genauer betrachtet. Von jenen wurde behauptet, dass sie „in der Selbstdarstellung und Architektur des Dritten Reichs zum Teil Wirklichkeit wurden“ (Kramer 1995: 220). Dieser Aussage kann man selbstverständlich zustimmen, das Gleiche würde aber auch für die Architektur der Stalin-Ära in der Sowjetunion gelten, was z.B. bei einem Vergleich der Architekturphantasien aus METROPOLIS und den Entwürfen zum „Palast der Sowjets“ (1935) oder den stalinistischen Masseninszenierungen deutlich wird (Stommer/Delügge 1995).

Folgt man den Kritikereinschätzungen zu METROPOLIS, hatte sich für diesen Film anscheinend eine Gruppe deutscher Genies zusammengefunden, die von einem halbreligiösen Eifer gepackt war, alles neu zu machen und darin einen missionarischen Geist entwickelten, der gegen pseudoreligiöse Selbstsuggestionen nicht immun war (Kreimeier 1992: 132). Dabei harmonierten die Gedanken der Elitekünstler offenbar hervorragend mit dem „Vulgär-Idealismus" und der „vagen Herzensgläubigkeit" des deutschen Kleinbürgertums (ebd.). Während aus dem Ausland begeisterte Stimmen, wie z.B. ein enthusiastischer Arthur Conan Doyle (Kracauer 1995: 306), klein geredet wurden, stimmten die Großkritiker der deutschen Feuilletons dem futuristischen Schwarzseher Herbert George Wells zu:

„Ich habe neulich den dümmsten aller Filme gesehen. Ich glaube nicht, daß es möglich ist, einen dümmeren zu machen. Er heißt METROPOLIS [...]. Ich glaube nicht, daß eine einzige neuartige Idee, ein einziger Augenblick 
artistischer Schöpfung in dem prätentiösen Machwerk von Anfang bis Ende enthalten ist. [...] Diese ganze vertikale Gliederung der Stadt und der sozialen Struktur ist vollkommen veralteter Unsinn" (Wells in Brennicke/Hembus 1983: 138).

Folgerichtig gefiel den deutschen Kritikern diese Art, den größten Filmemacher Deutschlands herunterzumachen, denn sie teilten gewohnheitsmäßig die Allüre, nach der autonomen Vision des Regisseurs überhaupt nicht zu fragen und ihm stattdessen die eigene Vorstellung von Weltsicht und Filmemachen zu empfehlen (Brennicke/Hembus 1983: 138). Die Gründe für Wells' Verriss dürften wohl darin gelegen haben, sein eigenes Werk gegen das von Lang herauszustellen. In METROPOLIS ging es nicht in erster Linie um Ideen, dafür war Thea von Harbous Drehbuch zu schwach, es ging vielmehr darum, neue Bildwelten zu schaffen und diese auch filmisch umzusetzen. Diese Dichotomie erkannte beispeilsweise Luis Bunuel, der bemerkte:

„METROPOLIS ist nicht ein einziger Film. METROPOLIS sind zwei Filme, die an den Bäuchen zusammengeklebt sind, aber zwei Filme, deren innere Beweggründe in einem extremen Antagonismus divergieren. Wer im Kino einen behutsamen Geschichtenerzähler sieht, wird von METROPOLIS tief enttäuscht sein. Was uns hier erzählt wird, ist trivial, schwülstig und von einer altväterlichen Romantik. Ist uns am Film aber die ,plasticophotogénique'-Seite wichtiger als das Narrative, dann dürfen wir in METROPOLIS die Erfüllung all unserer Wünsche sehen und der Film wird uns entzücken als das herrlichste Bilderbuch, das sich denken läßt" (Bunuel in Brennicke/Hembus 1983: 136).

Die Gründe für diese Dichotomie lagen z.B. für Otto Kriegk nicht allein in dem Bestreben, etwas produzieren zu wollen, was nach der Meinung der Verkaufsabteilung für ein gutes Geschäft im Ausland nötig war (Kriegk 1943: 93), sondern auch in seinem völlig überzogenem Anspruch, allen Kritikern gerecht zu werden:

„Hunderte von dem Film nahestehenden Intellektuellen dieser Zeit erschraken, als sie erkannten, bis zu welcher Höhe des Wahnsinns der Versuch vorgetrieben werden konnte, allen Theorien, aber auch allen Ansprüchen gerecht zu werden, die für einen guten Film im Lexikon der Erfolgsmöglichkeiten verzeichnet waren" (Kriegk 1943: 90).

Im südafrikanischen Rezeptionskontext konnten diese Erwartungen gar nicht erst entstehen, da es zum damaligen Zeitpunkt weder in der Presse, noch im Geistesleben Südafrikas eine intellektuelle Debatte über Film und Kino gegeben hat. Demzufolge geriet die Medienrezeption von METROPOLIS nicht 
wie in Deutschland und den USA zu einem intellektuellen Spießrutenlauf, sondern der Respekt vor der Regieleistung Langs, dem Schauspiel der Darsteller und dem Drehbuch der Thea von Harbou standen im Vordergrund der zeitgenössischen Kritik. Vom Kino erwartete man Unterhaltung, und diese bot METROPOLIS als ein noch nie dagewesenes Spektakel, „Therefore, the skilled scenario writer had to provide for two important things, as necessary for the film as for the novel - sensation and love" (CT 21.5.28: 5). Das die zeitgenössische südafrikanische Rezeption dem Film eher gerecht wurde als spätere Theoretisierungen, wird an den Filmschriften Hans Rompels deutlich. Während er in seinen Rezensionen den Film fast uneingeschränkt lobte, schrieb er in seinem filmhistorischen Abriss aus dem Jahr 1942, dass Fritz Lang bereits mit METROPOLIS sein innerer Kunstsinn, seine Feinfühligkeit und seine Aufrichtigkeit verloren gegangen seien (Rompel 1942a: 107).

Die genannten nichtsüdafrikanischen Rezeptionsbeispiele in der Dokumentenanalyse zu METROPOLIS machen noch einmal deutlich, welche Bedeutung dem zeitgenössischen Kontext zukommt. Siegfried Kracauer schrieb über METROPOLIS, der Film habe das deutsche Publikum beeindruckt, die Amerikaner genossen seine technische Brillanz, die Engländer dünkten ihn erhaben, und die Franzosen zeigten sich von einem Film, der ihnen wie eine Mischung aus Wagner und Krupp und im Ganzen als alarmierendes Zeichen deutscher Vitalität erschien, beunruhigt (Kracauer 1995: 159).

Verallgemeinert man diese Kritiken zusammenfassend, wendet sich die ursprünglich abwertend gedachte Bemerkung, wonach Langs Film Utopie ohne Gesinnung, ohne Zuversicht, ohne Absicht biete und die Produzenten des Films keine andere Absicht gehabt hätten, als Geld zu verdienen (Eggebrecht 1927). Bei einem Regisseur wie Fritz Lang dürfte es keine ernsthafte Überraschung mehr gewesen sein, dass für ihn die Form über dem Inhalt stand. Das Filmproduzenten eher Geld verdienen als die Welt verändern wollen, bedarf eigentlich keines Kommentars.

In den USA hatte man Probleme mit dem Film ob seiner ,bolschewistischen Tendenzen', in der UdSSR wurde METROPOLIS gar nicht erst zur Vorführung zugelassen, da man ihn des Versuches beschuldigte, „unversöhnliche Klassengegensätze zu kaschieren“ (Gregor/Klejman 1995: 202). Aus der südafrikanischen Rezeption lässt sich schlussfolgern, dass die UFA mit METROPOLIS ihre Ziele erreicht hatte: Das durchgehend positive Medienecho hatte ohne Zweifel zur Steigerung des Ansehens des deutschen Films und so auch der UFA in der Welt beigetragen. Bei vielen anderen in Südafrika gezeigten UFA-Filmen wurde darauf hingewiesen, das die UFA der Filmproduzent sei, der auch METROPOLIS kreiert habe, ebenso wurde Fritz Lang 
als Schöpfer des Sensationsfilmes METROPOLIS in den Kritiken seiner weiteren Filme SPIONE und FRAU IM MOND genannt. Spätestens mit METROPOLIS wusste die südafrikanische Kinoöffentlichkeit, dass aus Deutschland Filme kamen, die vom üblichen Kinostandard Hollywoods abwichen. Und dies konnte METROPOLIS sogar noch in seiner verstümmelten Verleihfassung vermitteln. Der finanzielle Erfolg für die Kinos der Schlesinger-Organisation muss beträchtlich gewesen sein, die Aussicht auf einen ähnlichen Erfolg dürfte dem direkten Konkurrenten Kinemas Ansporn genug gewesen sein, sich ebenfalls verstärkt um deutsche Filme zu bemühen. Es war sicher kein Zufall, sondern zielgerichtetes Gewinnstreben, dass Kinemas bereits im Oktober 1928 ankündigen konnten, das komplette UFA-Programm des Jahres 1928 für Südafrika erworben zu haben (Gutsche 1972: 205).

\subsubsection{Untersuchung weiterer Genre 4-Filme}

Der zu den „Ml>10-Filmen“ gehörende Historienfilm UNSERE EMDEN ${ }^{185}$ wurde von Paimann's Filmlisten ob seiner geschichtlichen Ausrichtung nicht wie andere Spielfilme bewertet, belegte aber in der vom Filmkurier geführten Bestenliste des Jahres 1927 den sechsten Rang. Der Film handelt von der Kriegsteilnahme des deutschen Hilfskreuzers „Emden“, der im Indischen Ozean einen selbständigen Kaperkrieg führte und schließlich vom australischen Kreuzer "Sydney“ nahe der Cocos-Inseln aufgebracht und kampfunfähig gemacht wurde. Unter den Darstellern befanden sich ehemalige Besatzungsmitglieder der "Emden“, auch wurden Dokumentaraufnahmen von Seegefechten in die Spielhandlung mit eingebaut.

Tab. 44: Weitere Genre 4-Filme

\begin{tabular}{|c|c|c|l|c|}
\hline MI & PFL & FK & \multicolumn{1}{|c|}{ Filmtitel } & Erstbeleg SA \\
\hline 18 & 0 & 6 & Unsere Emden (Kreuzer Emden) (A) & 17.04 .1928 TS \\
\hline 12 & 4 & - & Am Rande der Welt (K) & 25.03 .1929 DFA \\
\hline
\end{tabular}

Die ausführliche südafrikanische Medienrezeption begann mit einer ReutersMeldung, wonach der Film als Gegenpropaganda zum sowjetischen „Panzerkreuzer Potjomkin" (1925, S. Eisenstein) in Berlin aufgeführt wurde, beim zeigen der kaiserlichen Kriegsflagge sollen ,Republikaner' die Veranstaltung gestört haben (EPH 5.1.1927: 7). Die Filmrezensentin der Sunday Times

185 TS 17.4.1928: 8, NM 5.5.1928: 23, NA 8.5.1928: 9, NM 8.5.1928: 13, VB 1.6.1928: 8, TF 2.6.1928: 12, EPH 24.7.1928: 12, NW 20.10.1928: 13, NW 23.10.1928: 7, DA 23.10.1928: 5, NW 24.10.1928: 9, NM 9.2.1929: 23, NM 12.2.1929: 8 (Johannesburg, Durban, Bloemfontein, Port Elizabeth, Pietermaritzburg, Durban). 
"Treble Violl" begrüßte die Tatsache, dass in Südafrika endlich ein Film des Seekrieges gezeigt werde, der unter Leitung der deutschen Admiralität zustandekam (TS 17.4.1928: 8). Die ,Heldentaten' der „Emden“ waren dem Publikum noch aus dem Krieg bekannt (NW 20.10.1928: 13), besonders das faire Verhalten zwischen Freund und Feind, dargestellt durch die gegnerischen Befehlshaber Kapitän von Müller („Emden“) und Captain Glossop („Sydney“), fand Anklang beim Publikum.

Die ohnehin vorhandene Vorbildwirkung der britischen Presse für die südafrikanischen Zeitungen wird bei diesem Film besonders deutlich und auch direkt erwähnt (NW 23.10.1928: 7). Die Presse der weitgehend britisch geprägten Hafenmetropole Durban ging ausführlich auf britische Pressemeldungen ein (NM 5.5.1928: 23). Überraschenderweise lief der Film auch in England sehr erfolgreich, was auch deutschen Zeitungen nicht verborgen blieb (LBB 13.6.1927: 4). Die positiven Berichte aus England wurden deshalb sowohl in der südafrikanischen, als auch der deutschen Presse aufgegriffen, was in den direkten Zitaten aus dem Manchester Guardian gipfelte: „THE EMDEN is the romance of gallantry; it belonges no more to German than to the whole world“ (NM 5.5.1928: 23) bzw. „Aber dieser deutsche Film ist eine Romanze der Tapferkeit, und er ist es nicht nur für Deutschland, sondern für die ganze Welt" (LBB ebd.). Die englischsprachige Presse war offenbar sehr überrascht von der weitgehend vorurteilslosen und nicht ins karrikaturenhafte verzerrten Darstellung des Films. Selbst die Reklamebotschaft „The Emden - the ship that hoped to blow Durban to pieces" kam ohne viel Geschrei daher, auf die Mitarbeit der deutschen Admiralität wurde wie selbstverständlich hingewiesen, der Film handele nur von der Kühnheit, dem goldenen Schlüssel aller Heldentaten (NM 8.5.1928: 10). Selbst manche Wörter der englischen Eskalationsrhetorik in Bezug auf alles Deutsche relativieren sich in der übrigen positiven Berichterstattung zu diesem Film:

"The principal movers in the film are Teutons, but there is an intangible something in the handling of the matter which removes any feeling of resentment; it is the full and free comradeship of the seaman who loves a hard scrap and fairplay all the way. This is the manner of treatment of the subject which, even in the heat of the battle, bears the stamp of chivalry" (NA 8.5.1928: 9).

Besonders die dokumentarischen Szenen der Seeschlacht mit echten Schlachtschiffen, als auch die eingebaute Liebesgeschichte, wurden als die gelungene Kombination aus historischen Fakten und menschlichen Gefühlen bezeichnet (NM 8.5.1928: 13). Zur kontextuellen Authentisierung der Film- 
handlung brachte die Presse einige Zeit nach dem Film zwei Augenzeugenberichte von ehemaligen Besatzungsmitgliedern der „Sydney“ (NM 26.10.1929: 9 und 9.11.1929: 9). Die afrikaanse Presse berichtete ebenso positiv, bemerkte aber etwas hämisch, dass der Filmvertrieb „New Era“ [u.a. Importeur von propagandistischen Kriegsfilmen wie „Zeebrugge“ (1924, A.V. Bramble), „Mons" (1926, W. Summers), „Ypres“ (1925, W. Summers) und „The Somme" (1927, M. Wetherell] den Film extra für das englische Publikum in „The Emden's last Fight" umgetauft habe (VB 1.6.1928: 8). Der ergreifende Realismus der Seeschlacht zeige die Gesichter der Toten und Verwundeten, und so müsse es auch sein: die Schrecken des Krieges dürfen nicht durch einen romantischen Nebel verhüllt werden (ebd.). ${ }^{186}$ Recht eindeutig kam Die Volksblad zu dem Schluss:

„In der Tat kann DIE EMDEN als ein vorbildlicher Kriegsfilm betrachtet werden: darin findet sich keinerlei Selbstverherrlichung oder Yankeetum, allein der bescheidene und gerechtfertigte Stolz auf die Heldentaten der deutschen Seeleute; und der Geist gegenüber dem Feind ist so ritterlich, dass die Engländer den Film mit dem größten Vergnügen übernommen haben. Was für ein Gegensatz zu deren eigenem geschichtsverfälschendem Cavell-Film! ${ }^{187}$ Die Zuschauer haben gestern Abend der deutschen Flagge und der weißen Fahne gleichermaßen zugejubelt, ein Beweis dafür, dass der Film den rechten Ton anzuschlagen weiß" (VB 1.6.1928: 8). ${ }^{188}$

Ähnlich äußerte sich auch der Eastern Province Herold:

„One cannot help being struck by the impartial way in which the film has been produced. There is not the slightest bias, and the utmost credit is given to both sides. The gallant deeds of Von Müller's crew were legion, and they fought with the utmost bravery. The actual battle itself is one of the finest bits of acting it has been our lot to witness, being thrillingly realistic and graphic. It was only after one of the hardest battles in the history of the War that Von Müller finally surrenderd" (EPH 24.7.1928: 12).

\footnotetext{
186 „Hierdie seeslag is met aangrypende realisme weergegee, en die gesig von dooies en gewondes word ons nie bespaar nie. Dit is soos dit moet wees: die verskrikkinge van die oorlog maag nie in ' $n$ romanties waas gesluier word nie."

187 Damit dürfte der Herbert Wilcox-Film „Dawn“ (1928) gemeint sein, in dem die Schauergeschichte einer von deutschen Soldaten während des 1. Weltkrieges im besetzten Belgien ermordeten Kranken schwester (,Edith Cavell') geschildert wird. Dieser Film wurde folgerichtig von der Zensurkommission der von Afrikaanern dominierten Provinz Transvaal (u.a. Johannesburg) beanstandet (Gutsche 1972: 296).

188 „Inderdaad kan die ,Emden' as 'n voorbeeldige oorlogsprent aangemerk word: daar is geen selfsverheerliking of jingoisme in nie, alleen ' $n$ beskeie maar regmatige trots op die heldedade van die Duitse seeluie; en die gees teenoor die vyand is so ridderlik dat die Engelse die prent met die grootste plesier oorgeneem het. Wel 'n teenstelling met hul eie geskiedsvervalsing in die Cavell-prent! Die publiek het gisteraand die Duitse vlag en die White Ensign eweseer toegejuig, wel 'n bewys dat die prent die regte nooit weet aan te slaan."
} 
In keiner südafrikanischen Filmbesprechung findet sich die Kritik wieder, wonach der Film als Schrittmacher einer glorreichen Kriegsstimmung eine Gefahr darstelle, was in der deutschen Rezeption wiederholt vorgebracht wurde (Kracauer 1927). Die Ursache dafür dürfte zweifellos in der vollkommen anderen Bedingungs- bzw. Bezugsrealität des südafrikanischen Kontextes zu suchen sein. Dort gab es innerhalb der zwei dominanten Bevölkerungsgruppen keine unterschwellige Revanchementalität in Bezug auf den Ersten Weltkrieg, zudem bemühte sich die deutschfreundliche Regierung des britischen Dominion Südafrika unter Premier J.B.M. Hertzog um ein positives Verhältnis zu Deutschland. Da man sich nicht als bedroht ansah, konnte die in UNSERE EMDEN demonstrierte Ritterlichkeit und Stärke der deutschen Marine keine Resentiments hervorrufen.

Die in der jenseits der politischen Mitte verortete Presse verspottete jedoch die Ankündigung der produzierenden EMELKA, dass der Film weder ein militärischer noch ein politischer Propaganda- oder Tendenzfilm, vielmehr für das ganze deutsche Volk und für die Welt, für Männer und Frauen aller Weltanschauungen sei, ohne in ihrer Überzeugung berührt zu werden (Rutra 1927), wird an Hand des britischen und südafrikanischen Medienechos als überzogenes deutsches Großkritikertum deutlich. Dass die britische und die südafrikanische Presse beider Sprachgruppen in ihren Filmkritiken so überzeugt Partei für den Film ergriffen, spricht eher für die tatsächlich in der Filmhandlung verwirklichten Postulate und gegen die deutsche Expertenkritik. Da der Film auch erfolgreich nach den USA und Australien exportiert wurde (Putz 1996: 72 und LBB 13.6.1927: 4), ist nicht von einer zu Südafrika gegenteiligen Rezeption auszugehen, zumal ein britischer Vertrieb wohl kaum antibritische Kriegspropaganda in Umlauf gebracht hätte.

Der Einschätzung des Films als „kriegsverherrlichend mit deutschnationaler Tendenz" (Korte 1998: 363) kann aus südafrikanischer Sicht klar widersprochen werden. Die südafrikanische Medienrezeption - und so wohl auch das Publikum - konnten im zeitgenössischen Kontext derartige Botschaften nicht wahrnehmen. Selbst die eher Deutschland-skeptischen Südafrikaner britischer Herkunft zollten der als ausgewogen eingeschätzten Darstellung Respekt, die Afrikaaner waren ohnehin germanophil und begrüßten den Film enthusiastisch. Programmgeschichtlich lässt sich diese Reaktion u.a. damit erklären, dass vor UNSERE EMDEN mit Kriegsfilmen wie "Ypres" (1925, W. Summers), „Mons“ (1926, W. Summers), "The Somme“ (1927, M. Wetherell) oder "The Battle of Coronel and Falkland Islands" (1928, W. Summers) (Gutsche 1972: 197 und 228) nur Produktionen zu sehen waren, die das Kriegsgeschehen stark parteilich und aus britischer Perspektive zeigten. Dies 
rief das Misstrauen der allem Britischen sehr skeptisch gegenüberstehenden Afrikaaner hervor, die durch ihre Sympathien für Deutschland der Propaganda keinen Glauben schenkten und sich neutralere Darstellungen wünschten. Diesem Bedürfnis kam UNSERE EMDEN beispielhaft nach, was die besonders positive Aufnahme des Films durch die afrikaanse Presse miterklärt.

Vor diesem Hintergrund wird auch die Übernahme der Argumentation des Kracauer-Zitates aus dem Jahre 1927 für das Tonfilmremake „Kreuzer Emden" (1932, L. Ralph) problematisch, da abweichend von der angenommenen Kategorisierung viele Filme in einer anderen historischen Situation, unter veränderten Rezeptionsbedingungen eine deutlich verschiedene Wirkung haben können (Korte 1998: 148). Die zwar ebenfalls ausländische, aber den deutschen Einschätzungen doch recht nahestehende Kritik in Paimann's Filmlisten bemerkte zu UNSERE EMDEN recht eindeutig, „[...] daß in der besprochenen Bearbeitung national oder politisch bedenkliche Momente fehlen" (PFL 1927: 6).

Mit AM RANDE DER WELT/AT THE EDGE OF THE WORLD ${ }^{189}$ findet sich in der Gruppe der Genre 4-Filme die einzige Produktion, die als tendenziell pazifistisch eingeschätzt werden kann. Mit einem MI-Wert von 12 und laut PFL-Einstufung nur mit 4 bewertet (,über dem Durchschnitt'), erhielt er innerhalb des Genres die schwächste Einschätzung. Der südafrikanische Erstbeleg im Diamond Fields Advertiser stellt ebenfalls eine Besonderheit dar, da in dem weit im Binnenland gelegenen Bergbaustädtchen Kimberley kaum eine Filmpremiere erfolgt sein dürfte.

Wie bei den meisten Filmvorbesprechungen handelte es sich um vorgefertigte Texte aus den Werbematerialien der Filmvertriebe, die den Journalisten entweder als Vorlage dienten oder direkt übernommen wurden. Die in drei Fällen abgedruckten Illustrationen dürften vom UFA-Auslandsdienst stammen (DFA 25.3.1929: 3, NW 18.5.1929: 13 und NM 13.7.1929: 23), die gleichen Bilder fanden sich auch in den UFA-Reklame-Ratschlägen für diesen Film. ${ }^{190}$ Die enthaltenen Rezeptionsempfehlungen der Filmvertriebe fanden so Eingang in die südafrikanischen Medien, da in den Vorbesprechungen nur die Inhaltsangaben wiederholt werden konnten und das Publikum durch die Nennung bekannter Stars, in diesem Falle Brigitte Helm, oder bekannter Filmstudios wie der UFA, angelockt werden sollte. Die zwei erwähnten Cha-

\footnotetext{
189 DFA 25.3.1929: 3, NW 18.5.1929: 13, CT 8.6.1929: 9, CA 11.6.1929: 15, Db 10.6.1929: 8, DB 11.6.1929: 9, CT 11.6.1929: 9, RDM 8.7.1929: 5, NA 13.7.1929: 4, NM 13.7.1929: 23, NM 16.7.1929: 15, NA 16.7.1929: 11 (Kimberley, Kapstadt, Johannesburg, Durban).

${ }^{190} \mathrm{Vgl}$. UFA-Reklame-Ratschlag für AM RANDE DER WELT, Berlin 1927/28: 4 (14 S.).
} 
rakteristika fehlen so auch in keiner der Vorbesprechungen, Hinweise auf die UFA-Filme SPIONE oder METROPOLIS wurden ebenfalls eingestreut.

Die Filmhandlung dreht sich um das Schicksal einer Müllersfamilie, deren Windmühle sich an einer unbestimmbaren Grenze befindet und nach Kriegsausbruch besetzt und später niedergebrannt wird. Darin eingebettet ist die Liebesgeschichte zwischen einem feindlichen Offizier und der Müllerstochter, die sich für ihren verhafteten und der Spionage bezichtigten Bruder einsetzt, dem der feindliche Offizier zur Flucht verhilft. Dadurch gerät der Offizier selbst unter Spionageverdacht, der nur durch das Selbstopfer des tatsächlichen Spions, der ebenfalls in die Müllerstochter verliebt ist, abgewendet werden kann.

Durch die bewusst angelegte örtliche und zeitliche Unbestimmbarkeit der Spielhandlung wurde der Eindruck erzeugt, nicht eine bestimmte Kriegsgeschichte zu erzählen, sondern um gleichsam allegorisch für alle Kriegsschicksale zu sprechen (CA 11.6.1929: 15). Obwohl inhaltlich als Kriegsfilm eingeschätzt, wurde er als „Anti-Kriegsfilm“ beschrieben (NM 16.7.1929: 15). Die Zeitungen waren sich in Bezug auf AM RANDE DER WELT weitgehend einig, dass der Film vor allem von seinen Charakterdarstellungen lebe und nicht in der Art eines gewöhnlichen Kriegsfilmes komponiert sei (CT 8.6.1929: 9). Einen Schwachpunkt stellte nach Einschätzung des Natal Mercury der allzu dramatische Auftritt des Spions in letzter Sekunde dar, was im wirklichen Leben eher unwahrscheinlich wäre (NM 16.7.1929: 15). Das konsequente Eintreten des Films gegen jegliche Art von Krieg wurde allgemein geschätzt, dass dabei bewusst vermieden wurde, irgendwelche nationalen Standpunkte einzunehmen, wurde besonders in der afrikaansen Presse begrüßt (DB 10.6.1929: 8). ${ }^{191}$ Die Botschaft des Films, des Glaubens an den Sieg des Guten über das Böse, der Liebe über den Hass, wurde klar erkannt (NA 16.7.1929: 11). Als neuartig eingeschätzt und ohne ideologische Implikationen wurde dem Film zugestanden:

„It is a picture that people will talk about - something different, and therefore welcome - a picture with a train of thought for those who desire it, and with a fine love story for those who are interested only in romance. In brief, it presents a unique opportunity for the exhibitor who is keen to exploit novelty and reap the benefits therefrom" (NM 13.7.1929: 23).

\footnotetext{
191 „Hoewel die gees van die prent teen die oorlog gerig is, kom daar byna geen oorlogstonele in voor nie, en is wyslik vermy om einige bepaalde volk se standpunt oor die oorlog te toon."
} 
Diese Einschätzung deckte sich auch mit der Bemerkung der afrikaansen Presse, dass hier wie gewohnt ein guter Film gezeigt würde, er aber keine der sonst besonders tiefgründigen UFA-Produktionen sei (DB 11.6.1929: 9). ${ }^{192}$ Zumindest diese letzte Beurteilung stand entgegen der in deutschen Medien vertretenen Auffassung, dass es das Interesse des Regisseurs gewesen sei, nicht die äußere Fassade der Welt und der Menschen abzuspiegeln, sondern vielmehr den inneren Sinn der Dinge, wie er sich ihm weltanschaulich darstellt, optisch entschleiern wolle (LBB 20.9.1927: 2).

Daraus kann geschlossen werden, dass im südafrikanischen Kinoprogramm generell nur wenige Filme mit ausgeprägt pazifistischer Tendenz zu sehen waren und ideologische Hintergründe kaum erkannt wurden. Die deutsche Medienrezeption lobte vor allem die filmkünstlerische Umsetzung der Handlung, kritisierte aber an Grunes Arbeit, dass die weltanschauliche Intention nur dann glaubhaft werde, „indem man die Wirklichkeit in realer Überzeugungskraft einfängt.[...] Jedenfalls wird es auf dem Umwege des allegorischen Films, des stilisierten Dramas nicht gelingen, nachhaltig auf den Filmbesucher einzuwirken. Grunes Film kann diese Überzeugung nur verstärken, und vielleicht liegt gerade hierin seine grundlegende Bedeutung" (ebd.).

Somit kann zwar festgehalten werden, dass die südafrikanische, wie auch die deutsche Medienrezeption die Einstufung von AM RANDE DER WELT als pazifistischen Film gleichermaßen bestätigen, dies allerdings auf südafrikanischer Seite mit einer völligen Verkennung der zeithistorischideologischen Grundtendenz einherging. Übrig blieb ein Film mit „... an unconvincing pacifist theme, distinguished only for the settings [...]" (Rotha/Griffith 1930/1967: 284). Diese Einschätzungen lassen sicher wiederum mit den in Südafrika nicht vorhandenen Kontextbezügen zur Bezugsund Bedingungsrealität in Deutschland erklären. Die Anti-VersaillesStimmung der ausgehenden 1920er Jahre und die subjektiv empfundene Bedrohungsstimmung (von Innen und von Außen) schufen einen als aktuell wahrgenommenen Rezeptionshintergrund, der in Südafrika nicht der Realität entsprach.

\footnotetext{
192 „ 'n Goeie rolprent van die gewone soort - nie een van die dieper UFA-produkte nie."
} 


\section{Ergebnisse - Schlussfolgerungen - Ausblick}

Nach Abschluss der Rezeptionsanalysen und am Ende dieser Untersuchung bleibt festzuhalten, dass trotz der intensiven Quellenarbeit, dem Indizien- und Argumentefinden und den zahllosen als Beweisersatz dienenden Gedankenverknüpfungen vor allem ein ,Dokument des Konjunktivs' entstanden ist.

Zu Beginn der Untersuchung wurde begründet, warum Südafrika als filmhistorischer Sonderfall anzusehen ist und weshalb sich ein rezeptions- und wirkungsgeschichtlich orientiertes Vorgehen als methodisch-analytischer Zugang zur Durchdringung der Thematik anbietet. Dazu konnte mit der Abkehr vom Herkunftslandprinzip in der Filmhistoriographie ein dem südafrikanischen Kontext angemessener Untersuchungsrahmen entworfen werden.

Um das Erkenntnisinteresse mit den Erkenntnismöglichkeiten in Einklang zu bringen, konnte mit dem Konzept einer Filmgeschichte als Analyse der Rezeptions- und Wirkungsgeschichte des deutschen Spielfilms in Südafrika verdeutlicht werden, mit welcher Methodenverschränkung erreicht werden sollte, auf Basis von Rezeptionsdokumenten filmhistorisch valide Aussagen zu gewinnen. Mit Blick auf den lückenhaften Überlieferungszusammenhang der Rezeptionsdokumente, der erschwerten Zugänglichkeit bzw. der Nichtexistenz bestimmter Quellen und der historischen Distanz des ausgewählten Untersuchungszeitraumes musste eingeräumt werden, dass mit der weitgehend indiziengestützten Argumentation am Ehesten ein Beitrag zur Strukturgeschichte von Kino und Film in Südafrika zu erwarten war.

Die Ergebnisse der in den Einzelkapiteln vorgenommenen Untersuchungen können nun für die Beantwortung der Eingangs formulierten Fragestellung herangezogen werden. Dabei wird der Versuch unternommen, die getätigten Feststellungen zu erklären und in einen übergeordneten medienhistorischen Zusammenhang zu stellen.

Die Kontextanalyse zum Themenkomplex Kino und Gesellschaft in Südafrika hatte das Ziel, die Struktur des südafrikanischen Unterhaltungssektors darzustellen und die Gründe für die massive Erweiterung des deutschen Filmangebots 1928/29 am dortigen Markt offenzulegen. Aus den zusammengetragenen Fakten ließ sich rekonstruieren, welche Ursachen dafür verantwortlich waren, dass Südafrika zu einem international attraktiven Filmmarkt wurde und eine in Afrika beispiellose Kinolandschaft entstand. Demnach fand der Film als ein hochentwickeltes Industrieprodukt, gebunden an die technischen Fortschritte dieser Zeit und als Massenmedium auf die Existenz einer möglichst großen und homogenen Konsumentenschar angewiesen, gerade im sich wirtschaftlich modernisierenden Südafrika einen 
idealen Markt vor. Wie in Europa oder Amerika sammelten sich in den neu entstandenen Industriegebieten zahlreiche potentielle Nachfrager, die durch ihre Sozialisation und ihre ähnliche Stellung im Produktionsprozess weitgehend gleichgeartete Bedürfnisse aufwiesen (Korte 1978: 17f.). Das Kino wiederum schuf für die Erfüllung dieser Bedürfnisse optimale Angebote, da der Film als Massenerzeugnis - im Gegensatz zum Konkurrenzmedium Theater - am Besten auf die Wünsche der homogenisierten Nachfragermassen eingehen konnte. Infolge der wirtschaftlichen Prosperität in Südafrika entstand zudem auch ein Publikum, dass durch neue Arbeitsgesetze über mehr Freizeit verfügte und einen größer werdenden Einkommensanteil tatsächlich zu deren Gestaltung verwenden konnte.

Ein Markteintritt des deutschen Films wurde zunächst bis etwa 1927 durch das allumfassende Angebotsmonopol der Schlesinger-Organisation erschwert. Mittels des Unternehmenskonglomerats des in Südafrika ansässigen US-Amerikaners I.W. Schlesinger fungierte v.a. dessen Kinokette African Theatres als Erweiterung der Distributionssphäre Hollywoods. Diese Markteintrittsbarriere wurde erst durch die Gründung eines konkurrierenden Filmvertriebs, der u.a. mit britischem Kapital ausgestatteten Unternehmung Kinemas Ltd., überwunden. Das Potential der Nachfrage im Anbietermarkt Südafrika ließ einen Konkurrenzkampf entstehen, in welchem die Monopolverhältnisse für kurze Zeit (1927-1931) beseitigt wurden und ein angebotsseitiges Duopol der Kinoketten entstand. Eingeschränkt durch die langfristigen Verträge der Schlesinger-Organisation mit den führenden HollywoodStudios, importierten Kinemas eine steigende Anzahl britischer und älterer Hollywoodfilme nach Südafrika. Um die Publikumsnachfrage zu befriedigen und das Gewinnpotential des Marktes optimal auszuschöpfen, suchten Kinemas zielstrebig nach neuen Programmangeboten und wurden auf den deutschen Film aufmerksam. Den Probelauf eines deutschen Films hatten African Theatres Mitte 1927 mit EIN WALZERTRAUM erfolgreichen vollzogen. Daraus entstand die Situation, dass beide Konkurrenten an die durch die UFA repräsentierte deutsche Filmindustrie mit Nachfragewünschen herantraten, was dieser wiederum in ihrer durch finanzielle Schwierigkeiten geprägten Umstrukturierungsphase sehr gelegen kam. Auf diese Weise trafen sich fast idealtypisch Angebot und Nachfrage, was im Jahr 1928 erstmals auch importstatistisch zu einem größeren Angebot deutscher Filme in Südafrika führte.

Auf Seiten von Kinemas verband man mit den deutschen Filmen die Hoffnung, mit Werken einer vorher weitgehend unbekannten Filmkultur das Zuschauerinteresse auf sich zu ziehen und dem Monopolisten African 
Theatres Marktanteile streitig zu machen. Um eben genau dies zu verhindern, importierte auch die Schlesinger-Organisation deutsche Spielfilme, wobei sie zunächst ältere Produktionen erwarben, was im südafrikanischen Kontext nicht weiter auffiel. Die Südafrikaner einte das kommerzielle Interesse am Import deutscher Spielfilme, da eine Neuaufteilung des Marktes nur mit einer konkurrierenden Angebotserweiterung gelingen konnte.

Die deutsche Seite hatte selbstverständlich auch kommerzielle Interessen, jedoch war die UFA eher bestrebt, eine langfristige Strategie zum dauerhaften Verbleib im südafrikanischen Markt zu verfolgen, was im Gegensatz zur kurzfristigen Marktverdrängungsstrategie der Südafrikaner stand, die den deutschen Film nur als Mittel zum Zweck sahen. Betrachtet man die Exportpolitik der UFA drängt sich der Verdacht auf, dass die Konkurrenten in Südafrika auch deshalb mit attraktiven Filmen versorgt wurden, um sich den lukrativen Absatzmarkt auch nach dem Sieg des Einen über den Anderen zu erhalten. Hinter dieser Strategie der UFA dürften folgende Überlegungen gestanden haben: Nach Abwenden der Bankrotterklärung durch den spektakulären Einstieg des Hugenberg-Konzerns im März 1927 bemühte sich die neue Führung um eine Konsolidierung des Geschäfts. Durch die Nachfrage aus Südafrika sah man die Chance, einige der künstlerisch hochstehenden, aber finanziell ruinösen Filme wie z.B. METROPOLIS in diesem bisher unerschlossenen Markt noch unter Erstaufführungsbedingungen loszuschlagen. Es ist denkbar, dass dafür die Filme der Produktionsjahre 1925 bis 1927 zu Vorzugsbedingungen oder im Paket angeboten wurden, um eine Abnahme für das Jahr 1928 und den Marktzugang zu sichern. Nach der positiven Resonanz von EIN WALZERTRAUM und VARIETE in den Kinos von African Theatres folgten die Interessensbekundungen von Kinemas. Diesen bot man weniger spektakuläre, dafür aktuellere Filme an, damit sich die südafrikanischen Konkurrenten besser untereinander abgrenzen konnten. Um 1928/29 hatte die UFA-Führung ohnehin Abstand von den künstlerisch spektakulären Produktionen genommen und eine konsequente Orientierung auf wirtschaftliche Effizienz und den Publikumsgeschmack verfügt (Garncarz 2004: 397). Wie ein Blick auf das südafrikanische Kinoprogramm der Jahre 1928 bis 1932 belegt, war diese Strategie erfolgreich, die Konkurrenz der dortigen Kinoketten hatten der UFA um 1928/29 einen neuen Markt erschlossen.

Die UFA hatte allerdings noch einen weiteren Grund, sich ein zusätzliches Absatzgebiet notfalls auch mit einigen kalkulierbaren Anfangsverlusten zu sichern. Ebenfalls um 1928/29 wurde deutlich, dass die technische Innovation des Tonfilms trotz enormer Anschubinvestitionen dem Stummfilm dauerhafte Konkurrenz machen würde und das dieser Prozess - trotz gegenläufi- 
ger publizistischer Debatten - infolge der starken Interessen der Elektroindustrie unumkehrbar war (Strohm 1934: 11). Dies hatten Kinemas schon frühzeitig erkannt und sich die Exklusivrechte für eine frühe Version des Tonfilms nach dem De Forrest-Verfahren gesichert. Bald darauf zogen African Theaters mit dem nach einem anderen Verfahren hergestellten „The Jazz Singer" gleich und mit den weiteren Tonfilmerfolgen war klar, dass die Zeit des Stummfilms abgelaufen war. Da allerdings lange Zeit nicht ausgemacht war, welches Verfahren sich durchsetzen würde oder welche Kinokette die enormen Investitionen am Schnellsten vornehmen konnte, kooperierte die UFA mit beiden Kinoketten. Vor diesem Hintergrund dürfte die UFA bestrebt gewesen sein, ihre Stummfilme noch ,in letzter Minute' besonders agressiv zu vermarkten, was zu den vermuteten Vorzugskonditionen geführt haben könnte. Darauf deutet auch der Höchststand des deutschen Filmexports im Jahre 1929 hin.

Durch die sich abzeichnende Umstellung auf den Tonfilm sah sich auch die UFA infolge der Weltwirtschaftskrise vor der doppelten Schwierigkeit, „einerseits eine breite Amortisationsbasis für die erheblich gestiegenen Herstellungskosten zu finden, andererseits sinkende Einnahmen der Kinos als Folge des sich verringernden Volkseinkommens zu verkraften (Spilker 1975 in Korte 1978: 85). Genau um diese Belastung zu schultern, bot der neu erschlossene südafrikanische Markt hervorragende Absatzchancen sowohl für die Stummfilme, als auch für die noch zu produzierende Tonfilme. Für diese hatten die einheimischen Kinoketten frühzeitig die entsprechenden Infrastrukturinvestitionen getätigt und ihre Kinos bereits 1930 auf den Tonfilm umgestellt (Eckardt 2005: 33). Da Südafrika die Folgen der Weltwirtschaftskrise nur stark verzögert ereilten und bis 1931 kaum Absatzprobleme eintraten, darüber hinaus über eine äußerst stabile Währung verfügte, lohnten sich Geschäfte mit Südafrika umso mehr.

Durch diese historische Gemengelage von übereinstimmenden deutschen und südafrikanischen Interessen lässt sich die Aufnahme des deutschen Spielfilms in das Programm der südafrikanischen Kinoketten erklären. Dass die deutsche Seite, wie bereits weiter oben erwähnt, auch nichtkommerzielle Interessen im Sinne einer positiven „Kulturpropaganda“ hegte, soll mit den Ausführungen zum Zustandekommen der ermittelten Filmauswahl erläutert werden.

Wie bei der Betrachtung des südafrikanischen Filmimports deutlich wurde, bewegte sich der deutsche Film quantitativ in relativ geringen Größenordnungen. Der rein wertmäßige Umfang spiegelte jedoch nicht die tatsächlichen Verhältnisse am Kinomarkt wieder. Diese ließen sich erst durch die 
partielle programmgeschichtliche Aufarbeitung des Filmangebots rekonstruieren. Demnach konnten für den Zeitraum von 1928 bis 1933 gut 50 deutsche Filme im Programm der südafrikanischen Kinos nachgewiesen werden. Die Mehrzahl der Filme waren Stummfilme der UFA ${ }^{193}$ und machten in den Jahren 1928 bis 1929 einen deutlich wahrnehmbaren Bestandteil des Kinoprogramms aus. Der Anteil deutscher Filme in den Kapstädter Premierenkinos betrug beispielsweise im Zeitraum von 1928 bis 1930 durchschnittlich 8 Prozent (s. Anhang I). Nach den Produktionen US-amerikanischer und britischer Herkunft nahmen die deutschen Spielfilme den unangefochtenen dritten Rang ein. Unter den Filmen mit einer im gleichen Zeitraum überdurchschnittlich langen Spielzeit fanden sich drei deutsche und eine deutschbritische Koproduktion.

Die klare Dominanz der UFA-Spielfilme (60\%) gibt bereits einen Hinweis darauf, wie diese Auswahl zustandekam und welche Filmthemen bzw. Genres durch die Konzentration auf die UFA-Filme nicht vertreten waren. Für die gesamte Filmproduktion der Weimarer Republik galt allgemein, dass den Produktionen mit sozialkritischer oder realistischer Tendenz eine zahlenmäßig erdrückende Übermacht reaktionärer, nationalistischer oder auch unpolitischer Lustspiele und Unterhaltungsfilme gegenüberstand (Korte 1978: 88). Die UFA selbst war seit ihrer Gründung und nach der Übernahme durch den Hugenberg-Konzern noch viel stärker bestrebt, ein affirmatives und den Zielen einer konservativen Politik nahestehendes Filmprogramm zu verwirklichen, in welchem der vordergründig unpolitische, spannende, lustige, nebenbei ,belehrende' und vor allem künstlerisch anspruchsvolle Spielfilm mit hohem Unterhaltungseffekt im Mittelpunkt stand (Korte 1978: 68). Mit diesen Spielfilmen verbunden war die Konzeption einer „versteckten“ Vermittlung bürgerlicher Weltanschauungen, die zur Tonfilmzeit u.a. in ,fröhlichen' Tonfilmoperetten wie z.B. DER KONGRESS TANZT ihren besonders wirksamen Ausdruck fand (Korte 1978: 88).

Dem Gesamtangebot ließ sich ein grobes Genremuster zugrundelegen, nach welchem sich die Filme als Genre 1: Kriminal- und Abenteuerfilme (18); Genre 2: Liebes- und Sittenfilme (12); Genre 3: Walzer- und Operettenfilme (8) und Genre 4: Science Fiction- und Kriegsfilme (4) einordnen ließen. Selbst wenn die zur besseren Operationalisierbarkeit weit gefassten und durch eine schwierige Binnendifferenzierung gekennzeichneten Vorschläge zur Genreklassifizierung einige Probleme aufwerfen, geht aus den Eingruppierungen dennoch deutlich hervor, dass mit der Dominanz der ersten beiden

\footnotetext{
${ }^{193}$ Von den ca. 50 nachweisbaren Filmen entfielen 30 auf die UFA oder mit ihr assoziierte Filmstudios.
} 
Genres (insgesamt 30 Filme) genau jene unpolitischen Unterhaltungsfilme und Lustspiele in den südafrikanischen Kinos auftauchten, welche der UFAKonzeption einer „versteckten“ Vermittlung bürgerlicher Weltanschauungen nahestanden. Mit dieser Produktions- und Vertriebspraxis kam die UFA auch den bei ihrer Gründung gehegten Erwartungen an ihr Unternehmensziel nahe, wonach sie volkstümlich-nationale, verkäufliche und anspruchsvolle Filme auf die nationalen und internationalen Märkte bringen sollte (MühlBenninghaus 2004: 325).

Da sich das Zustandekommens der Gesamtheit der deutschen Filme im südafrikanischen Kino weder aus den dortigen, noch aus den deutschen Quellen rekonstruieren ließ, konnte mit Hilfe eines vergleichbaren Dokuments aus dem Jahre 1929 für ein anderes Absatzgebiet die begründete Vermutung geäußert werden, dass ein ähnlicher Vertrag für Südafrika existiert haben muss (s. UFA/Mamatis-Liste, Anhang III). Die Übereinstimmung der in diesem Auswahlkatalog der UFA genannten Filmtitel mit den in Südafrika tatsächlich gezeigten Produktionen geht so weit, dass man eine gewisse Planmäßigkeit unterstellen kann, die nicht von einer zufälligen oder willkürlichen Auswahl herrührt. Gemessen an den in Umfragen der deutschen Filmpresse festgestellten populärsten oder erfolgreichsten Filmen des Untersuchungszeitraumes stellen sowohl die Filme des vorgefundenen Katalogs, als auch die als „S-Filme“ bezeichnete Gesamtheit der deutschen Spielfilme in Südafrika nicht eine auf nachvollziehbaren Kriterien beruhende Bestauswahl dar. Unter den „S-Filmen“ befanden sich nur 13 Produktionen, die von den Kinobetreibern als zu den fünf kommerziell erfolgreichsten Filmen der Saison gezählt wurden. Die so erstellten Top 10-Listen in der Zeitschrift Filmkurier nannten nur drei Erstplatzierungen (1926/27: AN DER SCHÖNEN BLAUEN DONAU, 1929/30: FRAU IM MOND und 1931/32: DER KONGRESS TANZT), obwohl unter den Topplatzierten stets deutsche Filme dominierten (Garncarz 1994: 122f.). Bei einer rein kommerziellen Ausrichtung der Exportbemühungen hätte man sicher unterstellen können, dass der Katalog nur die absoluten Kassenschlagen umfassen würde, was auch für die Filmimporteure eine gute Orientierung gewesen wäre. Da dem offensichtlich nicht so war, müssen andere Kritierien für die vorliegende Zusammenstellung maßgeblich gewesen sein.

Gewiss hat der erstmalige Erfolg eines Walzer- und Operettenfilms dazu geführt, dass in dessen Nachgang ähnliche Filme ausgewählt wurden und es durch deren anhaltenden Erfolg insgesamt neun Filmen dieses Genres in Südafrika gezeigt wurden. Die Wiederkehr bestimmter Schauspieler oder Werke bekannter Regisseure wie Fritz Lang dürften ebenfalls auf einen 
gewissen Publikumserfolg zurückzuführen sein, den die Importeure wiederholen wollten.

Einen anderen Erklärungsansatz liefert die in beiden Listen auffällige Häufigkeit der Filme, für die Erich Pommer als Produzent verantwortlich zeichnete. Unter den „S-Filmen“ befanden 13 Erich Pommer-Produktionen, in der UFA/Mamatis-Liste immerhin noch vier. Diese Häufung ist möglicherweise auf ein persönliches Interesse Pommers an der Auslandsvermarktung seiner Filme zurückzuführen, da ihm vertraglich eine Tantieme aus deren Auslandserträgen zugestanden wurde (Kreimeier 1992: 202). Aufgrund der einflussreichen Stellung Pommers bei der UFA kann aber auch auf ein übergeordnetes Interesse geschlossen werden, welches möglicherweise darauf zurückgeht, dass die UFA gerade in Pommers Produktionen ihre Konzeption des filmvermittelten ,unterschwelligen' politischen Einflusses am Besten umgesetzt sah.

Bereits mit der UFA-Gründung ging der Anspruch einher, den Kinobedarf nicht nur unter wirtschaftlichen, sondern auch unter politisch, ideologischen und kulturell-künstlerischen Interessen zu bedienen. Dies erforderte zwangsläufig auch eine gewisse Politisierung des Mediums bei gleichzeitiger Anerkennung seines künstlerischen Wertes (Mühl-Benninghaus 2004: 305). Diese im Ersten Weltkrieg entwickelte Grundhaltung der UFA wurde auch nach Kriegsende nicht aufgegeben, sondern bestimmte weiterhin die Leitlinien der Unternehmenspolitik:

„Hier liegen die Wurzeln des von Erich Pommer im Nachkriegsdeutschland entworfenen und wirtschaftlich äußerst riskanten Konzepts. Zum einen produzierte die UFA ,Stilfilme', also Kunstfilme, und sprach damit vor allem neben der deutschen auch die internationale Cineastenszene an. Zum anderen entstand eine Vielzahl von kostspieligen ,Großfilmen' also Ausstattungsfilmen, die begleitet von einem erheblichen Aufwand einem nationalen und internationalen Publikum gepriesen wurden. Offensichtlich entsprach das Konzept den Absichten der UFA-Gründer, die auch in den folgenden Jahren wichtige Positionen in der Holding besetzten. Pommer erfüllte wie kein anderer ihre Forderungen nach künstlerisch hochwertigen und gleichzeitig massenattraktiven Spielfilmen. Da diese nicht wie in den USA überwiegend unter kommerziellen, sondern auch unter übergeordneten, kulturell-künstlerischen Gesichtspunkten von den Auftraggebern bewertet wurden, standen ihm finanzielle Mittel wie kaum einem anderen Produzenten in dieser Zeit zur Verfügung" (Mühl-Benninghaus 2004: 306f.).

Diese Grundtendenz lässt sich auch aus der Gesamtheit der in Südafrika gezeigten deutschen Spielfilme herauslesen. So sollten mit Stilfilmen wie 
FAUST oder METROPOLIS die Cineasten angesprochen werden, mit Ausstattungsfilmen wie den Walzer- und Operettenfilmen (z.B. EIN WALZERTRAUM oder DER KONGRESS TANZT) ließ sich das nationale wie auch das internationale Publikum beeindrucken. Dazwischen fanden sich populäre Produktionen wie VARIETÈ, HEIMKEHR oder DIE WUNDERBARE LÜGE DER NINA PETROWNA, die Einzelschicksale im aktuellen Kontext thematisierten, mit denen eine möglichst hohe Identifikationsleistung gewährleistet werden sollte. In diesen Filmen deutet kaum etwas darauf hin, dass auch mit ihnen ein politisch-ideologischer und kulturell-künstlerischer Auftrag erfüllt werden sollte. Sie waren jedoch bereits das Ergebnis von Anstrengungen, genaus diese Ziele zu erfüllen, ohne jedoch als derartige ,Erfüllungsgehilfen' wahrgenommen zu werden. Innerhalb gewisser Kreise bestand bereits um 1920 ein Konsens darüber, dass Deutschland im Ausland nicht plump mit seiner ungebrochenen ökonomischen Leistungskraft werben, sondern dies mittels abendfüllender Unterhaltungsfilme versuchen solle. Zu diesem Zweck müssten die Spielfilme aber den Eindruck erwecken, dass sie nur um ihrer selbst Willen gedreht sind (Pabst 1920 in Kracauer 1995: 53 bzw. in Korte 1978: 75). Die inhaltliche Ausrichtung des Filmkanons auf Unterhaltungsfilme brachte es daher mit sich, dass die potentielle Wirkung der Filme mit deren intendierter Wirkung zusammenfiel, da die Unterhaltungsfilme selbst kaum ambivalente Lesarten boten.

Die Suche nach Anhaltspunkten für etwaige widerständige Lesarten musste somit im südafrikanischen Kontext negativ ausfallen. Paradoxerweise könnte man der Zensurbehörde in Kapstadt am ehesten eine oppositionelle Lesart des BLAUEN ENGELS zuschreiben. Da die wahrscheinlichen Verbotsgründe eben nicht nur auf die dominante Botschaft des Films zurückgingen, sondern auf einen ambivalenten Aspekt (die Rolle Lolas), dem im lokalen Kontext eine mögliche Vorzugslesart zugeschrieben wurde, deren moralische Implikation als verbotswürdig eingeschätzt wurde. Die Grundhaltung, dass die Filmrezeption durch eine Zensur gezielt steuerbar wäre, beruhte auf der dem Film unterstellten unmittelbaren Wirksamkeit im Sinne eines stark vereinfachten Reiz-Reaktions-Schemas.

Unmittelbar nach dem Krieg war man noch der Meinung, im Ausland zur Vorführung deutscher Filme von entsprechender Anziehungskraft eigene Kinos zu benötigen, um die Nachfrage nach deutschen Filmen trotz möglicher Boykottmaßnahmen der Ententestaaten zu befriedigen. Diese Anziehungskraft sollte neben den eigenen auch ausländische Verleiher dazu anregen, deutsche Filme zu vermarkten (Mühl-Benninghaus 2004: 306). Dafür war zunächst die UFA-Auslandsabteilung zuständig, die als „Interessengemein- 
schaft [...] den gemeinsamen Betrieb des Filmgeschäfts im Auslande unter Wahrung der allgemeinen deutschen Interessen politischer, kultureller und wirtschaftlicher Art" bewerkstelligen sollte. „Zur Erreichung des Gemeinschaftszweckes soll in erster Linie der Erwerb und Betrieb von Lichtspieltheatern, die Programmlieferung unter Mitberücksichtigung von Propagandafilmen, sowie die Verwertung deutscher Filme im Auslande, insbesondere auch das Verleihgeschäft dienen" (Protokollauszug in: ebd.: 312).

Bis 1927 wurden derartigen Vorhaben in Südafrika durch das überaus effektive Monopol der Schlesinger-Organisation verhindert. Da Schlesinger kein Interesse an einer Konkurrenz zu seinen US-amerikanischen Filmen hatte, hätte jeder andere Programmanbieter eine komplett neue Kinoinfrastruktur aufbauen müssen, da selbst die wenigen unabhängigen Kinos oft an den Monopolisten gebunden waren, der Vertragsverletzungen mit einem Ausschluss von der Vertriebsliste ahnden konnte. Ohne direkte Initiative von deutscher Seite aus hatten die Marktmechanismen um 1927/28 in Südafrika eine Situation geschaffen, die der „Verwertung deutscher Filme im Auslande" und dem Verleihgeschäft neue Möglichkeiten eröffnete. Die Konkurrenzsituation dort und der erste Erfolg deutscher Filme kreierten dann jene Anziehungskraft des deutschen Films, welche die ausländischen Verleiher dazu bewogen, deutsche Filme in ihr Programm aufzunehmen. In diesem Sinne fungierten zuerst African Theatres als verlängerter Arm der UFA für den Auslandsabsatz. Das Kalkül der Magnetwirkung auf andere Verleiher ging auf und mit Schlesingers Konkurrenz Kinemas gewann die UFA bzw. der deutsche Film einen Vetriebspartner, der ohnehin alle Infrastrukturinvestitionen tätigte, so dass kein zusätzliches Risikokapital zur Markterschließung eingesetzt werden musste. Durch diese außergewöhnliche Situation konnte der deutsche Film Einzug in die südafrikanischen Kinos halten.

Zumindest bis 1930 konnte man auch von einem deutschen Filmprogramm im südafrikanischen Kino sprechen, da beide Vertriebe für eine gewisse Kontinuität und Periodizität der Filme sorgten, die in ihrer Gesamtheit als ein Baustein des inhaltlich-thematisch, formal, genrespezifisch, adressatenbezogen verschieden ausformulierten und aus disparaten Einheiten bestehenden Kinoprogramms angesehen werden konnten (Hickethier 1993c: 175f.). Da sich diese Situation für den Zuschauer spürbar von der Zeit vor 1927/28 unterschieden haben muss, soll eine Auswertung der südafrikanischen Publikums- und Pressereaktionen im Nachgang der Dokumentenanalysen zu erklären versuchen, welche Wirkung der deutsche Film hinterlassen hat.

Generell lässt sich sagen, dass weder die englischsprachigen, noch die afrikaansen Südafrikaner dem deutschen Film negativ gegenüberstanden, 
nur beim ersten Film überhaupt (EIN WALZERTRAUM) gab es einige von Polaritäten bestimmte Diskussionen. ${ }^{194}$ Die historisch gewachsene Deutschfreundlichkeit der Afrikaaner (Kronauer 2000: 63ff.) schlug sich meist auch in den Filmrezensionen nieder, obwohl die afrikaanse Presse mit Hans Rompel über einen der urteilsfreudigsten und kritischsten Filmjournalisten verfügte. Politisch motivierte oder durch kriegsbedingte Resentiments genährte Urteile konnten nicht festgestellt werden. Selbst ein Film mit Kriegsthematik wie UNSERE EMDEN stieß in beiden Publikumsgruppen durch seine als ausgewogen eingeschätzte Darstellung auf eine ungeteilte Zustimmung. Innerhalb des Kinoprogramms wurden die deutschen Filme als Kontrast zu den bis dahin dominanten Hollywoodproduktionen wahrgenommen, da sie andere Inhalte präsentierten, als Ware für die Massen trotzdem (noch) die individuelle Handschrift eines sich als Künstler verstehenden Regisseurs trugen und für eine technisch hochstehende Bildästhetik standen. ${ }^{195}$ Besonders beeindruckt zeigte sich das Publikum von Filmen wie FAUST, METROPOLIS, SPIONE oder FRAU IM MOND, in denen Filmarchitektur und -effekte eine große Rolle spielten. Im Allgemeinen wurde bei den deutschen Filmen infolge des oftmals überlegenen „production value“ über Schwächen des "story value" hinweggesehen. Die Walzer- und Operettenfilme empfanden viele Zuschauer als angenehm exotisch, das Schauspiel der männlichen und weiblichen Hauptdarsteller wurde oft als feinsinniger als in US-Filmen kommentiert.

In keinem der Rezeptionsdokumente fand sich ein Hinweis auf das Bemühen der deutschen Filmproduzenten, verdeckte Propaganda im Sinne der bewussten Vermittlung eines geschönten Deutschlandbildes zu betreiben. Im Hinblick auf die Filmauswahl überrascht dies allerdings nicht, da keine Filme gezeigt wurden, die zu derartigen Diskussionen Anlass gegeben hätten. Es wurde vielmehr der Eindruck vermittelt, dass die deutschen Filme stets angenehme Unterhaltung, orginelle Settings, Spannung sowie Romantik auf hohem technischen und schauspielerischen Niveau böten. In Anlehnung an das von der UFA verfolgte Konzept, bürgerliche Werte mittels vordergründig unpolitischer, spannender, lustiger, nebenbei ,belehrender' und vor allem künstlerisch anspruchsvoller Spielfilme mit hohem Unterhaltungseffekt zu verbreiten, kann mit Blick auf das Filmprogramm und die Reaktionen des

\footnotetext{
194 „Oppinions expressed afterwards formed striking contrasts: some members of the audience condemmed the film wholeheartedly, while others stated that it was one of the finest exhibited for many month" (TS 3.5.1927: 3)

195 So wurde z.B. über MANON LESCAUT bemerkt: „A feature of the film is the photography. There is German thoroughness and originality here. The Germans have nothing to learn from their American and British rivals in the art of 'close-ups' and angle 'shots'" (CA 11.6.29: 15).
} 
Publikums und der Medien von einer erfolgreichen Umsetzung der Strategie gesprochen werden. Als exemplarisch für das hohe Ansehen des deutschen Films in Südafrika kann abschließend die Bemerkung der Sunday Times angeführt werden, die den Unterschied zu den britischen und USamerikanischen Produktionen auf den Punkt brachte:

„British and American films, however, considered from the twin standpoint of intelligence and artistry, sink almost into insignificance when compared with Germany's output, from which I choose the following ten films: METROPOLIS, FAUST, MANON LESCAUT, THE STUDENT OF PRAGUE, 'Out of the Mist', 'Bohemian Love' (silly title), 'A Daughter of the Hills', 'The Queen of Spades' and 'Dancing Maid'. Germany's war drama THE EMDEN also ranks with the best ever produced in that class. This list of German films is all the more significant because German films almost without exception, are grotesquely maltreated by British distributors" (ST 5.2.28: 6).

Eingedenk dieses positiven Gesamteindruckes verwundert es nicht, dass sich die Bezeichnung „UFA-Film” als ein werbewirksames Qualitätsmerkmal für alle gezeigten deutschen Produktionen durchsetzte. Durch die der Presse entnommenen Werthaltungen, die zu einem nicht geringen Teil den Einschätzungen des Publikums entsprachen, lässt sich abschließend auch Thelma Gutsches Urteil bestätigen, wonach die UFA-Produktionen als die am Besten bekannten und populärsten deutschen Filme 1928 in Südafrika „en vogue“ und fast überall mit großem Erfolg gezeigt wurden (Gutsche 1972: 205).

Die Gründe für diesen Erfolg wurden in den vorangegangenen Kapiteln schon genannt: neue Gesichter, neue und z.T. realistischere Inhalte, technische Exzellenz, künstlerisch ambitioniertes Schauspiel und Regie, eine andere Bildsprache, ,europäische Exotik' (z.B. Operettenfilme), kurzum innovative Filme die ob ihrer Andersartigkeit zum bisher dominierenden Hollywoodfilm geschätzt wurden. Dieser Eindruck entstand auch dadurch, dass die deutschen Spielfilme zumindest bis etwa 1930 mit einer gewissen Kontinuität im Kinoprogramm zu sehen waren und ein qualitativ hohes Niveau gehalten wurde.

Die genannten Erfolgskriterien geben allerdings auch Anlass zu der Frage, ob nicht jeder andere nationale Film in derselben Situation auf einen ähnlichen Erfolg hatte hoffen können. Dies hätte z.B. auf die etwa zeitgleich mit den deutschen Filmen importierten britischen Produktionen zutreffen können. Vom britischen Kino des ausgewählten Untersuchungszeitraums ist aber bekannt, dass es noch nicht den qualitativ hohen Stand der auf dem Festland führenden Filmnationen Frankreich und Deutschland erreicht hatte (Rotha 
544ff.). In der südafrikanischen Presse bzw. Sekundärliteratur fanden sich zudem kaum Belege dafür, dass über die britischen Filme (wenn man von nationalistischen Tendenzen bestimmter Zeitungen absieht) in ähnlich ausführlicher und enthusiastischer Weise berichtet wurde wie über die deutschen. Der Durchbruch des britischen Films im eigentlichen Sinne erfolgte erst mit der flächendeckenden Durchsetzung des Tonfilms, zu diesem Zeitpunkt war das Zwischenspiel des deutschen Spielfilms in Südafrika allerdings schon vorüber.

Um ein endgültiges Urteil über Wirkung und Rezeption der deutschen Filme in Südafrika abgeben zu können, müsste zunächst seine Rolle innerhalb der Programmgeschichte des südafrikanischen Kinos geklärt werden. Wie bereits erwähnt, kam dem deutschen Film entgegen, dass er bis 1930 mit einer gewissen Kontinuität gezeigt wurde und nicht als singuläre Werke wahrgenommen wurden, sondern als Baustein des regulären Kinoprogramms. Da eine Aufarbeitung der Programmgeschichte des südafrikanischen Kinos bis jetzt höchstens ansatzweise oder lediglich in Fragmenten vorliegt (Gutsche 1972 und Eckardt 2005: $101 \mathrm{ff}$.), lassen sich kaum befriedigende Antworten auf die Frage nach dem jeweiligen Status einzelner nationaler Filmkulturen innerhalb der Programmgeschichte finden. Einen ersten Anhaltspunkt zur Durchdringung der Thematik stellte die quantitative Erfassung des Kinoprogramms der Jahre 1928 bis 1930 am Beispiel Kapstadts dar. Aus jener ging klar hervor, dass sich das Programm hauptsächlich aus US-amerikanischen, britischen und deutschen Filmen zusammensetzte, wobei die letztgenannten den geringeren Teil ausmachten. Zur inhaltlichen Zusammensetzung des Programms können nur sehr vage Angaben auf Basis von Thelma Gutsches selektiven Ausführungen gemacht werden.

Eine Auffälligkeit ergibt sich jedoch beim Abgleich des Gesamtprogramms mit den in dieser Studie ermittelten "S-Filmen“. Im Gegensatz zum Hollywood-dominierten Normalprogramm fanden sich unter den deutschen Filmen, von wenigen grenzwertigen Ausnahmen einmal abgesehen, ${ }^{196}$ kaum Komödien oder ähnliche unsinnige Blödeleien. Möglicherweise geht der immer wieder betonte Realismus der deutschen Produktionen darauf zurück, dass vor dem Übermass an zu billiger Effektehascherei neigenden HollywoodDramen und Komödien genau dieses Fehlen beim deutschen Film als positiv empfunden wurde. Insofern spielten die „S-Filme“ als Baustein der Programmgeschichte des südafrikanischen Kinos die Rolle eines Korrektivs, des

196 Laut PFL z.B.: EIN WALTZERTRAUM: Komödie, HOKUSPOKUS: Kriminalkomödie, DIE BLAUE MAUS: Schwank, SOLDAT DER MARIE: Schwank.. 
Aufzeigens einer anderen Filmkultur die ohne viel Klamauk und Übertreibungen gute und spannende Unterhaltung bieten konnte.

Einen Erklärungsansatz dafür bieten wiederum die ,Produktionsphilosophie' der UFA bzw. deren Leitlinien der Filmexportpolitik. Ausgehend von der Überlegung, dass der moderne Film als neuestes Massenmedium dazu beitragen könne, „der geschichtslosen Masse als Produkt der Moderne die überlieferten Werte der Kultur und Rasse zu vermitteln“, diente die Beeinflussung durch den Film nicht nur der vordergründigen Machtsicherung in Deutschland, sondern war ebenso als ein Beitrag zur Rettung der abendländischen Kultur im In- und Ausland gedacht (Mühl-Benninghaus 2004: 302). Ironischerweise trat durch die im südafrikanischen Kontext als "S-Filme“ verwirklichte Produktionsphilosophie der UFA genau der gewünschte Effekt ein, dass die Kinobetreiber dieses Angebot dem Teil des Publikums präsentieren konnten, der an ,gutem Geschmack' interessiert war, um gleichzeitig „die Hintertreppenansprüche des (anderen, Anm. ME) Publikums zu unterdrücken" (ebd.). Mit einer derart hochkulturell eingestellten Filmpolitik wären normalerweise Einnahmeverluste der Kinbetreiber verbunden gewesen. Durch die südafrikanische Ausnahmesituation eines Konkurrenzkampfes innerhalb des angebotsseitigen Duopols im Verkäufermarkt waren diese jedoch höchst unwahrscheinlich bzw. konnten nicht nachgewiesen werden. Weitergehende programmhistorische Erklärungsansätze lassen sich ob der schwierigen Materiallage leider nicht zweifelsfrei ableiten. Aus diesem Grund muss die eigentlich erforderliche breite Kontextualisierung auf diesem unbefriedigendem Niveau verbleiben, bis die nötigen Grundlagenstudien zur Programmgeschichte nachgeholt worden sind.

Der Anfang des Tonfilmzeitalters markiert gleichzeitig des Ende des deutschen Filmengagements in Südafrika. Selbst wenn mit prominenten Tonfilmen wie DER BLAUE ENGEL (1931), LIEBESWALZER (1931) oder DER KONGRESS TANZT (1932) auch englischsprachige Tonfassungen deutscher Filme gezeigt wurden, konnte ab 1931 kaum noch von einem deutschen Filmprogramm im südafrikanischen Kino gesprochen werden. Dadurch brach die bis 1930 wahrnehmbare Kontinuität ein, 1931 gelangten nur noch fünf deutsche Filme ins Programm. Bei einer durchschnittlichen Anzahl von ca. 90 Filmen pro Jahr lag der deutsche Anteil somit nur knapp oberhalb der Wahrnehmungsschwelle. Selbst wenn in den Rezeptionsdokumenten auf genreähnliche Vorläuferfilme wie bei den Walzerfilmen eingegangen wurde, thematisierte man eher deren Tonfilmqualitäten, wenngleich stets betont wurde, dass sie in bester UFA-Tradition stehen würden. Der Umstand, dass die UFA nicht wie die US-amerikanische Konkurrenz in der Lage war, schnellstens 
genügend internationale Tonfilme zur Auffüllung des Programms zu produzieren, kostete den deutschen Film seinen Platz im südafrikanischen Kinoprogramm. Die Marktmacht der US-Studios ermöglichte es, ohne Zeitverzug die entstandenen Lücken mit eigenen Tonfilmproduktionen zu füllen und Südafrika stärker in seine Distributionssphäre einzubinden. Seit dem „Pariser Tonfilmfrieden“ 1930 galt Südafrika zwar als ,freies Gebiet', jedoch zeigte die Einfuhrstatistik für Filmprojektoren im Jahre 1930 eine so starke USDominanz, dass die Auslastung dieser Geräte eher mit US-Produktionen erfolgen würde als mit Filmen anderer Nationen.

Etwa zeitgleich erfolgte auch die Einstellung des zunehmend ruinösen Konkurrenzkampfes zwischen Kinemas und der Schlesinger-Organisation, da sich eine Ressourcenerschöpfung abzeichnete und die Weltwirtschaftskrise ihren Schatten vorauswarf. Bis zu diesem Zeitpunkt importierte jeder Vertrieb für sein mehrgliedriges Kinokettensystem noch sechs Vollprogramme (Gutsche 1972: 58), was nach der Fusion 1932 nicht mehr erforderlich war und auf die Hälfte gesenkt werden konnte. Damit entfielen auch die vorher notwendigen Abgrenzungsstrategien und das ständige Bedürfnis, dem Konkurrenten mit exklusiven Produktionen (z.B. deutscher Provinienz) Marktanteile abzujagen. Durch die Dominanz der Schlesinger-Organisation innerhalb der neuen African Consolidated Theatres konzentrierte man sich auch wieder stärker auf die Angebote des US-Marktes und stellte die gleichen Monopolbedingungen wie vor 1927 wieder her. Selbst wenn die UFA entsprechende Filme hätte liefern können, hätte der Marktzugang durch das Wiedererrichten des Monopols vollkommen anderen Bedingungen unterlegen als im Ausnahmejahr 1928. Das Ende des deutschen Spielfilms in Südafrika wurde demnach von deutscher Seite durch einen Angebotsengpass als Folge der Tonfilmumstellung und von südafrikanischer Seite durch einen rationalisierungsbedingten Nachfragerückgang herbeigeführt. Politische Gründe, wie z.B. eine Abneigung gegen die zunehmend nationaler werdenden deutschen Filmproduktionen ab 1932 (Korte 1998: 127) konnten nicht festgestellt werden, die geänderten technischen und wirtschaftlichen Verhältnisse auf dem südafrikanischen Kinomarkt um 1931/32 dürften für das Ende des deutschen Spielfilms verantwortlich gewesen sein.

Für die relativ kurze Zeitspanne von 1928 bis 1931 hatten sich sowohl die Hoffnungen der deutschen Filmexporteure, als auch die der südafrikanischen Importeure weitgehend erfüllt. Die deutsche Seite hatte sich in wirtschaftlich schwieriger Zeit einen lukrativen und zahlungskräftigen Auslandsmarkt erschlossen, die letzte Chance zum Losschlagen der schon bald veralteten Stummfilme genutzt und kontinuierlich Filmthemen im Ausland platzieren 
können, die im Sinne der UFA-Produktionsphilosophie als ,positive deutsche Kulturpropaganda' wirken konnten. Die südafrikanischen Partner erhofften sich vor allem eine Steigerung der Programmattraktivität, um sich im Kampf um das Publikum entsprechend positionieren zu können. Die wirtschaftlichen Vorteile lagen für beiden Seiten auf der Hand, da die ungewöhnliche Marktsituation nach dem Bruch des Schlesinger-Monopols genau nach dem Angebot suchte, für welches die deutsche Seite Nachfrager zu finden hoffte. Dass sich damit zusätzlich auch die Darstellung einer ungebrochenen deutschen Wirtschafts- und Schaffenskraft im Ausland bewerkstelligen ließ, war ein aktiv unterstützter Nebeneffekt. Besonders anstrengen musste sich die UFA dafür allerdings nicht, die südafrikanische Regierung unter Premierminister J.B.M Hertzog war für ihre Deutschfreundlichkeit bekannt.

Nach der Tonfilmumstellung geriet der deutsche Film durch den von nun an in Sprachgebiete aufgeteilten Weltmarkt gegenüber den US-Produktionen ins Hintertreffen. Der Tonfilm erforderte massive Investitionen, vor denen man in Deutschland noch zurückschreckte, als in den USA die Umstellung bereits den Markt zu verändern begann. Um ihre Konkurrenzfähigkeit zu erhalten, stellten auch die Südafrikaner ihre Kinolandschaft frühzeitig auf den Tonfilm um, was den US-Produktionen wiederum die Möglichkeit gab, die bestehende Nachfrage ohne Zeitverzug zu bedienen.

Die kurzzeitige Blüte des deutschen Films in Südafrika zum Ende der Stummfilmzeit und dessen vollständiges Verschwinden in den ersten Jahren nach der Tonfilmumstellung könnte man berechtigterweise als ein filmhistorisches Zwischenspiel, eine Art Episode abtun. Betrachtet man jedoch die sich seit Ende der 1930er Jahre verstetigenden Bemühungen zum Aufbau einer afrikaansen Filmindustrie und deren ästhetisch-inhaltliches Vorbild, wird klar, welch bleibenden Eindruck dieses Zwischenspiel bei gewissen Kreisen in Südafrika hinterlassen hat (Eckardt/Tomaselli 2007). Durch seine filmische Perfektion und seine realistisch dargestellten Inhalte war ausgerechnet der deutsche Film das Vorbild für eine zukünftige afrikaanse Filmproduktion. Man schätzte die spezifisch deutsche und doch international erfolgreiche Filmsprache der UFA und anderer Produktionen als beispielhaft für die filmische Umsetzung eines bestimmten Volksgefühls ein, welches man mit der Verfilmung von Inhalten aus der Geschichte der Afrikaaner imitieren wollte. Als Gegensatz zum Hollywood-Erzählkino schwebte den Ideengebern einer zu errichtenden afrikaansen Filmproduktion sogar die Einflechtung der sowjetrussischen Montagetechnik vor, die das revolutionäre Potential der neuen Filme unterstreichen sollte. 
Dass derartige Vorhaben bis zur Machtübernahme durch die erste von Afrikaaner-Nationalisten geführte Regierung 1948 scheitern mussten, steht auf einem anderen Blatt. Kein Zufall war es jedoch, dass diese Ideen von einem der besten südafrikanischen Filmkenner kam, der dem deutschen Film überaus gewogen war. Hatte sich Hans Rompel in den 1920er und 1930er Jahren noch für Die Burger und Die Huisgenoot vor allem als Filmkritiker verdient gemacht, trat er zum Ende der 1930er Jahre auch als Gründer einer afrikaansen Amateurfilmorganisation (RARO) auf, die später mit einigen halbdokumentarischen Produktionen die Idee einer afrikaansen Filmproduktion in die Tat umsetzte. Organisatorisch modellierte er seine Vorstellungen einer afrikaansen Filmproduktion sogar entlang der Leitlinien der gleichgeschalteten deutschen Filmindustrie der späten 1930er Jahre (Rompel 1942b: 23ff.).

Beim Vergleich der nationalen Besonderheiten der Rezeptionsdokumente entstand der Eindruck, dass die deutsche Filmkritik durch ihren höheren Organisationsgrad (Kritik in Tages- und Wochenzeitungen, zahlreichen Fan-, Film- und Branchenblättern, spezielle Filmjournalisten etc.), ihre vielgestaltigen politischen Anbindungen und ihr oftmals intellektuelles Sendungsbewusstsein weitaus stärker den zeithistorischen Kontext der Filme mitreflektierte als auf die Filme als solche einzugehen. Bei der südafrikanischen Filmkritik war fast das Gegenteil der Fall. Deren Organisationsgrad war eingliedrig (Kritik überwiegend in Tageszeitungen), die politischen wurden zugunsten der wirtschaftlichen Anbindungen zurückgedrängt, man konzentrierte sich auf Beschreibungen des Filminhalts und sendungsbewusste Intellektuelle waren rar. Aus diesem Mangel lässt sich vielleicht erklären, dass sich ohne eine entsprechend aussagenkomplexe Filmkritik und den dahinter stehenden Persönlichkeiten keine nennenswerte südafrikanische Film- oder besser Kinogeschichtsschreibung in und über diesen Zeitraum entwickeln konnte.

In Deutschland hingegen legte die zeitgenössische Kritk den Grundstein für eine wirkmächtige Filmhistoriographie, für welche das Werk von Siegfried Kracauer als Paradebeispiel angesehen werden kann. Wie vereinzelt in der Analyse der Rezeptionsdokumente nachgewiesen wurde, widersprachen seine aktuellen Filminterpretationen jedoch zuweilen seinen späteren filmhistorischen Schlussfolgerungen. In seiner im Exil und unter dem Eindruck der nach 1945 vollständig bekannt gewordenen Verbrechen des NS-Regimes entstandenen Studie „Von Caligari zu Hitler“ (Kracauer 1995), bemühte er sich, in einer Art ,kollektiver Tiefenpsychologie' nachzuweisen, dass sich im Film der Weimarer Republik jene verborgenen inneren Dispositionen der Deutschen herauslesen lassen würden, die Hitlers Aufstieg und Machtergrei- 
fung ermöglicht hätten. Trotz der jeder historischen Methode widersprechenden Vorgehensweise von Kracauers, ex-post Projektion', ${ }^{197}$ gewannen seine Mutmaßungen eine beeindruckende filmhistorische Bedeutung. Über viele Jahre dominierten sie die Diskussion über den Film der Weimarer Republik, „[...] because it gave a social, political and economic background to the early German cinema that no one else [...] had tried to do" (Rotha/Griffith 1967: 18). Seine Lesart der deutschen Filmgeschichte lässt sich stark vereinfacht darauf reduzieren, dass an den Filmen der Weimarer Republik ein unterschwelliges Verlangen der Deutschen nach Autorität und Beherrschung ablesbar wäre, welches vorhersehbar in die NS-Herrschaft münden musste.

Anhand des in Südafrika ermittelnden Kanons der "S-Filme" und deren Rezeption lässt sich hingegen belegen, dass Kracauers Lesart eher als individuell-persönliches Interpretationsangebot denn als allgemeingültige filmhistorische Tatsache angesehen werden muss. Keine der von ihm nachträglich bemerkten faschistischen Tendenzen ließen sich in der südafrikanischen Rezeption nachweisen, was durchaus im Einklang zu Kracauers zeitgenössischen Einschätzungen stand. Durch die Konzentration auf publikumswirksame Unterhaltungsfilme von Seiten der Importeure und der außereuropäischen Beobachterposition der südafrikanischen Filmkritik entstand eine wesentlich nüchterne Bewertung des deutschen Filmschaffens. Als schauspielerisch-technisch hochstehend, wurde das (überwiegend stumme) deutsche Kino bei Publikum und Kritik gleichermaßen geschätzt, da es seine nationalen Eigenheiten in weltweit konsumierbare Medienprodukte umzusetzen wusste. Als ästhetisch-thematische Alternative zu Hollywood konnte sich der deutsche Film in Südafrika für eine kurze Zeit erfolgreich etablieren.

Die beschränkte Auswahl der „S-Filme“ erschwert allerdings die direkte Vergleichbarkeit mit den von Kracauer diagnostizierten ,volksseelenpathologischen Themen' vieler von ihm herangezogener Beispielfilme. Da er sich oftmals auf künstlerisch herausragende Filme wie z.B. „Das Cabinett des Dr. Caligari“ bezieht, in Südafrika aber weitaus weniger exponierte Filme und auch viel ,Durchschnittsware' gezeigt wurde, sind seine Erklärungsansätze nur bedingt im Rahmen dieser Studie verwendbar. Die von ihm festgestellten ,unbewussten Wirkungen' (z.B. Autoritätshörigkeit etc.) deutscher Filme konnten anhand der südafrikanischen Rezeptionsdokumente nicht ermittelt werden. Kracauers Intention, Filme als ästhetische Analogien zur sozialen

\footnotetext{
197 Thomas Elsaesser bezeichnet Kracauers Argumentation als aus der „Perspektive wissender Rückschau“ vorgenommen (Elsaesser 1997: 30).
} 
und nationalen Geschichte zu interpretieren, hat dazu geführt, dass er, um argumentative Lücken zu schließen, die narrative Logik der Filme glättete, kausale Abläufe verkehrte, bestimmte Intentionen übersah und zugleich die starken Widerstände und Zwiespältigkeiten bestritt oder ausklammerte, die diese Filme von einem realistisch-illusionistischen Kino trennten (Elsaesser 1997: 29). In seinen Exilschriften und vor allem in „Von Caligari zu Hitler“ lässt sich zudem eine unter permanentem nationalsozialistischem Assoziationszwang stehende Textauslegung feststellen. Diese resultiert aber in erster Linie aus den kontextdominanten Einflüssen auf inn selbst. Dies konnte mit der exemplarischen Gegenüberstellung von Kracauers zeitgenössischen Filmbesprechungen, seinen filmhistorischen Äußerungen und dem Korrektiv der südafrikanischen Filmkritik zu Filmen wie MÄDCHEN IN UNIFORM oder METROPOLIS nachgewiesen werden. Die gegenüber Kracauers Annahmen (das ,kollektiv Unbewusste' etc.) vorgebrachte Kritik zielt jedoch keineswegs darauf ab, seine Arbeiten in Misskredit zu bringen. Sein heuristisches Vorgehen war zeitbedingt, durch ihre temporäre Erklärungsleistung lassen sich Kracauers empirisch unzutreffende Prämissen in gewisser Weise rechtfertigen.

Um nicht die gleichen Fehler zu wiederholen, wurde in der vorliegenden Studie bewusst die methodisch übergreifende kinogeschichtliche Herangehensweise als Synthese aus der Produkt-, Kontext- und Rezeptionsanalyse gewählt. Damit sollten generalisierende Aussagen vermieden werden, die gerade in Bezug auf Film und Kino oft nur in einem eng begrenzten zeitlichen und räumlichen Kontext zutreffend sind. Durch die angestrebte Erfassung der erreichbaren Rezeptionsdokumente, deren Einbettung in den jeweiligen nationalen, wie auch den internationalen medienhistorischen Überlieferungszusammenhang, sollte ein zu analysierendes ,Strukturganzes' geschaffen werden, dass eine ergebnisoffene wissenschaftliche Durchdringung sicherstellt. Siegfried Kracauers filmhistorische Vergangenheitsbewältigung hingegen hatte sich zum Ziel gesetzt, einen vermuteten übergeordneten Zusammenhang zu belegen. Die politisch-moralische Intention des Autors scheint dabei einen Teil der eigenen Erfahrung ausgeblendet zu haben.

Als ein wesentlicher Ertrag der Studie kann daher angesehen werden, dass die außereuropäisch-südafrikanische Perspektive zu anderen Werthaltungen gegenüber dem deutsche Kino geführt hat als in Deutschland selbst bzw. im Rahmen bisheriger filmhistorischer Untersuchungen. In der Vergangenheit erklärte man den Erfolg des Kinos der Weimarer Republik vielfach in seiner Eigenschaft, einen ,künstlerischen Spiegel der Seele' darzustellen, das ohne die spezifisch deutsche Mentalität kaum seine besondere Anziehungs- 
kraft hätte entfalten können. In Südafrika hingegen schätzte man die technisch-darstellerische Unterhaltungsqualität, die maßgeblich zum internationalen Erfolg des Weimarer Kinos beitrug. Der zeitgenössische Erfolg des deutschen Kinos beruhte vielmehr auf der Tatsache, dass die Filmindustrie in kultureller Hinsicht spezifisch deutsche Filme produzierte und sich nicht an die von Hollywood geprägten internationalen Standards anpasste (Garncarz 2004: 398).

Der Umstand, dass Südafrika über den einzigen entwickelten Unterhaltungsmarkt in Afrika verfügte, hat tatsächlich dazu geführt, dass die deutsche Filmindustrie Südafrika als gewinnbringenden Auslandsmarkt erkannt hatte. Die damit mögliche Außenperspektive auf den deutschen Film wurde von südafrikanischer Seite maßgeblich durch wirtschaftliche Einflüsse geprägt, die auch dem Zustandekommen des gezeigten Filmkanons zugrundelagen. Aus deutscher Perspektive wurde einer strikten Trennung der wirtschaftlichen und der politischen Aspekte auf subtiler Weise entgegengewirkt, da die UFA nur jene Filme anbot, die am Ehesten ihrer Produktionsphilosophie entsprachen und im Ausland für Deutschland werbend wirken sollten. Das diese Strategie eine gewisse Langzeitwirkung hatte, ließ sich an den Bemühungen um die Konzeption einer zukünftigen nationalen afrikaansen Filmindustrie ablesen, die sich ästhetisch-bildsprachlich an den deutschen Spielfilm der Weimarer Republik anlehnen sollte. Auf wirtschaftlichorganisatorischer Ebene nahm man sich sogar die nach 1933 schrittweise gleichgeschaltete deutsche Filmindustrie zum Vorbild.

Der persönliche Ansatz hinter dieser Studie war das Streben, einem kinogeschichtlichen ,weißen Fleck' mittels quellenbasierter Forschung zur historischen Artikulation zu verhelfen. Mittels der rezeptions- und wirkungsanalytischen Methode konnte bewiesen werden, welches wissenschaftliche Potential die zielgerichtete Auswertung der vorhandenen Rezeptionsdokumente entfalten kann. Als Teil der internationalen Kinogeschichte konnte im südafrikanischen Kontext herausgearbeitet werden, dass der (v.a. stumme) Spielfilm der Weimarer Republik weltweit als eine der ambitioniertesten Äußerungen europäischen Filmschaffens geschätzt wurde. Dass ein Erkennen dieses Potentials möglich war, lag an den transnationalen Exportanstrengungen der deutschen Filmindustrie und an Südafrika als medienhistorischem Sonderfall. Mit dieser Feststellung kann der afrikazentrierten Filmgeschichtsschreibung entgegengehalten werden, dass die eigentliche afrikanische Filmgeschichte nicht erst mit der gestiegenen Filmproduktion nach dem Ende der Kolonialzeit begonnen hat, sondern mit der südafrikanischen Kinogeschichte seit 1895. 
Im Sinne der aus der Ethnologie bekannten Methode der ,dichten Beschreibung' und der bei jeder Quelle irgendwann eintretenden argumentativen Erschöpfung, ist an dieser Stelle verständlicherweise ein Endpunkt erreicht. „Wenn man [...] (jedoch) die subjektive Seite des Verstehens in die Auffassung vom Objekt hineinzunehmen hat, kommt der Prozess des Verstehens nie zu einem definitiven Ende" (Ritter 2006: 35). 


\section{Literaturverzeichnis}

Die Bibliographie dieser Studie folgt den Vorgaben des Textes und gibt alle zitierten Quellen an. Wie im südafrikanischen Forschungskontext üblich, werden akademische Qualifikationsschriften gleichberechtigt neben den Verlagsveröffentlichungen vermerkt. Zur besseren Recherchierbarkeit sind Doktordissertation als „(Univ., Diss.)“, alle anderen Arbeiten wie Diplom-, Honours-, Magister-, Master-, Lizenziats- und Staatsexamensarbeiten zusammenfassend als „(Univ., MA)“ gekennzeichnet.

Abel, Richard (ed.)(2005): Encyclopedia of Early Cinema. London/New York.

Ainslee, Rosalynde (1966): The Press in Africa. Communications Past and Present. London.

Albertyn, J.R. (1932): The Poor White and Society (Part V.a of the Report of the Carnegie Commission of Investigation on the Poor White Question in South Africa; Sociological Report). Stellenbosch.

Allen, Robert C./Gomery, Douglas (1985): Film History: Theory and Practice. New York.

Ambler, Charles (2000): Popular Films and Colonial Audiences: The Movies in Northern Rhodesia; in: American Historical Review 106(2001)1, 81-105.

Ambrosch, Ingrid (1970): Presse, Staat und Zensur in der Republik Südafrika. Wien (Univ., Diss.).

Andersen, Curt (1929): Über die deutsche Filmindustrie und ihre volkswirtschaftliche Bedeutung unter Berücksichtigung ihrer internationalen Beziehungen. München (Univ., Diss.).

Anderson, Margaret (1930): Oh, that Agony of Waiting!; in: The Outspan 7(1930)176, 33-35 (11.7.1930)

Annual Statement of the Trade and Shipping of the Union of South Africa, Southern and Northern Rhodesia, and Terretory of SouthWest Africa, No. 22-29 (1928-1936). Pretoria.

Antonowa, Irina/Merkert, Jörn (Hg.)(1995): Berlin-Moskau/Moskau-Berlin 1900-1950. München/New York.

Arliss, L.S. (1928): Sidakwa: what our Natives call Charlie Chaplin; in: The Outspan 2(1928)48, 47+73 (27.01.1928).

Armes, Roy (2005): Postcolonial images: Studies in North African film. Bloomington.

Arnheim, Rudolf (1931): Film als Kunst. Berlin.

Ayisi, Florence etc. (1996): Africa and the History of cinematic Ideas Conference; in: Screen, 37(1996)1, 85-90.
Bachtin, Michail (1989): Formen der Zeit im Roman. Untersuchungen zur historischen Poetik. Frankfurt/M.

Bailey, Thomas A./Ryan, Paul B. (1975): The Lusitania Disaster: An Episode in Modern Warfare and Diplomacy. New York/London.

Balseiro, Isabel /Masilela, Ntongela (Hg.) (2003): To Change Reels. Film and Culture in South Africa. Detroit.

Baron, Reuben/Kenny, David (1986): The Moderator-Mediator Variable Distinction in Social Psychological Research: Conceptual, Strategic, and Statistical Considerations; in: Journal of Personality and Social Psychology 51(1986)6, 1173-1182.

Barton, Frank (1979): The Press of Africa. London.

Barton, Frank (1979): The White South (IX. Kapitel); in: Barton 1979: 185-218.

Bawden, Liz-Anne (ed.)(1976): The Oxford companion to film. London.

Bawden, Liz-Anne/Tichy, Wolfram (Hg.)(1978): rororo-Filmlexikon (6 Bde.). Reinbek bei Hamburg.

Baxter, Peter (2001): 'Fallen Angels'; in: Sight and Sound 11(2001)11, 62-67.

Beaton, Wedford (1927): Metropolis; [The Film Spectator 4(1927)1, 4-5]; in Slide 1982: 191. 193.

Behrens, Hans Peter Hermann (1955): The Pretoria Press Story. Pretoria.

Beicken, Peter (2004): Wie interpretiert man einen Film? Stuttgart.

Beller, Hans (1995): Gegen den Krieg: Im Westen nichts Neues (All quiet at the western Front, 1929); in: Korte/Faulstich 1995 100-129.

Benali, Abdelkader (1998): Le cinéma colonial au Maghreb: l'imaginaire en trompe-l'œil. Paris.

Bergmann, Kristina (1993): Filmkultur in Ägypten. Darmstadt. 
Bernhard, Ludwig (1928): Der ,HugenbergKonzern': Psychologie und Technik einer Großorganisation der Presse. Berlin.

Beuckes, Piet (1946): Present Policies and Recent Growth of Press of Union of South Africa; in: Journalism Quarterly 23(1946)4 390-395.

Bie, Richard (1936): Emil Jannings. Eine Diagnose des deutschen Films. Berlin

Biermann, Heinrich/Schurf, Bernd (Hg.)(1990): Texte, Themen und Strukturen. Bielefeld.

Bilger, Harald S. (1976): Südafrika in Geschichte und Gegenwart. Konstanz.

Bisky, Lothar/Wiedmann, Dieter (1985): Der Spielfilm. Rezeption und Wirkung. Berlin.

Blaisdell, George (1930): The White Hell of Pitz Palü [The International Photographer 2(1930)10, 20-21]; in: Slide 1982: 194

Blaisdell, George (1931): Atlantic [The International Photographer 3(1931)5, 37]; in: Slide 1982: 7-9.

Blumenthal, Marsha (1985): Auctions with Contrained Information: Blind Bidding for Motion Pictures. Minneapolis (Univ., Diss.).

Bömer, Karl (1934): Das internationale Zeitungswesen. Berlin/Leipzig.

Bömer, Karl (1937): Handbuch der Weltpresse. Berlin (3. Auflage).

Botha, Graham (1935): The Development of Printing and Newspaper Publication in the Union; in: Official Yearbook of the Union of South Africa 17(1934/35), 32-35.

Bowser, Eileen (1990): The Transformation of Cinema 1907-1915. New York et al.

Breyne, Marcel Romeo (1925): Etwas über die südafrikanische Tagespresse; in: Deutsche Presse 15(1925)29, 4-5.

Brill, Olaf (1997): Traditionelle Filmgeschichtsschreibung versus New Film History; in: Neitzel 1997: 9-23.

Brügge, Joachim (Hg.)(2007): Kulturstereotype und Unbekannte Kulturlandschaften - am Beispiel von Amerika und Europa. Salzburg (im Druck).

Buchner, Hans (1927): Im Banne des Films. München.

Bureau of Census and Statistics, Pretoria (ed.)(1960): Union Statistics for Fifty Years 1910-1960. Pretoria.

Burns, James (2000): Watching Africans watch Films: Theories of Spectatorship in British colonial Africa; in: Historical Journal of Film, Radio and Television 20(2000)2, 197-213.

Burns, James (2002): Flickering shadows: cinema and identity in colonial Zimbabwe. Athens (Ohio)

Burns, James (2003): A Source of innocent Merriment: Cinema and Society in Colonial
Zimbabwe; in: South African Historical Journal 48(2003)1, 130-138.

Carels, Stéphanie (2004): Matamata \& Pilipili. Een studie naar de overlevering van westerse waarden en normen in Belgisch Congo via komische en educatieve films. Leuven (Univ., MA); unter: http://www.ethesis.net/ matamata/matamata inhoud.htm [15.8.2006].

Cartright, A.P. (1960): I.W. Schlesinger; in: Cartright, A.P. (ed.): South Africas Hall of Fame. Cape Town, 185-198.

Celsus (Pseudonym) (1930): Der Film gegen Heinrich Mann [Die Weltbühne, Nr. 18, 29.4.1930]; in: Sudendorf 1980: 128-1930.

Collins, Clarissa (1933): Early Days of the Cinema in South Africa; in: The Outspan 14(1933)340, 49 (1.9.1933).

Convents, Guido (1982): Beeldvorming over zwart Afrika: films over de Belgische Congo: 1897-1914; in: Tijdschrift voor Sociale Geschiedenis 8(1982)28, 389-414.

Convents, Guido (2005): South Africa; in: Abel, Richard (ed.): Encyclopedia of Early Cinema. London/New York, 598-599.

Dahlke, Günther/Karl, Günter (Hg.)(1988): Deutsche Spielfilme von den Anfängen bis 1933. Berlin.

Davenport, T.R.H. (1977): South Africa. A Modern History. London/Basingstoke.

De Beer, Arri S. (ed.)(1993): Mass Media for the Nineties: The South African Handbook of Mass Communication. Pretoria.

De Jager, Johannes Ignatius (1980): Die betekenis van die Suid-Afrikaanse plaaslike pers: ' $n$ empiriese studie. Potcheftstroom (Univ., Diss.).

De Villiers, Johan (1976): South African communities and its newspapers - a sociohistorical study. Bloemfontein (Univ., Diss.).

d'Ester, Karl (1937): Die Presse Afrikas; in: Zeitungswissenschaft 12(1937)5, 297-307.

Diawara, Manthia (1992): African Cinema: Politics and Culture. Bloomington.

Dickson, Patricia (1977): Schlesinger - horse trader or horse thief?; in: Management 8(1977)May, 23-27+33.

Dietrich, Marlene (1997): Ich bin, Gott sei Dank, Berlinerin: Memoiren. Berlin.

Dirscherl, Luise/Nickel, Gunther (2000): Der Blaue Engel: die Drehbuchentwürfe. Sankt Ingbert.

Doernfeldt, Paul Carl (1926): 1906-1926 Scherffs Lichtspielhaus Weimar: Gedenkschrift zum 20jährigen Bestehen. Weimar.

Dressel, Guido (1995): 75 Jahre Freistaat Thüringen. Wahlen und Abstimmungsergebnisse 1920-1995. Erfurt.

Druker, Kalman Gordon (1979): The administration of censorship in South Africa, with par- 
ticular reference to the cinema. Cape Town (Univ., MA).

Du Plessis, Josias Hendrik Otto (1943): Die Afrikaanse pers: ' $n$ Studie van die ontstaan, ontwikkeling en rol van die HollandseAfrikaanse pers as sosiale instelling. Stellenbosch (Univ., Diss.).

Du Plessis, Pieter Georg (Hg.)(1967): Hoogtepunte. 'n Keur uit die artikels wat vyftig jaar in ,Die Huisgenoot' verskyn het. Kaapstad.

Du Wayne, G. Clark (1930): Motion Pictures in South Africa, in: Commerce Reports 32(1930)46, 425.

Dunger, Hella (1978): Konzepte zur Filmkritik aus den Jahren 1927-1933; in: Rump, G.C. (Hg.): Medium und Kunst. Hildesheim, 120165.

Eckardt, Michael (2000): The Reception of German Films in South Africa. A Case Study for Durban in 1928. Durban (Univ., MA).

Eckardt, Michael (2004): A privilleged access to the history of popular culture in South Africa: the Thelma Gutsche Papers; in: South African Theatre Journal 18(2004), 250-254.

Eckardt, Michael (2005a): Film Criticism in Cape Town 1928-1930. Stellenbosch.

Eckardt, Michael (2005b): Pioneers in South African Film History: Thelma Gutsches Tribute to William Kennedy Laurie Dickson, the Man who filmed the Boer War; in: Historical Journal of Film, Radio and Television 25(2005)4, 637-646.

Eckardt, Michael (2005c): Das Fach Deutsch/Germanistik in Südafrika im Spiegel seiner Hochschulschriften 1922-2001: eine bibliographische Dokumentation; in: Jahrbuch für Internationale Germanistik 37(2005)1, 169-185.

Eckardt, Michael (2006): South African film historiography revisited. A plea for the use of domestic sources; in: South African Theatre Journal 20(2006), 177-191.

Eckardt, Michael (2007): The Influence of Hans Rompel for the Writing of South African Film History (unpublished typescript).

Eckardt, Michael/Tomaselli, Keyan (2007): Brown-red Shadows: The Influence of Third Reich and Soviet Cinema on Afrikaans Film; in: Vande Winkel/Welch 2007: 231-242.

Eckert, Andreas (2007): Ordnung durch Terror. Koloniale Herrschaft und Gewalt im 19. und 20. Jahrhundert; in: Frankfurter Allgemeine Zeitung 60(2007)172, 8 (27.7.2007).

Eggebrecht, Axel (1926): Faust [Die Welt am Abend, Nr. 242, 16.10.1926]; unter: http://www.filmportal.de [2.1.2007]

Eggebrecht, Axel (1927): Technik, Arbeit und Wissenschaft der Zukunft. Möglichkeiten eines Zukunftsfilms [Kulturwille 6/1927]; in: Jakob-sen/Sudendorf 2000: 30.
Eisner, Lotte (1955): Dämonische Leinwand: die Blütezeit des deutschen Films. Wiesbaden-Biebrich.

Eisner, Lotte (1969): The haunted Screen: expressionism in the German Cinema and the influence of Max Reinhardt. London.

Ellwood, David W./Kroes, Rob (eds.) (1994): Hollywood in Europe. Experiences of a Cultural Hegemony. Amsterdam.

Elsaesser, Thomas (1986): The New Film History; in: Sight \& Sound 55(1986)4, 246251.

Elsaesser, Thomas (1997): Zwischen Filmtheorie und Cultural Studies. Mit Kracauer (noch einmal) ins Kino; in: Koebner 1997: 22-39.

Elsaesser, Thomas (1999): Das Weimarer Kino - aufgeklärt und doppelbödig. Berlin.

Elsaesser, Thomas (2001): Metropolis, der Filmklassiker von Fritz Lang. Hamburg/Wien.

Engelen, Leen (2006): The Black Face of Cinema in Africa; in: Historical Journal of Film, Radio and Television 26(2006)1, 103109.

Engell, Lorenz (1992): Sinn und Industrie. Einführung in die Filmgeschichte. Frankfurt/M./New York.

Engell, Lorenz (1995): Bewegen beschreiben. Theorie zur Filmgeschichte. Weimar.

Faulstich, Werner (1990/91): Stars: Idole, Werbeträger, Helden. Sozialer Wandel durch Medien; in: Funkkolleg Medien und Kommunikation. Konstruktion von Wirklichkeit. Weinheim/Basel, 39-88.

Faulstich, Werner (1997): Filmanalyse als Filmgeschichte: Prinzipien einer konstruktivistischen Filmgeschichtsschreibung; in: Hikkethier/Müller/Rother 1997: 153-162.

Faulstich, Werner (2005): Filmgeschichte. München.

Faulstich, Werner/Korte, Helmut (1995): Fischer Filmgeschichte. Frankfurt (4 Bände).

Fawcett, L'Estrange (1927): Films: Facts and Forecasts. London.

Fawcett, L'Estrange (1928): Die Welt des Films. Zürich.

Fedderke, Johannes/Simkins, Charles (2006): Economic Growth in South Africa since the late nineteenth Century; unter:

http://www.commerce.uct.ac.za/Economics /staff/jfedderke/Documents/2006/ross30. pdf; 79 p. [12.6.2006].

Feinstein, Charles H. (2005): Economic History of South Africa. New Haven/London.

Feld, Hans (1926): Das „Happy end“ des Faustfilms [Film-Kurier, Nr. 199, 26.8.1926]; unter: http://www.filmportal.de [2.1.2007].

Fiske, John (1987): Television Culture. London/New York. 
Fontane, Theodor (1855): Rezension zu „Soll und Haben"; in: Literatur-Blatt des Deutschen Kunstblattes 2(1855)15, 59-63 (26.7.1855).

Fourie, Pieter (ed.)(2001): Media Studies. Volume I: Institutions, Theories and Issues. Lansdowne.

Frank, Georg (1998): Ökonomie der Aufmerksamkeit. Ein Entwurf. München/Wien.

Frankel, S.Herbert/Herzfeld H. (1944): An analysis of the growth of the national income of the Union in the period of prosperity before the War; in: South African Journal of Economics 12(1944)2, 112-138.

Frewin, Leslie (1992): Marlene Dietrich: ihre Filme - ihr Leben. München.

Friebel, Otto (1935): Erinnerungen an deutsche Siedlungs- und Zeitungsarbeit im englischen Südafrika; in: Zeitungswissenschaft 10(1935)4, 159-166.

Frieden, Sandra et al. (eds.)(1992): Gender and German Cinema. Feminist Interventions (Vol. II). Providence.

Gandert, Gero (Hg.)(1993): Der Film in der Weimarer Republik 1929 : ein Handbuch der zeitgenössischen Kritik. Berlin.

Garncarz, Joseph (1994): Hollywood in Germany. The Role of American Films in Germany, 1825-1990; in: Ellwood/Kroes 1994: 94-135.

Garncarz, Joseph (2004): Art and Industry. German Cinema of the 1920; in: Grieveson/Krämer 2004: 389-400.

Gehler, Fred/Kasten, Ullrich (1990): Fritz Lang - Die Stimme von Metropolis. Berlin.

Geller, Friedhelm (1999): Lexikon Religion im Film. Köln.

Gerich, Karl (1937): Außenhandel und Handelspolitik der Südafrikanischen Union unter besonderer Berücksichtigung der Wirtschaftsexpansion der Union. Leipzig (Univ., Diss.).

Gernet, Hans von (1929): Eingesandt (Leserbrief zu LUTHER); in: Der Deutsch-Afrikaner 9(1929)16, 3 (31.10.1929).

Gerstein, Evelyn (1927): Metropolis; in: The Nation 124(1927)March, 323-324 (23.3.27).

Geser, Guntram (1999): Fritz Lang, Metropolis und Die Frau im Mond: Zukunftsfilm und Zukunftstechnik in der Stabilisierungszeit der Weimarer Republik. Meitingen.

Giliomee, Hermann (2003): The Afrikaners. Biography of a People. Kapstadt.

Gischler, Katrin (2005): Sequence Analysis of Fritz Lang's ,Metropolis'. München.

Glöckner, Eckhard/Lange, Thomas (Hg.)(1998): Materialien. Heinrich Mann „Professor Unrat". Stuttgart u.a.

Golden, N.D. (1929): Short-Subject Film Market in Latin America, Canada, The Far
East, Africa, and The Near East, in: Trade Information Bulletin Nr. 544.

Golden, N.D. (1930): Markets für American Motion-Picture Equipment in Asia, Africa, and Oceania, in: Trade Information Bulletin Nr. 701.

Gomery, John D. (1975): The Coming of Sound to the American Cinema: A History of the Transformation of an Industry. Madison (Univ., Diss.).

Gregor, Ulrich/Patalas, Enno (1989): Geschichte des Films. Reinbek bei Hamburg (4 Bände).

Gregor, Ulrich/Klejman, Naum (1995): Deutscher und sowjetischer Film. Ein Dialog bei der Filmkulturen; in: Antonowa/Merkert 1995: 199-203.

Grieveson, Lee/Krämer, Peter (Hg.)(2004): The Silent Cinema Reader. London/New York.

Grosskopf, J.F.W. (1932): Rural Impoverishment and Rural Exodus. (Part I of the Report of the Carnegie Commission of Investigation on the Poor White Question in South Africa; Economic Report). Stellenbosch.

Gunter, Christiaan Frans Gerhardus (1930): Die eerste nuusblaaie aan die Kaap, 1800-1830 en die stry vir die vryheid van die pers, 18231829. Pretoria (Univ., MA).

Gutsche, Thelma (1972: The History and Social Significance of Motion Pictures in South Africa 1895-1940. Cape Town.

Gutsche, Thelma (1940): Criticism that Lacks Fire; in: The Forum 3(1940)34, 17 (16.11.1940).

Haacke, Wilmont (1970): Publizistik und Gesellschaft. Stuttgart.

Haas, Willy (1926): Faust [Film-Kurier, Nr. 242, 15.10.1926]; in: http://www.filmportal.de [2.1.2007].

Haasbroek, Johannes (2001): Die ontstaan van die eerste bioskoop (1922) vir die swart gemeenskap van Bloemfontein; in: Navorsinge van die Nasionale Museum Bloemfontein 17(2001)6, 137-161.

Hachten, William A. (1971): An important Exception: South Africa (XI. Kapitel); in ders.: Muffled Drums. The News Media in Africa. Ames (lowa), 234-270.

Hamilton, James Shelley (1930): The White Hell of Pitz Palü [Cinema 1(1930)8, 41-42]; in: Slide 1982: 194-195.

Handel, Leo A. (1950): Hollywood looks at its Audience. A report on film audience research. Urbana (III.).

Haney, Gerhard (2007): Streiflichter wissenschaftlicher Streitstände bei den Juristen; in: RLS-Thüringen (Hg.): Gemeinschaftlich bewegte Wissenschaft. Jena, 37-69. 
Hardt, Ursula (1991): Erich Pommer; in: Cinegraph, 18. Lieferung (15.6.1991), B1 B6, F1-F34, E1-E6 (46 S.).

Hauke, Lutz (Hg.)(2005): Film - Künste - TVShows. Film- und fernsehwissenschaftliche Studien (Auswahl 1978-2004). Berlin.

Hauke, Lutz (2005): Früher Stummfilm und nationalspezifische Anfänge. Kulturkreise Länder - Pioniere; in: Hauke 2005: 11-28.

Hees, Edwin (2003): The Birth of a Nation: Contextualizing 'De Voortrekkers' (1916); in: Balseiro/Masilela 2003: 49-69.

Herzog, Charlotte (1980): The Motion Picture Theatre and Film Exhibition 1896-1932 (2 Bde.). Chickago (Univ., Diss.).

Hickethier, Knut (1980): KinowahrnehmungKinorezeption-Film im Kopf. Feststellungen bei einem Durchgang durch theoretische Ansätze; in: Ästhetik \& Kommunikation 11 (1980)42, 75-90.

Hickethier, Knut (Hg.)(1989): Filmgeschichte schreiben. Berlin.

Hickethier, Knut (Hg.)(1993a): Insitution, Technik und Programm. Rahmenaspekte der Programmgeschichte des Fernsehens (Geschichte des Fernsehens in der Bundesrepublik Deutschland, Band 1). München.

Hickethier, Knut (1993b): Einleitung: Zu den Rahmenbedingungen der Programmgeschichte des bundesrepublikanischen Fernsehens; in: Hickethier 1993a: 21-30.

Hickethier, Knut (1993c): Dispositiv Fernsehen, Programm und Programmstrukturen in der Bundesrepublik Deutschland; in: Hickethier 1993a: 171-243.

Hickethier, Knut/Müller, Eggo/Rother, Rainer (Hg.)(1997): Der Film in der Geschichte. Berlin.

Hickethier, Knut u.a. (1997): Geschichte und Film. Zur Einleitung; in: Hickethier/Müller/Rother 1997: 8-10.

Hieber, Heinz (1931): Der Kongreß tanzt (Sozialistische Bildung, Nr. 12, Dezember 1931); in: Jakobsen 1989: 107.

Hill, John/Gibson, Pamela Church (ed.)(1998): The Oxford Guide to Film Studies. Oxford.

Holba, Herbert (1979): Emil Jannings. NeuUlm.

Holloway, J.E. (1936): Das Problem Schwarz und Weiß in Südafrika; in: Europäische Re vue 12(1936)12, 1018-1024.

Huber, Martin/Böhm, Elisabeth (2005): Botenbericht, Teichoskopie, Vertrautenrede; in: Literaturwissenschaftliche Grundbegriffe online, unter: http://www.ligo.de/definitionsansicht/drama/botenberich tteichoskopievertrautenrede.html [6.6.2007].

Hubrich, Peter-Heinz (1974): Gustav Freytags "Deutsche Ideologie“ in „Soll und Haben“. Kronberg/Tn.
Hungwe, Kedmon Nyasha (2005): Narrative and Ideology: 50 Years of Film-Making in Zimbabwe; in: Media, Culture \& Society 27(2005)1, 83-101.

Hussong, Friedrich (1930): Neuland [Der Montag vom 31.3.1930, 2. Ausgabe]; in: Sudendorf 1980: 111-113

Ihering, Herbert (1929a): Die Filmsaison beginnt [Berliner Börsen-Courier 23.8.29]; in Gandert 1993: 419.

Ihering, Herbert (1929b): Frau im Mond [Berliner Börsen-Courier, 16.10.1929]; in: Gandert 1993: 201-202.

Ihrering, Herbert (1930): Der blaue Engel [Berliner Börsen-Courier, Nr. 162, 2.4.1930, Abendausga-be]; in: Sudendorf 1980: 121 123.

Ihrering, Herbert (1941): Emil Jannings: Baumeister seines Lebens und seiner Filme. Heidelberg u.a.

Jacobsen, Wolfgang (1989): Erich Pommer: Ein Produzent macht Filmgeschichte. Berlin.

Jacobsen, Wolfgang/Kaes, Anton/Prinzler, Hans Helmut (Hg.)(1993): Geschichte des deutschen Films. Stuttgart.

Jacobsen, Wolfgang/Sudendorf, Werner (Hg.)(2000): Metropolis. Aus dem Laboratorium der filmischen Moderne. Stuttgart.

Jahn-Sudmann, Andreas (2007): Das europäische Kino in Amerika. Zur Filmgeschichte transatlanischer Filmbeziehungen; in: Brügge 2007

Jason, A. (1932): Handbuch der Filmwirtschaft, Band III. Berlin.

Jeanne, René/Ford, Charles (1947): Histoire encyclopédique du cinéma (3 Bände). Paris.

Jens, Walter (Hg.)(1989): Kindlers Neues Literatur-exikon (Bd. 5). Stuttgart, 821-822.

Johnson, Shaun (1991): An Historical Overview of the Black Press; in: Tomaselli/Louw 1991:15-32.

Jossé, Harald (1984): Die Entstehung des Tonfilms: Beitrag zu einer faktenorientierten Mediengeschichtsschreibung. Freiburg im $\mathrm{Br}$.

Joubert, Jurie Jacobus (1983): Geskiedskrywing in ,Die Huisgenoot' 1923-1949. Pretoria (Univ., MA).

Kaczmarek, Ludger (1996): „Verstehen Sie Film?"; in: Montage/AV 5(1996)2, 89-107.

Kaes, Anton (1993): Film in der Weimarer Republik. Motor der Moderne, in: Jacobsen/Kaes/Prinzler 1993: 39-100.

Karasek, Hellmuth (1965): Der Kongreß tanzt. Wiener Abziehbilder; in: Film 3(1965)3, 45.

Kater, Gordian (2005): Seminararbeit „Utopien im Spielfilm der Weimarer Republik“", Sommersemester 2005, Seminar „Träume und Alpträume der Moderne“, Universität Göttingen. 
Kayser, Erika (1983): Deutsche Unterhaltungsfilme der 20er und 30er Jahre. Untersuchungen am Beispiel der Filme mit Lilian Harvey und Willy Fritsch. Osnabrück (Univ., Diss.)

Kelly, T.H. (1954): South Africa's Foreign Trade, 1933-1953; in: South African Journal of Economics 22(1954)1, 73-90.

Kemmeny, Alfred (Pseudonym ,Kamen')(1930): Ausmerzung des kämpferischen zugunsten des „Dichterischen“ [Die Rote Fahne, Nr. 79, 3.4.1930, Beilage]; in: Sudendorf 1980: 130 131.

Kenney, Roy W./Klein, Benjamin (1983): The Economics of Block-Booking; in: Journal of Law \& Economics 26(1983)3, 497-540.

Kidem, Gorham (ed.)(2000): The International Movie Industry. Carbondale/Edwardswille.

Kilcoin, W.L. (1929a): Theatre Building active in South Africa; in: Commerce Reports 32(1929)2, 101

Kilcoin, W.L. (1929b): South African Picture Company Increases Capital; in: Commerce Reports 32(1929)17, 297.

Kitchen, Helen (ed.)(1956): The Press in Africa. Washington D.C.

Kitchen, Helen (1956): South Africa; in: Kitchen 1956, 42-50.

Klee, Cornelius (1991): Die Transocean $\mathrm{GmbH}$; in: Wilke 1991: 135-211.

Klein, Ingeborg (1929): Handelsbeziehungen zwischen Deutschland und den vier britischen Dominien Kanada, Südafrika, Australien und Neuseeland seit der Beendigung des Weltkrieges. Berlin (Univ., Diss.).

Kloppenburg, Julia/Panchyrz, Martina/ Ruprecht, Alisa (2005): Seminararbeit „Krisen des Bürgertums“, Sommersemester 2005, Seminar „Träume und Alpträume der Moderne“, Universität Göttingen.

Koebner, Thomas (Hg.)(1997): Idole des deutschen Films. München.

Koepnick, Lutz (2002): Zwischen Textanalyse und Kulturkritik. Zum Standort deutscher Filmstudien in den vereinigten Staaten; in: Internationales Archiv für Sozialgeschichte der deutschen Literatur 27(2002)1, 198-224.

Korte, Helmut (Hg.)(1978): Film und Realität in der Weimarer Republik. München/Wien.

Korte, Helmut (1989): Filmgeschichte, Einzelwerkanalyse und die Möglichkeiten der elektronischen Datenverarbeitung. Plädoyer für einen Paradigmenwechsel der Filmgeschichtsschreibung; in: Hickethier 1989: 134 152.

Korte, Helmut (1998): Der Spielfilm und das Ende der Weimarer Republik. Göttingen.

Korte, Helmut (2001): Einführung in die Systematische Filmanalyse. Berlin.

Korte, Helmut/Lowry, Stephen (2000): Der Filmstar. Stuttgart.
Korte, Helmut/Strake-Behrendt, Gabriele (1991): Der Filmstar. Forschungsstand, kommentierte Bibliographie, Starliste. Braunschweig.

Koszarski, Richard (1990): An Evenings Entertainment: The Age of the Silent Feature Picture 1915-1928. New York et.al.

Kracauer, Siegfried (1927): Der Emden-Film (Frankfurter Zeitung vom 13.4.1927); in: Ders. (1995): Von Caligari zu Hitler. Frankfurt/M., 401-402.

Kracauer, Siegfried (1930): Der blaue Engel [Die Neue Rundschau, Bd. I, 41. Jg. der Freien Bühne 1930, I]; in: Sudendorf 1980: 124-127.

Kracauer, Siegfried (1931): Kunst der Dekoration (Frankfurter Zeitung vom 28.10.1931); in: Kracauer 1995): 511-512.

Kracauer, Siegfried (1963): Das Ornament der Masse. Frankfurt/M.

Kracauer, Siegfried (1995): Von Caligari zu Hitler. Frankfurt/M.

Kramer, Thomas (Hg.)(1995): Reclams Lexikon des deutschen Films. Stuttgart.

Kraus, Anna Lisa (2005): Seminararbeit „Der Kongreß tanzt - ein Film über das Glück", Sommersemester 2005, Seminar „Träume und Alpträume der Moderne“, Universität Göttingen.

Kreimeier, Klaus (1992): Die UFA-Story. München.

Kreimeier, Klaus (1996): The UFA-Story. A History of Germany's greatest Film Company 1918-1945. New York.

Kriegk, Otto (1943): Der deutsche Film im Spiegel der UFA. 25 Jahre Kampf und Vollendung. Berlin.

Kriel, Frederik Hendrik Johannes (1930): Einige aspekte van die invloed van die pers op die Suid-Afrikaanse moraal. Stellenbosch (Univ., MA).

Kronauer, Iris (2000): Vergnügen, Politik und Propaganda: Kinematographie im Berlin der Jahrhundertwende (1896 - 1905). Berlin (Univ., Diss.).

Krützen, Michaela (1996): "Esperanto für den Tonfilm". Die Produktion von Sprachversionen für den frühen Tonfilm-Martkt; in: Schaudig 1996: 119-154.

Kruger, Loren (1996): Lights \& Shadows. The Autobiography of Leontine Sagan. Johannesburg.

Kurowski, Ulrich/Römhild, Jürgen (Hg.)(1975): Lexikon des internationalen Films: Filmgeschichte nach Ländern. München.

Kusters, Paul (1996): New Film History; in: Montage/AV 5(1996)1, 39-60.

Lamprecht, Gerhard (1969a): Deutsche Stummfilme 1923-1926. Berlin. 
Lamprecht, Gerhard (1969b): Deutsche Stummfilme 1927-1931. Berlin.

Lawson, Edward B. (1936): Advertising in the Union of South Africa; in: Trade Information Bulletin Nr. 829.

Le Roux, Willem (1942): Ons VoortrekkerEeufeesrolprent, 'n Nasie Hou Koers; in: Heese, Jacaob de Villiers (Hg.): Ons Hou Koers. Kaapstad: Nasionale Pers, 56-64.

Louw, P.E./Botha, J.R. (1993): Film: the captivating power of fleeting images; in: $\mathrm{De}$ Beer 1993: $161 \mathrm{f}$.

Lowry, Stephen (1992): Film - Wahrnehmung Subjekt. Theorien des Filmzuschauers; in: Montage/AV 1(1992)1, 113-128.

Lucius, Robert von (2004): Letzter Tag. Südafrikas ambitionierteste Qualitätszeitung schließt; in: Frankfurter Allgemeine Zeitung 57(2004)275, 38 (24.11.2004).

Ludes, Peter (1999): Programmgeschichte des Fernsehens; in: Wilke 1999: 255-276.

Magombe, P. Vincent (1998): Schwarzafrikanische Kinematographien; in: Nowell-Smith 1998: 629-633.

Maingard, Jacqueline (2003): South African Cinema in the 1940s: Reviewing Black Identities. Konferenzbeitrag: Workshop on South Africa in the 1940s, Southern African Research Centre, Kingston, September, 2003; unter: http://www.queensu.ca/sarc/ Conferences/1940s/Maingard.htm [27.2.2006].

Mandel, Ernest (1978): Late Capitalism. London.

Masilela, Ntongela (1996): Presence Africaine and the Emergence of African Film Criticism; in: Communicare, 15(1996)1, 1-44.

Masilela, Ntongela (2000): Thelma Gutsche: A Great South African Film Scholar; in: Critical Arts 14(2000)2, 49-78.

Masilela, Ntongela (2003): The New African Movement and the Beginnings of Film Culture in South Africa; in: Baliseiro/Masilela 2003: $15-30$

Mathys, G. (2003): De ster in het land van de afgoden. Interpretatie van de beeldvorming in de koloniale cinema (1947-1957). Films met als thema (koloniaal) onderwijs. Groningen (Univ., MA).

Mertsch, Alfred (1935): Entwicklungsepochen und Entwicklungstendenzen der Handelsbeziehungen zwischen Deutschland und Südafrika. Hamburg (Univ., Diss.).

Midgley, Peter (2000): Sol Plaatje. An Introduction. Grahamstown.

Mikos, Lothar (1993). Filmgeschichte als Rezeptions- und Wirkungsanalyse; in: Beiträge zur Film- und Fernsehwissenschaft 12(1993)47, 155-175.

Monaco, James (2000): Film verstehen: Kunst, Technik, Sprache, Geschichte und Theorie des Films und der Medien; mit einer Einführung in Multimedia. Reinbeck bei Hamburg.

Monaco, James (2006): Film verstehen: Kunst, Technik, Sprache, Geschichte und Theorie des Films und der Medien; mit einer Einführung in Multimedia. Reinbek bei Hamburg.

Moses, Trevor (2006): Riding The High Wind. Pretoria (unpublished manuscript, South African National Film, Video and Sound Archives).

Mühl-Benninghaus, Wolfgang (1987): Zur Rolle des Staatsmonopolistischen Kapitalismus bei der Herausbildung eines Systems von Massenkommunikation zwischen 1900 und 1933. Überlegungen zum Zusammenhang zwischen Ökonomie und Kultur. Berlin (HU, Diss. $B=$ Habil., 2 Bände).

Mühl-Benninghaus, Wolfgang (1999): Das Ringen um den Tonfilm. Strategien der Elektro- und der Filmindustrie in den 20er und 30er Jahren. Düsseldorf.

Mühl-Benninghaus, Wolfgang (2004): Vom Augusterlebnis zur UFA-Gründung. Der deutsche Film im 1. Weltkrieg. Berlin.

Müller, Robert (2006): Die deutsche Garbo. Jahrhundert der Sphinx: Die Schauspielerin Brigitte Helm; in: Frankfurter Allgemeine Zeitung 58(2006)64, 41 (16.3.2006).

Murray, Bruce (1982): An Introduction to the Commercial Film Industry in Germany from 1895 to 1933, in: Plummer 1982: 23-34.

Nagel, Josef (1988): Frühe Entwicklungstendenzen einer medienspezifischen Filmsprache. Erlangen (Univ., Diss.).

Neale, Steve (1985): Cinema and Technology: Image. Colour. Sound. London.

Neitzel, Britta (Hg.)(1997): FFK 9. Dokumentation des 9. Film- und Fernsehwissenschaftlichen Kolloquiums an der BauhausUniversität Weimar, Oktober 1996. Weimar.

Niang, Sada (2003): Cinema; in: Zeleza/Eyoh 2003: 89-95.

Niedhardt, G. (2006): Sympathie für die Hunnen. Deutschlandbild in den britischen Medien nach dem Ersten Weltkrieg; in: Frankfurter Allgemeine Zeitung 59(2006)133, 8 (10.6.2006).

Nienaber, P.J. (1951): Uit die geskiedenis van ons tydskrifte; in: Tydskrif vir wetenskap en kuns 11(1951)1, 142-176.

Niessen, Carl (1934): Der Film - eine unabhängige deutsche Erfindung. Emsdetten.

Nowell-Smith, Geoffrey (Hg.)(1998): Geschichte des internationalen Films (Übers. der "Oxford History of World Cinema", Oxford 1997). Stuttgart/Weimar.

O'Dowd, M.C. (1978): The stages of economic growth and the future of South Africa; in: Schlemmer/Webster 1978: 28-50. 
Official Yearbook of the Union of South Africa and of Basutoland, Bechuanaland Protectorate and Swaziland, No. 9-19 (1927-1938). Kapstadt/Pretoria.

Ohne Autor (1926): Faust [Welt am Sonntag Nr. 42, 18.10.1926]; unter: http://www.filmportal.de [2.1.2007].

Ohne Autor (1941): Dr. Hans Rompel; in: Inspan 1(1941)3, 17.

Ohne Autor (1951): First Census of Distribution and Service Establisments 1946-1947. Preliminary Report, No. 51, Cinemas. Pretoria (Registriernr.: G.P.-S.9087-1951-2-650).

Olimsky, Fritz (1931): Tendenzen der Filmwirtschaft und deren Auswirkungen auf die Filmpresse. Berlin (Univ., Diss.).

Paech, Anne (1989): Von der Filmgeschichte vergessen: Die Geschichte des Kinos; in: Hickethier 1989: 41-49.

Pardoe, F.E. (1945/46): Film Critics and Criticism; in: Sight and Sound 14(1945/46)56, 119-120

Parsons, Talcott (1951): Social Systems. Glencoe.

Patalas, Enno (2001): Metropolis in / aus Trümmern. München.

Picton, L.G. (1969): Nicprint 50: Being some account of the history of the printing, packaging and newspaper industry of South Africa, and the National Industrial Council for Printing, prepared to mark the jubilee of the Council 1919-1969. Cape Town (Univ., MA).

Pinthus, Kurt (1930): Der blaue Engel [Das Tagebuch, Nr. 14, 5.4.1930]; in: Suddendorf 1980: 119-121.

Plummer, Thomas et.al. (eds.)(1982): Film and Politics in the Weimar Republic. New York.

Pohl, Johannes (1943): Die Jiddische Presse in Südafrika; in: Zentralblatt für Bibliothekswesen 60(1943)4, 168-170.

Pohl, Volker (1988): Unternehmer im Unternehmerroman des 19. und 20. Jahrhunderts: dargestellt anhand von Freytag: „Soll und Haben“, Spielhagen: „Hammer und Amboss“, und Herzog: „Die Wiskottens“. Hamburg (Univ., MA).

Poliva, Joseph A. (1962): A short History of the Jewish Press and Literature of South Africa from its earliest Days until the present Time. Johannesburg.

Potter, Elaine (1975): The Press as Opposition. The Political Role of South African Newspapers. London.

Prakke, Henk (1962): Publizist und Publikum in Afrika. Eine erste Erkundung. Köln.

Prawer, Siegbert S. (2002): The Blue Angel (Der Blaue Engel). London.

Prechner, Marks (1933): How the Cinema first come to South Africa; in: The Outspan 13(1933)330, 22-23 (23.6.1933).
Pretorius, S.J. (1947): Krannige Ruiter van Kunssinnige Stockperdjies; in: Die Ruiter 1(1947)20, 24ff. (19.9.1947).

Prokop, Dieter (1982): Soziologie des Films. Frankfurt/M.

Prümm, Karl (1989): Historiographie einer Epochenschwelle: Der Übergang vom Stummfilm zum Tonfilm in Deutschland (1928-1932); in: Hickethier 1989: 93-102.

Putz, Petra (1996): Waterloo in Geiselgasteig : die Geschichte des Münchner Filmkonzerns Emelka (1919 - 1933) im Antagonismus zwischen Bayern und dem Reich. Trier.

Ramirez, F./Rolot, C. (1985): Histoire du cinéma colonial au Zaïre, Rwanda et au Burundi. Tervuren.

Rathgeb, Kaspar (1935): Die Filmindustrie als Problem der Handelspolitik. Hamburg (Univ., Diss.).

Rich, B. Ruby (1992): From Repressive Tolerance to Erotic Liberation. Girls in Uniform (Mädchen in Uniform); in: Frieden 1992: 61 96.

Ritter, Henning (2006): Der Anthropologe als Schriftsteller. Dichte Erscheinung: Zum Tod von Clifford Geertz; in: Frankfurter Allgemeine Zeitung 59(2006)256, 35 (3.11.2006).

Robertson, James C. (1985): The British Board of Film Censors: film censorship in Britain 1896-1950. London et.al.

Rodriguez, José (1932): Maedchen in Uniform [Rob Wagner's Script 10.12.32: 10-11]; in: Slide 1982: 103-106.

Rompel, Hans (1929): Brigitte Helm - Die Sfinks van die Bioskoop-Aktriese; in: Die Huisgenoot 14(1929)397, 37+39+43 (8.11.29).

Rompel, Hans (1930): Die Taak van die Rolprent; in: Die Burger 5.5.1930, 8.

Rompel, Hans (1931a): Jannings: Die Goedhartige Demoon; in: Die Huisgenoot 15(1931)472, $21+49+51$ (17.04.31).

Rompel, Hans (1931b): Charles Chaplin - Die Eensame; in: Die Huisgenoot 15(1931)485, $23+25+77(17.07 .31)$.

Rompel, Hans (1937): Die Herlewing van die Duitse Film; in: Die Huisgenoot 22(1937)807, 47+89+91 (10.09.1937).

Rompel, Hans (1938): Die Geskiedenis van die Rolprent (I-III); in: Die Huisgenoot 23(1938)867, 15+17+89+91 (04.11.1938); 23(1938)868, $21+23+87$. (11.11.1938) und $23(1938) 869,30-31+103+105$ (18.11.1938)

Rompel, Hans (1942a): Die bioskoop in diens van die volk (I). Bloemfontein u.a.

Rompel, Hans (1942b): Die bioskoop in diens van die volk (II). Bloemfontein u.a.

Rompel, Hans (1945): Die vrytyd as ekonomiese probleem; in: Reddingsdaadbond (eds.): 
Vyf jaar Reddingsdaadbond. Fessbrosjure. Johannesburg, 52-57.

Rompel, H. (1948): Kan ons goeie Afrikaanse rolprente maak?; in: Die Huisgenoot 33(1388): 20-21 +60-63 (29.10.1948).

Rompel, Hans (1965): Ek was ,Die Burger' se eerste persfotograaf; in: Scannell 1965: 107 . 111.

Ross, Robert (1999): A Concise History of South Africa. Cambridge et.al.

Rotha, Paul/Griffith, Richard (1967): The Film till now: a survey of World Cinema. London (1st Edition 1930).

Rothmann, M.E. (1932): The Mother and Daughter in the Poor Family; in: Albertyn 1932: 147-217.

Rutra, Arthur Ernst (1927): Impotemkin; in: Wolf/Hauff 1988: 80.

Sacks, George (1937): The Press in South Africa; in: The Critic 5(1937)1, 21-25.

Sadoul, George (1957): Geschichte der Filmkunst. Wien.

Sahl, Hans (1930): Der blaue Engel [Der Montag Morgen, Nr. 14, 7.4.1930]; in: Sudendorf 1980: 123-124.

Salt, Barry (1983): Film Style and Technology: History and Analysis. London.

Scannell, P. (ed.)(1965): Keeromstraat 30. Kaapstad.

Schaudig, Michael (Hg.)(1996): Positionen deutscher Filmgeschichte. 100 Jahre Kinematographie: Strukturen, Diskurse, Kontexte. München.

Scheible, Hartmut (2006): Rot und schön ist das gleiche. Moskauer Lehrstück vom Einverständnis: Walter Benjamin entdeckte 1926 in Rußland Wirklichkeit und Wahrheit im Straßenverkehr; in: Frankfurter Allgemeine Zeitung 59(2006)251, 41 (28.10.2006).

Schlemmer, Lawrence/Webster, Eddie (eds.)(1978): Change, Reform and economic Growth in South Africa. Johannesburg.

Schmidt, Eckhart (1965): Der blaue Engel (Filmprotokoll); in: Film 3(1965)1, 47-60.

Schmidt-Pretoria, Werner (1955): Deutsche Wanderung nach Südafrika im 19. Jahrhundert. Berlin.

Schoeman, Karel (1980): Bloemfontein: die ontstaan van ' $n$ stad 1846-1946. Kaapstad.

Schramme, Ingrid (1985): Formen imaginierter Weiblichkeit: Vergleichende Untersuchung zu Heinrich Manns „Professor Unrat", Josef von Sternbergs „Der Blaue Engel“ und Rainer Werner Fassbinders „Lola“ (inkl. Filmtranskript von „Der Blaue Engel“, 83 S.). Göttingen (Univ., MA).

Shafik, Viola (1996): Der arabische Film. Geschichte und kulturelle Identität. Bielefeld.
Shaka, Femi Okiremuete (2004): Modernity and the African cinema: a study in colonialist discourse, postcoloniality, and modern African identities. Trenton (NJ).

Slide, Anthony (ed.)(1982): Selected film criticism (1921-1930). Metuchen (NJ).

Smyth, Rosaleen (1989): The Feature Film in Tanzania; in: African Affairs 88(1989)352, 389-396.

Sorlin, Pierre (1996): Ist es möglich, eine Geschichte des Kinos zu schreiben?; in: Montage/AV 5(1996)1, 23-37.

Standish, Abedian and B. (1985): Poor Whites and the Role of the State: The Evidence; in: South African Journal of Economics 53(1985)2, 141-165

St. Leger, Frederick York (1975): The African Press in South Africa. Grahamstown (Univ., Diss.).

Statistisches Jahrbuch für das Deutsche Reich Nr. 46-54 (1927-1935). Berlin.

Sternberg, Joseph von (1967): Ich - Josef von Sternberg. Erinnerungen. Velbert bei Hannover.

Steyn, Jacob Cornelius (1986): Die rol van die Afrikaanse pers in die taalstryd van die jaare 1930; in: Ecquid Novi 7(1986)1, 4-16.

Stolleis, Michael (2005): Meine Ex hat im Haus geklaut. Ein Buch, das alle angeht: Die Digesten sind Europas Juristenbibel; in: Frankfurter Allgemeine Zeitung 58(2005)277, 37 (28.11.2005).

Stommer, Rainer/Delügge, Marina (1995): Masse - Kollektiv - Volksgemeinschaft. Massenästhetische Inszenierungen der zwanziger und dreißiger Jahre; in: Antonowa/Merkert 1995: 349-355

Strebel, Elizabeth G. (1979): The Voortrekkers: A Cinematographic Reflection of Rising Afrikaner Nationalism; in: Film \& History 9(1979)2, 25-31.

Strebel, Elizabeth G. (1976/77): Primitive Propaganda: The Boer War Films; in: Sight \& Sound 46(1976/77)1, 45-47.

Strohm, Walter (1934): Die Umstellung der deutschen Filmwirtschaft vom Stummfilm auf den Tonfilm unter dem Einfluß des Tonfilmpatentmonopols. Freiburg im Breisgau.

Stürmer, Heinrich (1925): Das Tage-Buch; in: Brennicke/Hembus 1983: 124.

Sudendorf, Werner (Hg.)(1980): Marlene Dietrich. Dokumente, Essays, Filme. Frankfurt/M. u.a.

Switzer, Les (Hg.)(1996): South Africa's Alternative Press. Cambridge.

Thackway, Melissa (2003): Africa shoots back: alternative perspectives in Sub-Saharan Francophone African film. Bloomington. 
Theron, Erika (1932): Elisabeth Bergner - die Duitse Rolprentspeelster; in: Die Burger 22.11.32, 3.

Thiele, Wilhelm (1930): Operette im Film [Filmkurier 1929, Nr. 29]; in: Jakobsen 1989 : 108-109.

Thompson, Kristin (1985): Exporting Entertainment. America in the World Film Market 1907-34. London.

Thompson, Kristin/Bordwell, David (1994): Film history: an introduction. New York et.al.

Thompson, Kristin (1995): Neoformalistische Filmanalyse; in: Montage/AV 4(1995)1, 2362.

Thompson, Leonard (2001): A History of South Africa. New Haven/London.

Thuleen, Nancy (1994): „Mädchen in Uniform”: Traditional and Innovative Strategies in an Early Women's Film; unter: http://www.nthuleen.com/papers/655paper html [25.6.2005]

Todorow, Almut (1988): „Wollten die Eintagsfliegen in den Rang höherer Insekten aufsteigen?" Die Feuilletonkonzeption der ,Frankfurter Zeitung' während der Weimarer Republik im redaktionellen Selbstverständnis; in: Deutsche Vierteljahrsschrift für Literaturwissenschaft und Geistesgeschichte 62(1988)4 697-740.

Todorow, Almut (1996): Das Feuilleton der ,Frankfurter Zeitung' in der Weimarer Republik: zur Grundlegung einer rhetorischen Medienforschung. Tübingen.

Toeplitz, Jerzy (1992): Geschichte des Films. Berlin (5 Bände).

Tomaselli, Keyan (1980a): The South African Film Industry. Johannesburg.

Tomaselli, Keyan (1980b): Semiotics of film: an investigation of some influences on the language of film (Univ., MA).

Tomaselli, Keyan (1983): Ideology and Cultural Production in South African Cinema. Johannesburg (Univ., Diss.).

Tomaselli, Keyan (1985a): Grierson in South Africa. Culture, state and nationalist ideology in the South African film industry: 19401981; Cinema Canada (1985)122, 24-27.

Tomaselli, Keyan (1985b): Popular Memory and the Voortrekker films; Critical Arts 3(1985)3, 15-24.

Tomaselli, Keyan (1986): Capitalism and Culture in South African Cinema: Jingoism, Nationalism, and the Historical Epic; Wide Angle 8(1986)2, 33-43.

Tomaselli, Keyan (1989): Cinema of Apartheid. Race and Class in South Africa. London.

Tomaselli, Keyan (1996): Südafrika - Kino in der Peripherie; in: Afrika Initiative Hannover (Hg.): Touki bouki: Ein Lesebuch zum afrikanischen Film. Hannover, 61-63.
Tomaselli, Keyan (2006): Encountering Modernity. Twentieth Century South African Cinemas. Amsterdam/Pretoria.

Tomaselli, Keyan G./Louw, Eric (eds.)(1991): The Alternative Press in South Africa. Bellville.

Tomaselli, Keyan/Shepperson, Arnold (2000): South Africa; in: Kidem 2000: 140-164.

Traubner, Richard (1996): Operette: The German and Austrian Musical Film. New York (Univ., Diss.)(Ann Arbor 1997).

Udeman, Adrienne (1972): The South African film industry, a bibliography 1940-1971. Johannesburg (Univ., MA).

UdK-Universität der Künste Berlin, Filminstitut (Hg.)(2005): Metropolis: DVDStudienfassung. Berlin.

Ukadike, Frank (1994): Black African Cinema. Berkeley.

Ukadike, Frank (1998): African Cinema; in: Hill/Gibson 1998: 569-575.

Vaessen, Kurt (1938): Daten aus der Entwicklung des Rundfunks. Würzburg.

Van de Perre, M. (1990): De Congo-film: beschavingsfactor en bron voor mentaliteitsgeschiedenis. Groningen (Univ., MA).

Van Dijk, Eduard (2003): Linden Grove (Manuskript, Archiv ME), $1 \mathrm{~S}$.

Van Dijk, Eduard (2004): Peace (Manuskript, Archiv ME), 2 S.

Vande Winkel, Roel /Welch, David (eds.)(2007): Cinema and the Swastika: The International Expansion of Third Reich Cinema (1933-1945). London/New York .

Varley, Douglas Harold (1952): 'n Kort geskiedenis van die koerantwese in Suid-Afrika. Kaapstad.

Vints, L. (1981): Het Miskende Eldorado op het Zilveren Scherm. Exotische Films en Propaganda (1895-1940). Leuven (Univ., MA).

Vogt, Guntram (2001): Die Stadt im Film. Deutsche Spielfilme 1900-2000. Marburg.

Waldekranz, Rune/Arpe, Verner (1956): Knaurs Buch vom Film. München u.a.

Weber, Mark (1999): The Boer War Remembered; in: The Journal for Historical Review 18(1999)3, 14-28.

Wehnert, Stefanie (Hg.)(1996): Mein Kopf und die Beine von Marlene Dietrich: Heinrich Manns ,Professor Unrat' und ,Der blaue Engel'. Lübeck.

Weniger, Kay (Hg.)(2001): Das große Personenlexikon des Films (8 Bände). Berlin.

Wernecke, Klaus/Heller, Peter (1982): Der vergessene Führer: Alfred Hugenberg; Pressemacht und Nationalsozialismus. Hamburg.

Wheeler, Philippus Ferdinand (1988): Lokale Realisme in Speelprente van RARO en 
CARFO: ' $n$ Inhoudsontleding. Bloemfontein (Univ., MA).

Widera, Esther (1996): Rolle und Funktion des Films in der Weimarer Republik als ein möglicher Wegbereiter des Nationalsozialismus analysiert am Beispiel des Films „Der Blaue Engel“ (von Josef von Sternberg) im Kontext der politischen Ereignisse und der gesellschaftlichen Lebensbedingungen in den Jahren 1924 bis 1930. Braunschweig (HdKHochschule der Künste, Seminararbeit, Wintersemester 1995/96, Seminar „Film und Politik in der Weimarer Republik").

Widera, Esther (1999): Literaturverfilmung am Beispiel DER BLAUE ENGEL (Mann 1905/von Sternberg 1930). Braunschweig (HdK, MA).

Wigston, David (2001): A South African Media Map; in: Fourie 2001: 3-104.

Wilcocks, R.W. (1932): The Poor White. Stellenbosch.

Wilke, Jürgen (Hg.)(1991): Telegraphenbüros und Nachrichtenagenturen in Deutschland. München u.a.

Wilke, Jürgen (Hg.)(1999): Mediengeschichte der Bundesrepublik Deutschland. Köln (Lizenzausgabe der Bundeszentrale für politische Bildung; Schriftenreihe, Band 361).

Willan, Brian (ed.)(1996): Sol Plaatje: Selected Writings. Johannesburg.

Winkler, Heinrich August (2000): Deutsche Geschichte vom Ende des Alten Reiches bis zum Untergang der Weimarer Republik. München.
Wolf, Sylvia/Hauff, Eberhard (Hg.)(1988): Das Münchner Film- und Kinobuch. München.

Wolffsohn, Karl (Hg.)(1930): Jahrbuch der Filmindustrie. 4. Jahrgang. Berlin.

Wolffsohn, Karl (Hg.)(1933): Jahrbuch der Filmindustrie. 5. Jahrgang. Berlin.

Wollenberg, Hans (1926): Der Faust-Film [Lichtbild-Bühne, Nr. 246, 15.10.1926]; unter: http://www.filmportal.de [2.1.2007].

Worden, Nigel (2000): The Making of Modern South Africa: Conquest, Segregation and Apartheid. Oxford/Malden (MA).

Wuss, Peter (1992): Der Rote Faden der Filmgeschichten und seine unbewußten Komponenten; in: Montage/AV 1(1992)1, 25-35.

Wuss, Peter (1999): Filmanalyse und Psychologie: Strukturen des Films im Wahrnehmungsprozeß. Berlin.

Zapp, Manfred (1938): Die Struktur der Südafrikanischen Presse sowie der Presse in dem Mandatsgebiet von Südwestafrika und in Portugiesisch Ostafrika (Manuskript). Berlin (Bundesarchiv Berlin, Bibliothek, BA 15288).

Zeleza, Paul T./Eyoh, Dickson (eds.)(2003): Encyclopedia of Twentieth Century African History. London/New York.

Zglinicky, Friedrich von (1956): Der Weg des Films. Die Geschichte der Kinematographie und ihrer Vorläufer. Berlin.

Zucker, Wolf (1930): Der blaue Engel [Die Literarische Welt, Nr. 15, 11.4.1930]; in: Sudendorf 1980: 117-119. 


\section{Anhang I}

Tab. 45: Anzahl der im Zeitraum 1928 - 1930 in den Premierenkinos Kapstadts gezeigten Spielfilme

\begin{tabular}{|c|c|c|c|c|c|c|c|c|c|c|c|c|c|c|}
\hline \multirow[t]{2}{*}{ Jahr } & \multirow[t]{2}{*}{ Total } & \multicolumn{2}{|c|}{ US } & \multicolumn{2}{|c|}{ UK } & \multicolumn{2}{|c|}{ D } & \multicolumn{2}{|c|}{ Koprod. } & \multicolumn{2}{|c|}{ sonstige } & \multicolumn{2}{|c|}{ unbekannt } & \multirow[t]{2}{*}{ Ohne $^{198}$} \\
\hline & & A & K & A & $\mathrm{K}$ & $A$ & $\mathrm{~K}$ & $A$ & K & $A$ & K & $A$ & $\mathrm{~K}$ & \\
\hline \multirow[t]{2}{*}{1928} & 74 & 48 & 6 & 3 & 8 & 3 & 1 & 1 & 1 & 1 & - & 1 & 1 & 69 \\
\hline & Anteil & $78 \%$ & & $16 \%$ & & $6 \%$ & & & & & & & & \\
\hline \multirow[t]{2}{*}{1929} & 115 & 46 & 14 & 6 & 17 & 2 & 13 & - & 4 & 1 & 1 & 1 & 11 & 97 \\
\hline & Anteil & $62 \%$ & & $23 \%$ & & $15 \%$ & & & & & & & & \\
\hline \multirow[t]{2}{*}{1930} & 79 & 37 & 24 & 3 & 12 & - & - & 1 & 1 & - & - & - & 1 & 76 \\
\hline & Anteil & $80 \%$ & & $20 \%$ & & - & & & & & & & & \\
\hline Gesamt & 268 & 131 & 44 & 12 & 37 & 5 & 14 & 2 & 6 & 2 & 1 & 2 & 13 & 242 \\
\hline \multicolumn{15}{|c|}{$\varnothing: 90$ pro Jahr } \\
\hline & $\varnothing$ Anteil $^{199}$ & $72 \%$ & & $20 \%$ & & $8 \%$ & & & & & & & & \\
\hline
\end{tabular}

\section{Liste der „K-Filme“ als Gesamtheit der in den Premierenkinos Alhambra und Astoria in Kapstadt gezeigten Filme der Jahre 1928 bis 1930}

Tab. 46: Programm des Alhambra-Kinos 1928

\begin{tabular}{|l|l|c|c|c|}
\hline \multicolumn{1}{|c|}{ Filmtitel } & \multicolumn{1}{c|}{ Regie } & UA & Spielzeit & Tage \\
\hline Roses of Picardy & M. Elvey & 1927 & $03.01 .-07.01$. & 4 \\
\hline The Love of Sunya & A. Parker & 1927 & $09.01 .-14.01$. & 5 \\
\hline The Cohens and Kellys & H. Pollard & 1926 & $16.01 .-21.01$. & 5 \\
\hline The Missing Link & C. Reiser & 1927 & $23.01 .-28.01$. & 5 \\
\hline He Who Gets Slapped & V. Sjöström & 1924 & $30.01 .-04.02$. & 5 \\
\hline The Torrent & W. Doner/A. Younger & 1924 & $06.02 .-11.02$. & 5 \\
\hline The Eagle & C. Brown & 1925 & $13.02 .-18.02$. & 5 \\
\hline Nell Gwyn (UK) & H. Wilcox & 1926 & $20.02 .-25.02$. & 5 \\
\hline The Eagle of the Sea & F. Lloyd & 1926 & $27.02 .-03.03$. & 5 \\
\hline Michail Strogoff (F/D) & V. Turschanski & 1926 & $05.03 .-10.03$. & 5 \\
\hline Behind the Front & A.E. Sutherland & 1926 & $12.03 .-17.03$. & 5 \\
\hline The Greater Glory & C. Rehfeld & 1926 & $19.03 .-24.03$. & 5 \\
\hline Faust (D) & F. Murnau & 1926 & $26.03 .-31.03$. & 5 \\
\hline Fine Manners & R. Roosen & 1926 & $02.04 .-07.04$. & 5 \\
\hline The Ring & A. Hitchcock & 1927 & $09.04 .-14.04$. & 5 \\
\hline $\begin{array}{l}\text { The Battle of Coronel and Falkland } \\
\text { Islands (UK) }\end{array}$ & W. Summers & 1928 & $16.04 .-21.04$. & 5 \\
\hline The Country Doctor & & 1927 & $23.04 .-28.04$. & 5 \\
\hline
\end{tabular}

${ }^{198}$ Filme der Kategorien ,Koproduktionen', ,Sonstige' und ,Unbekannt' wurden nicht mit eingerechnet.

199 Berechnungsgrundlage ist die Gesamtanzahl der Filme in den Jahren 1928 bis 1930 („K-Filme“), abzüglich der Koproduktionen, sonstiger und unbekannter Filme (242). Die Angaben wurden gerundet. 


\begin{tabular}{|c|c|c|c|c|}
\hline Filmtitel & Regie & UA & Spielzeit & Tage \\
\hline Girl Shy & F. Newmeyer/S. Taylor & 1924 & $30.04-05.05$ & 5 \\
\hline Blonde or Brunette? & R. Roosen & 1927 & 07.05. - 10.05. & 3 \\
\hline Her Night of Romance & S. Franklin & 1924 & 11.05. - 12.05 & 1 \\
\hline The Black Bird & T. Browning & 1926 & 14.05. - 19.05. & 5 \\
\hline Metropolis (D) & F. Lang & 1927 & $21.05 .-30.05$ & 9 \\
\hline Kiki & C. Brown & 1926 & $31.05 .-02.06$ & 2 \\
\hline Marriage & R. Neill & 1927 & 04.06. - 06.06 & 2 \\
\hline Poppies of Flandres (UK) & A. Maude & 1927 & 07.06. - 09.06. & 2 \\
\hline Don Juan & A. Crossland & 1926 & 11.06. - 16.06. & 5 \\
\hline We're in the Navy Now & A. Sutherland & 1926 & 18.06. - 23.06. & 5 \\
\hline The Winning of Barbara Worth & H. King & 1926 & 25.06. - 30.06. & 5 \\
\hline The Barrier & G. Hill & 1926 & 02.07. - 07.07. & 5 \\
\hline Children of Divorce & F. Lloyd & 1927 & 09.07. - 14.07. & 5 \\
\hline Chang & M. Cooper & 1927 & 16.07. - 21.07. & 5 \\
\hline The Temptress & F. Niblo & 1926 & 23.07. - 28.07. & 5 \\
\hline Midnight Lovers & J. Dillon & 1926 & 30.07. - 04.08 & 5 \\
\hline Sparrows & W. Beaudine & 1926 & 08.02. - 04.08 & 2 \\
\hline Prince of Adventurers (F) & A. Wolkoff & 1927 & 06.08. - 11.08. & 5 \\
\hline The Magician & R. Ingram & 1926 & 13.08. - 18.08 & 5 \\
\hline $\begin{array}{l}\text { The Trumpet Calls (The Rough } \\
\text { Riders) }\end{array}$ & V. Fleming & 1927 & $20.08 .-25.08$ & 5 \\
\hline Barbed Wire & R. Lee & 1927 & 27.08. - 01.09 & 5 \\
\hline Beau Geste & H. Brenon & 1926 & 03.09. - 14.09. & 11 \\
\hline Sparkling Youth & $?$ & $?$ & 15.09. - 15.09. & 1 \\
\hline When a Man Loves & A. Crossland & 1927 & 17.09. - 22.09. & 5 \\
\hline The Dove & R. West & 1927 & 24.09. - 29.09. & 5 \\
\hline Bardelys the Magnificent & K. Vidor & 1926 & $01.10 .-06.10$ & 5 \\
\hline Old San Francisco & A. Crossland & 1927 & $08.10 .-13.10$ & 5 \\
\hline The Volga Boatman & C. de Mille & 1926 & 15.10. - 22.10 & 5 \\
\hline The Road to Mandelay & T. Browning & 1926 & $22.10 .-27.10$ & 5 \\
\hline Sons of the Sea & J. Cruze & 1926 & 29.10. - 03.11 & 5 \\
\hline Underworld & J. v. Sternberg & 1927 & 05.11.- 10.11 & 5 \\
\hline Hotel Imperial & M. Stiller & 1927 & 12.11. - 17.11 & 5 \\
\hline Prince of Tempters & L. Mendes & 1926 & 19.11. - 24.11. & 5 \\
\hline The Arab & R. Ingram & 1924 & 26.11. - 29.11. & 3 \\
\hline The Woman on Trial & M. Stiller & 1927 & $30.11 .-01.12$ & 1 \\
\hline Sorrows of Satan & D. Griffith & 1926 & 03. 12. -08.12 . & 5 \\
\hline The Cohens and the Kellys in Paris & W. Beaudine & 1928 & 10.12. - 15.12 & 5 \\
\hline The Show & T. Browning & 1927 & 17.12. - 21.12. & 4 \\
\hline The Gaucho & R. Jones & 1927 & 24.12. - 29.12. & 5 \\
\hline The Last Waltz (D) & A. Robison & 1927 & 31.12. -05.01 & 5 \\
\hline
\end{tabular}


Tab. 47: Programm des Astoria Kinema 1928

\begin{tabular}{|l|l|c|c|c|}
\hline \multicolumn{1}{|c|}{ Filmtitel } & \multicolumn{1}{|c|}{ Regie } & UA & \multicolumn{1}{c|}{ Spielzeit } & Tage \\
\hline The Rat (UK) & G. Cutts & 1925 & $22.10 .-24.10$. & 2 \\
\hline $\begin{array}{l}\text { The Further Adventures of the Flag } \\
\text { Lieutenant (UK) }\end{array}$ & W. Kellino & 1927 & $25.10 .-28.10$. & 3 \\
\hline The Blue Danube (D) & F. Zelnik & 1926 & $29.10 .-03.11$. & 5 \\
\hline The Constant Nymph (UK) & A. Brunel/B. Dean & 1928 & $05.11 .-07.11$. & 2 \\
\hline Breed of the Sea & R. Ince & 1926 & $08.11 .-10.11$. & 2 \\
\hline Clancy's Kosher Wedding & A. Gillstrom & 1927 & $12.11 .-17.11$. & 5 \\
\hline Love's Crucifixion & ? & $?$ & $19.11 .-24.11$. & 5 \\
\hline The Ghost Train (UK/A) & G. v. Bolváry & 1927 & $26.11 .-01.12$. & 5 \\
\hline Magic Garden & J. Meehan & 1927 & $03.12 .-05.12$. & 2 \\
\hline Flaming Waters & F. Weight & 1925 & $06.12 .-09.12$. & 3 \\
\hline Carry On! (UK) & D. Shurey & 1927 & $10.12 .-13.12$. & 3 \\
\hline Moulders of Men & R. Ince & 1927 & $14.12 .-15.12$. & 1 \\
\hline King of the Turf & J. Hogan & 1926 & $17.12 .-19.12$. & 2 \\
\hline The Arcadians (UK) & V. Saville & 1927 & $20.12 .-22.12$. & 2 \\
\hline Somehow Good (UK) & J. Raymond & 1927 & $24.12 .-25.12$. & 1 \\
\hline The Bohemian Girl (UK) & H. Parkinson & 1927 & $27.12 .-29.12$. & 2 \\
\hline Easy Virtue (UK) & A. Hitchcock & 1928 & $31.12 .-01.01$. & 1 \\
\hline & Total: 17; 6 US, 8 UK, 1 D, 1 sonstige, 1 unbekannt & \\
\hline
\end{tabular}

Tab. 48: Programm des Alhambra-Kinos 1929

\begin{tabular}{|l|l|c|c|c|}
\hline \multicolumn{1}{|c|}{ Filmtitel } & \multicolumn{1}{c|}{ Regie } & UA & \multicolumn{1}{c|}{ Spielzeit } & Tage \\
\hline Les Miserables (F) & H. Fescourt & 1925 & $07.01 .-12.01$. & 5 \\
\hline The Farmers Wife (UK) & A. Hitchcock & 1928 & $10.01 .-11.01$. & 1 \\
\hline A Gentleman of Paris & H. d'Abbadie d'Arrast & 1927 & $14.01 .-16.01$. & 2 \\
\hline Venus of Venice & M. Neilan & 1927 & $17.01 .-19.01$. & 2 \\
\hline Hula & V. Fleming & 1927 & $21.01 .-26.01$. & 5 \\
\hline The Melody Master & ? & $?$ & $21.01 .-26.01$. & 5 \\
\hline The Jazz Singer & A. Crossland & 1927 & $28.01 .-06.02$. & 9 \\
\hline Camille & F. Niblo & 1926 & $07.02 .-09.02$. & 2 \\
\hline Twelve Miles Out & J. Conway & 1927 & $11.02 .-16.02$. & 5 \\
\hline Resurrection & E. Carewe & 1927 & $18.02 .-23.02$. & 5 \\
\hline Oh Baby & H. Knowles & 1926 & $25.02 .-02.03$. & 5 \\
\hline A Little Bit of Fluff (UK) & W. Dryden & 1928 & $04.03 .-09.03$. & 5 \\
\hline Butterflies in the Rain & E. Sloman & 1926 & $11.03 .-16.03$. & 5 \\
\hline The Way of All Flesh & V. Fleming & 1927 & $18.03 .-28.03$. & 10 \\
\hline The Ringer (UK) & A. Maude & 1928 & $28.03 .-30.03$. & 2 \\
\hline The Night of Love & G. Fitzmaurice & 1927 & $01.04 .-06.04$. & 5 \\
\hline Serenade & H. d'Abbadie d'Arrast & 1927 & $08.04 .-13.04$. & 5 \\
\hline Pleasure before Business & F. Strayer & 1927 & $08.04 .-13.04$. & 5 \\
\hline
\end{tabular}




\begin{tabular}{|c|c|c|c|c|}
\hline Filmtitel & Regie & UA & Spielzeit & Tage \\
\hline Q Ships (UK) & G. Barkas/M. Barringer & 1928 & 15. $04 .-20.05$ & 35 \\
\hline Captain Salvation & J. Robertsen & 1927 & 22. $04 .-27.04$ & 5 \\
\hline Three Hours & J. Flood & 1927 & 29. 04. - 04.05 . & 5 \\
\hline Mr. WU & W. Nigh & 1927 & 06. 05. - 11.05. & 5 \\
\hline Wife Savers & R. Ceder & 1928 & 13. $05 .-18.05$ & 5 \\
\hline Easy Pickings & G. Archainbaud & 1927 & 13. $05 .-18.05$ & 5 \\
\hline The Circus & C. Chaplin & 1928 & 20. 05. - 29.05 & 9 \\
\hline The Fire Brigade & W. Nigh & 1926 & 30. 05. - 01.06 & 2 \\
\hline The Merry Widow & E. v. Stroheim & 1925 & 03. 06. - 08.06 & 5 \\
\hline Manon Lescaut (D) & A. Robison & 1926 & 10. 06. - 12.06 & 2 \\
\hline The Three Sinners & R. Lee & 1928 & 13. $06 .-15.06$ & 2 \\
\hline The Kid Brother & T. Wilde/J. Howe & 1927 & 17. $06 .-22.06$. & 5 \\
\hline The Forbidden Woman & P. Stein & 1927 & 24. 06. - 29.06 . & 5 \\
\hline Seventh Heaven & F. Borzage & 1927 & 01. 07. - 09.07. & 8 \\
\hline Name the Woman & E. Kenton & 1928 & 10. $07 .-13.07$ & 3 \\
\hline The General & B. Keaton/C. Bruckman & 1927 & 10. $07 .-13.07$ & 3 \\
\hline Beau Sabreur & J. Waters & 1928 & 15. 07. - 18.07 & 3 \\
\hline Volga, Volga (D) & V. Turschanski & 1928 & 22. $07 .-27.07$ & 5 \\
\hline The Certain Thin & F. Capra & 1928 & 26. 07. - 27.07. & 1 \\
\hline Red Hair & C. Badger & 1928 & 29. 07. - 03.08 . & 5 \\
\hline Sorrell and Son & H. Brenon & 1927 & 05. 08. - 10.08 & 5 \\
\hline The Scarlet Letter & V. Sjöström & 1926 & 12. $08 .-17.08$ & 5 \\
\hline Tempest & S. Taylor & 1928 & 19. $08 .-24.08$ & 5 \\
\hline Piccadilly (UK) & A. Bennett & 1929 & 26. 08. - 31.08. & 5 \\
\hline Sunrise & F. Murnau & 1927 & 02. 09. - 07.09. & 5 \\
\hline Two Arabian Knights & L. Milestone & 1927 & 09. 09. - 14.09. & 5 \\
\hline Simba & M. Johnson/T. Ramsaye & 1928 & 16. 09. - 21.09 . & 5 \\
\hline The Patent Leather Kid & A. Santell & 1927 & 23. 09. - 28.09. & 5 \\
\hline Sadie Thomson & R. Walsh & 1928 & 30. 09. - 04.10 & 4 \\
\hline Submarine & F. Capra & 1928 & $07.10 .-12.10$ & 5 \\
\hline La Boheme & K. Vidor & 1926 & 14. 10. - 19.10 & 5 \\
\hline The Unknown & T. Browning & 1927 & 21. 10. -26.10 & 5 \\
\hline Wings (UK) & W. Wellman & 1927 & 28. 10. - 09.11 & 12 \\
\hline Flesh and the Devil & C. Brown & 1926 & 11. 11. - 16.11 & 5 \\
\hline Fazil & H. Hawks & 1928 & 18. 11. -23.11 & 5 \\
\hline Ramona & E. Carewe & 1928 & 25. 11. -30.11 & 5 \\
\hline The Singing Fool & L. Bacon & 1928 & 02. 12. - 14.12 & 12 \\
\hline In old Arizona & I. Cummings/R. Walsh & 1928 & 16. 12. -28.12 & 12 \\
\hline My Man & A. Mayo & 1928 & 30. 12. - 11.01 & 12 \\
\hline
\end{tabular}


Tab. 49: Programm des Astoria Kinema 1929

\begin{tabular}{|c|c|c|c|c|}
\hline Filmtitel & Regie & UA & Spielzeit & Tage \\
\hline The Dancer of Barcelona & $?$ & $?$ & 03. 01. - 05.01 & 2 \\
\hline One of the Best (UK) & T. Hunter & 1927 & $07.01 .-09.01$ & 2 \\
\hline Wallflowers & J. Meehan & 1928 & 14. $01 .-16.01$ & 2 \\
\hline Vortex & A. Brunel & 1928 & 17. $01 .-19.01$ & 2 \\
\hline The Rolling Road & G. Cutts & 1928 & 21. 01.-23.01. & 2 \\
\hline Jake the Plumber & E. Ludwig & 1927 & 24. $01 .-26.01$ & 2 \\
\hline The Harvester & J. Meehan & 1927 & 28. $01 .-30.01$ & 2 \\
\hline The Spy (D) & F. Lang & 1928 & $31.01 .-06.02$ & 6 \\
\hline Mademoiselle Parley-Voo & M. Elvey & 1928 & 07. 02. - 09.02. & 2 \\
\hline Show Life (D/UK) & R. Eichberg & 1928 & 11. $02 .-16.02$ & 5 \\
\hline The Ware Case (UK) & H. Manning Haynes & 1928 & 18. $02 .-23.02$ & 5 \\
\hline Shiraz (D/UK/IN) & F. Osten & 1928 & 25. 02. -07.03 & 10 \\
\hline Life's Circus & $?$ & $?$ & 11. 03. - 16.03 & 5 \\
\hline The Physician (UK) & G. Jacoby & 1928 & 18. $03 .-23.03$ & 5 \\
\hline Fear (D) & H. Steinhoff & 1928 & 25. 03. -27.03 & 2 \\
\hline The City of Pleasure & $?$ & $?$ & 28. 03. -30.03 & 2 \\
\hline $\begin{array}{l}\text { The Triumph of Scarlet Pimpernel } \\
\text { (UK) }\end{array}$ & T. Hayes Hunter & 1928 & $01.04 .-10.04$ & 9 \\
\hline The Passing of Mr. Quinn & J. Hagen/L. Hiscott & 1928 & 11. $04 .-13.04$ & 2 \\
\hline The Trial of Donald Westhof (D) & F. Wendhausen & 1927 & 15. $04 .-18.04$ & 3 \\
\hline The Chinese Bungalow (UK) & S. Hill & 1926 & 18. $04 .-20.04$ & 2 \\
\hline Chance the Idol & $?$ & $?$ & 22. $04 .-27.04$ & 5 \\
\hline Apaches of Paris (D/F) & N. Malikoff & 1927 & 29. $04 .-04.05$ & 5 \\
\hline Monkey Nuts & $?$ & $?$ & 06. 05. - 11.05. & 5 \\
\hline The South Sea Bubble (UK) & T. Hayes Hunter & 1928 & 13. $05 .-18.05$ & 5 \\
\hline The Fugitive Lover & $?$ & $?$ & 20. 05. -25.05 & 5 \\
\hline Palais de Danse (UK) & M. Elvey & 1928 & 27. 05. -01.06 & 5 \\
\hline Freckles & J. Meehan & 1928 & 03. 06. - 08.06 & 5 \\
\hline At the Edge of the World (D) & K. Grune & 1927 & 10. $06 .-11.06$ & 1 \\
\hline Looping the Loop (D) & A. Robison & 1928 & 17. $06 .-22.06$ & 5 \\
\hline The Murder in the Red Barn 200 & $?$ & $?$ & 24. 06. - 29.06 & 5 \\
\hline Paradise (UK) & D. Clift & 1929 & 27. 06. -29.06 & 2 \\
\hline The Perfect Crime (UK) & W. Summers & 1925 & $01.07 .-06.07$. & 5 \\
\hline Ghost of the Night & ? & $?$ & $08.07 .-13.07$ & 5 \\
\hline Little Devil-May Care (F) & M. L'Herbier & 1928 & 15. $07 .-18.07$ & 3 \\
\hline Virginia's Husband (UK) & H. Hughes & 1928 & 19. $07 .-20.07$ & 1 \\
\hline Tommy Atkins (UK) & N. Walker & 1928 & 22. $07 .-27.07$ & 5 \\
\hline The Triumph of the Rat (UK) & G. Cutts & 1928 & 29. $07 .-03.08$ & 5 \\
\hline Bondage (D) & R. Eichberg & 1928 & 05. 08. - 10.08 & 5 \\
\hline
\end{tabular}

${ }^{200}$ UK, S. Hill, $1924 ?$ 


\begin{tabular}{|l|l|c|c|c|}
\hline \multicolumn{1}{|c|}{ Filmtitel } & \multicolumn{1}{|c|}{ Regie } & UA & \multicolumn{1}{c|}{ Spielzeit } & Tage \\
\hline The Silent House (UK) & W. Forde & 1929 & $12.08 .-17.08$. & 5 \\
\hline The Cage of Death & ? & $?$ & $19.08 .-24.08$. & 5 \\
\hline Hell Ship Bronson & J. Henabery & 1928 & $26.08 .-31.08$. & 5 \\
\hline Mr. Smith Wakes Up (UK) & J. Harrison & 1929 & $26.08 .-31.08$. & 5 \\
\hline Homecoming (D) & J. May & 1928 & $02.09 .-07.09$. & 5 \\
\hline The Alley Cat (UK/D) ${ }^{201}$ & H. Steinhoff & 1929 & $09.09 .-14.09$. & 5 \\
\hline The Bondman (UK) & H. Wilcox & 1929 & $16.09 .-21.09$. & 5 \\
\hline The Water Rat (D) & E. Waschnek & 1928 & $23.09 .-30.09$. & 7 \\
\hline Dancing Vienna (D) & F. Zelnik & 1927 & $30.09 .-05.10$. & 5 \\
\hline The Wonderful Lie (D) & H. Schwarz & 1929 & $10.07 .-10.12$. & 5 \\
\hline Nr. 17 & ? & $?$ & $14.10 .-21.10$. & 7 \\
\hline Temptation (D) & J. May & 1929 & $21.10 .-26.10$. & 5 \\
\hline The Yacht of Seven Sins (D) & J. u. L. Fleck & 1928 & $28.10 .-02.11$. & 5 \\
\hline The Lost Patrol (UK) & W. Summers & 1929 & $04.11 .-08.11$. & 4 \\
\hline The Woman in Flames & ? & $?$ & $11.11 .-16.11$. & 5 \\
\hline The Secret Courier (D) & G. Righelli & 1928 & $18.11 .-22.11$. & 4 \\
\hline High Treason (UK) & M. Elvey & 1928 & $22.11 .-07.12$. & 15 \\
\hline Street Girl & W. Ruggles & 1929 & $09.12 .-14.12$. & 5 \\
\hline Syncopation & B. Glennon & $16.12 .-28.12$. & 12 \\
\hline Blockade & G. Seitz & $30.12 .-04.01$. & 5 \\
\hline & & 17 UK, 13 D, 4 Kproduktionen, 11 unbekannt & \\
\hline
\end{tabular}

Tab. 50: Programm des Alhambra-Kinos 1930

\begin{tabular}{|l|l|c|c|c|}
\hline \multicolumn{1}{|c|}{ Filmtitel } & \multicolumn{1}{|c|}{ Regie } & UA & Spielzeit & Tage \\
\hline Love in the Dessert & G. Melford & 1929 & $13.01 .-18.01$. & 5 \\
\hline Movietone Follies & D. Buttler & 1929 & $13.01 .-27.01$. & 14 \\
\hline The Donovan Affair & F. Capra & 1929 & $28.01 .-.08 .02$. & 11 \\
\hline Lucky Boy & N. Taurog/C. Wilson & 1929 & $10.02 .-12.02$. & 2 \\
\hline Blackmail (UK) & A. Hitchcock & 1929 & $17.02 .-01.03$. & 12 \\
\hline Conquest & R. Del Ruth & 1928 & $03.03 .-08.03$. & 5 \\
\hline The Fall of Eve & F. Strayer & 1929 & $10.03 .-15.03$. & 5 \\
\hline Through Different Eyes & J. Blystone & 1929 & $17.03 .-22.03$. & 5 \\
\hline Masquerade & R. Birdwell & 1929 & $24.03 .-29.03$. & 5 \\
\hline Bulldog Drummond & F. Jones & 1929 & $31.03 .-13.04$. & 13 \\
\hline Broadway Hoofer & G. Archainbaud & 1929 & $14.04 .-19.04$. & 5 \\
\hline The Great Gabbo & J. Cruze & 1929 & $21.04 .-03.05$. & 12 \\
\hline Iron Mask & A. Dwan & 1929 & $05.05 .-10.05$. & 5 \\
\hline Flight & F. Capra & 1929 & $12.05 .-24.05$. & 12 \\
\hline On with the Show & A. Crossland & 1929 & $26.05 .-07.06$. & 12 \\
\hline Queen of the Night Clubs & B. Foy & 1929 & $09.06 .-14.06$. & 5 \\
\hline
\end{tabular}

${ }^{201}$ Nachtgestalten 


\begin{tabular}{|l|l|c|c|c|}
\hline \multicolumn{1}{|c|}{ Filmtitel } & \multicolumn{1}{|c|}{ Regie } & UA & Spielzeit & Tage \\
\hline Wanted & H. Higgin & 1929 & $16.06 .-21.06$. & 5 \\
\hline The Grand Parade & F. Newmeyer & 1930 & $23.06 .-28.06$. & 5 \\
\hline Atlantic (D/UK) & E. Dupont & 1929 & $30.06 .-12.07$. & 12 \\
\hline The Desert Song & R. Del Ruth & 1929 & $14.07 .-19.07$. & 5 \\
\hline This Thing Called Love & P. Stein & 1929 & $28.07 .-02.08$. & 5 \\
\hline The Glad Rag Doll & M. Curtiz & 1929 & $04.08 .-09.08$. & 5 \\
\hline Broadway Scandals & G. Archainbaud & 1929 & $11.08 .-16.08$. & 5 \\
\hline Alibi & D. West & 1929 & $18.08 .-23.08$. & 5 \\
\hline The Awful Truth & M. Neilan & 1929 & $26.08 .-30.08$. & 4 \\
\hline Kings of the Khyber Rifles & J. Ford & 1929 & $01.09 .-06.09$. & 5 \\
\hline Cocoanuts & R. Florey/J. Santley & 1929 & $08.09 .-13.09$. & 5 \\
\hline The Mysterious Dr. Fu Manchu & L. Corrigan & 1929 & $15.09 .-20.09$. & 5 \\
\hline Lucky in Love & K. Webb & 1929 & $22.09 .-27.09$. & 5 \\
\hline Paris Bound & E. Griffith & 1929 & $29.09 .-04.10$. & 5 \\
\hline The Vagabond King & L. Berger & 1930 & $06.10 .-18.10$. & 12 \\
\hline Ladies of Leisure & F. Capra & 1930 & $20.10 .-25.10$. & 5 \\
\hline Innocent of Paris & R. Wallace & 1929 & $27.10 .-01.11$. & 5 \\
\hline Loose Ends (UK) & M. Walker & 1930 & $03.11 .-08.11$. & 5 \\
\hline All Quiet at the Western Front & L. Milestone & 1930 & $10.11 .-18.11$. & 8 \\
\hline Just for a Song (UK) & G. Gundrey & 1929 & $10.11 .-12.11$. & 2 \\
\hline Why Bring That Up? & G. Abbot & 1929 & $24.11 .-29.11$. & 5 \\
\hline King of Jazz & J. Anderson & 1930 & $01.12 .-13.12$. & 12 \\
\hline Broadway & P. Felös & $19.12 .-20.12$. & 5 \\
\hline Taming of the Shrew & S. Taylor & $22.12 .-27.12$. & 5 \\
\hline No, No Nanette & C. Badger & 1930 & $29.12 .-02.01$. & 4 \\
\hline & Total: 41; 37 US, 3 UK, 1 D/UK & & \\
\hline
\end{tabular}

Tab. 51: Programm des Astoria-Kinema 1930

\begin{tabular}{|l|l|c|c|c|}
\hline \multicolumn{1}{|c|}{ Filmtitel } & \multicolumn{1}{|c|}{ Regie } & \multicolumn{1}{c|}{ UA } & \multicolumn{1}{c|}{ Spielzeit } & Tage \\
\hline The Wrecker (UK/D) & G. v. Bolváry & 1929 & $13.01 .-27.01$. & 14 \\
\hline Three Brothers & M. St. Clair & 1929 & $20.01 .-25.01$. & 5 \\
\hline Woman to Woman (UK) & V. Saville & 1929 & $27.01 .-08.02$. & 12 \\
\hline High Treason (UK) & M. Elvey & 1928 & $10.02 .-12.02$. & 2 \\
\hline Half Marriage & W. Cowen & 1929 & $13.02 .-18.02$. & 5 \\
\hline Rio Rita & L. Reed & 1929 & $19.02 .-05.04$. & 45 \\
\hline Three Live Ghosts & T. Freeland & 1929 & $07.04 .-19.04$. & 12 \\
\hline Splinters (UK) & J. Raymond & 1929 & $21.04 .-03.05$. & 12 \\
\hline The Trespasser & E. Goulding & 1929 & $05.05 .-17.05$. & 12 \\
\hline La Traviata (UK) & H. Parkinson & 1927 & $15.05 .-15.05$. & 1 \\
\hline The Delightful Rogue & L. Shores/L. Pearce & 1929 & $19.05 .-31.05$. & 12 \\
\hline Rookery Nook (UK) & T. Walls & 1930 & $02.06 .-07.06$. & 5 \\
\hline
\end{tabular}




\begin{tabular}{|l|l|c|c|c|}
\hline \multicolumn{1}{|c|}{ Filmtitel } & \multicolumn{1}{|c|}{ Regie } & UA & Spielzeit & Tage \\
\hline The Vagabond Lover & M. Neilan & 1929 & $23.06 .-05.07$. & 12 \\
\hline Rio Rita & L. Reed & 1929 & $07.07 .-16.07$. & 9 \\
\hline Black Waters & M. Neilan & 1929 & $17.07 .-23.07$. & 6 \\
\hline Love at First Sight & E. Lewis & 1929 & $24.07 .-26.07$. & 2 \\
\hline The Great Night Parade & ? & $?$ & $28.07 .-02.08$. & 5 \\
\hline Love Comes Along & R. Julian & 1930 & $04.08 .-09.08$. & 5 \\
\hline Jazz Heaven & M. Brown & 1929 & $11.08 .-16.08$. & 5 \\
\hline The Rampant Age & P. Rosen & 1930 & $18.08 .-23.08$. & 5 \\
\hline Rookery Nook (UK) & T. Walls & 1930 & $26.08 .-30.08$. & 4 \\
\hline Lummox & H. Brenon & 1930 & $01.09 .-06.09$. & 5 \\
\hline Dance Hall & M. Brown & 1929 & $08.09 .-13.09$. & 5 \\
\hline Tanned Legs & M. Neilan & 1929 & $15.09 .-20.09$. & 5 \\
\hline Blaze O' Glory & G. Crone/R.Hoffman & 1929 & $22.09 .-27.09$. & 5 \\
\hline What a Man & G. Crone & 1930 & $29.09 .-08.10$. & 9 \\
\hline Taxi for Two (UK) & D. Clift/A. Esway & 1929 & $09.10 .-11.10$. & 2 \\
\hline The Cuckoos & P. Sloane & 1930 & $13.10 .-25.10$. & 12 \\
\hline The Crooked Billet (UK) & A. Brunel & 1929 & $23.10 .-25.10$. & 2 \\
\hline Second Wives & R. Mack & 1930 & $27.10 .-01.11$. & 5 \\
\hline Girl of the Port & B. Glennon & 1930 & $03.11 .-12.11$. & 9 \\
\hline Balaclava (UK) & M. Elvey/M. Rosmer & 1928 & $13.11 .-17.11$. & 4 \\
\hline Puttin' on the Ritz & E. Sloman & 1930 & $22.11 .-30.11$. & 8 \\
\hline The Love of Robert Burns (UK) & H. Wilcox & 1930 & $24.11 .-06.12$. & 12 \\
\hline At the Villa Rose(UK) & L. Hiscott & 1930 & $08.12 .-13.12$. & 5 \\
\hline Love finds a Way & G. Archainbaud & $15.12 .-20.12$. & 5 \\
\hline Worldly Goods & P. Rosen & 1930 & $22.12 .-22.12$. & 1 \\
\hline Last Hour (UK) & W. Forde & $29.12 .-02.01$. & 4 \\
\hline & T8: 24 US, 12 UK, 1 UK/D, 1 unbekannt & & \\
\hline
\end{tabular}

Tab. 52: Filme mit einer überdurchschnittlichen Spielzeit in Kapstadt $1928-1930$ ( $>5$ Tage, beginnend mit der längsten Spielzeit)

\begin{tabular}{|l|l|c|c|c|}
\hline \multicolumn{1}{|c|}{ Filmtitel $^{202}$} & \multicolumn{1}{c|}{ Regie } & UA & \multicolumn{1}{c|}{ Spielzeit \& Jahr } & Tage \\
\hline RIO RITA * & L. Reed & 1929 & $19.02 .-05.04 .30$ & 45 \\
\hline Q SHIPS & G. Barkas/M.Barringer & 1928 & $15.04 .-20.05 .29$ & 35 \\
\hline HIGH TREASON (UK)* & M. Elvey & 1928 & $11.22 .-12.07 .29$ & 15 \\
\hline MOVIETONE FOLLIES & D. Buttler & 1929 & $13.01 .-27.01 .30$ & 14 \\
\hline BULLDOG DRUMMOND* & F. Jones & 1929 & $31.03 .-13.04 .30$ & 13 \\
\hline WINGS (UK)* & W. Wellman & 1927 & $28.10 .-09.11 .29$ & 12 \\
\hline KING OF JAZZ* & J. Anderson & 1930 & $01.12 .-13.12 .30$ & 12 \\
\hline
\end{tabular}

202 Die mit einem * gekennzeichneten Filme listet Thelma Gutsche als „outstanding films of each year“ (Gutsche 1972: 228f.). Daraus ergibt sich, dass von den 41 Spielfilmen mit längerer Spielzeit ungefähr die Hälfte (20) als „outstanding“ eingeschätzt wurden. 


\begin{tabular}{|c|c|c|c|c|}
\hline IN OLD ARIZONA & I. Cummings/R. Walsh & 1928 & 16.12. -28.12 .29 & 12 \\
\hline FLIGHT & F. Capra & 1929 & 12.05. -24.05 .30 & 12 \\
\hline WOMAN TO WOMAN (UK) & V. Saville & 1929 & 27.01. -08.02 .30 & 12 \\
\hline THE SINGING FOOL* & L. Bacon & 1928 & 02.12. - 14.12 .29 & 12 \\
\hline THE GREAT GabBo* & J. Cruze & 1929 & $21.04 .-03.05 .30$ & 12 \\
\hline ON WITH THE SHOW & A. Crossland & 1929 & 26.05. -07.06 .30 & 12 \\
\hline MY MAN & A. Mayo & 1928 & 30.12. - 11.01.29 & 12 \\
\hline THE VAGABOND KING* & L. Berger & 1930 & 06.10. - 18.10.30 & 12 \\
\hline ATLANTIC (UK/D)* & E. Dupont & 1929 & 30.06. - 12.07.30 & 12 \\
\hline THE TRESPASSER* & E. Goulding & 1929 & 05.05. -17.05 .30 & 12 \\
\hline The DELIGHTFul ROGue & L. Shores/L. Pearce & 1929 & 19.05. -31.05 .30 & 12 \\
\hline THE LOVE OF ROBERT BURNS (UK) & H. Wilcox & 1930 & $24.11 .-06.12 .30$ & 12 \\
\hline BLACKMAIL (UK)* & A. Hitchcock & 1929 & 17.02. -01.03 .30 & 12 \\
\hline THE CuCKOOS & P. Sloane & 1930 & 13.10. -25.10 .30 & 12 \\
\hline THREE LIVE GHOSTS & T. Freeland & 1929 & 07.04. - 19.04.30 & 12 \\
\hline SYNCOPATION* & B. Glennon & 1929 & 12.16. - 12.28.29 & 12 \\
\hline SPLINTERS (UK)* & J. Raymond & 1929 & 21.04. - 03.05.30 & 12 \\
\hline THE DONOVAN AFFAIR & F. Capra & 1929 & $28.01 .-.08 .02 .30$ & 11 \\
\hline BeAu GEste* & H. Brenon & 1926 & 03.09. - 14.09.28 & 11 \\
\hline THE WAY OF ALL FLESH* & V. Fleming & 1927 & 18.03. - 28.03.29 & 10 \\
\hline SHIRAZ(D/UK/IN)* & F. Osten & 1928 & 25.02. - 07.03.29 & 10 \\
\hline METROPOLIS (D)* & F. Lang & 1927 & $21.05 .-30.05 .28$ & 9 \\
\hline THE CIRCUS & C. Chaplin & 1928 & 20.05. - 29.05.29 & 9 \\
\hline GIRL OF THE PORT & B. Glennon & 1930 & $03.11 .-12.11 .30$ & 9 \\
\hline $\begin{array}{l}\text { THE TRIUMPH OF SCARLET PIMPERNEL } \\
(\text { UK) }\end{array}$ & T. Hayes Hunter & 1928 & $01.04 .-10.04 .29$ & 9 \\
\hline WHAT A MAN & G. Crone & 1930 & 29.09. - 08.10.30 & 9 \\
\hline THE JAZZ SINGER* & A. Crossland & 1927 & 28.01.-06.02.29 & 9 \\
\hline PUTTIN' ON THE RITZ & E. Sloman & 1930 & $22.11 .-30.11 .30$ & 8 \\
\hline ALL QUIET AT THE WESTERN FRONT* & L. Milestone & 1930 & 10.11. - 18.11 .30 & 8 \\
\hline SEVENTH HEAVEN* & F. Bozarge & 1927 & 01.07.- 09.07.29 & 8 \\
\hline THE WATER RAT (D) & E. Waschnek & 1928 & 23.09. -30.09 .29 & 7 \\
\hline NR. 17 & $?$ & $?$ & 14.10. -21.10 .29 & 7 \\
\hline THE SPY (D) & F. Lang & 1928 & $31.01 .-06.02 .29$ & 6 \\
\hline BLACK WATERS & M. Neilan & 1929 & 17.07. - 23.07.30 & 6 \\
\hline TOTAL: 41 (21:20 TG) & & & & \\
\hline
\end{tabular}




\title{
Anhang II
}

\section{Aufstellung der im Zeitraum 1917 - 1926 vom Cape Censorship Board zurückgewiesenen Filme}

\author{
Quelle: Western Cape Provincial Archives and Records Service, Kapstadt, \\ Signatur PAS 3/57 P5/38/28G, Censorship Board, list 'films disapproved'
}

\author{
1917 (3) \\ Innocence of Lizzette (1916, J. Kirkwood) \\ Life (?) \\ Enlighten Thy Daughter (1917, I. Abramson)
}

\section{$1918(10)$}

The Night Cap (1917, R. Clements)

Where Are Thy Children (?)

Those Who Pay (1917, R.B. West)

Susie's Scheme 1917 (?)

Susie Steps Out (?)

Baby Mine (1917, H. Ballin/J. S. Robertson)

Sapho (1917, H. Ford/E. Chautard)

Body and Soul (1915, G. Irving)

Mr. Wu (1919, M. Elvey)

Hula Hula Land (1917, W. Campbell)

\section{9 (12)}

Carmen of Klondyke (1918, R. Barker)

Easiest Way (1917, A. Capellani)

Blue Streak (1917, W. Nigh)

Sea Nymphs (1916, H. Davey)

Devil's Playground (1917, H. McRae Webster)

The Sin Woman (1917, G.W. Lederer)

The Libertine (1916, J.A. Golden/J. Steger)

One Law for Both (1917, I. Abramson)

The Children Pay or The Duty of Parents (?)

Women (?)

Willard Johnston (Boxing Film) (?)

Mr. Wu (1919, L. Pick) (D)

1920 (14)

When Men Betray (1918, I. Abramson)

Paid in Advance (1918, A. Holubar)

Three Weeks (1914, P.N. Vekroff)

Miracle of Life (1915, H.A. Pollard)

Man and the Woman (1917, H. Blaché/A. Guy)

Pride and The Devil (1917, R. Ridgely)

Sparrows (1916, M. Binger) (NL/UK)

Five Nights (1915, B. Haldane)

Glorious Lady (1919, G. Irving)
In the Clutches of the Gangsters (1914, R.

Stanton)

Spreading Evil (1918, J. Keane)

Decreed to Die (?)

Honors Cross (1918, W. Worsley)

Song of Song (1918, J. Kaufman)

1921 (8)

Civilisations Child (1916, C. Giblyn)

Bright Lights Dimmer (1918, S. Drew)

Damaged Goods (1919, A. Butler)

Sea Sirens (1919, W. Beaudine)

Mary Regan (1919, L. Weber)

Old Dad (1920, L. Ingraham)

House Without Children (1919, S. Brodsky)

Battle of Life (1919, J. Vincent)

1922 (7)

End of the Road (1919, E. H. Griffith)

Passion (1917, R. Ridgely)

Woman's Story (?)

The Shark (1920, D. Henderson)

When the Whale Jonahed (1921, Buch: H.M.

Dawley/T. Sarg)

Secret Trunk (?)

Wanted an Alibi (?)

$1923(11)$

Olive Branch (?)

Strange Transgressor (1917, R. Barker)

Berth Scandal (1917, J.F. Dillon)

Ten of Diamonds (1917, R.B. West)

The Bachelors Finish (1917, J.F. Dillon)

Dad's Downfall (1917, H.C. Raymaker)

What Do Men Want? (1921, L. Weber)

White Hands (1922, L. Hillyer)

One Stolen Night (1923, R. Ensminger)

East is West (1922, S. Franklin)

Man above the Law (1918, R. Wells)

1924 (13)

Woman to Woman (1923, G. Cutts)

Innocent Cheat (1921, B.F. Wilson) 
Woman's Honour (1916, R. West) Cliff Dwellers (1911, E.S. Porter)

Sand Witch (?)

The Street (1923, K. Grune)(D)

Great Impersonation (1921, G. Melford)

His Saving Grace (1917, H. McCoy)

Down and Out (1922, R. Ceder)

Sanitarium Scandal (1917, W. Beaudine)

Thundering Dawn (1923, H. Garson)

Gabaretting under Difficulties (?)

What the German Emperor Forgot in His Memoirs (?)

\section{5 (18)}

For the Defence (1922, P. Powell) Empty Arms (1920, F. Reicher)

Trouble in the Ark (?)

Birthday Blunder (?)

Lilies of the Field (1924, J.F. Dillon)

Three Weeks (1924, A. Crosland)
Big Flood (1922)

Not my Sister (1916, C. Giblyn)

Idolators (1917, W. Edwards)

Ruined by a Dumb Waiter (1918)

Dark Road (1917, C. Miller)

White Rose (1923, D.W. Griffith)

Gambling Wives (1924, D. Henderson)

Cytheria (1924, G. Fitzmaurice)

Wine (1924, L.J. Gasnier)

Love and the Law (1922, W.P. Burt)

Great Impersonation (1921, G. Melford)

Wolf Man (1924, E. Mortimer)

\section{6 (5)}

For Heaven's Sake (1926, S. Taylor)

Love Nest (1923, E.F. Cline/B. Keaton)

The Demidoff (?)

Girl who wouldn't work (1925, M. De Sano)

Painted Lady (1924, C. Bennett) 


\section{Anhang III}

\section{Auszug aus der Liste der für das Monopolgebiet Ägypten, Sy- rien und Palästina ausgewählten Filme; Anhang zum Vertrag der UFA mit der Mamatis \& Co.IAlliance Cinematographique Egyp- tienne (Alexandria) vom 11.10.1929 ${ }^{203}$}

Quelle: Bundesarchiv Berlin, R/109/I, 5430, pp. 518-520

\begin{tabular}{|c|c|c|c|}
\hline & Deutscher Originalitel & Englischer Verleihtitel & Französischer Verleihtitel \\
\hline & \multicolumn{3}{|c|}{ Produktionsjahr 1928/29 } \\
\hline 1 & Looping the Loop * & Looping the Loop & Looping the Loop \\
\hline 2 & Ungarische Rhapsodie * & Hungarian Rhapsodie & Rhapsodié hongoroise \\
\hline 3 & Heimkehr * & Homecoming & Chant de Prisonnier \\
\hline 4 & Asphalt * & Temptation & Asphalte \\
\hline 5 & $\begin{array}{l}\text { Die wunderbare Lüge der Nina } \\
\text { Petrowna * }\end{array}$ & The wonderful Lie & $\begin{array}{l}\text { Le douloureux messonge de } \\
\text { Nina Petrowna }\end{array}$ \\
\hline 6 & Das Girl von der Revue & Girl from the Revue & Kitty Comtesse \\
\hline 7 & Vom Täter fehlt jede Spur & Under Suspicion & Aucune trace du criminel \\
\hline 8 & Mann gegen Mann * & For Men only & Corps à corps \\
\hline 9 & Seine stärkste Waffe & Nerve & Sa plus forte arme \\
\hline 10 & Die Carmen von St. Pauli * & Water Rat & Carmen de St. Pauli \\
\hline 11 & Die Yacht der sieben Sünden * & The Yacht of seven Sins & Yought des sept péchés \\
\hline 12 & Die Dame mit der Maske & The Lady with the Mask & La dame au masque \\
\hline 13 & Der Tanzstudent & Because I love you & Etudiant danseur \\
\hline 14 & Die blaue Maus * & The blue Mouse & La sourie bleu \\
\hline 15 & Ihr dunkler Punkt & Her dark Spot & Son grain de beauté \\
\hline 16 & Skandal in Baden-Baden * & A Society Scandal & Le scandale der Beden-Baden \\
\hline 17 & Grabmahl einer großen Liebe & Shiraz & Chant Hindu \\
\hline \multirow[t]{2}{*}{18} & Hurra ich lebe & Hurra I am alive & Vive la vie \\
\hline & \multicolumn{3}{|c|}{ Produktionsjahr 1927/28 } \\
\hline 19 & Schuldig & Guilty & Coupable \\
\hline 20 & Die geheime Macht & Secret Power & Puissance secrète \\
\hline 21 & Der große Sprung & - & - \\
\hline 22 & Fürst von Pappenheim & Duke of Pappenheim & Ce coquin du printemps \\
\hline 23 & Gustav Mond, du gehst so stille & A temporary Husband & \\
\hline 24 & Herkules Meyer & - & - \\
\hline 25 & Milak der Grönlandjäger & The great Unknown & Le chasseur groenlandais \\
\hline 26 & Natur und Liebe & Nature and Love & Nature créatrice \\
\hline 27 & Panik & Panic (Trixt men a beast) & Panique \\
\hline
\end{tabular}

203 Die sowohl in dieser, als auch der Liste der „S-Filme“ verzeichneten Produktionen sind durch Fettdruck hervorgehoben bzw. mit einem * versehen. 


\begin{tabular}{|c|c|c|c|}
\hline 28 & Spione * & Spies & Les Espion \\
\hline & \multicolumn{3}{|c|}{ Alte Produktionen } \\
\hline 29 & Der Heilige Berg & The wrath of the Gods & La montagne sacrée \\
\hline 30 & Der Juxbaron & - & Baron Vadronille \\
\hline 31 & Amazonas & - & - \\
\hline 32 & Tartuffe & The Hipocrit & Tratuffe \\
\hline 33 & Drei Kuckucksuhren & Adventure made & Les trois coucoux \\
\hline 34 & Zum Schneegipfel Afrikas & - & - \\
\hline 35 & Wunderwelt des blauen Golfs & - & - \\
\hline \multirow[t]{21}{*}{36} & Tierwelt im Urwald & - & - \\
\hline & \multicolumn{3}{|c|}{ Unverbindliche Liste der für Ägypten, Syrien und Palästina freien Filme } \\
\hline & \multicolumn{3}{|c|}{ Produktionsjahr 1928/29 } \\
\hline & Lotte & - & - \\
\hline & Zuflucht & Refuge & - \\
\hline & \multicolumn{3}{|c|}{ Produktionsjahr 1927/28 } \\
\hline & Am Rande der Welt * & At the Edge of the World & - \\
\hline & Seine seelige Exzellenz & Secrets of his late Excellency & - \\
\hline & Die Liebe der Jeanny Ney * & The Loves of Jeanny Ney & L' amour de Jeanne Ney \\
\hline & Kampf des Donald Westhoff * & The Trail of Donald Westhoff & - \\
\hline & Familientag im Hause Prellstein & Prellsteins Family & - \\
\hline & Grand Hotel & Hotel Boulevard & - \\
\hline & Jugendrausch * & Nemesis & - \\
\hline & Himmel auf Erden & Heaven on Earth & - \\
\hline & Üb' immer Treu und Redlichkeit & & - \\
\hline & Dr. Monnier und die Frauen & The Doctor's Women & - \\
\hline & Die große Pause & - & - \\
\hline & Liebe und Diebe & Loves and Thieves & - \\
\hline & Weltkrieg I. und II. & Behind the German Lines & - \\
\hline & Die erwachende Sphinx & - & - \\
\hline & \multicolumn{3}{|c|}{ Für die Jahre 1925-1927 verzeichnet die Liste noch weitere 33 Filme. } \\
\hline
\end{tabular}




\section{Anhang IV}

Um den im Text erwähnten Inhalt der Filme nebst deren Besprechungen nachvollziehbar zu machen, versammelt die folgende Tabelle die Grunddaten der Filme sowie eine kurze Inhaltsangabe. Zu diesem Zweck wurde bis auf eine Ausnahme (MÄDCHEN IN UNIFORM) durchgängig auf die zeitgenössischen Kurzkritiken aus Paimann's Filmlisten-PFL (Wien) zurückgegriffen. Trotz der zuweilen vorkommenden Austriazismen und dem aus heutiger Sicht ungewohnten Duktus der Wiener Filmkritik der 1920er Jahre, ermöglichen diese vor allem für die Kinobesitzer gedachten Zusammenfassungen eine strikt inhaltlich-funktionale Sicht auf die erwähnten Filme. Dadurch soll das Problem der bereits Bewertungen enthaltenden zeitgenössischen Filmberichterstattung der politischen Tendenzpresse umgangen werden. Ein weiterer Vorteil dieser Kurzrezensionen besteht darin, dass sie einen externen Blick (aus Österreich) auf die deutsche Filmproduktion ermöglichen und somit aus der Sicht des Auslands national oder politisch bedenkliche Motive möglicherweise eher benannt wurden. ${ }^{204}$

Den Inhaltsbeschreibungen folgt eine standardisierte Bewertung mit abschließendem Qualitätsprädikat (,Gesamtqualifikation'). Zu dessen Operationalisierung wurde dem Prädikat ein Zahlenwert zugeordnet, welcher der Inhaltsbeschreibung vorangeht:

1: Schlager; 2: fast ein Schlager; 3: stark über dem Durchschnitt; 4: über dem Durchschnitt; 5: guter Mittelfilm; 6: passabler Mittelfilm; 7: unter dem Durchschnitt; 0: ohne Qualitätsbezeichnung.

Die Bewertung erwähnt stichwortartige Einschätzungen zu Sujet, Handlung, Regie, schauspielerischer Leistung, Inszenierung, Darstellung, Photographie etc. Der Umstellung vom Stumm- auf den Tonfilm rechnung tragend, wurden bei Tonfilmen Bewertungen zu Dialogen, Musik, Geräuschen etc. beigefügt. Eine systematisch-abgrenzende Genrezuordnung wurde nicht vollzogen, allerdings wurde eine genreähnliche Kategorisierung vorgenommen und am Anfang der Inhaltsbeschreibung wiedergegeben. Zur Operationalisierung dieser Kategorien kann man vier große Gruppen unterscheiden, was an anderer Stelle bereits thematisiert wurde (Kap. IV). Demnach könnte man beispielsweise die Filme den Oberbegriffen ernst (z.B. Familiendrama, Tragödie), heiter (z.B. Kriminalkomödie, Filmschwank), indifferent (z.B. Lebensbild, Filmspiel) und historisch (z.B. Kulturfilm, biographisches Film-

${ }^{204}$ Filme mit thematischem Bezug zum Österreich der Habsburger oder Wien wurden hingegen durchgängig recht wohlwollend beurteilt. 
werk) zuordnen. Der guten inhaltlichen Binnendifferenzierung steht jedoch ein nicht unerhebliches systematisches Abgrenzungsproblem gegenüber, da die Kriterien der genreähnlichen Kategorisierung nur schwer nachvollziehbar sind. Aus diesem Grunde können die erwähnten Schlagworte allenfalls eine erste Orientierung bieten.

Die Filme wurden desweiteren den in Südafrika tätigen Filmverleihen Kinemas (K), African Films bwz. Theatres $(A)$ und den unabhängigen Vertrieben $(U)$ zugeordnet, zudem wurden alle Angaben mittels der einschlägigen Standardliteratur auf ihre Korrektheit geprüft (B: Bauer 1950; Lamprecht 1969ff., Abk. L1 \& L2) und nötigenfalls mit den entsprechenden Archivdokumenten abgeglichen. ${ }^{205}$ Die Daten der Uraufführung (UA) beziehen sich in der Regel auf die Premiere in Deutschland. Nur wenn sich in der Sekundärliteratur keine exakten Daten finden ließen, wurde in der Internet Movie Database (www.imdb.de) oder unter www.filmportal.de recherchiert. Das Datum und die Quelle des in Südafrika gefundenen Erstbeleges sind unter SA angegeben, der Materialindikator (MI) weist auf die Anzahl der gefundenen Rezeptionsdokumente hin. Zusätzlich wurden die Fundstellen in der maßgeblichen südafrikanischen Sekundärliteratur (HR: Rompel 1942a; TG: Gutsche 1972) angegeben.

Die für Deutschland bzw. Südafrika angeführten Titel gelten auch für alle deutschsprachigen (D) bzw. alle englischsprachigen (E) Gebiete in denen die Filme gezeigt wurden, zusätzliche Verleihtitel oder Arbeitstitel sind ebenfalls angegeben. Die in den Originalbesprechungen häufig vorkommenden Druckfehler wurden stillschweigend korrigiert, Hervorhebungen beibehalten und vereinheitlicht. ${ }^{206}$

Tab. 53: Gesamtqualifikation der „S-Filme“ Südafrika nach Paimann's Filmlisten

\begin{tabular}{|c|c|c|c|c|c|c|c|}
\hline $\begin{array}{c}1: \\
\text { Schlager }\end{array}$ & $\begin{array}{c}2: \\
\text { fast ein } \\
\text { Schlager }\end{array}$ & $\begin{array}{c}3: \\
\text { stark über d. } \\
\text { Durchschnitt }\end{array}$ & $\begin{array}{c}4: \\
\text { über dem } \\
\text { Durchschnitt }\end{array}$ & $\begin{array}{c}5: \\
\text { guter } \\
\text { Mittelfilm }\end{array}$ & $\begin{array}{c}6: \\
\text { passabler } \\
\text { Mittelfilm }\end{array}$ & $\begin{array}{c}\text { 7: } \\
\text { unter dem } \\
\text { Durchschnitt }\end{array}$ & $\begin{array}{c}0: \\
\text { ohne } \\
\text { Prädikat }\end{array}$ \\
\hline 14 & 9 & 2 & 14 & 4 & 1 & 0 & 5 \\
\hline Total & $49 / 50$ & \multicolumn{7}{|r}{} \\
\hline
\end{tabular}

${ }^{205}$ Vgl. Vertrag vom 10.10.1929 zwischen der UFA und der Mamatis \& Co./Alliance Cinematographique Egyptienne, Alexandria; Anhang: unverbindliche Liste der für Ägypten, Syrien und Palästina freien Filme; in: BArch, R/109/I, 5430, pp. 508-520.

${ }^{206}$ Die variierenden Quellenangaben der PFL (mit bzw. ohne Jahrgangs- und Heftzählung) gehen auf deren unterschiedliche bibliographische Erschließung zurück. Wenn vorhanden, wurden zur besseren Nachprüfbarkeit die Angaben zum Jahrgang und die Nummer des Einzelheftes vermerkt. 
Tab. 54: Stammdaten und Kurzbeschreibung aus Paimann's Filmlisten, sowie ergänzende Angaben

\begin{tabular}{|c|c|}
\hline Titel (D/SA/Verleihtitel) & Inhalt/Kurzkritik \\
\hline & VERTRIEB: KINEMAS (K) \\
\hline $\begin{array}{l}\text { Der blaue Engel, } 1929 / 30 \\
\text { SA: THE BLUE ANGEL (K) } \\
\text { MI: } 48 \\
\text { BELEGE } \\
\text { UA : } 1.4 .30 \\
\text { SA : } 16.01 .31 \text { CT } \\
\text { B : } 14 \\
\text { TG : } 224\end{array}$ & $\begin{array}{l}\text { 1: Sittendrama (Ton-, Geräusch- und [deutscher] Dialogfilm) nach } \\
\text { Motiven des Romans „Professor Unrat “ von Heinrich Mann, mit Emil } \\
\text { Jannings, Kurt Gerron, Hans Albers, Eduard von Winterstein, Rolf } \\
\text { Müller, Karl Huszar-Puffy, Wilhelm Diegelmann, Marlene Dietrich, Rosa } \\
\text { Valetti. Regie: Josef v. Sternberg. Manuskript: Karl Zuckmayer und Karl } \\
\text { Vollmöller. Musik: Friedrich Holländer. - Die nächtlichen Ausflüge seiner } \\
\text { Schüler bringen den Gymnasialprofessor Rat mit einer obskuren Varieté- } \\
\text { sängerin in Berührung, die er in seiner Einfalt heiratet. An ihrer Seite zum } \\
\text { Clown degradiert, erleidet er einen Wahnsinnsanfall und stirbt, nachdem } \\
\text { er des Nachts ins Gymnasium eingedrungen, auf dem Katheder. - } \\
\text { Heinrich Mann's Buch hat nur die Grundzüge der bis ins kleinste Detail } \\
\text { lebenswahren Handlung geliefert, welche nach der Mitte (Rat's Ehe- } \\
\text { schließung) etwas abflaut und erst gegen Ende (Wahnsinn und Tod) die } \\
\text { frühere Höhe erreicht. Dies trotz strenger Kontinuität der Regie, welche } \\
\text { das Ensemble ausgezeichnet führt und Jannings in Mimik und Dialog } \\
\text { gleich großer Leistung eine würdige Ergänzung schafft. Fest ebenbürtig } \\
\text { steht ihm die Dietrich gegenüber, deren Rollenauffassung sich in bewun- } \\
\text { dernswerter Weise mit der zu verkörpernden Gestalt deckt, wenn man } \\
\text { sie auch stellenweise neben spezifisch norddeutschen Redewendungen } \\
\text { infolge zu schnellen Sprechens weniger gut versteht. Der maßvoll } \\
\text { angewendete Dialog fällt niemals aus dem Rahmen; wo die stumme } \\
\text { Szene wirkunsgvoller, verzichtet man wohlweislich auf ihn. Der Kompo- } \\
\text { nist liefert neben einer Volksliedvariation als Motiv lediglich zwei oder } \\
\text { drei, das meisterhaft gezeichnete Milieu wirkungsvoll charakterisierende, } \\
\text { Lieder; die Tonkulissen erfüllen durchgehends ihren Zweck. Auch } \\
\text { Architekt und Kameramann werden den Intentionen der Autoren gerecht. } \\
\text { Die Wiedergabe ist einwandfrei. - Gesamtqualifikation: Schlager [PFL } \\
\text { 1930: 62]. }\end{array}$ \\
\hline $\begin{array}{l}\text { Spione, } 1928 \\
\text { SA: The Spy (K) } \\
\text { Spies (E) } \\
\text { MI: } 18 \\
\text { BELEGE } \\
\text { UA : } 22.3 .28 \\
\text { SA }: 1.2 .29 \text { DB } \\
\text { L2 }: 448 \\
\text { TG }: 217 \\
\text { HR }: 107\end{array}$ & $\begin{array}{l}\text { 1: Kriminaldrama nach dem Roman von Thea v. Harbou mit Willy Fritsch, } \\
\text { Rudolf Klein-Rogge, Louis Ralph, Paul Hörbiger, Lupu Pick, Fritz Rasp, } \\
\text { Gerda Maurus, Lien Deyers. Regie: Fritz Lang. - Ein Bankier hat noch } \\
\text { andere einträglichere Geschäfte. Unter seinem Geschäftshause befindet } \\
\text { sich eine Spionagezentrale, raffiniert organisiert, mit vor keiner Gewalt- } \\
\text { tat zurückschreckenden Agenten, deren Verbinungen sogar bis in die } \\
\text { Büros der Kriminalpolizei reichen. Diese setzt ihre letzte Hoffnung auf } \\
\text { einen jungen Beamten, der dem geheimnisvollen Verbrecher auch bei } \\
\text { einem weiblichen Mitgliede des Spionagebüros ein Rivale ist. Um den } \\
\text { jungen Mann vor der Rache ihres Chefs zu retten, will sie die Photogra- } \\
\text { phie eines mit Japan abgeschlossenen Geheimvertrages, dessen Dieb- } \\
\text { stahl den Gesandten dieser Macht zum Selbstmorde getrieben, ins } \\
\text { Ausland schaffen. Als der Verbrecher aber nichtsdestoweniger einen } \\
\text { Anschlag auf ihren Geliebten ausführen läßt, verrät sie ihn. Das Verbre- } \\
\text { chernest wird ausgehoben, sie selbst in letzter Stunde aus dem, von den } \\
\text { Flüchtenden unter Gas gesetzten Gebäude gerettet. - Fritz Lang hat } \\
\text { keinen monumentalen, wohl aber einen ungeheuer spannenden Film } \\
\text { geschaffen. Dies wiegt mehr: es ist ihm gelungen, das Sekundäre dem } \\
\text { Primären unterzuordnen. Die im Verhältnis zur Gesamtlänge des Films } \\
\text { eigentlich kleine Haupthandlung wird durch eine Fülle von Details } \\
\text { weitergebracht, welche ein rasendes Tempo und dementsprechenden } \\
\text { Schnitt verlangen. Dieser erfordert beim Zuschauer gespannteste } \\
\text { Aufmerksamkeit, aber nicht mehr. Unklar oder verworren ist nichts. In } \\
\text { den Hauptrollen debutieren zwei weibliche Darstellerinnen sehr glücklich, } \\
\text { Fritsch zeigt sich von einer neuen Seite, Rogge ist besser als in seinen } \\
\text { letzten Filmen. Auch die kleinste Charge ist mit ersten Kräften besetzt. } \\
\text { Die Aufmachung ist großzügig, ohne in Überdimensioniertheit zu erstar- } \\
\text { ren, die Photographie seltener Güte. - Gesamtqualifikation: ein Schlager } \\
\text { [PFL 1928: 68]. 20.4.28: 68 }\end{array}$ \\
\hline $\begin{array}{l}\text { Heimkehr, } 1928 \\
\text { SA: Homecoming (K) }\end{array}$ & $\begin{array}{l}\text { 1: Kammerspiel nach der Novelle "Karl und Anna" von Leonhard Frank, } \\
\text { mit Lars Hanson, Gustav Fröhlich, Dita Parlo. Regie: Joe May. - Zwei }\end{array}$ \\
\hline
\end{tabular}




\begin{tabular}{|c|c|}
\hline $\begin{array}{l}\text { KETTEN (D) } \\
\text { MI: } 18 \\
\text { BELEGE } \\
\text { UA : } 29.8 .28 \\
\text { SA : } 08.02 .29 \text { NA } \\
\text { L2 }: 337 \\
\text { HR }: 100\end{array}$ & $\begin{array}{l}\text { deutsche Soldaten, - Richard verheiratet, Karl ledig, - haben in russischer } \\
\text { Gefangenschaft so viel von ihrer Heimat gesprochen, daß Karl die } \\
\text { Wohnung des Freundes und dessen Frau besser kennt ohne sie jemals } \\
\text { gesehen zu haben. Als ihm später die Flucht gelingt und er nach endloser } \\
\text { Wanderung in die Heimat zurückkehrt, führt dieser Umstand zu einer } \\
\text { eigentlich ungewollten Vertraulichkeit zwischen Karl und Richard's Anna, } \\
\text { die die junge Frau schließlich später erfolgende Heimkehr ihres Mannes } \\
\text { bedauern läßt. Dieser verzichtet darauf, eine Frau an sich zu ketten, die } \\
\text { ihn nicht mehr liebt, überläßt sie seinem Freunde und geht zur See. - } \\
\text { Nach einer, trotz ihrer Unerläßlichkeit für das Verständnis des späteren } \\
\text { Konfliktes etwas ausgedehnten Exposition wird dieser nach streng } \\
\text { dramatischen Gesetzen unter Verzicht auf allzu moderne Regieschikanen } \\
\text { in kontinuierlichen, wenn auch sehr lang ausgespielten Szenenfolgen } \\
\text { packend entwickelt. Das meisterhaft gezeichnete Milieu unterstreicht, } \\
\text { gerade infolge seiner Gleichförmigkeit, die Vorgänge wirkungsvoll. } \\
\text { Darstellerisch ist Lars Hanson's Richard eine Meisterleistung, der Karl } \\
\text { Gustav Fröhlich's ist inm durchaus ebenbürtig. Dita Parlo, eine Novize, } \\
\text { der Joe May die Rolle der Anna anzuvertrauen gewagt, wird, wenn auch } \\
\text { in den ersten Szenen ihres Auftretens rein äußerlich mit der zu verkör- } \\
\text { pernden Gestalt nicht kongruent, den Anforderungen gerecht und läßt } \\
\text { angenehme Perspektiven auf ihr weiteres Wirken zu. Die Photographie } \\
\text { ist vorbildlich. - Gesamtqualifikation: Ein Schlager [PFL 1928: 163-164]. }\end{array}$ \\
\hline $\begin{array}{l}\text { Asphalt, } 1929 \\
\text { SA: Temptation (K) } \\
\text { Der Polizeiwachtmeister und } \\
\text { die Diamantenelse (D); } \\
\text { Temptation (E) } \\
\text { MI: } 16 \\
\text { BELEGE } \\
\text { UA : } 12.3 .29 \\
\text { SA : } 16.10 .29 \text { CT } \\
\text { L2: } 486 \\
\text { HR }: 32\end{array}$ & $\begin{array}{l}\text { 2: Sittenbild mit Gustav Fröhlich, Albert Steinrück, Hans Adalbert } \\
\text { Schlettow, Betty Amann, Else Heller. Regie: Joe May. - Der Schupo- } \\
\text { Hauptwachtmeister ist im Dienste grau geworden, sein Sohn, ebenfalls } \\
\text { Wachtmeister, ein pflichtgetreuer Beamter. Eines Tages arretiert er eine } \\
\text { elegante Juwelendiebin, die ihn unter einem Vorwande in ihre Wohnung } \\
\text { lockt und ihn zu einem Schäferstündchen verleitet, worauf er sie entwi- } \\
\text { schen läßt. Als er tags darauf dorthin zurückkehrt um ein Präsent des } \\
\text { Mädchens zurückzugeben, trifft er mit ihrem Geliebten zusammen und } \\
\text { erschlägt ihn. Der Vater Hauptwachtmeister führt den Sohn nach dessen } \\
\text { Geständnis zur Polizei, wo bald zu aller Erstaunen die Diebin erscheint, } \\
\text { alles gesteht und aussagt, daß der Todschlag in Notwehr erfolgte. Der } \\
\text { junge Schupomann wird auf freien Fuß gesetzt, das Mädchen zwar in } \\
\text { Haft genommen, doch steht eine spätere Vereinigung der beiden in } \\
\text { Aussicht. - Der Titel steht zu der Handlung in etwas losem Zusammen- } \\
\text { hange. Sie ist nicht mit dem Milieu verwachsen, wie man es erwartet } \\
\text { hätte; ihr recht unvermittelter Schluß fällt etwas ab. Trotzdem ist es den } \\
\text { Buchverfassern wie nur bei wenigen Filmen gelungen, eine verhältnismä- } \\
\text { Big spärliche Idee so plastisch zu gestalten, daß die Spannung von der } \\
\text { ersten bis zur letzten Szene erhalten bleibt, einige Höhepunkte starke } \\
\text { Wirkungen auslösen. Dies ist zum großen Teil der Regie zu danken, } \\
\text { welche neben unbedingter Kontinuität in Einstellungen und Montage } \\
\text { Ausgezeichnetes leistet und das bis in die kleinsten Rollen aus Könnern } \\
\text { bestehende Ensemble virtuos führt. Fröhlich (Wachtmeister) war noch } \\
\text { nie so gut. Seine Partnerin Betty Amann spielt für eine Debütantin sehr } \\
\text { brav, das Elternpaar Steinrück-Heller bietet eine Kabinett-Leistung. } \\
\text { Auch Aufmachung und Photographie halten sich auf der Höhe des } \\
\text { Vorerwähnten. - Gesamtqualifikation: Fast ein Schlager [PFL } \\
\text { 14(1929)676, 35-36]. }\end{array}$ \\
\hline $\begin{array}{l}\text { Liebeswalzer, } 1930 \\
\text { SA: The Love Waltz (K) } \\
\text { Der Chauffeur-Prinz (D) } \\
\text { MI: } 14 \\
\text { BELEGE } \\
\text { UA : } 7.11 .30 \\
\text { SA : } 16.05 .31 \text { NA } \\
\text { B : } 33 \\
\text { TG : } 220\end{array}$ & $\begin{array}{l}\text { 2: Tonfilmoperette (Ton-, Geräusch-, Gesang- und (deutscher) Dialog- } \\
\text { film) mit Lilian Harvey, Julie Serda, Willy Fritsch, Georg Alexander, } \\
\text { Hans Junkermann, Viktor Schwannecke, Karl Ettlinger, Karl Ludwig } \\
\text { Diehl. Regie: Wilhelm Thiele. Musik: Werner R. Heymann. - Eine } \\
\text { Prinzessin soll mit einem Erzherzog verlobt werden. Dieser schickt seinen } \\
\text { Sekretär an seiner Stelle. Die Prinzessin verliebt sich prompt in den } \\
\text { Stellvertreter, der aber vor der Proklamation der Verlobung die Mystifi- } \\
\text { kation eingesteht. Da der Sekretär jedoch Sohn eines amerikanischen } \\
\text { Autokönigs und das Ländchen kapitalschwach, kommt es doch zu einem } \\
\text { "happy end“. - Dem Stil der Filmoperette ist man hier, sich der Stärke- } \\
\text { ren beider Kunstgattungen zu Nutze machend, am nächsten gekommen. } \\
\text { Durch den Schmiß und die Sentimentalität von sehr hörenswerten } \\
\text { Schlagerliedern gegebene Operettenstimmung in Verbindung mit dem }\end{array}$ \\
\hline
\end{tabular}




\begin{tabular}{|c|c|}
\hline & $\begin{array}{l}\text { regietechnischen und optischen Möglichkeiten des Films, durch fließende } \\
\text { pointenreichen Dialog verbunden, schafft dem, in Musik und Sprache } \\
\text { gleich guten Ensemble eine dankbare Atmosphäre. Die einige durch } \\
\text { Geräuscheffekte charakterisierte wie auch Dialogszenen untermalende, } \\
\text { Begleitmusik ist ansprechend, sehr großzügig die Aufmachung, die } \\
\text { Photographie meist auf der Höhe. Die Wiedergabe ist, von stellenweiser } \\
\text { Unreinheit des Tones abgesehen, einwandfrei. - Gesamtqualifikation: } \\
\text { Fast eine Schlager [PFL 1930: 40]. }\end{array}$ \\
\hline $\begin{array}{l}\text { Die Apachen von Paris, } 1927 \\
\text { SA: Apaches of Paris (K) } \\
\text { Der Apachenlord (D); Apaches } \\
\text { of Paris (E) } 207 \\
\text { MI: } 13 \\
\text { BELEGE } \\
\text { UA : } 19.12 .27 \\
\text { SA : } 27.4 .29 \text { DB } \\
\text { L2: } 13\end{array}$ & $\begin{array}{l}\text { 5: Abenteuerdrama nach dem Roman "Les innocents" von Francis } \\
\text { Carco, mit Jacques Catelain, Charles Vanél, Nicolai Malikoff, Jakob } \\
\text { Tiedtke, Lia Eibenschütz, Ruth Weyher, Olga Limburg. Regie: Nicolai } \\
\text { Malikoff. - Eine prüde Amerikanerin kommt mit Mann und Tochter nach } \\
\text { Paris, um die Europäer vor Alkohol und Sinnlichkeit zu retten, fällt aber } \\
\text { einer Apachenbande in die Hände, die sie ausplündern will, vor welchem } \\
\text { Schicksal die Fremden nur durch den Umstand gerettet werden, daß sich } \\
\text { ein Mitglied der Bande in die Tochter der Familie verliebt und sie schließ- } \\
\text { lich heiratet, die Gefährten und die zugehörige Geliebte im Stiche } \\
\text { lassend. Eine Seele ist wenigstens gerettet ... - Das Sujet ist bis auf } \\
\text { seine bedeutenden Längen in der ersten Hälfte des Films - wo herzhafte } \\
\text { Schnitte am Platze wären - eine ansprechende Variation eines sattsam } \\
\text { bekannten Kaschemmen-Themas, die Darstellung fast durchgehend gut, } \\
\text { auch die Aufmachung sorgfältig. Die Regie hält sich in den Milieuzeich- } \\
\text { nungen von Übertreibungen fern, die Photographie ist ungleich, aber } \\
\text { befriedigend. Gesamtqualifikation: guter Mittelfilm [PFL 1928: 20-21]. }\end{array}$ \\
\hline $\begin{array}{l}\text { Die Todesschleife, } 1928 \\
\text { SA: Looping the Loop (K) } \\
\text { Der Sprung (D) } \\
\text { MI: } 13 \\
\text { BELEGE } \\
\text { UA : } 15.9 .28 \\
\text { SA : } 14.5 .29 \text { CT } \\
\text { L2: } 384 \\
\text { HR : } 99\end{array}$ & $\begin{array}{l}\text { 3: Zirkusdrama mit Werner Krauß, Warwick Ward, Siegfried Arno, Julius } \\
\text { von Szöreghy, Jenny Jugo, Gina Manès. Regie: Arthur Robison. - Ein } \\
\text { junges Mädchen verlobt sich, von einem Akrobaten betrogen, mit dem } \\
\text { Clown des Zirkusses, der ihr, eingedenk der unglücklichen Liebesaffairen } \\
\text { seiner Kollegen, seinen Beruf verschweigt. Bald aber zerstreitet sie sich } \\
\text { trotzdem mit ihm, folgt dem Akrobaten als Partnerin ins Ausland, wo sie } \\
\text { der Clown, in dem sie den Verehrer nicht erkennt, vor dessen Zudring- } \\
\text { lichkeit schützt und sich ihm erst nach einer mißlungenen Sensations- } \\
\text { nummer zu erkennen gibt. Nun hat sie inn lieben gelernt ... - Die typische } \\
\text { Zirkusgeschichte mit dem Bajazzomotiv kombiniert, in gefälliger Variation } \\
\text { flüssig gearbeitet. Daß dieses Sujet keine volle Wirkung erzielt, mag an } \\
\text { der spärlichen mimischen Ausdrucksfähigkeit der sehr hübschen Jenny } \\
\text { Jugo (Das Mädchen) liegen, welche die ausgezeichnete Leistung Werner } \\
\text { Krauß' (Der Clown), der hier, frei von der in letzter Zeit bei ihm aufgetre- } \\
\text { tenen Maniriertheit, einen Menschen von Fleisch und Blut geschaffen, } \\
\text { nicht ergänzt. Dafür entschädigen reichlich originelle und gut gesehene } \\
\text { Bilder aus der Welt des Zirkusses, eine reibungslose Regieführung und } \\
\text { die ausgezeichnete Photographie. - Gesamtqualifikation: Stark über dem } \\
\text { Durchschnitt [PFL 14.1.1929: 2]. }\end{array}$ \\
\hline $\begin{array}{l}\text { Am Rande der Welt, } 1927 \\
\text { SA: At the Edge of the World } \\
\text { (K) } \\
\text { MI: } 12 \\
\text { BELEGE } \\
\text { UA : } 19.9 .27 \\
\text { SA : } 25.3 .29 \text { DFA } \\
\text { L2: } 9\end{array}$ & $\begin{array}{l}\text { 4: Kriegsdrama mit Albert Steinrück, Wilhelm Dieterle, Imre Raday, } \\
\text { Viktor Jasson, Jean Bradin, Max Schreck, Brigitte Helm, Camilla Holley. } \\
\text { Regie: Karl Grune. - Eine an der Grenze gelegene Windmühle wird } \\
\text { vorerst von feindlichen Truppen zur Versorgung ihres Heeres herangezo- } \\
\text { gen, später aus strategischen Rücksichten niedergebrannt. Der Sohn des } \\
\text { Besitzers, den man verhaftet, wird von einem feindlichen Offizier um } \\
\text { seiner Schwester Willen befreit und entkommt, während ein Spion, um } \\
\text { den Verdacht nicht auf den Offizier zu lenken, selbst seine Schuld } \\
\text { gesteht und erschossen wird. - Es sei vor allem konstatiert, daß dieser } \\
\text { Film sorgfältige Regiearbeit aufweist. Grune gibt sich aber in den ersten } \\
\text { Akten zuviel mit der Zeichnung des Milieus, später mit Details, ausge- } \\
\text { dehnten Einstellungen und sonstigem Beiwerk ab, so daß dieses schließ- } \\
\text { lich oft die Handlung überwuchert und sich als Länge auswirkt. Sehr gut } \\
\text { ist die Darstellung, desgleichen auch die Photographie, sorgfältig } \\
\text { gearbeitet die im Atelier gestellten Landschaftsbilder [PFL 1927: 68]. }\end{array}$ \\
\hline $\begin{array}{l}\text { Die Carmen von St. Pauli, } \\
1928\end{array}$ & $\begin{array}{l}\text { 5: Abenteuerdrama mit Willy Fritsch, Fritz Rasp, Max Maximilian, Fritz } \\
\text { Alberti, Wolfgang Zilzer, Otto Kronburger, Jenny Jugo, Betty Astor. }\end{array}$ \\
\hline
\end{tabular}

207 Nicht zu verwechseln mit „Underworld“ oder „Apachen“, alternative Titel: „Moderne Apachen“/ "Unterwelt“ (D), „Paying the Penalty“ (UK), Regie: Joseph von Sternberg (1927). 


\begin{tabular}{|c|c|}
\hline $\begin{array}{l}\text { SA: The Water Rat (K) } \\
\text { Gestrandet (D) } \\
\text { MI: } 12 \\
\text { BELEGE } \\
\text { UA: } 10.10 .28 \\
\text { SA : } 10.8 .29 \text { NM } \\
\text { L2 : } 265 \\
\text { HR: } 100\end{array}$ & $\begin{array}{l}\text { Regie: Erich Waschnek. - Ein Steuermann wird durch ein Mädchen, } \\
\text { welches in einer Hafenkneipe tanzt und mit den Schmugglern arbeitet, } \\
\text { zur Vernachlässigung seines Dienstes verleitet. Entlassen, sinkt er immer } \\
\text { tiefer und wird beinahe zum Verbrecher. Er gerät in den Verdacht, einen } \\
\text { Mann niedergeschlagen zu haben, wird aber später durch die Selbststel- } \\
\text { lung des wirklichen Täters entlastet. Er und das Mädchen beginnen ein } \\
\text { neues Leben. - Das einfache unkomplizierte Sujet interessiert mäßig } \\
\text { ohne stärkere Wirkung auszulösen, woran das nicht sonderlich orginell } \\
\text { gezeichnete Milieu Anteil hat. Die Darstellung ist durchgehends befriedi- } \\
\text { gend, Fritsch spielt sehr brav, die Jugo sieht gut aus. Die Regieführung } \\
\text { hätte durch größere Straffheit gewonnen, die Photographie ist entspre- } \\
\text { chend. - Gesamtqualifikation: Guter Mittelfilm [PFL 1928: 147]. }\end{array}$ \\
\hline $\begin{array}{l}\text { Die Jacht der sieben Sünden, } \\
1928 \\
\text { SA: Yacht of Seven Sins (K) } \\
\text { Die Yacht der sieben Sünden, } \\
\text { Die Yacht Yoshiwara (D) } \\
\text { MI: } 7 \\
\text { BELEGE } \\
\text { UA : } 6.8 .28 \\
\text { SA : } 5.10 .29 \text { NM } \\
\text { L2 : } 356\end{array}$ & $\begin{array}{l}\text { 5: Kriminaldrama nach dem Zeitungsroman von Paul Rosenhayn, mit } \\
\text { Rina Marsa, Brigitte Helm, John Stuart, Hugo Werner-Kahle, Curt } \\
\text { Vespermann, Alfred Gerasch, Kurt Gerron. Regie: J. und L. Fleck. - Ein } \\
\text { Mädchenhändler engagiert für ein, eine Luxusreise antretendes, Schiff } \\
\text { Sängerinnen, Tänzerinnen und Girls. Der Bräutigam einer der Artistinnen, } \\
\text { welcher Verdacht geschöpft, gerät unschuldig in Mordverdacht, was ihn } \\
\text { hindert, die polizeiliche Anzeige zu machen und ihn zwingt, selbst auf } \\
\text { dem Schiff Zuflucht zu suchen. Die Behörden haben aber doch Verdacht } \\
\text { geschöpft; Patrouillenboote halten den Dampfer auf hoher See auf und } \\
\text { nehmen die Mädchenhändlerbande gefangen, auch eine an dem Morde } \\
\text { wirklich schuldige Tänzerin. - Man hat der Durcharbeitung eines zwar } \\
\text { kolportagemäßigen aber nichtsdestoweniger spannenden Sujets nicht die } \\
\text { erforderliche Sorgfalt zugewendet, was zu unlogischen Stellen geführt, } \\
\text { woran auch die etwas sprunghafte Regieführung Anteil haben mag. Die } \\
\text { Darstellung ist im allgemeinen gut, während die Helm im Hinblick auf } \\
\text { frühere Rollen etwas enttäuscht. Sehr sorgfältig hingegen ist die Aufma- } \\
\text { chung, die Photographie sauber. Trotz mancher Fehler immerhin ein } \\
\text { guter Mittelfilm [PFL 1928: 146]. }\end{array}$ \\
\hline $\begin{array}{l}\text { Die Leibeigenen, } 1927 \\
\text { SA: Bondage (K) } \\
\text { Weiße Sklaven, Die Dani- } \\
\text { scheffs (D) } \\
\text { MI: } 6 \\
\text { BELEGE } \\
\text { UA : } 11.1 .28 \\
\text { SA : } 26.5 .29 \text { ST } \\
\text { L2: } 133\end{array}$ & $\begin{array}{l}\text { 4: Russisches Lebensbild (Kostüm) nach dem Roman „Die Danischeffs“ } \\
\text { von Pierre Newsky mit Harry Halm, Heinrich George, Oskar Homolka, } \\
\text { Monna Maris, Jutta Jol, Marie Reishofer. Regie: Richard Eichberg. - Um } \\
1850 \text { auf einem russichen Gute. Der Sohn der gräflichen Besitzerin liebt } \\
\text { ein leibeigenes Mädchen, das erstere zur Heirat mit Einem ihresgleichen } \\
\text { zwingt, was den jungen Grafen an ihre Untreue glauben läßt. Am Abend } \\
\text { der Verlobung mit einer anderen erfährt er die Wahrheit, löst die Verlo- } \\
\text { bung und will den Gatten der Geliebten züchtigen, welche aber dazwi- } \\
\text { schentritt und ihn aufklärt, daß der Mann sie nur geheiratet, um sie ihm } \\
\text { zu bewahren und auf seine Gattenrechte verzichtete. Als man nun die } \\
\text { beiden Leibeigenen nach Sibirien schicken will, opfert der Mann bei } \\
\text { einem Bauernaufstande sein Leben, um seinen Herrn den Weg zu der } \\
\text { jungen Frau freizumachen. - Das Sujet ist ohne künstlerische Ampiratio- } \\
\text { nen publikumswirksam gearbeitet und in der richtigen Dosierung von } \\
\text { sentimentalen und heiteren Momenten kontinuierlich inszeniert. Darstel- } \\
\text { lerisch dominieren George und die Maris, während sich Harry Halm } \\
\text { darauf beschränkt, liebenswürdig zu sein. Stimmungsvolle Naturbilder } \\
\text { unterstreichen die Geschehnisse; die Photographie ist gut. - Gesamtqua- } \\
\text { lifikation: über dem Durchschnitt [PFL 13(1928)624, 39-40]. }\end{array}$ \\
\hline $\begin{array}{l}\text { Ungarische Rhapsodie, } 1928 \\
\text { SA: Hungarian Rhapsody (K) } \\
\text { MI: } 6 \\
\text { BELEGE } \\
\text { UA : } 6.11 .28 \\
\text { SA : } 23.4 .30 \text { CT } \\
\text { L2 : } 457\end{array}$ & $\begin{array}{l}\text { 1: Liebesdrama mit Willy Fritsch, Fritz Greiner, Erich Kaiser-Tietz, Harry } \\
\text { Hardt, Andor Heltai, Dita Parlo, Lil Dagover. Regie: Hans Schwarz. - } \\
1912 \text { in Ungarn ... Ein Honvedleutnant ohne Kaution liebt die Tochter } \\
\text { eines Gutsverwalters, kann sich aber nicht entschließen um ihretwillen } \\
\text { den bunten Rock auszuziehen. Erst als ihm das Mädchen während eines } \\
\text { Schäferstündchens mit der Frau eines Vorgesetzten vor der Entdeckung } \\
\text { durch den Gatten rettet und sich kompromitiert, nimmt er seinen Ab- } \\
\text { schied und will für sie arbeiten. - Noch selten hat ein Titel so treffend ein } \\
\text { Filmsujet unschrieben, waren dessen Konflikte so erdverbunden, ist die } \\
\text { Stimmung einer Landschaft so restlos eingefangen worden. Eine trotz } \\
\text { oder gerade durch ihre Einfachheit packende Handlung wurde mit } \\
\text { Sorgfalt und Treffsicherheit detailreich inszeniert, einem gewählten } \\
\text { Ensemble die Verkörperung ihrer Hauptgestalten anvertraut. Fritsch } \\
\text { spielt den Leutnant ohne Liedtke-Süßlichkeit. Die Parlo macht die }\end{array}$ \\
\hline
\end{tabular}




\begin{tabular}{|c|c|}
\hline & $\begin{array}{l}\text { Unberührtheit ihrer Gutsverwalterstochter glaubhaft, welche in der } \\
\text { Generalsfrau der Dagover eine auf mondän-dämonische Mätzchen } \\
\text { verzichtende Gegenspielerin findet. Landschaftsbilder und Interrieurs in } \\
\text { sorgfältiger, weicher Photographie fügen sich ebenso wie die sparsame, } \\
\text { schlichte Titelsprache dem gegebenen Rahmen ein und unterstreichen } \\
\text { die über dem Ganzen liegende versonnene Stimmung. - Gesamtqualifika- } \\
\text { tion: Ein Schlager [PFL 1928: 188]. }\end{array}$ \\
\hline $\begin{array}{l}\text { Angst - Die schwache Stunde } \\
\text { einer Frau, } 1928 \\
\text { SA: Fear (K) } \\
\text { MI: } 4 \\
\text { BELEGE } \\
\text { UA : } 22.8 .28 \\
\text { SA : } 4.2 .29 \text { RDM } \\
\text { L2 : } 258\end{array}$ & $\begin{array}{l}\text { 4: Ehedrama nach einer Novelle von Stefan Zweig mit Elga Brink, Valery } \\
\text { Boothby, Vivian Gibson, Margit Manstad, Henry Edwards, Gustav } \\
\text { Fröhlich, Bruna Kastner. Regie: Hans Steinhoff. - Die sich vernachlässigt } \\
\text { fühlende Frau eines Advokaten reist allein nach dem Süden, wo sie, ohne } \\
\text { es eigentlich zu wollen, die Geliebte eines Malers wird. Wieder heimge- } \\
\text { kehrt, fürchtet sie für ihr Eheglück und gesteht nach einem Selbstmord- } \\
\text { versuch ihrem Manne alles, der ihr verzeiht. - Das Sujet durchaus } \\
\text { interessant und klar gearbeitet, steigert sich nach anfänglichen Breiten } \\
\text { und wird recht spannend. Die Regie ist erfreulicherweise auf die psycho- } \\
\text { logische Fundierung der Konflikte eingegangen und hat die Schilderung } \\
\text { seelischer Zustände der handelnden Personen geschickt visuell gestaltet. } \\
\text { Dies allerdings vielfach auf Kosten des Tempos. Gespielt wird durchge- } \\
\text { hends sehr gut, wie auch Aufmachung und Photographie Anerkennung } \\
\text { verdienen, letztere besonders hinsichtlich der schönen Landschaftsbilder. } \\
\text { - Ein über dem Durchschnitt stehendes Bild, das sich vornehmlich an } \\
\text { intelligentere Publikumskreise wendet [PFL 1928: 167]. }\end{array}$ \\
\hline $\begin{array}{l}\text { An der schönen blauen Donau } \\
\text { (I), } 1926 \\
\text { SA: The Blue Danube (1.) (K) } \\
\text { MI: } 4 \\
\text { BELEGE } \\
\text { UA : } 26.6 .26 \\
\text { SA : } 30.10 .28 \text { CT } \\
\text { L1 : } 699\end{array}$ & $\begin{array}{l}\text { 1: Ein Wiener Lebensbild mit Lya Mara, Frieda Richard, Olga Engel, } \\
\text { Harry Liedtke, Karl Falkenstein, Hans Junkermann, Albert Paulig, Ernst } \\
\text { Verebes, Robert Leffler, Hans Albers, Karl Platen. Regie: Friedrich } \\
\text { Zelnik. - Ein echter Wiener (wenn auch zum großen Teile in Berlin } \\
\text { gedrehter) Film, der die alte Kaiserstadt und ihre Bewohner so bringt, } \\
\text { wie die in Aller Erinnerung fortleben, mit ihrer goldenen Leichtlebigkeit } \\
\text { und einem Schuß Sentimentalität, ohne aber auch nur in einer einzigen } \\
\text { Szene ins Klischée zu verfallen. Man sieht die kleine Wiener Volkssänge- } \\
\text { rin, die einen frechen Leutnant abfertigt, sich dafür aber in dessen Vetter } \\
\text { verliebt, der der drohenden Mesalliance vorbeugen sollte, schließlich } \\
\text { aber das Mädel selbst um jeden Preis heiraten will. Nun tritt seine } \\
\text { Kaiserliche Hoheit Erzherzog auf die Bildfläche und erreicht bei dem } \\
\text { wütenden Erbonkel die Zustimmung zu dieser Heirat. - Das Filmbuch ist } \\
\text { leichtflüssig, die Regie im Walzertakt arbeitend, die Darstellung in allen } \\
\text { Rollen liebenswürdig, Lya Mara ihren bisherigen Erfolgen einen weiteren } \\
\text { hinzufügend. Die Aufmachung ist recht sauber, mit schönen Außenauf- } \\
\text { nahmen aus unsere Stadt, die Photographie auf der Höhe. Ein ausge- } \\
\text { zeichneter Publikumsfilm, der auch qualitativ nichts zu wünschen übrig } \\
\text { läßt. Oder doch: die zu langen Liedertexte in den ersten Akten, welche } \\
\text { der Gang der Handlung etwas stören, sollten bedeutend gekürzt werden } \\
\text { [PFL 1926: 125]. }\end{array}$ \\
\hline $\begin{array}{l}\text { Das tanzende Wien (An der } \\
\text { schönen blauen Donau (II). } \\
\text { Teil), } 1927 \\
\text { SA: Dancing Vienna (2.)(K) } \\
\text { MI: } 4 \\
\text { BELEGE } \\
\text { UA : } 1.10 .27 \\
\text { SA : } 4.7 .30 \text { CT } \\
\text { L2: } 219\end{array}$ & $\begin{array}{l}\text { 4: Ein sentimental-heiteres Filmspiel mit Lya Mara, Olga Engl, Ben Lyon, } \\
\text { Albert Paulig, Arnold Korff, Alfred Abel, Julius v. Szöreghi, Julius } \\
\text { Falkenstein, Regie: Friedrich Zelnik. - Der verwaiste Komtesse Fritzi } \\
\text { Zirsky, Tochter der Volkssängerin Marie Staudinger und des Grafen } \\
\text { Zirsky, aus „An der schönen blauen Donau“, verliebt sich in ihren Vetter } \\
\text { Jonny, der von seinem in Amerika zu Reichtum gekommenen Vater nach } \\
\text { Wien geschickt worden, um das alte Palais, das an das Zirsky’sche Haus } \\
\text { grenzt wieder instandsetzen zu lassen. Trotz seines Vaters Verbot } \\
\text { verlobt sich Jonny mit der Kusine. Er wird nach Amerika zurückberufen, } \\
\text { durchschaut aber den Plan seines Vaters und kehrt zur Fritzi zurück, } \\
\text { welche nach dem Bruche mit ihren Verwandten Tänzerin geworden. - Lya } \\
\text { Mara ist ein Star und Wiener Lokalstücke sind meistens ein Geschäft ... } \\
\text { Daraus haben sich Autor und Regiesseur viel zugute getan, beinahe zu } \\
\text { viel, daß es fraglich erscheint, ob Mara's glänzendes Spiel, die sehr } \\
\text { hübsche Ausstattung und die zahlreichen unleugbar wirksamen, recht } \\
\text { sentimentalen Situationen im Vereine mit viel Heiterem das Publikum } \\
\text { über die Fadenscheinigkeit und Tempolosigkeit des Sujets, die oft recht } \\
\text { verzeichnete "Wiener Note“ und einige Entgleisungen hinweghelfen } \\
\text { werden. Die Photographie ist gut, Also: qualitativ höchstens „über dem }\end{array}$ \\
\hline
\end{tabular}




\begin{tabular}{|c|c|}
\hline & $\begin{array}{l}\text { Durchschnitt", wenn die Spekulation auf das Vorerwähnte gelingt, } \\
\text { geschäftlich vielleicht mehr [PFL 1928: 36-37]. }\end{array}$ \\
\hline $\begin{array}{l}\text { Frau im Mond, } 1928 / 29 \\
\text { SA: The Girl in the Moon (K) } \\
\text { Girl in the Moon, By Rocket to } \\
\text { the Moon, Woman in the } \\
\text { Moon (E) } \\
\text { MI: } 4 \\
\text { BELEGE } \\
\text { UA : } 15.10 .29 \\
\text { SA : } 13.2 .31 \text { CT } \\
\text { L2: } 527 \\
\text { HR : } 107\end{array}$ & $\begin{array}{l}\text { 1: Utopisches Drama nach dem Roman von Thea v. Harbou mit Gerda } \\
\text { Maurus, Margarethe Kupfer, Tilla Durieux, Willy Fritsch, Gustav v. } \\
\text { Wangenheim, Klaus Pohl, Fritz Rasp, Gustl Stark-Gstettenbauer. Regie: } \\
\text { Fritz Lang. - "Metropolis“ war monumental aber blutleer, „Spione“ } \\
\text { packend doch nicht in Lang's sonstigem Format. Sein neuester Film } \\
\text { vereinigt die Vorzüge beider Vorgänger in sich ... Die Fabel - der } \\
\text { Professor, der auf dem Monde Gold vermutet, und von einem Finanztrust } \\
\text { gezwungen wird auch dessen Vertreter, außer zwei Technikern und der } \\
\text { Verlobten des einen derselben, auf seine Fahrt mitzunehmen - ist aktuell } \\
\text { und heute nicht mehr so wirklichkeitsfern als vor kurzem, umsomehr als } \\
\text { man die darauffolgende Bezwingung des Weltraumes und die Landung } \\
\text { auf dem Monde durch Hypothesen gut fundiert. Nachdem dort der } \\
\text { Gelehrte durch seine Goldgier und der Zwangspassagier ob seiner } \\
\text { Verschlagenheit den Tod gefunden, muß die Weltraumrakete infolge } \\
\text { Sauerstoffmangels bei der Heimfahrt zur Erde den einen Techniker } \\
\text { zurücklassen. Bei ihm bleibt freiwillig die Braut des anderen ... - Die } \\
\text { letzten Klippen hinsichtlich der Glaubhaftigkeit der Ereignisse beseitigt } \\
\text { die geradezu gigantische Aufmachung, bis ins kleinste Detail durchdacht } \\
\text { und die Spannung fördernd. Sorgfältige Darstellung, exakter Schnitt, } \\
\text { gute Beschriftung und eine ausgezeichnete Photographie fügen sich dem } \\
\text { Rahmen des Ganzen ein. - Gesamtqualifikation: Schlager [PFL 1929: } \\
\text { 162]. }\end{array}$ \\
\hline $\begin{array}{l}\text { Das Letzte Fort, } 1928 \\
\text { SA: The Last Fort (K) } \\
\text { Die Zitadelle von Tunis (D) } \\
\text { MI: } 3 \\
\text { BELEGE } \\
\text { UA : } 9.7 .29 \\
\text { SA : } 19.10 .29 \mathrm{NM} \\
\text { L2: } 373\end{array}$ & $\begin{array}{l}\text { 4: Lebensbild mit Heinrich George, Fritz Odemar, Rolla Normann, Albert } \\
\text { Steinrück, Maria Paudler. Regie: Kurt Bernhardt. - Drei Kameraden, von } \\
\text { denen jeder durch eine Frau zu Fall gekommen, verteidigen in Nordafrika } \\
\text { ein Fort der aufständischen Araber gegen die Franzosen. Als die Tochter } \\
\text { eines gefangenen Majors der Kolonialtruppen auf dem Fort eintrifft, } \\
\text { verlieren alle drei wieder den Kopf, besinnen sich später aber ihrer } \\
\text { kameradschaftlichen Pflichten. Das Fort fällt, und einer von innen findet } \\
\text { sich mit der Offizierstochter, der ihr samt ihrem Vater zur Flucht verhol- } \\
\text { fen. - Nach einer recht orginellen Exposition setzt sich die Handlung auf } \\
\text { einem ziemlich beschränkten Schauplatze fort, sodaß nur die kontinuierli- } \\
\text { che Regieführung und die vorzügliche Darstellung aller Rollen das ganze } \\
\text { vor Länge bewahren. Soweit Aufmachung in Frage kommt, ist sie ebenso } \\
\text { wie die Photographie und die recht gut gesehenen Landschaftsbilder } \\
\text { sauber. - Gesamtqualifikation: Über dem Durchschnitt [PFL 1929: 2]. }\end{array}$ \\
\hline $\begin{array}{l}\text { Die Liebe der Jeanne Ney, } \\
1927 \\
\text { SA: The Loves of Jenny Ney } \\
\text { (K) } \\
\text { Der Leidensweg der Jeanne } \\
\text { Ney, Sklaven der Begierden } \\
\text { (D); Lusts of the Flesh, The } \\
\text { Love of Jeanne Ney (E) } \\
\text { MI: } 3 \\
\text { BELEGE } \\
\text { UA : } 6.12 .27 \\
\text { SA : } 25.3 .29 \text { RDM } \\
\text { L2 : } 139 \\
\text { TG : } 228\end{array}$ & $\begin{array}{l}\text { 4: Kriminaldrama nach dem Roman von Ilja Ehrenburg, mit Edith Jehan- } \\
\text { ne, Brigitte Helm, Hertha von Walther, Uno Henning, Fritz Rasp, Eugen } \\
\text { Jensen, A.E. Liche, Wladimir Sokoloff, Jack Trevor. Regie: G.W. Pabst. } \\
\text { - Die Tochter eines von Bolschewiken in der Krim ermordeten französi- } \\
\text { schen Korrespondenten flieht mit Hilfe eines Sowjetagenten, den sie als } \\
\text { Studienkollegen in Moskau lieben gelernt, nach Paris, wo sie ihn später } \\
\text { wiedertrifft. Ein Spitzel ermordet ihren Onkel und der Russe, der als } \\
\text { Emissär nach Toulon reisen soll, wird als Täter verhaftet. Das Mädchen } \\
\text { verfolgt nun die Spur des Spitzels, den sie als Alibizeugen gewinnen will, } \\
\text { erkennt den sie Bedrängenden als den wirklichen Täter und überliefert } \\
\text { ihn den Behörden. - Ein zweifellos interessantes und packendes Sujet, } \\
\text { das allerdings oft von einer überreichen Fülle von Details überwuchert } \\
\text { wird, mit welchen es der Regisseur ausgestattet, der sich neben einer } \\
\text { täuschend getreuen Zeichnung des russischen Milieus erfolgreich } \\
\text { bemüht, neue Wege zu beschreiten. Keine Szene ist ausgespielt, jede } \\
\text { einzelne in eine Anzahl von Teilbildern zerlegt, welche starke visuelle } \\
\text { Eindrücke vermitteln. Vorbildlich ist die Führung der Darsteller. Soweit } \\
\text { Aufmachung in Frage kommt, ist sie ebenso wie die Photographie } \\
\text { sorgfältig. - Gesamtqualifikation: über dem Durchschnitt [PFL } \\
\text { 13(1928)614, 3]. }\end{array}$ \\
\hline $\begin{array}{l}\text { Hokuspokus, } 1930 \\
\text { SA: Temporary Widow (K) } \\
\text { Der Prozess der Kitty Keller- } \\
\text { mann (D) }\end{array}$ & $\begin{array}{l}\text { 2: Kriminalkomödie (Ton-, Geräusch- und [deutscher] Dialogfilm) nach } \\
\text { dem Stück von Kurt Götz, mit Lilian Harvey, Ruth Albu, Margarethe } \\
\text { Schön, Willy Fritsch, Oskar Homolka, Gustav Gründgens, Otto Wall- } \\
\text { burg, Kurt Lilien, Max Ehrlich. Regie: Gustav Ucicky. - Eine Frau wird, } \\
\text { auf Grund von Indizien des Gattenmordes angeklagt, freigesprochen, da }\end{array}$ \\
\hline
\end{tabular}




\begin{tabular}{|c|c|}
\hline $\begin{array}{l}\text { MI: } 3 \\
\text { BELEGE } \\
\text { UA : } 11.7 .30 \\
\text { SA : } 13.7 .31 \text { DB } \\
\text { B : }\end{array}$ & $\begin{array}{l}\text { ein junger Mann sich als Täter bekennt. Dieser entflieht bald darauf und } \\
\text { entpuppt sich schließlich als der angeblich Ermordete, der um seine } \\
\text { Bilder an den Mann zu bringen, Selbstmord vortäuschte. - Die amüsante, } \\
\text { spannende Handlung beschränkt sich außer Prolog und Epilog im } \\
\text { Wesentlichen nur auf einen Schauplatz (Gerichtssaal) und wird vorwie- } \\
\text { gend durch abwechslungsreichen, lebendigen Dialog fortbewegt. Dieser } \\
\text { ist meist verständlich und klangecht wiedergegeben, wenn man von der } \\
\text { durch eigentümliche Sprechart und Dialekt gegebenen schwereren } \\
\text { Verständlichkeit einzelner Darsteller, deren Kollektiv die Regie glänzend } \\
\text { führt, absieht. Sorgfältige Aufmachung und ebensolche Photographie } \\
\text { vervollständigen den ansprechenden Eindruck des Bildes. - Gesamtquali- } \\
\text { fiation: Fast ein Schlager [PFL 1930:112]. }\end{array}$ \\
\hline $\begin{array}{l}\text { Der Kampf des Donald } \\
\text { Westhof, } 1927 \\
\text { SA: The Trial of Donald } \\
\text { Westhof (K) } \\
\text { Das Verbrechen des Donald } \\
\text { Westhof, Das Erwachen des } \\
\text { Donald Westhof (D) } \\
\text { MI: } 2 \\
\text { BELEGE } \\
\text { UA : } 29.9 .27 \\
\text { SA : } 16.4 .29 \text { DB } \\
\text { L2 : } 122 \\
\text { TG : } 229 \\
\text { HR : }\end{array}$ & $\begin{array}{l}\text { 4: Kriminal-psychologisches Drama nach dem Roman von Felix Hollän- } \\
\text { der, mit Imre Raday, Oskar Homolka, Hermann Vallentin, Paul Otto, } \\
\text { Nikolai Marikoff, Elizza la Porta, Erna Morena, Karin Evans. Regie: Fritz } \\
\text { Wendhausen. - Ein junger Mann mit stark ausgeprägtem Selbstbewußt- } \\
\text { sein weist stets fremde Hilfe von sich, gerät in Bedrängnis, fällt aber } \\
\text { nicht... In der Schule leidet er Schiffbruch, kommt nach dem Tode der } \\
\text { Mutter zu Verwandten und sieht sich nach einem Streite gezwungen, als } \\
\text { Sekretär eines Wucherers sein Brot zu verdienen, den er daran hindert, } \\
\text { ein vom eigenen Vater verkrüppeltes Mädchen zu heiraten. Als der } \\
\text { "Rentier" tot aufgefunden wird, gerät der Sekretär unter Mordverdacht, } \\
\text { das Mädchen schweigt, obwohl es dem jungen Manne in Beziehung } \\
\text { gestanden, und nur die Aussage seiner Jugendfreundin rettet ihn vor der } \\
\text { Verurteilung. - Dieser Film läßt Einwände zu, die aber den zweifellos } \\
\text { günstigen Gesamteindruck nicht entscheidend zu beeinträchtigen } \\
\text { vermögen. Das Sujet ist entsprechend seinem Vorwurfe kolportagehaft, } \\
\text { aber immerhin spannend und dramatisch wirksam, die Darstellung durch } \\
\text { gut gewählte Typen wirkungsvoll, wenn diese auch oft etwas grell } \\
\text { gezeichnet. Die Regieführung mit Ausnahme einiger toter Stellen } \\
\text { sorgfältig. Soweit Aufmachung in Frage kommt, ist ebenso wie die } \\
\text { Photographie auf der Höhe, hinsichtlich letzterer einige gelungene } \\
\text { photographische und Kopier-Tricks zu erwähnen [PFL 1927: 174]. }\end{array}$ \\
\hline $\begin{array}{l}\text { Mann gegen Mann, } 1928 \\
\text { SA: For Men Only (K) } \\
\text { Man aginst Man (E) } \\
\text { MI: } 2 \\
\text { BELEGE } \\
\text { UA : } 14.5 .28 \\
\text { SA : } 15.6 .29 \mathrm{EPH} \\
\text { L2 : } 392\end{array}$ & $\begin{array}{l}\text { 2: Sensationsdrama mit Harry Piel, Fritz Beckmann, Dr. Philipp Manning, } \\
\text { Eugen Burg, Georg John, Dary Holm, Hertha von Walter. Regie: Harry } \\
\text { Piel. - Piel ist Banknotenfälschern auf der Spur, während ihn eine } \\
\text { Detektivin für einen Hochstapler hält und verhaften will. Er stöbert den } \\
\text { Standort der Notenpresse auf und läßt die Bande in ihrer Mausefalle } \\
\text { sitzen, um schließlich noch die den Transport der Falsifikate besorgenden } \\
\text { Schmuggler den Grenzern in die Hände zu spielen und den Haupttrumpf, } \\
\text { die Verhaftung eines Bankkassiers als Oberhaupt der Bande, galant der } \\
\text { Detektivin zu überlassen, mit der ihn bereits zarte Bande zu verbinden } \\
\text { scheinen. - Im Sujet sind Spannung, Sensation und die heitere Intermezzi } \\
\text { richtig dosiert, so daß es niemals den Boden des Glaubhaften verlässt, } \\
\text { wie auch die Regie streng kontinuierlich und ohne Mätzchen arbeitet. Die } \\
\text { Darstellung ist in allen Rollen sehr gut, Aufmachung und Photographie } \\
\text { sauber, auch eine Reihe schöner Hochgebirgsbilder erwähnenswert. - } \\
\text { Gesamtqualifikation: Stark über dem Durchschnitt [PFL 1928: 110]. }\end{array}$ \\
\hline $\begin{array}{l}\text { Der Geheime Kurier } \\
\text { SA: The Secret Cou } \\
\text { MI: } 1 \\
\text { BELEGE } \\
\text { UA : } 25.10 .28 \\
\text { SA : } 19.11 .29 \text { DB } \\
\text { L2 : } 316\end{array}$ & $\begin{array}{l}\text { 2: Liebesdrama (Kostüm) nach dem Stendal'schen Roman „Rouge et } \\
\text { Noir“, mit Iwan Mosjoukin, José Davert, Jean Dax, Lil Dagover, Agnes } \\
\text { Petersen. Regie: Gennaro Righelli. - Um } 1830 \text { in Frankreich. Der } \\
\text { Sekretär eines Bürgermeisters und Geliebter von dessen Frau verläßt } \\
\text { beide, um dem Rufe eines Marquis nach Paris zu folgen, dessen Tochter } \\
\text { er heiraten möchte. Als die Bürgermeistersfrau dem Marquis eine } \\
\text { schlechte Auskunft über den Sekretär gibt, schießt dieser sie nieder und } \\
\text { wird als Mörder und Hochverräter zur Guillotine verurteilt. Durch den } \\
\text { Regierungsantritt des Bürgerkönigs Louis Phillippe, in dessen Dienst er } \\
\text { sich gestellt, in letzter Stunde befreit, stirbt er, von einer Kugel der } \\
\text { Barrikadenkämpfer getroffen, in den Armen seiner Braut. - Trotz } \\
\text { anfänglicher Längen vermittelt das nicht immer ganz der Historie } \\
\text { entsprechende Sujet starke Wirkungen, besonders gegen Schluß des } \\
\text { Films. Ausgezeichnet ist die Darstellung, woran der sie geschickt } \\
\text { führenden Regie wesentlicher Anteil gebührt, wie auch eine sorgfältige }\end{array}$ \\
\hline
\end{tabular}




\begin{tabular}{|c|c|}
\hline & $\begin{array}{l}\text { Aufmachung und schöne Außenaufnahmen den günstigen Gesamtein- } \\
\text { druck vervollständigen. Die Aufnahmen sind bildhaft wirksam, in rein } \\
\text { photographischer Hinsicht aber etwas ungleich. - Gesamtqualifikation: } \\
\text { Fast ein Schlager [PFL 1928: 179]. }\end{array}$ \\
\hline $\begin{array}{l}\text { Skandal in Baden-Baden, } \\
1928 \\
\text { SA: A Society Scandal (K) } \\
\text { Die Geliebte Roswolskys (D); } \\
\text { Scandal in Baden-Baden (E) } \\
\text { MI: } 1 \\
\text { BELEGE } \\
\text { UA : } 18.1 .29 \\
\text { SA : } 22.03 .30 \text { CT } \\
\text { L2 : } 444\end{array}$ & $\begin{array}{l}\text { 5: Sittendrama nach dem Roman von Georg Fröschel, mit Brigitte Helm, } \\
\text { Lilly Alexandra, Henry Stuart, Ernst Stahl-Nachbaur, Leo Peukert, Regie: } \\
\text { Erich Waschneck. - Ein bekannter Industriemagnat hat einem halb } \\
\text { verhungerten Chormädchen geholfen, was ein findiger Manager benützt, } \\
\text { die als des Ersteren Geliebte zu lancieren und nebendei Betrügereinen } \\
\text { auszuführen. Die letzteren führen nach dem Erscheinen des Industriellen } \\
\text { zu seiner Verhaftung, während sich die Choristin mit einem jungen } \\
\text { Manne der Gesellschaft findet. - Die Neubearbeitung eines von der Ufa } \\
\text { schon einmal mit der Nielsen verfilmten Vorwurfes (Ufa-Film der „Colle- } \\
\text { gia-Sascha“, Filmliste 287/1921), ohne unnötige Breiten interessant und } \\
\text { ansprechend, in allen Rollen gut dargestellt. Die Regieführung ist } \\
\text { kontinuierlich und ebenso wie Aufmachung und Photographie durchaus } \\
\text { saubere Arbeit. - Gesamtqualifikation: Guter Mittelfilm [PFL } \\
\text { 14(1929)667,5-6]. }\end{array}$ \\
\hline \multirow[t]{2}{*}{$\begin{array}{l}\text { Die Blaue Maus, } 1928 \\
\text { SA: The Blue Mouse (K) } \\
\text { MI: } 1 \\
\text { BELEGE } \\
\text { UA : } 16.11 .28 \\
\text { SA : } 12.5 .30 \text { DFA } \\
\text { L2 : } 264\end{array}$} & $\begin{array}{l}\text { 4: Schwank nach französischen Motiven mit Jenny Jugo, Britta A- } \\
\text { pelgreen, Hermine Sterler, Harry Halm, Alber Paulig, Julius Falkenstein, } \\
\text { Regie: Dr. Johannes Guter. - Ein lediger Sekretät weiß, daß in seinem } \\
\text { Büro nur solche Beamten auf Beförderung hoffen dürfen, deren Gattin- } \\
\text { nen den Chef entsprechend entschädigen. Er nimmt daher das Anerbie- } \\
\text { ten der „blauen Maus“, einer Bartänzerin, bei dem Vorgesetzten die } \\
\text { Rolle seiner Frau zu spielen, an. Sie entledigt sich ihrer Aufgabe so gut, } \\
\text { daß sie nicht nur die Beförderung des Sekretärs durchsetzt, sondern von } \\
\text { ihm auch geheiratet wird. - Der schon vor mehr als einem Jahrzehnt von } \\
\text { Max Mack erstmalig bearbeitete Stoff wirkt trotz seiner Modernisierung } \\
\text { etwas antiquiert, wie auch der Regiesseur von dessen Bühnenentwurf } \\
\text { nicht recht loskam. Dafür entschädigen eine liebenswürdige Darstellung, } \\
\text { moderne Aufmachung und sehr gute Photographie, so daß man sich } \\
\text { trotzdem recht gut unterhält. Gesamtqualifikation: Über dem Durch- } \\
\text { schnitt [PFL 1928: 188). }\end{array}$ \\
\hline & VERTRIEB: AFRICAN FILMS (A) \\
\hline $\begin{array}{l}\text { Metropolis, } 1925 / 26 \\
\text { SA: Metropolis (A) } \\
\text { MI: } 34 \\
\text { BELEGE } \\
\text { UA : } 10.1 .27 \\
\text { SA : } 22.1 .28 \text { ST } \\
\text { L1 : } 821 \\
\text { TG }: 217 \\
\text { HR }: 100\end{array}$ & $\begin{array}{l}\text { 1: Ein Monumentalfilm, Manuskript: Thea von Harbou, Regie: Fritz Lang, } \\
\text { mit Brigitte Helm, Alfred Abel, Rudolf Klein-Rogge, Theodor Loos, Fritz } \\
\text { Rasp, Erwin Binswanger, Gustav Fröhlich, Heinrich George. - Zeit- und } \\
\text { ortlos in nicht allzuferner Zukunft. Metropolis besteht aus drei Teilen: der } \\
\text { Geschäftsstadt, der Arbeiterstadt unter ihr, und den Lustgärten ihrer } \\
\text { Beherrscher über den Wolkenkratzern. Die Arbeiter, schon selbst zu } \\
\text { Maschinen geworden, betreuen die unterirdischen Kraftmaschinen, } \\
\text { welche der Stadt Leben spenden, einen Erlöser erwartend, der als } \\
\text { Mittler zwischen Hirn und Händen, zwischen Brotherrn und den für sie } \\
\text { Arbeitenden auftreten soll. Ein junges Mädchen ermahnt sie zur Ausdau- } \\
\text { er, welchem die Bosheit eines dem Beherrscher der Stadt übel gesinnten } \\
\text { Gelehrten einen künstlichen Menschen als Doppelgängerin entgegen- } \\
\text { stellt, welche die Arbeitssklaven zum Aufruhr reizt. Sie zerstören die } \\
\text { Maschinen, mit ihnen aber die Stadt. Der glückliche Ausgang eines } \\
\text { Kampfes zwischen dem Gelehrten und dem Sohne des Industriefürsten } \\
\text { bringt diesen, die Rettung der Kinder der Arbeiterschaft, seine Gegner } \\
\text { zur Einsicht. Und - der Mittler kann sein Werk beginnen. - Der Ausdruck } \\
\text { "Monumentalfilm“ ist hier nicht als Reklame-Superlativ sondern als } \\
\text { Bezeichnung des Genres aufzufassen. Die Besprechung und Qualifikati- } \\
\text { on dieses Bildes kann nur eine Referenz vor der gigantischen Regiearbeit } \\
\text { Lang's, vor einer Großtat der deutschen Filmindustrie, die Konstatierung } \\
\text { des Achtungserfolges sein, den „Metropolis“ beim Publikum der Erstauf- } \\
\text { führungswoche gefunden hat. Im Übrigen fehlt, um das Motto des } \\
\text { Manuskriptes auch auf die Rezension anzuwenden, dem Film selbst der } \\
\text { Mittler zwischen zwischen einer verhältnismäßig kleinen Handlung und } \\
\text { gewaltigen Massenszenen mit überdimensionalen Atelierbauten als } \\
\text { Hintergrund. Man bewundert von Szene zu Szene die Regie- und } \\
\text { Aufmachungsarbeit, verfolgt die Handlung mit Interesse, gewinnt aber } \\
\text { immer mehr Distanz zu den Vorgängen und wird nicht warm. Brigitte }\end{array}$ \\
\hline
\end{tabular}




\begin{tabular}{|c|c|}
\hline & $\begin{array}{l}\text { Helm ist im ersten Teile ihrer Doppelrolle darstellerisch sehr gut, weniger } \\
\text { im zweiten, ausgezeichnet Abel, Klein-Rogge etwas matt. Auch der } \\
\text { Photographie gebührt uneingeschränktes Lob [PFL 1926: 3]. }\end{array}$ \\
\hline $\begin{array}{l}\text { Faust, } 1926 \\
\text { SA: Faust (A) } \\
\text { Faust - Eine deutsche Volks- } \\
\text { sage (D); Faust-A German } \\
\text { Folk Legend (E) } \\
\text { MI: } 26 \\
\text { BELEGE } \\
\text { UA: } 14.10 .26 \\
\text { SA : } 7.12 .27 \mathrm{SCL} \\
\text { L1: } 732 \\
\text { TG : } 228 \\
\text { HR : } 99\end{array}$ & $\begin{array}{l}\text { 1: Eine verfilmte deutsche Volkssage mit Gösta Eckmann, Emil Jan- } \\
\text { nings, Wilhelm Dieterle, Werner Fuetterer, Hans Brausewetter, Camilla } \\
\text { Horn, Frieda Richard, Yvette Gilbert, Hanna Ralph. Regie: F.W. Murnau. } \\
\text { - Trotz eifrigstem Studium steht Faus, als die Pest seine Stadt heim- } \\
\text { sucht, der Seuche ratlos gegenüber. Die Bitten der Hilfesuchenden } \\
\text { veranlassen ihn, vorerst für einen Tag, den ihm vom Teufel angebotenen } \\
\text { Pakt zu schließen und mit der Hilfe des Bösen die Kranken zu heilen. Als } \\
\text { Ketzer erkannt, wird er vom Teufel nach dem Süden entführt, wo Faust } \\
\text { im Getändel mit einer Herzogin nach des Tages Ablauf den Pakt nicht } \\
\text { löst und für ewig dem Satan anheimfällt. Später verführt er Gretchen, } \\
\text { läßt sie in Schande und Elend zurück und erkennt erst, als die Unglückli- } \\
\text { che wegen des Kindesmordes verbrannt werden soll, sein Unrecht. Der } \\
\text { ihm beim Abschluß seines Bündnisses wiedergegebenen Jugend verlus- } \\
\text { tig geworden, besteigt er mit ihr den Scheiterhaufen und beide gehen } \\
\text { geläutert zu Gott ein. - Das Szenarium, welches mit nur ganz geringen } \\
\text { Anlehnungen an Goethe auf den Ur-Faust zurückgeht, stellt, was für eine } \\
\text { Filmbearbeitung zweifellos das Beste ist, das Erotische in den Vorder- } \\
\text { grund, ist durchgehends packend ohne jede Länge gearbeitet, auch das } \\
\text { Mystische sehr geschickt mit Realem verquickt. Der Darstellung gebührt } \\
\text { uneingeschränkte Anerkennung. Camilla Horn, eine sehr bemerkenswer- } \\
\text { te Neuerscheinung, ist ein vorbildliches Gretchen, Eckmann sowohl } \\
\text { persönlich wie auch schauspielerisch äusserst gewinnend, Jannings der } \\
\text { schlaue Bauernteufel der Volkssage. Ein Kapitel für sich ist die techni- } \\
\text { sche Seite des Films. Die Bauten unterstreichen lebhaft das Sagenhafte } \\
\text { dieser Faustbearbeitung, die Einkopierungen sind restlos gelungen, auch } \\
\text { die sonstige Güte der Photographie läßt nichts zu wünschen übrig [PFL } \\
\text { 1926: 154]. }\end{array}$ \\
\hline $\begin{array}{l}\text { Der letzte Walzer, } 1927 \\
\text { SA: The Last Waltz (A) } \\
\text { MI: } 25 \\
\text { BELEGE } \\
\text { UA : } 19.8 .27 \\
\text { SA : } 29.12 .28 \text { CA } \\
\text { L2 : } 137\end{array}$ & $\begin{array}{l}\text { 4: Liebesdrama mit Liane Haid, Suzy Vernon, Ida Wüst, Willy Fritsch, } \\
\text { H.A.v. Schlettow, Fritz Rasp. Regie: Arthur Robison. - Eine Prinzessin, } \\
\text { die sich mit dem Thronfolger des Landes verloben soll, tauscht bei der } \\
\text { ersten Begegnung mit ihrer Freundin, einer Komtesse, die Rollen, in } \\
\text { welche sich der Adjutant des Fürsten prompt verliebt. Als der Fürst, der } \\
\text { von der Mystifikation erfahren, gegen letztere zudringlich wird, attackiert } \\
\text { inn der Adjutant und soll standrechtlich erschossen werden. Sein letzter } \\
\text { Wunsch ist: Ein Walzer mit der Komtesse. Diese will ihn zur Flucht } \\
\text { bewegen, der aber seinem Ehrenwort getreu bleibt und schließlich vom } \\
\text { Fürsten begnadigt wird. - Das Sujet, welches die gleichnamige Operette } \\
\text { zum Vorwurf hat, ist nicht sonderlich aufregend, aber sauber gearbeitet, } \\
\text { sehr nett die Darstellung, die Regieführung sicher und kontinuierlich. Die } \\
\text { Ausstattung ist recht hübsch, auch die Photographie recht gut [PFL } \\
\text { 12(1927)597, 139]. }\end{array}$ \\
\hline $\begin{array}{l}\text { Atlantik, } 1929 \\
\text { SA: Atlantic (A) } \\
\text { Titanic (E) } \\
\text { MI: } 24 \\
\text { BELEGE } \\
\text { UA : } 28.20 .29 \\
\text { SA : } 26.6 .30 \text { CT } \\
\text { B : } 1 \\
\text { TG : } 229 \\
\text { HR : } 8\end{array}$ & $\begin{array}{l}\text { 1: Das Drama einer Schiffskatastrophe (Ton-, Geräusch- und [deutscher] } \\
\text { Dialogfilm) nach dem Bühnenstück von Ernest Raymond, mit Fritz } \\
\text { Kortner, Franz Lederer, Hermann Vallentin, Willi Forst, Heinrich Schroth, } \\
\text { Theodor Loos, Dr. Phillip Manning, Georg August Koch, Georg John, } \\
\text { Lucie Mannheim, Elfriede Borodin, Elsa Wagner, Julia Serda. Regie: } \\
\text { E.A. Dupont. - Die Handlung: ein Ereignis (Zusammenstoß eines } \\
\text { Ozeandampfers mit einem Eisberg, Untergang binnen drei Stunden, } \\
\text { Rettungsmöglichkeit nur für Frauen und Kinder, sicherer Ertrinkungstod } \\
\text { der Männer) mit zwei dramatischen Keimzellen (wie erhalten die einzel- } \\
\text { nen Passagiere von dem Fürchterlichen Kenntnis und wie benehmen sie } \\
\text { sich angesichts des Todes?). Dies an einigen Nebenpersonen und an drei } \\
\text { Paaren demonstriert: Dem jungverheirateten (er bringt seine Frau nur } \\
\text { durch eine List ins Rettungsboot und wird selbst später ohnmächtig in ein } \\
\text { solches getragen) - dem entzweiten (der Mann hat durch seine Untreue } \\
\text { den Einfluß auf seine Gattin und auf seine Tochter verloren und ein } \\
\text { anderer muß die Frauen zum Besteigen des Rettungsbootes veranlassen) } \\
\text { - und schließlich einem weltmüden (der Mann gelähmt, beide zusammen } \\
\text { den Tod erwartend). - Dieses Sujet gewinnt durch Einheit von Zeit und } \\
\text { Ort an Konzentration. Duponts Regie scheint endlich den Stil des }\end{array}$ \\
\hline
\end{tabular}




\begin{tabular}{|c|c|}
\hline & $\begin{array}{l}\text { Tonfilms gefunden zu haben und schafft durch die fugenlose Verquickung } \\
\text { von visuellen und akustischen Eindrücken eine Katastrophenatmosphäre } \\
\text { von ungeahnter Wirkung. Die Darstellung ist mimisch durchgehends } \\
\text { ungemein eindrucksvoll, der Dialog ungekünstelt, allgemein verständlich, } \\
\text { ernste und heitere Konversationsmotive geschickt verteilt, besonders } \\
\text { Kortner, Lederer und Forst bemerkenswert, deren Stimmen, wie die aller } \\
\text { Männer, klangechter als die der Damen. Die Aufmachung ist bis auf den } \\
\text { im Verhältnis zum übrigen zu wenig imposanten Zusammenstoß großzü- } \\
\text { gig, die Photographie mit Ausnahme einiger Szenen sehr gut. Musikun- } \\
\text { termalung von Szenen wird nur sparsam angewendet, die Geräuschef- } \\
\text { fekte kommen ausgezeichnet zur Geltung. Lediglich die unmittelbare } \\
\text { Aufeinanderfolge von Tonkulisse und ununtermaltem Dialog, was } \\
\text { letzteren dann gewissermaßen in der Luft hängen läßt, stört manchmal } \\
\text { die Illusion. Die Wiedergabe ist, von dem häufigen Krachen an Schnitt- } \\
\text { stellen des Phonogramms abgesehen, sehr gut, nur in einzelnen Szenen } \\
\text { die Schallrichtung nicht mit dem Standorte der sprechenden Person } \\
\text { völlig übereinstimmend. Gesamtqualifikation: Schlager } \\
\text { 15(1930)719, 7-8]. }\end{array}$ \\
\hline $\begin{array}{l}\text { Die Wunderbare Lüge der } \\
\text { Nina Petrowna, } 1928 \\
\text { SA: The Wonderful Lie (A) } \\
\text { The Wonderful Lies of Nina } \\
\text { Petrovna (E) } \\
\text { MI: } 19 \\
\text { BELEGE } \\
\text { UA : } 15.4 .29 \\
\text { SA : } 2.10 .29 \text { CT } \\
\text { L2 : } 667 \\
\text { TG : } 217 \\
\text { HR : } 100\end{array}$ & $\begin{array}{l}\text { 2: Liebesdrama mit Brigitte Helm, Franz Lederer, Warwick Ward, Harry } \\
\text { Hardt. Regie: Hanns Schwarz. - Die verwöhnte Freundin eines russichen } \\
\text { Obersten verliebt sich in einen Kornett, verläßt ihren goldenen Käfig, und } \\
\text { lebt einige Wochen in einer Mansarde nur für den Geliebten, der, als er } \\
\text { später ihre Geldsorgen bemerkt, im Kartenspiel mit dem Obersten das } \\
\text { Glück zu korrigieren versucht. Diese Verfehlung gibt den jungen Mann } \\
\text { seinem Feinde in die Hand, der als Preis für die Aplanierung der Angele- } \\
\text { genheit die Rückkehr der Freundin verlangt. Sie lügt dem Geliebten nun } \\
\text { vor, daß sie künftig ihre Liebe wieder verkaufen werde, zieht in das Haus } \\
\text { des Obersten, vergiftet sich aber dort. - Eigentlich ein Kammerspiel, } \\
\text { doch nur hinsichtlich der Motive der Handlung, ohne gekünstelte Be- } \\
\text { schränkung in der Zahl der handelnden Personen und des Schauplatzes, } \\
\text { wirkungsvoll exponiert, dann allerdings etwas verflachend, am Ende } \\
\text { wieder sehr stark. Die Helm ist weit besser gebracht als in ihren letzten } \\
\text { Filmen, von der Regie, welche auch das übrige Ensemble mit Fingerspit- } \\
\text { zengefühl leitet, gemäßigt, ohne die frühreren überspitzten Vamp- } \\
\text { Gesten. Szenenführung, Aufmachung, Zwischentexte und Photographie } \\
\text { vervollständigen den Eindruck eines kultivierten Werkes. - Gesamtquali- } \\
\text { fikation: Fast ein Schlager [PFL 14(1929)692, 101]. }\end{array}$ \\
\hline $\begin{array}{l}\text { Die Emden/Unsere Emden, } \\
1926 \\
\text { SA: The Emden/Our Emden) } \\
\text { (A) } \\
\text { Unsere Emden, Kreuzer } \\
\text { Emden, Die Heldenfahrt der } \\
\text { "Emden“ (D), The Emden's } \\
\text { Last Fight (E) } \\
\text { MI: } 18 \\
\text { BELEGE } \\
\text { UA : } 22.12 .26 \\
\text { SA : } 17.4 .28 \text { TS } \\
\text { L1 : } 867 \\
\text { TG: } 228\end{array}$ & $\begin{array}{l}\text { 0: Ein historisches Dokument. - Persönlich mitwirkend die bekannten } \\
\text { Emden-Offiziere und -Mannschaften, Kapitänleutnant a.D. Helmuth von } \\
\text { Mücke, Kapitänleutnant a.D. Lauterbach, Korvettenkapitän R. Witthoeft, } \\
\text { Oberleutnant a.D. Dietrich Benzler, Obermaschinistenmaat Erfurth, } \\
\text { Obermatrose Karl Berner, Obermatrose Alfred Bednore, weiters die } \\
\text { Darsteller Louis Ralph, Fritz Greiner, Jack Mylong-Münz, Charles Willy } \\
\text { Kaiser, Maria Mindszenti. Regie: Louis Ralph. - Vom Ausbruch des } \\
\text { Krieges in Tsingtau überrascht, erhielt die "Emden“ bei der Begegnung } \\
\text { mit dem Admiralsgeschwader den Auftrag, selbständig Kaperkrieg zu } \\
\text { führen, versenkte, selbst ein kleines Schiff und verhältnismäßig } \\
\text { schwacharmiert, fortgesetzt Handels- und später auch Kriegschiffe der } \\
\text { feindlichen Nationen, um schließlich auch Angriffe auf strategisch } \\
\text { wichtige Punkte der Alliierten vorzunehmen, bis sie vor Kap-Keeling von } \\
\text { dem weitaus größeren Kreuzer "Sidney“ gestellt und nach erbittertem } \\
\text { Gefechte kampfunfähig gemacht wurde. Auf der Sidney wurden Überle- } \\
\text { bende der "Emden“ mit militärischen Ehren empfangen. - Der Film } \\
\text { schildert schlicht, ohne jede Ausschmückung und daher um so eindrucks- } \\
\text { voller die Heldentaten der „Emden“. Eine verschwindend kleine Spiel- } \\
\text { handlung beeinflußt weder den Gesamteindruck nenneswert, noch würde } \\
\text { eventuell ihr Fehlen als Lücke empfunden werden. Daher sind an die } \\
\text { darstellerischen Qualitäten des Ensembles geringe Anforderungen } \\
\text { gestellt, denen es aber vollständig gerecht wird. Der Schwerpunkt liegt } \\
\text { in den Schiffs- und Gefechtsbildern, welche zum größten Teile gestellt } \\
\text { aber nichtsdestoweniger recht imposant sind, wie auch die Photographie } \\
\text { im allgemeinen befriedigt. Schließlich sei noch erwähnt, daß in der } \\
\text { besprochenen Bearbeitung national oder politisch bedenkliche Momente }\end{array}$ \\
\hline
\end{tabular}




\begin{tabular}{|c|c|}
\hline & fehlen [PFL 1927: 6]. \\
\hline $\begin{array}{l}\text { Varieté, } 1925 \\
\text { SA : Vaudeville (A) } \\
\text { Jealousy, Variety, Vaudeville } \\
\text { (E) } \\
\text { MI: } 17 \\
\text { BELEGE } \\
\text { UA : } 16.11 .25 \\
\text { SA : } 11.9 .27 \text { ST } \\
\text { L1 : } 656 \\
\text { TG : } 228 \\
\text { HR : } 100\end{array}$ & $\begin{array}{l}\text { 1: Eine Artistentragödie mit Emil Jannings, Warwick Ward, Lya de Putti, } \\
\text { Maly Delschaft. Regie: E.A. Dupont. - Ein Artist, Besitzer einer Jahr- } \\
\text { marktbude, nimmt ein elternloses Mädchen zu sich, verläßt später Frau } \\
\text { und Kind und tritt mit der Geliebten in der Großstadt in einer Luftnummer } \\
\text { auf. Als sie ihn mit einem Partner betrügt, widersteht er bei der nächsten } \\
\text { Vorstellung der Versuchung, seinen Rivalen durch einen Kunstfehler } \\
\text { verunglücken zu lassen, um ihn einige Stunden darauf in seinem Hotel- } \\
\text { zimmer zu töten. Dies erzählt er dem Gefängnisdirektor kurz bevor der, } \\
\text { über ein Gnadengesuch seiner Frau erfolgenden Entlassung. - Das Sujet } \\
\text { versteht es, einem oft benützen Thema neue Seiten abzugewinnen und } \\
\text { ist, von der Publikumswirksamkeit seine Milieus ganz abgesehen, von der } \\
\text { ersten bis zur letzten Szene spannend, oft erschütternd. Jannings spielt } \\
\text { den starken Mann; liebeshörig, gutgläubig, schließlich schrankenlos im } \\
\text { Zorn. Die Putti ist das kleine Artistenmädchen; unbewußt sündhaft, den } \\
\text { Geliebten beherrschend, schließlich dem angerichteten Unheil entsetzt } \\
\text { gegenüberstehend. Dupont's Regie verstand es, die handelnden Perso- } \\
\text { nen und ihre Umgebungen zu verquicken, die Konflikte logisch aus der } \\
\text { Atmosphäre heraus zu entwickeln. Die Aufmachung ist großzügig wo dies } \\
\text { am Platze ist, wirkungsvolle Kontraste schaffend. Auch die Photographie } \\
\text { steht auf bemerkenswerter Höhe [PFL 11(1926)510, 3]. 15.1.1926: } 3\end{array}$ \\
\hline $\begin{array}{l}\text { Die Weiße Hölle vom Piz Pali } \\
1929 \\
\text { SA: The White Hell of Pitz } \\
\text { Palu (A) } \\
\text { MI: } 17 \\
\text { BELEGE } \\
\text { UA : } 15.11 .29 \\
\text { SA : } 18.6 .31 \text { CT } \\
\text { L2 : } 659 \\
\text { TG : } 230\end{array}$ & $\begin{array}{l}\text { 1: Hochgebirgsdrama mit Leni Riefenstahl, Gustav Diessl, Ernst Petersen } \\
\text { und dem Meisterflieger Ernst Udet. Regie: Dr. Arnold Fanck und G.W. } \\
\text { Pabst. - Ein Tourist verliert die Braut durch einen Unfall bei der Bestei- } \\
\text { gung der Nordwand des Piz-Palü. Darauf sucht er wiederholt den Berg } \\
\text { allein zu bezwingen. Als er später die Tour zusammen mit einem jungen } \\
\text { Paare macht, geraten sie in Bergnot. Er leistet nun Übermenschliches für } \\
\text { die Rettung seiner Partner, welche nach Tagen von einer Expedition } \\
\text { geborgen werden, während er selbst den Tod sucht. - Der Konflikt ist } \\
\text { hier nicht konstruktiver Natur, sondern entwickelt sich logisch aus dem } \\
\text { Milieu, den Geschehnissen. Dies mach das Sujet suggestiv, gibt ihm } \\
\text { Atmosphäre. Der Regie ist die völlige Verquickung von Sport- und } \\
\text { Spielszenen gelungen; auch in der Auswahl und Führung des Ensembles } \\
\text { war sie glücklich. Die Hochgebirgsaufnahmen sind bildlich meisterhaft } \\
\text { gesehen, die Sensationen von unerhörter Präzision. Auch die Photogra- } \\
\text { phie ist vorbildlich, die Zwischentexte sparsam und treffend. Lediglich } \\
\text { gegen Ende wären einige geringe Kürzungen erwünscht. - Gesamtquali- } \\
\text { fikation: Ein Schlager [PFL 1929: 148]. }\end{array}$ \\
\hline $\begin{array}{l}\text { Der Kongreß tanzt, } 193 \\
\text { SA : Congress Dances } \\
\text { MI: } 15 \\
\text { BELEGE } \\
\text { UA : } 20.10 .31 \\
\text { SA : } 19.11 .32 \text { CT } \\
\text { B : } 60 \\
\text { TG : } 251\end{array}$ & $\begin{array}{l}\text { 2: Musikalische Ausstattungskomödie (100\%ig deutsch), mit Lilian } \\
\text { Harvey, Lil Dagover, Adele Sandrock, Margarethe Kupfer, Willy Fritsch } \\
\text { (Doppelrolle), Conradt Veidt, Paul Heinz Schroth, Otto Wallburg, Paul } \\
\text { Hörbiger, Julius Falkenstein. Regie: Eric Charell; Buch: Falk u. Lieb- } \\
\text { mann; Musik: Werner R. Heymann. - Eine kleine Handschuhverkäuferin } \\
\text { wird beim Wiener Kongreß mit dem Zaren bekannt, verliebt sich sterblich } \\
\text { in ihn. Metternich will diese und andere Amouren seines Gegners } \\
\text { benützen, diesen vom Kongreß fernzuhalten. Anfangs ohne Erfolg. Als es } \\
\text { endlich doch gelingt, ist Napoleon bereits wieder in Europa gelandet. Der } \\
\text { Kongreß löst sich auf, der Zar reist ab, ein Wiener Mädel bleibt zurück. - } \\
\text { Charell bringt den geschulten Blick für Massenszenen, für Genrebilder } \\
\text { mit, bereichert das ansprechende, nur stellenweise etwas breit angeleg- } \\
\text { te, Szenario durch eine Reihe teils neuer teils reproduktiver Einfälle, jagt } \\
\text { die Kamera allerdings zu oft über die Szene. Das Ensemble prominenter, } \\
\text { erprobtester Darsteller findet immer Kontakt zum Zuschauer, wenn man } \\
\text { auch manchmal mit zu norddeutschem Akzent spricht. Aufmachung groß, } \\
\text { Musik und Lieder einschmeichelnd, im Ohr bleibend. Photographie und } \\
\text { Ton waren - vielleicht lag es zum Teil an der Vorführung - nicht ganz } \\
\text { ausgeglichen. Gesamtqualifikation: Fast ein Schlager [PFL 16(1931)808, } \\
\text { 111]. }\end{array}$ \\
\hline $\begin{array}{l}\text { Manon Lescaut, } 1926 \\
\text { SA: Manon Lescaut (A) }\end{array}$ & $\begin{array}{l}\text { 1: Liebesdrama (Kostüm) nach der bekannten Oper mit Lya de Putti, } \\
\text { Frieda Richard, Lydia Potechina, Wladimir Gaidaroff, Eduard Rothauser, } \\
\text { Theodor Loos, Albert Paulig, Hans Junkermann. Regie: Arthur Robison. } \\
\text { - Ein fürs Kloster bestimmtes junges Mädchen wird von einem Gene- } \\
\text { ralsteuerpächter nach Paris entführt, der sie, als die ihre Liebe eínem für }\end{array}$ \\
\hline
\end{tabular}




\begin{tabular}{|c|c|}
\hline $\begin{array}{l}\text { MI: } 9 \\
\text { BELEGE } \\
\text { UA : 15.2.26 } \\
\text { SA : 8.6.29 CT } \\
\text { L1 : } 813\end{array}$ & $\begin{array}{l}\text { den Priesterberuf bestimmten Edelmann schenkt, fortgesetzt verfolgt } \\
\text { und durch Intriguen von dem Geliebten trennt, bis die Unglückliche } \\
\text { während der Deportation tödlich erkrankt und in des Letzteren Armen } \\
\text { stirbt. - Im Vordergrunde steht die große schauspielerische Leistung der } \\
\text { Putti, welche diesmal die fesseln ihrer Persönlichkeit gesprengt und eine } \\
\text { Gestalt im Sinne der gegebenen Rolle geschaffen. Auch Gaidaroff } \\
\text { verdient hinsichtlich seines diskreten Spieles volle Anerkennung, ganz } \\
\text { abgesehen von seinen persönlichen vorzügen. Die Regie ist sorgfältig, } \\
\text { die Aufmachung stilecht und die Geschehnisse wirkungsvoll unterstrei- } \\
\text { chend. Auch der Photographie gebührt allerhand Hochachtung [PFL } \\
11(1926) 512,11-12 \text { ]. }\end{array}$ \\
\hline $\begin{array}{l}\text { Jugendrausch, } 1926 / 27 \\
\text { SA: Nemesis (A) } \\
\text { Eva and the Grasshopper, } \\
\text { Youthful Extacy (E) } \\
\text { MI: } 8 \\
\text { BELEGE } \\
\text { UA : } 15.6 .27 \\
\text { SA : } 26.2 .29 \text { DB } \\
\text { L2: } 121\end{array}$ & $\begin{array}{l}\text { 6: Lebensbild mit Camilla Horn, Hertha von Walter, Warwick Ward, } \\
\text { Bruno Kastner, Hans Mierendorff, Gustav Fröhlich. Regie: Dr. Asaga- } \\
\text { row. - An zwei jungen Paaren wird gezeigt wie die Genuß- und Vergnü- } \\
\text { gungssüchtigen nach einer kurzen Zeit der Jugend und Freude immer } \\
\text { tiefer sinken, während die eifrigen Schritt für Schritt sich ihr Glück } \\
\text { erarbeiten. - Das Sujet ist mit seiner ausgeprägten moralischen Tendenz } \\
\text { sichtlich nach amerikanischem Muster gearbeitet, in seiner Anlage nicht } \\
\text { mehr ganz neu, im Detail aber durchaus modern. Die Hauptdarsteller } \\
\text { berühren größtenteils durch ihre Jugend sympathisch, die Besetzung der } \\
\text { übrigen Rollen ist gut. Die Regie hätte durch mehr Straffheit gewonnen, } \\
\text { während sie anderseits in den Trickbildern einer Parallelhandlung recht } \\
\text { originell arbeitet. Aufmachung und Photographie sind gut [PFL 1927: } \\
68] \text {. }\end{array}$ \\
\hline $\begin{array}{l}\text { Der Student von Prag, } 1926 \\
\text { SA: The Student of Prague (A) } \\
\text { The Man who cheated Life (E) } \\
\text { MI: } 5 \\
\text { BELEGE } \\
\text { UA : } 25.10 .26 \\
\text { SA }: 20.4 .28 \text { OUT } \\
\text { L1 : } 857 \\
\text { TG }: 218 \\
\text { HR }: 68\end{array}$ & $\begin{array}{l}\text { 1: Phantastisches Filmdrama mit Conrad Veidt, Werner Krauß, Fritz } \\
\text { Alberti, Ferdinand von Alten, Agnes Esterhazy, Elizza la Porta. Regie: } \\
\text { Henrik Galeen. - Um 1820. Ein mit seinem Los unzufriedener Student } \\
\text { erhält von einem geheimnisvollen Fremden } 600.000 \text { Goldgulden, wofür er } \\
\text { diesen berechtigt, aus seinem Zimmer mitzunehmen, was ihm beliebt. } \\
\text { Und der Fremde entführt - das Spiegelbild des Studenten. Dieser hält } \\
\text { nun ein großes Haus, bewirbt sich um eine Gräfin; wird aber von deren } \\
\text { Verlobten zur Rede gestellt und beleidigt. Ihr Vater nimmt ihm das } \\
\text { Versprechen ab, den Nebenbuhler im Duell zu schonen. Doch das } \\
\text { Spiegelbild, sein Doppelgänger, tötet ihn, was den Studenten das Haus } \\
\text { der Geliebten verschließt, während sein auffälliges Spielglück seine } \\
\text { Kameraden argwöhnisch werden läßt und er selbst ein Blumenmädchen, } \\
\text { das ihn trotz allem liebt, verstößt. Nun verfolgt ihn das Spiegelbild Tag } \\
\text { und Nacht, bis er in Verzweiflung auf daßelbe schießt und - sich selbst } \\
\text { tötet. - Der große filmische Möglichkeiten bietende Vorwurf hat auch } \\
\text { diesmal seine Wirkung nicht verfehlt und die Regie das mystische Dunkel } \\
\text { desselben gewahrt ohne die Grenzen des Glaubhaften zu überschreiten } \\
\text { oder in Längen zu verfallen. Die Darstellung ist durchgehends ausge- } \\
\text { zeichnet, Veidt eine Spitzenleistung, auch Krauß in hoher Form und die } \\
\text { Esterhazy in dieser Rolle sehr eindrucksvoll. Die Aufmachung ebenso wie } \\
\text { die sehr gute Photographie unterstreichen die Geschehnisse wirkungs- } \\
\text { voll. Also: ein qualitativ hochstehendes und der deutschen Filmindustrie } \\
\text { zur Ehre gereichendes Werk, das bei reiferem Publikum sicherlich Erfolg } \\
\text { haben finden, was nicht ausschließt, daß der Film auch einfacherer } \\
\text { Besucherkreise befriedigen wird [PFL 1926: 182-183]. }\end{array}$ \\
\hline $\begin{array}{l}\text { Der Mann, die Fra } \\
\text { Dritte (D); Jealou } \\
\text { MI: } 3 \\
\text { BELEGE } \\
\text { UA : } 17.9 .25 \\
\text { SA : } 19.3 .28 \text { CT } \\
\text { L1 : } 485\end{array}$ & $\begin{array}{l}\text { 4: Feinsinniges Kammerspiel mit Werner Krauß, Lya de Putti, und Georg } \\
\text { Alexander. In Nebenrollen Angelo Ferrari, Fritz Kampers, Mary Kid. } \\
\text { Regie: Karl Grune. - Ein Spießbürger fühlt sich seiner Frau zu sicher, bis } \\
\text { ein befreundeter Schriftsteller seine Eifersucht erregt. Doch der Um- } \\
\text { stand, daß der Mann ein Kind von seiner Jugendliebe besitzt, gibt auch } \\
\text { seiner Frau Grund zu ähnlichen Empfindungen, bis sich das Ganze, } \\
\text { nachdem die beiderseitige Erregung den Höhepunkt erreicht, in Wohlge- } \\
\text { fallen auflöst. - Das sehr feinsinnige Sujet bringt das vielbenützte } \\
\text { Dreiecksproblem in heiterer Bearbeitung, die Regie geht stark ins Detail, } \\
\text { begnügt sich mit Andeutungen, wo der Vorwurf zu Deutlichkeiten } \\
\text { verleiten könnte, und zeichnet sich durchgehends durch ein flottes } \\
\text { Tempo aus. Die Darstellung ist vorzüglich, Krauß eine Spitzenleistung, } \\
\text { Alexander durch seine Rolle mehr zur Passivität verurteilt. Die Aufma- } \\
\text { chung ist sauber, die Photos passabel [PFL 10(1925)503, 223]. }\end{array}$ \\
\hline
\end{tabular}




\begin{tabular}{|c|c|}
\hline $\begin{array}{l}\text { Wolga - Wolga, } 1928 \\
\text { SA: Volga, Volga (A) } \\
\text { Stenka Rasin (D) } \\
\text { MI: } 3 \\
\text { BELEGE } \\
\text { UA : } 15.11 .28 \\
\text { SA : } 19.7 .29 \text { CT } \\
\text { L2: } 473\end{array}$ & $\begin{array}{l}\text { 3: Abenteuerdrama, mit H.A. v. Schlettow, Boris de Fas, Rudolf Klein- } \\
\text { Rogge, Gustl Gstettenbauer, George Seroff, Lilian Hall-Davis. Regie: W. } \\
\text { Turjansky. - Eine russische Ballade aus dem 17. Jahrhundert. Stenka } \\
\text { Rasin, mit dem Zaren in erbittertstem Kampfe stehend, segelt zum } \\
\text { Abschlusse eines Bündnisses mit dem Schah nach Persien, wird aber von } \\
\text { dessen Statthalter verraten, muß fliehen und verliert sein Herz an des } \\
\text { letzteren Tochter, welche einer seiner Genossen gegen sein ausdrückli- } \\
\text { ches Verbot an Bord gebracht. Später muß er aber, durch eine Meuterei } \\
\text { seiner Leute gezwungen, seinem eigenen Gebote Geltung verschaffen } \\
\text { und sie erdolchen. Er selbst fällt dem Verrate eines Nebenbühlers zum } \\
\text { Opfer und versinkt auf seinem brennenden Schiffe. - Das, seinen } \\
\text { balladesken Vorwurf nicht leugnende Sujet ist, die verhältnismäßig kleine } \\
\text { romantische Handlung reichlich mit Details umgebend, in großen Teile } \\
\text { auf bildhafte Wirksamkeit eingestellt. Auch die Regie ist in dieser } \\
\text { Richtung orientiert und entschädigt für das, besonders im zweiten Teile } \\
\text { oft erlahmende Tempo durch eine sehr große stilechte Aufmachung, } \\
\text { deren Eindruck durch raffinierte Bildwirkungen erhöht wird. Neben einer } \\
\text { vorzüglichen Darstellung der Hauptrollen sind gute Typen zu erwähnen. } \\
\text { Die Photographie ist ausgezeichnet. Gesamtqualifikation: Stark über } \\
\text { dem Durchschnitt [PFL 1929: 43]. }\end{array}$ \\
\hline $\begin{array}{l}\text { Alraune, } 1927 \\
\text { SA: Daughter of Destiny (A) } \\
\text { A Daughter of Destiny; } \\
\text { Mandrake; Unholy Love (E) } \\
\text { MI: } 2 \\
\text { BELEGE } \\
\text { UA : } 25.1 .28 \\
\text { SA : } 4.9 .29 \mathrm{NW} \\
\text { L2 : } 255\end{array}$ & $\begin{array}{l}\text { 2: Sittenbild nach dem gleichnamigen Roman von Hans Heinz Ewers, mit } \\
\text { Brigitte Helm, Mia Pankau, Paul Wegener, Ivan Petrovich, Georg John, } \\
\text { Wolfgang Zilzer, Louis Ralph. Regie: Henrik Galeen. - Ein Professor } \\
\text { macht Versuche über künstliche Befruchtung, die darin gipfeln, eine } \\
\text { Zeugung ohne Beisammensein der Eltern durchzuführen und benützt } \\
\text { hiezu einen Raubmörder und eine Dirne. Alraune, ein Mädchen, das dem } \\
\text { gelungenen Experiment sein Leben verdankt, bringt allen Männern } \\
\text { Unglück. Als sie das Geheimnis ihrer Herkunft erfährt, nimmt sie an dem } \\
\text { Professor, den sie bisher für ihren Vater gehalten, Rache, indem sie ihn } \\
\text { bis zur tollsten Leidenschaft reizt, dann verhöhnt und - sich schließlich } \\
\text { besinnt und mit dem Neffen ein neues Leben beginnt ... - Dies eine } \\
\text { Konzession, die man der seit } 1919 \text { (siehe „Alraune“, „Neutral-Film“ von } \\
\text { Hugo Engel und "Luna-Film“ der „ „fuk“, Filmliste 149/1919) erfolgten } \\
\text { Änderung der Geschmacksrichtung machen zu müssen glaubte. Das } \\
\text { Sujet beginnt daher mystisch-psychologisch, um dann gegen das Gesell- } \\
\text { schaftliche hin abzuschwenken, was allerdings ein Nachlassen des } \\
\text { Interesses mit sich bringt. Dessenungeachtet ist das Buch sehr stark, } \\
\text { außerordentlich interessant, und kommt über die Klippen heikler Stellen } \\
\text { geschickt hinweg. Die Regie entschädigt für ein Zuviel an Episoden durch } \\
\text { abwechslungsreiche Bilder und leistet Ausgezeichnetes in der Führung } \\
\text { der Darsteller, von denen Wegener durch große MäBigung hervorragt, } \\
\text { während Brigitte Helm nicht immer die Dämonie der Alraune glaubhaft } \\
\text { machen kann. Allerdings wäre für diese Rolle schwerlich eine bessere } \\
\text { Darstellerin zu finden. Die Aufmachung unterstreicht anfangs das } \\
\text { Geheimnisvolle der Vorgänge, ist später elegant, die Photographie gut. - } \\
\text { Gesamtqualifikation: fast ein Schlager [PFL 1928: 45]. }\end{array}$ \\
\hline $\begin{array}{l}\text { Manolescu-Der König der } \\
\text { Hochstapler } \\
\text { SA: Manolescu } \\
\text { Der König der Hochstapler } \\
\text { MI: } 2 \\
\text { BELEGE } \\
\text { UA : } 22.8 .29 \\
\text { SA : } 26.7 .30 \text { NA } \\
\text { L2 : } 589\end{array}$ & $\begin{array}{l}\text { 2: Hochstaplerdrama nach einer Novelle von Hans Szekely, mit Iwan } \\
\text { Mosjoukin, Heinrich George, Brigitte Helm, Dita Parlo, Elsa Wagner. } \\
\text { Regie: V. Tourjansky. - Die Ansprüche einer eleganten Abenteurin } \\
\text { machen Lebemann Manolescu zum Dieb, Betrüger und Fälscher. Später } \\
\text { bekommt er spießerische Anwandlungen, während sie von ihrem früheren } \\
\text { Freund verfolgt wird, der Manolescu nierderschlägt. Im Spital verliebt } \\
\text { dieser sich in seine Pflegerin und gibt der Komplizin den Laufpaß, welche } \\
\text { ihn verrät. Als man Manolescu verhaftet, verspricht die Pflegerin auf ihn } \\
\text { zu warten ... - Manolescus Streiche, schon } 1920 \text { von Richard Oswald } \\
\text { verfilmt („Manolescus Memoiren“, Filmliste } 240 / 1920 \text { ), bilden auch die } \\
\text { Grundlage des vorliegenden, nach einem glänzenden Auftakt und frühen } \\
\text { Überschreiten des dramatischen Höhepunkts in Episoden zerflatternden } \\
\text { Sujets. Dafür entschädigt reichlich die glänzende Besetzung. Mosjoukin } \\
\text { spielt, vielleicht um eine Nuance zu passiv, den Manolescu, die Helm ist } \\
\text { ihm eine, diese Rollenauffassung begreiflich machende, temperamentvol- } \\
\text { le Partnerin, auch das übrige Ensemble ausgezeichnet, von einer kontinu- } \\
\text { ierlichen Regie geführt. Aufmachung und Photographie sind sorgfältig. - }\end{array}$ \\
\hline
\end{tabular}




\begin{tabular}{|c|c|}
\hline & Gesamtqualifikation: Fast ein Schlager [PFL 1929: 140-141]. \\
\hline $\begin{array}{l}\text { Ein Walzertraum, } 1925 \\
\text { SA: The Waltz Dream (A) } \\
\text { MI: } 2 \\
\text { BELEGE } \\
\text { UA : } 18.12 .25 \\
\text { SA : } 1.5 .27 \text { TS } \\
\text { L1 : } 668\end{array}$ & $\begin{array}{l}\text { 1: Komödie nach der Hans Müller'schen Novelle „Nux, der Prinzgemahl“ } \\
\text { und der gleichnamigen Operette von Oskar Strauß, mit Mady Christians, } \\
\text { Xenia Desni, Lydia Potechina, Willy Fritsch, Karl Beckersachs, Julius } \\
\text { Fasenstein, Jakob Tiedtke. Regie: Ludwig Berger. - Ein Erzherzog soll } \\
\text { eine ungeliebte Prinzessin, die zu Besuch an den Wiener Hof gekommen, } \\
\text { heiraten, läßt sich aber von seinem Adjutanten vertreten, der, als der } \\
\text { Vater der Hoheit gute Miene zum bösen Spiel machen muß, Prinzgemahl } \\
\text { wird, und, nachdem er sein Herz beinahe an eine Kapellmeisterin verloren } \\
\text { hätte, seine Gemahlin, welche von der, die Aussichtslosigkeit ihrer } \\
\text { Neigung einsehenden Musikerin im Umgange mit Männern unterrichtet } \\
\text { worden, auch lieben lernt. - Der Hauptvorzug dieses Films und seine } \\
\text { zweifellose Zugkraft ist das glänzend gezeichnete Milieu des Wien der } \\
\text { Vorkriegszeit, mit seiner Nonchalance und der richtigen Portion Senti- } \\
\text { mentalität, wie auch die liebenswürdige Darstellung aller Rollen mit Mady } \\
\text { Christians an der Spitze, welche hier eine ihrer besten Leistungen } \\
\text { geschaffen. Hinsichtlich der Regie seien die liebevolle Durcharbeitung } \\
\text { des Details und die vielen heiteren Nuancen erwähnt, wie auch die } \\
\text { Aufmachung und besonders die vorzüglich gelungene Photographie [PFL } \\
\text { 1926: 78]. }\end{array}$ \\
\hline $\begin{array}{l}\text { Soldat der Marie, } 1926 \\
\text { SA: Young Romance } \\
\text { MI: } 1 \\
\text { BELEGE } \\
\text { UA : } 4.3 .27 \\
\text { SA : } 23.2 .29 \mathrm{NW} \\
\text { L2 : } 850\end{array}$ & $\begin{array}{l}\text { 4: Filmschwank nach der gleichnamigen Operette von Leo Ascher, mit } \\
\text { Harry Liedtke, Siegfried Arno, Emil Albers, Xenia Desni, Grit Haid, Hilde } \\
\text { Maroff, Margareth Kupfer. Regie: Erich Schönfelder. - Ein Reichsgraf } \\
\text { besucht seine Tante auf ihrem Schlosse, bei welcher Gelegenheit er } \\
\text { nacheinander die Bekanntschaft dreier Müllerstöchter macht, deren erste } \\
\text { er in der Uniform seines Burschen getroffen, während die Andere ihn für } \\
\text { eine Lakei und die Dritte für einen Offizier hält. Um die diversen Stell- } \\
\text { dicheins einhalten zu können, begibt sich der Held in die gefährlichsten } \\
\text { Situationen, welche bei der Ankunft der neuen Stiefmutter der Grazien } \\
\text { noch verschärft werden. Schließlich muß er Farbe bekennen, und nimmt } \\
\text { die Erste von ihnen, der er sich als Soldat genähert, zu seiner Frau. } \\
\text { Das Ganze repräsentiert sich als ein gefilmter Schwank der alten Schule, } \\
\text { etwas zu behaglich und schwerfällig um flott aus sich heraus heiter zu } \\
\text { sein. Dafür muß die Darstellung einspringen, welche in der durch den } \\
\text { Vorwurf angedeuteten Richtung ihr Bestes leistet und szenenweise für } \\
\text { Heiterkeit sorgt. Auch fällt die Beliebtheit des Ensembles in die Wag- }- \text { - } \\
\text { schale. Zu größerer Aufmachung ist keine dringende Notwendigkeit; was } \\
\text { im Interieur zu sehen ist, stellt aber zufrieden. Auch die Photographie ist } \\
\text { gut. Auf Grund der vorstehenden Erwägungen ein guter Publikumsfilm } \\
\text { [PFL 1926: 169-170]. }\end{array}$ \\
\hline & VERTRIEB: BRITISH UNIVERSAL PICTURES \\
\hline \multirow[t]{2}{*}{$\begin{array}{l}\text { Mädchen in Uniform, } 1931 \\
\text { SA: Maidens/Maedchen in } \\
\text { Uniform (BUP) } \\
\text { Girls in Uniform, Children in } \\
\text { Uniform (E) }\end{array}$} & $\begin{array}{l}\text { Die 14-jährige Vollwaise Manuela von Meinhardis kommt an ein Stift für } \\
\text { höhere Töchter in Potsdam. Hier erlebt sie eine Erziehung, die von } \\
\text { preußischem Drill und dem Fehlen menschlicher Nähe geprägt ist. } \\
\text { Einziger Lichtblick ist für sie die Lehrerin Fräulein von Bernburg, die sich } \\
\text { dem rigiden Erziehungsideal der Oberin widersetzt. Als Manuela nach } \\
\text { einer Schultheateraufführung - beschwingt vom Erfolg und von Bowle - } \\
\text { Fräulein von Bernburg ihre Liebe gesteht, kommt es zum Eklat. Während } \\
\text { die Oberin Fräulein von Bernburg für das Geschehene verantwortlich } \\
\text { machen will, versucht Manuela, sich das Leben zu nehmen - was ihre } \\
\text { Mitschülerinnen im letzten Moment verhindern können (FP). }\end{array}$ \\
\hline & UNABHÄNIGE VERTRIEBE (U) \\
\hline $\begin{array}{l}\text { Luther, } 1927 \\
\text { SA: Luther (U) } \\
\text { Luther - Der Mönch von } \\
\text { Wittenberg (D); Martin Luther }\end{array}$ & $\begin{array}{l}\text { 0: Biographisches Filmwerk mit Eugen Klöpfer, Rudolf Lettinger, Livio } \\
\text { Pavanelli, Theodor Loos, Hermann Vallentin, Bruno Kastner, Leopold v. } \\
\text { Ledbour, Jakob Tiedtke, Alexander Murski, Elsa Wagner. Regie: Hans } \\
\text { Kyser. - Mit der ersten Lehrtätigkeit, der Berufung und dem Gelöbnisse } \\
\text { des Magisters Luther beginnend, streift der Film dessen Klosterjahre, um }\end{array}$ \\
\hline
\end{tabular}




\begin{tabular}{|c|c|}
\hline $\begin{array}{l}\text { MI: } 21 \\
\text { BELEGE } \\
\text { UA : } 16.2 .28 \\
\text { SA : } 17.10 .29 \text { DDA } \\
\text { L2 }: 147\end{array}$ & $\begin{array}{l}\text { dann ausführlicher auf seine Romfahrt, die Eindrücke auf der Reise und in } \\
\text { der heiligen Stadt selbst einzugehen. Diese und Tetzels Ablaßkrämerei } \\
\text { machen inn zum Grübler, lassen seine Reformideen reifen, die dann in } \\
\text { den } 13 \text { Thesen ihren Niederschlag finden, welche, vom Buchändler Luft } \\
\text { verbreitet, weiteste Kreise des deutschen Volkes zu seinen Anhängern } \\
\text { machen. Es folgt der Reichstag zu Worms, Acht und Bann, Schutzhaft } \\
\text { auf der Wartburg, und schließlich Luthers Auftreten gegen die Bilder- } \\
\text { stürmer. Mit dieser Epoche, welche den Sieg der Reformation und } \\
\text { zugleich den Höhepunkt in Luthers Leben darstellt, schließt der Film, } \\
\text { dessen Regisseur es verstanden hat, vor allem die urdeutsche Gestalt } \\
\text { des Reformators plastisch herauszuarbeiten und den Stoff soweit } \\
\text { dramatisch zu gestalten, daß trotz des rein biographischen Inhaltes das } \\
\text { Interesse bis zur letzten Szene gespannt bleibt und die bei derartigen } \\
\text { Filmen gefürchteten Längen vollständig vermieden wurden. Dies die rein } \\
\text { filmische Seite der Angelegenheit. Daß man auf Luthers späteren recht } \\
\text { bürgerlichen Lebenslauf nicht eingegangen, ist in vorerwähnter Hinsicht } \\
\text { ein Vorteil, daß man aber die Bilderstürmer selbst, Luthers Beziehungen } \\
\text { zu innen und später zu der protestantischen Gegenreformation arg } \\
\text { verzeichnet, beeinträchtigt den geschichtlichen Wert des Werkes. Die } \\
\text { Darstellung ist in allen Rollen ausgezeichnet, Klöpfer eine Prachtgestalt, } \\
\text { die stilgetreuen Bauten und die rein bildhafte Wirksamkeit vieler Szenen } \\
\text { eine nachhaltige Unterstreichung der Geschehnisse. Auch die Photogra- } \\
\text { phie ist gut. Die Zwischentexte hingegen genügen im Vereine mit dem } \\
\text { bildlich Dargestellten nur durch den protestantischen Religions- oder } \\
\text { Geschichtsunterricht Vorgebildeten zum Verständnis des Ganzen. Für } \\
\text { das breite Publikum aber müßte eine Umarbeitung des Titelsatzes - } \\
\text { allerdings mit größter Vorsicht - durchgeführt werden. (Ein Kulturfilm) } \\
\text { [PFL 1928: 83] }\end{array}$ \\
\hline $\begin{array}{l}\text { Der Alte Fritz - 1. Der Friede, } \\
1927 \\
\text { SA: Der Alte Fritz I. (U) } \\
\text { Der Einsiedler von Sanssouci: } \\
\text { 1. Der König als Mensch (D) } \\
\text { Der Alte Fritz - 2. Der Aus- } \\
\text { klang, } 1927 \\
\text { SA: Der Alte Fritz II. (U) } \\
\text { Der Einsiedler von Sanssouci: } \\
\text { 2. Die letzten Tage von } \\
\text { Sanssouci (D) } \\
\\
\text { MI: } 11 \\
\text { BELEGE } \\
\text { UA : } 3.1 .28 / 20.1 .28 \\
\text { SA : } 13.6 .30 \text { CT/18.06.30 DB } \\
\text { L2 : } 5-8\end{array}$ & $\begin{array}{l}\text { 0: Biographisches Filmwerk mit Otto Gebühr. Regie: Gerhard Lamprecht. } \\
\text { - Nach Beendigung des siebenjährigen Krieges kehrte König Friedrich } \\
\text { nach Potsdam zurück, bemühte sich vorerst die dem Lande geschlagenen } \\
\text { Wunden zu heilen, dessen Finanzen aufzuhelfen und schließlich in seiner } \\
\text { Familie Ordnung zu schaffen. Letzteres gelang ihm nicht. Die Armouren } \\
\text { des Kronprinzen führten zur Scheidung seiner ersten Ehe, auch die } \\
\text { zweite wurde zerrüttet und der alternde König fürchtete sein Erbe einem } \\
\text { Unwürdigen überlassen zu müssen ... Nun beginnt die den roten Faden } \\
\text { des Films darstellende Tragödie des großen Mannes. Seiner Familie war } \\
\text { er seit jeher fremd, seine wenigen Freunde starben vor ihm, und sein } \\
\text { immer mehr hervortretender Despotismus raubte ihm die Sympathie des } \\
\text { Volkes. Einsam, nur von wenigen Getreuen umgeben, starb er im } \\
\text { Schlosse von Sanssouci, während man im nahen Potsdam schon den } \\
\text { neuen Herrn umschmeichelte. - Die Titelrolle ist eine ganz große Leis- } \\
\text { tung Gebühr's. Das übrige Ensemble ist sorgfältig gewählt. Es kann sich } \\
\text { aber vermöge der Art der Rollen niemand mehr denn als gute Charge } \\
\text { betätigen. Autor und Regisseur haben sich anerkennenswerter Weise } \\
\text { streng an die Historie gehalten, sind dem Gewirr von Anekdoten und } \\
\text { Histörchen, die sich um die Person des Alten Fritz ranken, ausgewichen, } \\
\text { ebenso wie die naheliegende Gefahr, politische Themen zu berühren. } \\
\text { Dies hat aber naturgemäß zu einer gewissen Trockenheit geführt. Nur in } \\
\text { ganz wenigen Details sind die Ansätze zu dramatischer Gestaltung } \\
\text { wahrnehmbar. Die Aufmachung ist stilecht und ebenso wie die Photo- } \\
\text { graphie sehr sorgfältig. Mit geschichtlichen Daten durchsetzte Zwi- } \\
\text { schentexte verstärken den vorerwähnten Eindruck. (Ein Kulturfilm) [PFL } \\
\text { 13(1928)627, 61]. }\end{array}$ \\
\hline $\begin{array}{l}\text { MI: } 3 \\
\text { BELEGE } \\
\text { UA : } 9.4 .26 \\
\text { SA : } 5.8 .29 \text { DB } \\
\text { L1: } 890\end{array}$ & $\begin{array}{l}\text { 4: Lebensbild nach dem Roman von Rudolf Herzog, mit Harry Liedtke, } \\
\text { Johannes Riemann, Gottfried Hagedorn, Gustav Adolf Semler, Werner } \\
\text { Pitschau, Werner Fütterer, Karl Platen, Hermann Picha, Robert Leffler, } \\
\text { Hans Brausewetter, Gertrud Arnold, Frieda Richard, Maly Delschaft, } \\
\text { Camilla Hollay, Erika Glässner. Regie: Arthur Bergen. - Die sechs } \\
\text { Brüder Wiskotten teilen sich in der Leitung der Fabrik ihres Vaters; } \\
\text { Arbeit ist ihre Parole. Die Frau des Ältesten mißversteht dessen Lebens- } \\
\text { freude und läßt sich von ihrem Vater bewegen, das Haus ihres Mannes } \\
\text { zu verlassen. Doch dieser bringt den Schwiegervater, der ihm einen }\end{array}$ \\
\hline
\end{tabular}




\begin{tabular}{|c|c|}
\hline & $\begin{array}{l}\text { Konkurrenzkampf aufgezwungen zur Vernunft, welche auch schließlich } \\
\text { seine Frau annimmt. Auch der jüngste der Wiskottens, der durchaus } \\
\text { Künstler werden wollte und durch seinen Starrsinn beinahe verhungert, } \\
\text { kehrt zu seiner Familie zurück. - Es ist ein Verdienst der Manuskriptver- } \\
\text { fasserin (Louise } v \text {. Droop) und des Regisseurs, daß der umfangreiche } \\
\text { Stoff in prägnanter, flüssiger Form gestaltet und übermäßige Längen } \\
\text { vermieden worden. Die Darstellung durch ein Starensemble ist in allen } \\
\text { Rollen sehr gut, ohne daß jemand aus dem Rahmen fallen würde. Auch } \\
\text { Aufmachung und Photographie sind saubere Arbeit [PFL 1926: 122]. }\end{array}$ \\
\hline \multirow[t]{2}{*}{$\begin{array}{l}\text { Soll und Haben, } 1924 \\
\text { SA: Soll und Haben }(U) \\
\text { MI: } 3 \\
\text { BELEGE } \\
\text { UA : } 10.10 .24 \\
\text { SA : } 5.9 .29 \text { DB } \\
\text { L1: } 410\end{array}$} & $\begin{array}{l}\text { 4: Lebensbild nach dem gleichnamigen Roman von Gustav Freytag, mit } \\
\text { Hans Brausewetter, Theodor Loos, Robert Garrison, Ernst Deutsch, } \\
\text { Paul Kraetz, Hans Mierendorf, Bruno Kastner, Herman Picha, Hugo } \\
\text { Döblin, Karl Platen, Mady Christians, Gertrud de Lalsky, Ilka Grüning, } \\
\text { Olga Tschechowa, Margarethe Kupfer. Regie: Karl Wilhelm. - Zwei } \\
\text { Schulkameraden, ein Christ und ein Jude, versuchen in der Stadt ihr } \\
\text { Glück. Der Erstere tritt in ein altes Geschäft ein, wird ein tüchtiger } \\
\text { Mensch, verliebt sich erst in eine junge Adelige, deren Vater er vor dem } \\
\text { Ruin und später vor Aufständischen rettet, kehrt dann wieder in das } \\
\text { Geschäftshaus zurück und heiratet die Schwester des Chefs. Sein } \\
\text { Kamerad gewinnt, unterstützt von einem herabgekommenen Advokaten, } \\
\text { ein großes Vermögen durch unlautere Geschäfte und findet auf der } \\
\text { Flucht durch Polizisten den Tod. Das adelige Fräulein heiratet schließlich } \\
\text { einen Freund des Kaufmanns. - Die Handlung, welche stark von dem } \\
\text { zum Vorwurfe dienenden Roman abweicht, hat eine Reihe packender, } \\
\text { starker Szenen neben solchen voll Feinheit und Stimmung. Die Regie ist } \\
\text { ein wenig unausgeglichen, die Darstellung beinahe durchwegs sehr gut. } \\
\text { Die Photographie zeigt stellenweise sehr schöne Bilder, Aufmachung } \\
\text { und Kostüme sind stilecht und durchaus entsprechend [PFL 1926: 86- } \\
\text { 87]. }\end{array}$ \\
\hline & \begin{tabular}{|l|l} 
US-FILME MIT EMIL JANNINGS \\
\end{tabular} \\
\hline $\begin{array}{l}\text { Der Weg allen Fleisches, } 1928 \\
\text { SA: THE WAY OF ALL FLESH } \\
\text { (US, PARAMOUNT) } \\
\text { MI: } 22 \\
\text { BELEGE } \\
\text { UA : } 25.6 .27 \\
\text { SA : } 27.11 .28 \mathrm{EPH} \\
\text { TG }: 218\end{array}$ & $\begin{array}{l}\text { 1: Lebensbild nach einem Roman von Perley Poore Sheehan mit Emil } \\
\text { Jannings, Donald Keith, Belle Bennet, Phillis Haver. Regie: Victor } \\
\text { Flemming. - Ein Bankkassier, der es durch zwanzigjährige unermüdliche } \\
\text { Arbeit zu dieser Stelle gebracht hat, lebt nur seiner Familie. Auf einer } \\
\text { Geschäftsreise, der ersten seit langen Jahren, geht er einem Frauen- } \\
\text { zimmer ins Garn, das ihn bestiehlt. Um seiner Familie Schaden zu } \\
\text { ersparen, läßt er, als man die Leiche eines Zuhälters des Mädchens als } \\
\text { die seine agnosziert, damit sein Bewenden, fristet durch Jahre als } \\
\text { Hadersammler und Straßenhändler sein Leben, um eines Tages seinen } \\
\text { Sohn als gefeierten Violinvirtuosen und seine Familie in guten Verhältnis- } \\
\text { sen glücklich vereint zu sehen. Dann geht er, unerkannt von den Seinen, } \\
\text { wieder ins Elend ... - Jannings ist - in diesem amerikanischen Film - auf } \\
\text { der Höhe seines darstellerischen Könnens. Den geachteten Beamten } \\
\text { und zärtlichen Vater verkörpert er ebenso lebenswahr als den Verführ- } \\
\text { ten, Verzweifelnden und Entsagenden. Seine Mitspieler sind sorgfältig } \\
\text { ausgewählt, können aber nur den Rahmen seiner Leistung bilden. Das } \\
\text { Sujet ist trotz liebevoller Kleinarbeit kein Literaturprodukt wie - es } \\
\text { drängt sich unwillkürlich dieser Vergleich auf - im "Letzten Mann“, } \\
\text { sondern zielbewußte routinierte Publikumsarbeit. Die Regieführung hat } \\
\text { das Problem "deutscher Darsteller - amerikanischer Film“ glücklich } \\
\text { gelöst. Sie ist international, besser gesagt übernational. Daß Photogra- } \\
\text { phie und Aufmachung, soweit solche in Frage kommt, auf der Höhe, sei } \\
\text { der Vollständigkeit halber noch erwähnt. - Gesamtqualifikation: ein } \\
\text { Schlager [PFL 1928: 26]. }\end{array}$ \\
\hline $\begin{array}{l}\text { Der Patriot } \\
\text { SA: THE PATRIOT } \\
\text { (US, PARAMOUNT) } \\
\text { MI: } 9 \\
\text { BELEGE } \\
\text { UA : } 17.8 .28 \\
\text { SA : } 5.4 .30 \text { CT } \\
\text { TG : } 229\end{array}$ & $\begin{array}{l}\text { 1: Historisches Drama nach dem Schauspiel von Alfred Neumann mit } \\
\text { Emil Jannings, Lewis Stone, Tulio Carminatti, Neil Hamilton, Florence } \\
\text { Vidor, Wera Veronina. Regie: Ernst Lubitsch. - } 1801 \text { hatten die Wahn- } \\
\text { sinnstaten Paul I. nicht nur das russische Volk aus seiner Lethargie } \\
\text { aufgerüttelt, sondern auch die Hofkreise hielten seine Abdankung für } \\
\text { unausweichlich, welcher sich sein Sohn, der Tronfolger Alexander, trotz } \\
\text { der väterlichen Brutalitäten beharrlich widersetzte. Obwohl zu den } \\
\text { Wenigen gehörend, denen der mißtrauische Zar Freundschaft entgegen- } \\
\text { brachte, stellte sich der Kriegsminister Graf Paalen im Interesse des }\end{array}$ \\
\hline
\end{tabular}




\begin{tabular}{|c|c|}
\hline & $\begin{array}{l}\text { Vaterlandes an die Spitze der Verschwörer. Als diese Paul I. dann durch } \\
\text { einen Diener ermorden ließen, beendete Graf Paalen seinen Gewissens- } \\
\text { konflikt, indem er den Mörder bat auch ihn zu töten. - Dieser Jannings- } \\
\text { Film ist mehr als alle frühreren auf seine schauspielerische Leistung } \\
\text { gestellt und bietet ihm eine ergiebige aber, da sie oft die Grenzen des } \\
\text { Grotesken streift, sehr schwierige Rolle, der er in bewundernswerter } \\
\text { Weise gerecht wird. Lewis Stone (Graf Paalen) reicht beinahe an ihn } \\
\text { heran, wie auch das übrige Ensemble unter Lubitsch's, trotz ausgespiel- } \\
\text { ter Szenen ungemein straffer, Regie ausgezeichnet spielt. Die stilgetreue } \\
\text { und nicht kleinliche Aufmachung vervollständigt im Verein mit sauberer } \\
\text { Photographie den voll befriedigenden Eindruck des Werkes. - Gesamt- } \\
\text { qualifikation: Ein Schlager [PFL 14(1929)668, 7]. }\end{array}$ \\
\hline $\begin{array}{l}\text { Sein letzter Befehl } \\
\text { SA: THE LAST COMMAND } \\
\text { (US, PARAMOUNT) } \\
\text { MI: } 19 \\
\text { BELEGE } \\
\text { UA : } 22.1 .28 \\
\text { SA : } 26.10 .29 \text { NA } \\
\text { TG : } 229 \\
\text { HR }: 108\end{array}$ & $\begin{array}{l}\text { 1: Lebensbild mit Emil Jannings, William Powell, Evelyn Brent. Regie: } \\
\text { Joseph v. Sternberg. - Unter den um ein Tagesengagement raufenden } \\
\text { Hollywooder Komparsen ist ein russischer Emigrant, - vom Leben } \\
\text { zermürbt, frühzeitig gealtert, von einem Nervenchock geschüttelt, - den } \\
\text { man für eine Szene als General engagiert ... Er war es einst im kaiserli- } \\
\text { chen Rußland wirklich, ließ einen des Aufruhrs verdächtigen Schauspieler } \\
\text { ins Gefängnis werfen, und legte sich dessen Kollegin als Geliebte bei. Sie } \\
\text { rettete ihn später während der Revolution vor dem Pöbel und kam selbst } \\
\text { ums Leben, während er floh ... Jetzt wird er für die Aufnahme in eine } \\
\text { echte Uniform gesteckt und der Regisseur - ist der einstige Revolutionär. } \\
\text { Der „General“ lebt während der kommenden Szene sein Leben dort } \\
\text { weiter, wo es ihm das Schicksal einst vernichtet, und erliegt darauf } \\
\text { einem Herzschlag. - Vor allem eine große Leistung Jannings, der hier } \\
\text { zwar nicht die ganze Skala seines mimischen Könnens entfalten konnte, } \\
\text { wohl aber die Aufgabe virtuos meisterte, die ihm das Sujet gestellt. } \\
\text { Dieses überrascht durch das fugenlose Ineinandergreifen von Einstigem } \\
\text { und Gegenwärtigem, von Schein und Wirklichkeit. Es wirkt schon vom } \\
\text { Anfange an ungemein spannend, um gegen Ende wuchtige Eindrücke zu } \\
\text { vermitteln. Auch das übrige Ensemble arbeitet reibungslos, von einer } \\
\text { sorgfältigen Regie geführt, die auch Bauten und Innendekoration dem } \\
\text { gegebenen Rahmen angepaßt. Die Photographie ist sorgfältig. - Ge- } \\
\text { samtqualifikation: Ein Schlager [PFL 13(1928)655, 169-170]. }\end{array}$ \\
\hline $\begin{array}{l}\text { Sünden der Väter } \\
\text { SA: SINS OF THE FATHERS } \\
\text { (US, PARAMOUNT) } \\
\text { MI: } 10 \\
\text { BELEGE } \\
\text { UA : } 29.12 .28 \\
\text { SA : } 8.5 .30 \mathrm{CT}\end{array}$ & $\begin{array}{l}\text { 2: Familiendrama mit Emil Jannings, Barry Norton, Jack Luden, Ruth } \\
\text { Chatterton, Zazu Pitts. Regie: Ludwig Berger. - Ein Kellner bringt es in } \\
\text { Amerika zum Bierhallenbesitzer. Nach dem indirekt verschuldeten Todes } \\
\text { seiner Frau heiratet er ein Dämchen und wird nach dem Gesetzwerden } \\
\text { der Prohibition Spirituosenerzeuger. Sein eigener Sohn erblindet nach } \\
\text { dem Genuß dieses "Likörs“ und der Vater wandert ins Gefängnis. Nach } \\
\text { Jahren wieder Kellner, versöhnt er sich mit seinen Kindern. - Ein Sujet, } \\
\text { das zwar nicht die große Linie der letzten Jannings-Filme, wohl aber eine } \\
\text { Reihe erprobter Motive aufweist, welche die Regie geschickt ausgewer- } \\
\text { tet und dem Künstler Unterlagen zur Erhaltung seines großen Könnens } \\
\text { geboten. Auch das übrige Ensemble spielt ausgezeichnet, die Photogra- } \\
\text { phie ist gut, desgl. die Aufmachung, soweit solche in Frage kommt. - } \\
\text { Gesamtqualifikation: Fast eine Schlager [PFL 1929: 46]. }\end{array}$ \\
\hline $\begin{array}{l}\text { Der König von Soho } \\
\text { SA: STREET OF SIN } \\
\text { (US, PARAMOUNT) } \\
\text { MI: } 9 \\
\text { BELEGE } \\
\text { UA : } 26.5 .28 \\
\text { SA : } 26.6 .30 \mathrm{CT}\end{array}$ & $\begin{array}{l}\text { 4: Verbrecherdrama mit Emil Jannings, Johnnie Morris, Fay Wray, Olga } \\
\text { Baclanova. Regie: Mauritz Stiller. - Ein Zuhälter und Straßenräuber } \\
\text { verliebt sich derart in eine junge Heilsarmeeschwester, daß er diese bei } \\
\text { ihrer Arbeit unterstützt, auf den Anteil an der Beute seines letzten Coups } \\
\text { verzichtet, und schließlich, als inn eine Dirne verrät, bei einer Polizeiraz- } \\
\text { zia sein Leben für die Rettung gefährdeter Kinder opfert. - Jannings } \\
\text { erweist auch in dieser Rolle seine großen darstellerischen Fähigkeiten, } \\
\text { vermeidet die Klippen von Brutalität und Kitsch, kann aber über die } \\
\text { Unwahrscheinlichkeit des trotz des Londoner Schauplatzes nach spezi- } \\
\text { fisch amerikanischer Mentalität gearbeiteten Sujets nicht hinweghelfen. } \\
\text { Gegenüber der als Dirne ganz ausgezeichneten Baclanova bleibt Fay } \\
\text { Wray (Die Heilsarmeeschwester) blaß und süßlich. Ausgezeichnet } \\
\text { gelungen ist die Zeichnung des Milieus und die Auswahl der die Haupt- } \\
\text { darsteller umgebenden Verbrechertypen. Die Photographie ist gut. - } \\
\text { Gesamtqualifikation: Über dem Durchschnitt [PFL 14(1929)689, 87]. }\end{array}$ \\
\hline
\end{tabular}




\section{Anhang $\mathrm{V}$}

\section{Auszüge aus dem Einstellungsprotokoll von DER BLAUE ENGEL ${ }^{208}$}

Tab. 55: Einstellungsfolge E 89 - E 98 (18.20-20.27) „Raths Weg in den ,Blauen Engel'”

\begin{tabular}{|c|c|c|c|}
\hline Nr. & Zeit & Einst. & Handlung \\
\hline 89 & $25 s$ & $\begin{array}{l}\text { HT, } \\
\text { Schwe } \\
\text { nk, } \\
\text { Fahrt, } \\
\text { RATH } \\
\text { fol- } \\
\text { gend }\end{array}$ & $\begin{array}{l}\text { Schlecht erleuchtete Gasse. RATH in Mantel, Hut und Stock, geht eiligen } \\
\text { Schrittes den Gehsteig entlang. Die Kamera fährt und schwenkt mit. Es wird } \\
\text { zu Akkordeon-Begleitung „Es war ein treuer Husar..." gesungen. RATH geht } \\
\text { bis zu einer durch eine Laterne erhellte Hausecke, zögert, blickt unsicher, nach } \\
\text { dem richtigen Weg suchend, um sich. Im gegenüberliegenden Hauseingang } \\
\text { lehnt eine Dirne. Sie raucht. RATH überquert die Gasse. Die Kamera folgt ihm. } \\
\text { RATH dreht sich um, zieht seinen Mantel zurecht und verschwindet - Frauen- } \\
\text { lachen - in einer hellen Gasse. }\end{array}$ \\
\hline 90 & $26 s$ & $\begin{array}{l}\text { T } \\
\text { (dia- } \\
\text { gonal, } \\
\text { von } \\
\text { rechts) }\end{array}$ & $\begin{array}{l}\text { Bühne „Blauer Engel“. Die Dekorationen werden gewechselt, ein Bühnenar- } \\
\text { beiter tritt prüfend in die Bühnenmitte und blickt nach oben. Das Bild wird } \\
\text { geteilt durch eine Säule des Saals. Die Kapelle intoniert kurz „Oh du lieber } \\
\text { Augustin...". Unwillige Zurufe aus dem Publikum über den langsamen Büh- } \\
\text { nenumbau. Eine der auf der Bühne sitzenden ältlichen "Künstlerinnen“, } \\
\text { GUSTE, tritt nach vorn, nimmt die Haltung LOLAS an und singt. } \\
\text { GUSTE: Kinder, heut abend, da such ich mir was aus, einen Mann, einen } \\
\text { richtigen Mann! } \\
\text { GAST (off): Na, mein Lieber, wo ist die Beilage?! } \\
\text { GUSTE: Kinder, heut abend... }\end{array}$ \\
\hline 91 & $11 \mathrm{~s}$ & A & $\begin{array}{l}\text { LOLA in ihrer Garderobe. Sie pudert sich, das Gesicht zur Kamera, vor ihrem } \\
\text { Schminktisch sitzend. Links neben ihr sitzt Lohmann, rechts stehen Goldstaub } \\
\text { und Ertzum, die Korporationsmützen auf dem Kopf. Es klopft - übertönt von } \\
\text { Gesang. } \\
\text { GUSTE (off): ... da nehm ich mit nach Haus, einen Mann, einen richtigen } \\
\text { Mann! } \\
\text { LOLA gibt Goldstaub die Puderquaste und nimmt Lohmann die Zigarette aus } \\
\text { dem Mund; sie macht einen Zug und gibt sie Lohmann zurück. } \\
\text { GUSTE (singt): Einen Mann, dem das Herze noch in Liebe glüht, einen Mann, } \\
\text { dem das Feuer aus den Augen... } \\
\text { LOLA hat ihre Perücke zurechtgerückt, ihre Haare darunter versteckt. Ertzum } \\
\text { und Goldstaub schauen ihr fasziniert und lächelnd zu. }\end{array}$ \\
\hline 92 & $8 s$ & $\mathrm{~T}$ & $\begin{array}{l}\text { Bühne. GUSTE wiegt sich im Takt. Rechts wird von dem Bühnenarbeiter ein } \\
\text { Scheinwerfer aufgestellt und eingerichtet. } \\
\text { GUSTE (singt): Und einen Mann, der noch küssen will und kann. Einen } \\
\text { Mann, einen richtigen Mann. } \\
\text { Sie endet mit einer Art Knicks. }\end{array}$ \\
\hline 93 & $10 \mathrm{~s}$ & $\mathrm{~T}$ & $\begin{array}{l}\text { RATH geht durch eine dunkle Gasse mit schrägen Häusern auf eine Laterne } \\
\text { zu. Sein Schatten auf der Hauswand. Eine Schiffssirene ertönt. }\end{array}$ \\
\hline 94 & $4 \mathrm{~s}$ & A & Ein Polizist, der an einer Hauswand lehnte, wendet sich um. \\
\hline 95 & $15 s$ & $\mathrm{~T}$ & $\begin{array}{l}\text { Die Bühne. Von der linken Seite her photographiert. Die Dekoration zeigt } \\
\text { einen Brunnen. Links oben kommt ein Teil eines Stuhls ins Bild. Rechts steht }\end{array}$ \\
\hline
\end{tabular}

${ }^{208}$ Die Nummerierung und die Handlungsbeschreibung der Einstellungsfolgen sind aus dem von Eckhart Schmidt (1965) angefertigten Filmprotokoll übernommen. Ergänzend dazu wurde sich in Sachen der Einstellungsgrößen am Filmtransskript von Ingrid Schramme (1985) bzw. der eigenen Kategorisierung orientiert. Die Zeitangaben beziehen sich auf die englische Fassung des Films (s. DVD 2 der UFAKlassiker Edition von DER BLAUE ENGEL). Die einzige Abweichung zwischen den beiden Sprachfassungen stellen die von Lola gesungenen Lieder dar, die in der Fremdsprachenversion mit englischem Text wiedergebenen werden. 


\begin{tabular}{|c|c|c|c|}
\hline & & & $\begin{array}{l}\text { ein Scheinwerfer. Die Frauen der Truppe sitzen auf ihren Plätzen und trinken. } \\
\text { Musik. LOLA LOLA tritt auf mit weißer Perücke, mit rokokohaftem, ausge- } \\
\text { stelltem Kleid, durch das die Beine schimmern. Sie macht eine dezente } \\
\text { Verbeugung und lächelt. Sie wiegt sich ein paar Mal - die Hände liegen auf } \\
\text { dem Rücken - im Takt der Musik. Beifall im Saal und Geschrei. } \\
\text { LOLA (singt): Frühling kommt, der Sperling piept durch das grüne Tälchen. } \\
\text { Während sie die beiden ersten Verse singt, gestikuliert sie rhytmisch mit den } \\
\text { Händen, hält dann die linke Hand intensiv lauschend ans Ohr. Die Klarinette } \\
\text { antwortet mit dem Sperlingsruf auf ihre Geste. Lachen im Publikum. }\end{array}$ \\
\hline 96 & $5 s$ & $A$ & $\begin{array}{l}\text { Ertzum, Lohmann und Goldstaub. Sie stehen rauchend und Bier trinkend da } \\
\text { und schauen fasziniert lächelnd zur Bühne. } \\
\text { LOLA (singt im off): Bin in einen Mann verliebt, und weiß nicht in welchen. } \\
\text { Ob er Geld hat ist mir gleich. In diesem Augenblick setzt sich Goldstaub in } \\
\text { Bewegung und geht nach vorn aus dem Bild. }\end{array}$ \\
\hline 97 & $23 \mathrm{~s}$ & $\mathrm{~T}$ & $\begin{array}{l}\text { Bühne. LOLA breitet die Arme aus und scheint dabei Goldstaub anzusehen. } \\
\text { LOLA (singt): Denn mich macht die Liebe reich! Kinder, heut abend, da such } \\
\text { ich mir was aus, einen Mann, einen richtigen Mann. Eine Frau aus der Truppe } \\
\text { geht zum Scheinwerfer und richtet ihn ins Publikum. } \\
\text { KELLNER (off): Ein Grog! } \\
\text { LOLA (singt): Kinder, Jungs ziehn mir schon det halbe aus! Sie dreht sich } \\
\text { unter dem Quietschen des Publikums um. Ihr Rokokokleid hat kein Hinterteil } \\
\text { und gibt LOLAS Strümpfe und ein unten gerüschtes, nicht sehr straff sitzen- } \\
\text { des Höschen frei. Charmant lächelnd, mit zurückgeworfenem Kopf und weit } \\
\text { nach vorn gestreckten Armen singt sie weiter. } \\
\text { LOLA (singt): Einen Mann, dem das Herze noch in Liebe glüht. Einen Mann, } \\
\text { dem das Feuer aus den Augen sprüht. }\end{array}$ \\
\hline 98 & $6 s$ & $\begin{array}{l}N \text { (von } \\
\text { hinten } \\
\text { oben } \\
\text { be- } \\
\text { leuch- } \\
\text { tet) }\end{array}$ & $\begin{array}{l}\text { RATH erscheint hinter der Eingangstür zum „Blauen Engel“. Er blickt, sich hin- } \\
\text { und herbeugend, durch die schmutzigen Scheiben ins Publikum, öffnet } \\
\text { kurzentschlossen die Tür und betritt das Lokal. } \\
\text { LOLA (singt im off): Kurz, einen Mann, der noch küssen will und kann. Einen } \\
\text { Mann, einen richtigen Mann! }\end{array}$ \\
\hline
\end{tabular}

Tab. 56: Einstellungsfolge E 490 bis E 508 (97.45 - 102.14) „Raths Flucht aus dem ,Blauen Engel'“

\begin{tabular}{|c|c|c|l|}
\hline Nr. & Zeit & Einst. & \multicolumn{1}{c|}{ Handlung } \\
\hline 490 & $6,5 s$ & HT & $\begin{array}{l}\text { RATH. Er schleicht sich, sie immer wieder umdrehend, gebückt nach hinten } \\
\text { und verschwindet aus dem Bild. } \\
\text { LOLA (off): .. Ich kann halt lieben nur und sonst gar nichts! ... }\end{array}$ \\
\hline 491 & $27,5 s$ & A & $\begin{array}{l}\text { Lola beugt sich vor, legt einen Arm über die Lehne, umfaßt mit der anderen } \\
\text { Hand ihre Schulter. Sie lächelt. } \\
\text { LOLA (singt): ... Männer umschwirrn mich, wie Motten das Licht. / (Sie läßt } \\
\text { den Stuhl los, stützt sich mit entschlossenen, rhytmischen Bewegungen beide } \\
\text { Hände in die Hüften und singt) Ich bin von Kopf bis Fuß auf Liebe eingestellt, } \\
\text { / ich kann halt lieben nur und sonst gar nichts! }\end{array}$ \\
\hline 492 & $5,5 s$ & HN & $\begin{array}{l}\text { RATH. Er schleicht sich gebükt - Schwenk - bei den letzten Takten der Musik } \\
\text { und dem Beifall des Publikums an der Wand entlang. }\end{array}$ \\
\hline 493 & 10 s & A & $\begin{array}{l}\text { LOLA. Sie lächelt, über den Stuhl gelehnt. Sie blickt ins Publikum hinunter. } \\
\text { Bravorufe, Klatschen. }\end{array}$ \\
\hline 494 & $31,5 s$ & T & $\begin{array}{l}\text { RATH. Er humpelt, wobei er sich immer wieder an den Hauswänden stützt, } \\
\text { durch eine fast vollständig in Nacht getuachte Gasse. Er geht nach rechts. Die } \\
\text { Kamera schwenkt. Der Brunnen kommt im Vordergrund ins Bild. Das langezo- } \\
\text { gene Heulen einer Schiffssirene. RATH lehnt sich erschöpft an eine Hauswand. } \\
\text { Dann humpelt er weiter auf einem schneebedeckten Gehsteig. Mit den über } \\
\text { die Hauswände tastenden Fingern streift er Schnee von einem Finstersims. Er } \\
\text { wankt weiter. Das Heulen der Schiffssirene ertönt. Rath wankt weiter, sein } \\
\text { Schatten zeichnet sich auf der Hauswand ab. Überblendung. }\end{array}$ \\
\hline
\end{tabular}




\begin{tabular}{|c|c|c|c|}
\hline 495 & $7,5 s$ & $\begin{array}{l}\text { T, } \\
\text { Auf- } \\
\text { sicht }\end{array}$ & $\begin{array}{l}\text { Schuleingang. RATHS riesiger Schatten fällt auf die Schule. RATH geht } \\
\text { langsam, unsicher, sich ummer wieder festhaltend, auf den Eingang zu. }\end{array}$ \\
\hline 496 & $7,5 \mathrm{~s}$ & A & RATH am Schuleingang. Er läutet. \\
\hline 497 & $1,5 \mathrm{~s}$ & $\mathrm{D}$ & Die Glockenanlage. Die Glocke läutet. \\
\hline 498 & $10,5 s$ & A & RATH am Eingang. Er läutet immer wieder. \\
\hline 499 & $12,5 \mathrm{~s}$ & HT & $\begin{array}{l}\text { In Nacht getauchtes Treppenhaus in der Schule. Ein kreisrunder Lichtkegel } \\
\text { wandert über ein Fenster, eine Tür, das Treppenhaus. Die Lampe kommt ins } \\
\text { Bild und, angedeutet, ihr Träger. }\end{array}$ \\
\hline 500 & $8 s$ & A & $\begin{array}{l}\text { RATH vor der Eingangstür. Die Tür öffnet sich. Der Lichtstrahl der Taschen- } \\
\text { lampe fällt RATH ins Gesicht. Er geht hinein. Schwenk. }\end{array}$ \\
\hline 501 & $10,5 s$ & A & RATH geht, von hinten beleuchtet, unsicher eine Treppe hinauf. \\
\hline 502 & $14 \mathrm{~s}$ & HT & $\begin{array}{l}\text { RATH wankt, sich immer wieder an der Wand stützend, den Korridor entlang } \\
\text { auf sein Klassenzimmer zu. Er öffnet die Tür und geht hinein. Musik. }\end{array}$ \\
\hline 503 & $9,5 s$ & HT & $\begin{array}{l}\text { Treppenhaus. Dann, mit der Taschenlampe in der Hand, der Pedell. Er blickt } \\
\text { die Treppe hinauf. Musik. }\end{array}$ \\
\hline 504 & 9s & A & $\begin{array}{l}\text { Die Tür von RATHS Klassenzimmer. Der Lichtkegel rückt auf ihr auf und ab. } \\
\text { Schließlich erscheint der Pedell im Bild, stutzt. Die Musik wird übertönt von } \\
\text { der Melodie der Uhr: „Üb immer Treu und Redlichkeit”. }\end{array}$ \\
\hline 505 & $17,5 \mathrm{~s}$ & A & $\begin{array}{l}\text { RATH liegt auf dem Pult. Der Lichtstrahl erfaßt inn. Er hält mit beiden Händen } \\
\text { das Pult fest umklammert, der Kopf liegt wie leblos auf dem rechten Arm. Der } \\
\text { Pedell hinkt ins Bild, zerrt an RATH, geht um ihn herum. Musik. }\end{array}$ \\
\hline 506 & $2 s$ & $\mathrm{D}$ & Die rechte Hand RATHS um die Pultplatte gekrallt. Musik. \\
\hline 507 & $21 \mathrm{~s}$ & A & $\begin{array}{l}\text { Der Pedell versucht mit aller Kraft, RATHS Hand vom Pult zu lösen. Es gelingt } \\
\text { ihm nicht. Er betrachtet RATH irritiert und eilt dann in Richtung Tür. Die } \\
\text { Taschenlampe läßt er liegen. Musik bricht ab. }\end{array}$ \\
\hline 508 & $32 s$ & $\begin{array}{l}\text { HT, } \\
\text { Fahrt } \\
\text { zurück } \\
\text { bis zu } \\
\text { Totale }\end{array}$ & $\begin{array}{l}\text { RATH über das Pult gestreckt, vom Licht der Taschenlampe erhellt. Im } \\
\text { Vordergrund angeschnitten die Sitzreihen. Die Kamera fährt, während die Uhr } \\
\text { zwölfmal schlägt, zurück und gibt die drei schwach erleuchteten Reihen und } \\
\text { Fenster frei. RATH liegt, kleiner werdend, reglos auf dem Pult. Beim zwölften } \\
\text { Schlag erscheint das Wort ENDE. Abblenden. }\end{array}$ \\
\hline
\end{tabular}




\section{Versicherung}

Ich versichere, dass ich die eingereichte Dissertation „Zur Rezeption des Spielfilms der Weimarer Republik in Südafrika 1928 - 1933. Eine kinohistorische Untersuchung" selbständig und ohne unerlaubte Hilfsmittel verfaßt habe. Anderer als der von mir angegebenen Hilfsmittel und Schriften habe ich mich nicht bedient. Alle wörtlich oder sinngemäß den Schriften anderer Autoren entnommenen Stellen habe ich kenntlich gemacht.

Göttingen, den 


\section{Personalia und Bildungsgang}

\section{Zur Person}

Michael Eckardt, Dipl.-Kulturwiss. (Medien), Master of Philosophy (Journalism), geboren am 6. November 1974 in Schmalkalden/Thür., Deutscher

\section{Bildungsgang}

1993 Abitur, Staatliches Gymnasium Schmalkalden, Leistungskurse Englisch und Informatik

1994-96 Fachhochschule Schmalkalden, Grundstudium Betriebswirtschaftslehre

1996- Bauhaus-Universität Weimar, Fakultät Medien, Diplomstudiengang Medienkultur

1999 Universität für angewandte Kunst bzw. Universität Wien, u.a. außerordentlicher Hörer an der Lehrkanzel für Kommunikationstheorie

2000 University of Natal-Durban (Südafrika), Honours class, Cultural and Media Studies

2001 Universitätsabschluss als Diplomkulturwissenschaftler (Medien)

2002-03 Friedrich-Schiller-Universität Jena, Ergänzungsstudium Geschichte der Naturwissenschaften (Wissenschaftsgeschichte)

2003-04 DAAD-Stipendiat an der Universiteit van Stellenbosch (Südafrika), Aufbaustudium Journalistik, Abschluss als Master of Philosophy

2004-07 Georg-August-Universität Göttingen, Promotion im Fach Medienund Kommunikationswissenschaft

\section{Universitäre Tätigkeiten}

1997-00 studentische Hilfskraft an den Universitäten in Weimar, Erfurt und Durban

2001-07 wissenschaftliche Hilfskraft, Vertragsmitarbeiter bzw. Doktorand an den Universitäten in Weimar, Stellenbosch, Jena und Göttingen

\section{Veröffentlichungen (Buchauswahl)}

2006 Gesamtbibliographie der „Wissenschaftlichen Zeitschrift” der Universität Jena 1951-1990. Jena.

2005 Film Criticism in Cape Town 1928-1930. Stellenbosch.

2005 Medientheorie vor der Medientheorie. Überlegungen im Anschluß an Georg Klaus. Berlin.

2002 Mensch-Maschine-Symbiose. Ausgewählte Schriften von Georg Klaus zur Konstruktionswissenschaft und Medientheorie. Weimar.

2002 Das Programm des Schönen. Ausgewählte Beiträge der Stuttgarter Schule zur Semiotik der Künste und der Medien. Weimar. 